\begin{tabular}{|l|l|}
\hline $\begin{array}{l}\text { 2. To: (Receiving Organization) } \\
\text { Distribution }\end{array}$ & $\begin{array}{l}\text { 3. From; Coriginating Organization) } \\
\text { Process Engineering }\end{array}$ \\
\hline 5. Proj./Prog./Dept./Div.: & $\begin{array}{l}\text { 6. Design Authority/ Design Agent/Cog. } \\
\text { Engr.: } \\
\text { Spent Nuclear Fuels Project }\end{array}$ \\
\hline
\end{tabular}

B. Originator Remarks:

For approval and release.

11. Receiver Remarks: 11A. Design Baseline Document? [] Yes [X] No

\section{Related EDT No.: N/A}

7. Purchese Order No.: $N / A$

9. Equip./Cormponent No.: $N / A$

10. System/Bldg./Facility: $N / A$

12. Major Assm. Dwg. No.: $N / A$

13. Permit/Permit Application No.: $N / A$

14. Required Response Date: N/A

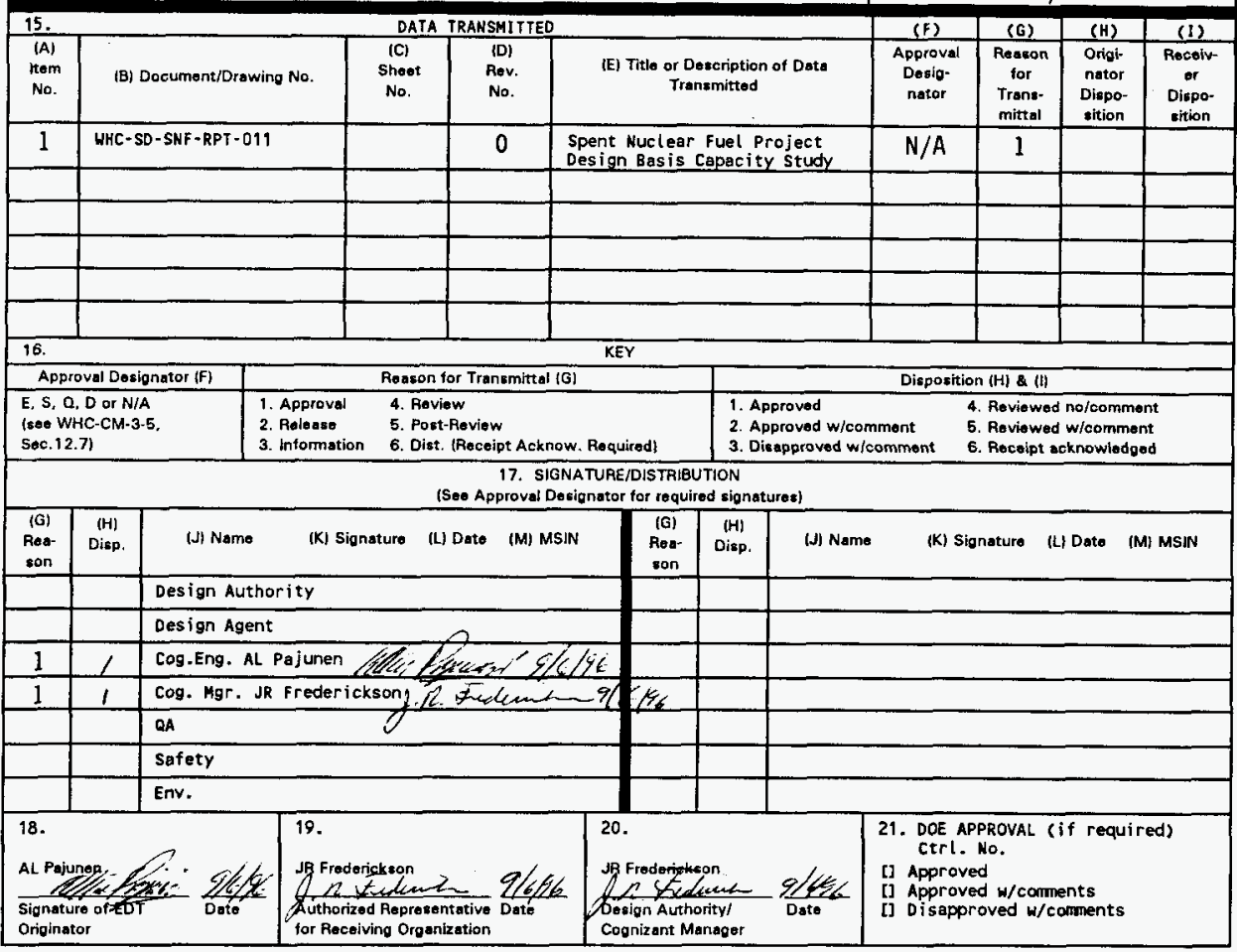




\section{Spent Nuclear Fuel Project Design Basis Capacity Study}

K. J. Clevel and

ICF Kaiser Hanford Company, Richland, WA 99352

U.S. Department of Energy Contract DE-AC06-87RL10930

EDT/ECN: 616135

Org Code: 2C400

B\&R Code: EW3135040

UC: 600

Charge Code: LBO14

Total Pages: 281

Key Words: Spent Fuel, Capacity

Abstract: A parametric study of the Spent Nuclear Fuel Project system capacity is presented. The study was completed using a commercially available software package to develop a summary level model of the major project systems. Alternative configurations, sub-system cycle times, and operating scenarios were test to identify their impact on total project duration and equipment requirements.

TRADEMARK DISCLAIMER. Reference herein to any specific commercial product, process, or service by trade name, tradenark, manufacturer, or otherwise, does not necessarily constitute or imply its endorsement, recomendation, or favoring by the United States Government or any agency thereof or its contractors or subcontractors.

Printed in the United States of America. To obtain copies of this document, contact: UHC/BCS Document Control Services, P.O. BOx 1970, Mailstop H6-08, Richland WA 99352, Phone (509) 372-2420; Fax (509) 376-4989.
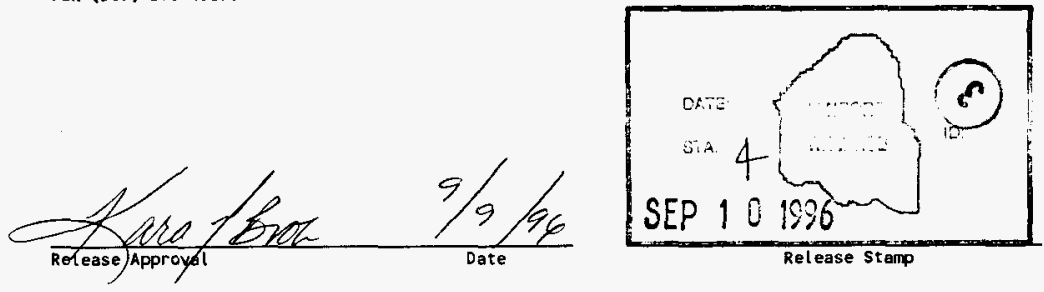

Approved for Public Release 
WHC-SD-SNF-RPT-011

Rev. 0

\title{
SPENT NUCLEAR FUEL PROJECT DESIGN BASIS
}

Spent Nuclear Fuel Project (E56128 / F5K5R3)

\author{
Prepared by \\ Kevin J. Cleveland, Engineer \\ Spent Nuclear Fuel, ICF Kaiser Hanford Company \\ for \\ Westinghouse Hanford Company \\ P.0. Box 1970 \\ Richland, WA 99352
}

Hanford Operations and Engineering Contractor for the U.S. Department of Energy under contract DOE-AC06-87RL10930 
WHC-SD-SNF-RPT-011

Rev. 0

ENGINEERING REPORT

\title{
SPENT NUCLEAR FUEL PROJECT DESIGN BASIS
}

\author{
Spent Nuclear Fuel Project (E56128 / F5K5R3) \\ Prepared by \\ ICF Kaiser Hanford Company \\ Richland, Washington \\ for \\ Westinghouse Hanford Company \\ Richland, Washington
}

Compiled by:

$\frac{\text { Kem }}{\text { K. J. Cleveland, Engineer }}$

$\frac{7 / 23 / 96}{\text { Date }}$

Reviewed by:
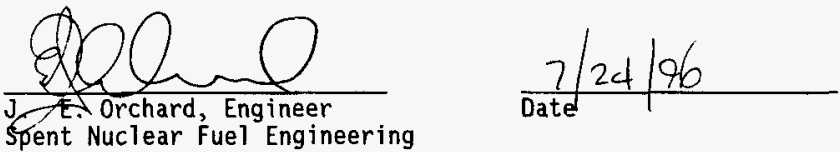

Approved by:
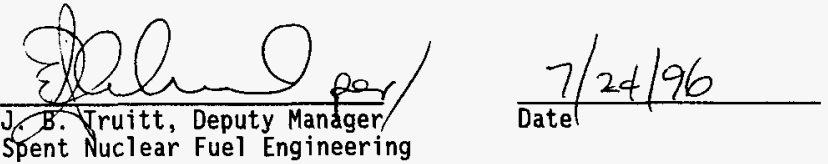

Westinghouse Hanford Company

Approved by:
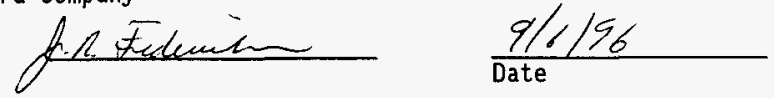
WHC-SD-SNF-RPT-011

Rev. 0

\section{CONTENTS}

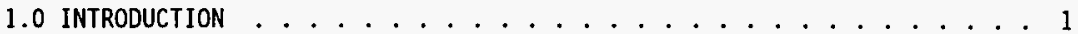

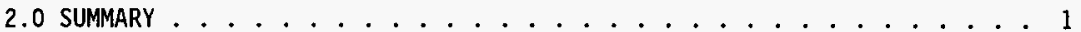

2.1 METHOD . . . . . . . . . . . . . . 1

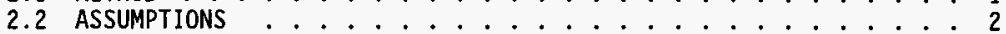

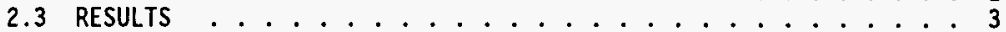

3.0 RECOMMENDATIONS ...................... . . . . 6

3.1 SYSTEM MODEL REFINEMENT . . . . . . . . . . . . . . . 6

3.2 CASK HANDLING AND TRANSPORTATION CREW . . . . . . . . . 6

3.3 CSB OPERATIONS ..................... . . . . . . . .

3.4 ACCOUNTING FOR MAINTENANCE, BREAKDOWNS, REWORK, AND ACCIDENT . . 6

3.5 LABOR RESOURCE ALLOCATION .............. 7

4.0 DETAILED DISCUSSION . . . . . . . . . . . . . . 7

4.1 BASE CASE (THREE 8 HR SHIFTS/DAY, 5 DAYS/WEEK) . . . . 10

4.2 CASE 1. TWO 12 HR SHIFTS/DAY, 5 DAYS/WEEK. . . . . . . . 13

4.3 CASE 2. THREE 8HR SHIFTS/DAY, 5 DAYS/WEEK. FUEL RETRIEVAL OPERATING AT 90\% EFFICIENCY. . . . . . . . . . 14

4.4 CASE 3. THREE 8HR SHIFTS/DAY, 5 DAYS/WEEK. FUEL RETRIEVAL OPERATING AT 80\% EFFICIENCY . . . . . . . . . . 15

4.5 CASE 4. THREE 8 HR SHIFTS/DAY, 5 DAYS/WEEK. FUEL RETRIEVAL CYCLE TIMES OF MIN $=16$, MODE $=17$, AND MAX $=30 \ldots 16$

4.6 CASE 5. THREE 8 HR SHIFTS/DAY, 5 DAYS/WEEK. WITH LONG REPAIR TIMES ON FUEL RETRIEVAL, MHM, AND HOT CONDITIONING. ..... 17

4.7 CASE 6. THREE 8 HR SHIFTS/DAY, 7 DAYS/WEEK ....... 18

4.8 CASE 7. TWO 12 HR SHIFTS/DAY, 7 DAYS/WEEK . . . . . . 20

4.9 CASE 8. THREE 8 HR SHIFTS/DAY, 7 DAYS/WEEK. USING 5 COLD VACUUM DRYING STATIONS . . . . . . . . . . 21

4.10 CASE 9. THREE 8HR SHIFTS/DAY, 7 DAYS/WEEK. USING 4 COLD

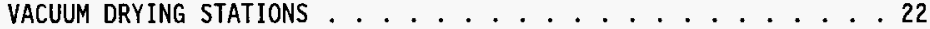

4.11 CASE 10. THREE 8HR SHIFTS/DAY, 7 DAYS/WEEK. USING 2 LOADIN/LOADOUT PITS IN THE CSB ............ 23

4.12 CASE 11. THREE 8HR SHIFTS/DAY, 7 DAYS/WEEK. USING 5 HOT CONDITIONING STATIONS . . . . 24

4.13 CASE 12. THREE 8HR SHIFTS/DAY, 7 DAYS/WEEK. USING 4 HOT

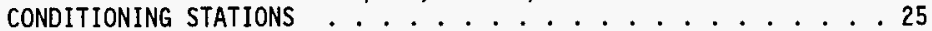

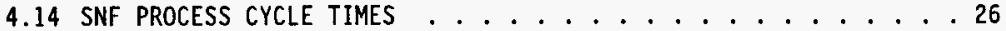

5.0 REFERENCES . . . . . . . . . . . . . . . 29

APPENDIX A. VALIDATION REQUIREMENTS ............. . A-1

APPENDIX B. WITNESS OUTPUT . . . . . . . . . . . . . . B B-1

APPENDIX $c$. WITNESS MODEL TRIAL RUNS $\ldots \ldots \ldots$ 
WHC-SD-SNF-RPT-011

Rev. 0

Figures

4.1. Illustration of a One-1ine, One Server Queuing System. . . . . . 8

4.2. Spent Nuclear Fuel Project Schematic Used for Witness Modeling : : : 9

4.3. Base Case Machine Usage ... . . . . . . . . . . . . . . . 11

4.4. Case 1 Machine Usage ... . . . . . . . . . . . . . . 13

4.5. Case 2 Machine Usage .. . . . . . . . . . . . . . . . . 14

4.6. Case 3 Machine Usage . . . . . . . . . . . . . . . . . 15

4.7. Case 4 Machine Usage ....................... . . 16

4.8. Case 5 Machine Usage ...................... . . . 17

4.9. Case 6 Machine Usage . . . . . . . . . . . . . . . . . . . . . 19

4.10. Case 7 Machine Usage . . . . . . . . . . . . . . . . 20

4.11 Case 8 Machine Usage . . . . . . . . . . . . . . . . . . . . . . 21

4.12. Case 9 Machine Usage . . . . . . . . . . . . . . . . . 22

4.14. Case 10 Machine Usage . . . . . . . . . . . . . . . . . . 23

4.15. Case 11 Machine Usage . . . . . . . . . . . . . . . . . . . 24

4.16. Case 12 Machine Usage . . . . . . . . . . . . . . . . . 25

\section{Tables}

1. Results of case studies for the SNF Project . . . . . . . . . . . . 4

2. Comparison of cases studied. .................. 5

2. Ramp-up cycle for $K$ West basin . . . . . . . . . . . . . . 10

3. Ramp-up cycle for K East basin . . . . . . . . . . . . . 10

4. Spent Nuclear Fuel Project Element Time Cycles used for Model

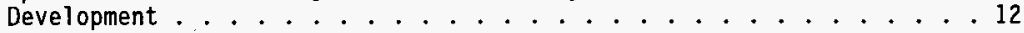


WHC-SD-SNF-RPT-011

Rev. 0

\section{SPENT NUCLEAR FUELS PROJECT \\ DESIGN BASIS CAPACITY STUDY}

\subsection{INTRODUCTION}

The mission of the Spent Nuclear Fuel Project (SNFP) is to repackage the fuel from the 100K Area fuel storage basins and transfer the fuel to a safe dry storage facility in the 200E Area plateau. The MuIti-Canister Overpacks (MCO) are filled with fuel rods retrieved from the 100K East and 100K West wet storage basins, moved into a vacuum drying process line, transported to staging at the Canister Storage Building (CSB), then conditioned in a heated vacuum process, and finally returned to dry storage in the CSB.

The first purpose of this task was to develop a process simulation model that depicts the architecture of the Spent Nuclear Fuels (SNF) process systems. The model is a basic high-level model that includes the fuel retrieval system; cask loadout station; transportation to the vacuum drying stations; vacuum drying stations; transportation to the CSB; the MCO handling machine and the hot vacuum conditioning stations; and return of the empty cask to the basin. The model can be refined with detailed information if needed to support additional studies.

The second purpose of this task was to evaluate a variety of SNF operating scenarios using the process simulation model.

\subsection{SUMMARY}

\subsection{METHOD}

Witness -TM (TRADEMARK), developed by AT\&T ISTEL, is a general discrete simulation language that is in common use by manufacturing industries to investigate production line capability, capacity, efficiency, equipment utilization, queues, bottlenecks, and other problems. Witness models are flexible and allow different scenarios to be developed and tested quickly and efficiently.

Currently this software package is being used by the Fuel Retrieval and Cold Vacuum Drying sub-projects of the SNFP to simulate the production activities/elements as part of design efforts. A demonstration model, developed for fuel retrieval, was viewed and this language appears to have the capabilities required to simulate the SNF Project top level process.

Witness extends the analytic capability of an industrial engineer, by enabling him to perform repeated random experiments on a system. Simulation allows the engineer to test various system changes without building the physical system and achieve optimum design of the physical system. 
WHC-SD-SNF-RPT-011

Rev. 0

\subsection{ASSUMPTIONS}

Assumptions were made in developing the Witness model of SNFP subproject interactions. The accuracy of these assumptions could affect the validity of the results of this study. They include:

- Analysis results based on the utilization of the Witness software will not affect health or safety of the personnel engaged with the SNF Project.

- Boeing Hanford IRM Department validated the licensing of this software according to WHC-CM-3-10.

- Test models developed were based upon the methodology of the initial system configuration from the "Development of Design Basis Capacity for Spent Nuclear Fuel Project Systems" (Pajunen 1996).

- Process times of the model were based upon triangular distributions. These distributions are characterized with a low, high, and mode cycle time for production of a MCO. Low indicates the low value hours per cycle time or high throughput rate, high indicates the high value hours per cycle time or the low throughput rate. Mode is the expected time for the distribution, in the limit the expected value is considered the average time hours per cycle.

- Supply of MCO satisfy the processing requirement, either an adequate inventory of MCO will exist or delivery of the MCO's will be just-intime to satisfy any rate or production requirement.

- The design is based on removing the fuel from the basins within two years. The design basis capacity for each of the simulated systems relates the desired annual processing rate divided by the estimate operating efficiencies.

- This system will run 200 cycles at both $K$ East and $K$ West Basins to completely remove all of the estimated spent nuclear fuel.

- A11 processes are based on working 18 hours per day for three $8 \mathrm{hr}$ shifts or 20 hour per day for $12 \mathrm{hr}$ shifts.

- The model is not 7 abor resource limited or restricted. There is an unlimited labor pool available for the required operation and repairs.

- The system runs long enough to achieve a steady-state condition, the probability law governing the behavior of the real system will stabilize.

- Once a loaded MCO is in the system it may not leave the queue.

- Cycle times of the MHM and CSB loadin/loadout crane are independent. Interferences between the two were not modeled. 
WHC-SD-SNF-RPT-011

Rev. 0

\subsection{RESULTS}

Results in this report are based on process cycle times determined from input by the sub-project design authorities. The results should not be taken as absolute answers but should be used as guides in decision making. Further detailed modeling should be done to refine the model and add in factors such as transportation crews, equipment breakdown analysis, availability of operating crews and repair crews. Some key areas looked at in this report are: time to empty the basins, time to finish hot conditioning, number of operations of cold vacuum drying and hot conditioning, and the number of casks needed for the various cases. The results are listed in Table 1. Table 2 is a summarized comparison of the differences between some of cases studied. Detailed descriptions of each case are listed in sections 4.1 to 4.13 .

Some general observations of the results indicate the following trends.

1. Fuel retrieval is the limiting process in this model.

2. Speeding up fuel retrieval by improving the production rates, working more days per week, or increasing the "operating efficiency" will directly and significantly reduce the basin emptying time.

3. Limiting the number of CVD or HVC stations to 4, or casks to 6 , wi11 not adversely impact the basin emptying time. (Only the HVC completion time is increased by reducing the number of HVC stations.)

4. Using more CVD stations (or using more of the stations more of the time) wi11 require using more casks.

5. Marginal increases in breakdown severity cause marginal increases in the basin emptying time.

6. The MCO pit in the CSB is not a bottleneck (for the range of breakdown severities modeled here).

7. The MHM and overhead crane in the CSB are not bottlenecks (for the range of breakdown severities modeled here).

8. The cask transporters are not bottlenecks as modeled here as independent operating units. 
Table 1. Results of case studies for the SNF Project.

\begin{tabular}{|c|c|c|c|c|c|c|c|c|c|c|c|c|c|c|c|c|c|c|c|c|c|c|c|c|}
\hline \multirow[b]{2}{*}{$\begin{array}{l}\text { Case } \\
\text { No. }\end{array}$} & \multicolumn{3}{|c|}{ Shift schedule } & \multicolumn{4}{|c|}{ Operating efficiency } & \multirow{2}{*}{ Notes } & \multicolumn{3}{|c|}{$\begin{array}{l}\text { rime to finish } \\
\text { (yrs) }\end{array}$} & \multicolumn{6}{|c|}{ No. Cold vac of operations } & \multicolumn{6}{|c|}{ No. Hot cond operations } & \multirow{2}{*}{$\begin{array}{l}\text { Casks } \\
\text { needed }\end{array}$} \\
\hline & $\begin{array}{l}\text { No. } \\
\text { Shift }\end{array}$ & $\begin{array}{l}\text { days / } \\
\text { week }\end{array}$ & $\begin{array}{l}\text { hrl } \\
\text { day }\end{array}$ & $\begin{array}{l}\text { Fuel } \\
\text { ret. }\end{array}$ & $\begin{array}{l}\text { CSB } \\
\text { crane }\end{array}$ & MHM & $\begin{array}{l}\text { All } \\
\text { others }\end{array}$ & & KH & KE & HC & cri & cv2 & $\mathrm{cr} 3$ & CV4 & evs & CV6 & HC1 & HC2 & $\operatorname{HC3}$ & HC4 & HCS & HC6 & \\
\hline Base & 3 & 5 & 18 & $70 x$ & $95 \%$ & $90 \%$ & $70 x$ & $\begin{array}{l}\text { Relatively short } \\
\text { frequent breakdowns }\end{array}$ & 2.7 & 2.8 & 2.9 & 137 & 123 & 104 & 35 & 1 & 0 & 73 & 72 & 70 & 66 & 63 & 56 & 6 \\
\hline 1 & 2 & 5 & 20 & $70 x$ & $95 \%$ & $90 \%$ & $70 x$ & 2 shifts/day & 2.5 & 2.6 & 2.7 & 124 & 113 & 99 & 64 & 0 & 0 & 67 & 68 & 68 & 68 & 65 & 64 & 6 \\
\hline 2 & 3 & 5 & 18 & $90 x$ & $95 \%$ & $90 \%$ & $70 \%$ & $\begin{array}{l}90 x \text { toe on fuel } \\
\text { retrieval }\end{array}$ & 2.2 & 2.3 & 2.6 & 115 & 103 & 88 & 74 & 20 & 0 & 67 & 67 & 67 & 67 & 66 & 66 & $7 *$ \\
\hline 3 & 3 & 5 & 18 & $80 x$ & $95 x$ & $90 \%$ & $70 x$ & $\begin{array}{l}\text { 80X ToE on fuel } \\
\text { retrieval }\end{array}$ & 2.5 & 2.6 & 2.6 & 124 & 113 & 96 & 63 & 4 & 0 & 67 & 68 & 67 & 67 & 66 & 65 & $6 *$ \\
\hline 4 & 3 & 5 & 18 & $70 x$ & $95 x$ & $90 \%$ & $70 x$ & $\begin{array}{l}\text { Fuel retrieval } \\
\text { times were reduced } \\
\text { by } 20 \text { hrs per MCo }\end{array}$ & 1.6 & 1.7 & 2.6 & 85 & 78 & 69 & 60 & 55 & 53 & 66 & 67 & 67 & 67 & 67 & 66 & 9 \\
\hline 5 & 3 & 5 & 18 & $70 x$ & $95 \%$ & $90 \%$ & $70 x$ & $\begin{array}{l}\text { Time to repair fuel } \\
\text { retrieval, MHH, and } \\
\text { hot conditioning } \\
\text { was increased }\end{array}$ & 2.8 & 2.8 & 2.8 & 135 & 119 & 98 & 44 & 4 & 0 & 69 & 70 & 67 & 66 & 64 & 64 & $6^{*}$ \\
\hline 6 & 3 & 7 & 18 & $70 \%$ & $95 \%$ & $90 x$ & $70 x$ & Horking 7 day/week & 2.0 & 2.1 & 2.5 & 112 & 102 & 90 & 81 & 15 & 0 & 68 & 67 & 66 & 66 & 67 & 66 & 6* \\
\hline 7 & 2 & 7 & 20 & $70 \%$ & $95 x$ & $90 x$ & $70 x$ & $\begin{array}{l}2 \text { shifts/day } 7 \\
\text { day/week }\end{array}$ & 1.9 & 2.0 & 2.5 & 106 & 92 & 86 & 73 & 43 & $\mathbf{0}$ & 67 & 67 & 67 & 67 & 67 & 65 & 7 \\
\hline 8 & 3 & 7 & 18 & $70 \%$ & $95 x$ & $90 \%$ & $70 x$ & $\begin{array}{l}5 \text { cold vacum } \\
\text { drying stations }\end{array}$ & 2.0 & 2.1 & 2.5 & 113 & 103 & 91 & 82 & 11 & ma & 68 & 66 & 67 & 67 & 67 & 65 & $6 *$ \\
\hline 9 & 3 & 7 & 18 & $70 \%$ & $95 x$ & $90 \%$ & $70 x$ & $\begin{array}{l}4 \text { cold vecuum } \\
\text { drying stations }\end{array}$ & 2.0 & 2.2 & 2.5 & 113 & 103 & 96 & 88 & MA & $\mathrm{Mn}$ & 66 & 67 & 67 & 67 & 67 & 66 & $6 *$ \\
\hline 10 & 3 & 7 & 18 & $70 x$ & $95 x$ & $90 x$ & $70 x$ & $\begin{array}{l}\text { Two CSB loedin/ } \\
\text { loadout pits }\end{array}$ & 2.0 & 2.2 & 2.5 & 116 & 102 & 93 & 84 & 5 & 0 & 65 & 67 & 66 & 68 & 68 & 66 & $6^{*}$ \\
\hline 11 & 3 & 7 & 18 & $70 \%$ & $95 \%$ & $90 \%$ & $70 x$ & $\begin{array}{l}5 \text { hot condition } \\
\text { stations }\end{array}$ & 2.0 & 2.1 & 2.8 & 111 & 102 & 89 & 80 & 18 & 0 & 79 & 80 & 79 & 81 & 81 & NA & 6 \\
\hline 12 & 3 & 7 & 18 & $70 x$ & $95 \%$ & $90 \%$ & $70 \%$ & $\begin{array}{l}4 \text { hot condition } \\
\text { stations }\end{array}$ & 2.0 & 2.1 & 3.3 & 112 & 102 & 92 & 82 & 12 & 0 & 101 & 100 & 100 & 99 & NA & MA & $6^{*}$ \\
\hline
\end{tabular}

* Uses one additional MCO less than 10 times. Using the amount specified should not significantly increase the time to finish. 
Table 2. Comparison of cases studied.

\begin{tabular}{|c|c|c|}
\hline $\begin{array}{l}\text { CASE COMPA- } \\
\text { RISON }\end{array}$ & $\begin{array}{l}\text { COMPARISON } \\
\text { DESCRIPTION }\end{array}$ & INTERPRETATION DF RESULTS \\
\hline BASE CASE & $\begin{array}{l}3 \text { shifts/day ( } 18 \text { hrs) } \\
5 \text { days/week (FRS) } \\
70 x \text { efficiency (FRS) }\end{array}$ & $\begin{array}{l}\text { Jakes } 2.7 \text { years to enpty basins; } K \text { West; } 2.8 \text { yrs to mpty KE; } \\
\text { takes } 2.9 \text { years to complete HVC; uses up to } 6 \text { cBsks. }\end{array}$ \\
\hline $\begin{array}{l}\text { BASE } \\
\text { CAS }\end{array}$ & $\begin{array}{l}\text { NUMBER OF SHIFTS/DAY: } \\
\text { Compare } 38 \mathrm{hr} \text { vs } 212 \mathrm{hr} \\
\text { shifts } / \mathrm{d} \text {, ie } 18 \mathrm{vs} 20 \mathrm{hr} / \mathrm{d} \\
\text { (for } 5 \mathrm{~d} / \text { wk operation) }\end{array}$ & $\begin{array}{l}\text { Reduces time to empty basins and complete HVC by } 2 \text { months; doesn't } \\
\text { affect number of casks used; doesn't affect number of CVD stations. }\end{array}$ \\
\hline $\begin{array}{l}\text { CASE } 6 \\
\text { VS } \\
\text { CASE } 7\end{array}$ & $\begin{array}{l}\text { NUMBER OF SHIFTS/DAY: } \\
\text { Compare } 38 \mathrm{hr} \text { vs } 212 \mathrm{hr} \\
\text { shifts } / \mathrm{d}, \text { ie } 18 \mathrm{vs} 20 \mathrm{hr} / \mathrm{d} \\
\text { (for } 7 \mathrm{~d} / \mathrm{wk} \text { operation) }\end{array}$ & $\begin{array}{l}\text { Doesn't affect time to empty basins; doesn't affect time to complete } \\
\text { HVC; doesn't affect number of casks used; } \\
\text { doesn't affect number of CVD stations. }\end{array}$ \\
\hline $\begin{array}{l}\text { BASE } \\
\text { VASE } 6\end{array}$ & $\begin{array}{l}\text { FRS OPERATING DAYS: } \\
\text { Compare } 5 \text { d/wk vs } \\
7 \text { d/wk FRS operations } \\
\text { (for } 38 \mathrm{hr} \text { shifts/d ops) }\end{array}$ & $\begin{array}{l}\text { Reduces time to empty basins by } 8 \text { months; reduces time to complete } \\
\text { HVC by } 5 \text { months; doesn't affect number of casks used; } \\
\text { doesn't affect number of CVD stations. }\end{array}$ \\
\hline $\begin{array}{l}\text { CASE } 1 \\
\text { VAS } \\
\text { CASE } 7\end{array}$ & $\begin{array}{l}\text { FRS OPERATING DAYS: } \\
\text { COMPare } 5 \mathrm{~d} / \mathrm{wk} \text { vs } \\
7 \mathrm{~d} / \mathrm{wk} \text { FRS operations } \\
\text { (for } 212 \mathrm{hr} \text { shifts/d ops) }\end{array}$ & $\begin{array}{l}\text { Reduces time to empty basins by } 6 \text { months; reduces time to complete } \\
\text { HVC by } 2 \text { month; increases number of casks used to } 7 \text {; doesn't affect } \\
\text { number of cVo stations. }\end{array}$ \\
\hline $\begin{array}{l}\text { BASE } \\
\text { CASE } \\
\text { CASE } 2\end{array}$ & $\begin{array}{l}\text { FRS OPERATING EFFICIENCIES: } \\
\text { Compare FRS operating efficiencies } \\
\text { of } 70 \% \text { (base), } 80 \% \text {, and } 90 \% \text {. }\end{array}$ & $\begin{array}{l}\text { Reduces time to empty basins by } 2 \text { and } 6 \text { months, respectively; } \\
\text { reduces time to complete HVC by } 4 \text { months, in either case; } \\
\text { increases the number of casks to } 6 \text { and } 7 \text {, respectively; } \\
\text { doesn't affect number of CVD stations. }\end{array}$ \\
\hline $\begin{array}{l}\text { BASE } \\
\text { CASE } \\
\end{array}$ & $\begin{array}{l}\text { FRS CYCLE TIMES: } \\
\text { Compare FRS cycle times of } 37 \\
\text { hrs /MCO (base) vs } 17 \text { hrs/MCo. }\end{array}$ & $\begin{array}{l}\text { Reduces time to empty basins } 13 \text { months; reduces time to complete HVC } \\
\text { by } 4 \text { months; increases the number of casks used to } 9 ; \\
\text { increases number of CVD stations to } 6 \text {. }\end{array}$ \\
\hline $\begin{array}{l}\text { BASE } \\
\text { CASE } 5\end{array}$ & $\begin{array}{l}\text { BREAKDOWN SEVERITY: } \\
\text { Compare base case breakdown } \\
\text { frequency and repsir times vs } \\
\text { fewer occurrences but longer } \\
\text { repair times. }\end{array}$ & $\begin{array}{l}\text { Marginally increases time to empty basins doesn't affect time to } \\
\text { complete HVC; doesn't affect number of casks used; } \\
\text { doesn't affect number of CVD stations. }\end{array}$ \\
\hline $\begin{array}{l}\text { CASE } 6 \\
\text { VS } \\
\text { CASE } 8 \\
\text { VAS } \\
\text { CASE } 9\end{array}$ & $\begin{array}{l}\text { NUMBER OF CVD STATIONS: } \\
\text { COMpare } 6 \text { CVD stations Vs } 5 \text { and } 4 \\
\text { CVD stations } \\
\text { ( } 7 \text { d/wk FRS operations) }\end{array}$ & $\begin{array}{l}\text { No apparent affect. } \\
\text { Doesn't affect time to empty basins; doesn't time to complete HVC; } \\
\text { doesn't affect number of casks used. }\end{array}$ \\
\hline $\begin{array}{l}\text { CASE } 6 \\
\text { VS } \\
\text { CASE } 11 \\
\text { VAS } 12 \\
\end{array}$ & $\begin{array}{l}\text { NUMBER OF HVC STATIONS: } \\
\text { Compare } 6 \text { HVC stations Vs } 5 \text { and } 4 \\
\text { HVC stations } \\
\text { ( } 7 \text { d/wk FRS operations) }\end{array}$ & $\begin{array}{l}\text { Doesn't affect time to empty besins; increases time to complete HVC } \\
\text { by } 4 \text { and } 10 \text { months, respectively; } \\
\text { doesn't affect number of casks used; } \\
\text { doesn't affect number of CVD stations. }\end{array}$ \\
\hline $\begin{array}{l}\text { CASE } 6 \\
\text { CASE } 10\end{array}$ & $\begin{array}{l}\text { NUMBER OF MCO PITS: } \\
\text { Compare } 1 \text { MCO pit in the CSB to } 2 \\
\text { MCO pits. } \\
\text { ( } 7 \text { d/wk FRS operations) }\end{array}$ & $\begin{array}{l}\text { No apparent affect. } \\
\text { Doesn't affect time to empty basins; doesn't time to complete HVC; } \\
\text { doesn't affect number of casks used; } \\
\text { doesn't affect number of CVD stations. }\end{array}$ \\
\hline
\end{tabular}


WHC-SD-SNF-RPT-011

Rev. 0

\subsection{RECOMMENDATIONS}

\subsection{SYSTEM MODEL REFINEMENT}

The process simulation model evaluates the flow of spent nuclear fuel from retrieval to storage using the base case configuration and cycle times. Comparison cases were run using different operating configurations or cycle times (i.e., five vacuum stations instead of six or 17 hours to fill an MCO instead of 37), to determine the effects on throughput and schedule. Additional sensitivity analyses can be run to evaluate the effects of changing other parameters or combinations.

The results of process simulation studies from each of the SNF subprojects can be imported into the integrating model to further refine the overall project capacity and queue sizing. There is a need to verify the consistency of data for each element of the model with the responsible design authority, and to review the development of the cycle times to ensure common assumptions and limitations, and definitions of terms.

\subsection{CASK HANDLING AND TRANSPORTATION CREW}

Additional studies can be performed to analyze the cask handling and transportation system to determine how many trucks and crews will be required. This can most easily be done by decomposing the main processes into functions performed by the fixed crew and functions performed by the traveling crew, then apportioning the cycle times to these sequences of functions. The process simulation model can be modified to incorporate these changes and further refine the system capacity.

\subsection{CSB OPERATIONS}

There are a number of uncertainties in the process cycle times for the CSB, which could cause distortions to model results and conclusions. This is compounded by the fact that there are several pieces of equipment that are single items with no identified work-arounds, and because of schedule conflicts when some of this equipment is competing for common space. Receiving, inspecting, and rework/testing of empty MCO's is not addressed in the mode1. Schedule interferences between the cask handling function of the overhead crane and the HVC loading/unloading function of material handling machine working in the same common space is not currently addressed in the model. Cycle time for the truck in the CSB could be greatly improved if the number of cask pits were increased and the work flow modified; al so empty MCO handling could be improved, and schedule conflicts with the MHM could be mitigated.

\subsection{ACCOUNTING FOR MAINTENANCE, BREAKDOWNS, REWORK, AND ACCIDENTS}

The case comparisons showed that marginal increases in breakdown severity result in marginal increases in basin emptying time. However, the breakdown frequencies and repair times in both the base case and the comparison case were somewhat arbitrary, leading to potential distortion of 
WHC-SD-SNF-RPT-011

Rev. 0

the results and conclusions. A better representation of breakdown frequencies and repair times can be estimated by identifying equipment suspect of failure, and contacting suppliers and users for reliability and maintainability analyses of similar mechanical and electrical equipment. Similar studies can examine the effects of product rework, and accident scenarios on fuel throughput and how they affect the schedule.

\subsection{LABOR RESOURCE ALLOCATION}

The Witness model assumes that there is an unlimited supply of labor resources available, as and where needed. This deficiency detracts from the validity of the results, and should be addressed in the model. Accurately allocating labor resources within the model will require the development of process flow charts, precedence network diagrams, time standards and work allowances, and line balancing and manpower models. A process flow chart provides graphic representation of the work performed on a product as it passes through each stage of a process, including quantity, distance moved, type of work done, and equipment used. A precedence network diagram graphically depicts the discrete tasks within each work element, the predecessors, successors, restrictions, and limitations on each task, and logically connects them in parallel or series to show how the work could be structured. Time standards can then be developed for each task by using the $K$ Basins studies performed last year., industrial engineering handbooks and texts, and Department of Defense work measurements and standards. Work allowances are applied to cover the use of personnel protective equipment, personnel fatigue and mental stress, radiation exposure and environmental conditions, etc. Then the line balancing and manpower modeling optimizes the work process and allocates the labor resources. This information can be incorporated into the Witness model to further improve the accuracy of the simulation and validity of the results.

\subsection{DETAILED DISCUSSION}

Witness is a simulation programming language used to build computer models of queuing systems. The SNF project simulation is a closed system with a set amount of serving devices moving through a series of processes. Each of these processes may be seen as a simple queuing model. Each of these simple models consist of a single process containing a piece or group of equipment performing some sort of service on demand. "Customers" come up to this "server" at random times, wait their turn (if necessary) for service, are served on a first-come-first-served basis, then leave. This situation depicted schematically in Figure 4.1 in which the row of circles represents waiting customers, the square represents the server, and the circle within the square represents the customer currently being served. 
WHC-SD-SNF-RPT-011

Rev. 0

Figure 4.1. Illustration of a One-line, One Server Queuing System.

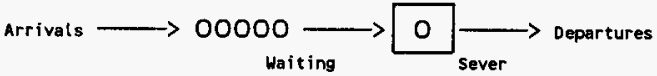

The line formed by those waiting for service is termed a "queue". The configuration consisting of the server, the customer being served, and those waiting to be served, is termed a "queuing system".

The simple system shown in Figure 1.1 is characterized by two independent random variables. The time between consecutive arrivals of customers to the system, often called the "interval time," is a random variable. Time required for the server to perform a service is also a random variable and termed "service time". The distributions followed by these two independent random variables influence system properties and are listed below.

1. Number of customers who arrive for service during a given time span.

2. Number of customers who are able to go immediately into service when they arrive.

3. Average time customers spend in the queue.

4. Average length of the queue.

5. Maximum length of the queue.

6. Server's utilization; that is the fraction of the time that the server spends providing service during a given time span. System properties such as these are of special interest when economic considerations or project milestones are involved.

Analyzing the SNF Project is a series of simple models that are integrated into a larger system, adding complexity because of the interaction between each model. Additional constraints are added because of the interaction to the queuing system, consequently increasing its complexity.

Discrete simulation occurs when the dependent system variables change at specifies points in simulated time. The time variable may be either continuous or discrete in such a model. Depending on whether the discrete changes in the dependent variable can occur at any time or only at specified times.

Running a discrete simulation model on a computer is in essence a complex sampling experiment. Thus the procedures for designing and analyzing simulation runs are similar to the techniques used in other scientific experiments. The main difference is that the simulation analyst has greater control over the experimental conditions. An appropriate statistical analysis is necessary (1) use simulation-generated data efficientiy in the estimation of system performance measures and (2) reveal the scope and limitations of the conclusions based on the data. 
It is necessary to characterize the random variables of a system by particular probability distributions when formulating a simulation model. When selecting an appropriate distribution for an input process, the analyst must understand some of the basic properties of common distributions and the circumstances in which those distributions arise. Initially a uniform distribution was used to examine the system response. This distribution is often used as a first approximation when the real quantity varies between two values but little else is known. Following the initial model development a triangular distribution was selected because of confidence that a minimum, maximum and a most likely value - mode could be established.

The schematic of the SNFP system shown in Figure 4.2 and process cycle times and efficiencies from Table 4 were used to develop the base model. Additionally, startup of $K$ East basins are delayed three months from the startup of $K$ West basins and the hot conditioning stations start nine months after, $K$ West. Table 4 lists each process involved, a description of what's included in the cycle time, the operating efficiency, the distribution type, mid, mode and max hours for each process, and the process work week.

Figure 4.2. Spent Nuclear Fuel Project Schematic Used for Witness Modeling.

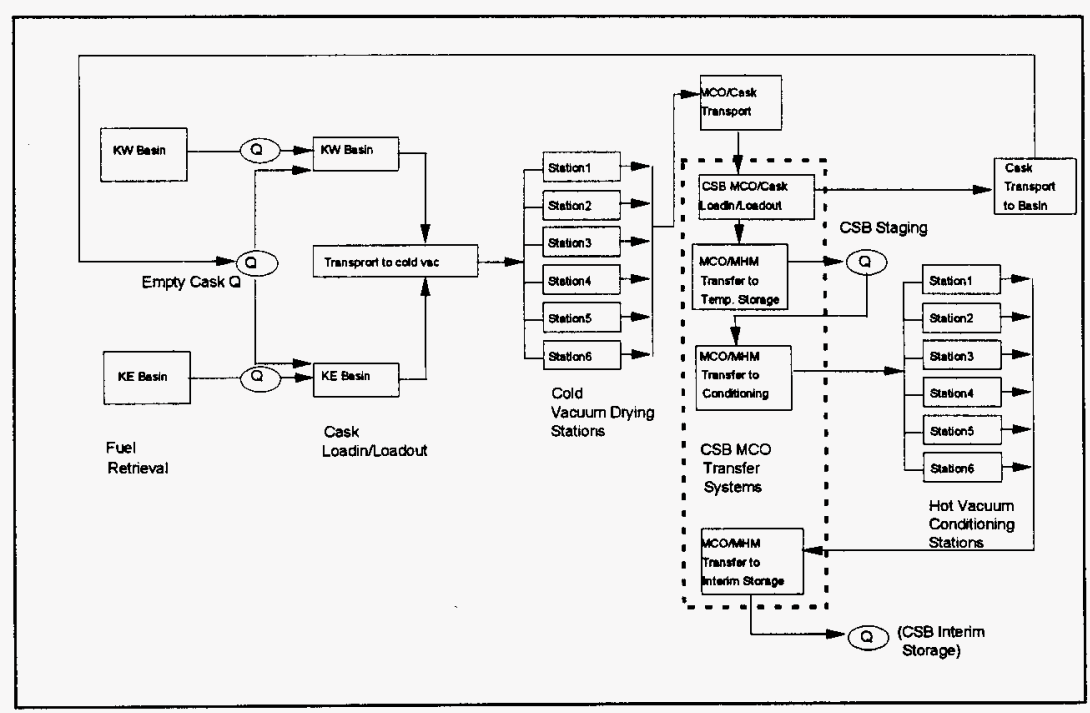

A1l cases examined have a learning curve factored into the model. The learning curve is 3 months for $K$ East and 6 months for $K$ West. Table 2 and Table 3 shows a breakdown of the hours worked per day for each month of the learning curve. 
Table 2. Ramp-up cycle for K West basin.

\begin{tabular}{||l|l|l|l|l|l|l|l|}
\hline Month & 1 & 2 & 3 & 4 & 5 & 6 & 7 \\
\hline Hrs work & 2 & 5 & 8 & 11 & 14 & 17 & 18 \\
\hline Hrs Rest & 22 & 19 & 16 & 13 & 10 & 7 & 6 \\
\hline Hrs delay & 0 & 720 & 1440 & 2184 & 2904 & 3624 & 4368 \\
\hline
\end{tabular}

Table 3. Ramp-up cycle for K East basin.

\begin{tabular}{|l|l|l|l|l|l|l|l||}
\hline Month & 1 & 2 & 3 & 4 & 5 & 6 & 7 \\
\hline Hrs work & 0.00 & 0.00 & 0.00 & 3 & 9 & 15 & 18 \\
\hline Hrs Rest & 0.00 & 0.00 & 0.00 & 21 & 15 & 9 & 6 \\
\hline Hrs delay & 0.00 & NA & NA & 2184 & 2904 & 3624 & 4368 \\
\hline
\end{tabular}

\subsection{BASE CASE (THREE 8 HR SHIFTS/DAY, 5 DAYS/WEEK)}

In the base model all processes are based on a five day work week except for cold vacuum drying and the hot vacuum conditioning, they have a seven day work week. Each process operates 3 shifts/day assuming schedules achieve $18 \mathrm{hrs}$ of system operation per $24 \mathrm{hr}$ day.

The operating efficiency for all systems is approximately $70 \%$ except the crane in the CSB loadin/loadout pit (95\%) and the MHM (90\%). The cycle times for each process and a description of what's included in the cycle times are shown in Table 4.

The base model has one fuel retrieval line and one MCO loading station in each basin. There is one transportation device that picks up the MCO's from either the East or West basin and transports it to one of the six available vacuum drying stations. From vacuum drying there is another transporter that takes the MCO to the loadin/loadout pit at the CSB and a third transporter that takes empty MCO's back to the basin. There is one crane in the CSB that removes the MCO from the cask and one material handling machine for placing the MCO's into hot conditioning or storage. Finally there are six hot conditioning stations in an annex attached to the CSB. 
WHC-SD-SNF-RPT-011

Rev. 0

Figure 4.3 Is a representation of the percentage of time that each machine was busy processing the fueT, blocked and waiting to release a MCO or breakdown.

Figure 4.3. Base Case Machine Usage.

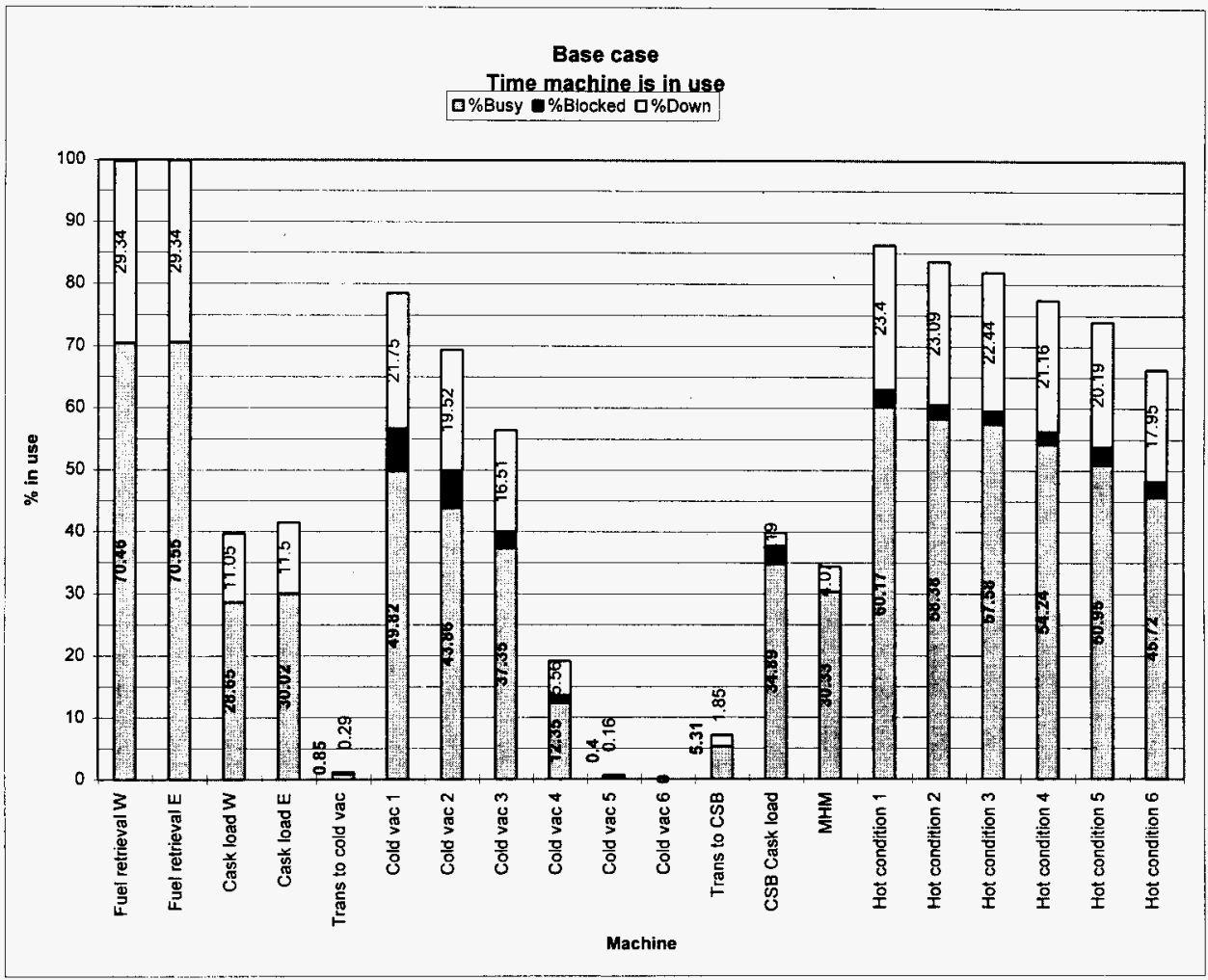


WHC-SD-SNF-RPT-011

Rev. 0 Table 4. Spent Nuclear Fuel Project Element Time Cycles used for Model
Development.

\begin{tabular}{|c|c|c|c|c|c|}
\hline Process Name & Cycle Time Description & $\begin{array}{l}\text { Operating } \\
\text { efficiency }\end{array}$ & \multicolumn{2}{|c|}{$\begin{array}{l}\text { Dist. Type } \\
\text { min/mode/max }\end{array}$} & Work Week \\
\hline $\begin{array}{l}\text { Transport new } \\
\text { MCO from CSB } \\
\text { to basin }\end{array}$ & $\begin{array}{l}\text { Time to transfer new MCO cask from just outside the CSB to just outside the basin } \\
\text { Loadout area door. }\end{array}$ & $70 \%$ & \multicolumn{2}{|c|}{$\begin{array}{c}\text { Triangular } \\
0.5 / 1 / 4\end{array}$} & $\begin{array}{l}5 \text { days/week } \\
3 \text { shifts/day } 3 \\
\text { shifts/day }\end{array}$ \\
\hline Fuel Retrieval & $\begin{array}{l}\text { Time to produce the equivalent of one MCO of fuel baskets placed in the basin } \\
\text { queue. }\end{array}$ & $70 \%$ & \multicolumn{2}{|c|}{$\begin{array}{l}\text { Triangular } \\
36 / 37 / 50 \\
\end{array}$} & $\begin{array}{l}5 \text { days/week } \\
3 \text { shifts/day }\end{array}$ \\
\hline $\begin{array}{l}\text { Cask Loadin } \\
\text { Loadout }\end{array}$ & $\begin{array}{l}\text { Time basin loadout area is occupied by a single MCO/Cask. Includes transport } \\
\text { entering basin loadout area door, placing cask in loadout plt, loading baskets in } \\
\text { MCO, placing shield plug on MCO, returning MCO to transport, removing transport } \\
\text { from loadout area, and preparing to receive next empty caskMCO at basin. }\end{array}$ & $70 \%$ & \multicolumn{2}{|c|}{$\begin{array}{l}\text { Triangular } \\
12 / 16.9 / 26\end{array}$} & $\begin{array}{l}5 \text { days/week } \\
3 \text { shifts/day }\end{array}$ \\
\hline $\begin{array}{l}\text { Transport MCO } \\
\text { from Basin to } \\
\text { Cold Vacuum } \\
\text { Drying }\end{array}$ & $\begin{array}{l}\text { Time to transfer MCO/Cask from just outside basin door to just outside entry point of } \\
\text { a Vacuum Drying station within the } 100 \mathrm{~K} \text { Area. }\end{array}$ & $70 \%$ & \multicolumn{2}{|c|}{$\begin{array}{l}\text { Triangular } \\
0.1 / 0.25 / 0.5\end{array}$} & $\begin{array}{l}5 \text { days/week } \\
3 \text { shifts/day }\end{array}$ \\
\hline $\begin{array}{l}\text { K Basin } \\
\text { Vacuum Drying } \\
\text { Stations, } \\
\text { includes } \\
\text { welding }\end{array}$ & $\begin{array}{l}\text { Time a single Vacuum Drying station is occupied by a MCO. Includes time to bring } \\
\text { MCO/Cask from entry point into station, secure MCO/Cask in station, weld shield } \\
\text { plug on MCO, complete pre-processing attachments, complete the actual drying } \\
\text { cycle, test the MCO weld based on } 63 \mathrm{hr} \text { base cycle time, remove the dried } \\
\text { MCO/Cask from the station to just outside the drying station entry point, and prepare } \\
\text { the drying station to recelve another MCO/Cask, includes short drying time for good } \\
\text { fuel in minimum, long drying time for weld repair in maximum. }\end{array}$ & $70 \%$ & \multicolumn{2}{|c|}{$\begin{array}{l}\text { Triangular } \\
74 / 84 / 113\end{array}$} & $\begin{array}{l}7 \text { days/week } \\
3 \text { shifts/day }\end{array}$ \\
\hline $\begin{array}{l}\text { Transport MCO } \\
\text { from } 100 \mathrm{~K} \text { to } \\
200 \mathrm{E} \text { Area }\end{array}$ & $\begin{array}{l}\text { Time to move the MCO/Cask from just outside a Vacuum Drying station located in } \\
\text { the } 100 \mathrm{~K} \text { Area to a point just outside the Canister Storage Building entry point } \\
\text { located in the } 200 \text { E Area }\end{array}$ & $70 \%$ & \multicolumn{2}{|c|}{$\begin{array}{l}\text { Triangular } \\
0.5 / 1 / 4\end{array}$} & $\begin{array}{l}5 \text { days/week } \\
3 \text { shifts/day }\end{array}$ \\
\hline $\begin{array}{l}\text { CSB } \\
\text { MCO/Cask } \\
\text { Loadin' } \\
\text { Loadout }\end{array}$ & $\begin{array}{l}\text { Time the CSB cask loadin/loadout area is occupied by a single cask. Includes } \\
\text { transport entering the bullding with a loaded MCO/Cask from just outside the CSB } \\
\text { entry point, off loading the cask to the service pit, vent and purge of the MCO, } \\
\text { removal of MCO from the cask by the MHM, insertion of a new MCO in the cask, } \\
\text { returning the cask to the transport, ready the transport for hookup, and any } \\
\text { preparations of the CSB loadinloadout area for receipt of the next cask. }\end{array}$ & $95 \%$ & \multicolumn{2}{|c|}{$\begin{array}{l}\text { Triangular } \\
10.4 / 11.4 / \\
13.4\end{array}$} & $\begin{array}{l}5 \text { days/week } \\
3 \text { shifts/day }\end{array}$ \\
\hline $\begin{array}{l}\text { MCOMHM } \\
\text { Transfer to } \\
\text { Staging }\end{array}$ & $\begin{array}{l}\text { Time the MHM is occupied with transfer of a MCO trom the CSB service pit to } \\
\text { placement in a staging tube. Includes moving the MHM to a position over the cask } \\
\text { in the service pit for removal of a MCO, removal of the MCO from the cask, moving } \\
\text { the MHMMCO to a staging tube, placing the MCO in the tube, and any other time } \\
\text { the MHM is used to support placing that specific MCO in staging until it is free to } \\
\text { move another MCO. }\end{array}$ & $90 \%$ & \multicolumn{2}{|c|}{$\begin{array}{l}\text { Triangular } \\
3 / 3.25 / 4\end{array}$} & $\begin{array}{l}5 \text { days/week } \\
3 \text { shifts/day }\end{array}$ \\
\hline $\begin{array}{l}\text { MCOMHM } \\
\text { Transfer to } \\
\text { Conditioning }\end{array}$ & $\begin{array}{l}\text { Time the MHM is occupied with transfer of a MCO from a staging tube to Hot } \\
\text { Vacuum Conditioning. Includes moving the MHM to a staging tube position, } \\
\text { removing the MCO from the tube, moving the MHMMCO to a Hot Vacuum } \\
\text { Conditioning station, placing the MCO in the station, and any other time the MHM is } \\
\text { used to support moving that specific MCO to a Hot Vacuum Conditioning station until } \\
\text { it is free to move another MCO. }\end{array}$ & $90 \%$ & \multicolumn{2}{|c|}{$\begin{array}{l}\text { Triangular } \\
3 / 3.25 / 4\end{array}$} & $\begin{array}{l}5 \text { days/week } \\
3 \text { shifts/day }\end{array}$ \\
\hline $\begin{array}{l}\text { Hot Vacuum } \\
\text { Conditioning } \\
\text { Stations }\end{array}$ & $\begin{array}{l}\text { Time a single Hot Vacuum Conditioning station is occupied by a MCO. Includes time } \\
\text { to place MCO in a station by the MHM, cooling and pre-processing hookups, } \\
\text { complete the actual conditioning cycle, inserting and closure of the MCO, removal of } \\
\text { the MCO from a station by the MHM, and any preparation of the conditioning station } \\
\text { to receive another MCO. }\end{array}$ & $70 \%$ & $\begin{array}{l}80 \% \\
\text { of } \\
M C O\end{array}$ & $\begin{array}{l}20 \% \\
\text { of } \\
\text { MCO }\end{array}$ & $\begin{array}{l}7 \text { days/week } \\
3 \text { shifts/day }\end{array}$ \\
\hline $\begin{array}{l}\text { MCOMHM } \\
\text { Transfer from } \\
\text { Conditioning }\end{array}$ & $\begin{array}{l}\text { Time the MHM is occupied with transfer of a MCO from a Hot Vacuum Conditioning } \\
\text { station to an interim storage tube. Includes moving the MHM to a conditioning } \\
\text { station, removal of the MCO from the station, moving the MHMMCO to an interim } \\
\text { storage tube, placing the MCO in the tube, and any other time the MHM is used to } \\
\text { support placing that specific MCO in interim storage until it is free to move another } \\
\text { MCO. }\end{array}$ & $90 \%$ & \multicolumn{2}{|c|}{$\begin{array}{l}\text { Triangular } \\
3 / 3.25 / 4\end{array}$} & $\begin{array}{l}5 \text { days/week } \\
3 \text { shifts/day }\end{array}$ \\
\hline
\end{tabular}


WHC-SD-SNF-RPT-011

Rev. 0

\subsection{CASE 1. TWO 12 HR SHIFTS/DAY, 5 DAYS/WEEK.}

Case 1 has the same operating efficiency and number of stations as the base case. There are two shifts in case 1 operating 12 hrs/day to achieve 20 hrs production in a $24 \mathrm{hr}$ day.

Figure 4.4 Is a representation of the percentage of time that each machine was busy processing the fuel, blocked and waiting to release a MCO or breakdown.

Figure 4.4. Case 1 Machine Usage.

Case 1.

Time machine is in use

[\% \%usy \%Blocked Q\%Down

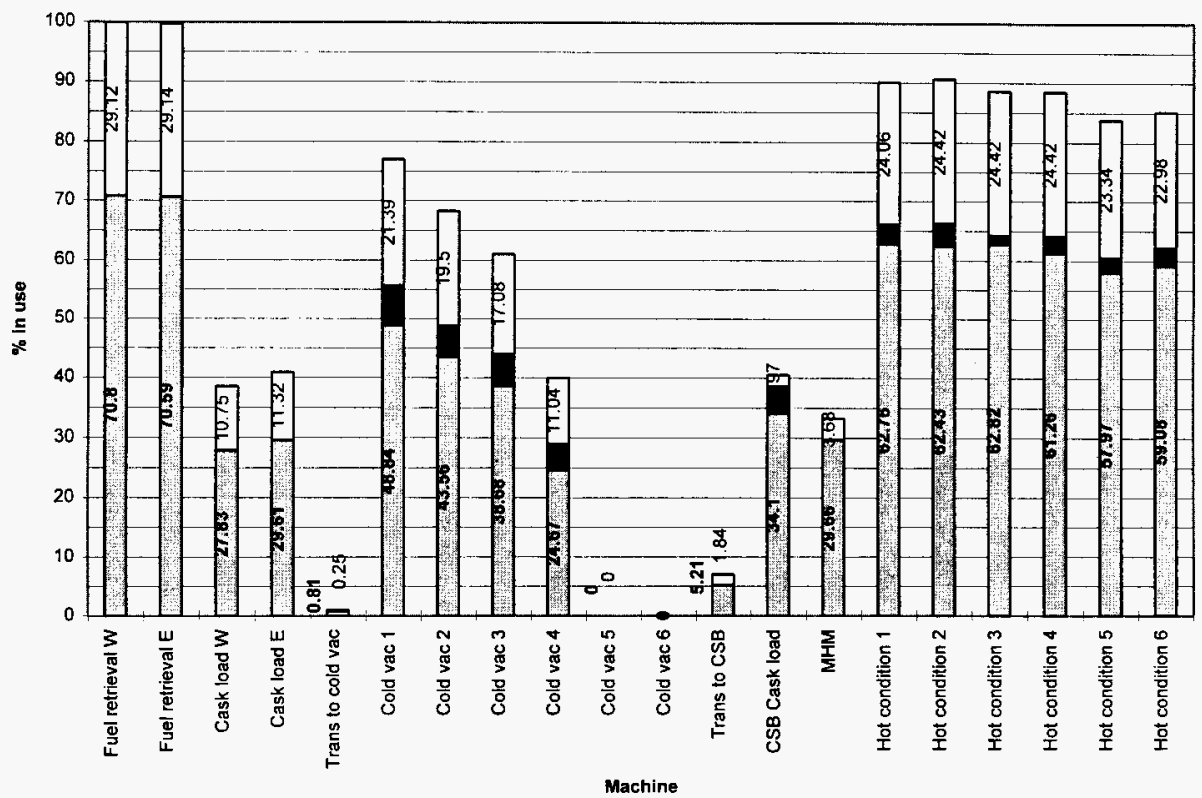


WHC-SD-SNF-RPT-011

Rev. 0

\subsection{CASE 2. THREE BHR SHIFTS/DAY, 5 DAYS/WEEK. FUEL RETRIEVAL OPERATING AT $90 \%$ EFFICIENCY.}

Case 2 has the same number of stations and the same shifts as the base case but the operating efficiency of the fuel retrieval lines in both $K$ East and $K$ West are at $90 \%$. All other processes have the same operating efficiency as the base case.

Figure 4.5 Is a representation of the percentage of time that each machine was busy processing the fuel, blocked and waiting to release a MCO or breakdown.

Figure 4.5. Case 2 Machine Usage.

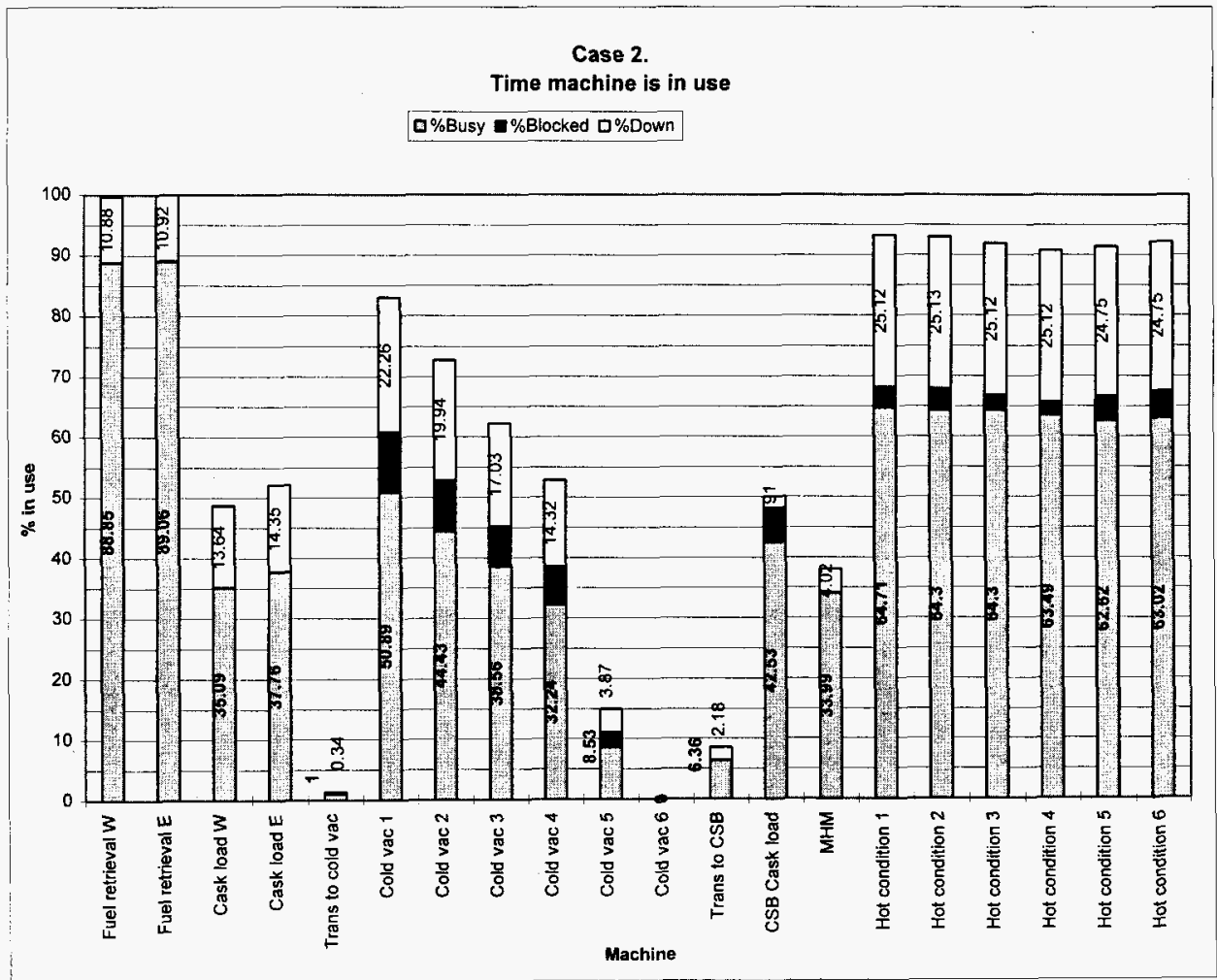


WHC-SD-SNF-RPT-011

Rev. 0

\subsection{CASE 3. THREE 8HR SHIFTS/DAY, 5 DAYS/WEEK. FUEL RETRIEVAL OPERATING AT $80 \%$ EFFICIENCY.}

Case 3 has the same number of stations and the same shifts as the base case but the operating efficiency of the fuel retrieval lines in both $K$ East and $K$ West are at $80 \%$. All other processes have the same operating efficiency as the base case.

Figure 4.6 Is a representation of the percentage of time that each machine was busy processing the fuel, blocked and waiting to release a MCO or breakdown.

Figure 4.6. Case 3 Machine Usage.

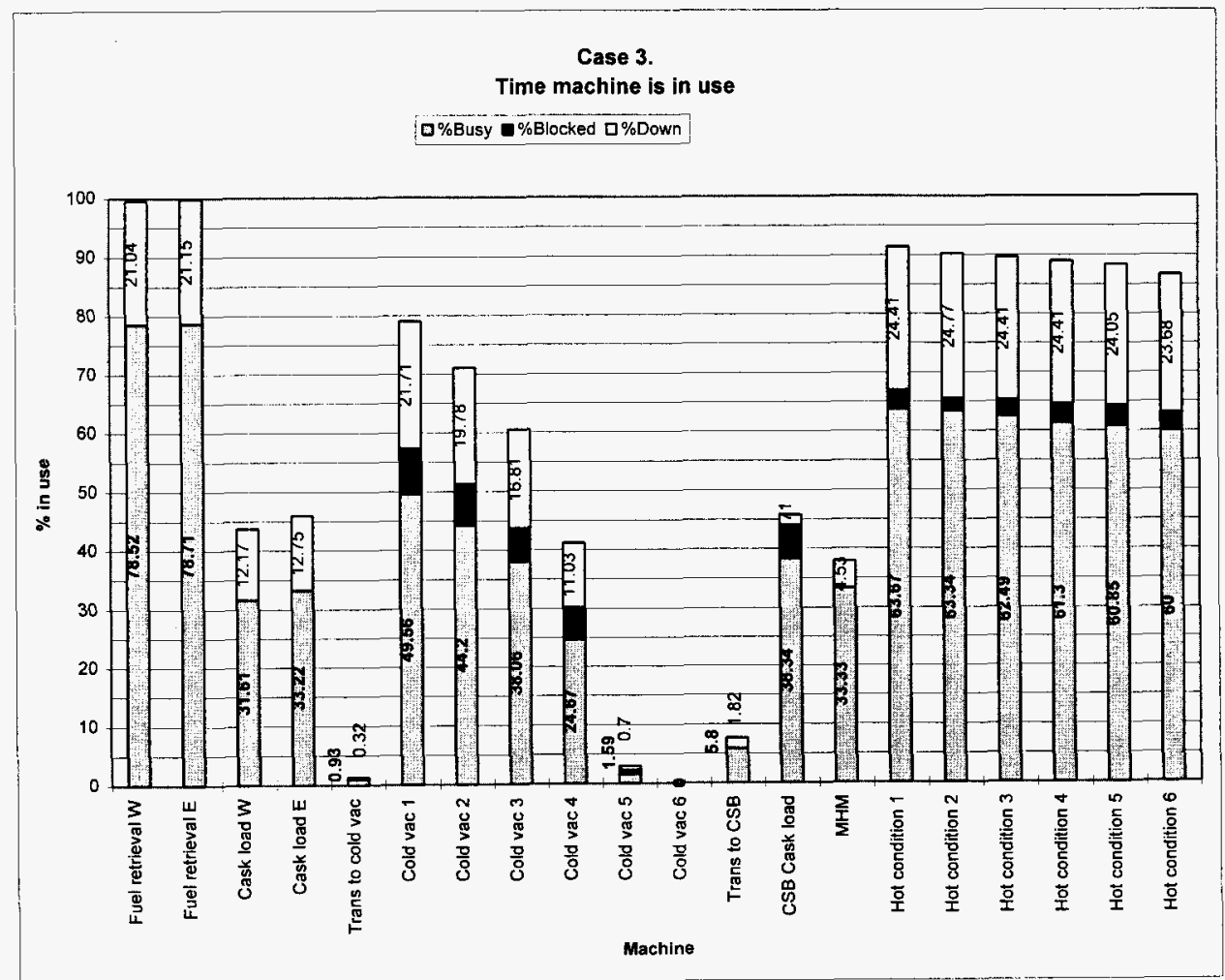


WHC-SD-SNF-RPT-011

Rev. 0

\subsection{CASE 4. THREE 8 HR SHIFTS/DAY, 5 DAYS/WEEK. FUEL RETRIEVAL CYCLE TIMES OF MIN $=16$, MODE $=17$, AND MAX $=30$.}

Case 4 has the same operating efficiencies, the same shifts and the same number of stations as the base case. The fuel retrieval cycle has the same triangular distribution with the min, mode, and $\max$ of 16,17 , and $30 \mathrm{hr}$, respectively.

Figure 4.7 Is a representation of the percentage of time that each machine was busy processing the fuel, blocked and waiting to release a MCO or breakdown.

Figure 4.7. Case 4 Machine Usage.

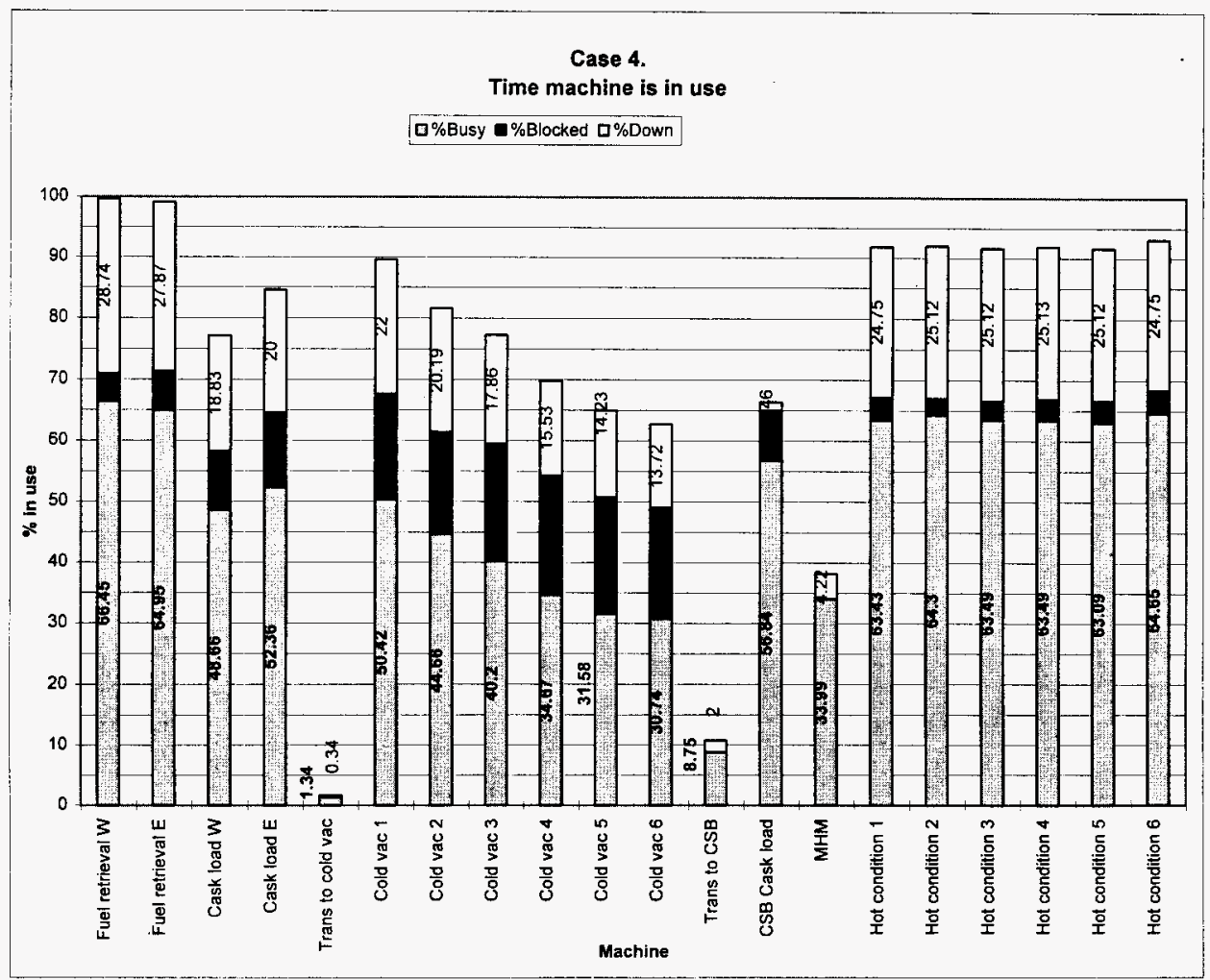


WHC-SD-SNF-RPT-011

Rev. 0

\subsection{CASE 5. THREE 8 HR SHIFTS/DAY, 5 DAYS/WEEK. WITH LONG REPAIR TIMES ON FUEL RETRIEVAL, MHM, AND HOT CONDITIONING.}

Case 5 has the same operating efficiencies, the same shifts and the same number of stations as the base case. The time to repair various machines was increased and the interval between breakdowns was al so increased to keep the operating efficiency at $70 \%$. The repair time for fuel retrieval went from 17 to $23 \mathrm{hrs}$, the MHM went from 6 to $15 \mathrm{hrs}$, and hot conditioning went from 60 to 120 hrs.

Figure 4.8 Is a representation of the percentage of time that each machine was busy processing the fuel, blocked and waiting to release a MCO or breakdown.

Figure 4.8. Case 5 Machine Usage.

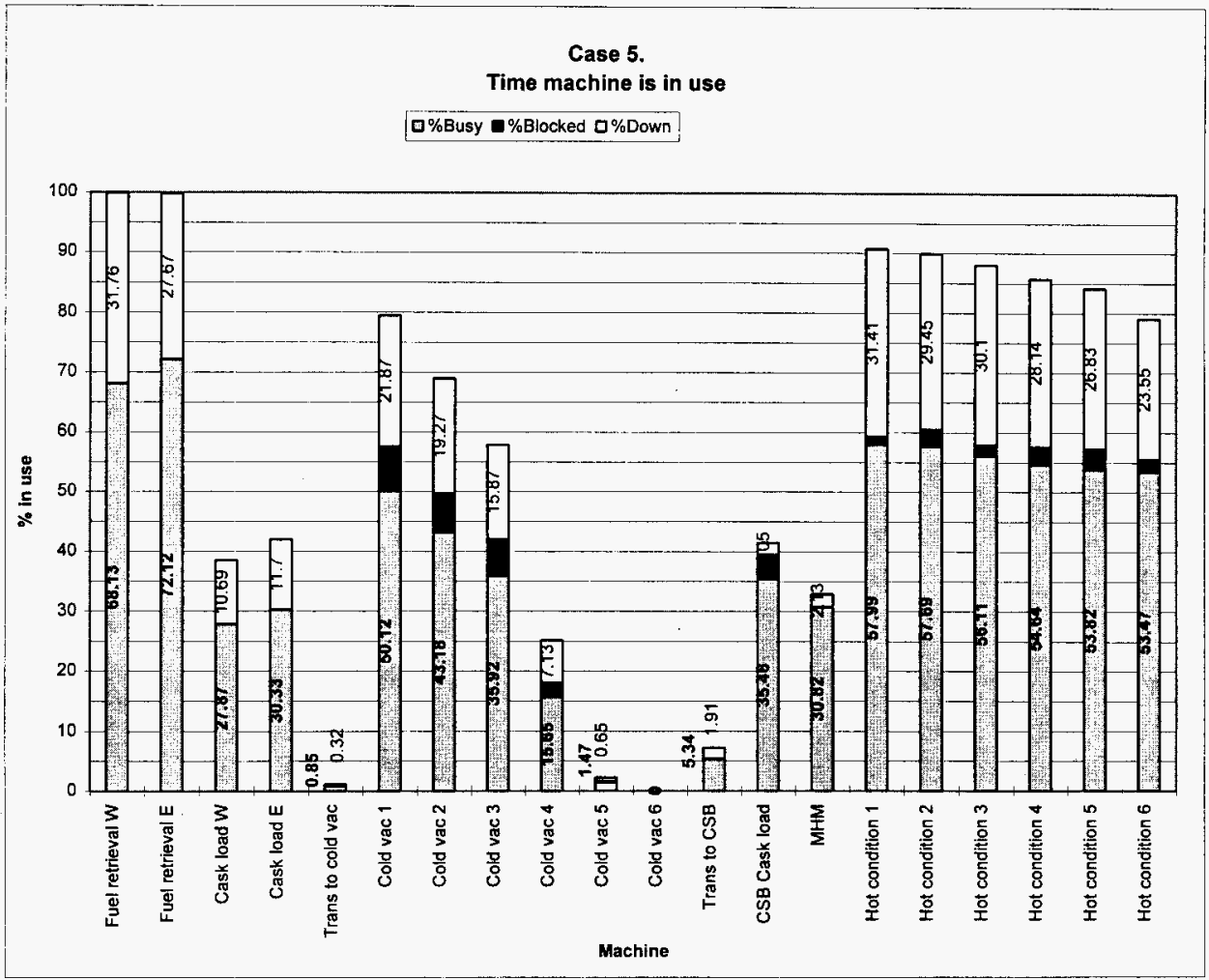


WHC-SD-SNF-RPT-011

Rev. 0

\subsection{CASE 6. THREE 8 HR SHIFTS/DAY, 7 DAYS/WEEK.}

Case 6 is used as a base model for 7 day/week operations. A11 processes are based on a seven day work week. Each process operates 3 shifts/day assuming achieve $18 \mathrm{hrs}$ of system operation per $24 \mathrm{hr}$ day.

The operating efficiency for all systems is approximately $70 \%$ except for the crane in the CSB loadin/loadout pit (95\%) and the MHM (90\%). The cycle times for each process and a description of what's included in the cycle times are shown in Table 4.

Case 6 model has one fuel retrieval line and one MCO loading station in each basin. There is one transportation device that picks up the MCO's from either the East or West basin and transports it to one of the six available vacuum drying stations. From vacuum drying there is another transporter that takes the MCO to the loadin/loadout pit at the CSB and a third transporter that takes empty MCO's back to the basin. There is one crane in the CSB that removes the $M C O$ from the cask and one material handling machine for placing the MCO's into hot conditioning or storage. Finally there are six hot conditioning stations available in an annex attached to the CSB. 
Figure 4.9 Is a representation of the percentage of time that each machine was busy processing the fuel, blocked and waiting to release a MCO or breakdown.

Figure 4.9. Case 6 Machine Usage.

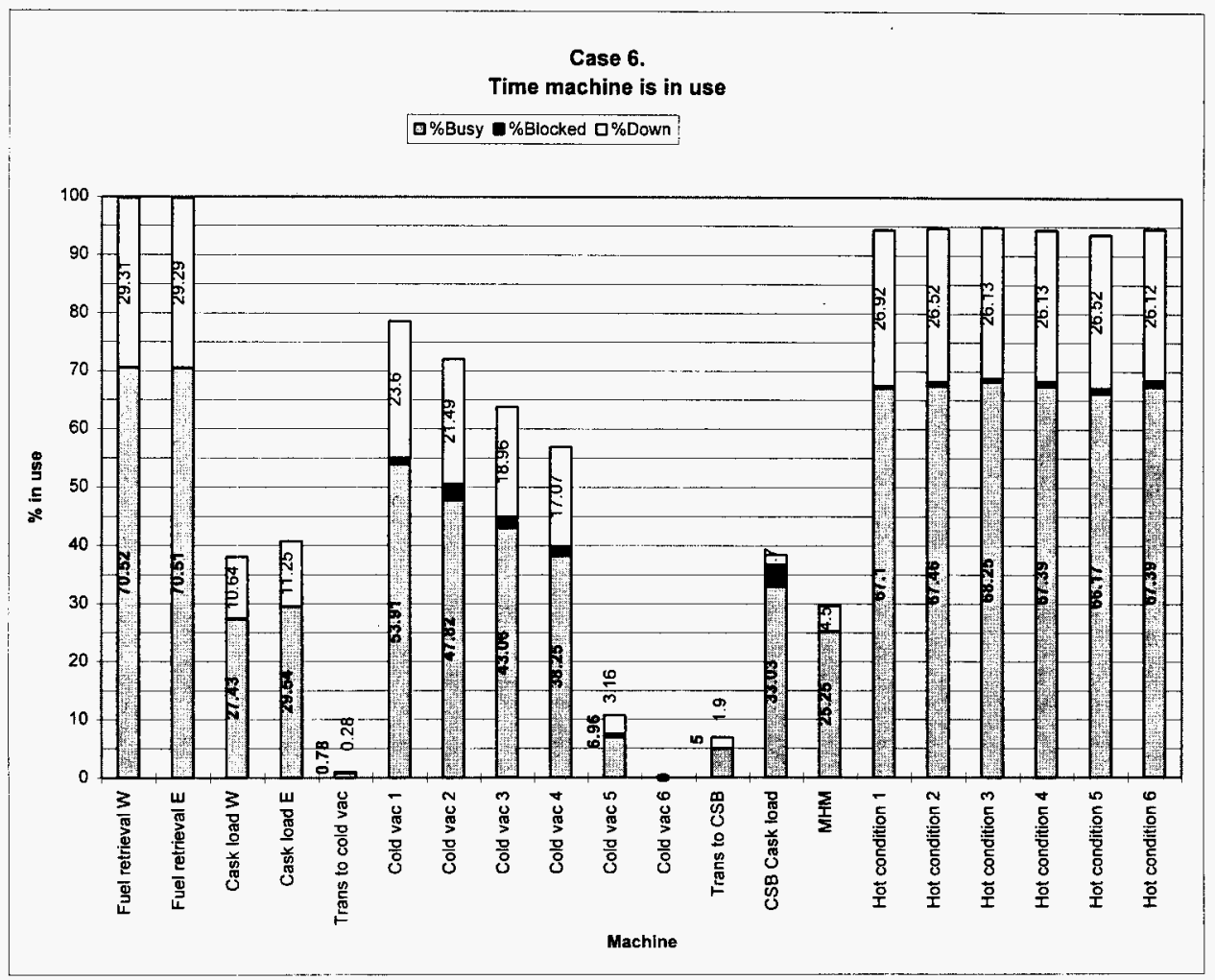


WHC-SD-SNF-RPT-011

Rev. 0

\subsection{CASE 7. TWO 12 HR SHIFTS/DAY, 7 DAYS/WEEK.}

Case 7 has the same operating efficiency and number of stations as case 6. There are two shifts in case 7 operating 12 hrs/day to achieve 20 hrs production in a $24 \mathrm{hr}$ day.

Figure 4.10 Is a representation of the percentage of time that each machine was busy processing the fuel, blocked and waiting to release a MCO or breakdown.

Figure 4.10. Case 7 Machine Usage.

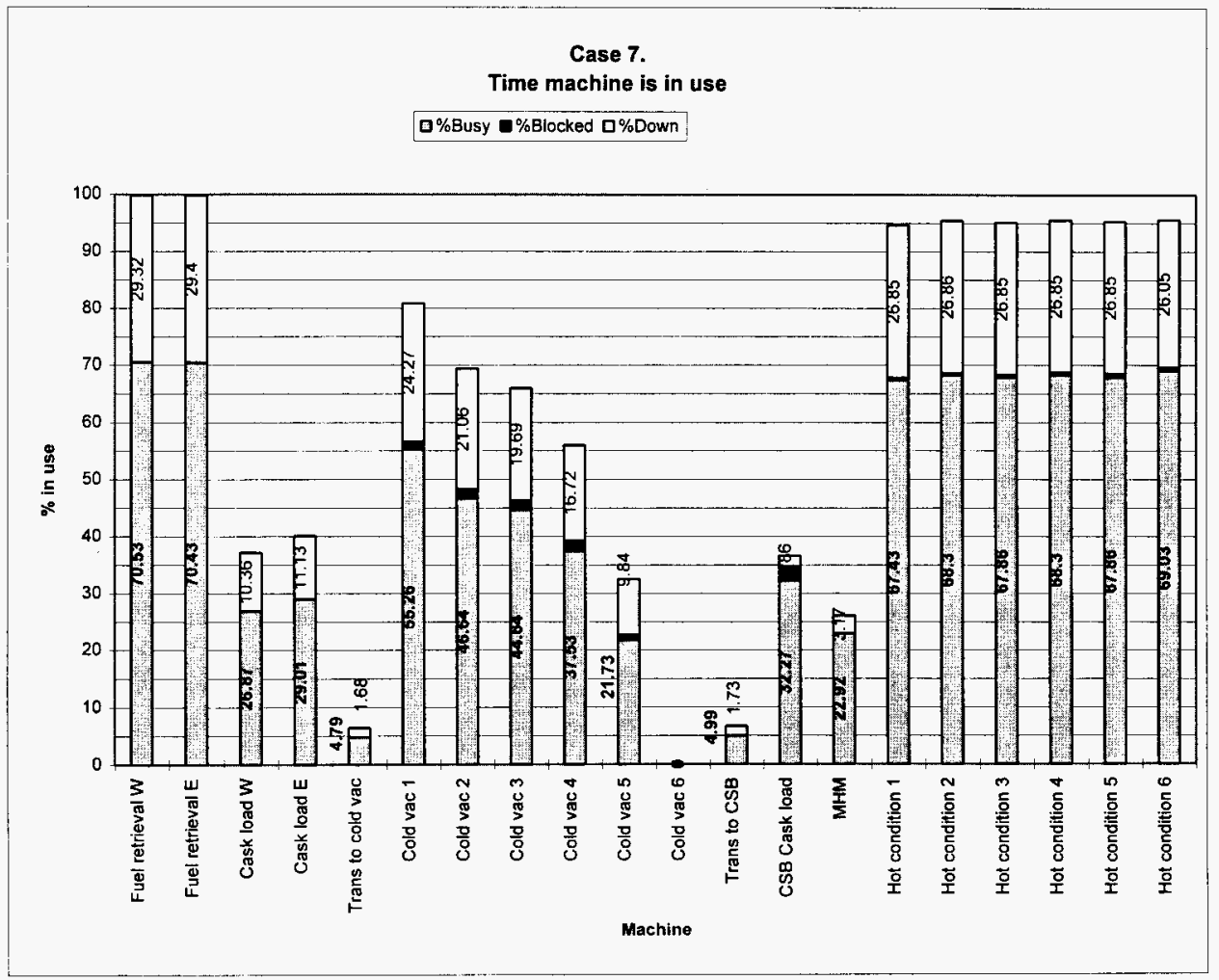


WHC-SD-SNF-RPT-011

Rev. 0

\subsection{CASE 8. THREE 8 HR SHIFTS/DAY, 7 DAYS/WEEK. USING 5 COLD VACUUM DRYING STATIONS.}

Case 8 has the same operating efficiency and the same shifts as case 6 . There are only 5 cold vacuum drying stations in case 8 .

Figure 4.11 Is a representation of the percentage of time that each machine was busy processing the fuel, blocked and waiting to release a MCO or breakdown.

Figure 4.11. Case 8 Machine Usage.

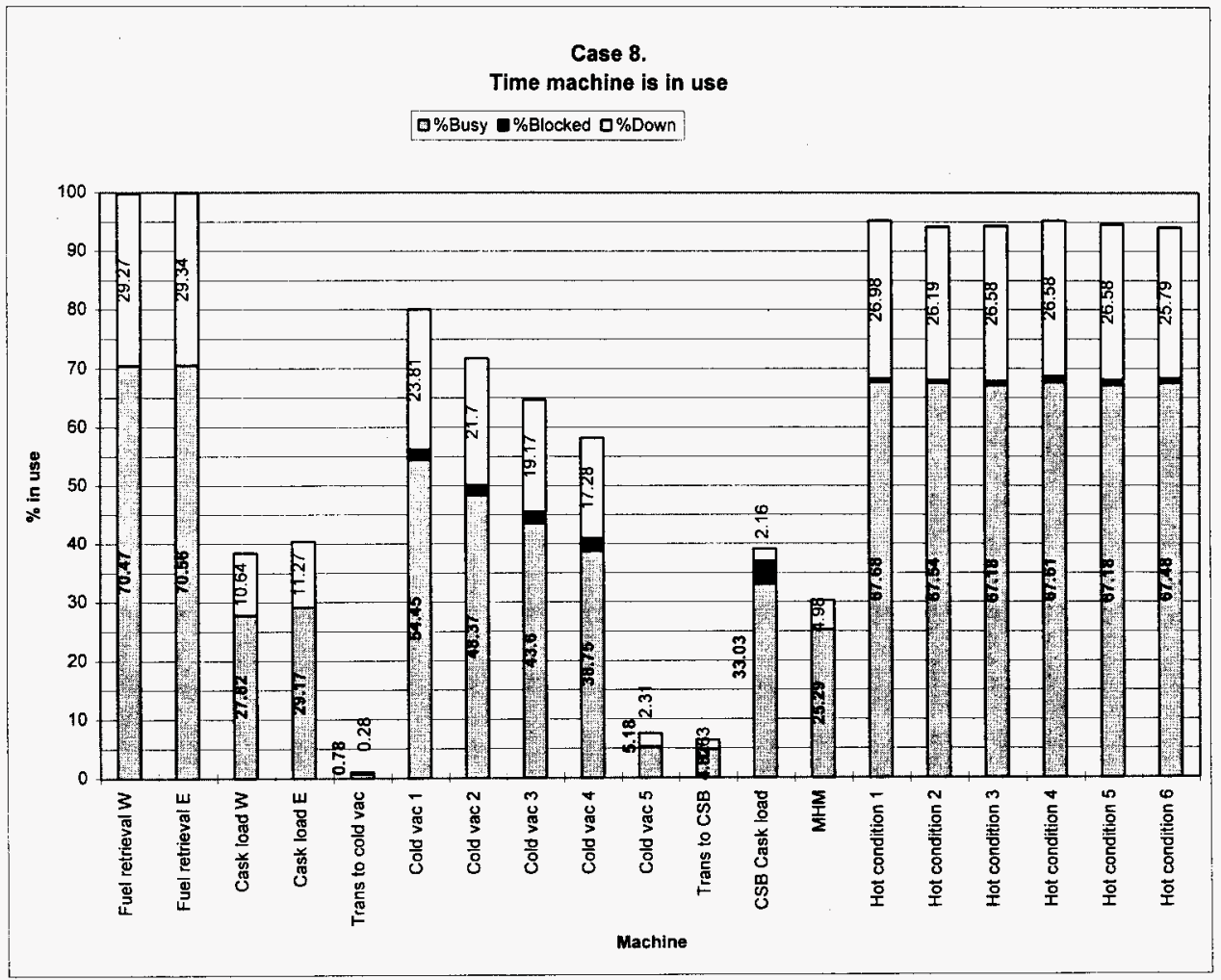


WHC-SD-SNF-RPT-011

Rev. 0

\subsection{CASE 9 . THREE 8HR SHIFTS/DAY, 7 DAYS/WEEK. USING 4 COLD VACUUM DRYING STATIONS.}

Case 9 has the same operating efficiency and the same shifts as case 6 . There are only 4 cold vacuum drying stations in case 9.

Figure 4.12 is a representation of the percentage of time that each machine was busy processing the fuel, blocked and waiting to release a MCO or breakdown.

Figure 4.12. Case 9 Machine Usage.

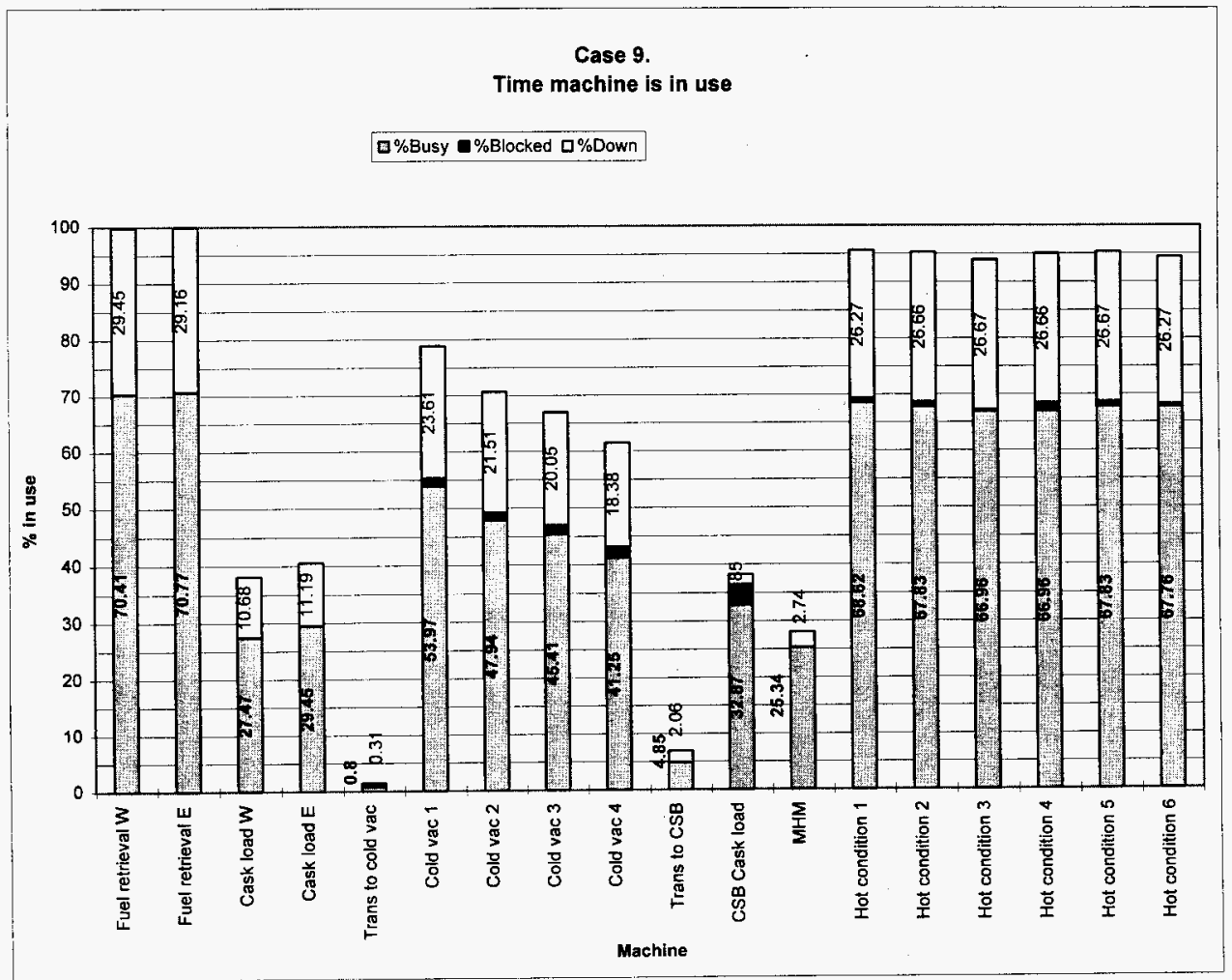


WHC-SD-SNF-RPT-011

Rev. 0

\subsection{CASE 10. THREE 8HR SHIFTS/DAY, 7 DAYS/WEEK. USING 2 LOADIN/LOADOUT PITS IN THE CSB.}

Case 10 has the same operating efficiency and the same shifts as case 6 . There are 2 loadin/loadout pits in the CSB in case 10.

Figure 4.14 is a representation of the percentage of time that each machine was busy processing the fuel, blocked and waiting to release a MCO or breakdown.

Figure 4.14. Case 10 Machine Usage.

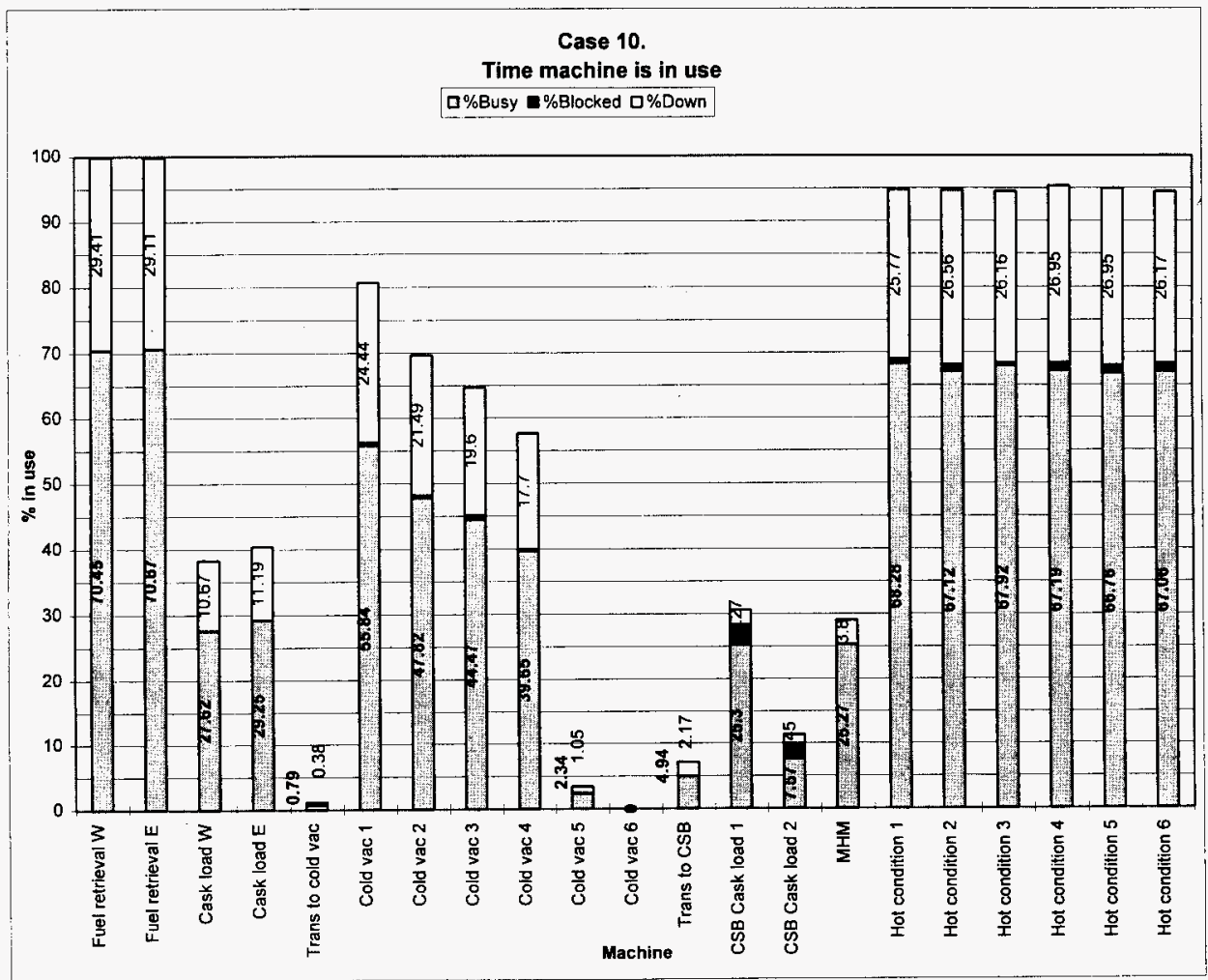


WHC-SD-SNF-RPT-011

Rev. 0

\subsection{CASE 11. THREE 8HR SHIFTS/DAY, 7 DAYS/WEEK. USING 5 HOT CONDITIONING STATIONS.}

Case 11 has the same operating efficiency and the same shifts as case 6 . There are only 5 hot conditioning stations in case 11 .

Figure 4.15 is a representation of the percentage of time that each machine was busy processing the fuel, blocked and waiting to release a MCO or breakdown.

Figure 4.15. Case 11 Machine Usage.

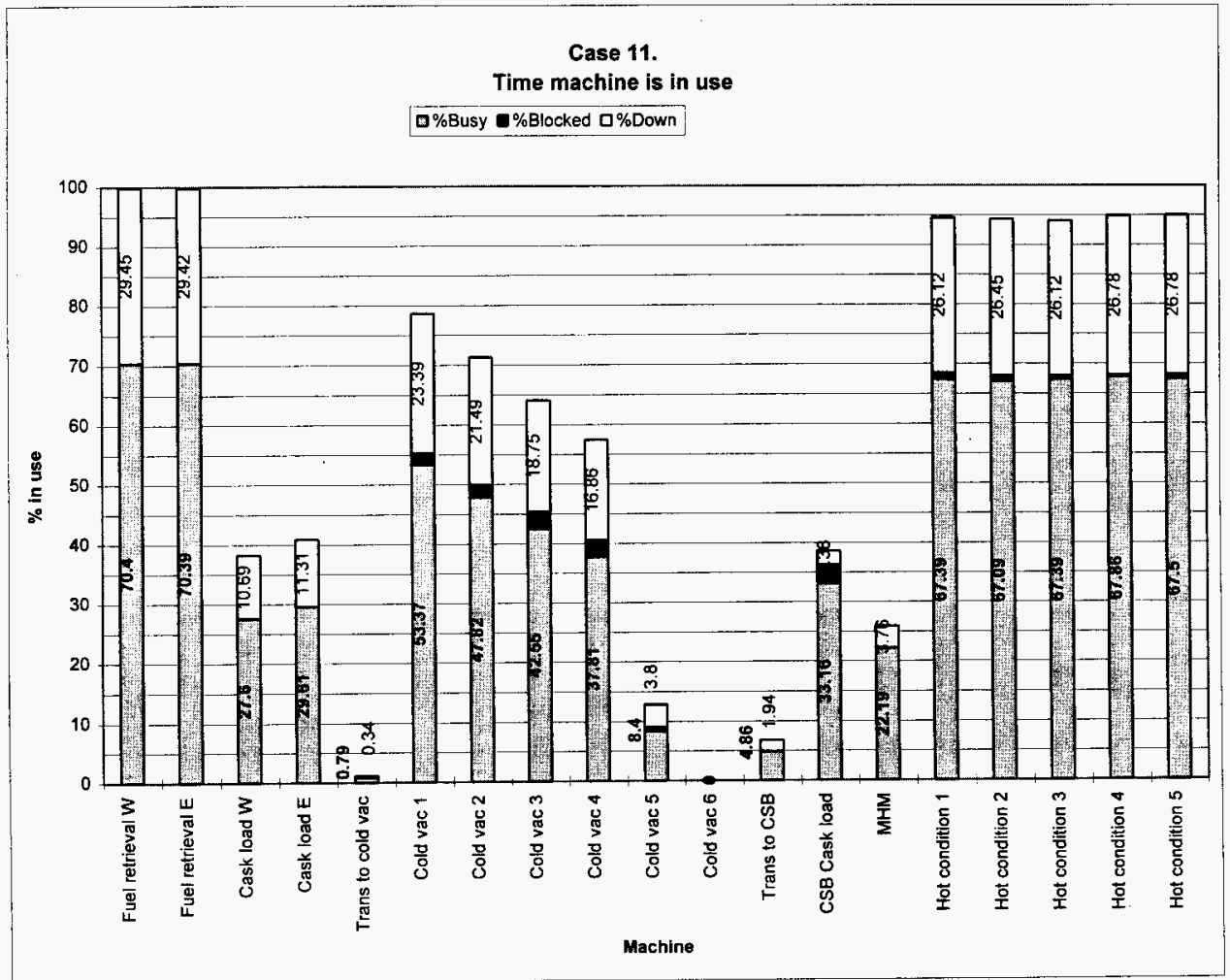


WHC-SD-SNF-RPT-011

Rev. 0

\subsection{CASE 12. THREE 8HR SHIFTS/DAY, 7 DAYS/WEEK. USING 4 HOT CONDITIONING STATIONS.}

Case 12 has the same operating efficiency and the same shifts as case 6 . There are only 4 hot conditioning stations in case 15.

Figure 4.16 is a representation of the percentage of time that each machine was busy processing the fuel, blocked and waiting to release a MCO or breakdown.

Figure 4.16. Case 12 Machine Usage.

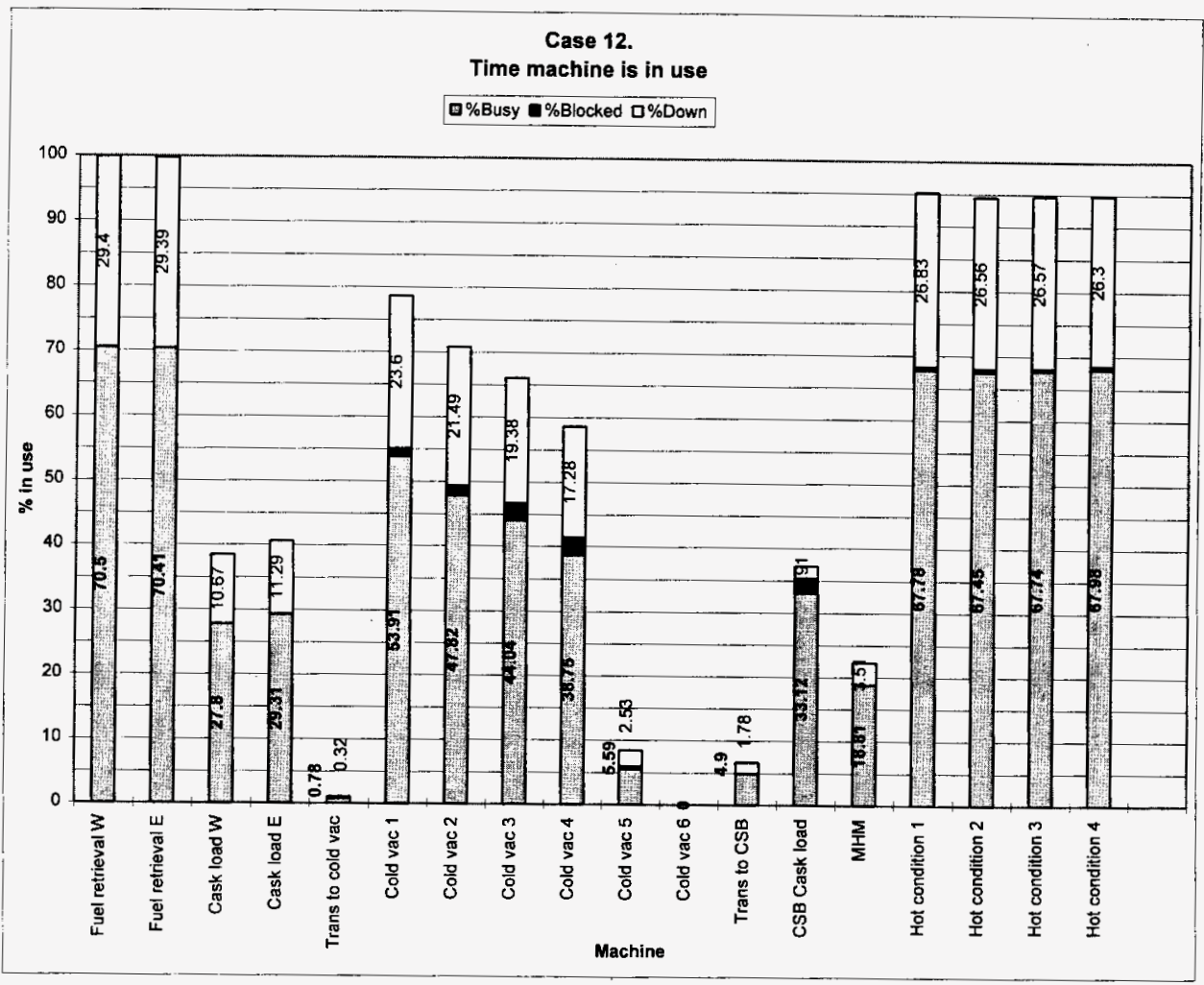


WHC-SD-SNF-RPT-011

Rev. 0

\subsection{SNF PROCESS CYCLE TIMES}

The following discussion describes the basis for cycle time estimates used to model the production of an $M C O$ by each process element. These cycle times represent the peak throughput of each process element, or the actual work time needed to produce a MCO. Potential system down time from equipment failure or operating environment inefficiencies, is included as a separate model input parameter.

\section{Fuel Retrieval}

Fuel retrieval cycle time estimates are based on the peak capacity estimates reported in conceptual design (LATA/BNFL/Foster Wheeler, nd). Capacity estimates for a single fuel retrieval line are estimated at 9.2 canisters/day assuming $100 \%$ assembly inspection and 12.9 canisters/day assuming no inspection. Based on 14 assemblies per canister and 270 assemblies per $M C O$, the reported peak capacities represent cycle times ranging from $50.2 \mathrm{hr}$ to $35.9 \mathrm{hr}$ for producing a MCO with $100 \%$ and no inspection, respectively. Current plans anticipate inspecting every 100 th assembly ( $1 \%$ inspection). It is assumed that the no inspection cycle time is derated by $5 \%$ of the cycle time difference between no inspection and $100 \%$ inspection to model the cycle time of current plans. This results in an estimated cycle time of $36.6 \mathrm{hr}$ to produce a $\mathrm{MCO}$. Based on these estimates, a triangular distribution with minimum time of $36 \mathrm{hr}$, mode time of $37 \mathrm{hr}$, and maximum time of $50 \mathrm{hr}$ was used to model fuel retrieval activities.

\section{Cold Vacuum Drying}

The cycle time for a cold vacuum drying station to produce a MCO is derived from a preliminary cycle time estimate of $63 \mathrm{hr}$ to produce a $\mathrm{MCO}$. This was increased to incorporate time for MCO welding and increasing the MCO process temperature from $50{ }^{\circ} \mathrm{C}$ to $75{ }^{\circ} \mathrm{C}$. A welding alternatives analysis (Goldmann 1996) estimated that MCO welding will add $14.7 \mathrm{hr}$ to the drying station cycle time and weld repairs, if required, add another $9 \mathrm{hr}$ to the cycle time. Time was also added to the base cycle time to heat to $75{ }^{\circ} \mathrm{C}$ (instead of $50{ }^{\circ} \mathrm{C}$ in the base estimate), hold for $1 \mathrm{hr}$ at $75^{\circ} \mathrm{C}$, and cool from $75^{\circ} \mathrm{C}$. Assuming MCO temperature changes during cold vacuum drying are 1 imited to $10^{\circ} \mathrm{C} / \mathrm{hr}$, the operating condition changes result in adding $6 \mathrm{hr}$ to the base time cycle. Finally, cycle times are expected to vary based on the condition of the fuel. A firm basis for predicting this variation is not currently available. To model the logistic impact of fuel condition variations, it was assumed good fuel could be processed with a $10 \mathrm{hr}$ shorter cycle and bad fuel processed with a $20 \mathrm{hr}$ longer cycle as compared to the base. These estimates result in a triangular cycle time distribution with the following characteristics: 
WHC-SD-SNF-RPT-011

Rev. 0

\begin{tabular}{|l|c|c|c|c|c|c|}
\hline & Base & $\begin{array}{c}75^{\circ} \mathrm{C} \\
\text { Operating } \\
\text { Temperature }\end{array}$ & MCo Helding & $\begin{array}{c}\text { Mco Weld } \\
\text { Repair }\end{array}$ & $\begin{array}{c}\text { Fuel } \\
\text { Condition } \\
\text { Variation }\end{array}$ & $\begin{array}{c}\text { Total Cycle } \\
\text { Time }\end{array}$ \\
\hline $\begin{array}{l}\text { Minimum } \\
\text { Time, } \mathrm{Hr}\end{array}$ & 63 & +6 & +15 & - & -10 & 74 \\
\hline $\begin{array}{l}\text { Mode Time, } \\
\mathrm{Hr}\end{array}$ & 63 & +6 & +15 & - & - & 84 \\
\hline $\begin{array}{l}\text { Maximum } \\
\text { Time, } \mathrm{Kr}\end{array}$ & 63 & +6 & +15 & +9 & +20 & 113 \\
\hline
\end{tabular}

Duncan 1996 presents an estimate for the minimum cold vacuum drying station cycle time of $64 \mathrm{hr}$. Therefore, the cold vacuum drying station cycle times currently used for investigating the overall project interactions appear to be conservative.

\section{Canister Storage Building}

Time cycle estimates for the cask loadin/loadout and MCO Handling Machine (MHM) transfer activities within the Canister Storage Building were derived from a draft operator exposure analysis that was available in March 1996. The exposure analys is divided the material handling actions within the CSB into 39 separate tasks, estimating the time required to complete each task. The task descriptions were reviewed and assigned to either cask loadin/loadout or identified as associated with the MHM transfer.

Based on the task time estimates, $11.4 \mathrm{hr}$ is required to complete cask loadin/loadout. A triangular distribution of the loadin/loadout time was developed by assuming the vent and purge task could be reduced from $1.5 \mathrm{hr}$ to $0.5 \mathrm{hr}$ for some of the MCOs containing fuel in good condition. A maximum time was estimated by assuming the two decon/survey tasks identified take $1 \mathrm{hr}$ instead of $0.5 \mathrm{hr}$, the pit enclosure installation takes $1.5 \mathrm{hr}$ instead of $1 \mathrm{hr}$, and installation of the vent purge system takes $0.75 \mathrm{hr}$ instead of $0.25 \mathrm{hr}$ for some MCOs. These assumptions result in a triangular distribution estimate for CSB cask loadin/loadout with a minimum time of $10.4 \mathrm{hr}$, mode time of $11.4 \mathrm{hr}$, and maximum time of $13.4 \mathrm{hr}$.

Based on the task time estimates, $3.25 \mathrm{hr}$ is estimated to be required to complete activities using the MHM to transfer a MCO from the cask pit to a tube for staging. This includes the $175 \mathrm{~min}$ identified in the exposure analysis task list plus $10 \mathrm{~min}$ to move the MHM from a neutral position in the CSB to a position over the cask and 10 min to move the MHM from the tube being loaded back to a neutral position. A minimum time for completing a transfer with the MHM was assumed to be $3 \mathrm{hr}$. A maximum time for completing the transfer was assumed to be $4 \mathrm{hr}$, based on assuming the time to inert the storage tube during the transfer takes 55 min instead of $10 \mathrm{~min}$. These assumptions result in a triangular distribution estimate for the MHM transfer of a MCO with a minimum time of $3 \mathrm{hr}$, mode time of $3.25 \mathrm{hr}$, and maximum time of $4 \mathrm{hr}$.

The time cycle distributions for transfer of a MCO from a staging tube to the Hot Conditioning System (HCS) and from HCS back to a storage tube was 
WHC-SD-SNF-RPT-011

Rev. 0

assumed to be equivalent to the triangular distribution based on MHM transfers from the cask pit to a storage tube.

\section{Hot Vacuum Conditioning}

Duncan 1996 includes an estimate for the minimum time cycle for a HCS station to process a MCO of $122 \mathrm{hr}$. Preliminary estimates from draft conceptual design information provide a nominal cycle time estimate of $140 \mathrm{hr}$ for the HCS cycle time. Uncertainty exists as to the impact of fuel condition variability on the conditioning system cycle time. In order to provide a conservative estimate of the HCS cycle time which addresses fuel condition variability, a two point distribution of the cycle time was used to model the HCS which assumes $80 \%$ of the fuel was processed with a $140 \mathrm{hr}$ cycle and $20 \%$ of the fuel was processed with a $205 \mathrm{hr}$ cycle. The basis for these cycle time estimates may need to be modified upon completion of conceptual design activities.

\section{Bas in Cask Loadin/Loadout and Transportation}

A preliminary exposure evaluation of the basin cask loadin/loadout activities was used as a basis for estimating the cycle time for basin cask loadin/loadout activities (Transnuclear, nd). The exposure evaluation estimated a total cycle time of $10.9 \mathrm{hr}$ to prepare the cask for MCO loading (cask loadin), load the MCO, and loadout the cask. Additional conservatism was added to this cycle time estimate by increasing the MCO basket loading from 1 to $4 \mathrm{hr}$, increasing the MCO shield plug decontamination time from 0.5 to $1.5 \mathrm{hr}$, and increasing the final cask survey and decontamination time from 0.1 to $2.1 \mathrm{hr}$. The conservatism increases the loadin/loadout cycle time to 16.9 hr, which was used as the mode time of a triangular distribution for the cask cycle time.

A minimum cycle time was estimated at two shifts of operating time, or $12 \mathrm{hr}$. A maximum cycle time was estimated by tripling the time required for installing the shield plug and decon/survey activities, resulting is increasing the cask loadin/loadout time to $26 \mathrm{hr}$. These assumptions result in a triangular distribution estimate for the basin cask loadin/loadout with a minimum time of $12 \mathrm{hr}$, mode time of $16.9 \mathrm{hr}$, and maximum time of $26 \mathrm{hr}$.

Transportation time estimates are based on allocations based on the approximate distance traveled. The transfer from just outside the door at a basin to the cold vacuum drying location is approximately $1000 \mathrm{ft}$. Based on discussion with the transportation design authority, a triangular distribution with minimum time of $0.1 \mathrm{hr}$, mode time of $0.25 \mathrm{hr}$, and maximum time of $0.5 \mathrm{hr}$ was used to model the transfer from the basin to just outside a cold vacuum drying station.

The transport distance from cold vacuum drying to the canister storage building is approximately $7 \mathrm{mi}$. Based on discussion with the transportation design authority, a triangular distribution with minimum time of $0.5 \mathrm{hr}$, mode time of $1 \mathrm{hr}$, and maximum time of $4 \mathrm{hr}$ was used to model the transportation time required to move a MCO from just outside the cold vacuum drying station to just outside the canister storage building. This triangular time distribution was also used to model the time required to return a cask loaded with an empty MCO back to the basin. 
WHC-SD-SNF-RPT-011

Rev. 0

\subsection{REFERENCES}

Duncan, D. R., 1996, Spent Nuclear Fuel Project Operational Description, WHC-SD-SNF-RPT-010, (Rev 0), Westinghouse Hanford Company, Richland, Washington.

Goldmann, L. H., 1996, Multi-Canister Overpack Closure Operations Location Study, WHC-SD-SNF-RPT-002, (Rev 0), Westinghouse Hanford Company,

Richland, Washington.

LATA/BNFL/Foster Wheeler, nd, Fuel Retrieval Sub-Project Conceptual Design Report, L/B-SD-SNF-RPT-009, Rev 0, Los Alamos Technical

Associates/British Nuclear Fuels Limited/Foster Wheeler, Richland, Washington.

Pajunen, A. L., 1996, Development of Design Basis Capacity for Spent Nuclear Fuel Project Systems, WHC-SD-SNF-TI-016, Rev. 0, Westinghouse Hanford Company, Richland, Washington.

Transnuclear, nd, "Preliminary Design Analysis Report for the TN-WHC Cask and Transportation System - Project 3035," E-14573, Transnuclear, Inc., Hawthorn, New York. 
WHC-SD-SNF-RPT-011

Rev. 0

APPENDIX A

VALIDATION REQUIREMENTS 
WHC-SD-SNF-RPT-011

Rev. 0

\section{APPENDIX A}

\section{VALIDATION REQUIREMENTS}

Software used by ICF Kaiser Hanford Company is controlled by Engineering Department Process Instruction number ENG-DPI-6, Control of Engineering Software. Commercially available (off-the-shelf) software programs must be verified and accepted by the Software Administrator, who places the software onto the "master list of programs approved for use", in accordance with Section 2, Verification of Commercial Programs.

Software used by Westinghouse is controlled by WHC-CM-4-2, Quality Assurance Manual (QR 19.0, Software Quality Assurance Requirements) and WHC-CM-3-10, Software Practices.

WHC-CM-4-2, paragraph 4.6.2 Commercially Available (off-the-shelf) Software says, "If the software can be used as is, the requirements of paragraph 4.4.1 shall apply." WHC-CM-4-2, paragraph 4.4.1 Minimum Required Documentation lists the six minimum documents that must be produced, reviewed, approved, and released according to WHC-CM-3-5, Section 12.7 Approval of Environmenta7, Safety, and Quality Affecting Documents. WHC-CM-3-5 SeC 12.7, Rev 0, Change 4, 4/10/96, indicates the appropriate Approval Designator is "NA", which means "there are no approvals required other than the cognizant engineer and cognizant manager".

Validation of this off-the-shelf software addresses only the SNF application of the process model and is not intended as overall software validation. Other groups using this software will need to validate their particular applications.

To meet the intent of the ICF KH procedures, the following verification task will be performed.

Verify that the program does the job it was intended/advertised to do.

This will be accomplished by receiving information from Istel on the internal validating and beta testing they performed and on the number of copies in use.

Verify that the program works on the user's machine just as does on the supplier's machine.

This will be done by running a demonstration model on Istel's computer, then running the same model on our computer, and comparing the results.

Verify that the user has applied the software correctly.

This will be done by an ongoing review of the reasonableness of the output of each scenario by some or all of the contributors, and modifying the model where necessary to produce an output within the expected range.

Verify that the user has input the variables as intended. 
WHC-SD-SNF-RPT-011

Rev. 0

This will be done by checking the input stream for the intended values of the variables for each scenario.

To meet the intent of the WHC procedures six items require documentation as follows:

\section{Software Requirements}

The Witness software package is intended to be used as a simulation program to model the SNF project and subprojects. The simulation program must be capable of performing "what if" scenarios when analyzing method or process alternatives, performing time and motion studies, determining queuing sizes and frequencies, determining problem elimination or learning curves, evaluating flow restrictions and $\mathrm{plant}$ and work station layout, incorporating machine breakdown cycles and repair times, and including workstation staffing. Suitability of this program to satisfy these requirements was based on recommendations of previous on-site users, and on vendor supplied promotional information.

Witness is a commercially available off-the-shelf software; it will not modified and it will not be incorporated into the development of other software. The use of this software does not invoke or address any health or safety issues.

\section{User Documentation}

User documentation for the software package was developed and distributed by the software vendor.

Modeling for this application was based on the flow diagram shown in figure 4.2 and the operating efficiencies and cycle times listed in table 4. Each machine or queue was input into the model along with the proper logic ties to create a representation of the SNF project.

Appendix $B$ is the input file for the base case used in this study.

\section{Test Case Specification}

There was no formal test case specification prepared for this study. In various meetings with the software administrator, design authorities and responsible engineers it was decided that the design authority and the responsible project engineers would review input to the model and determine if the desired results were obtained.

\section{Test Procedure Specification}

As new items or features were added to the base model the output was checked to see if the expected results were obtained. Both the responsible engineer and the design authority checked the output against the SNF operating baseline. If the output didn't represent the actual SNF processes the logic 
was examined and revised to characterize system operations. A couple of examples of how modeling didn't represent the base system and how it was changed are listed below.

In one example, the cold vacuum drying stations release an MCO to the transporter to 200 East. Then the transporter would take the MCO to the CSB and unload it. In reviewing the output it was found that if the CSB loadin/loadout pit was busy or blocked the truck would wait until it was open then release the $\mathrm{MCO}$, in affect making the truck into a queue. In the actual system the cold vacuum drying is the queue and will not release an MCO if the CSB is blocked or busy so the logic was modified to reflect actual system operations.

A second example is the learning curve ramp-up cycle. The ramp-up cycle was created by defining the hours worked per day for each month during the ramp-up cycle and hours worked per day for steady state operations. While running the model it was found that instead of repeating the steady state month after the ramp-up was complete, the complete ramp-up cycle was repeated for the duration of the project. New logic was written to repeat only the steady state month, thus simulating the proper shift schedules.

\section{Test Results}

The final version of the base model was reviewed by the design authority and the responsible engineer and was found to accurately represent the overall SNF project.

\section{Software Configuration Control Plan}

Witness is a proprietary software program for which we do not modify the code. The vendor develops and distributes any required software modifications, along with any related modifications to the user documentation. The modified software and documentation is distributed to the code custodian of the registered owner of the program. The code custodian controls the disks and the software access key, and keeps track of who has the software installed on their machine so it can be updated as necessary. 
WHC-SD-SNF-RPT-011

Rev. 0

APPENDIX B

WITNESS OUTPUT

B-I 
WHC-SD-SNF-RPT-011

Rev. 0

BASE CASE (THREE 8 HR SHIFTS/DAY, 5 DAYS/MEEK) 
SNF Project operating 3 shifts, 5 days/week. Cold vacuum drying Hot conditioning operating 7 days/week
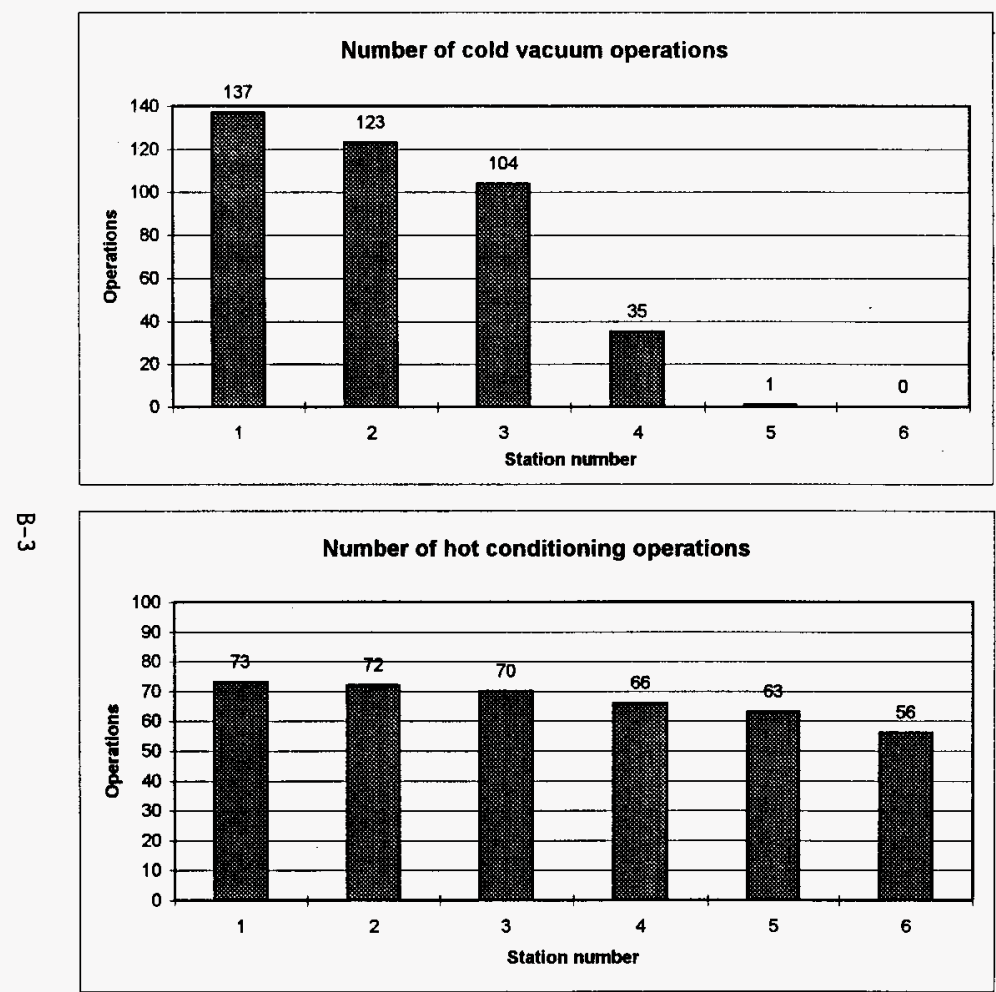


\section{SNF Project operating 3 shifts, 5 days/week. Cold vacuum drying Hot conditioning operating 7 days/week}

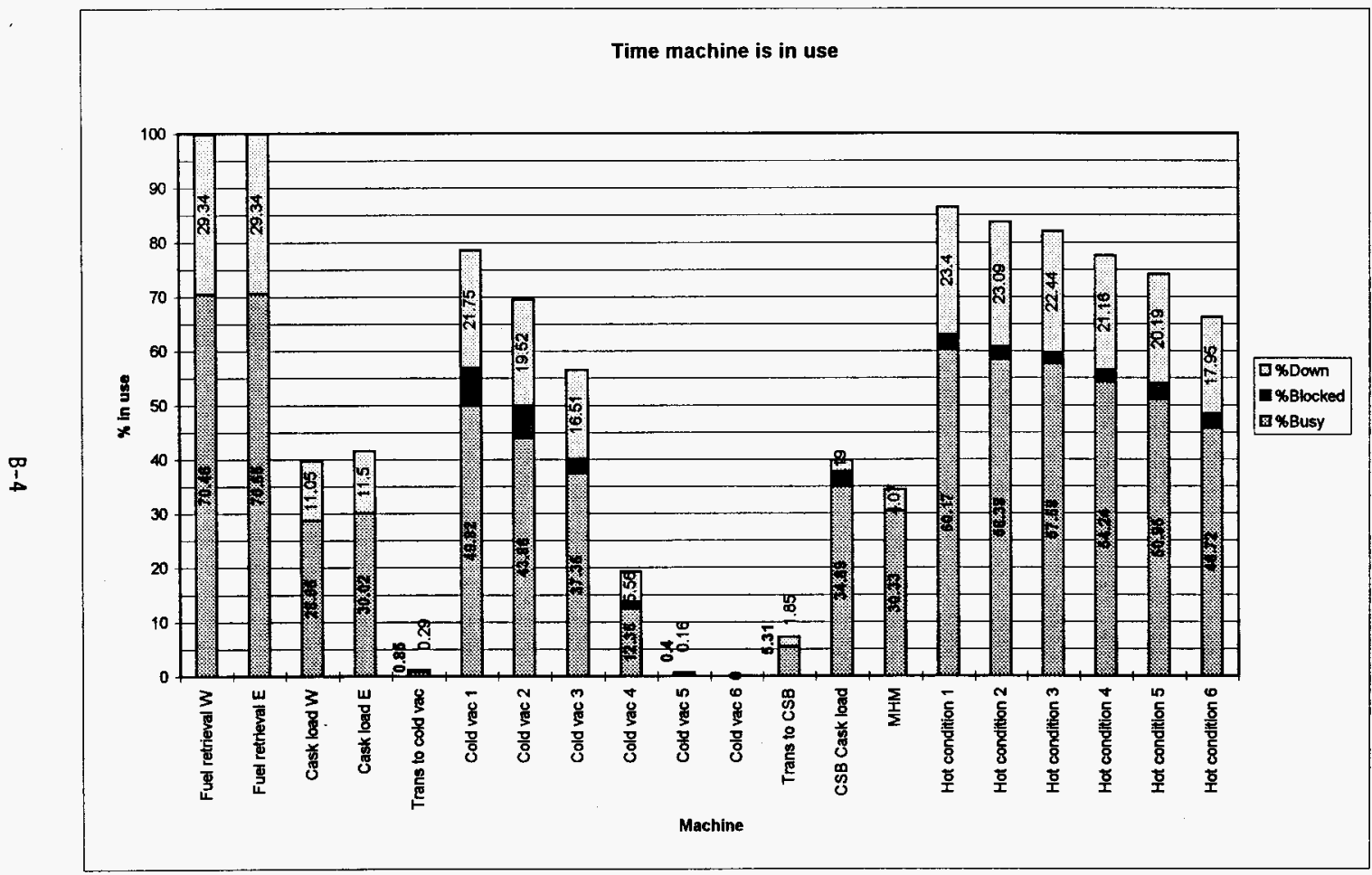



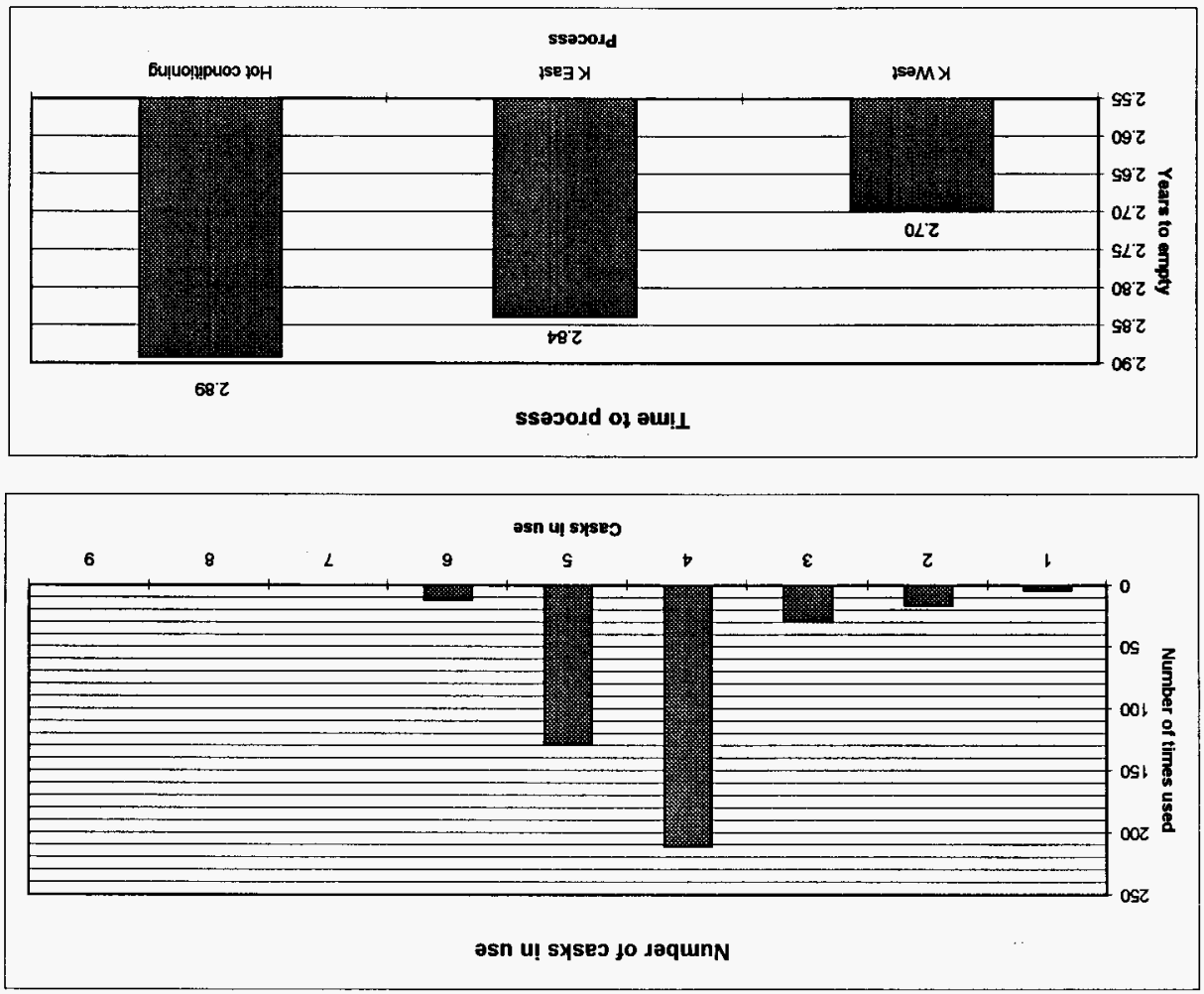


\begin{tabular}{|c|c|c|}
\hline 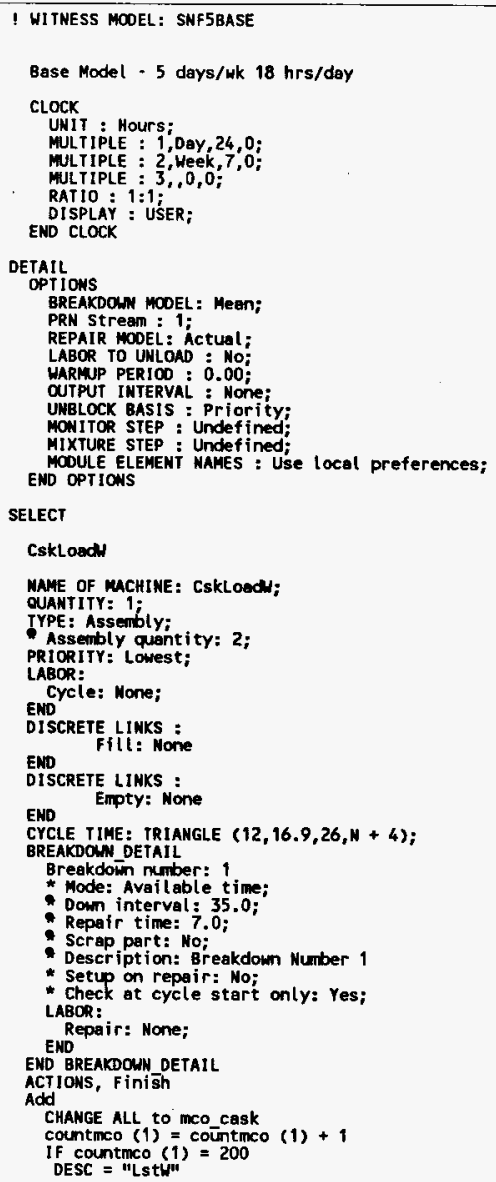 & 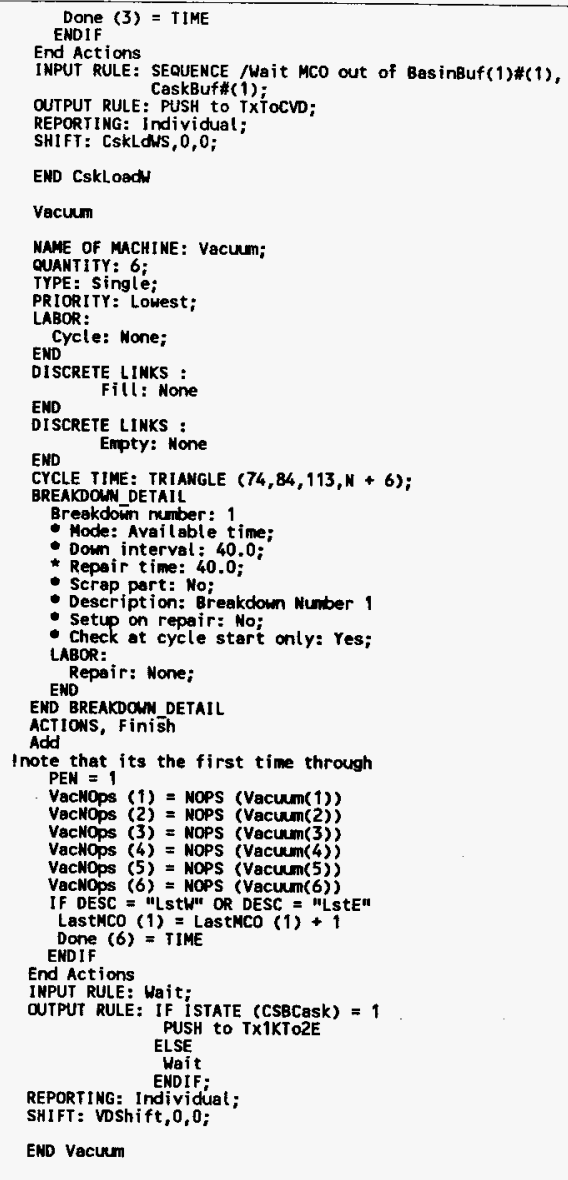 & 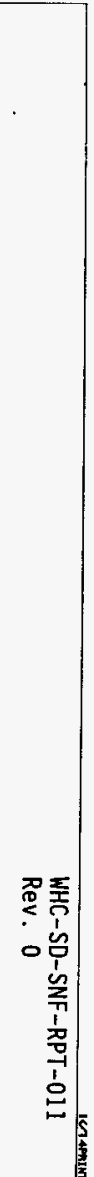 \\
\hline
\end{tabular}




\begin{tabular}{|c|c|c|}
\hline 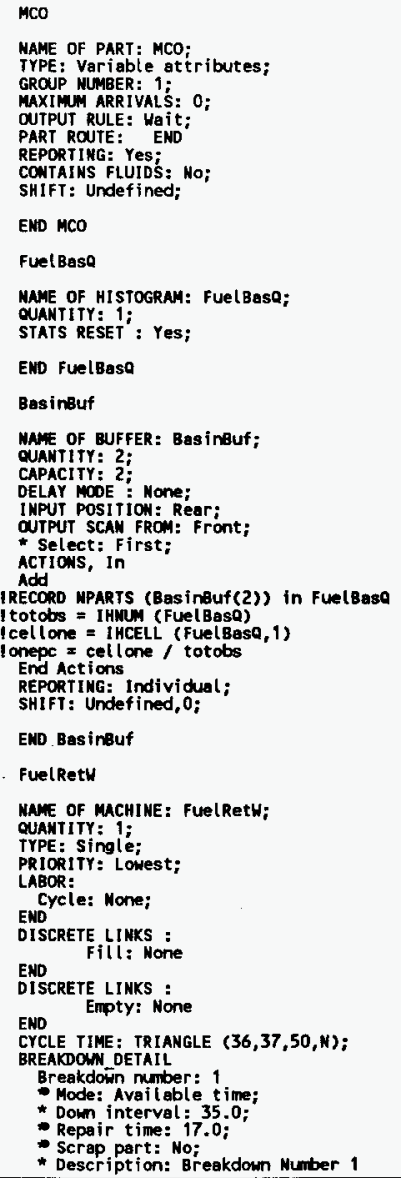 & 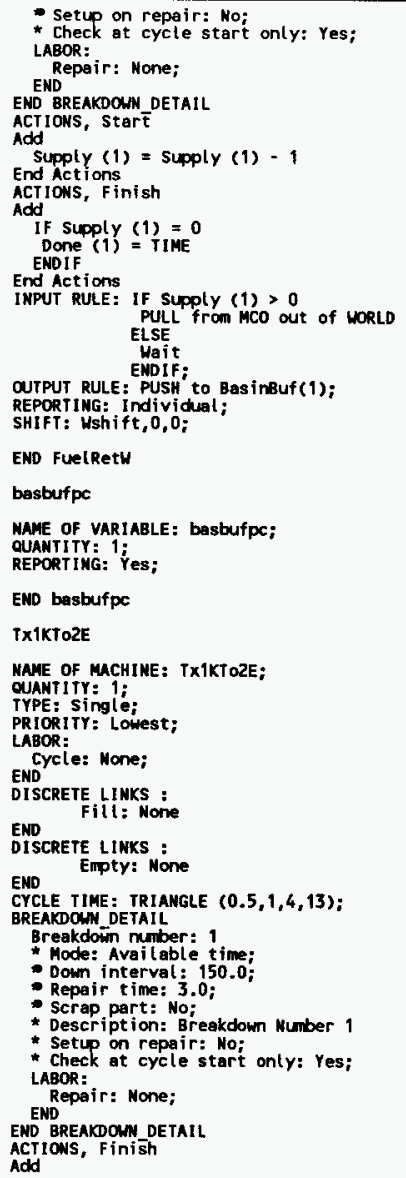 & 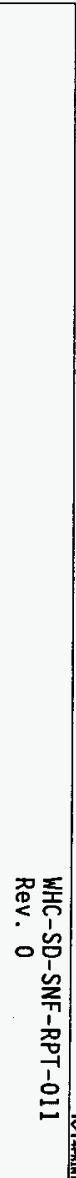 \\
\hline
\end{tabular}




\begin{tabular}{|c|c|c|}
\hline 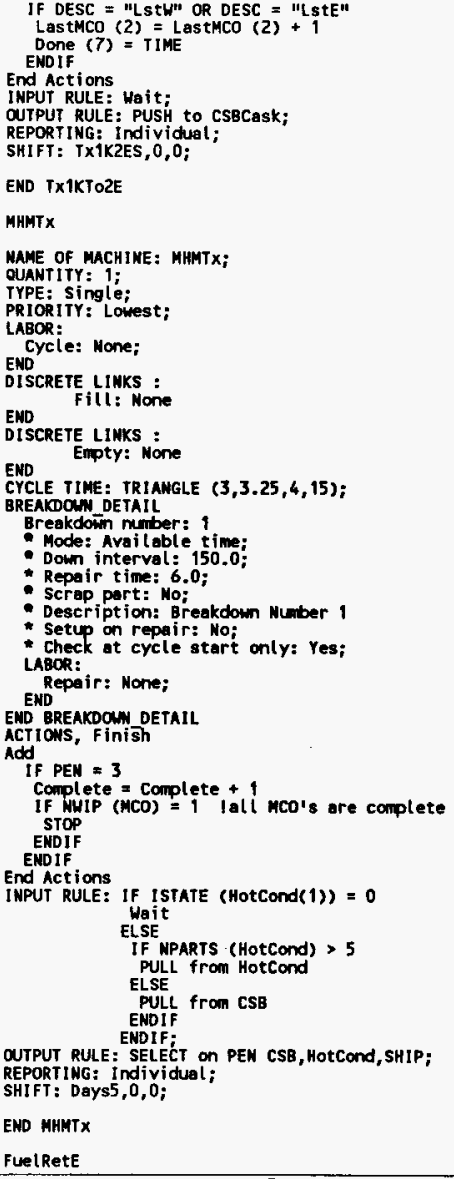 & 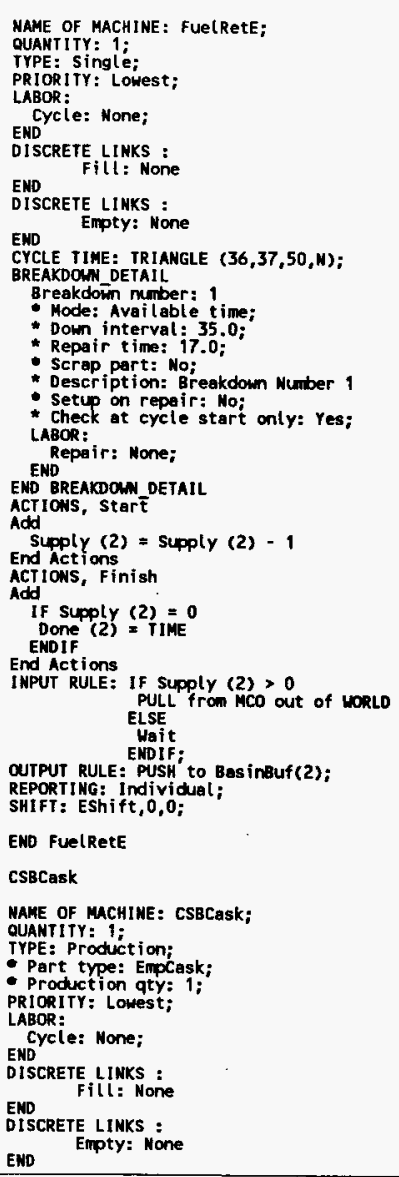 & 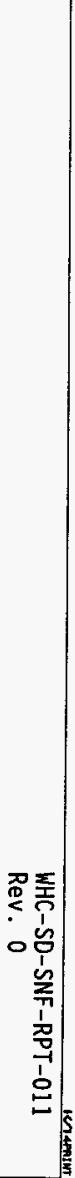 \\
\hline
\end{tabular}




\begin{tabular}{|c|c|c|}
\hline 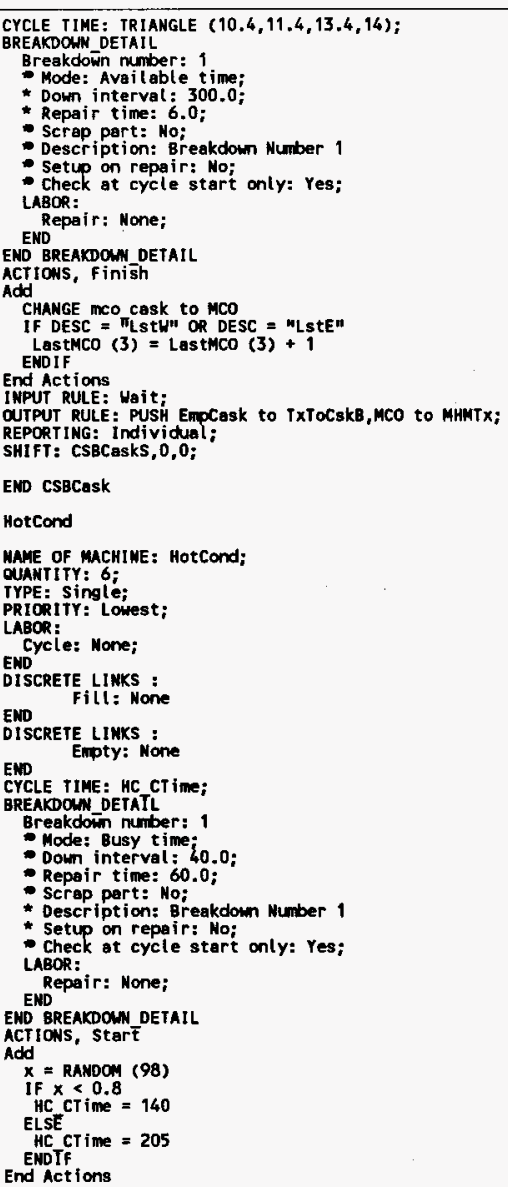 & 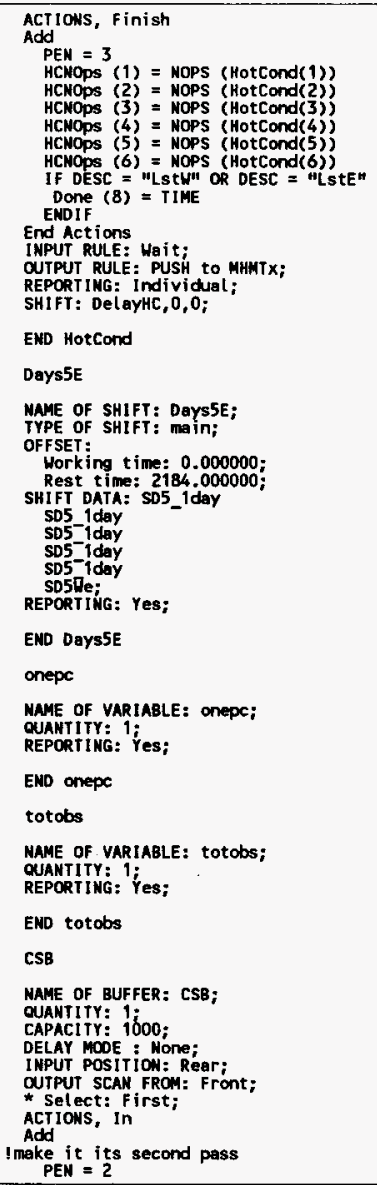 & 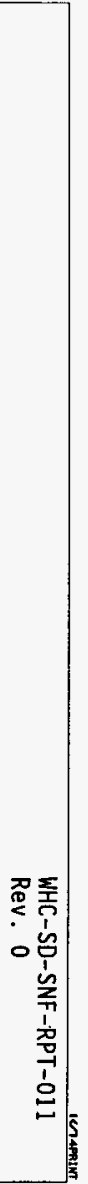 \\
\hline
\end{tabular}




\begin{tabular}{|c|c|c|}
\hline 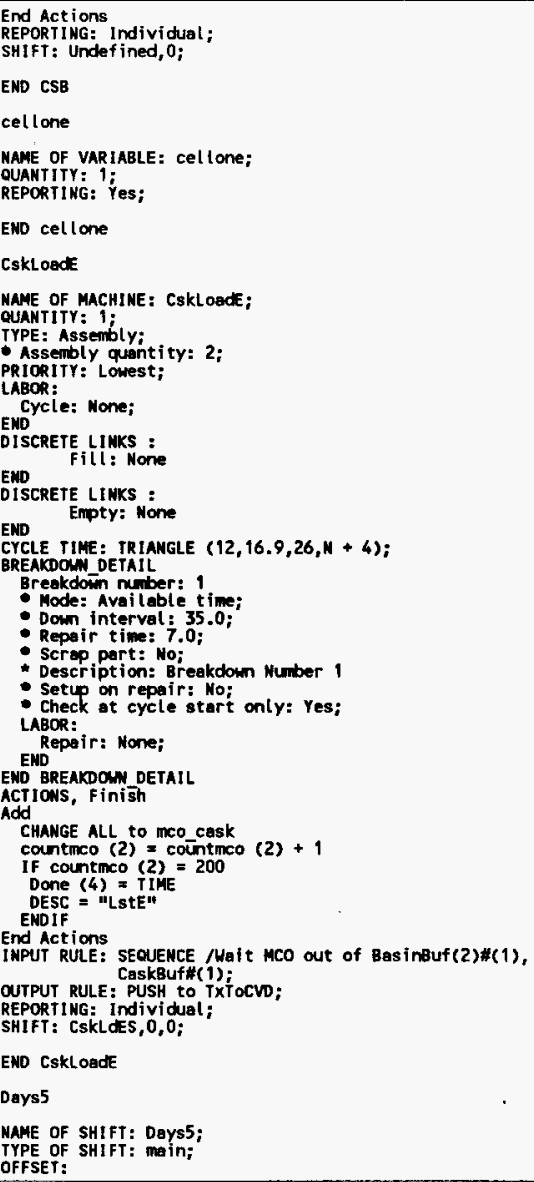 & 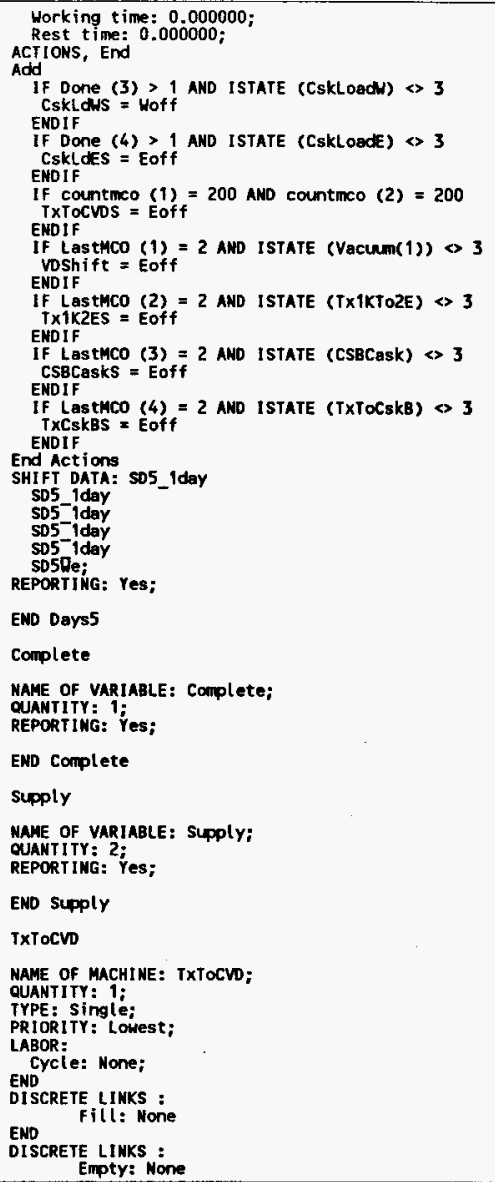 & 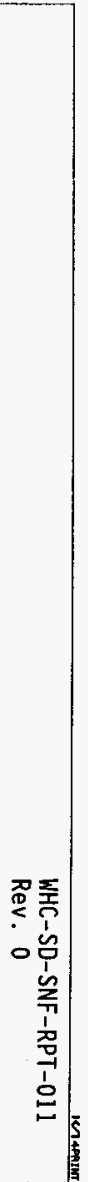 \\
\hline
\end{tabular}




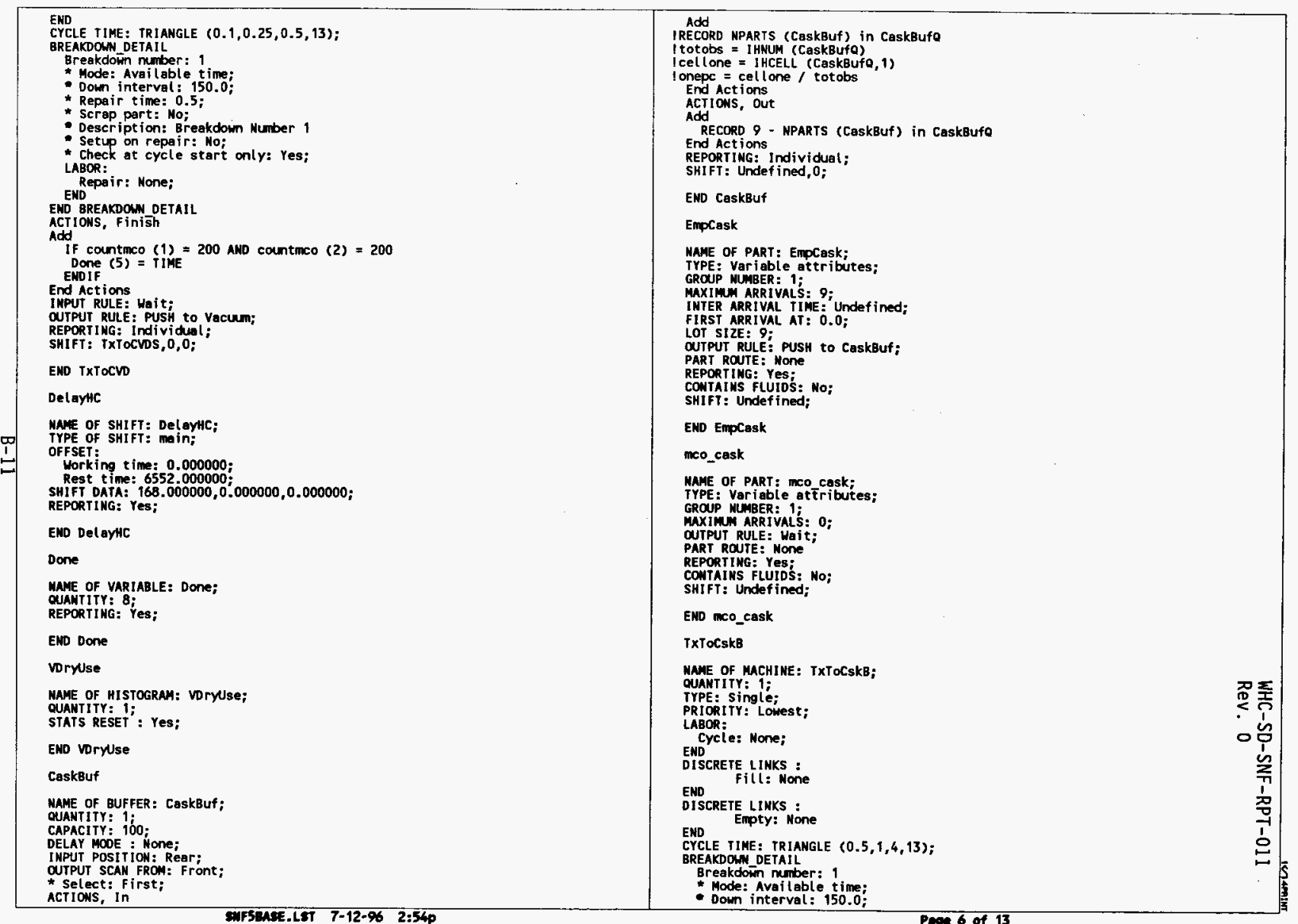




\begin{tabular}{|c|c|c|}
\hline 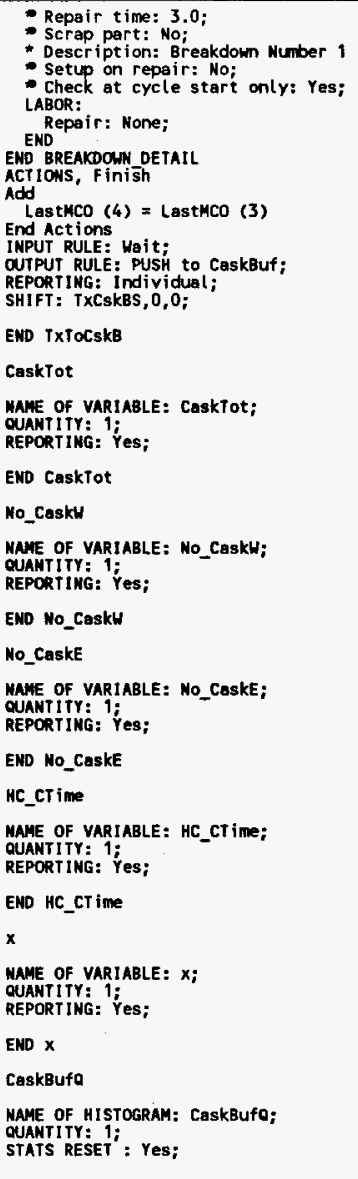 & 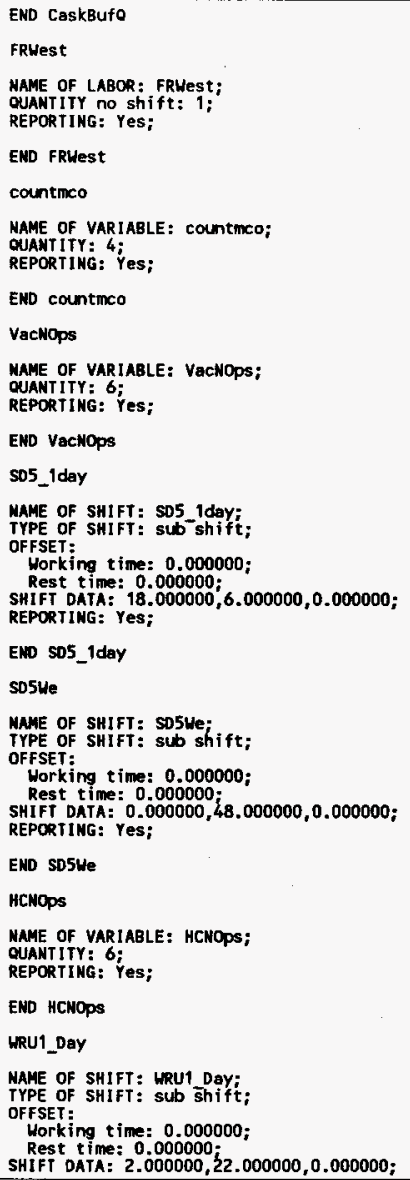 & 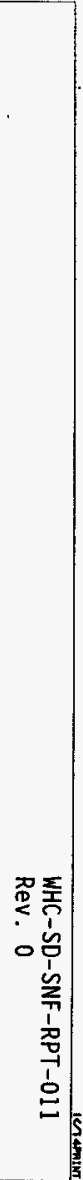 \\
\hline
\end{tabular}




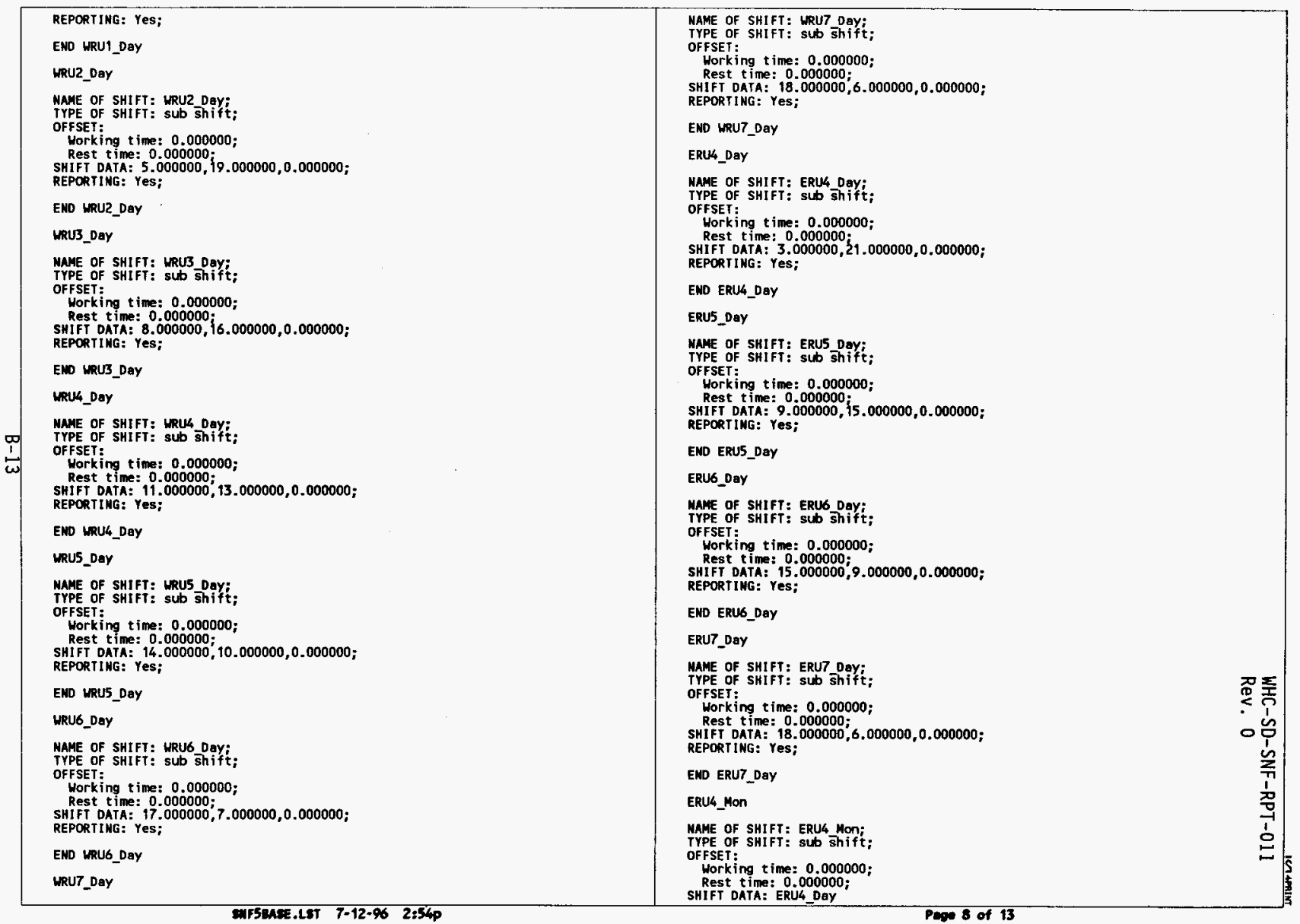




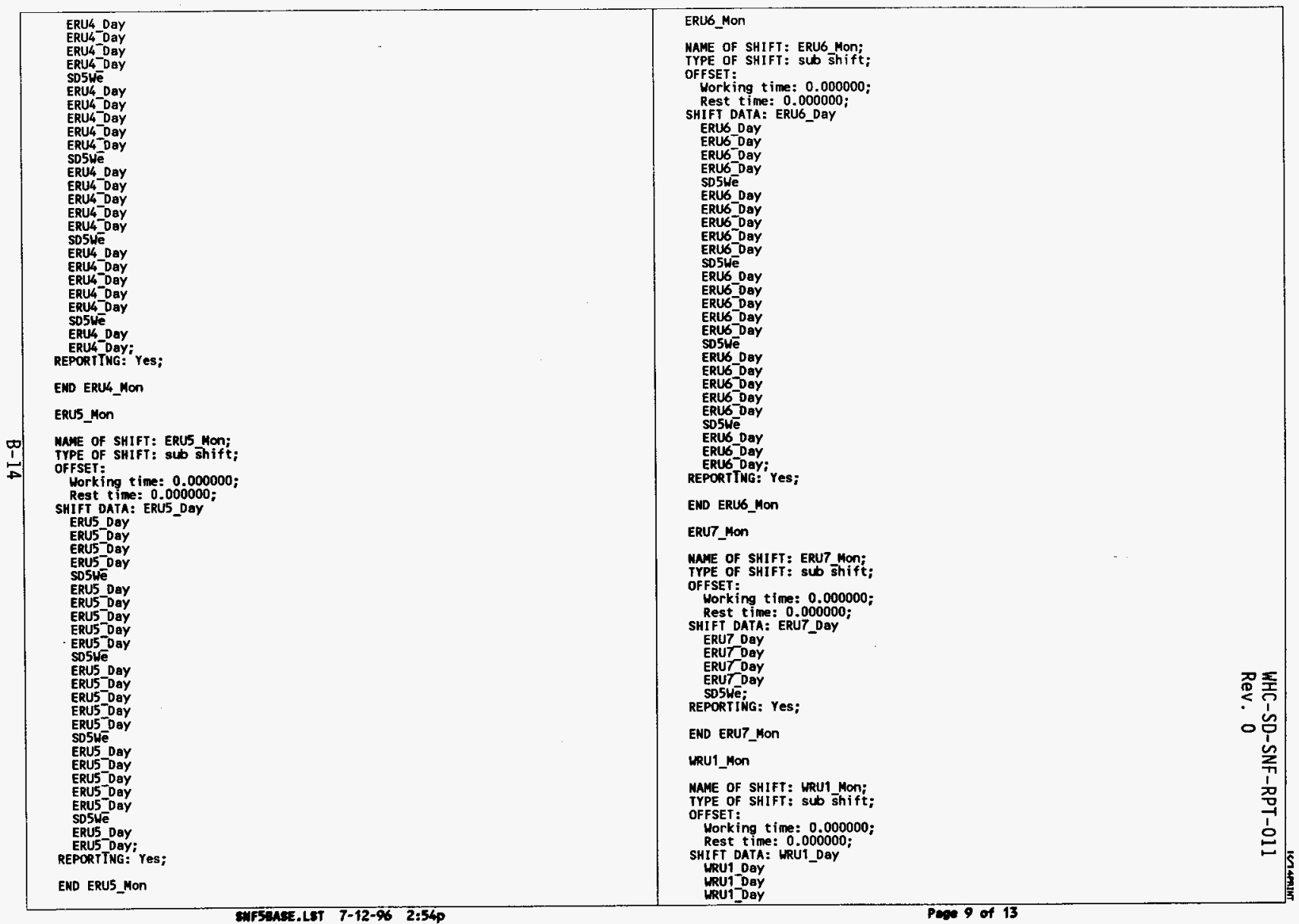




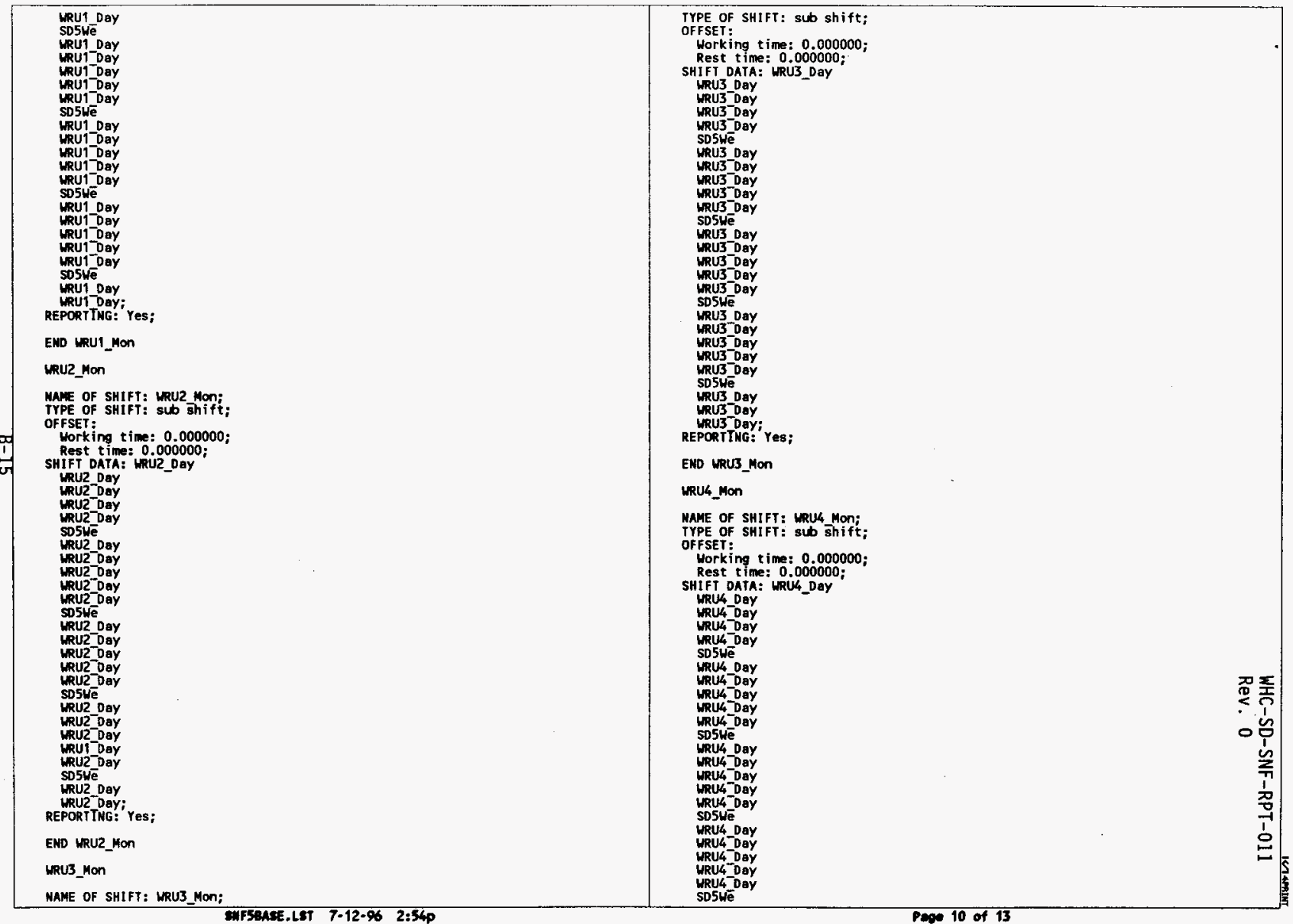




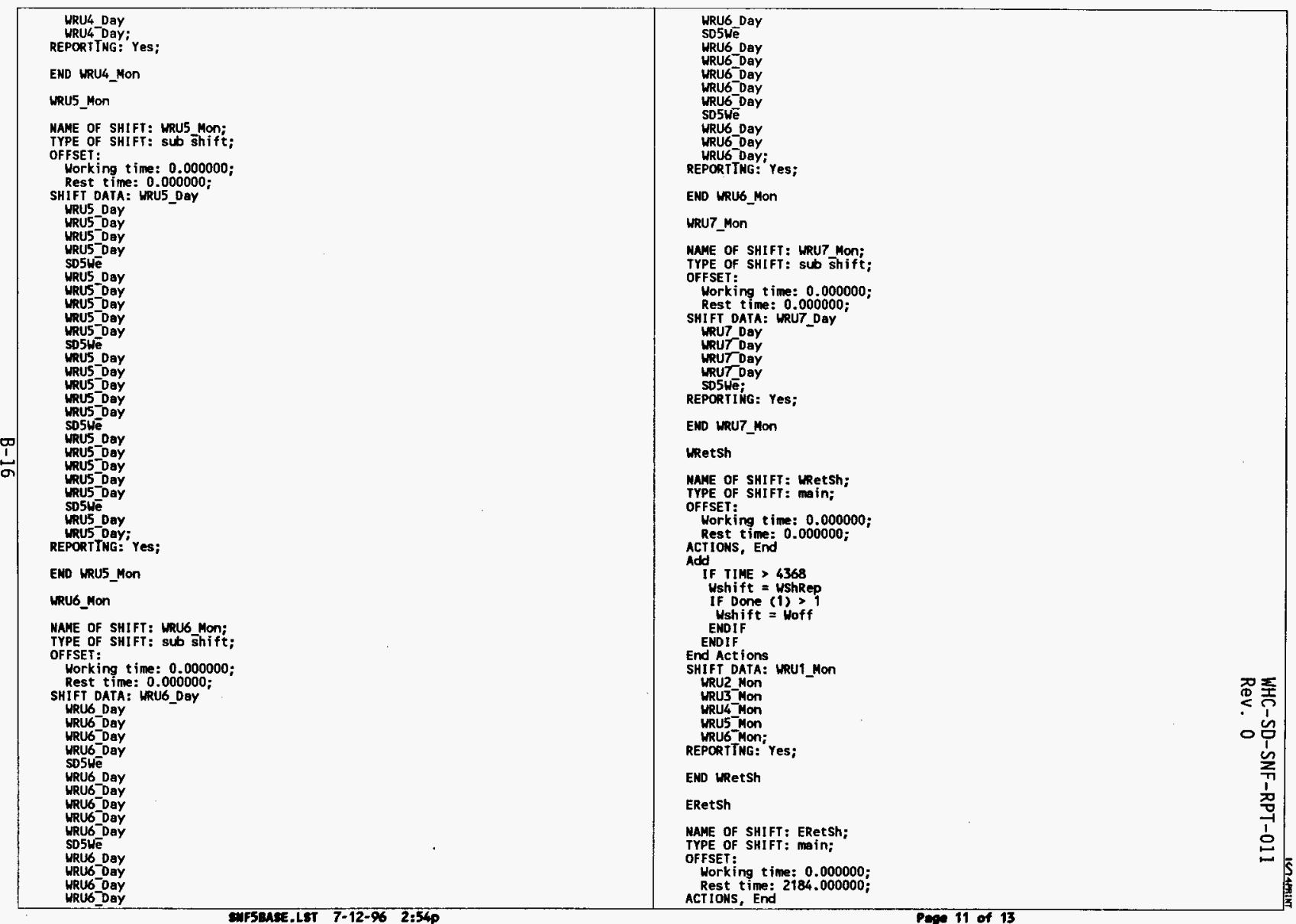




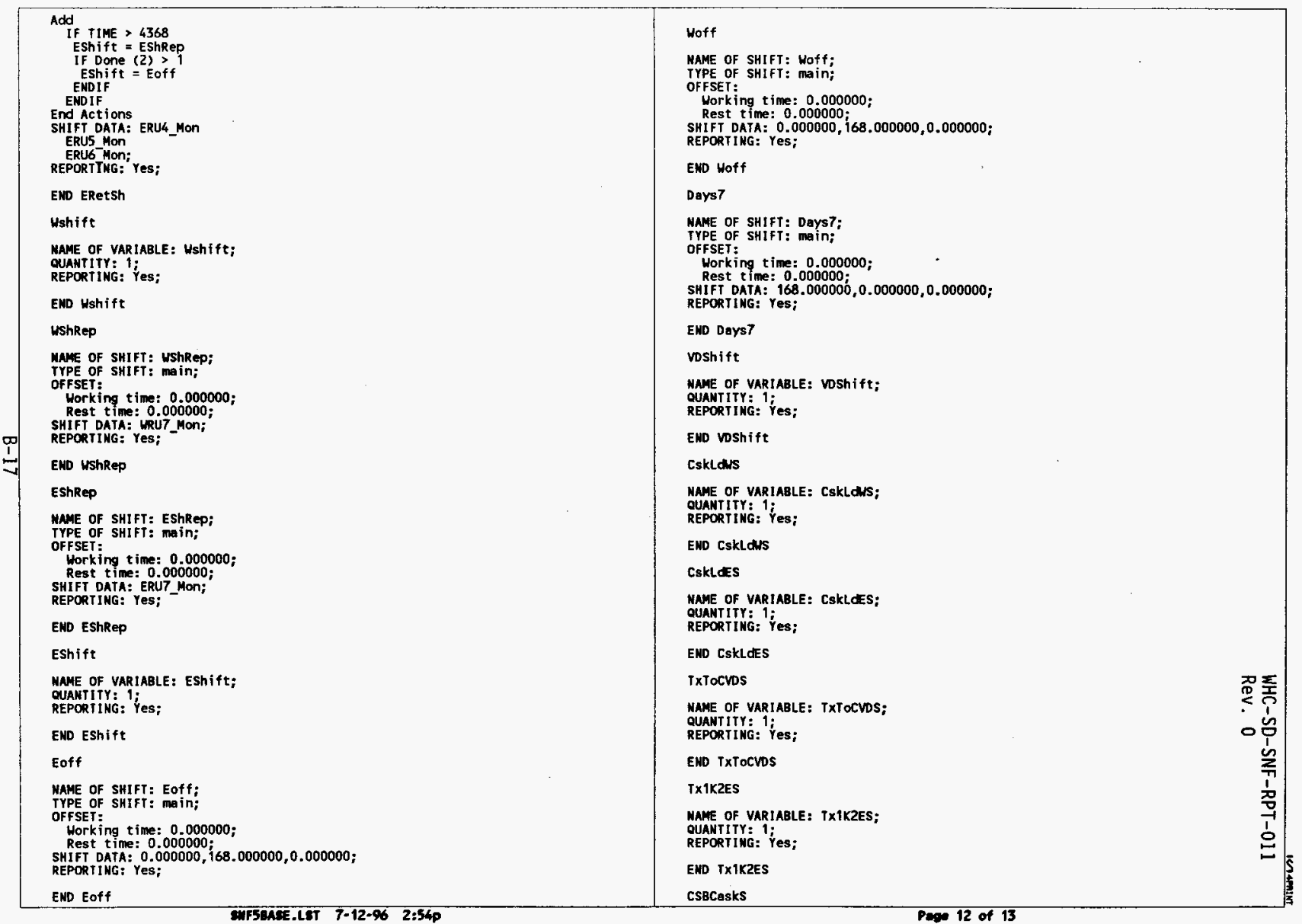


NAME OF VARIABLE: CSBCaskS;

QUANTITY: ';

END CSBCasks

\section{TxCskBs}

MAAE OF VARIABLE: TXCSkBS;

OUANT I TY: 1;

REPORTING: Yes;

END TXCskBS

Lastico

MAME OF VARIABLE: LAS TMCO;

QUANTITY: 4 ;

END Lastmco

END SELECT

EMD DETAIL

INITIALISE

Add

Add

IKE Basic

Tine Units are in HOURS

IxW Buspin

Supoly (2) $\approx 200$

Ushift =

EShift $=$ ERetSh

CskLdws $=$ Days5

CskLdES $=$ Doys5E

TXTOCVDS $=$ Days 5

DShift $=$ Days?

TX1K2ES $=$ Days5

CSBCasks $=$ Days

END INIIIALISE 
WHC-SD-SNF-RPT-011

Rev. 0

CASE 1. THO 12 HR SHIFTS/DAY, 5 DAYS/MEEK

B-19 


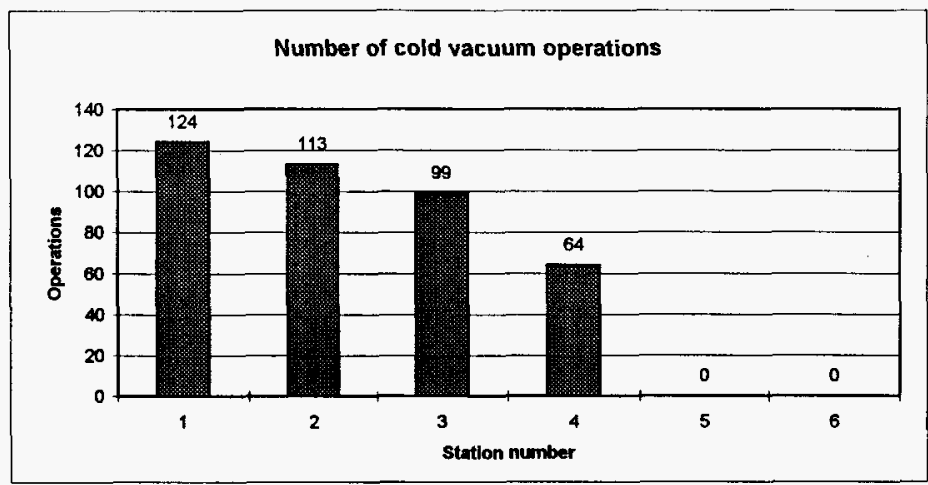

0
1
1
0

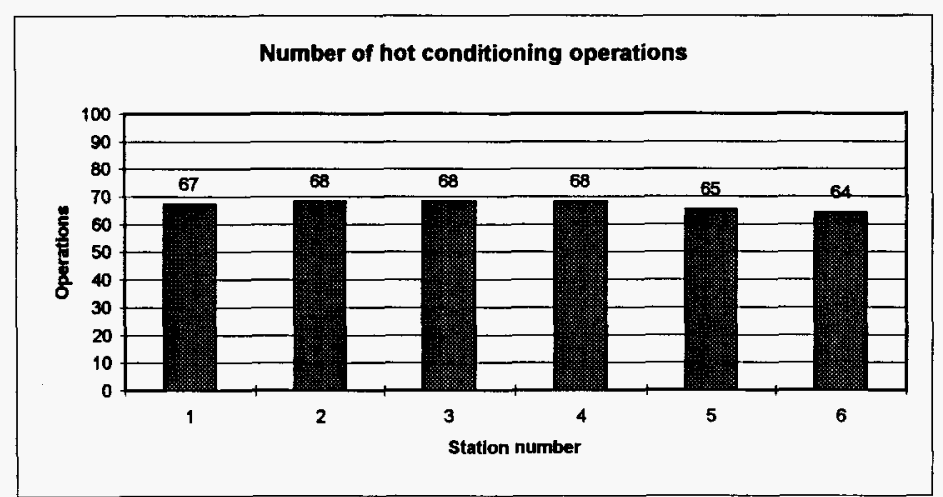


SNF Project operating 2 twelve hr shifts, 5 days/week. Cold vacuum drying Hot conditioning operating 7 days/week

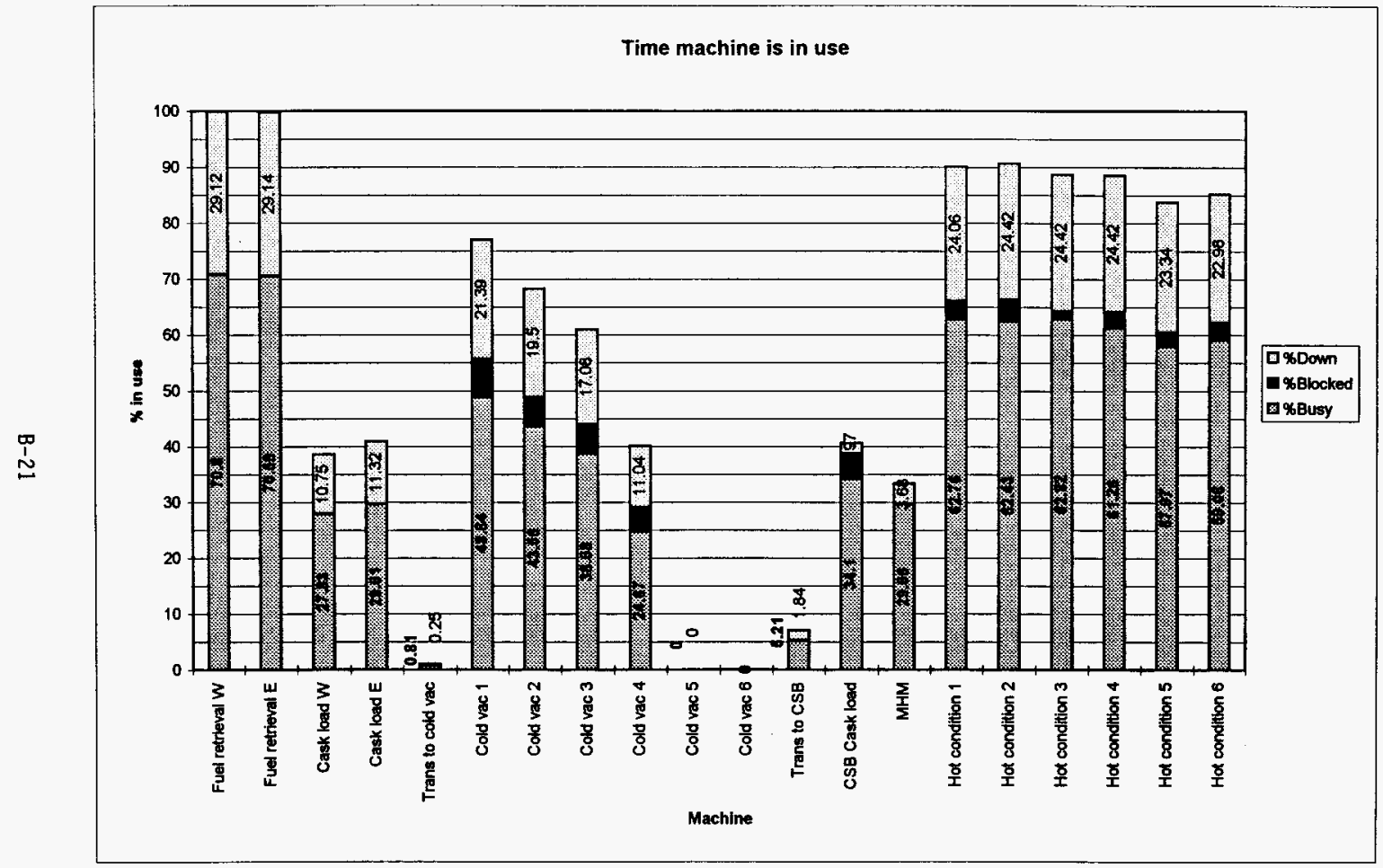


WHC-SD-SNF-RPT-011

Rev. 0

$\frac{9}{N}$

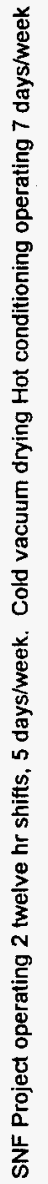
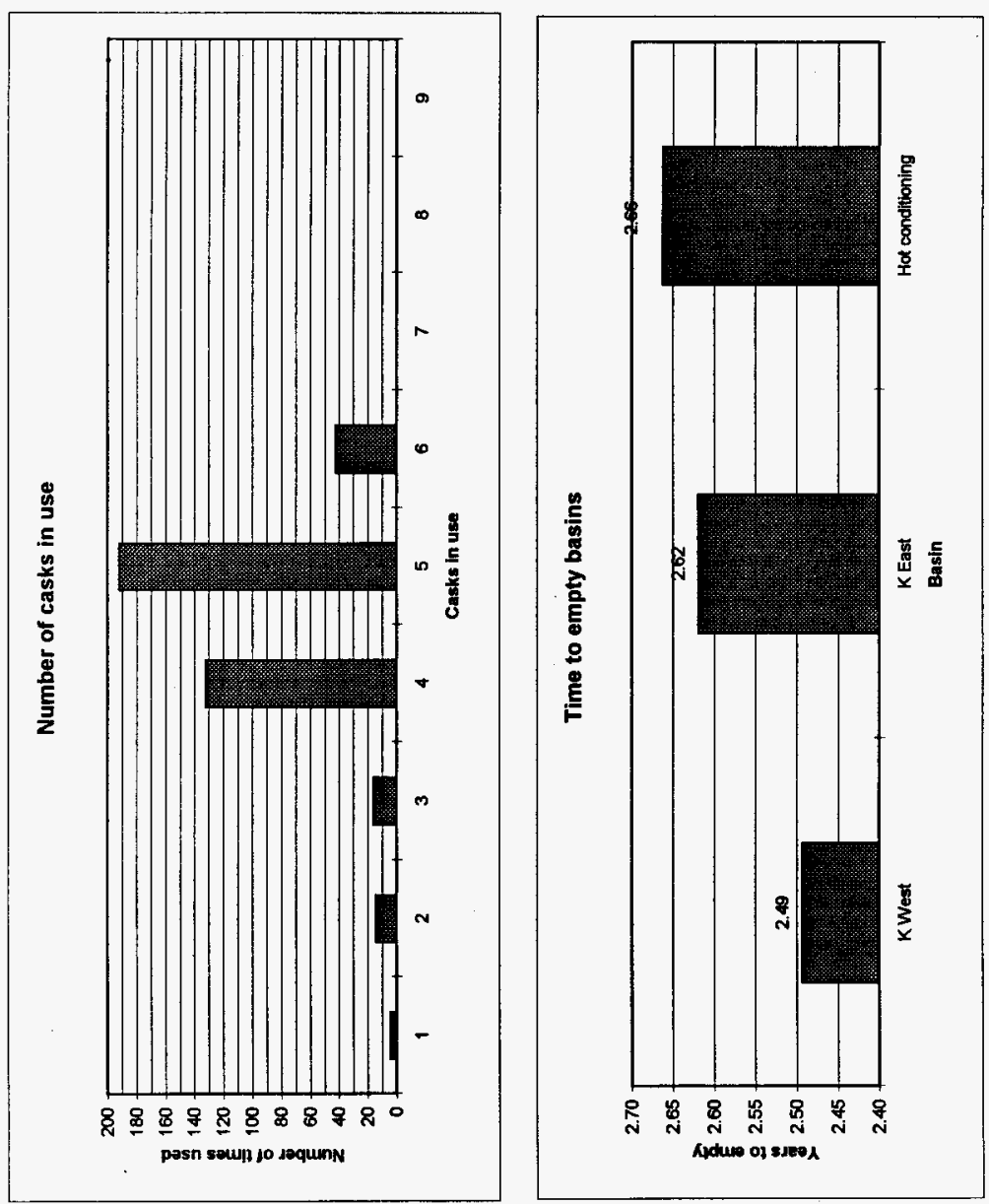

@

产 


\begin{tabular}{|c|c|c|}
\hline 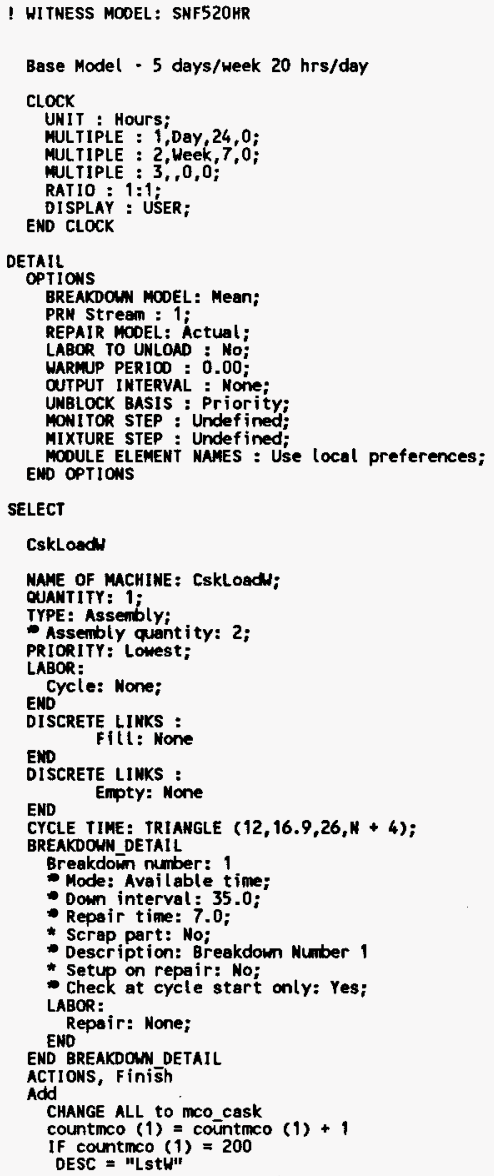 & 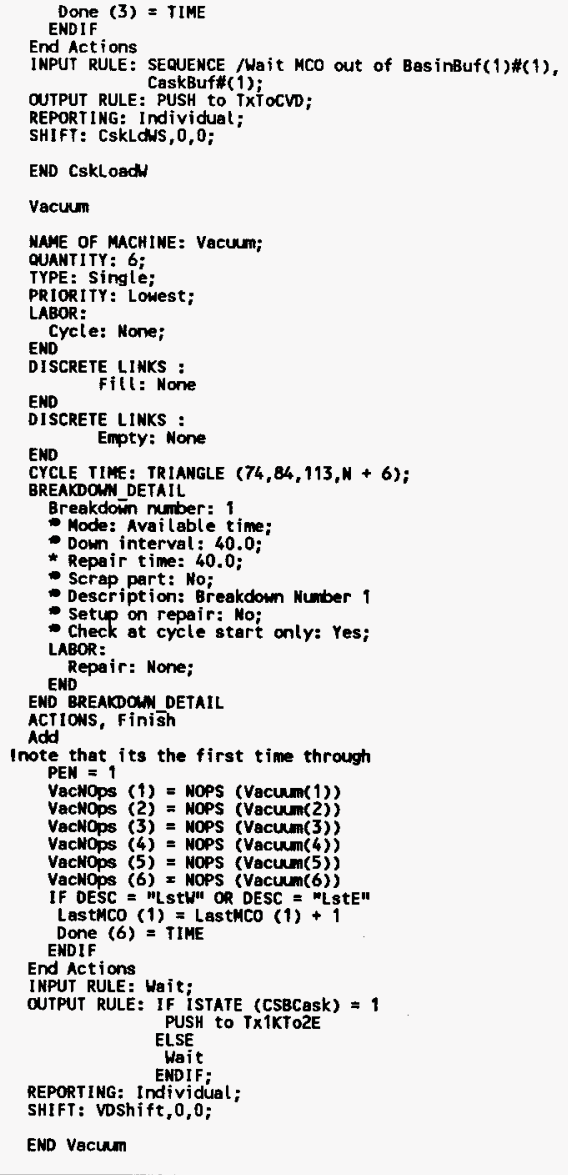 & 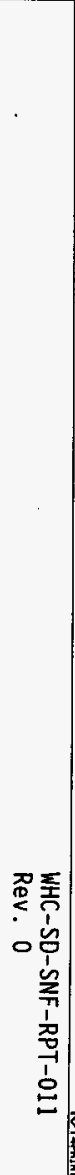 \\
\hline
\end{tabular}




\begin{tabular}{|c|c|c|}
\hline 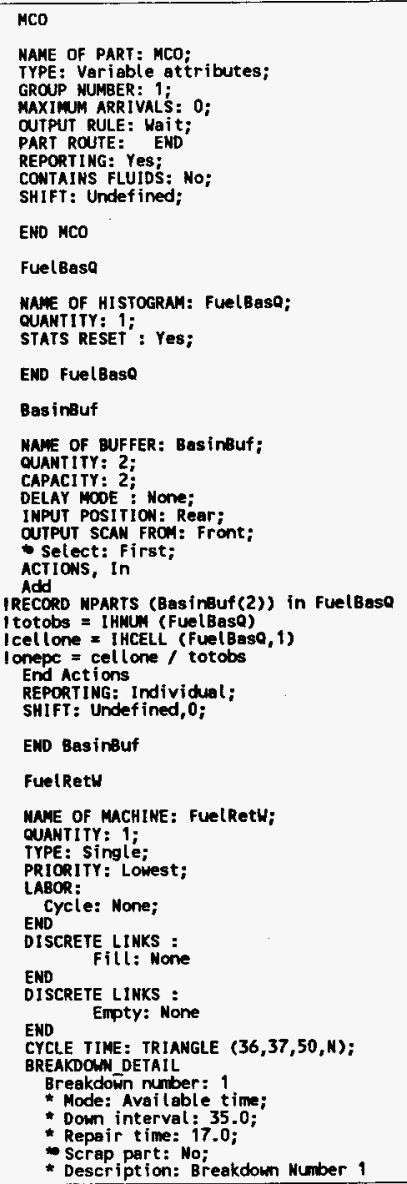 & 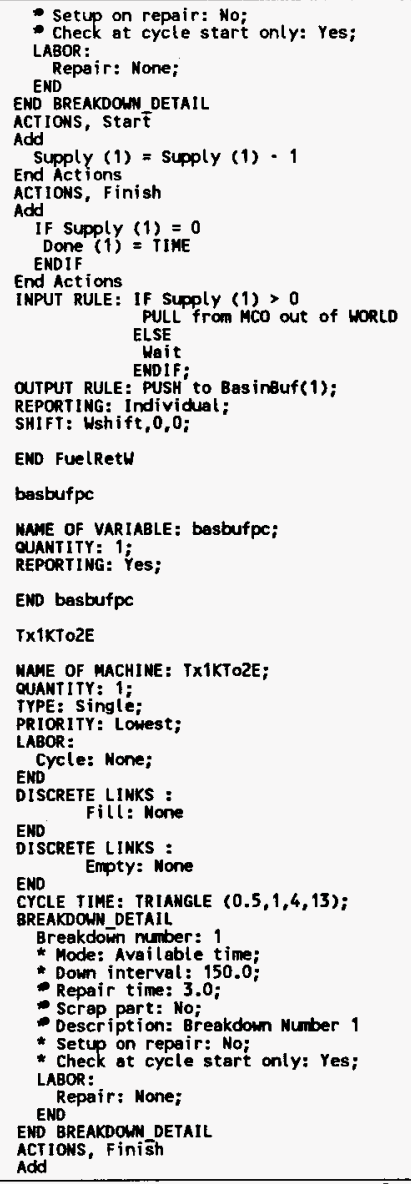 & 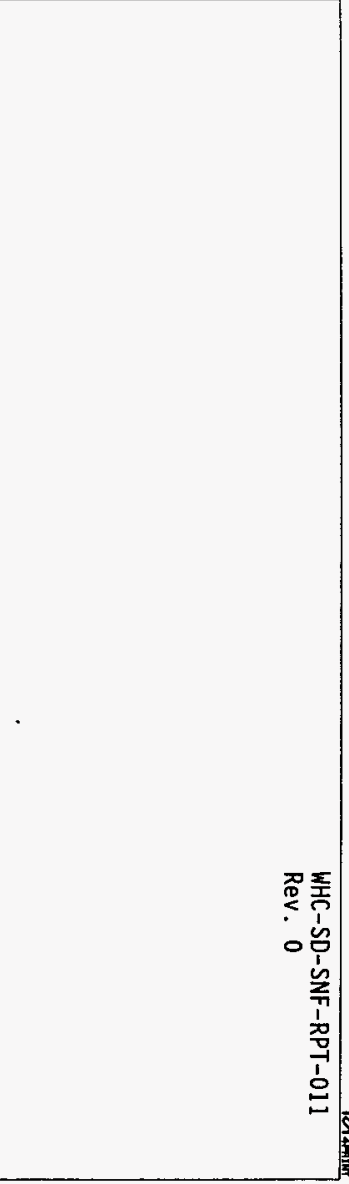 \\
\hline
\end{tabular}




\begin{tabular}{|c|c|c|}
\hline 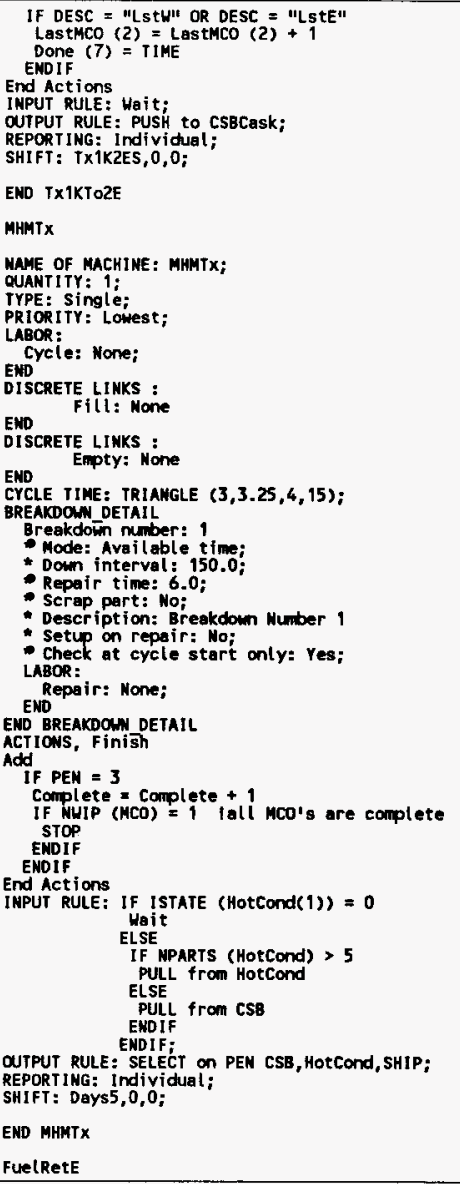 & 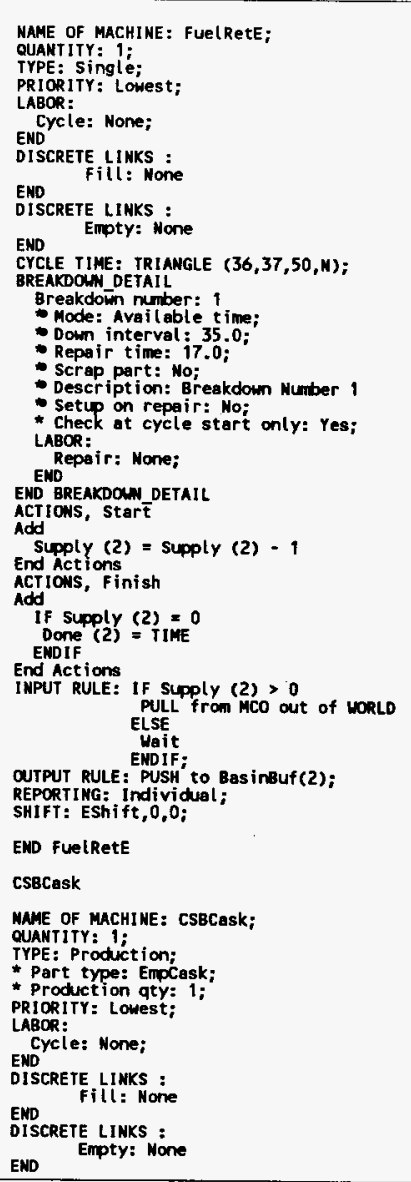 & 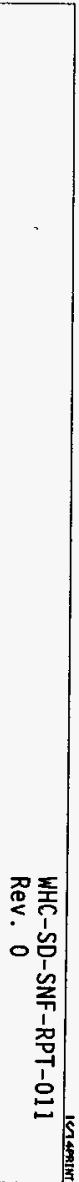 \\
\hline
\end{tabular}




\begin{tabular}{|c|c|c|}
\hline 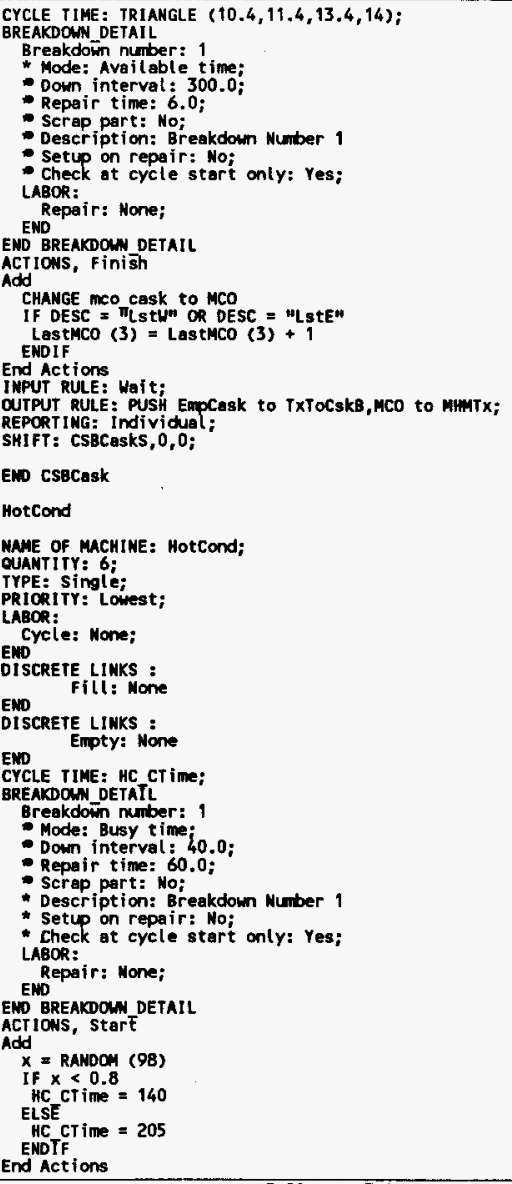 & 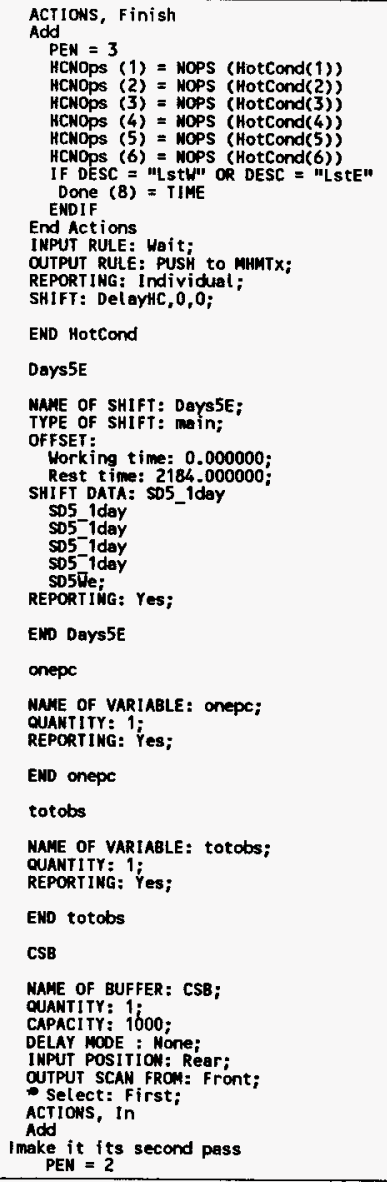 & 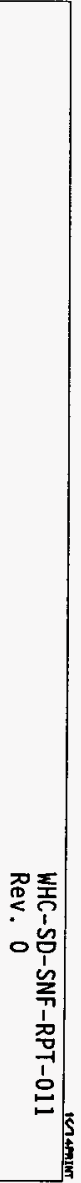 \\
\hline
\end{tabular}




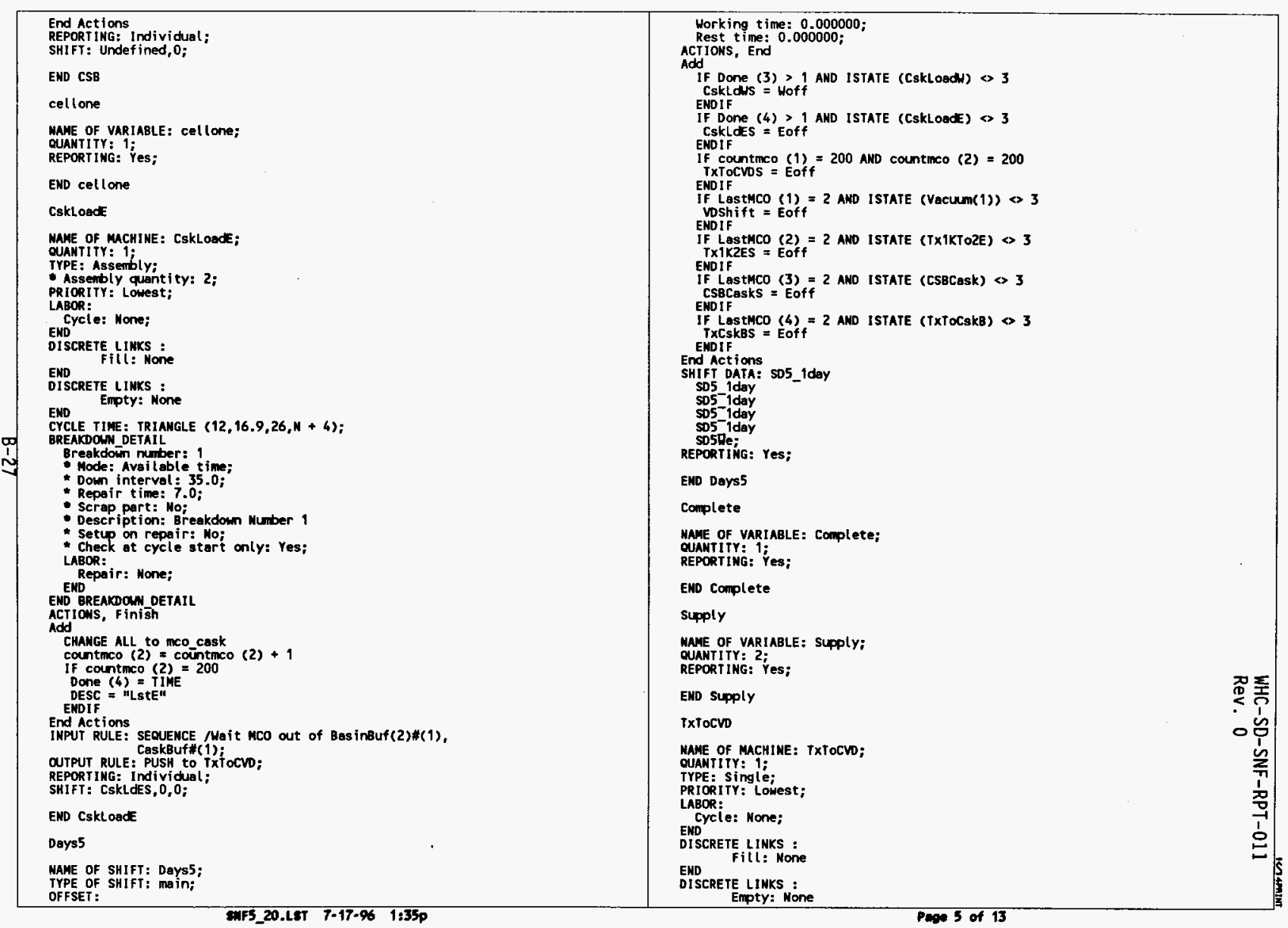




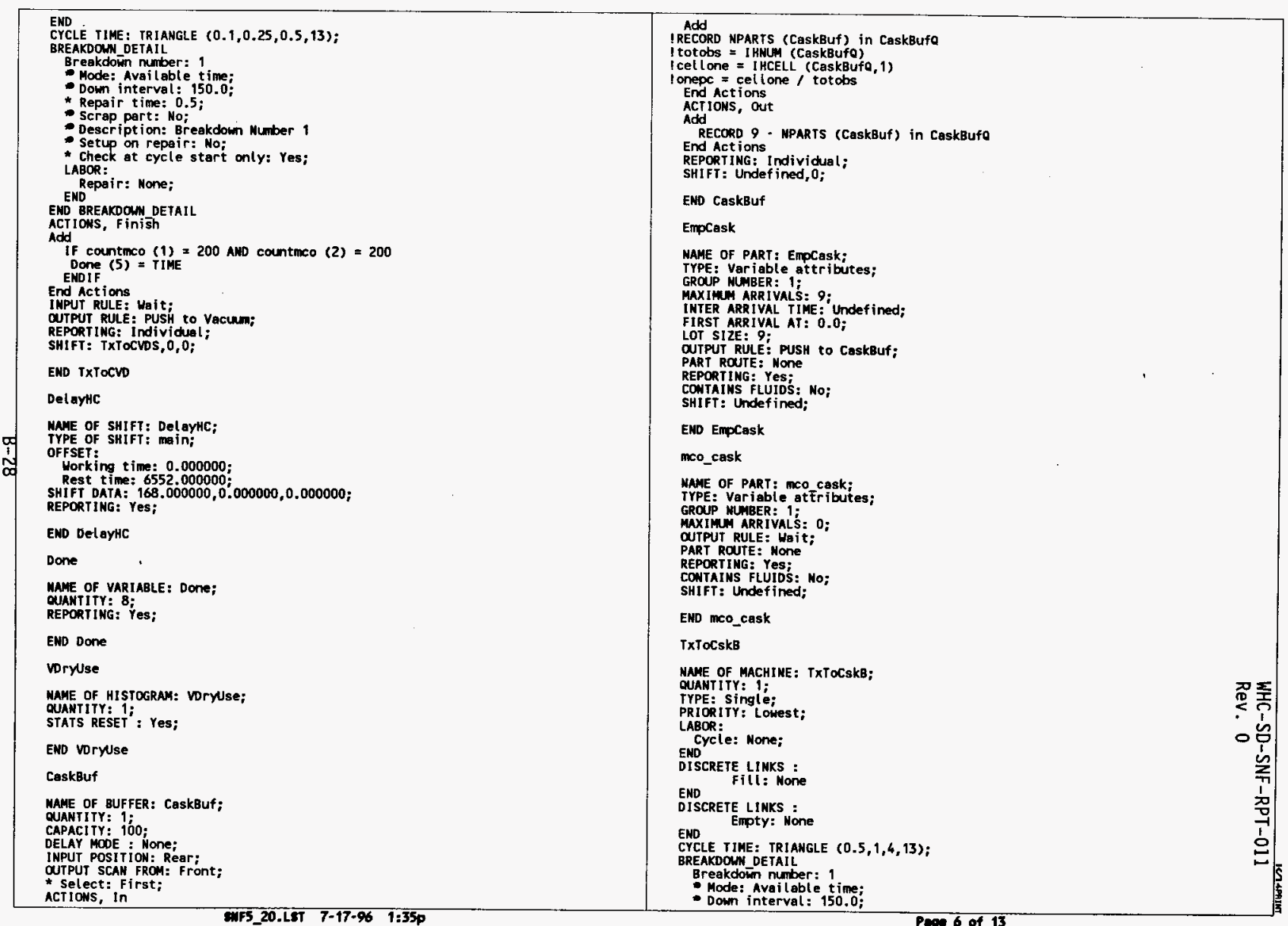




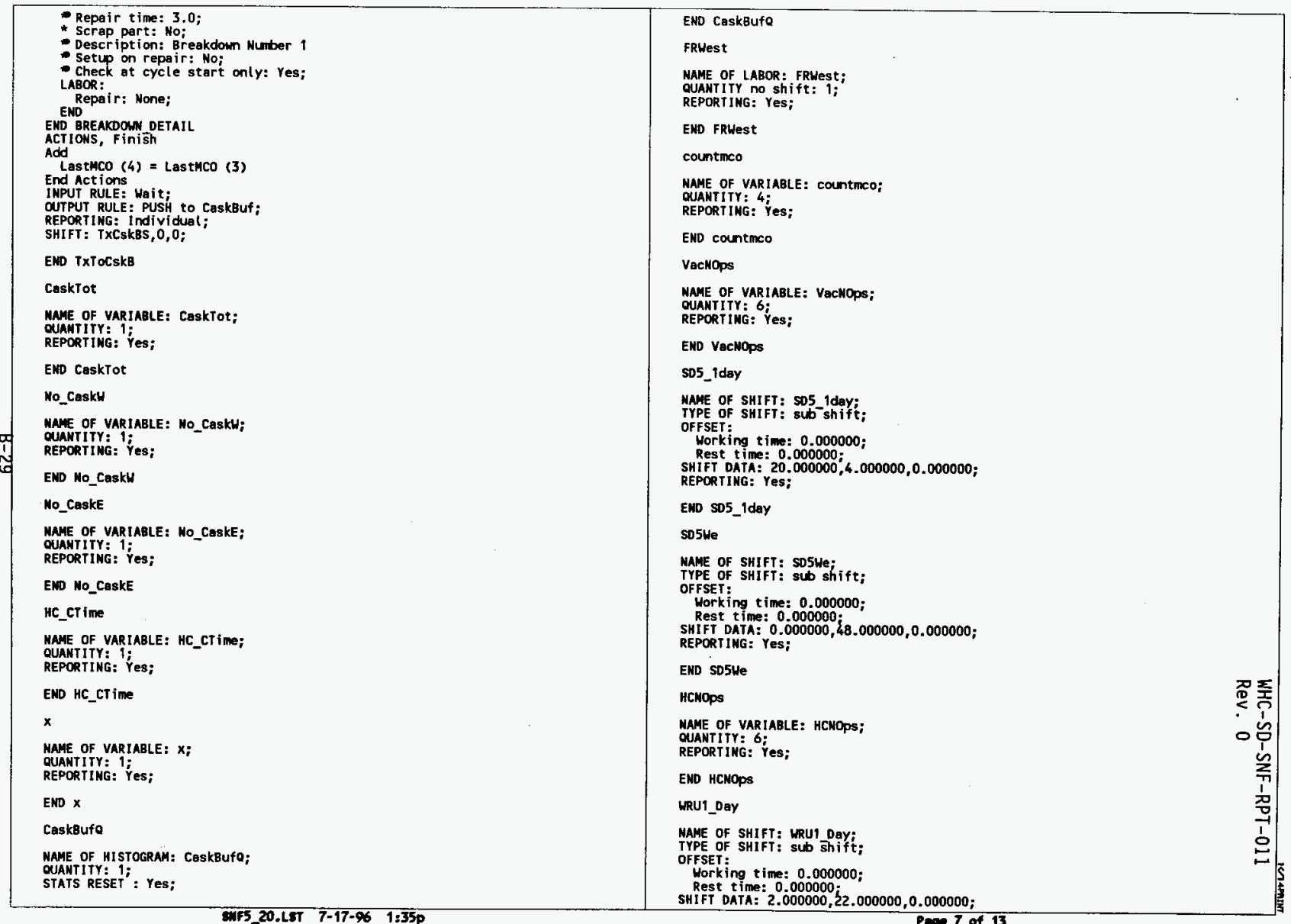




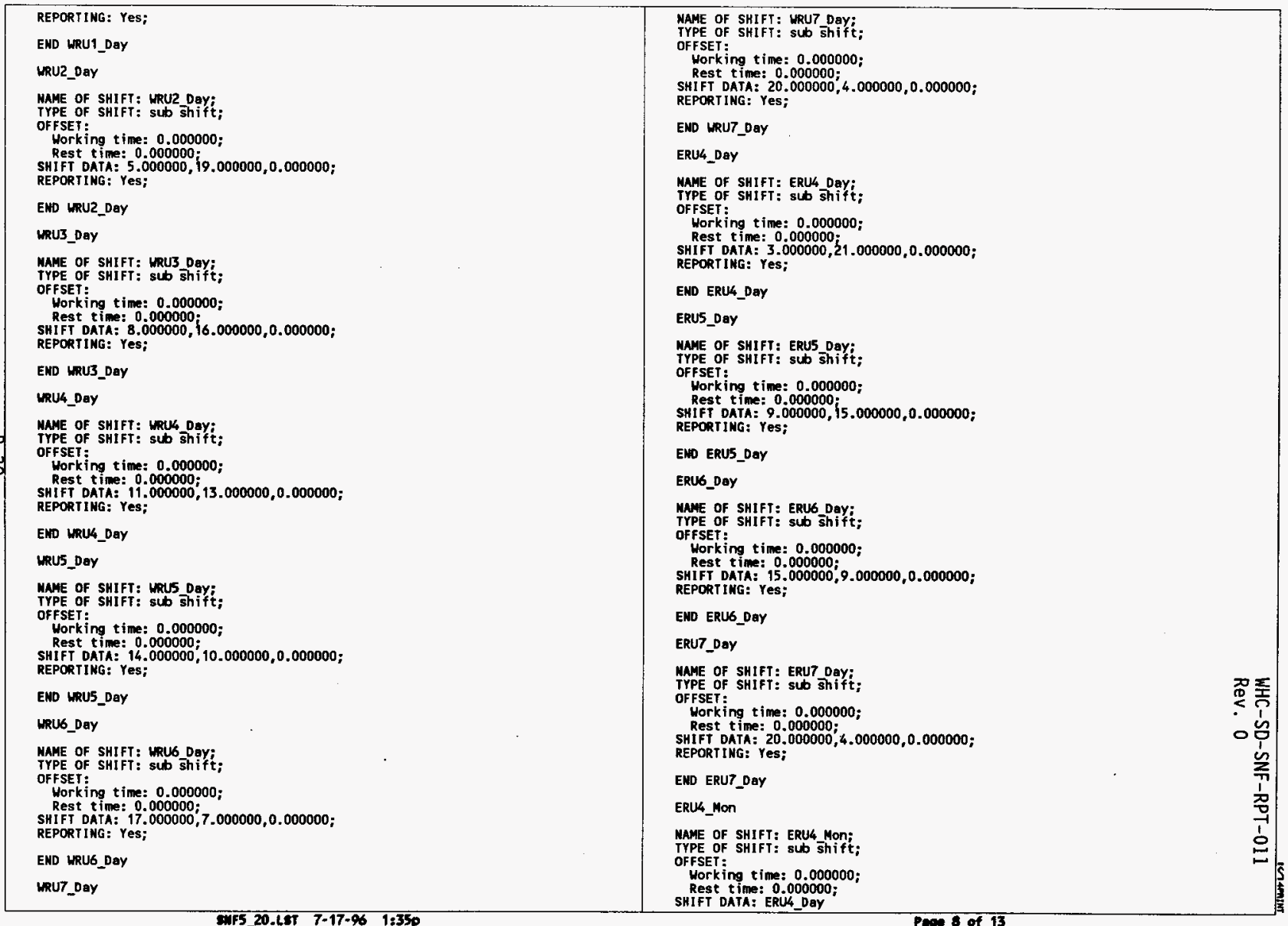




\begin{tabular}{|c|c|c|}
\hline 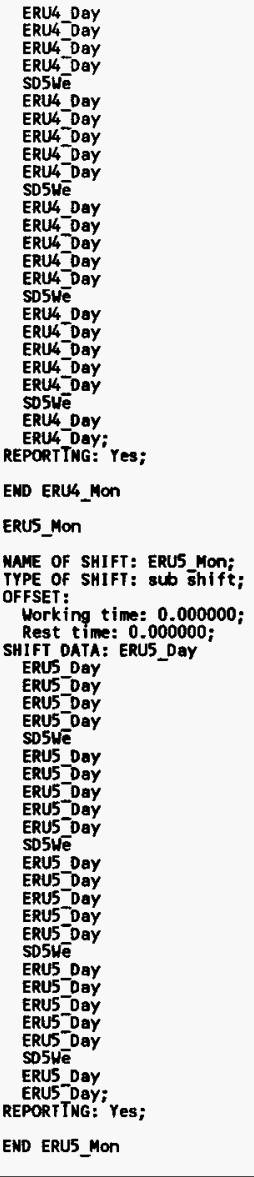 & 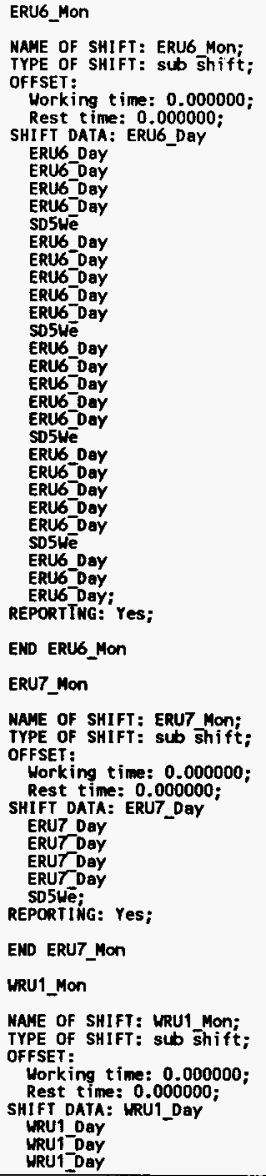 & 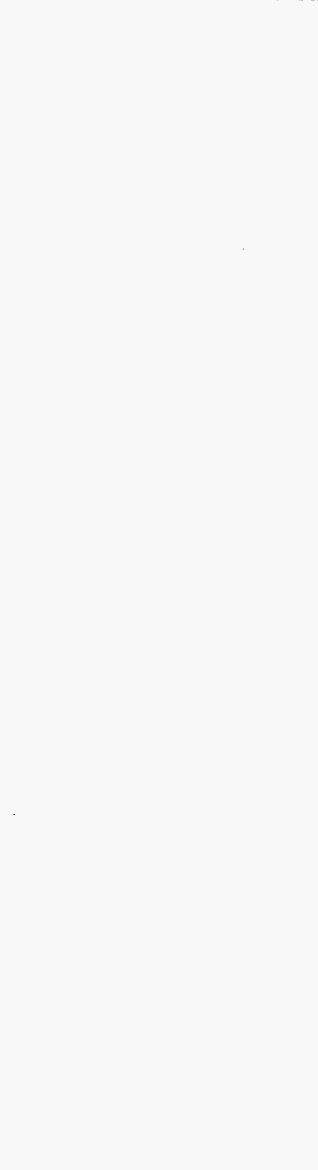 \\
\hline
\end{tabular}




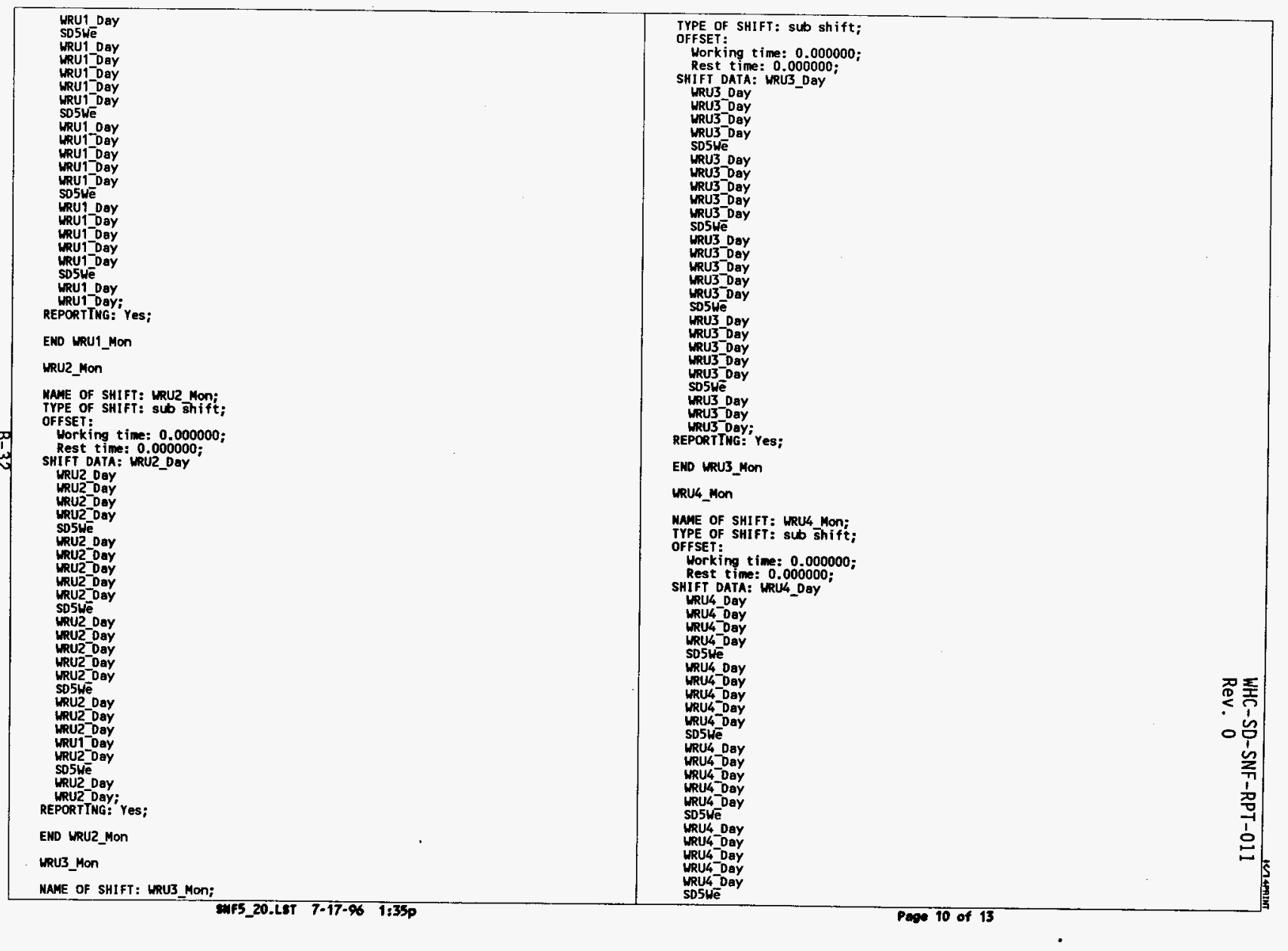




\begin{tabular}{|c|c|c|}
\hline 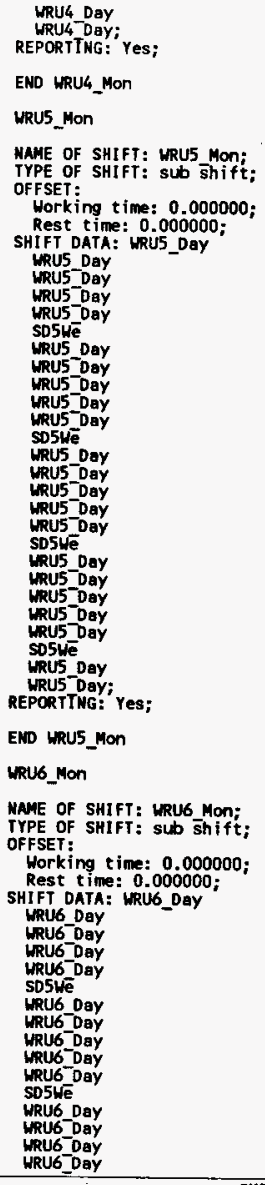 & 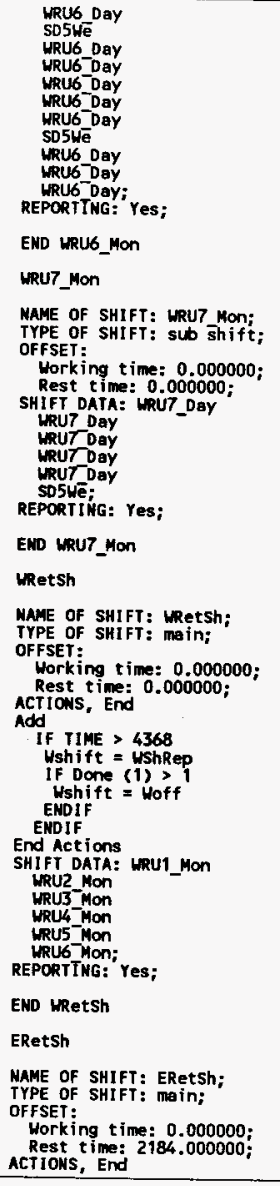 & 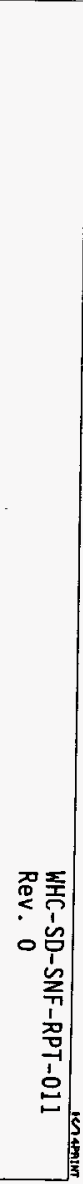 \\
\hline
\end{tabular}




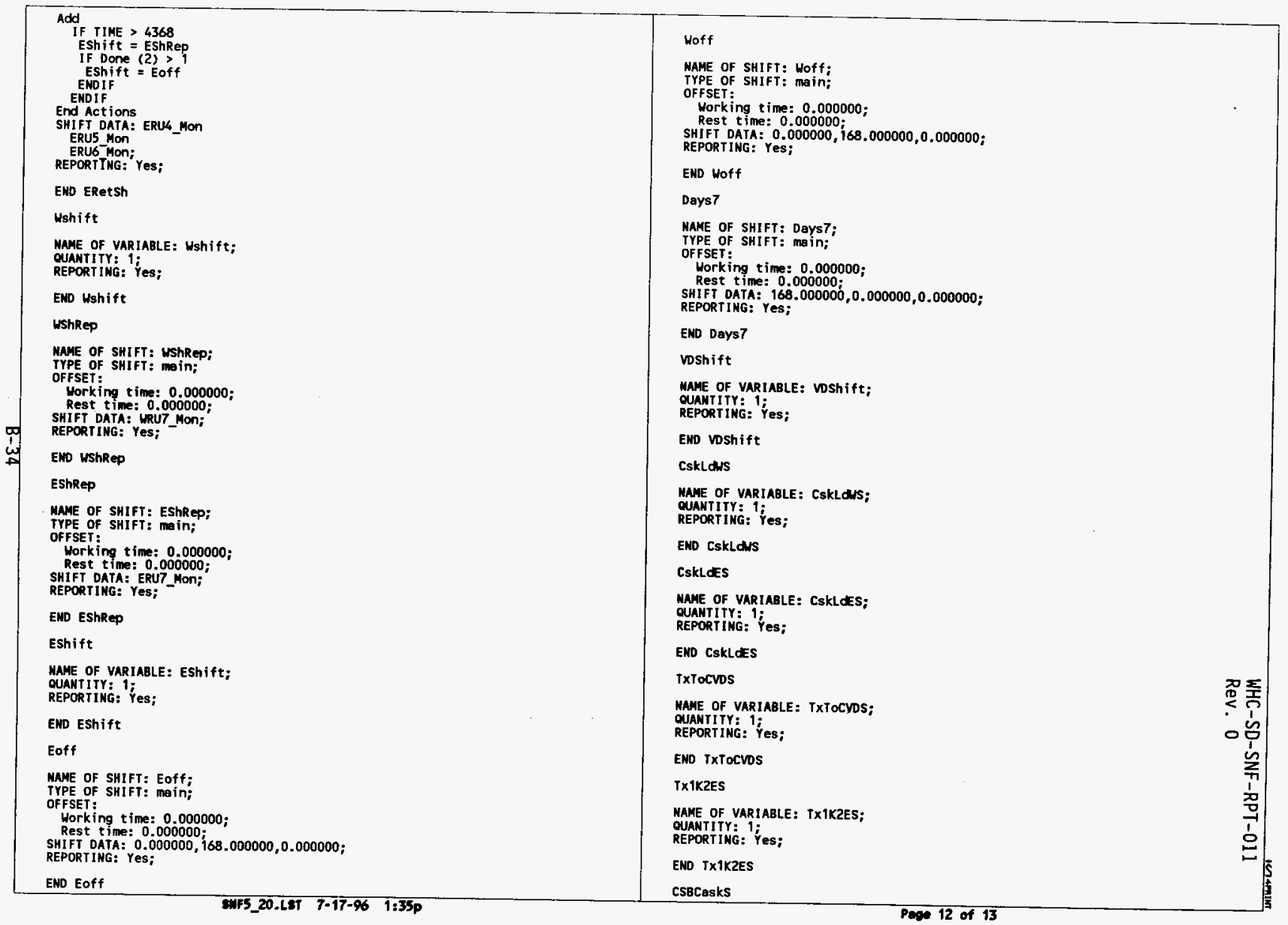


MAME OF VAR IABLE: CSBCasks;

QUANTI TY: 1

END CSBCasks

TxCskBS

NAME OF VARIABLE: TXCskBS;

QUANIIIYY: 1 ;

ENO TXCskBS

Las tMCO

NAME OF VARIABLE: LQSTMCO;

QUANTITY: 4 ;

REPORT ING: Yes;

END Lastmco

EHD SELECT

END DETAIL

INITIALISE

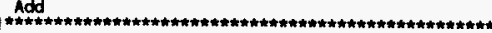

प्रे।

Time Units are in HOURS

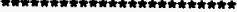

IKE Basic

Supply $(1)=200$

Ka Basin

Supply (2) = 200

Ushift = WRetSh

Eshift = ERetsh

Csklds = Darss

TXIocvos $=$ Deys 5

Voshift $=$ Deys?

TX1K2ES $=$ Days5

CSBCasks = Days

TXCskBS $=$ Days 5

End Actions

END INITIALISE 
WHC-5D-SNF-RPT-011

Rev. 0

CASE 2. THREE 8HR SHIFTS/DAY, 5 DAYS/WEEK.

FUEL RETRIEVAL OPERATING AT 90\% EFFICIENCY 
SNF Project operating 3 shifts, 5 days/week. Cold vacuum drying Hot conditioning operating 7 days/week. With an $90 \%$ TOE on fuel retrieval

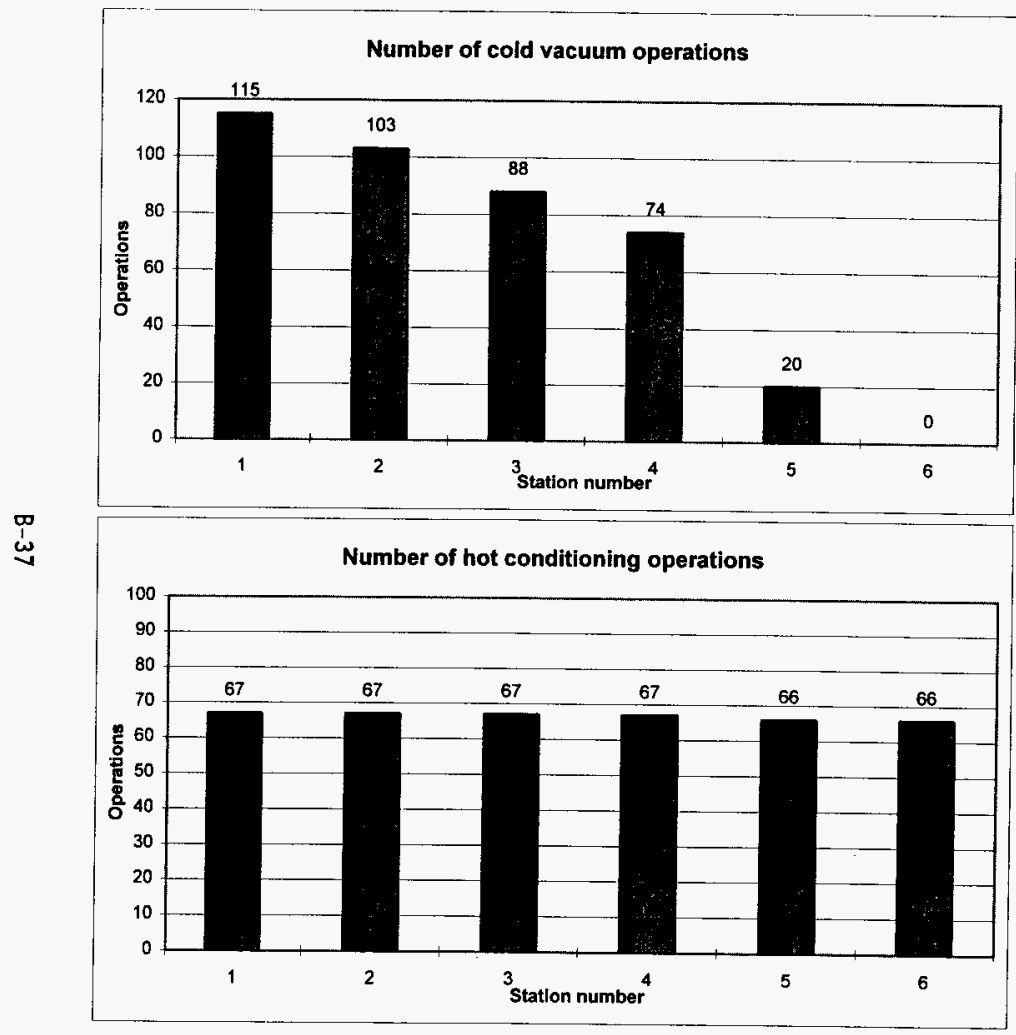


WHC-SD-SNF-RPT-011

Rev. 0

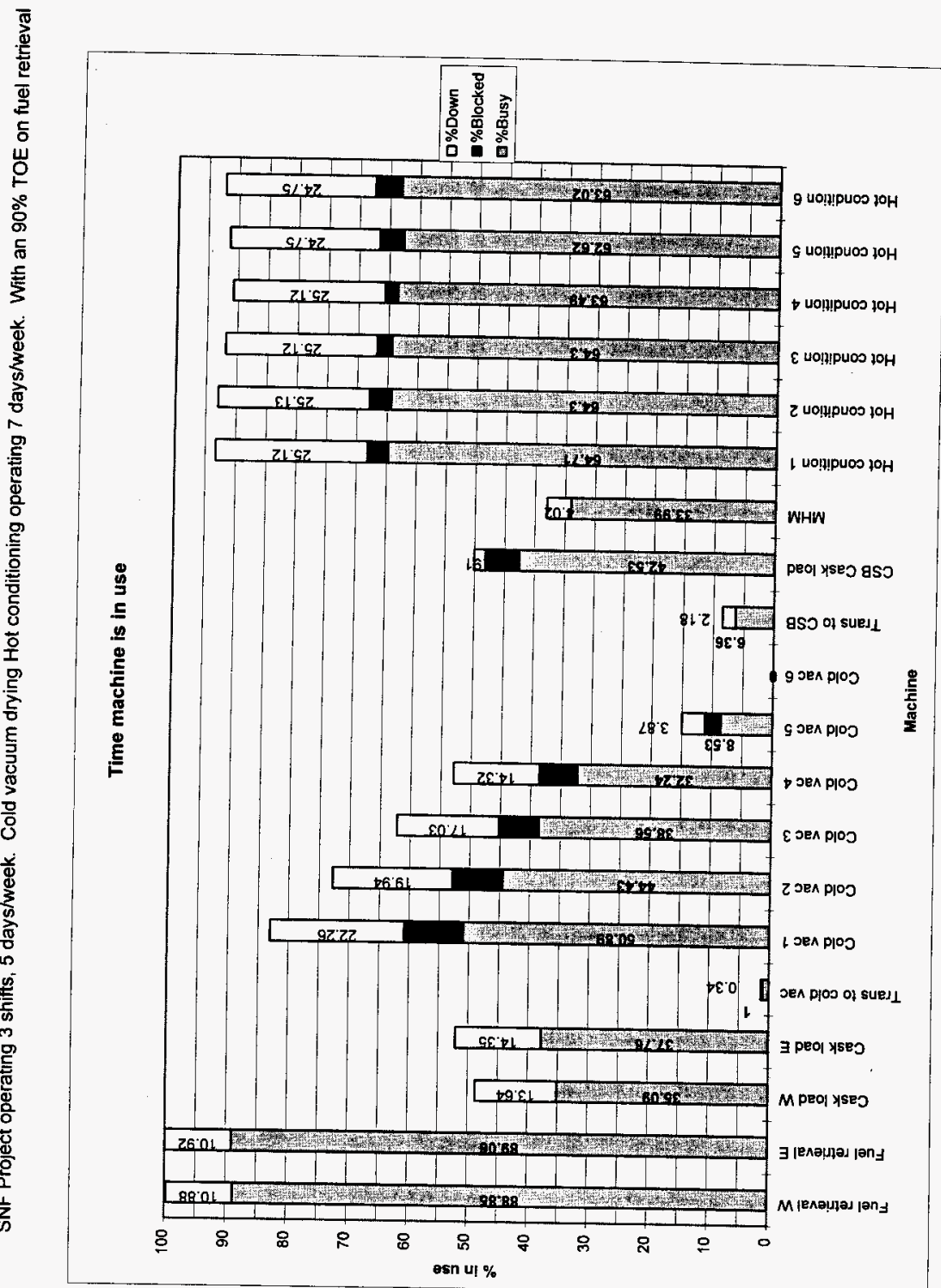

ำ 
SNF Project operating 3 shifts, 5 days/week. Cold vacuum drying Hot conditioning operating 7 days/week. With an $90 \%$ TOE on fuel retrieval

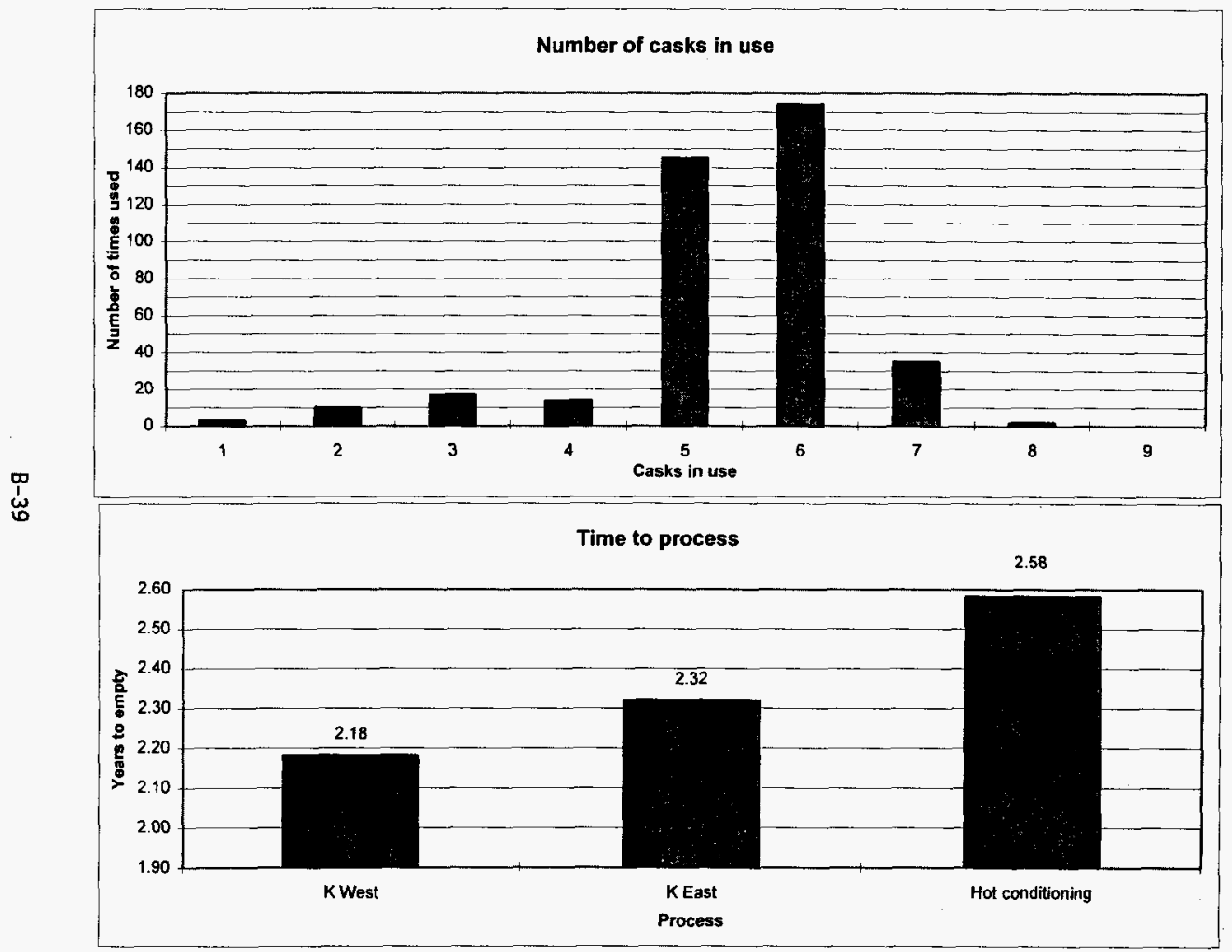




\begin{tabular}{|c|c|c|}
\hline 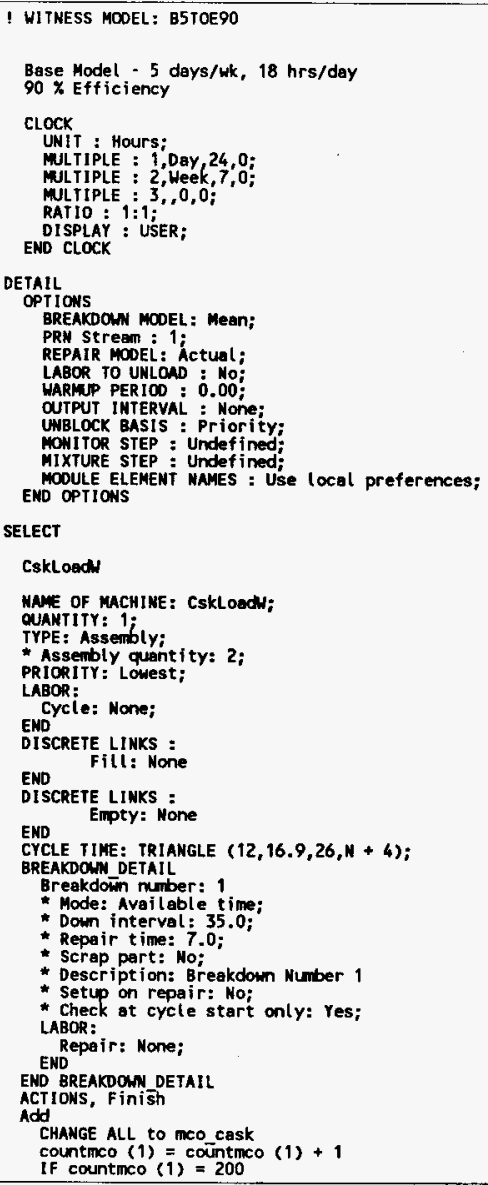 & 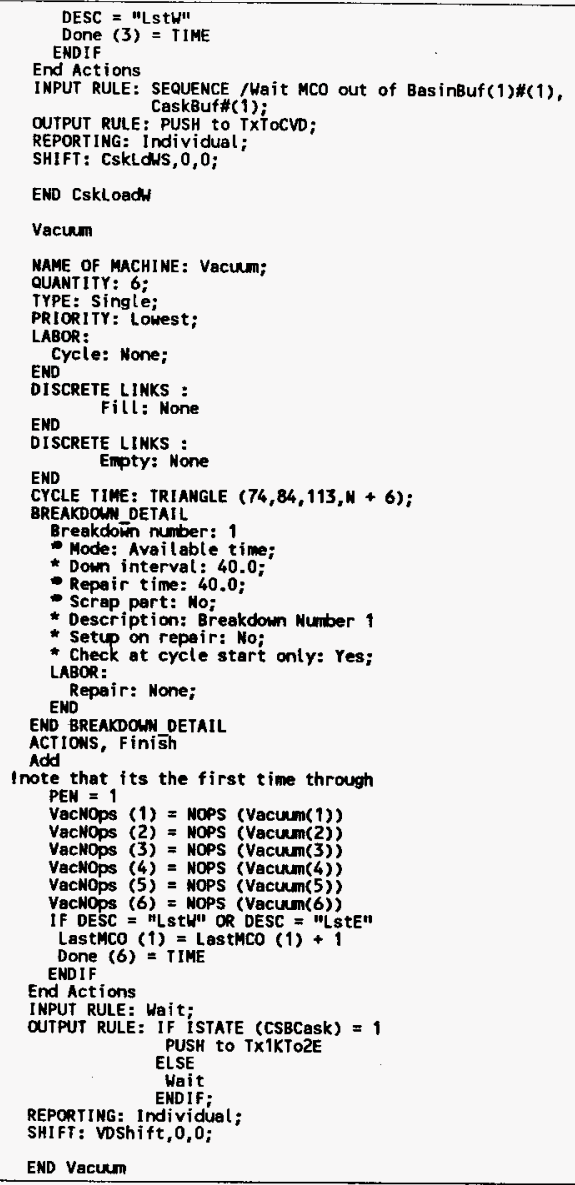 & 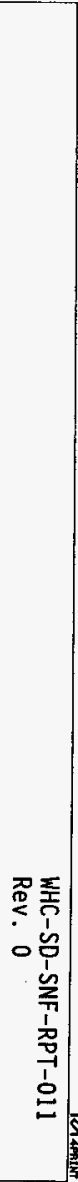 \\
\hline
\end{tabular}




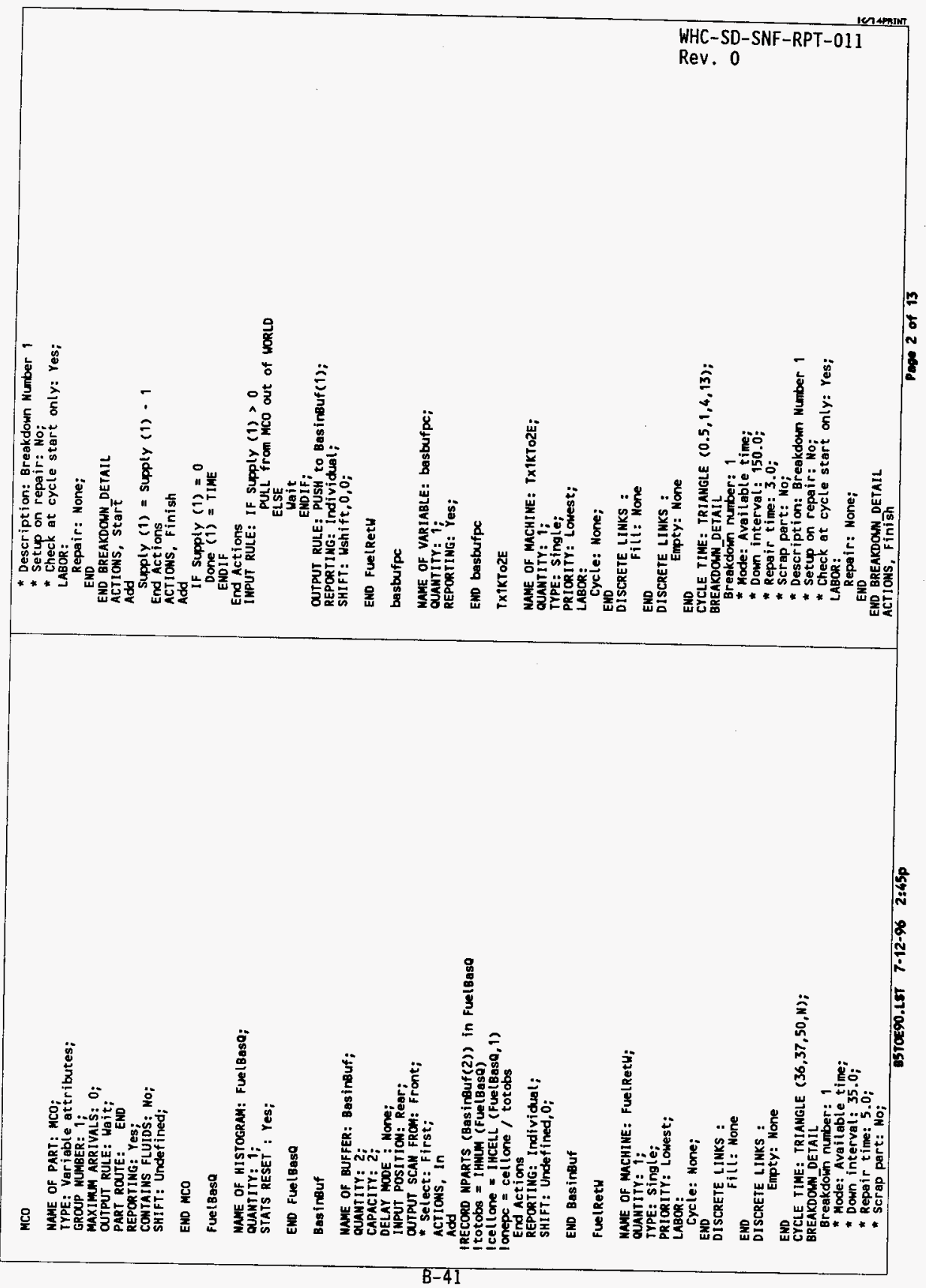




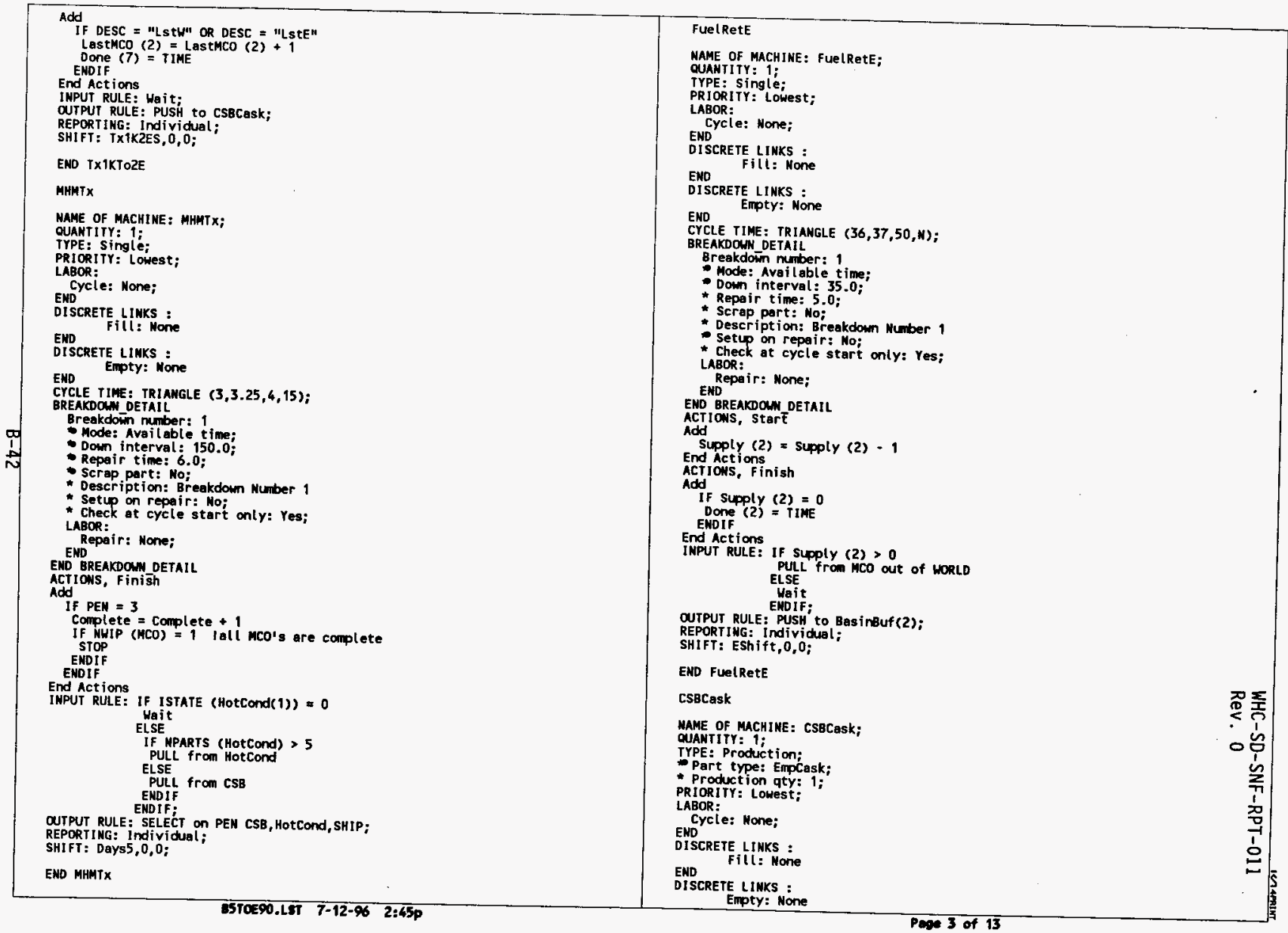




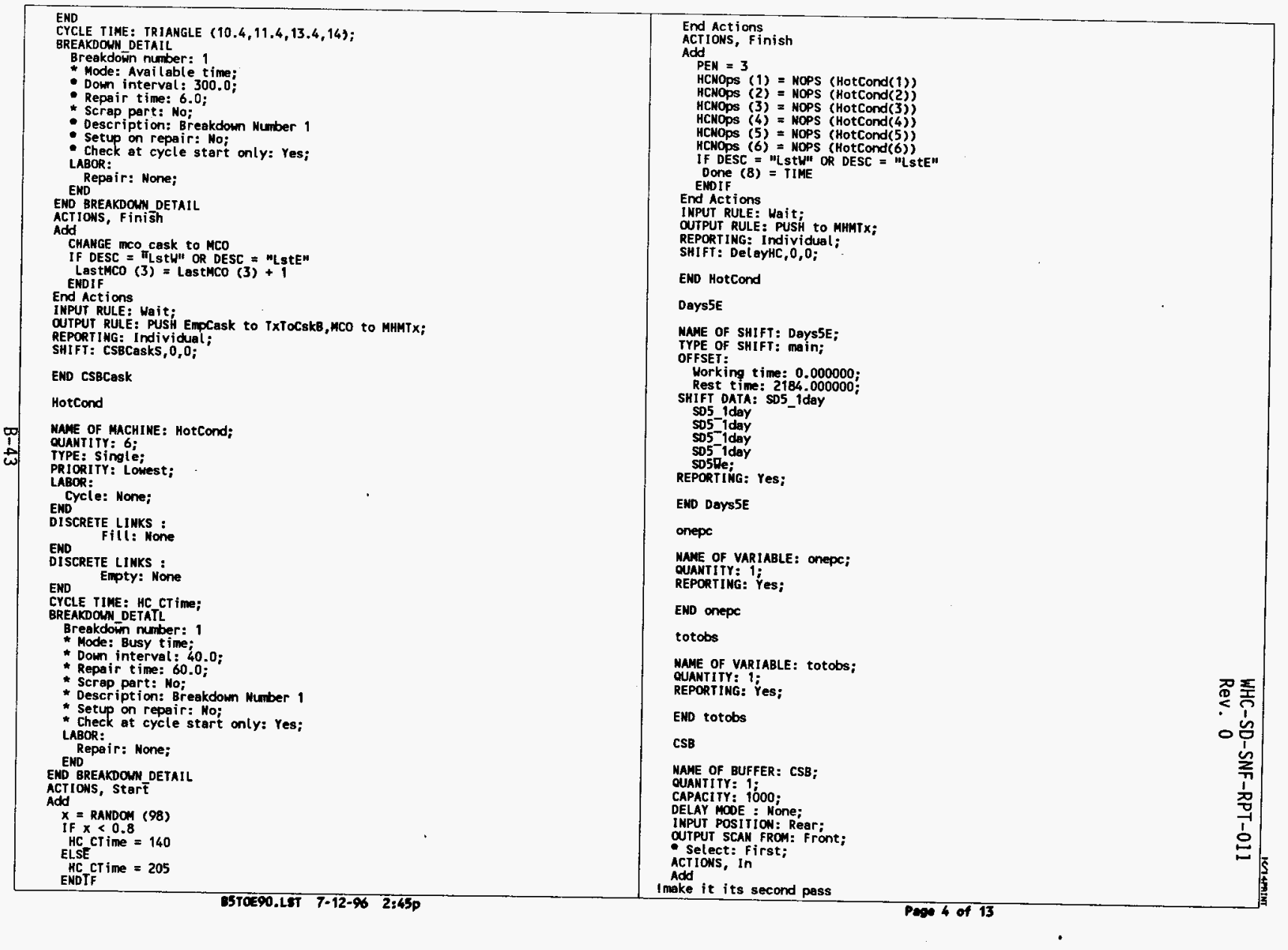




\begin{tabular}{|c|c|c|}
\hline 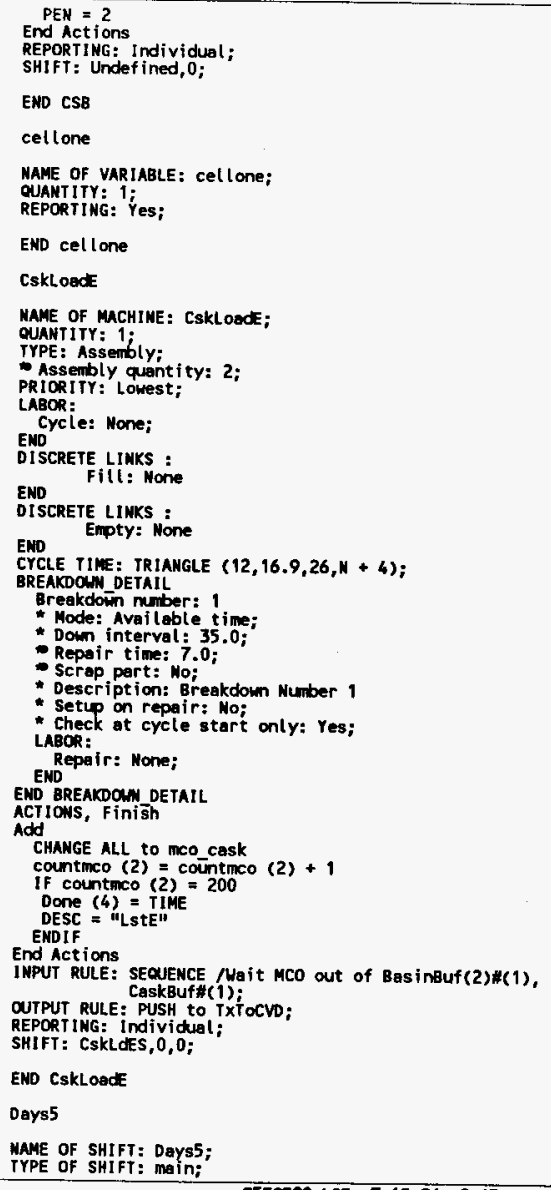 & 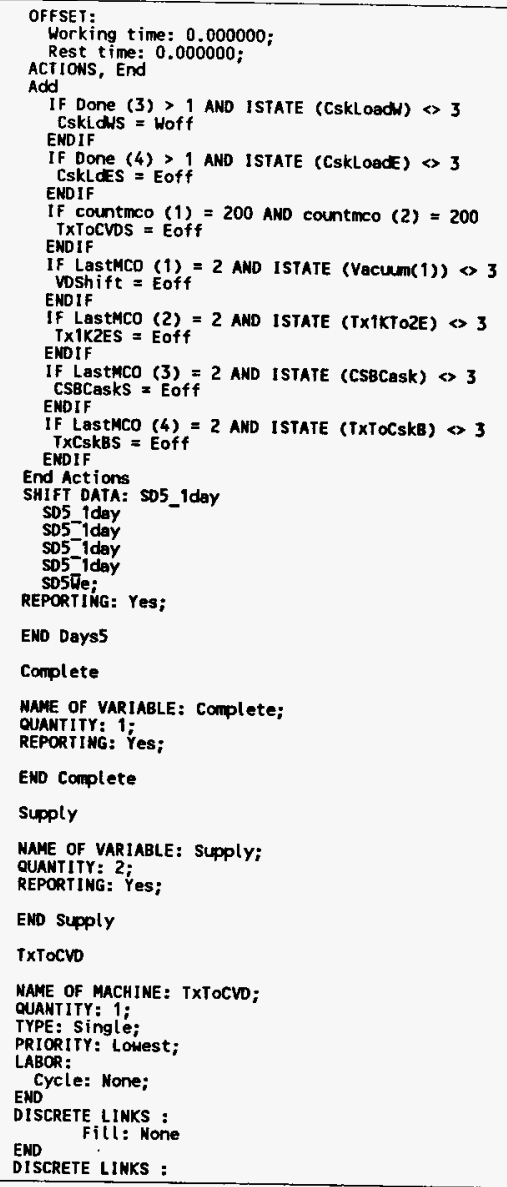 & 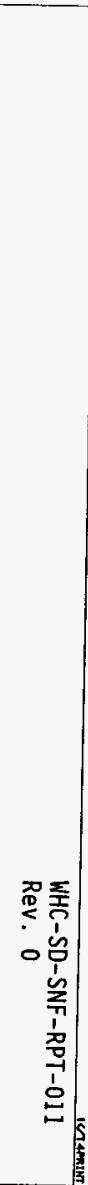 \\
\hline
\end{tabular}




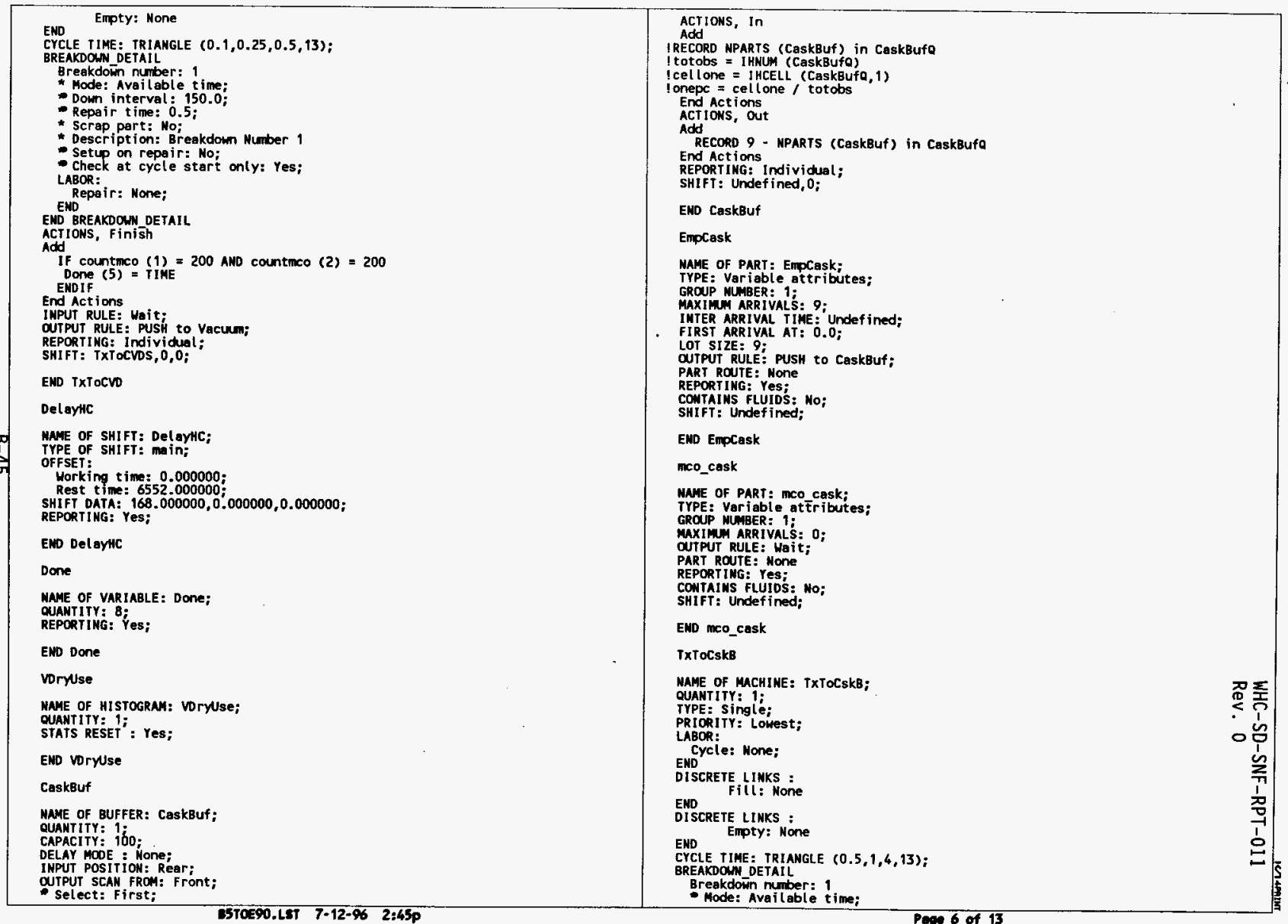




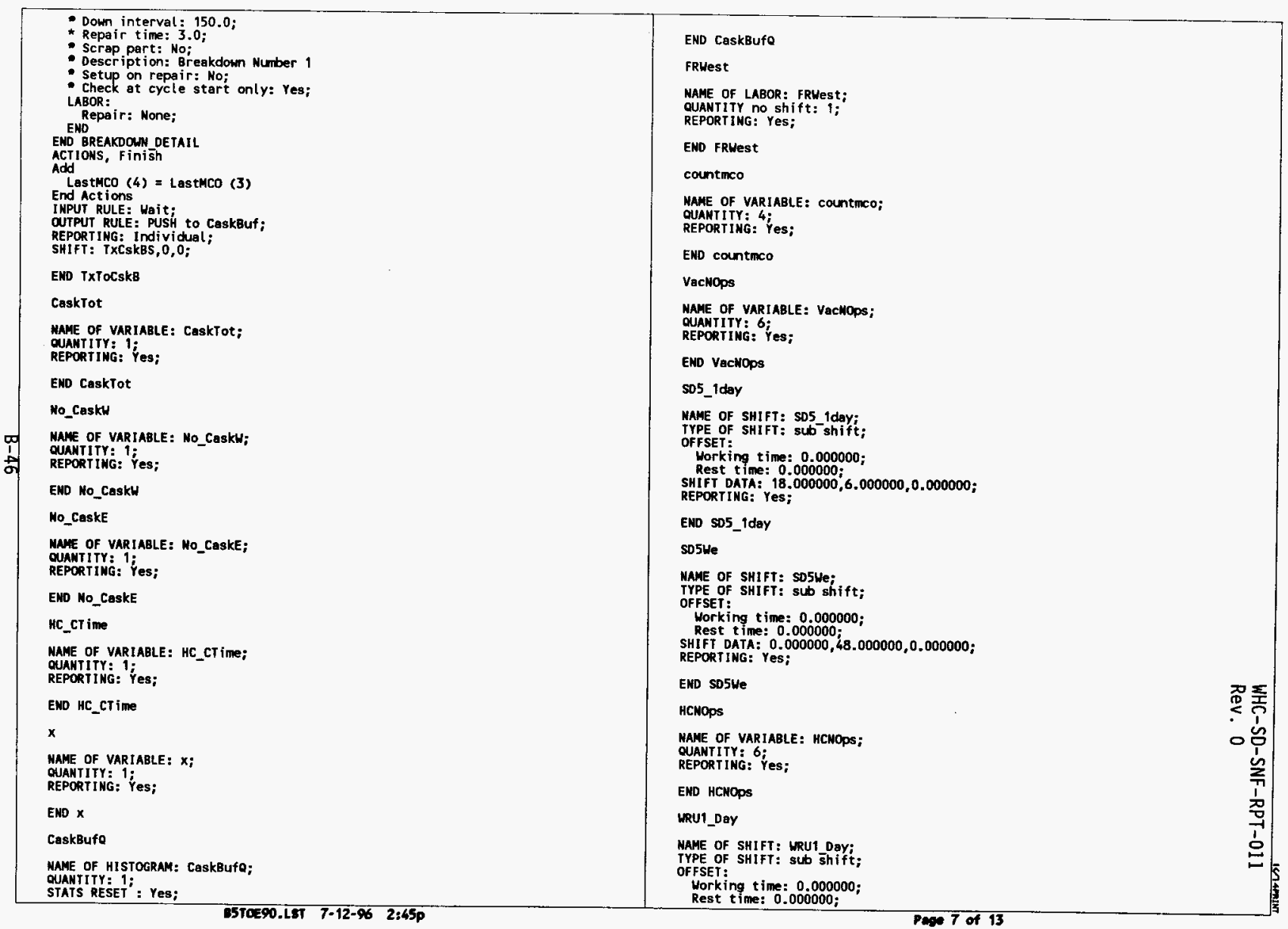




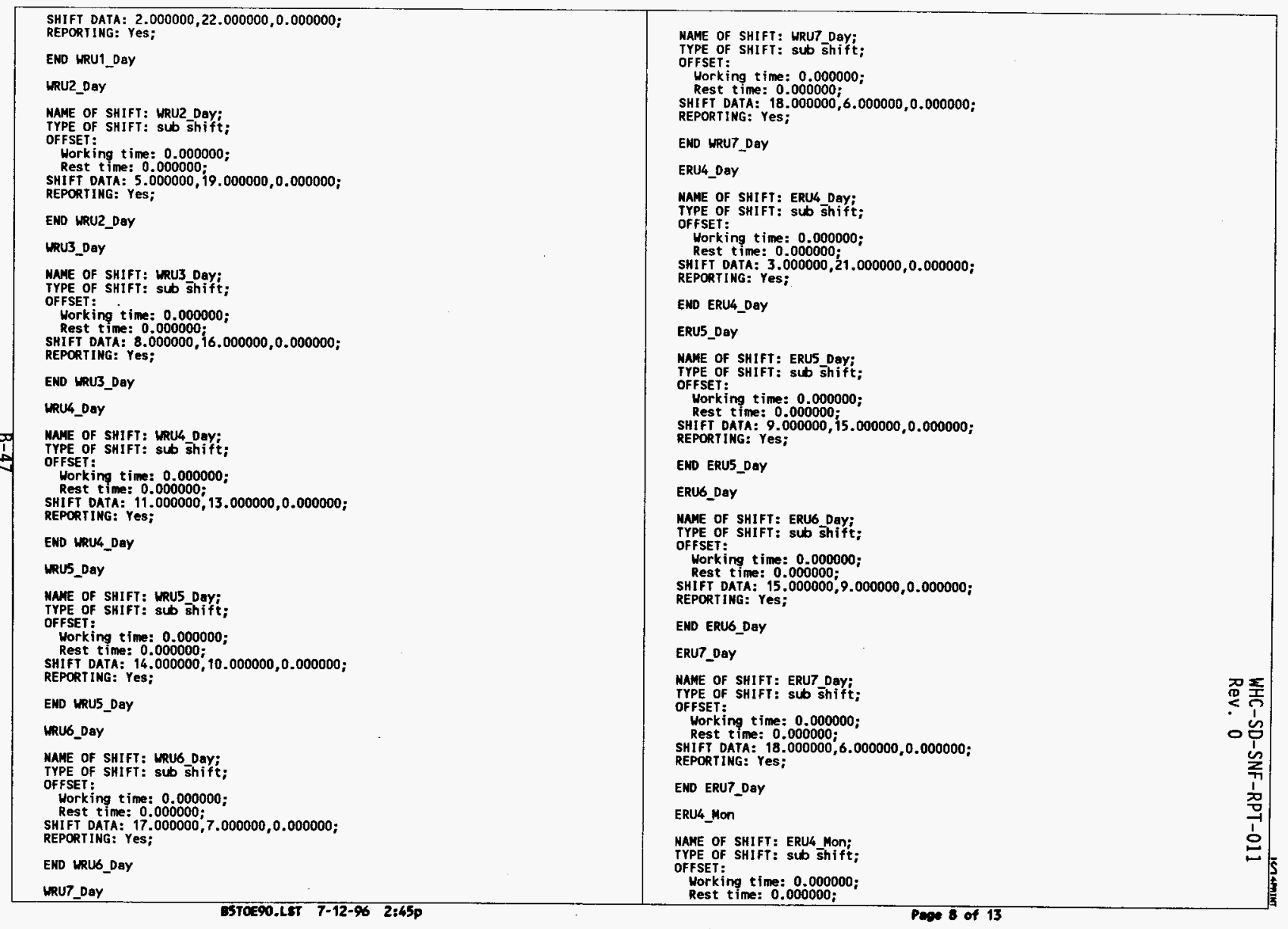




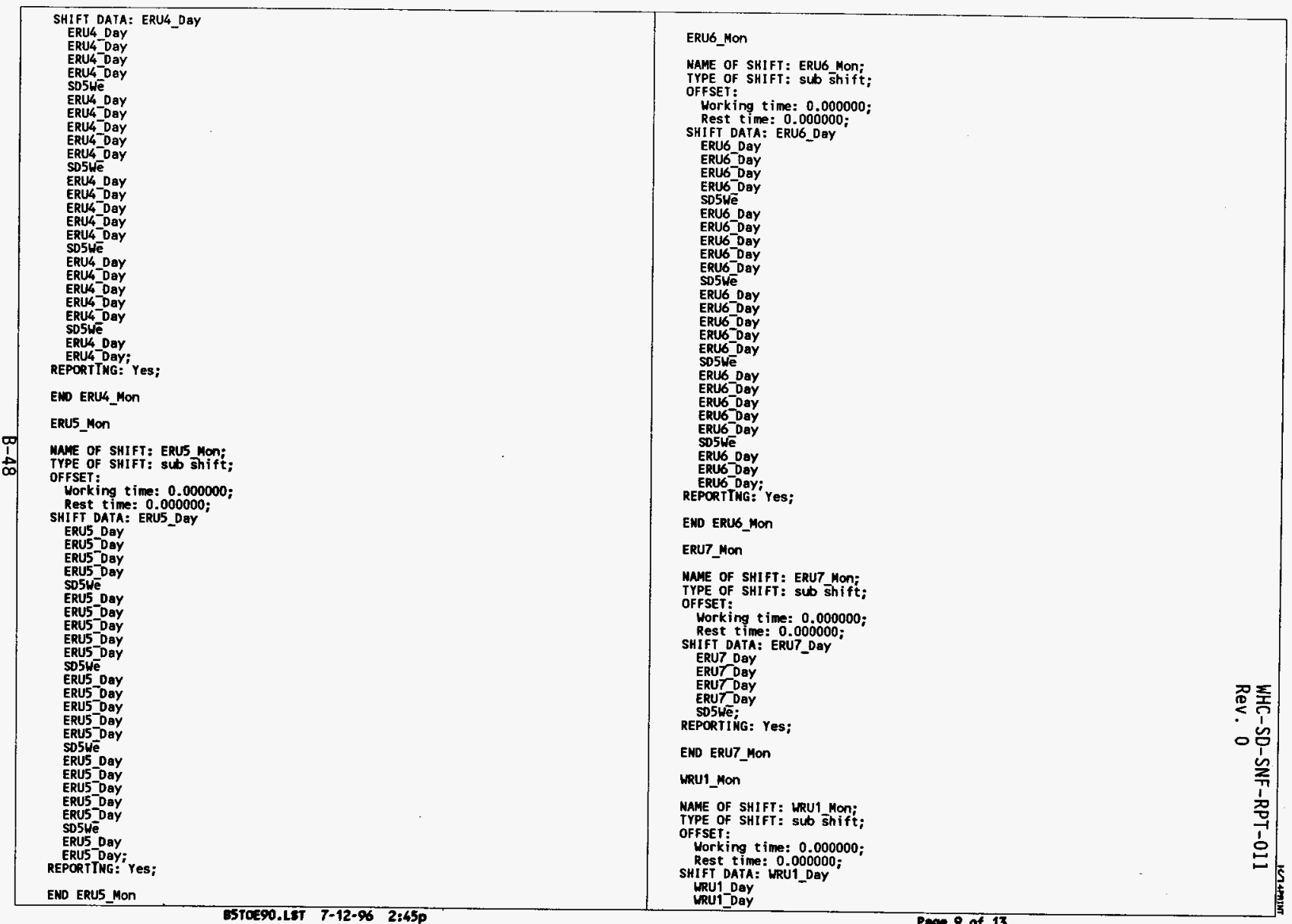




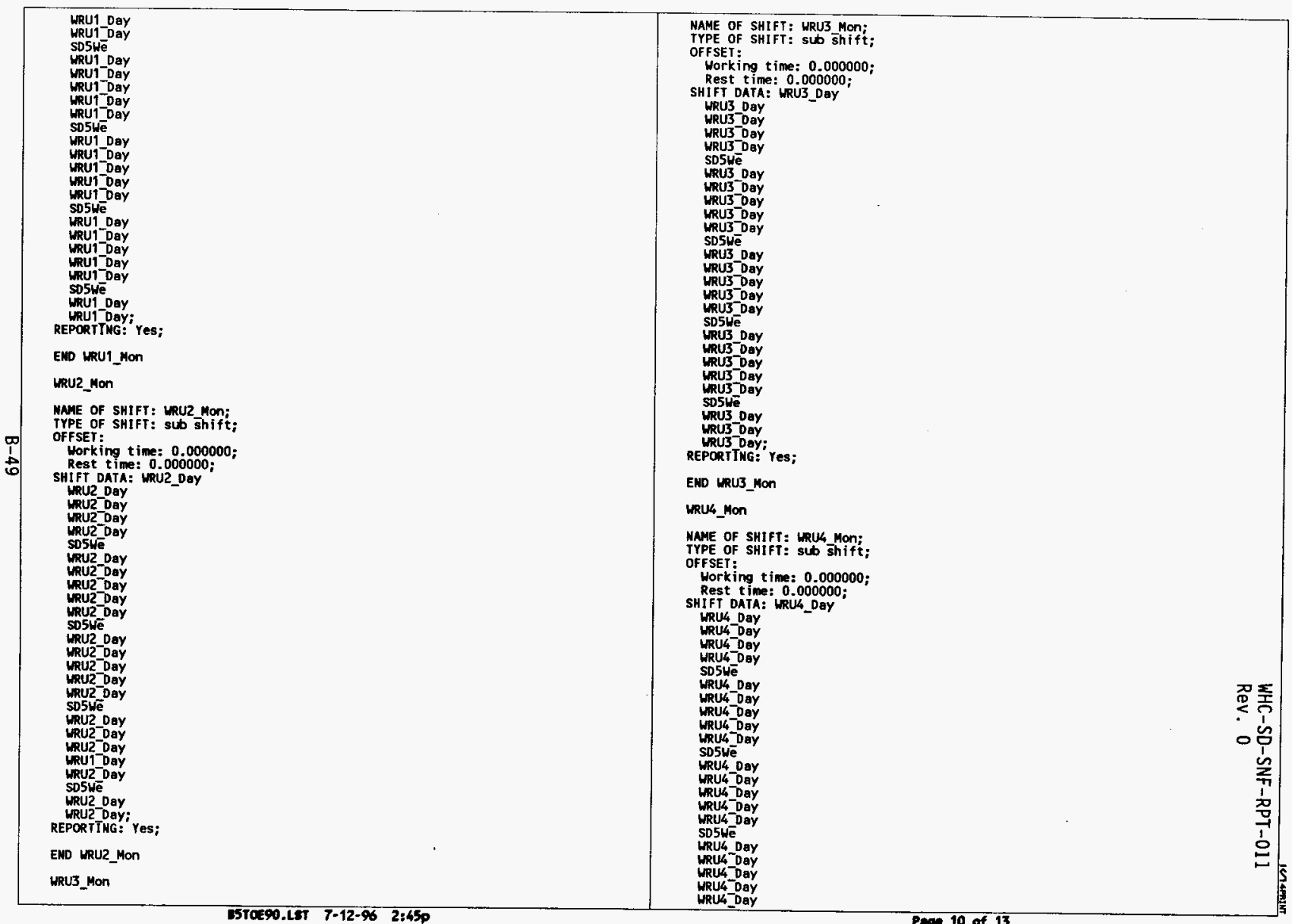




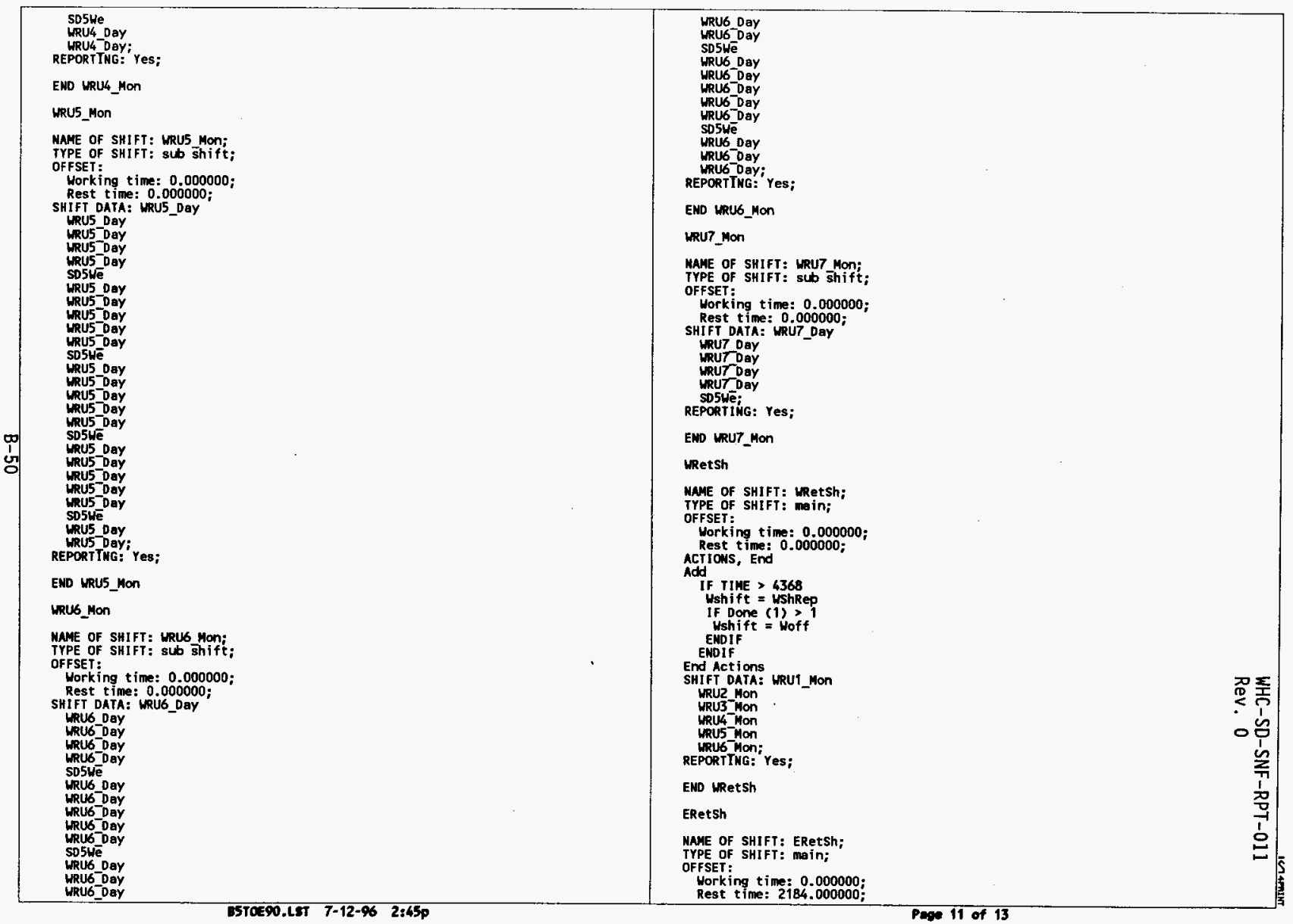




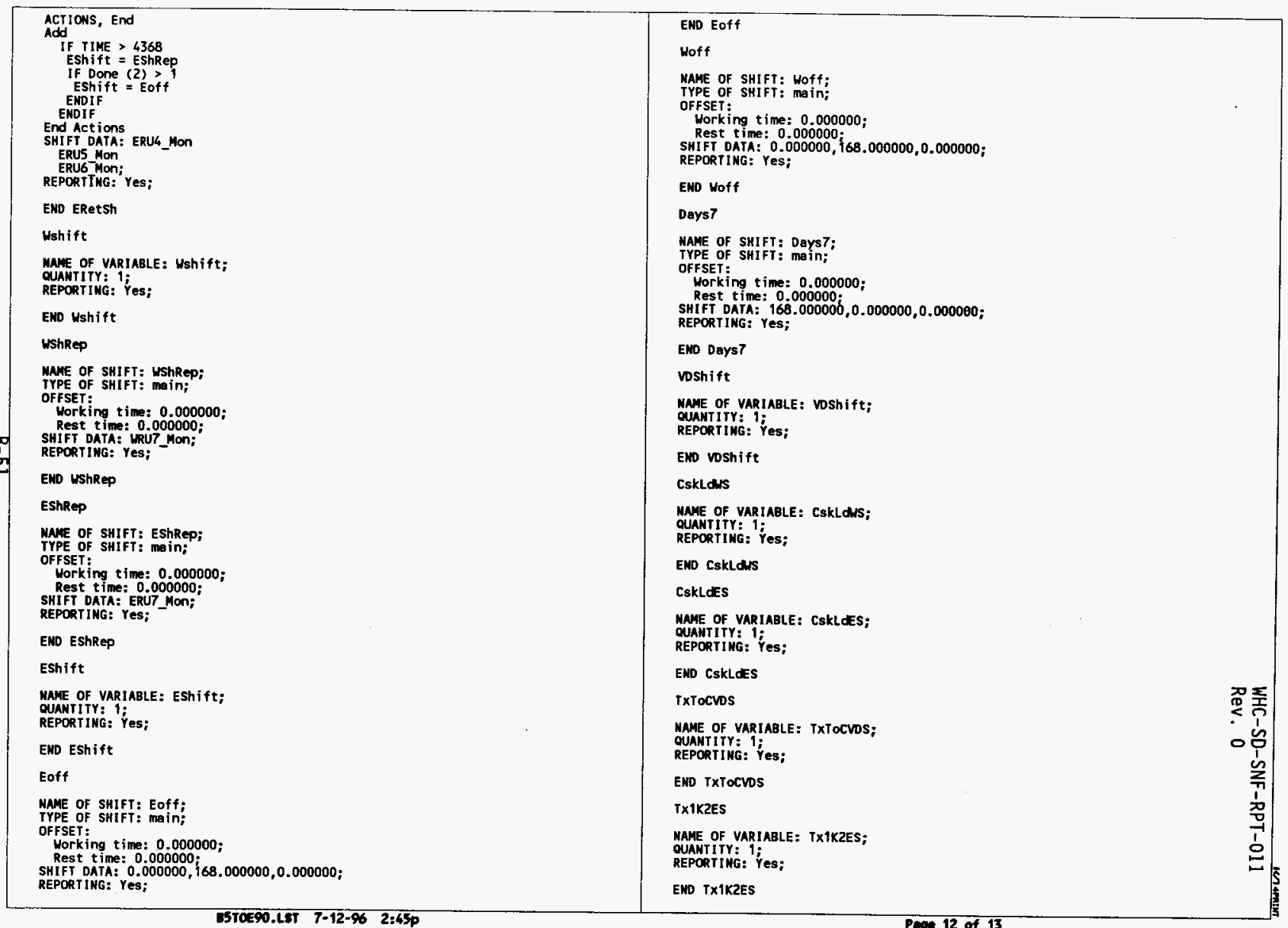


CSBCaskS

NAME OF VAR IABLE: CSBCaSkS;

QUANTITY: 1;

REPORTING: Yes;

END CSBCasks

TXCskBS

NAME OF VARIABLE: TXCSKBS ;

QUANTITY: 1 ;

REPORTIMG: Y'es;

END TXCskBS

LastMco

NAWE OF VARIABLE: LastMCO;

QUANTITY: $4 ;$

REPORTING: Yes;

END LastMCO

ENO SELECT

END DETAIL

INI TIAL ISE

A Add

Time Units ore in Hours

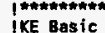

Supply (1) $=200$

KW Basin

supply (2) $=200$

Ushift = WRetsh

EShift = ERetsh

CskLdWs = Days5

CskLdES $=$ Days5E

TXToCVDS = Days5

VDShift $=$ Days?

TX1K2ES $=$ Days5

CSBCasks $=$ Days 5

End Actions 
WHC-SD-SNF-RPT-011

Rev. 0

CASE 3. THREE BHR SHIFTS/DAY, 5 DAYS/WEEK.

FUEL RETRIEVAL OPERATING AT $80 \%$ EFFICIENCY. 
SNF Project operating 3 shifts, 5 days/week. Cold vacuum drying Hot conditioning operating 7 days/week. With an $80 \%$ TOE on fuel retrieval

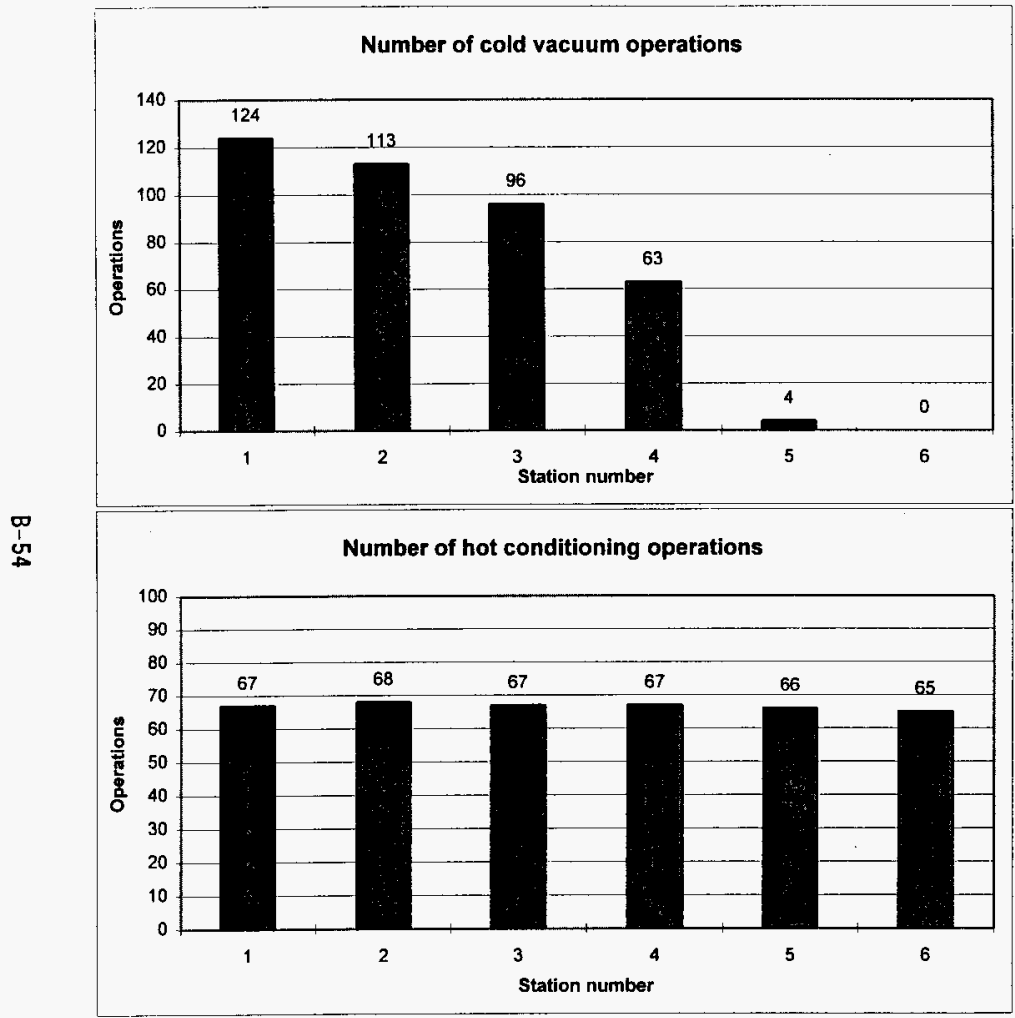




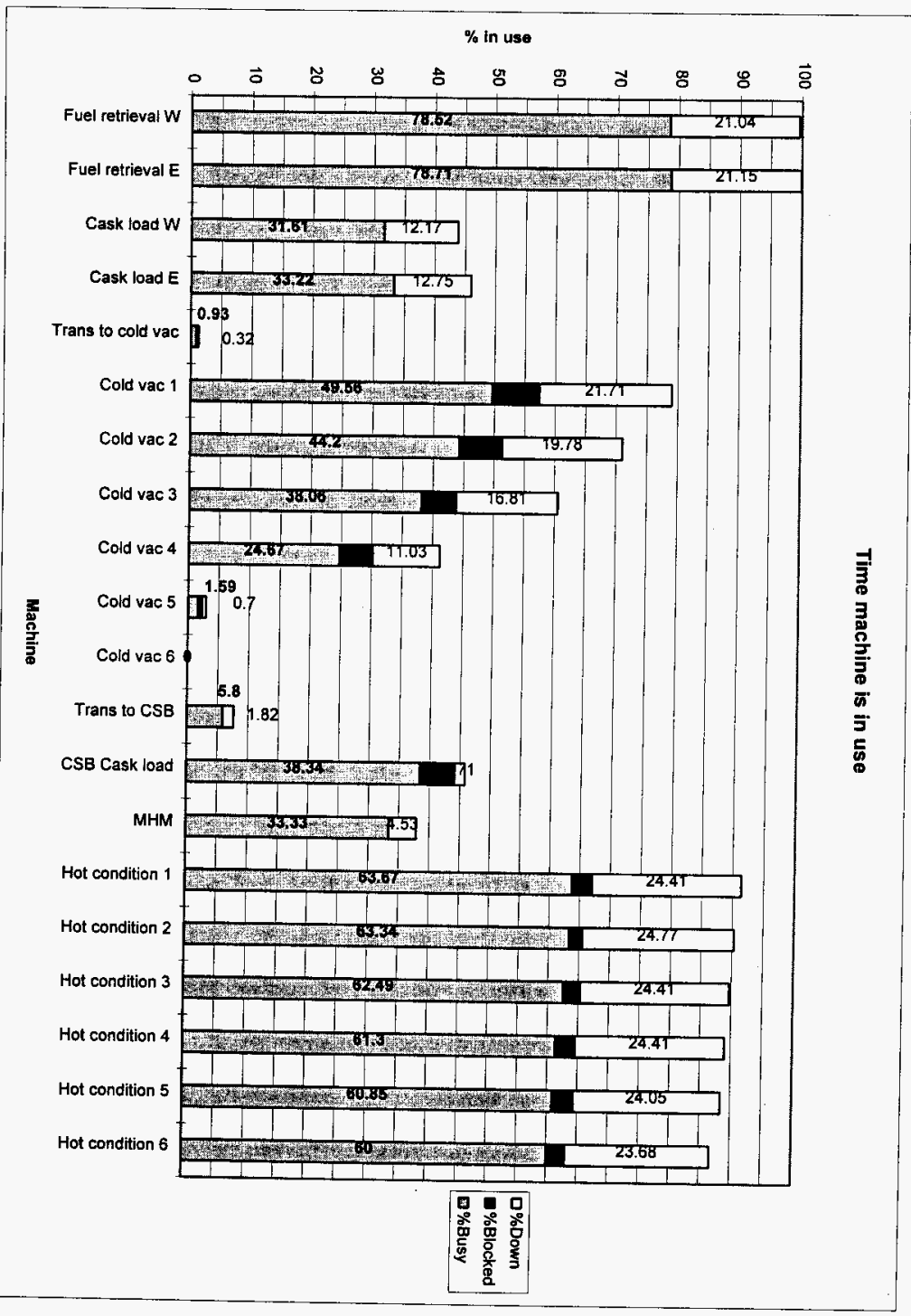

ڤ్ 
SNF Project operating 3 shifts, 5 days/week. Cold vacuum drying Hot conditioning operating 7 days/week. With an $80 \%$ TOE on fuel retrieval

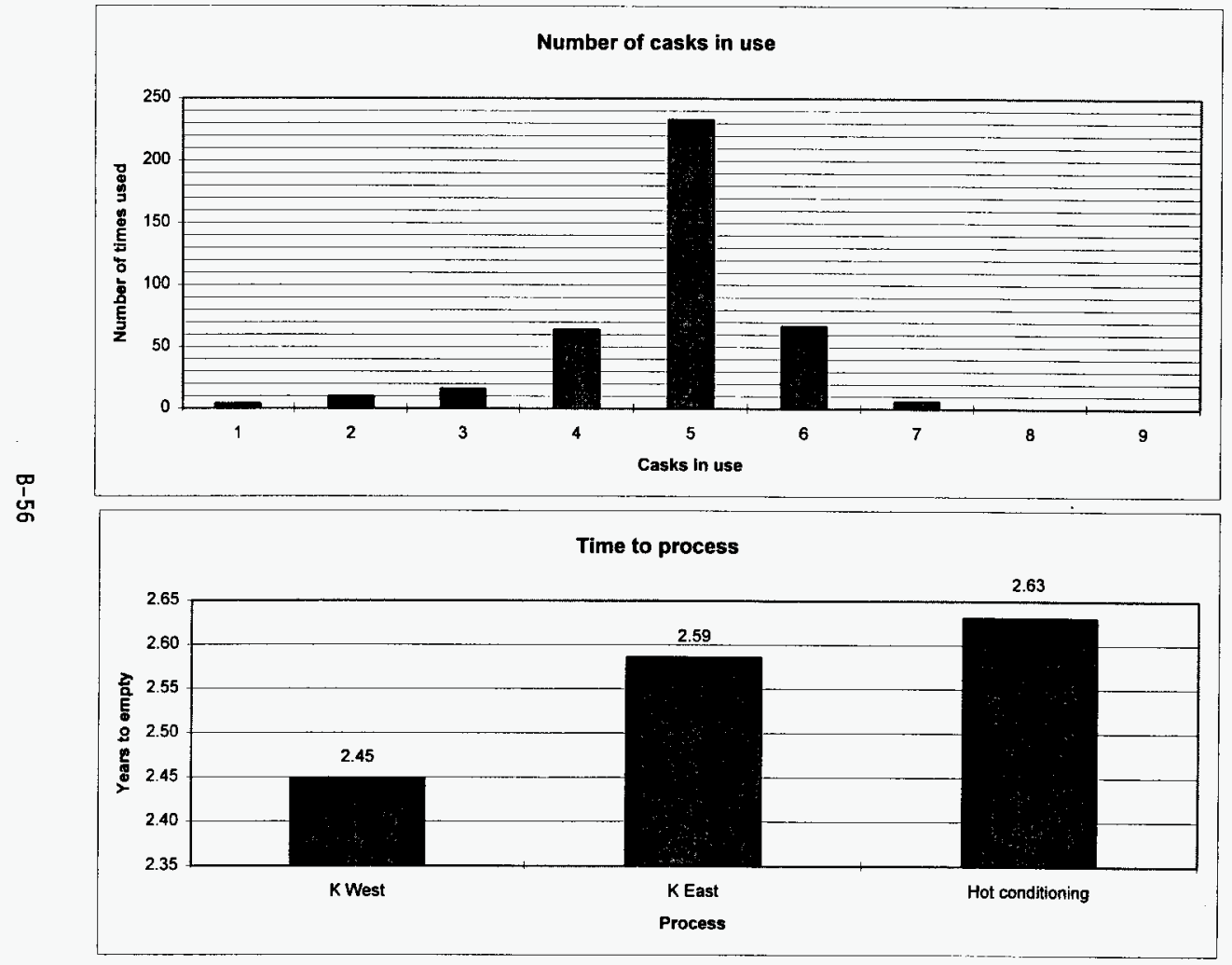




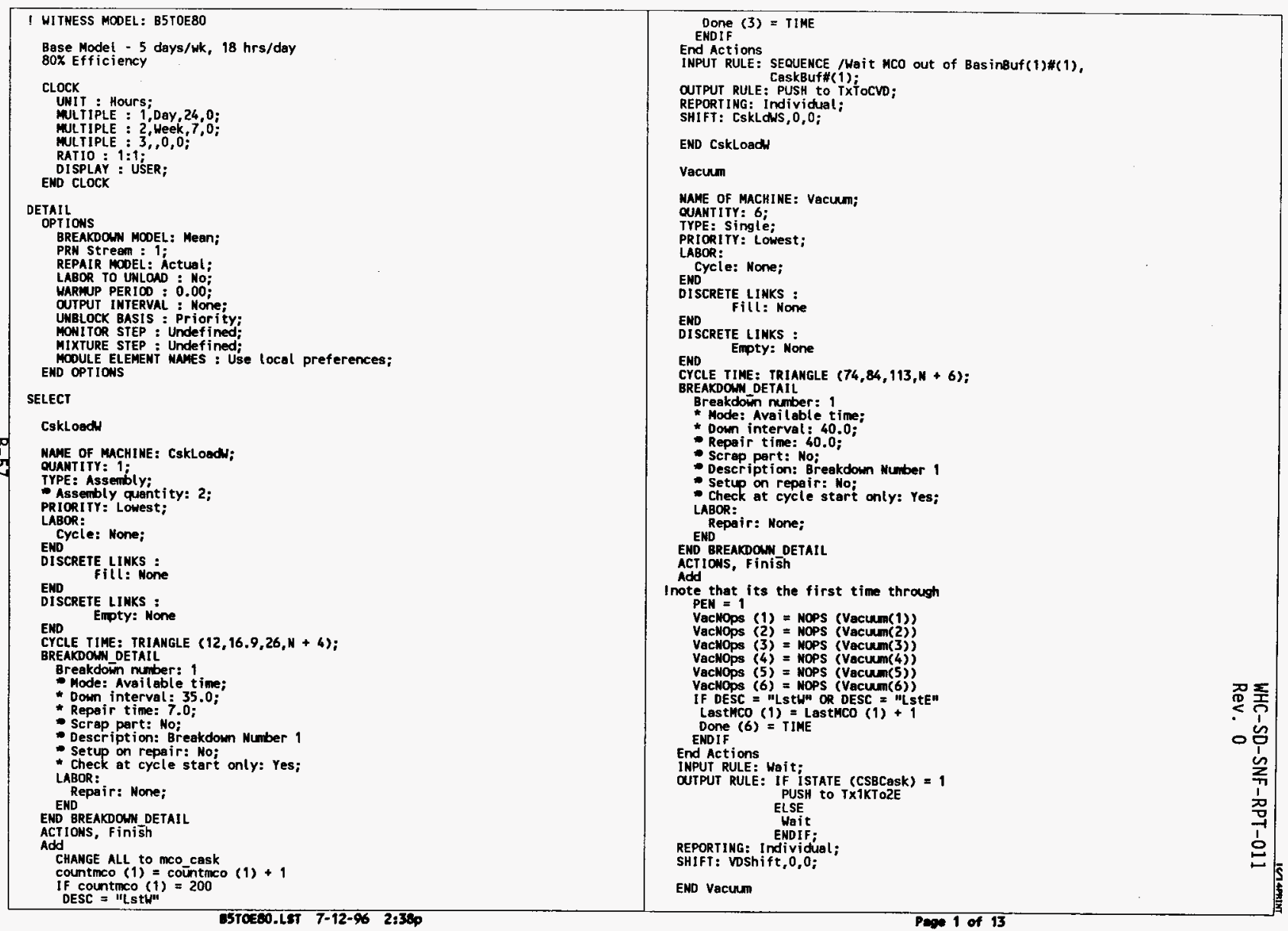




\begin{tabular}{|c|c|c|}
\hline 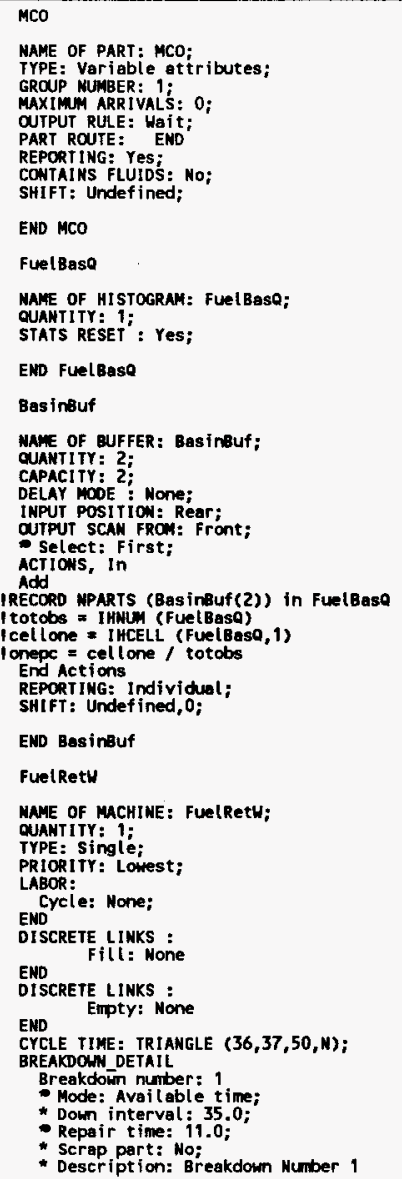 & 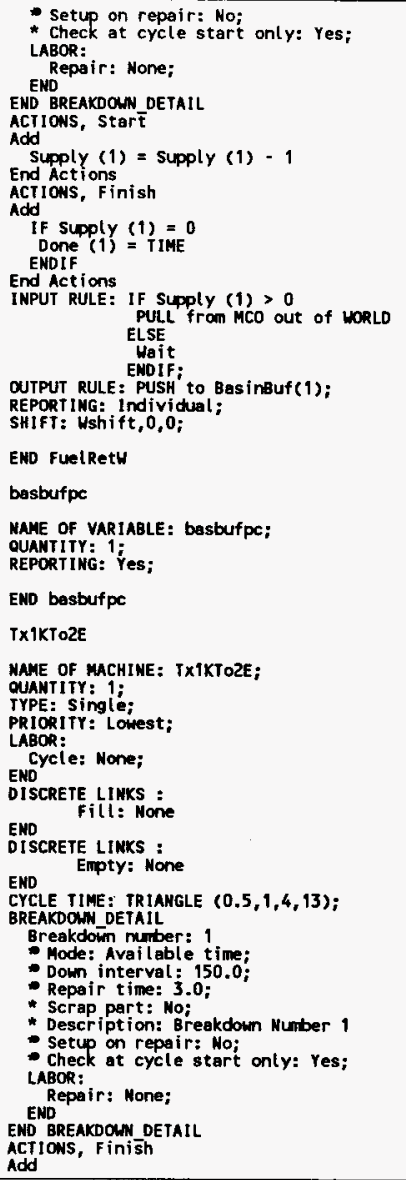 & 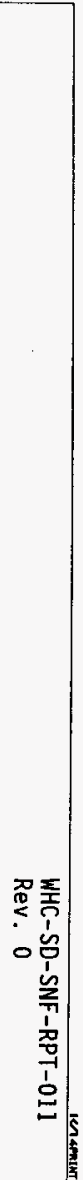 \\
\hline
\end{tabular}




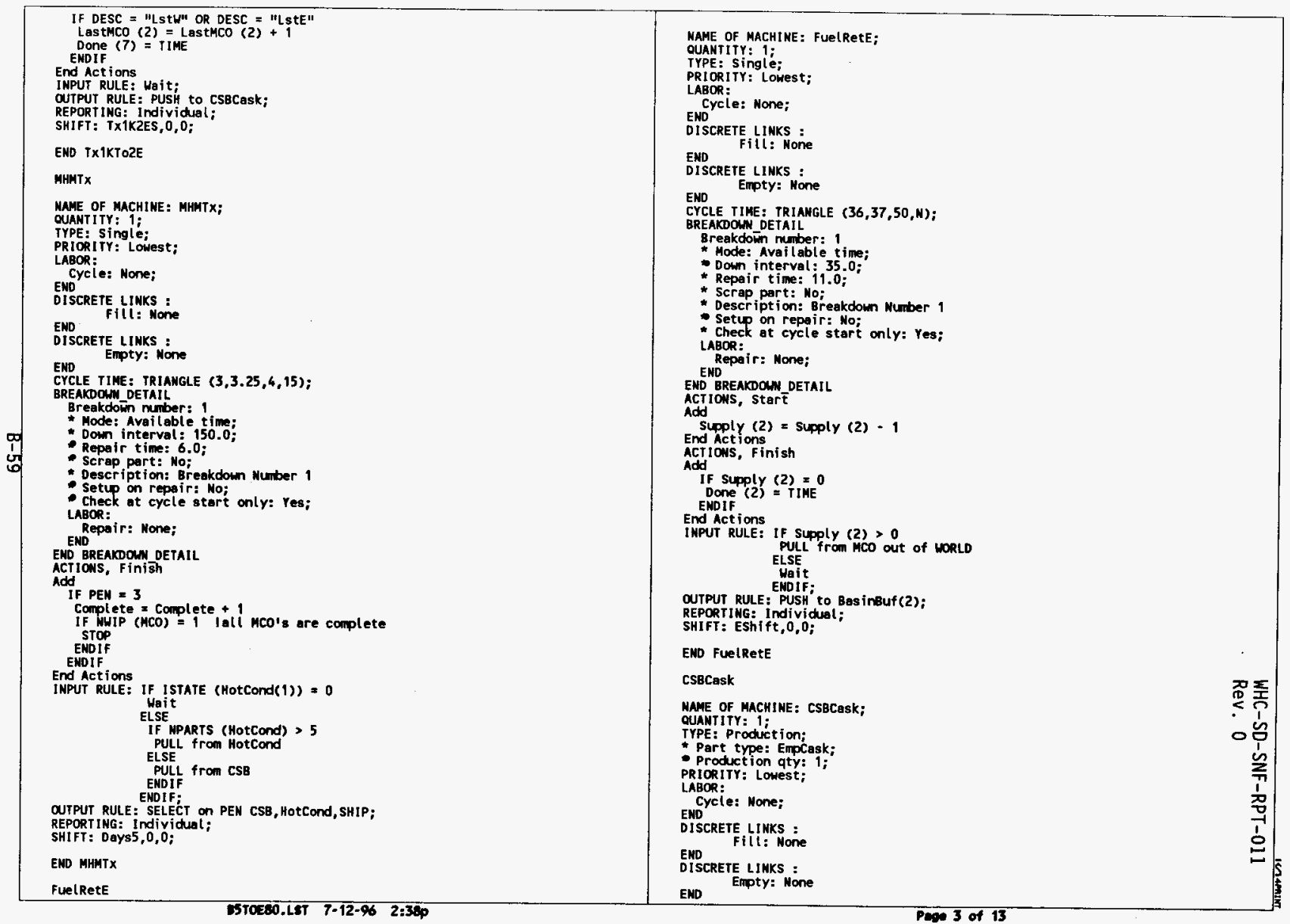




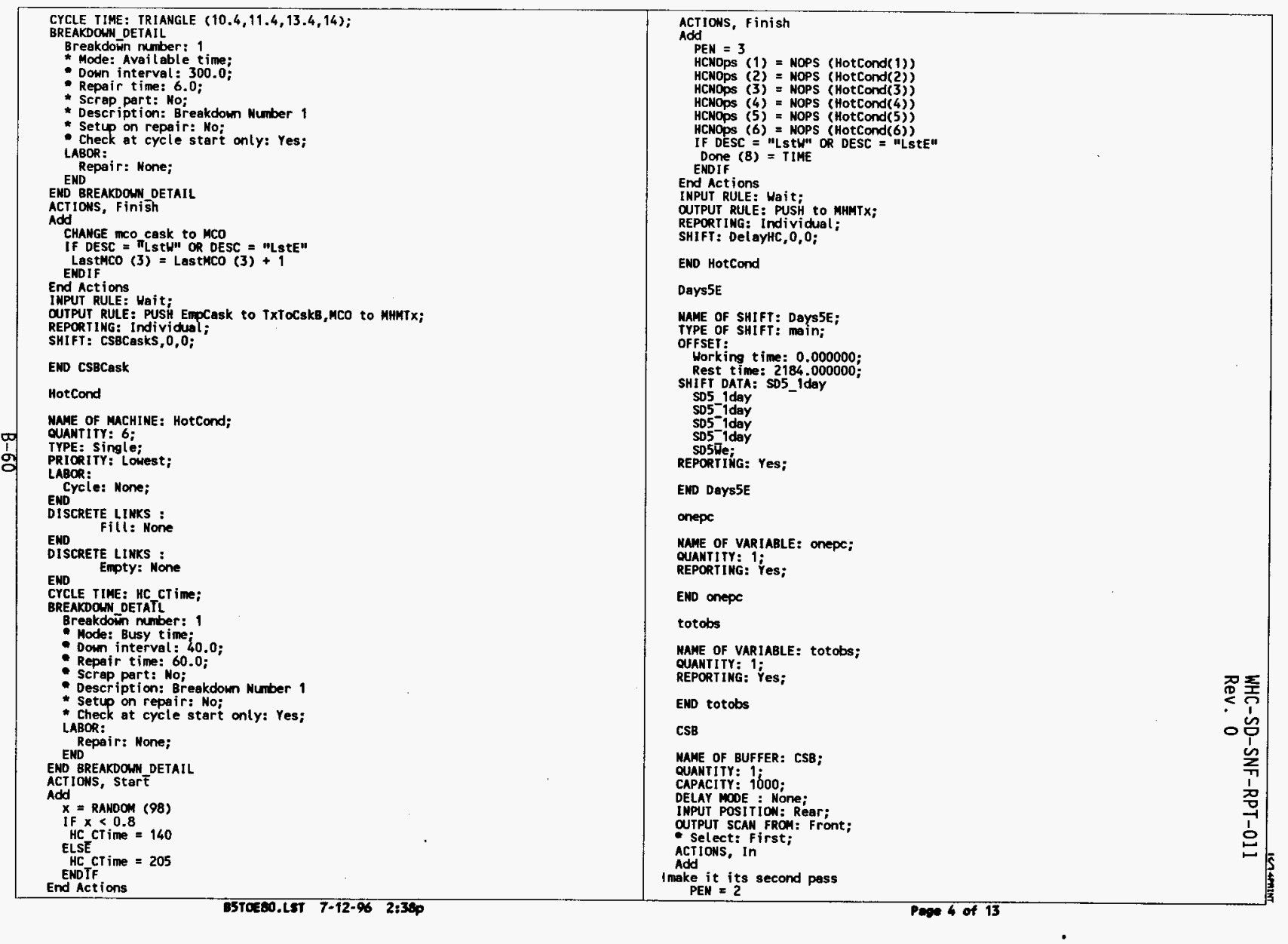




\begin{tabular}{|c|c|c|}
\hline 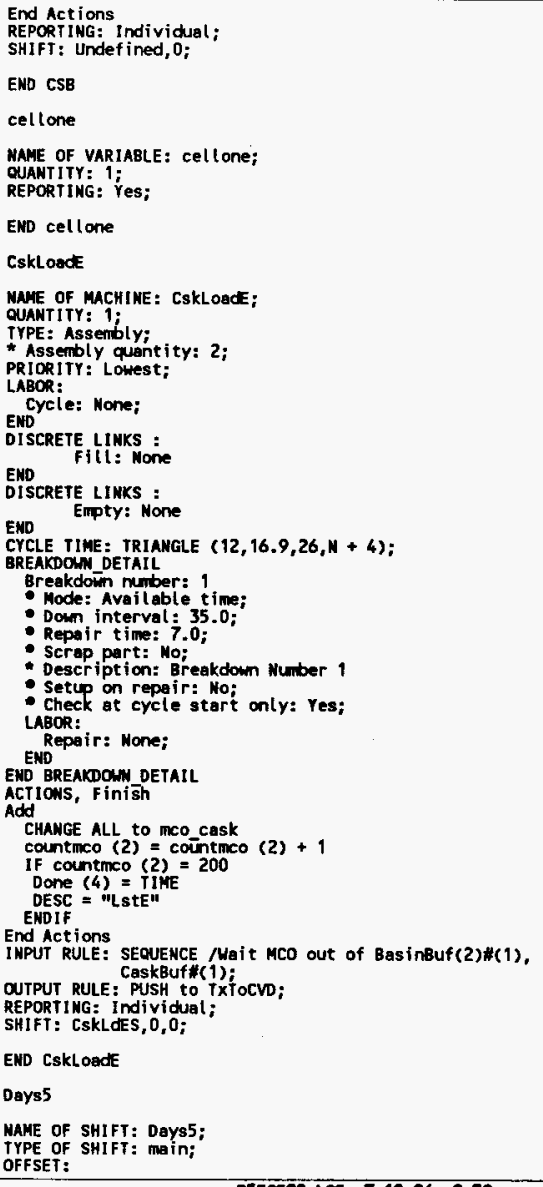 & 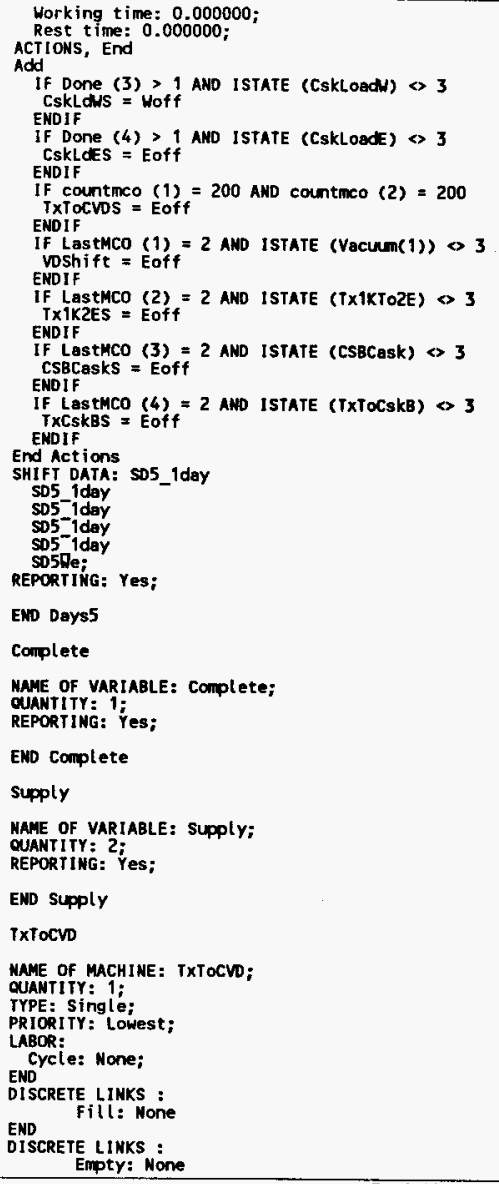 & 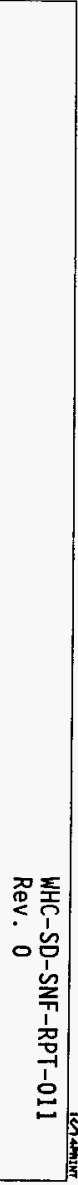 \\
\hline
\end{tabular}




\begin{tabular}{|c|c|c|}
\hline 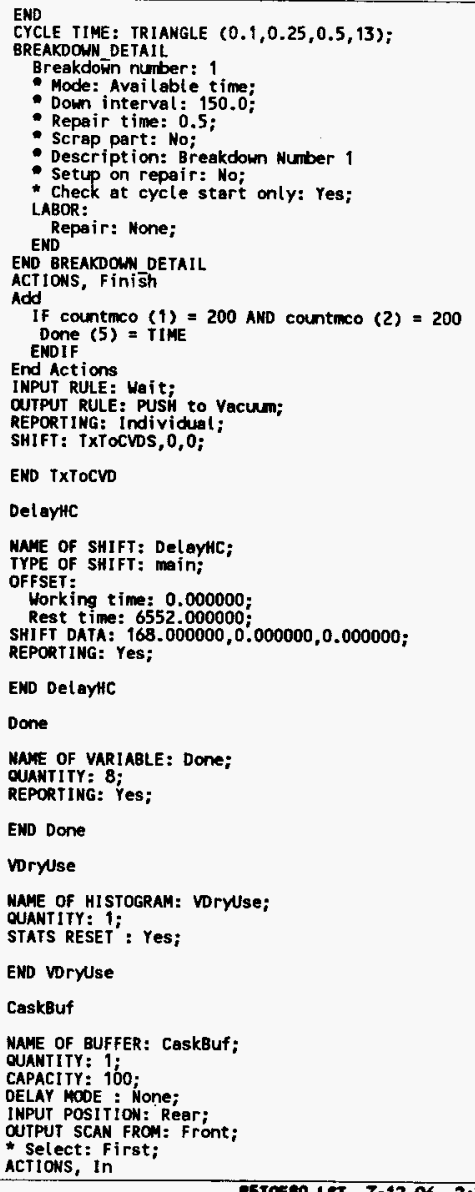 & 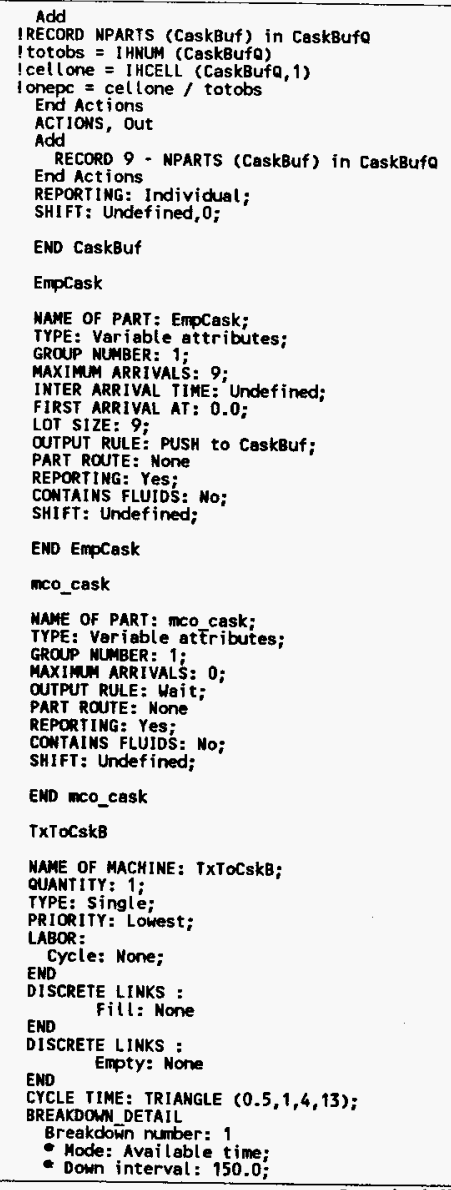 & 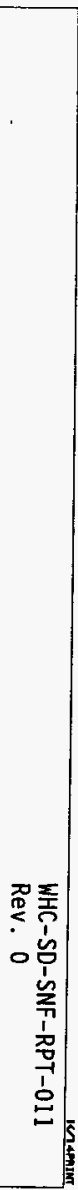 \\
\hline
\end{tabular}




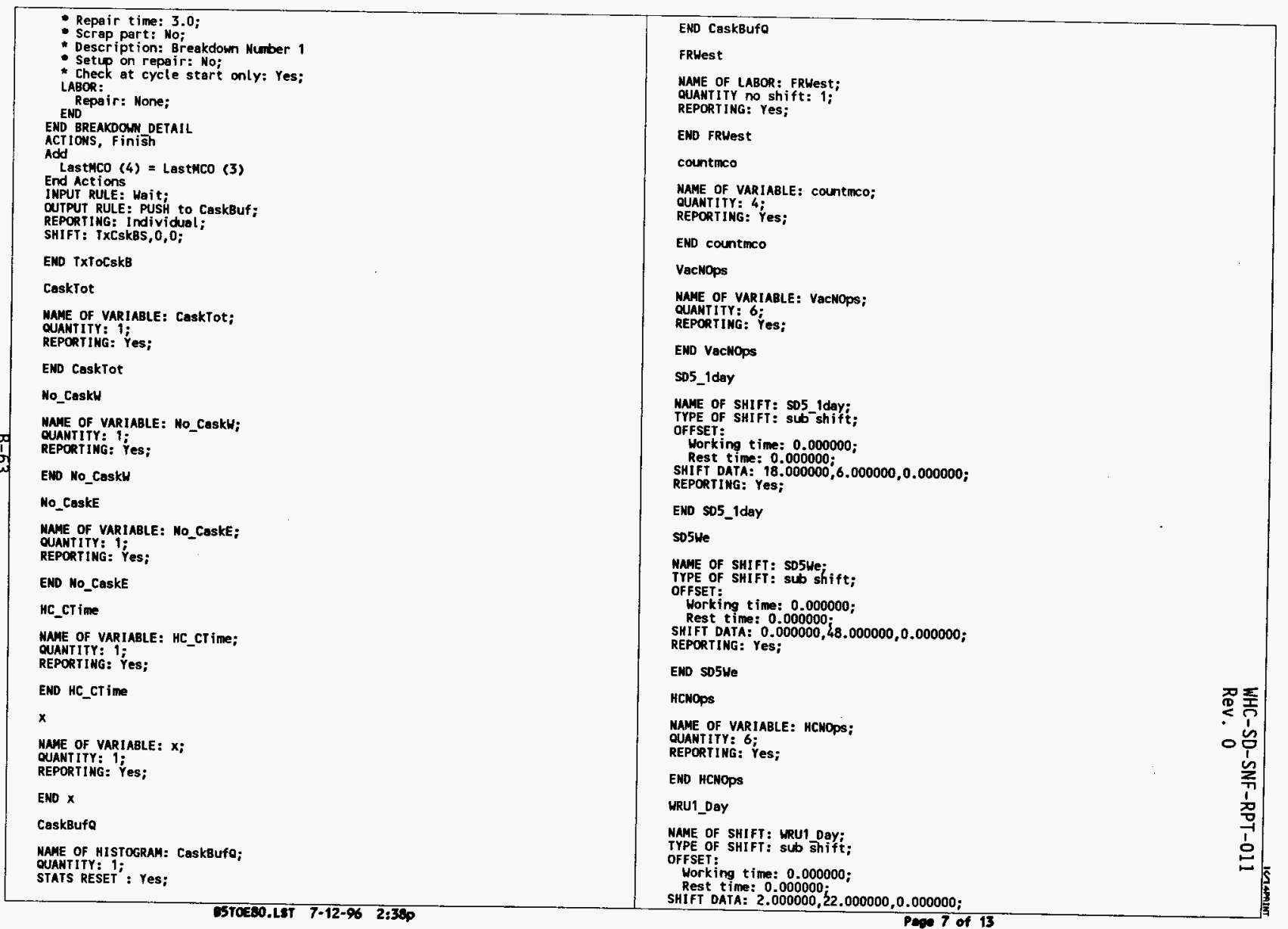




\begin{tabular}{|c|c|c|}
\hline 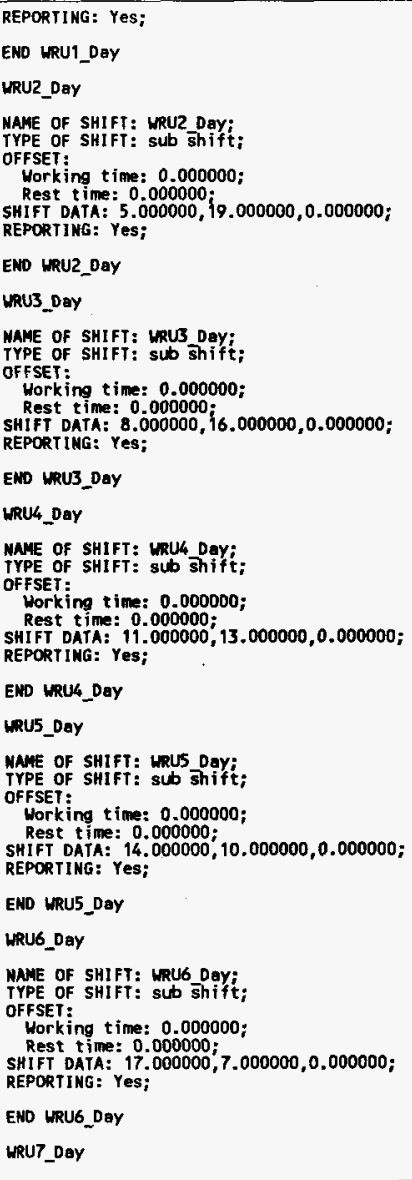 & 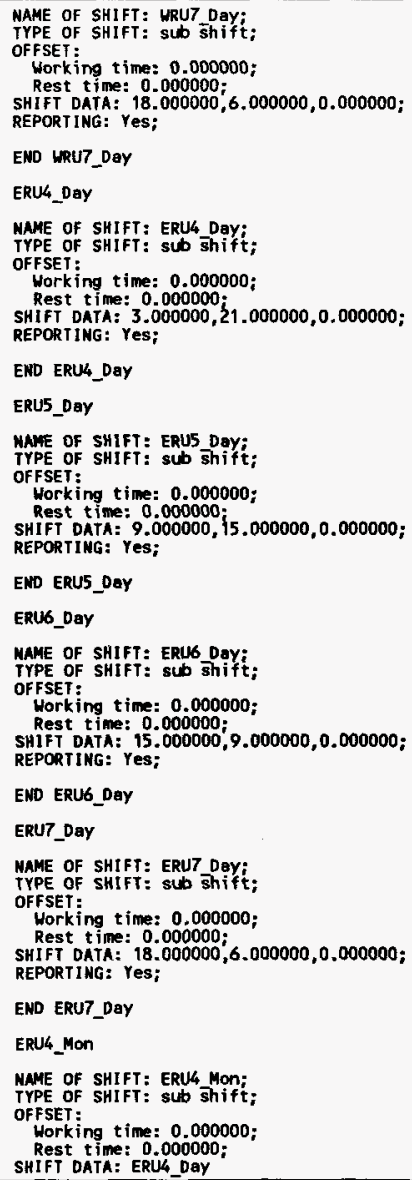 & 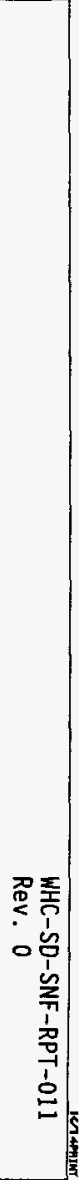 \\
\hline
\end{tabular}




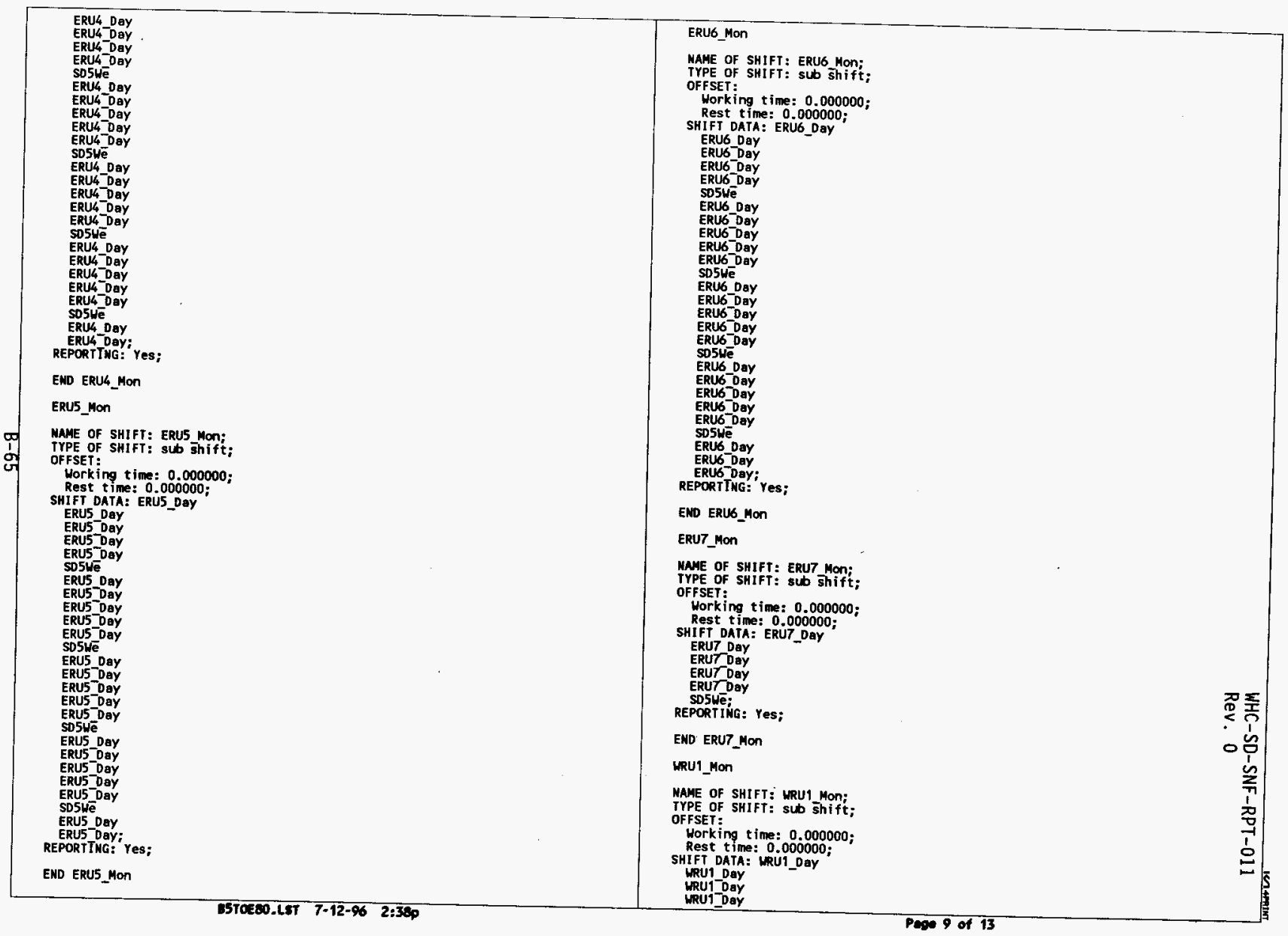




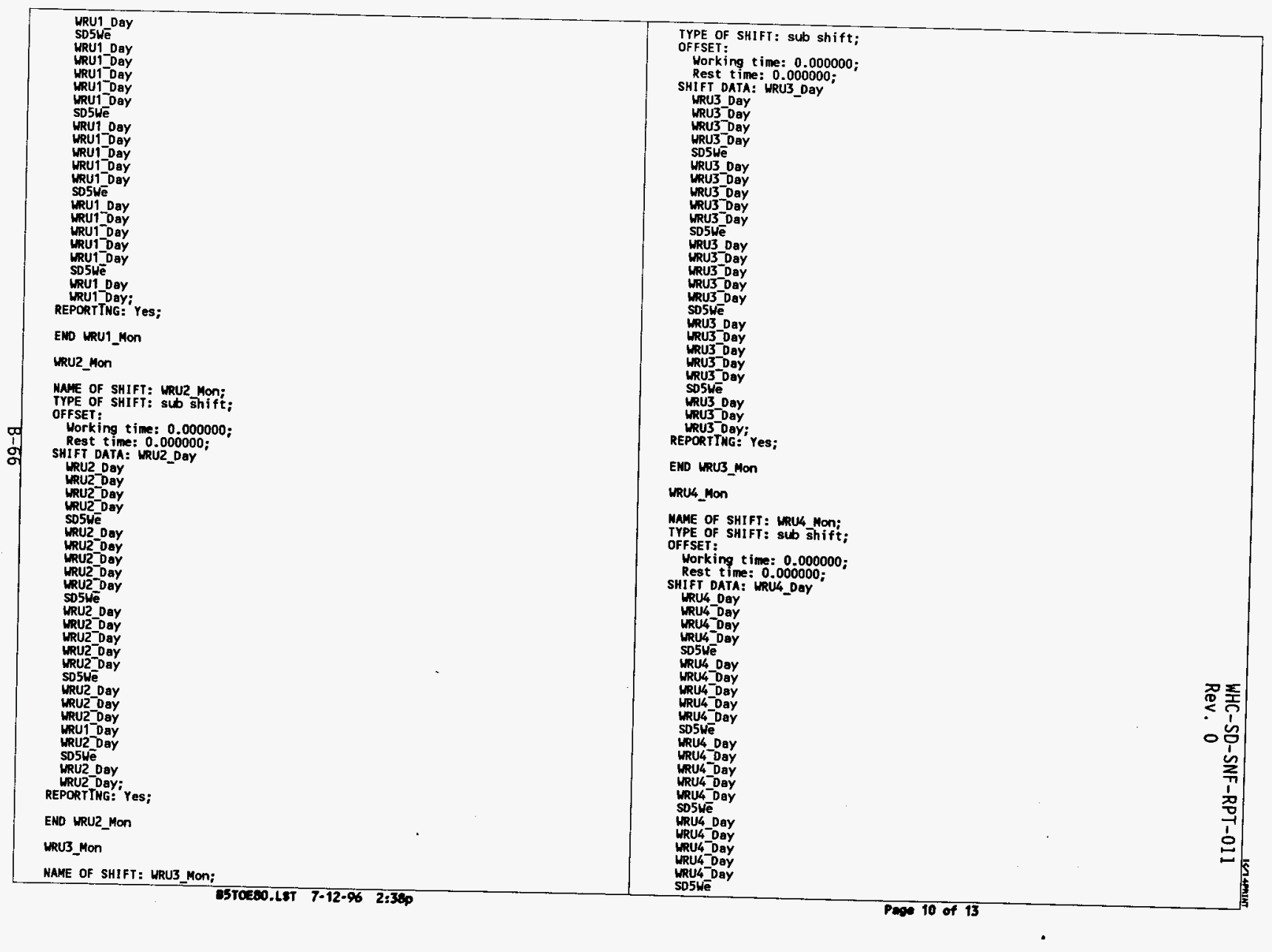




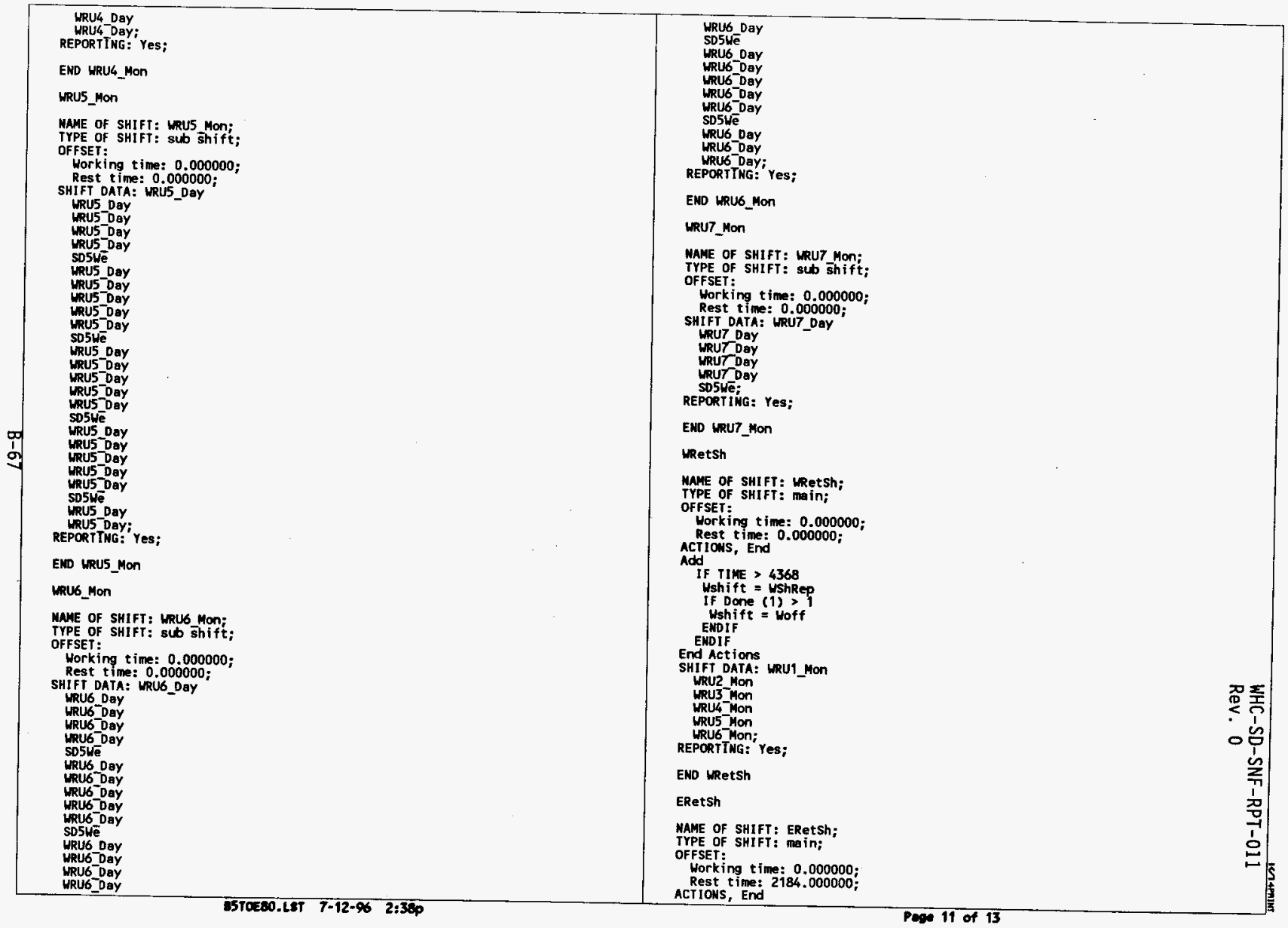




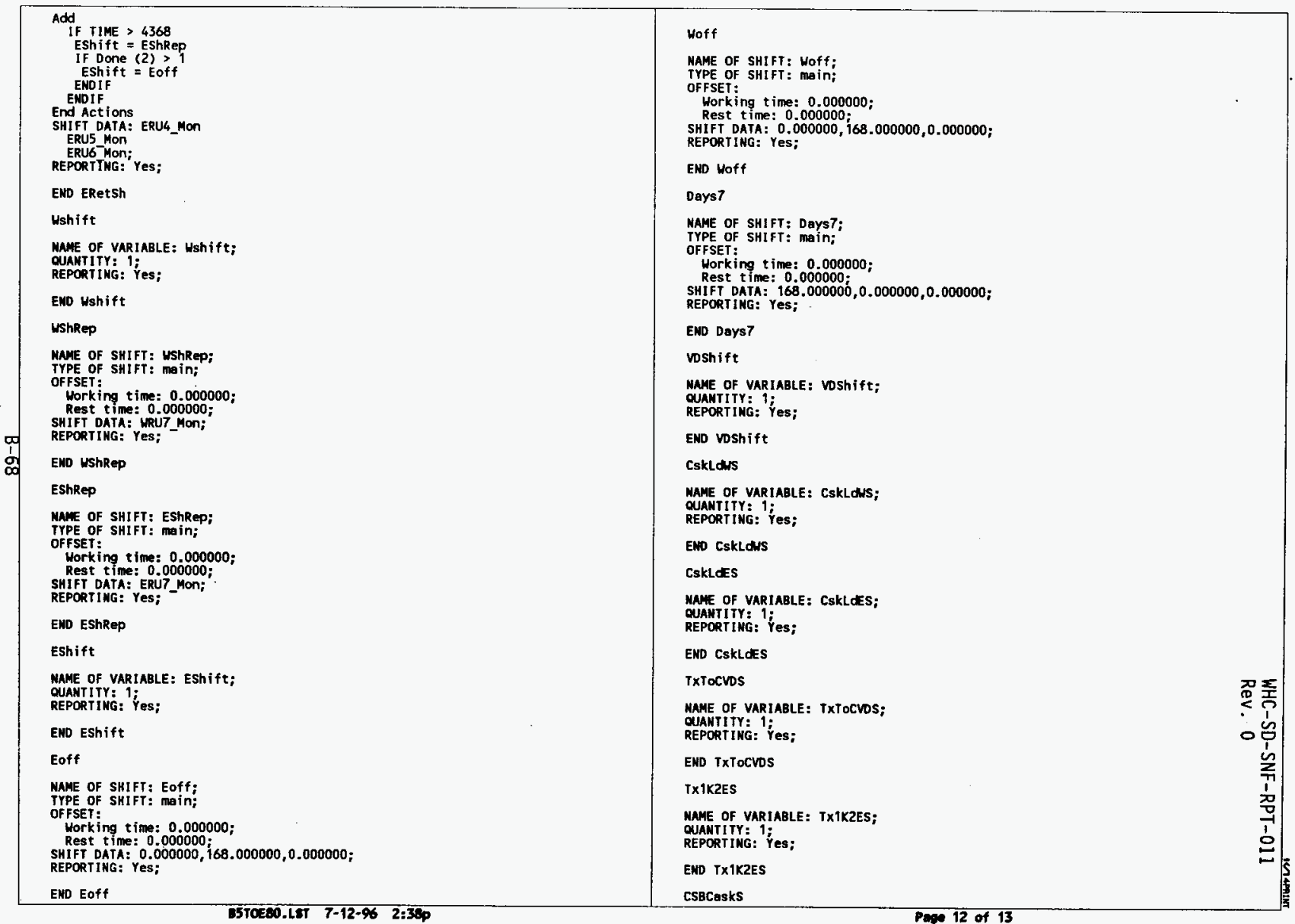


NAME OF VARIABLE: CSBCasks:

DUANIITY: 1 ;

END CSBCaskS

TXCskBS

NAME OF VARIABLE: TXCSKBS;

OUANT ITY: 1 ;

TING: Yes:

EMD TXCskBS

Los tMco

MAME OF VARIABLE: Las TMCO;

QUANTITY: 4;

END LastMCO

END SELECT

END DEIAIL

IWITIALISE

Add

a 1

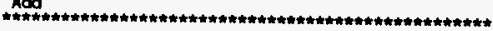

IKE Basic

Supply $(1)=200$

KW Basin

Supply (2) $=200$

Ushift = WRetsh

EShift $=$ ERetsh

Csklans = Days5

TXToCVS $=$ Days

WShift $=$ Days 7

TXIK2ES = Days5

CSBCasks = Days

TKCskBS = Days5

End Actions

NITIALISE 
WHC-SD-SNF-RPT-011

Rev. 0

CASE 4. THREE 8 HR SHIFTS/DAY, 5 DAYS/WEEK.

FUEL RETRIEVAL CYCLE TIMES OF MIN $=16$, MODE $=17$, AND MAX $=30$. 
SNF Project operating 3 shifts, 5 days/week. Cold vacuum drying Hot conditioning operating 7 days/week. With a $(16,17,30)$ distribution on fuel retrieval

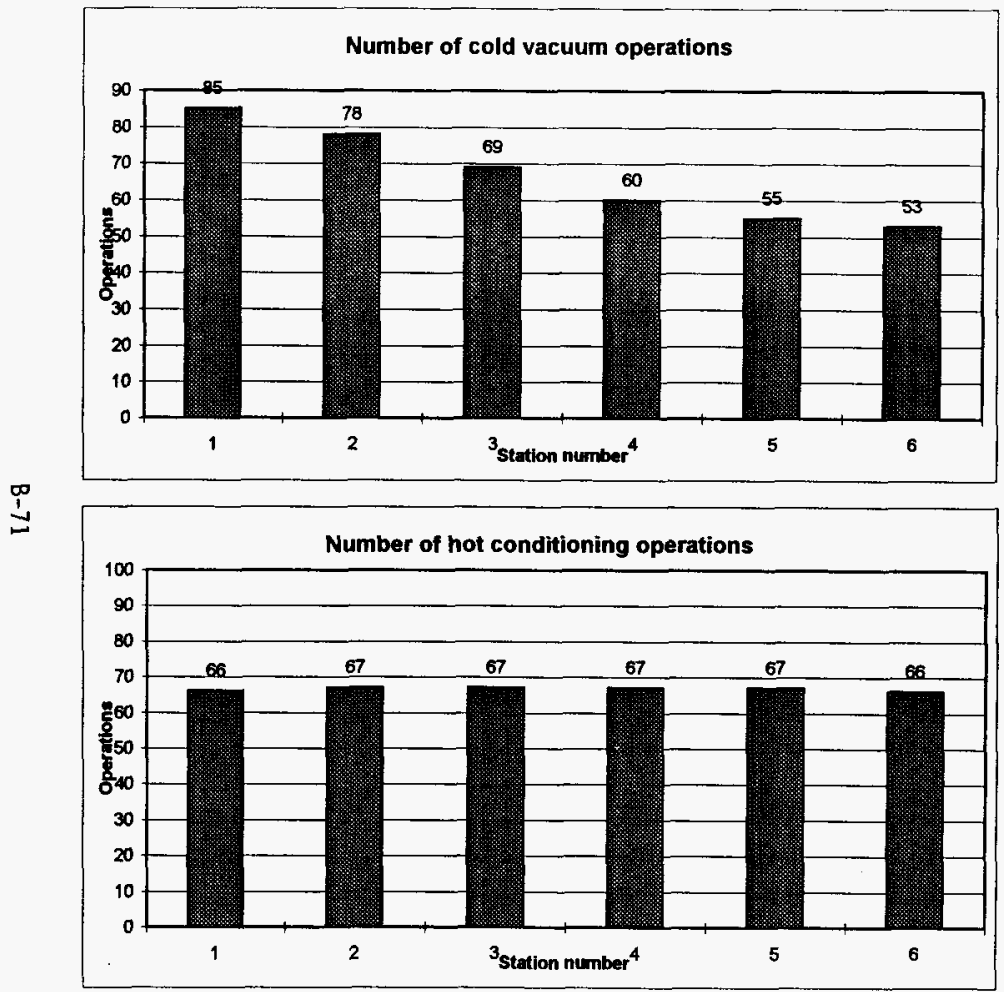


SNF Project operating 3 shifts, 5 days/week. Cold vacuum drying Hot conditioning operating 7 days/week. With a $(16,17,30)$ distribution on fuel retrieval

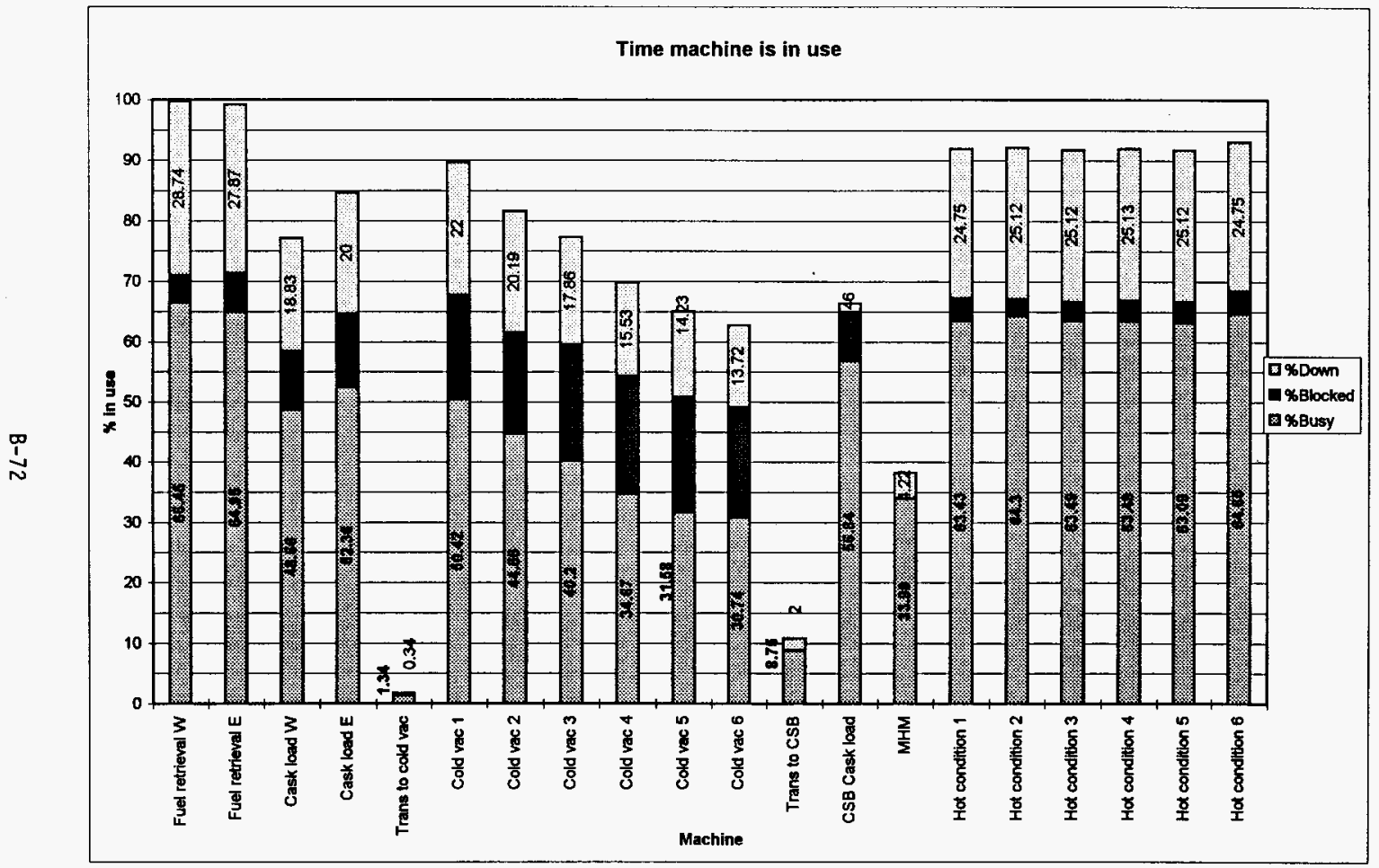


SNF Project operating 3 shifts, 5 days/week. Cold vacuum drying Hot conditioning operating 7 days/week. With a $(16,17,30)$ distribution on fuel retrieval
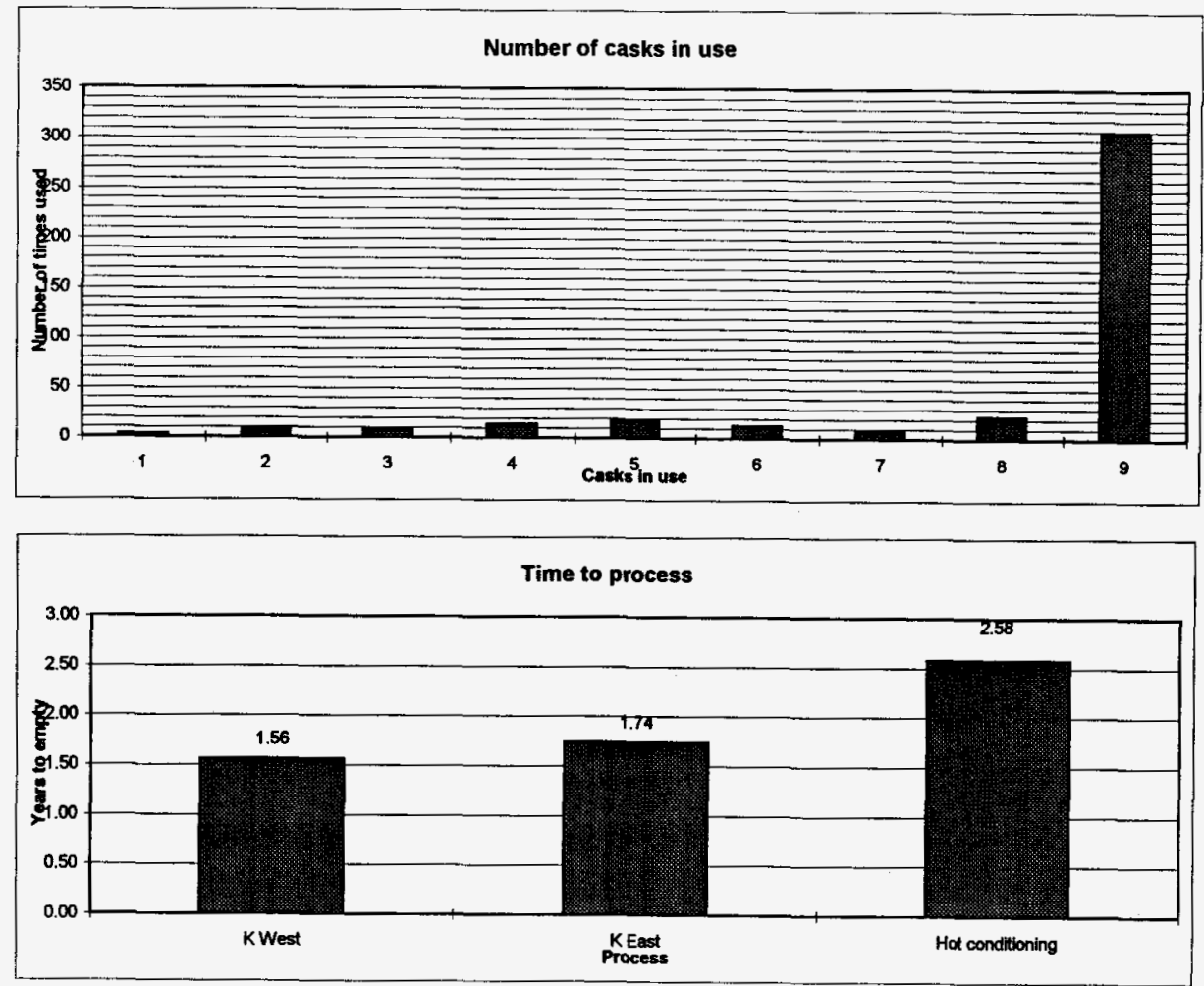


\begin{tabular}{|c|c|}
\hline 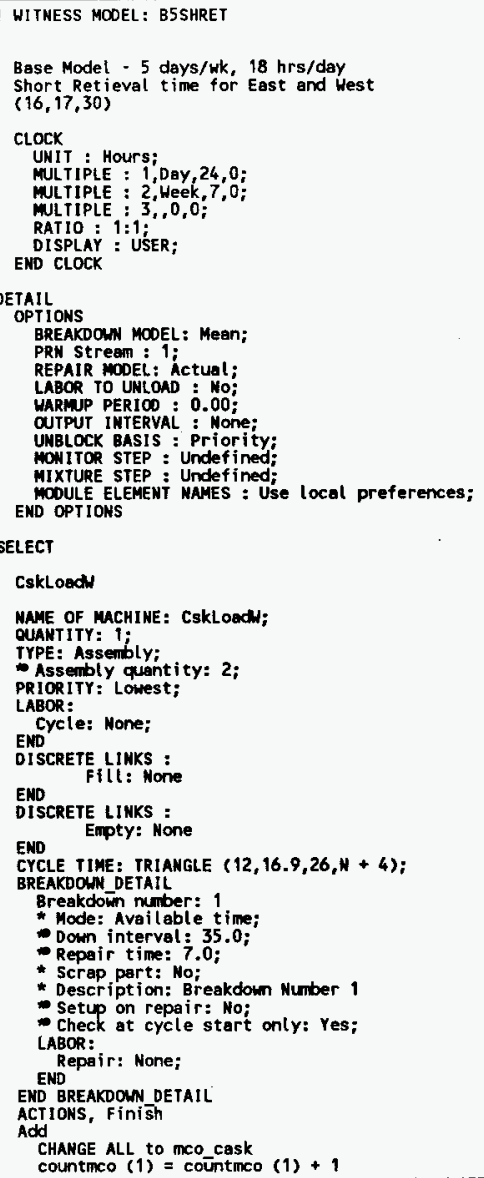 & 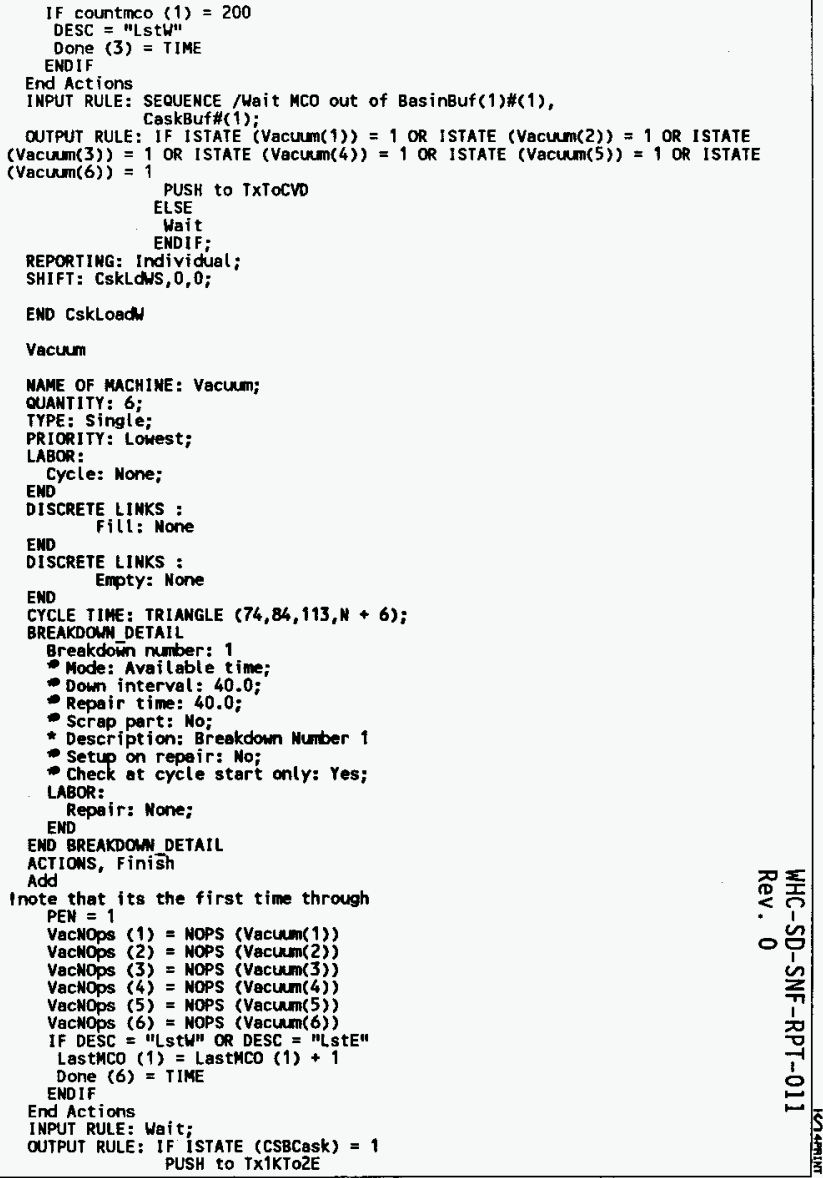 \\
\hline
\end{tabular}




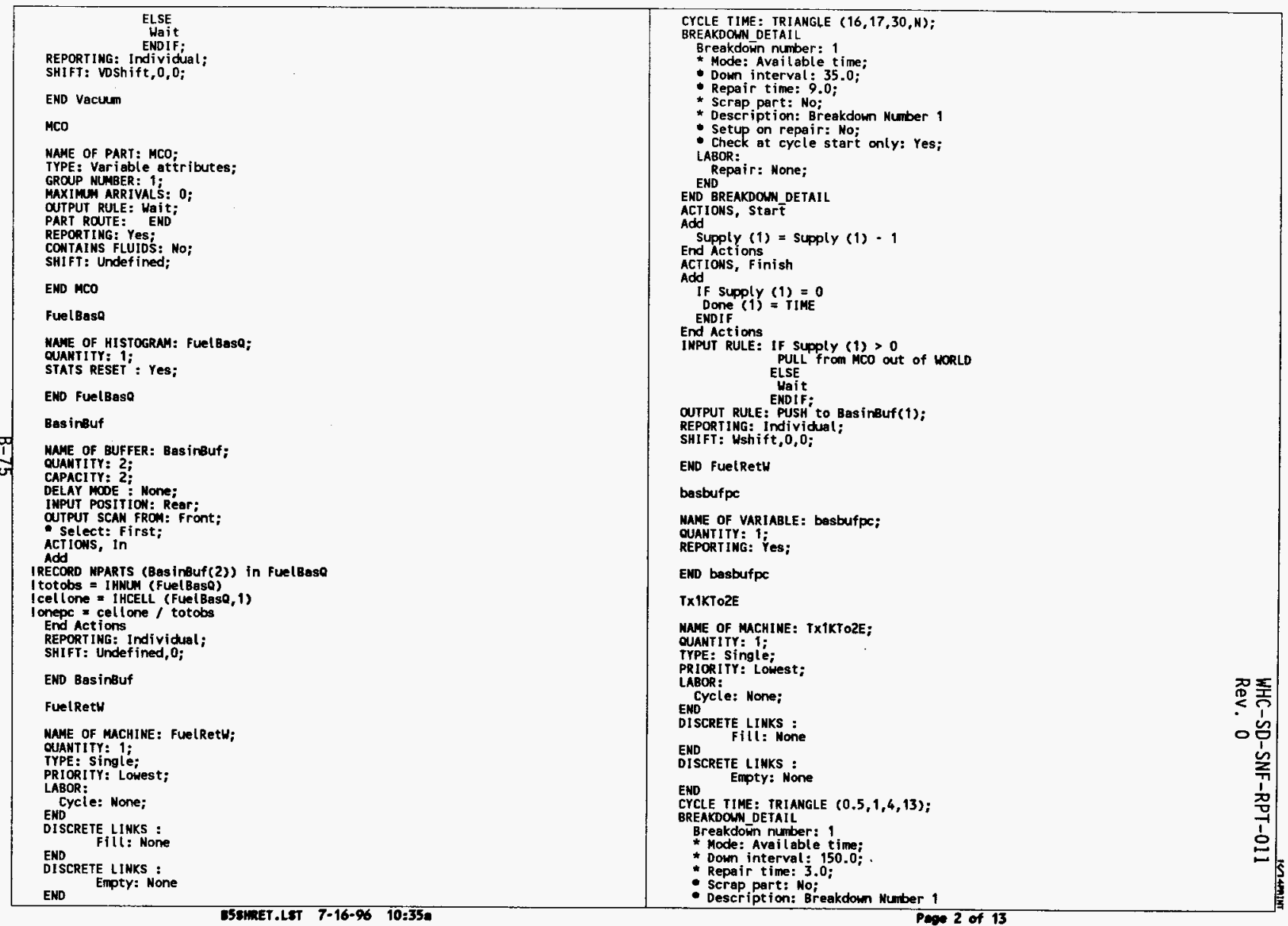




\begin{tabular}{|c|c|c|}
\hline 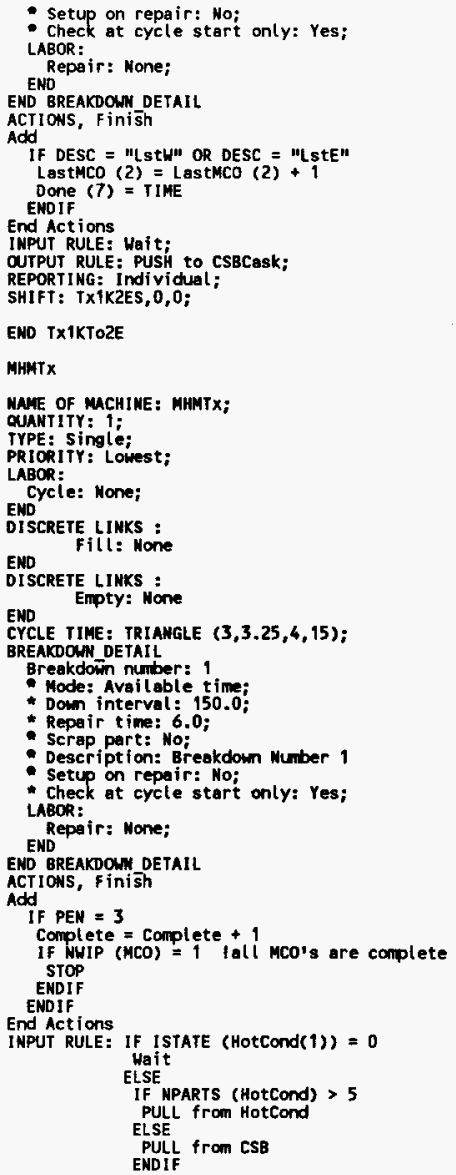 & 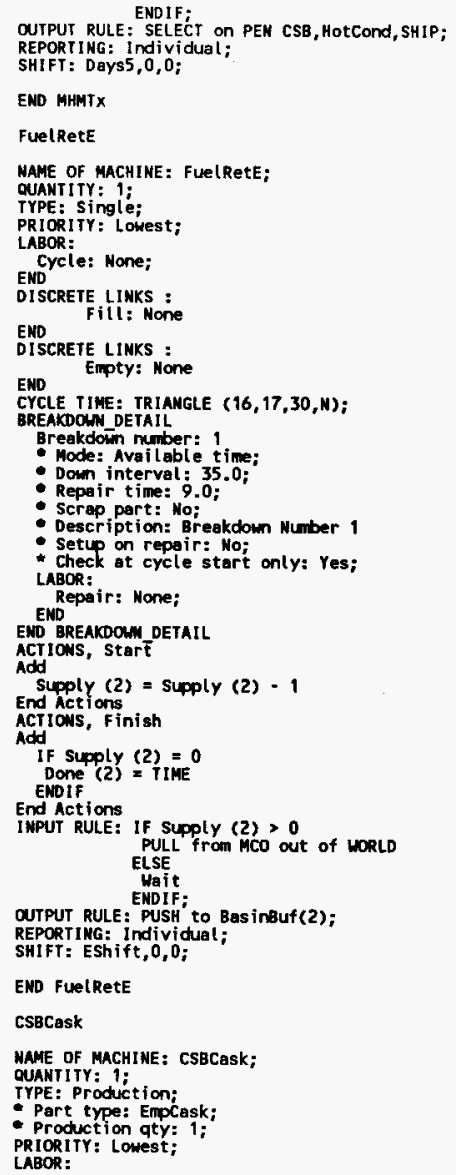 & 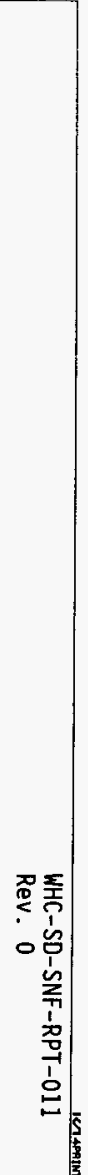 \\
\hline
\end{tabular}




\begin{tabular}{|c|c|c|}
\hline 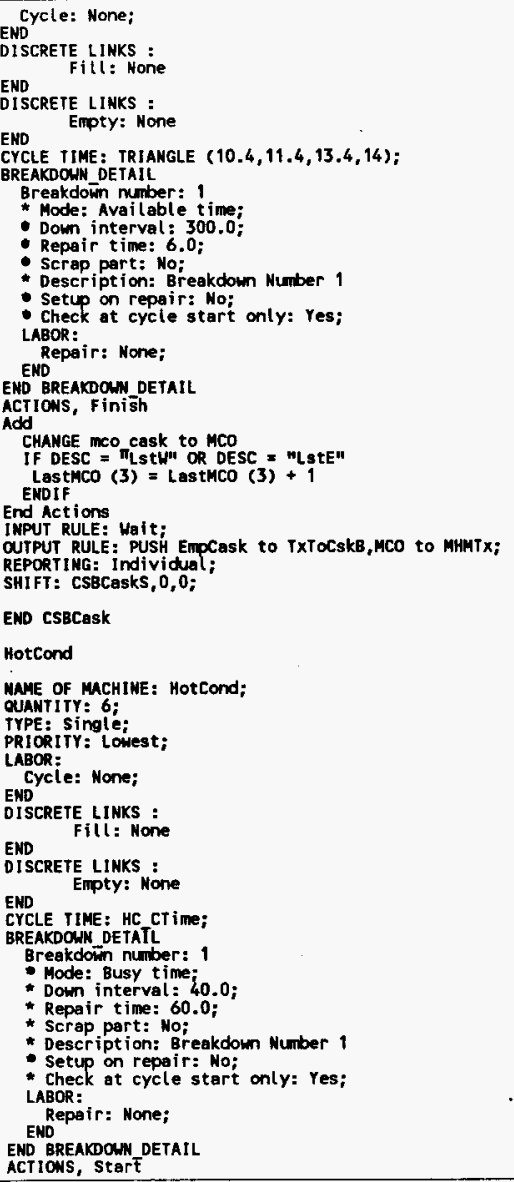 & 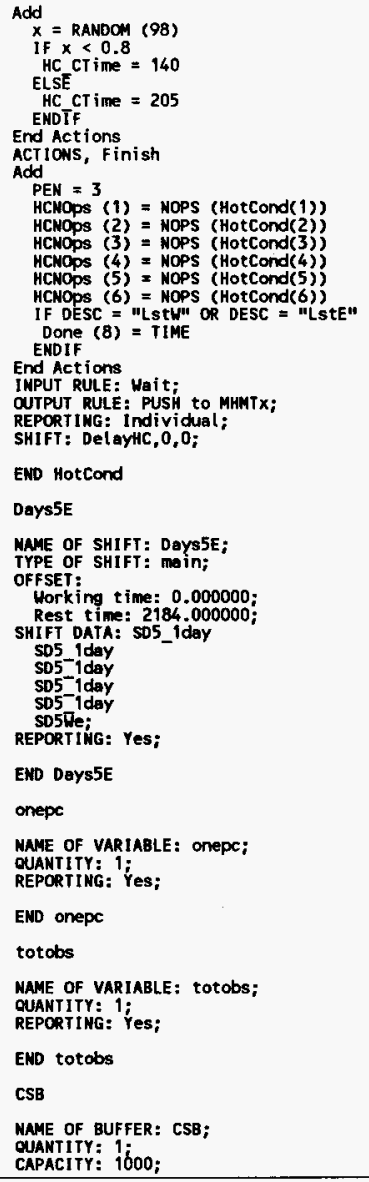 & 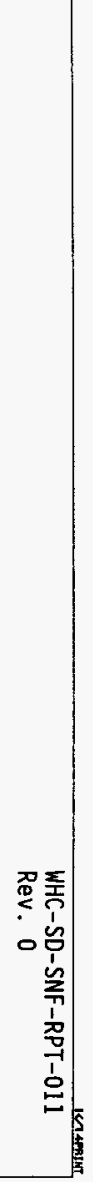 \\
\hline
\end{tabular}




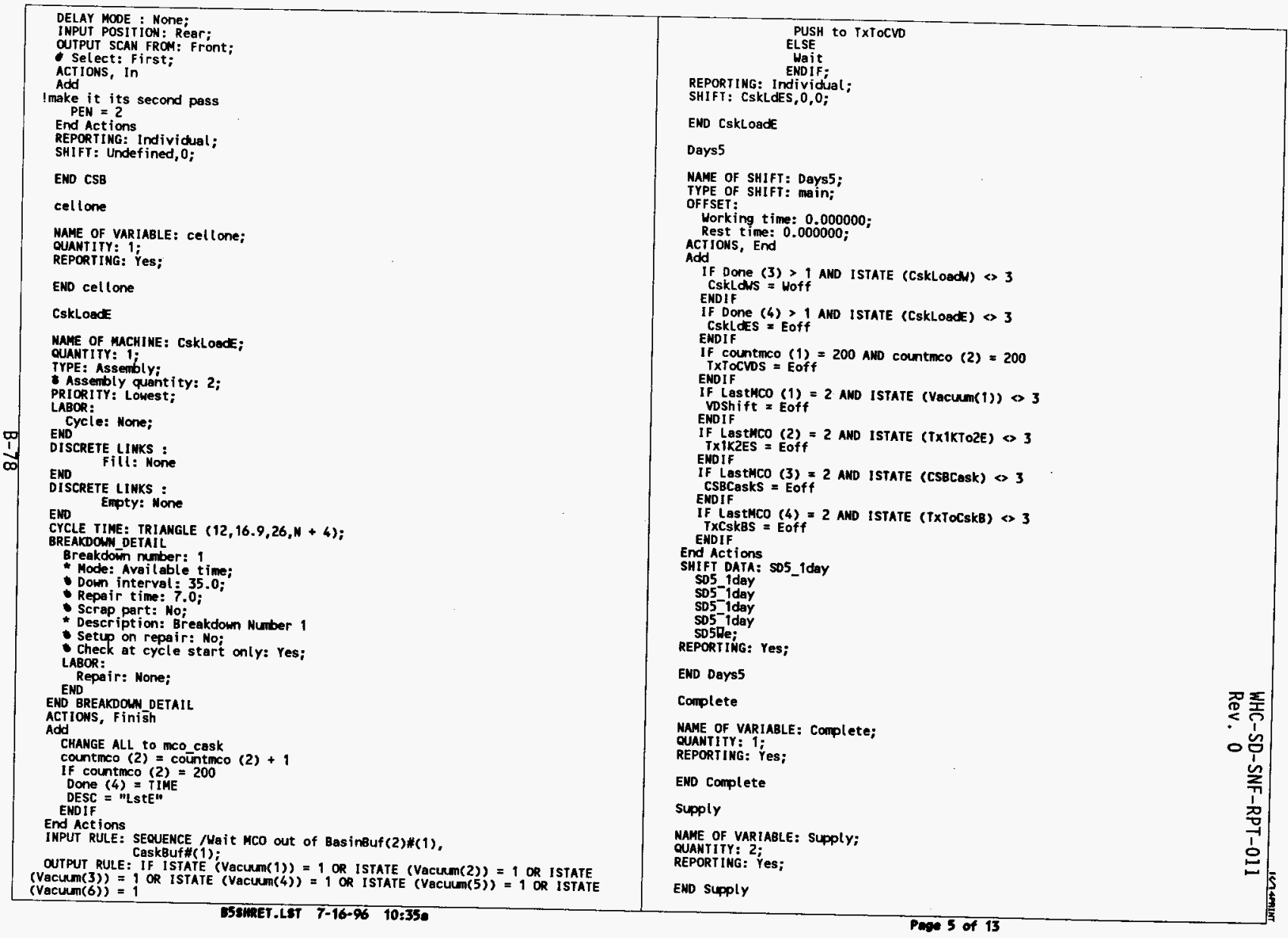




\begin{tabular}{|c|c|c|}
\hline 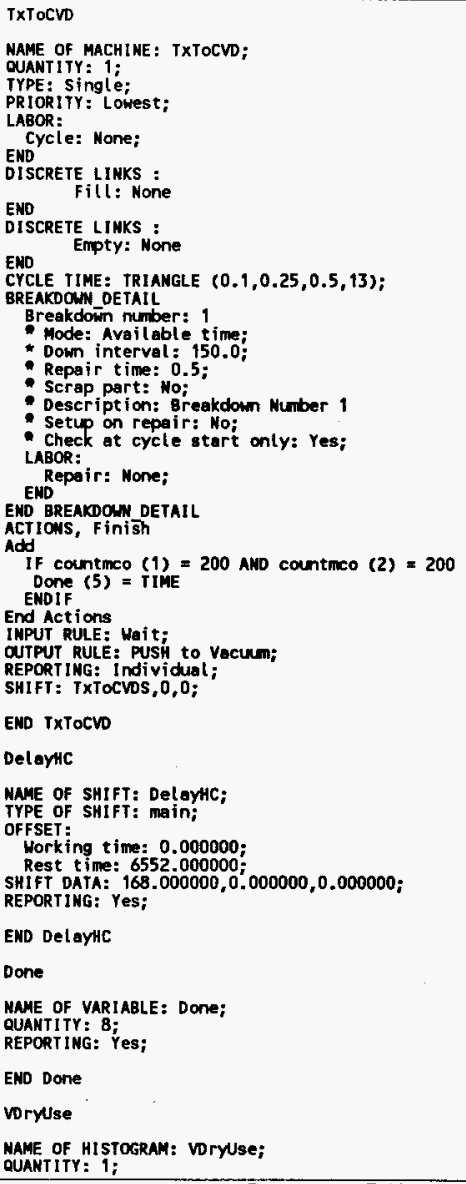 & 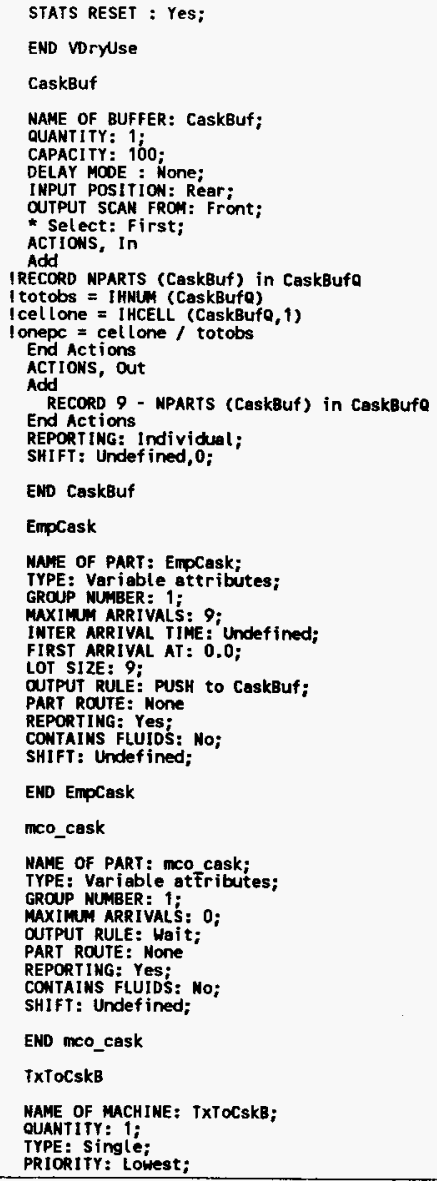 & 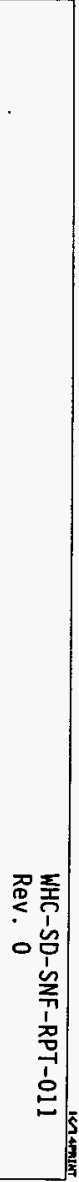 \\
\hline
\end{tabular}




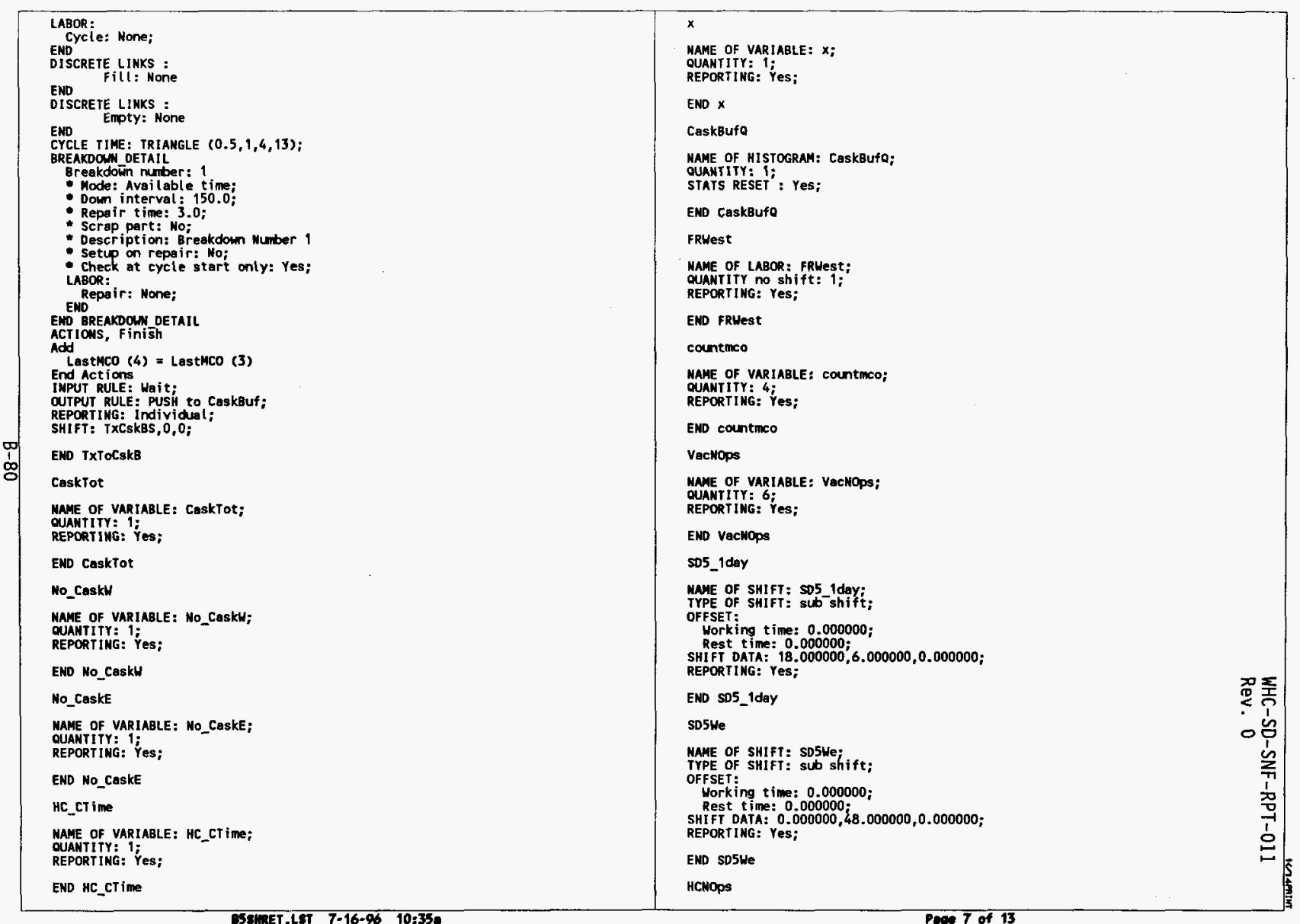


NAME OF VAR IABLE: HCNOPS;

QUANTITY: 6;

END HCHOPS

URU1_DaY

NAME OF SHIFT: WRU1 Day; OFFSET:

Horking time: 0.000000

Rest time: 0000000 .

SHIFT DATA: $2.000000,22.000000,0.000000$ REPORTING: Yes;

\section{END MRU1_DaY}

\section{WRuz_Day}

NAME OF SHIFT: WRU2 Day;

TYPE of SHIFT: sub shift;

$$
\text { OFFSET: }
$$

Working time: $0.000000_{3}$

SHIFT DATA: $5.000000,19.000000,0.000000$;

REPORTING: Yes:

END WRU2_Day

WRu3_Day

I
$\infty$ TYME OF SHIFT: IrUS Doy;

OFFSET:

Working time: 0.000000 ;

REST time: $0.000000 ;$

REPORTING: Yes;

END WRU3 DaY

WRU_DaY

MAME OF SHIFT: WRU4 Day;

OFFSET:

Working time: 0.000000

Rest time: 0.000000 .

SHIFI DATA: 11.000000, 13.000000,0.000000;

REPORTING: Yes;

END MRU4_DaY

WRU5_DaY

NAME OF SHIFT: WRUS DaY

TYPE OF SHIFT: sub shift

OFFSET:

Working time: 0.000000

Rest time: 0.000000 ;

SHIFT DATA: $14.000000,10.000000,0.000000$

END URUS DaY

WRU6_DaY

MAME OF SHIFT: WRUG Day;

OFFSET:

Working time: 0.000000

Rest time: 0.000000

SHIFT DATA: $17.000000,7.000000,0.000000$; REPORTING: Yes;

END WRUG_DaY

URU7_DaY

NAME OF SHIFT: WRU7 Day;

OFFSET

Working time: 0.000000

Rest time: 0.000000

SHIFT DATA: $18.000000,6.000000,0.000000$; REPORTIHG: YES;

END MRU7_DaY

ERU4_DaY

NAME OF SHIFT: ERU4 Day

TYPE OF SHIFT: sub shift;

Working time: 0.000000 ;

SHIFT DATA: $3.000000,21.000000,0.000000$; EPORTING: Yes:

EMD ERU4_DaY

ERUS_DoY

WAME OF SHIFT: ERUS Day;

OFFSET:

Working time: 0.000000 ;

Rest time: 0.000000

SHIFT DATA: $9.000000,15.000000,0.000000$; REPORTING: Yes;

END ERU5_Day

ERU6_Day

NAME OF SHIFT: ERUG Day;

OFFSET:

Working time: 0 .000000,

Rest time: 0.000000 .

SHIFT DATA: $15.000000,9.000000,0.000000$;

REPORTIMG: YES;

END ERUG_DaY

ERU7_DaY

NAME OF SHIFI: ERU7 DaY:

TYPE OF SHIFT: sub shift; 


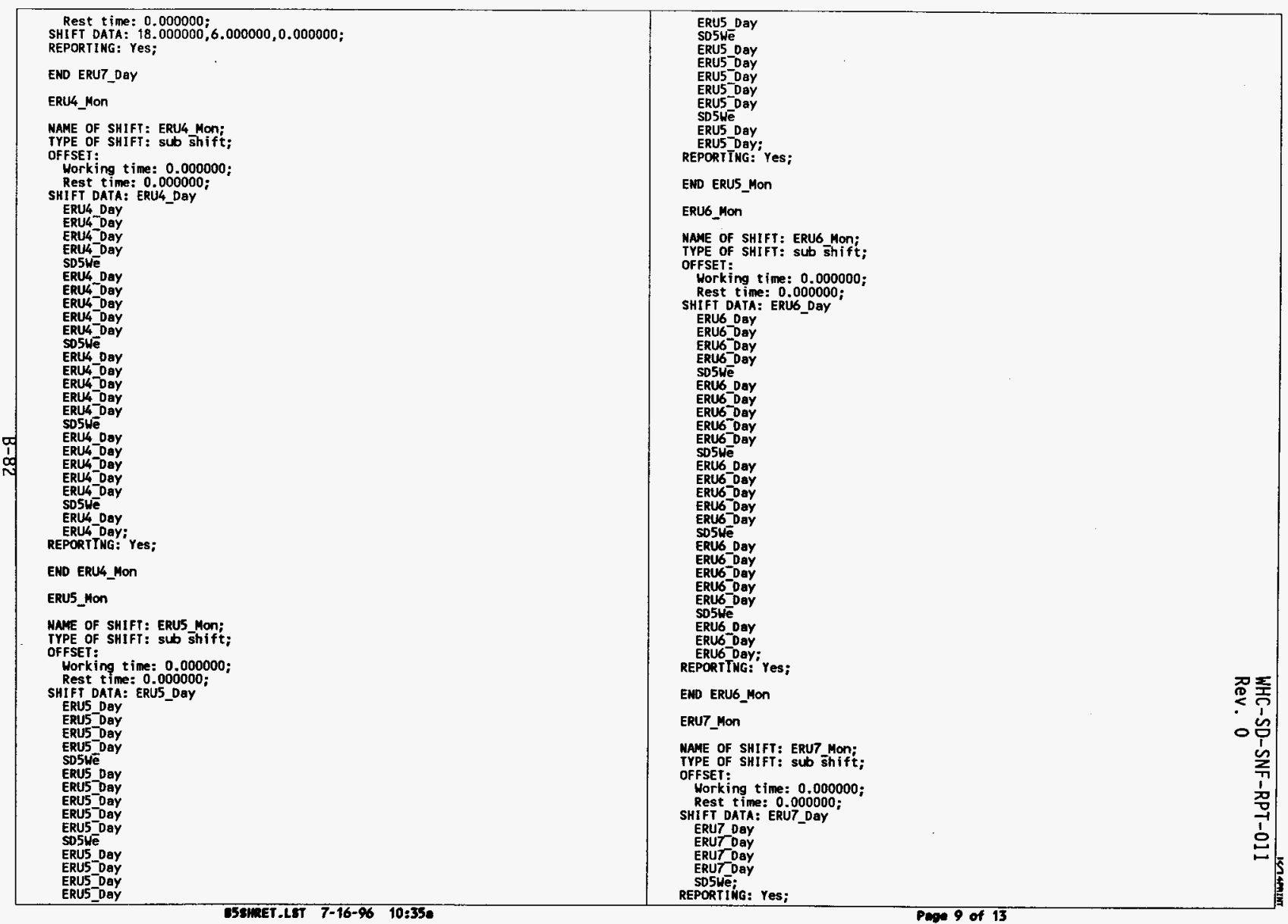




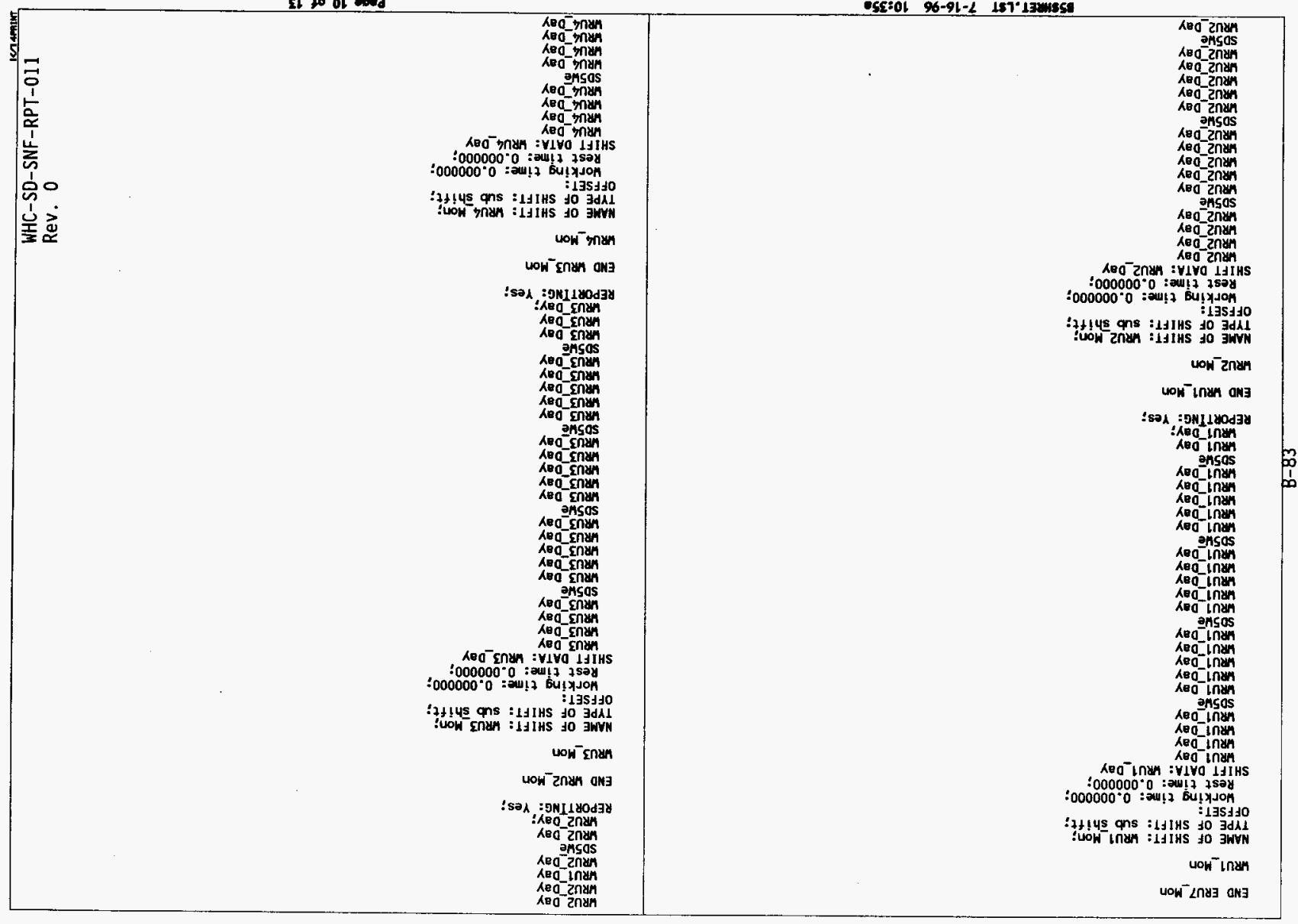




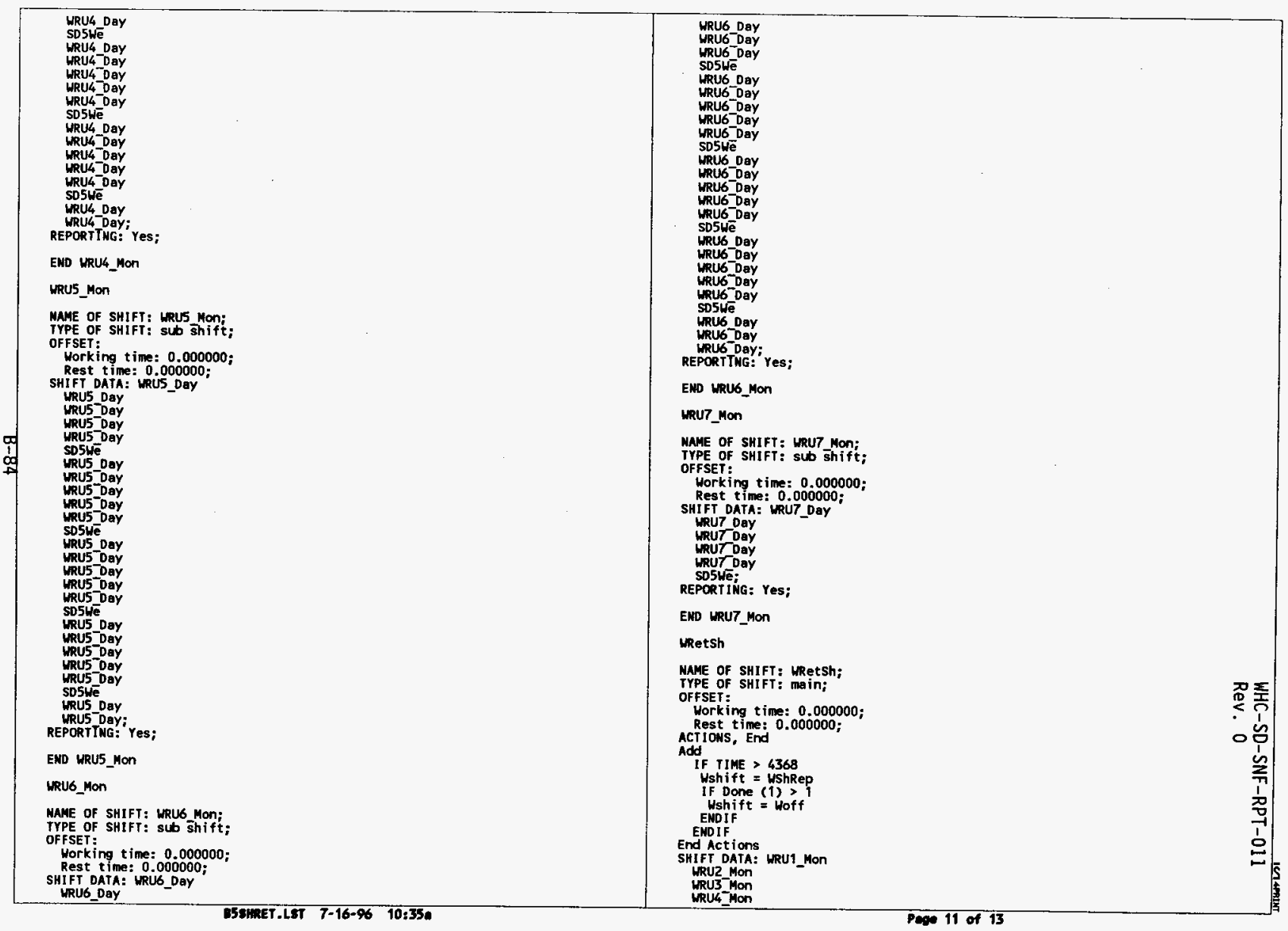




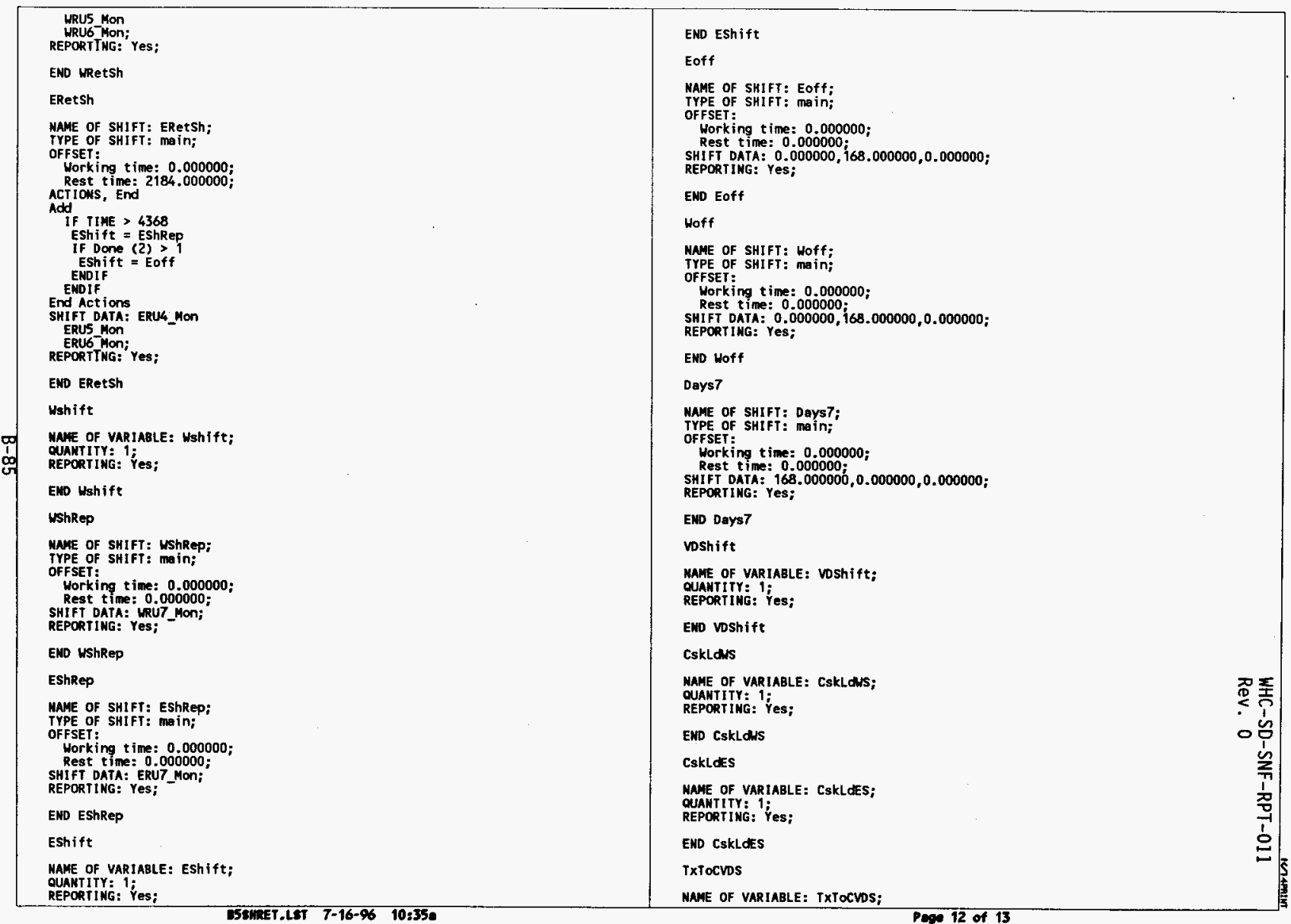




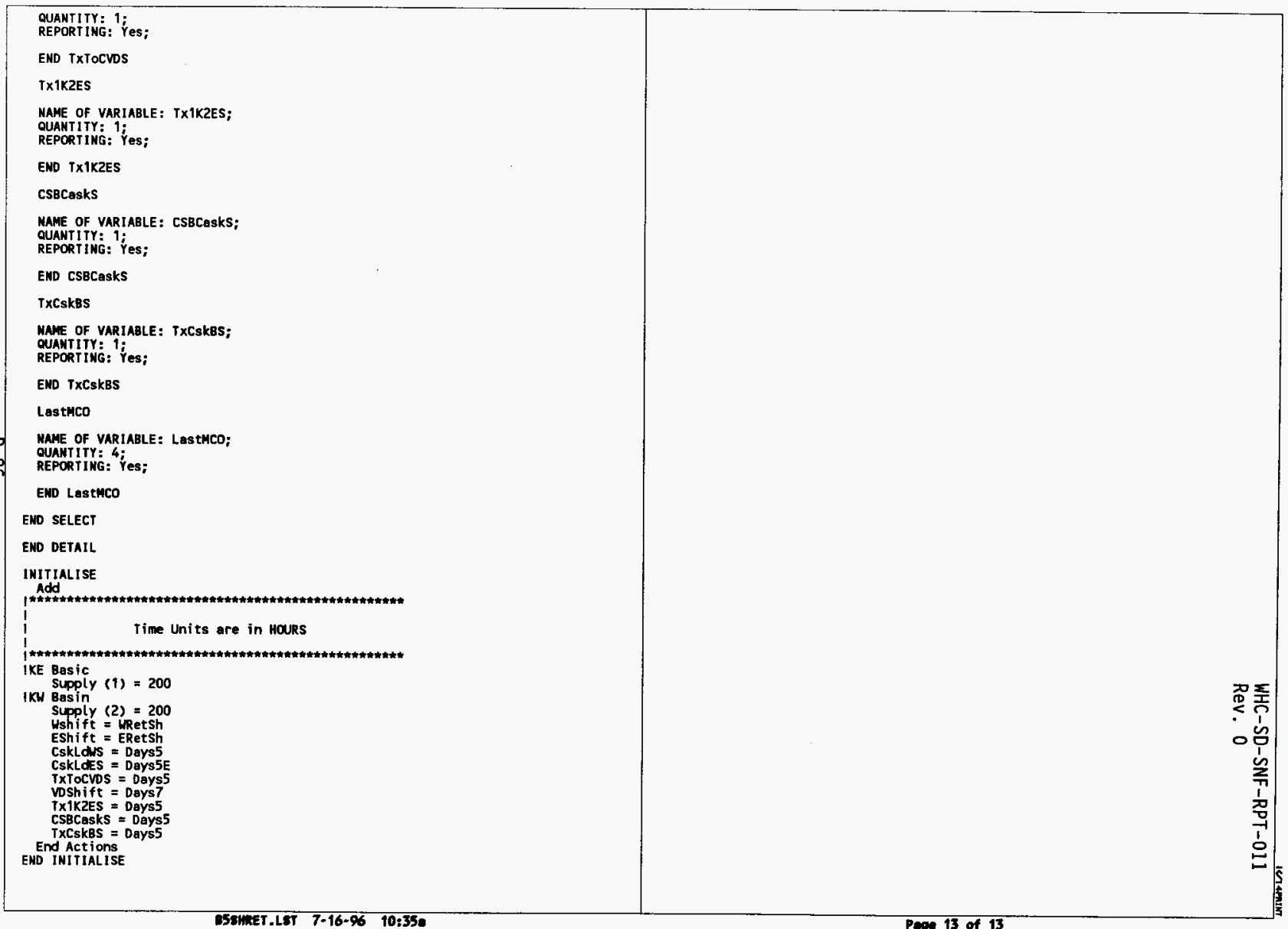


WHC-SD-SNF-RPT-0I1

Rev. 0

CASE 5. THREE 8 HR SHIFTS/DAY, 5 DAYS/WEEK.

WITH LONG REPAIR TIMES ON FUEL RETRIEVAL, MHM, AND HOT CONDITIONING 
SNF Project operating 3 shifts, 5 days/week. Cold vacuum drying Hot conditioning operating 7 days/week. Fuel retrieval, the MHM, and hot conditioning have long repair times.

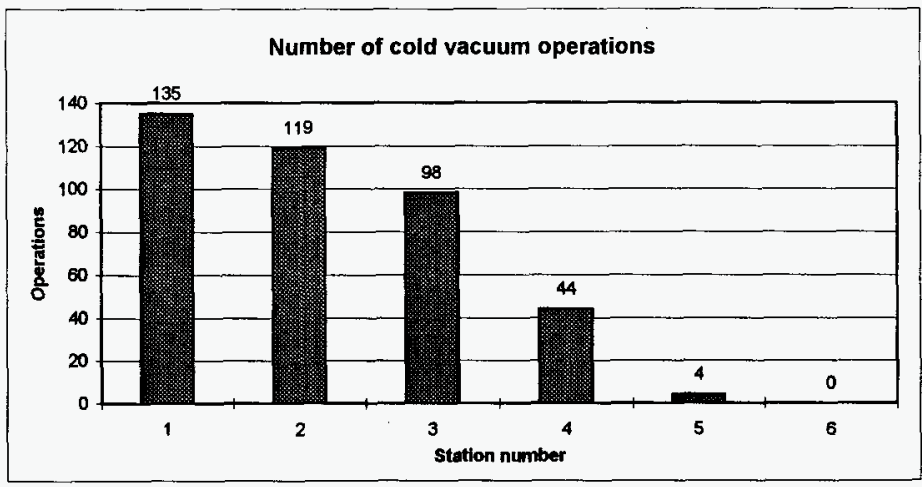

D
$\stackrel{1}{0}$
$\infty$

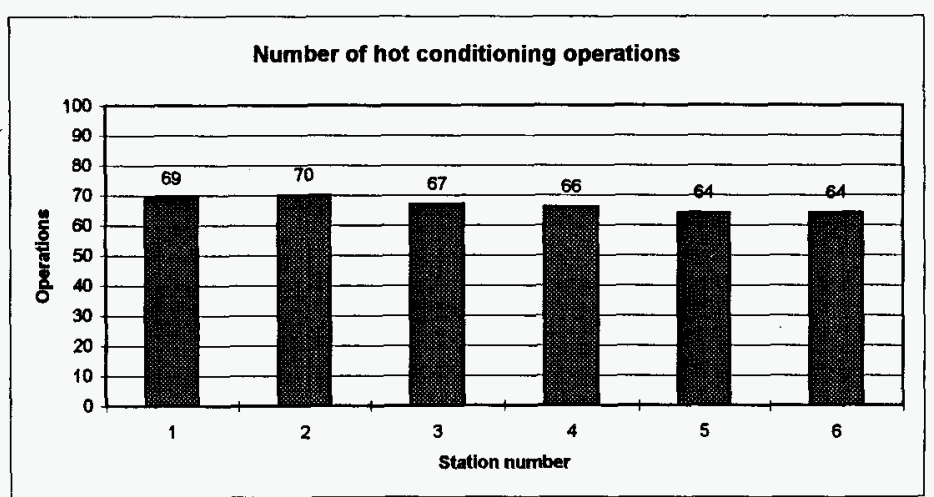


WHC-SD-SNF-RPT-011

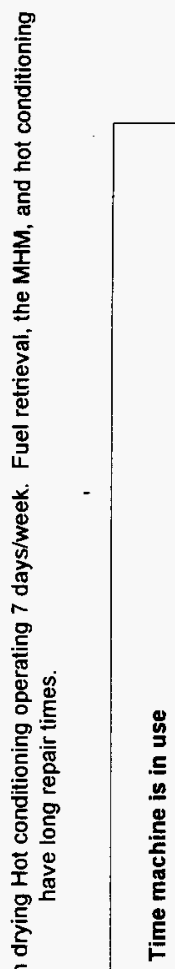

Rev. 0

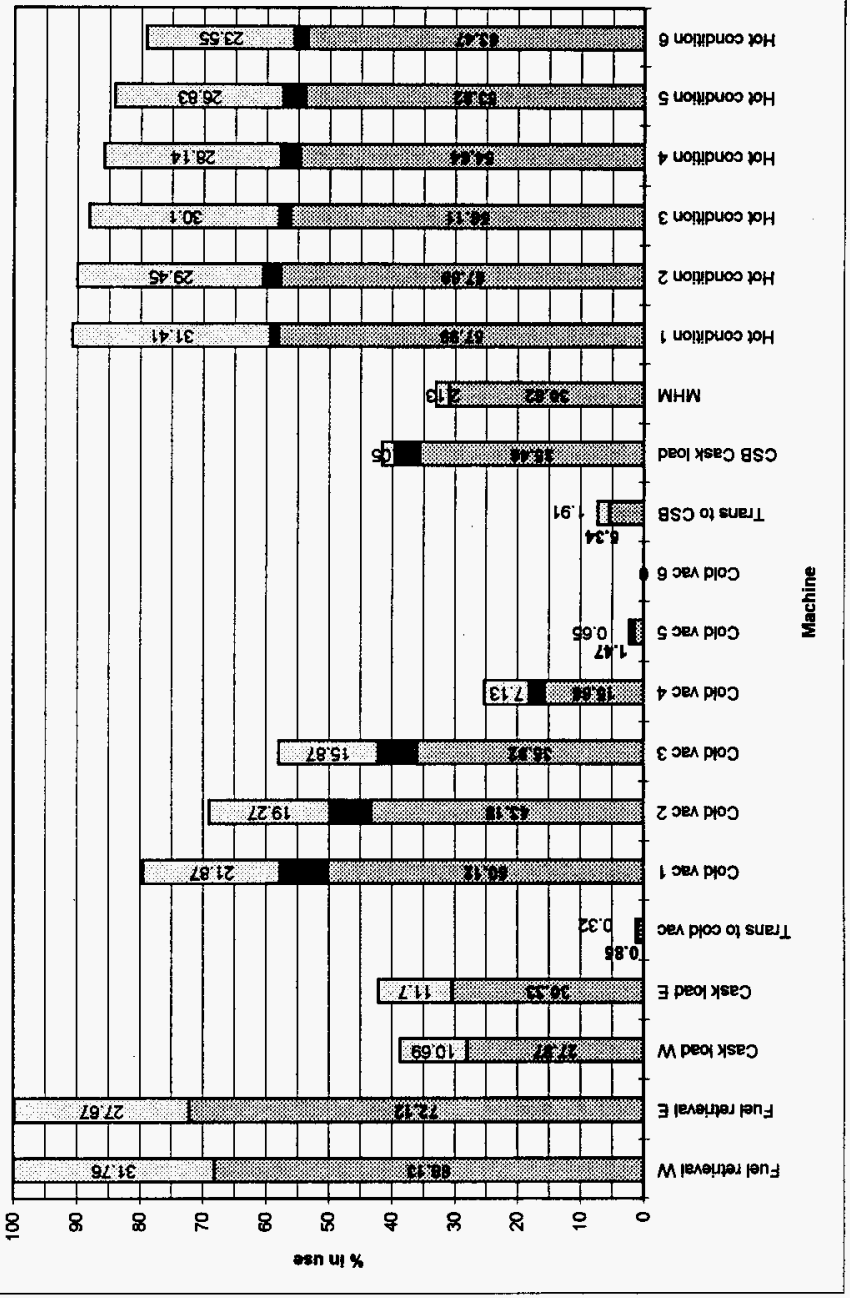




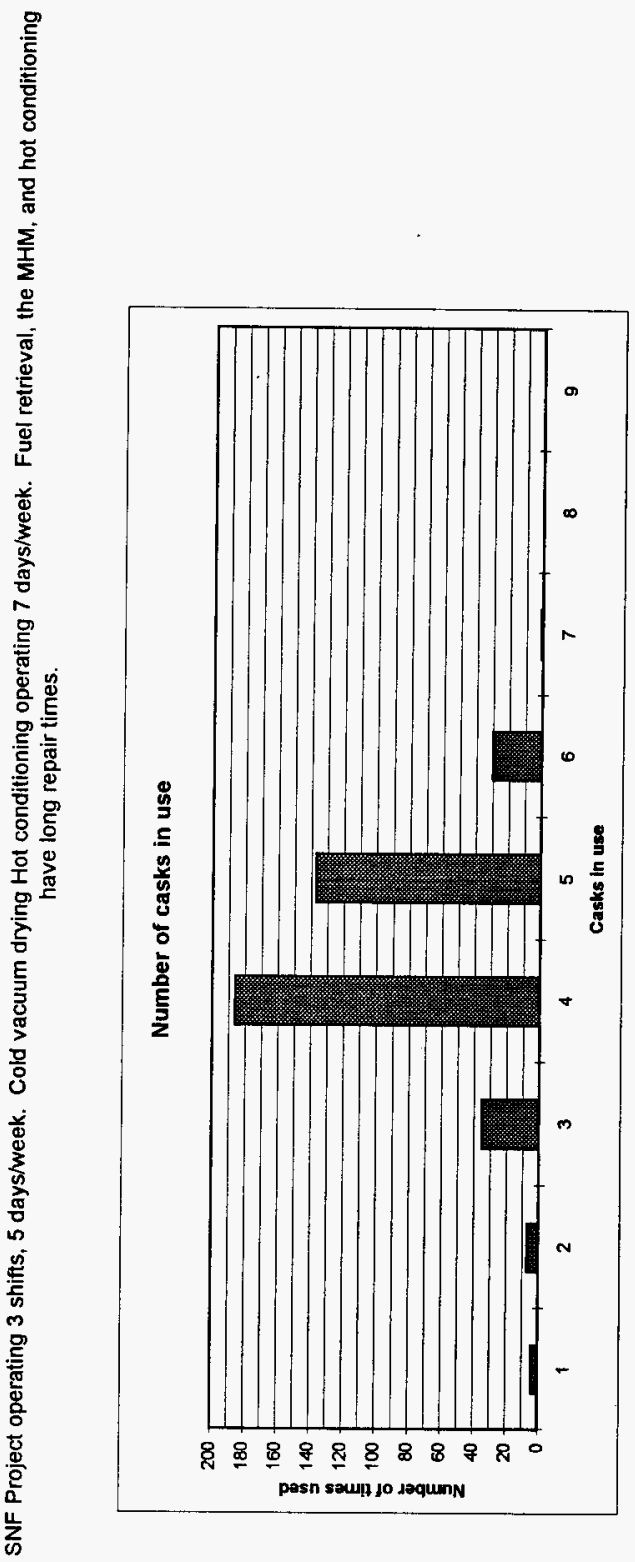

WHC-SD-SNF-RPT-011

Rev. 0

$\frac{\mathscr{9}}{\stackrel{0}{*}}$

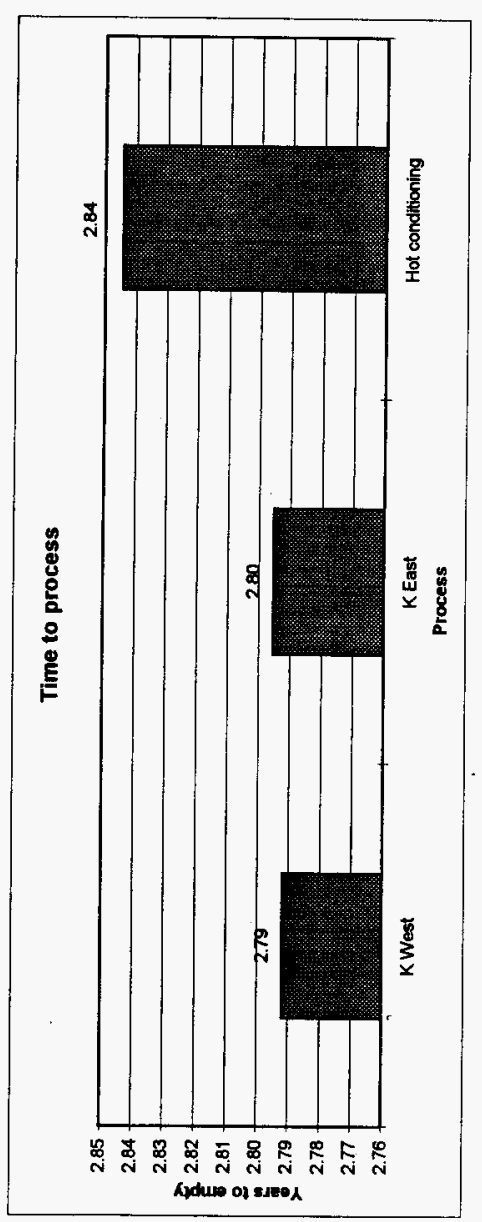

$m$
$\stackrel{5}{0}$
0
0 


\begin{tabular}{|c|c|c|}
\hline 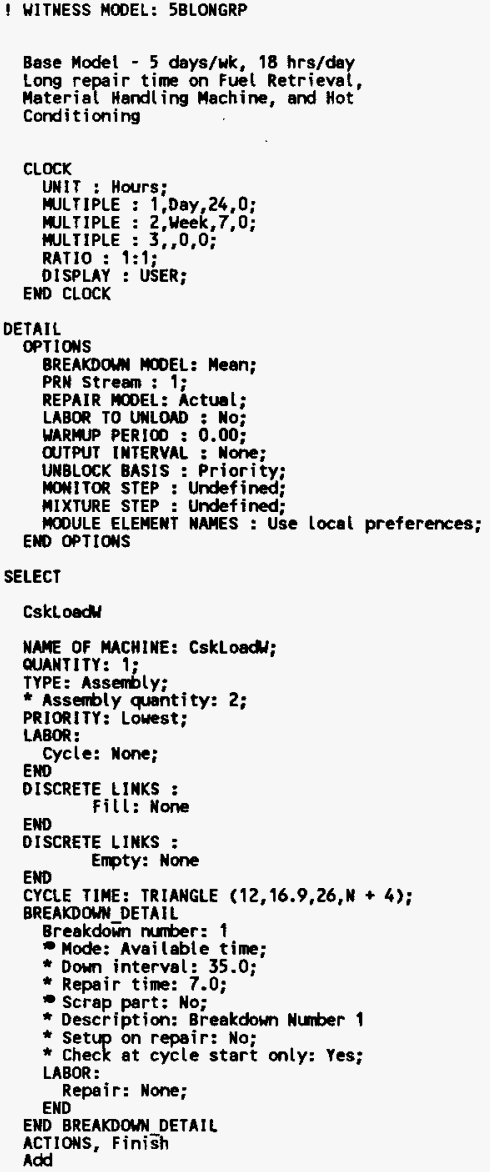 & 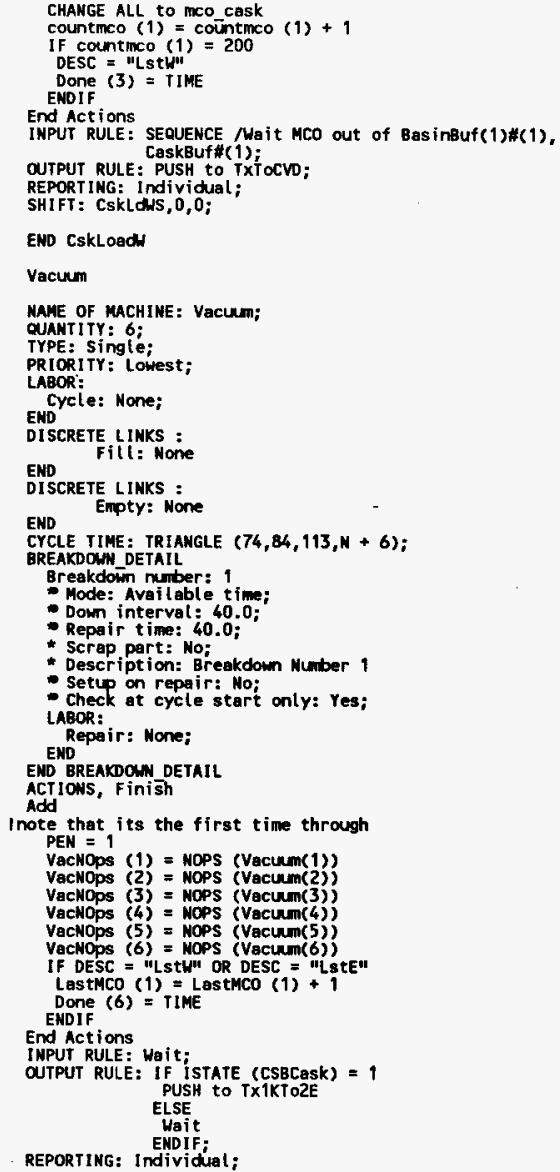 & 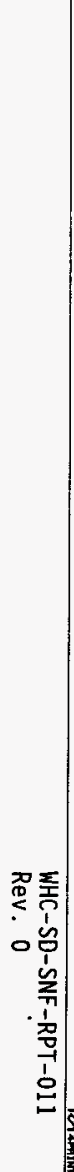 \\
\hline
\end{tabular}




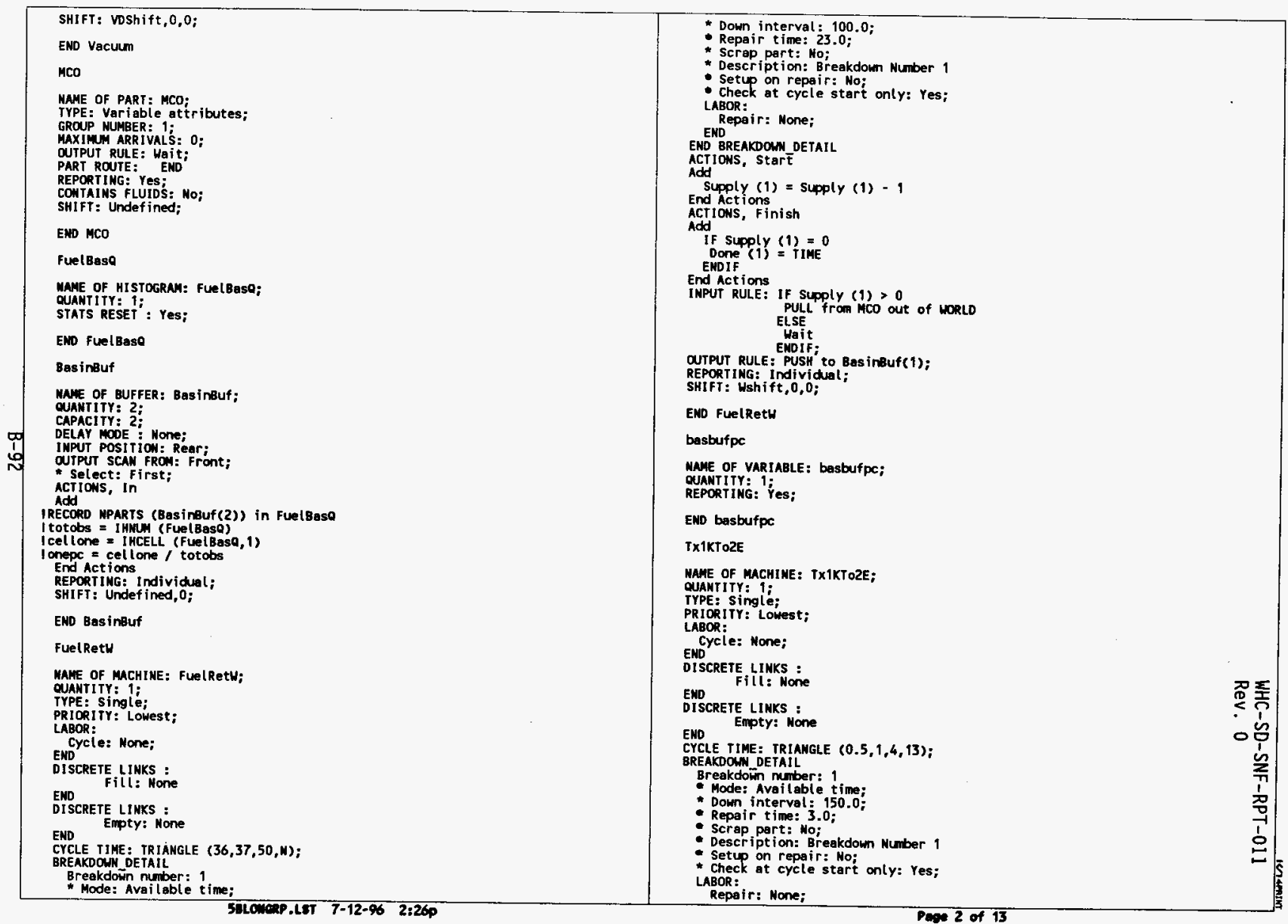




\begin{tabular}{|c|c|c|}
\hline 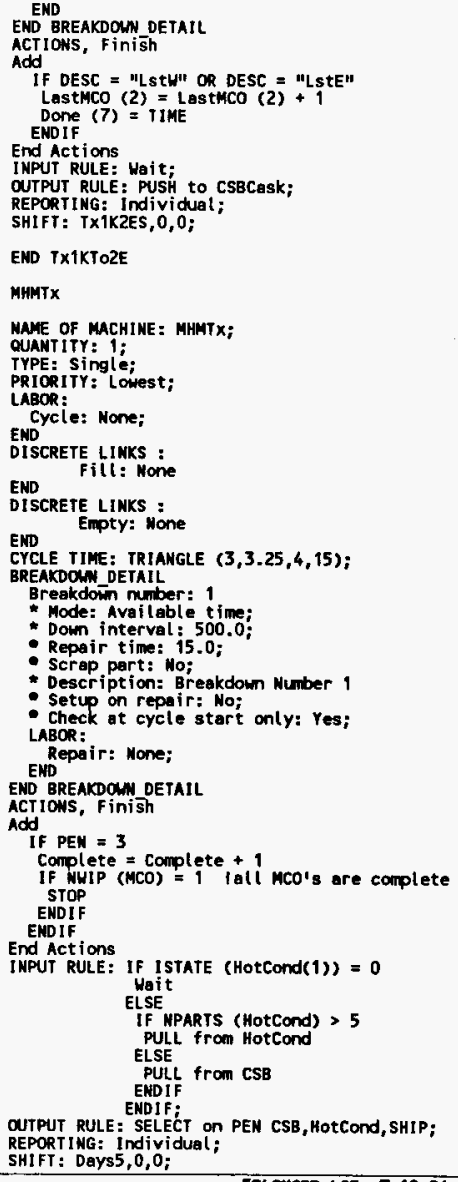 & 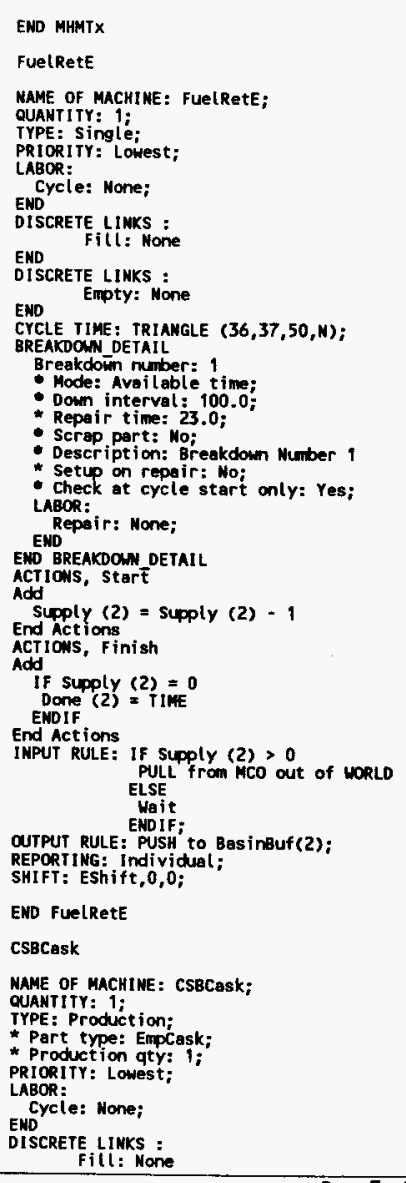 & 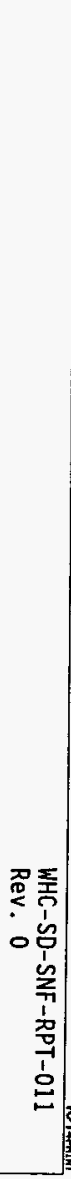 \\
\hline
\end{tabular}




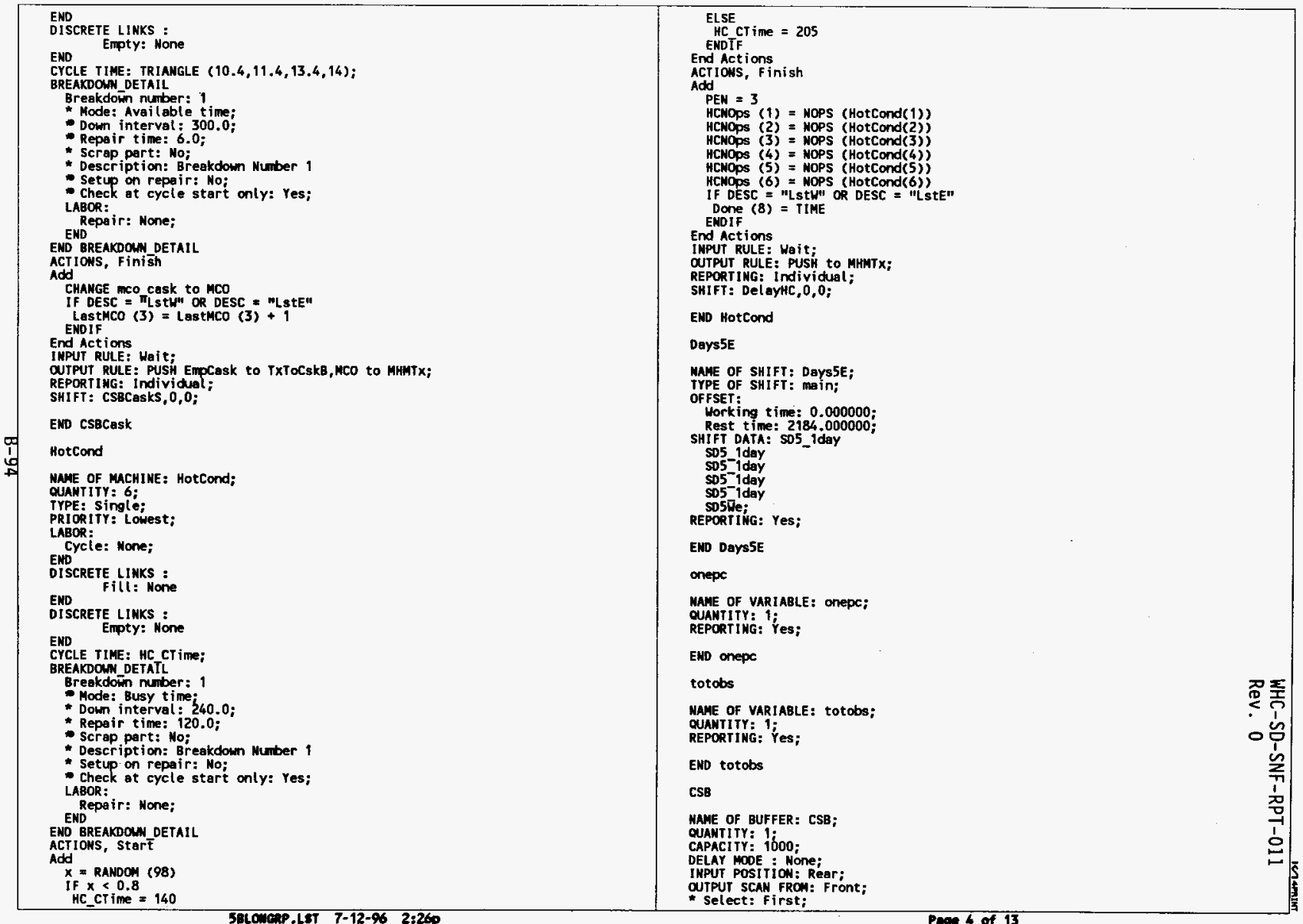




\begin{tabular}{|c|c|c|}
\hline 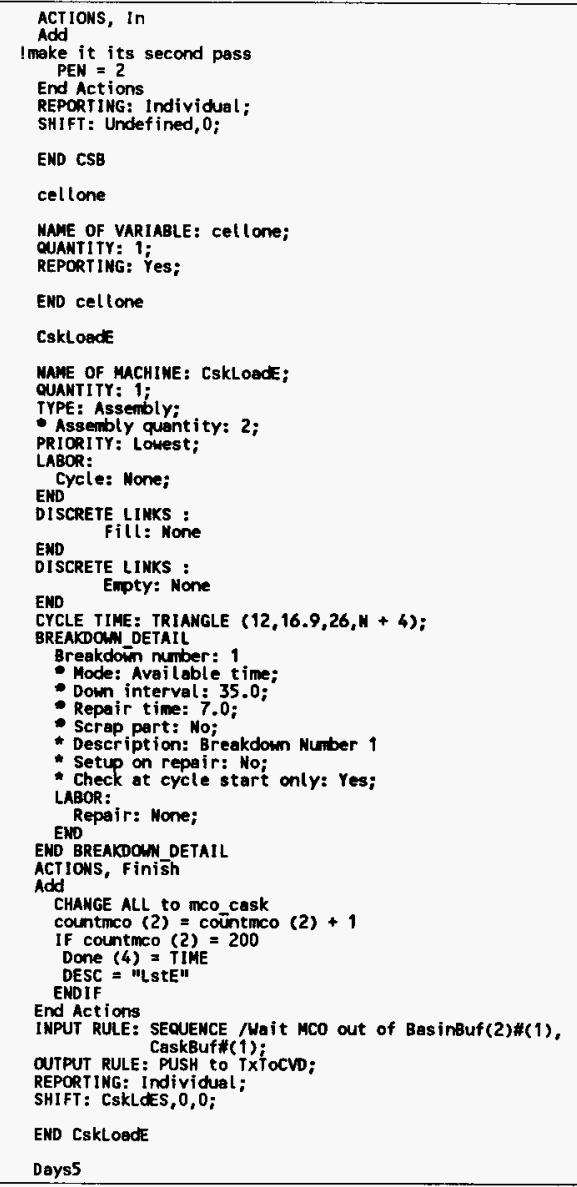 & 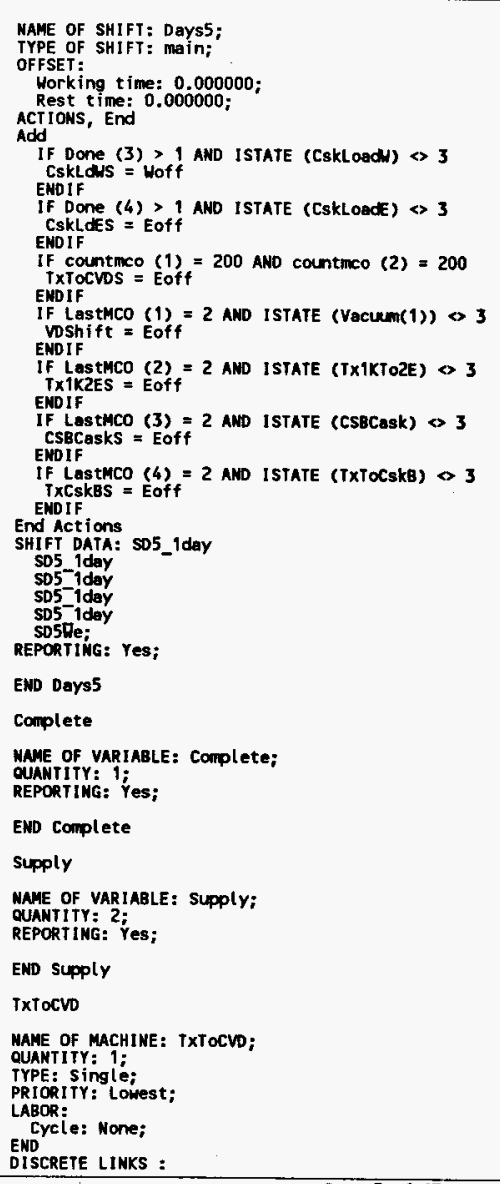 & 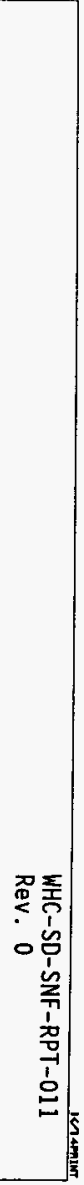 \\
\hline
\end{tabular}




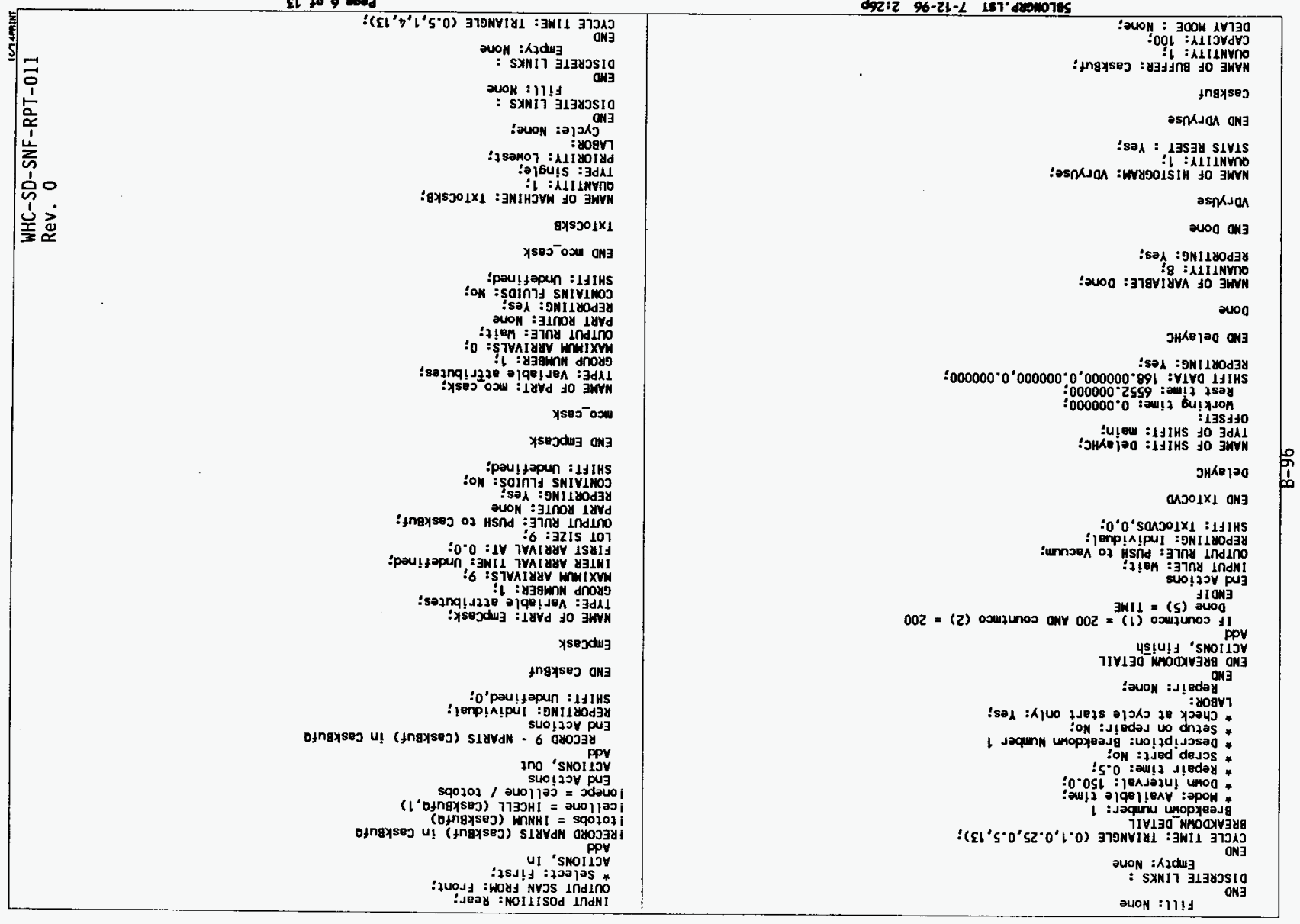




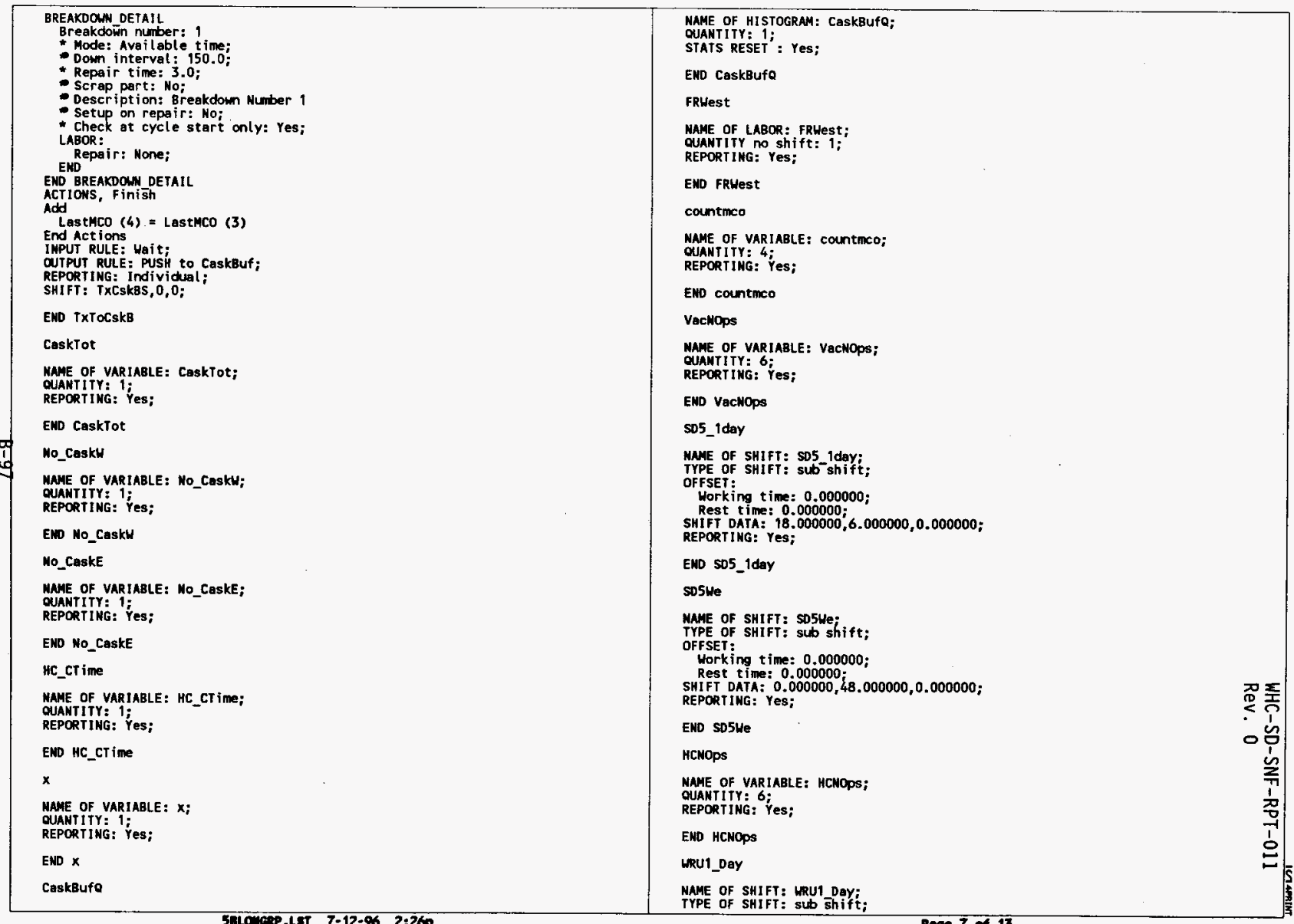




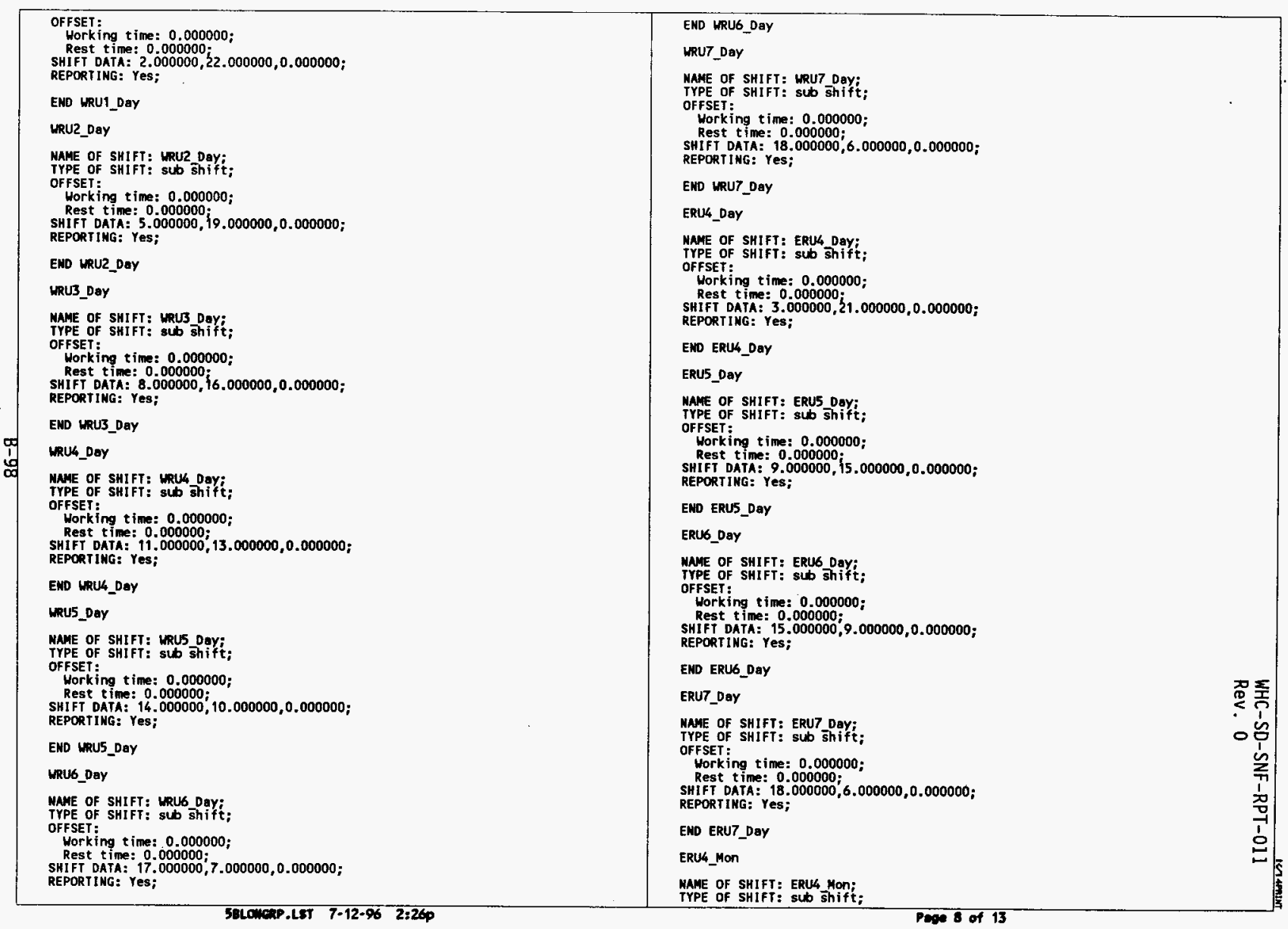




\begin{tabular}{|c|c|c|}
\hline 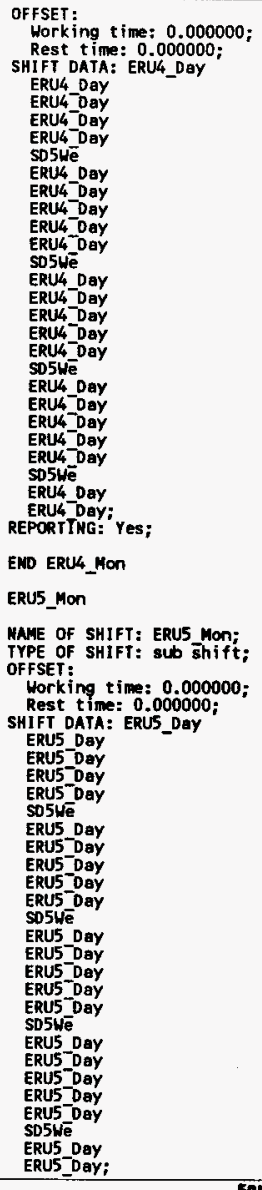 & 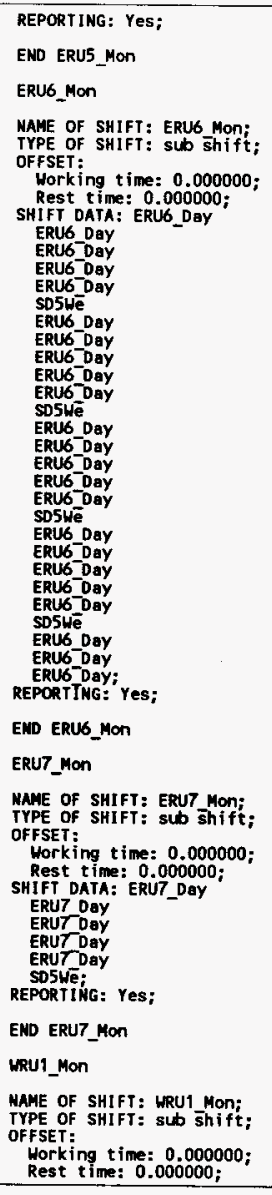 & 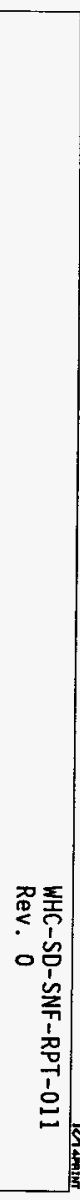 \\
\hline
\end{tabular}




\begin{tabular}{|c|c|c|}
\hline 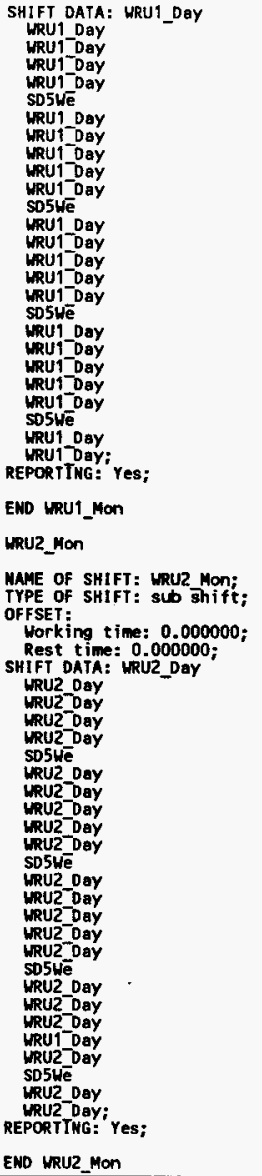 & 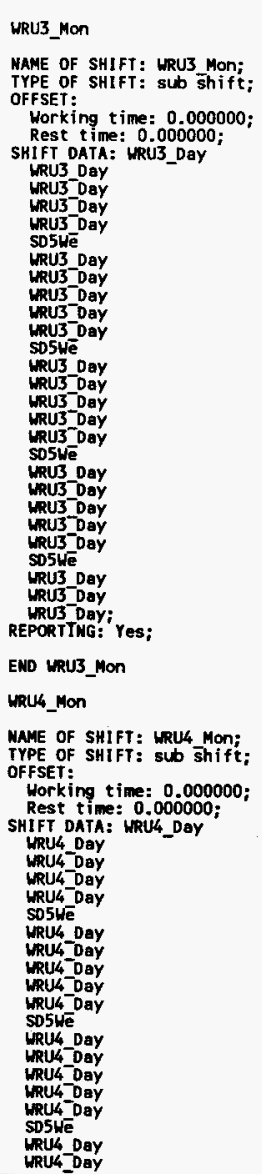 & 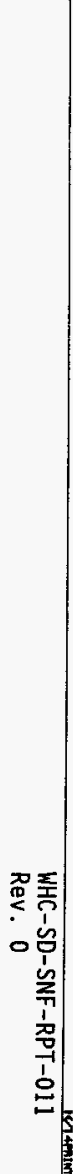 \\
\hline
\end{tabular}




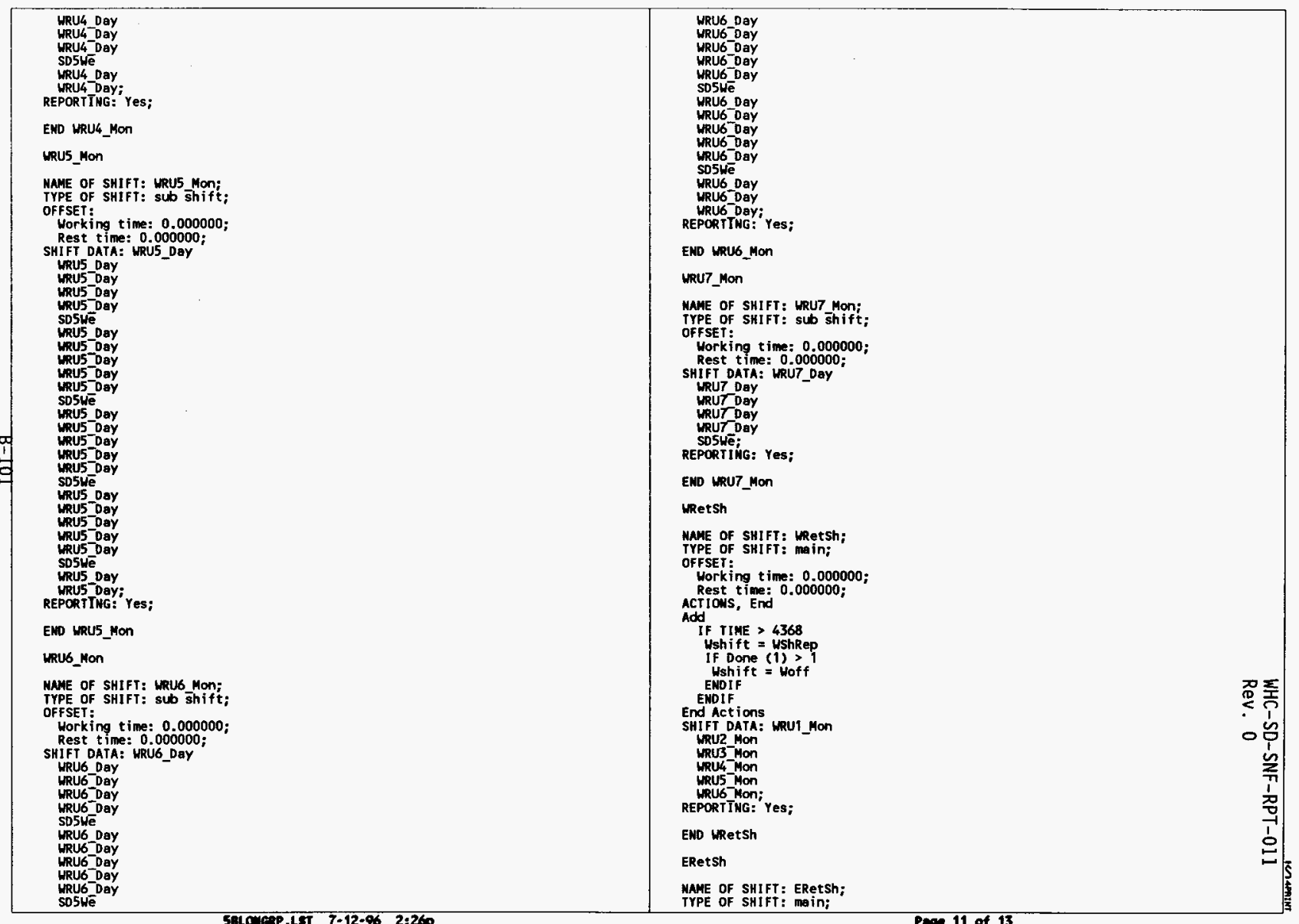




\begin{tabular}{|c|c|c|}
\hline 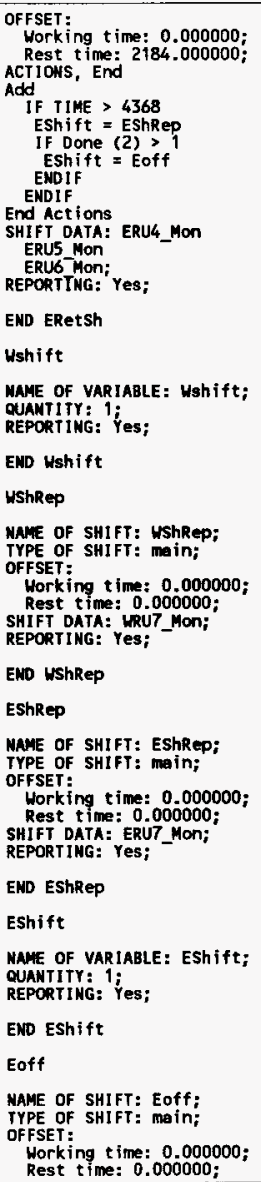 & 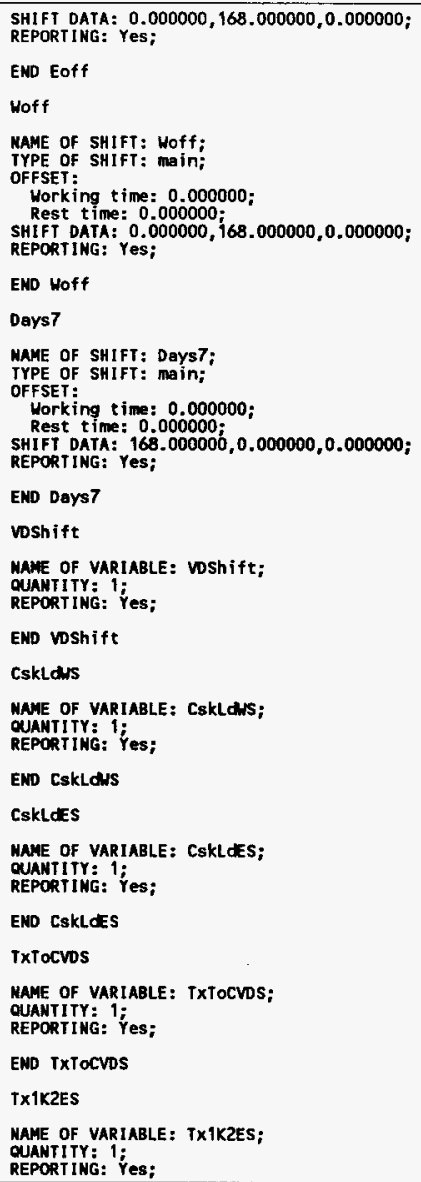 & 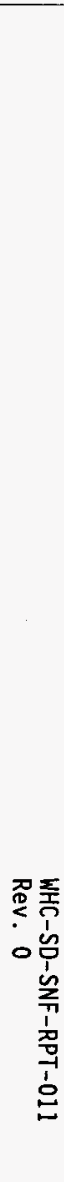 \\
\hline
\end{tabular}




\section{EMD TX1K2ES}

CSBCasks

MAME OF VARIABLE: cSBCasks;

QUANTI IY: 1;

END CSBCasks

TXCskBS

NAME OF VARIABLE: TXCskBS;

QUANTIIY: $1 ;$

END TXCskBS

LastMCO

HAME OF VARIABLE: LaS TMCO;

OUANTITY: 4

REPORTING: Yes;

END Lastmco

END SELECT

END DETAIL

Co INITIALISE

6)

Iine Units are in Hours

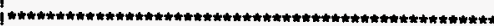

IKE Basic

Supply (1) $=200$

Basin

supply (2) $=200$

Ushift = WRetSh

EShift $=$ ERetSh

CskLdNS = Days5

IXTocros = Days

TXToCVD $=$ Days5

TX1K2ES = Days 5

(SBCesks = Days

TXCskBS = Days5

TXCskBS = Days

END INITIALISE 
WHC-SD-SNF-RPT-011

Rev, $O$

CASE 6. THREE 8 HR SHIFTS/DAY, 7 DAYS/WEEK. 
SNF Project operating 3 shifts, 7 days a week

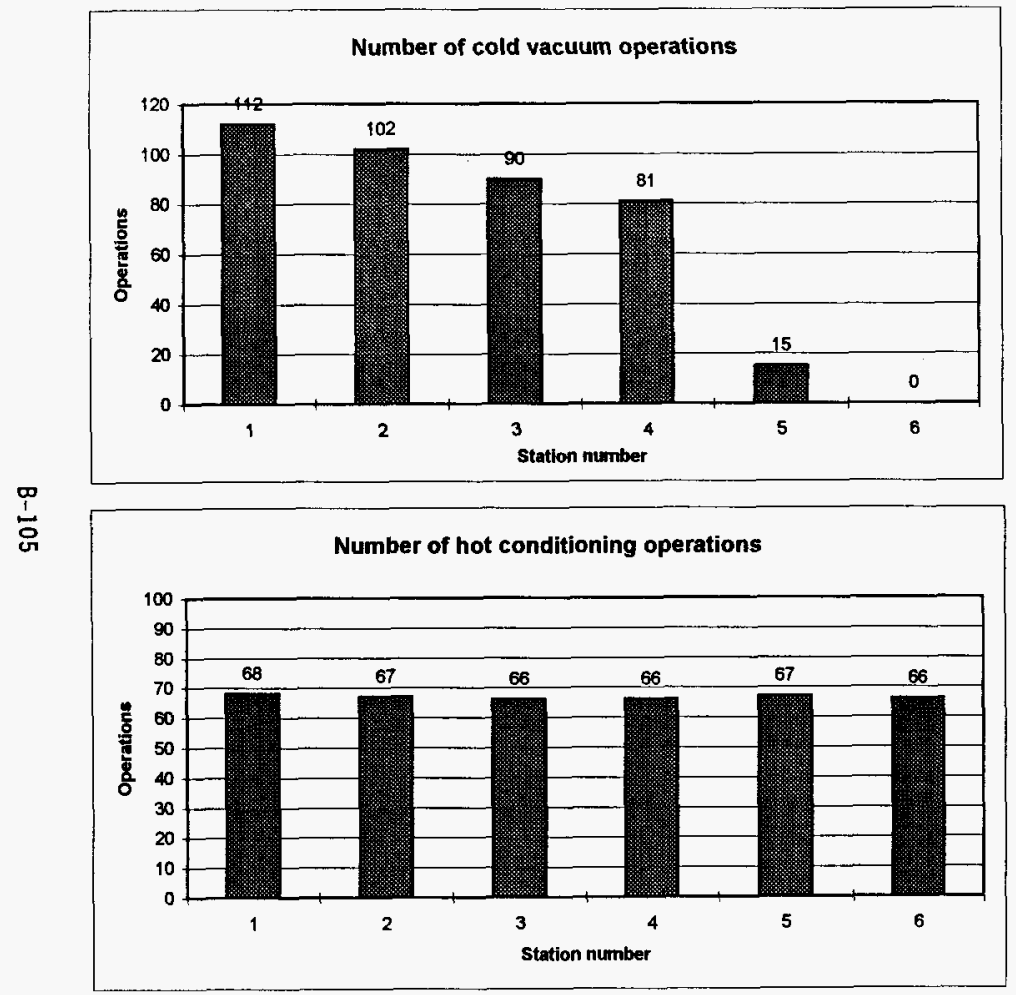


SNF Project operating 3 shifts, 7 days a week

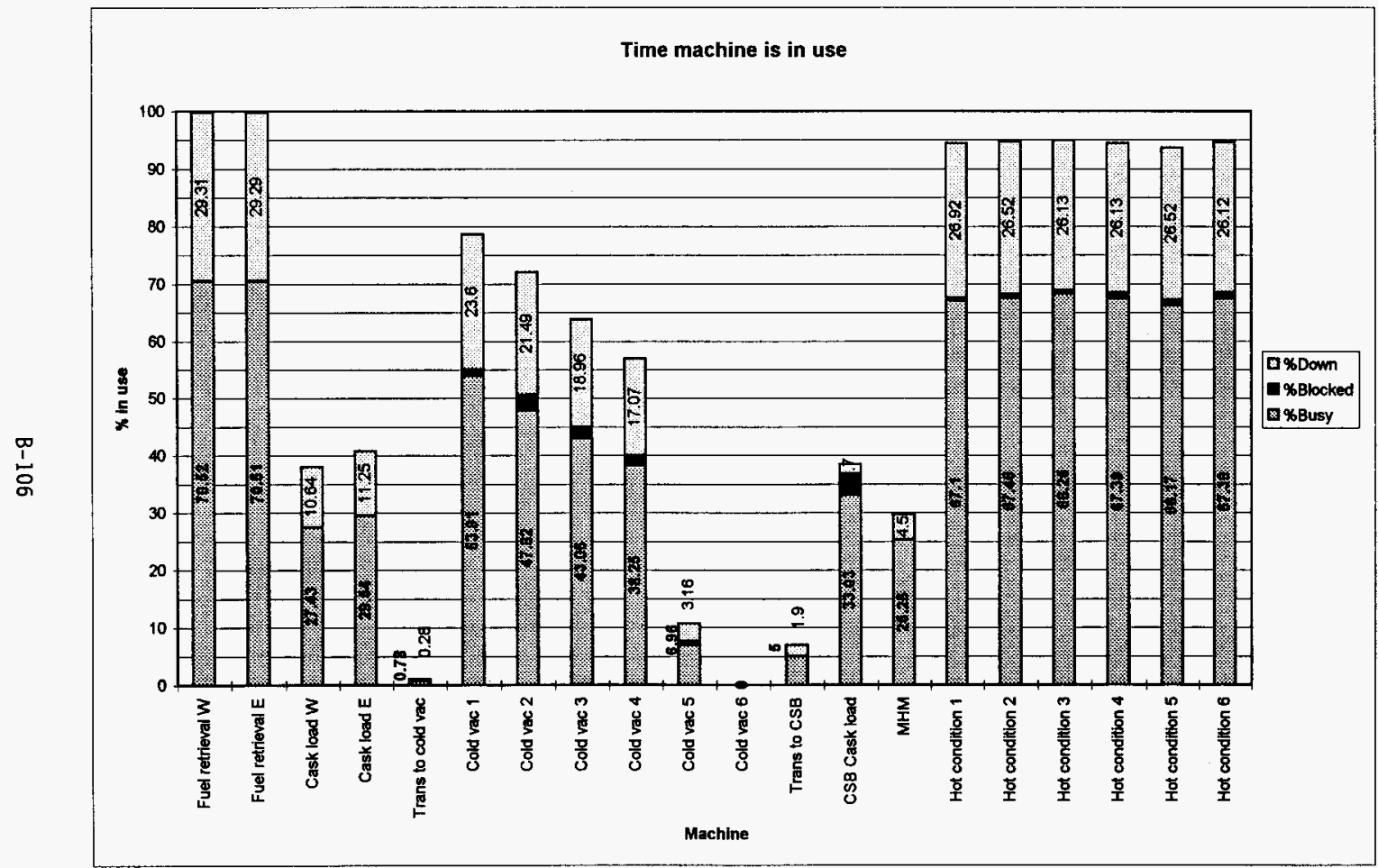

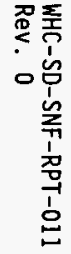




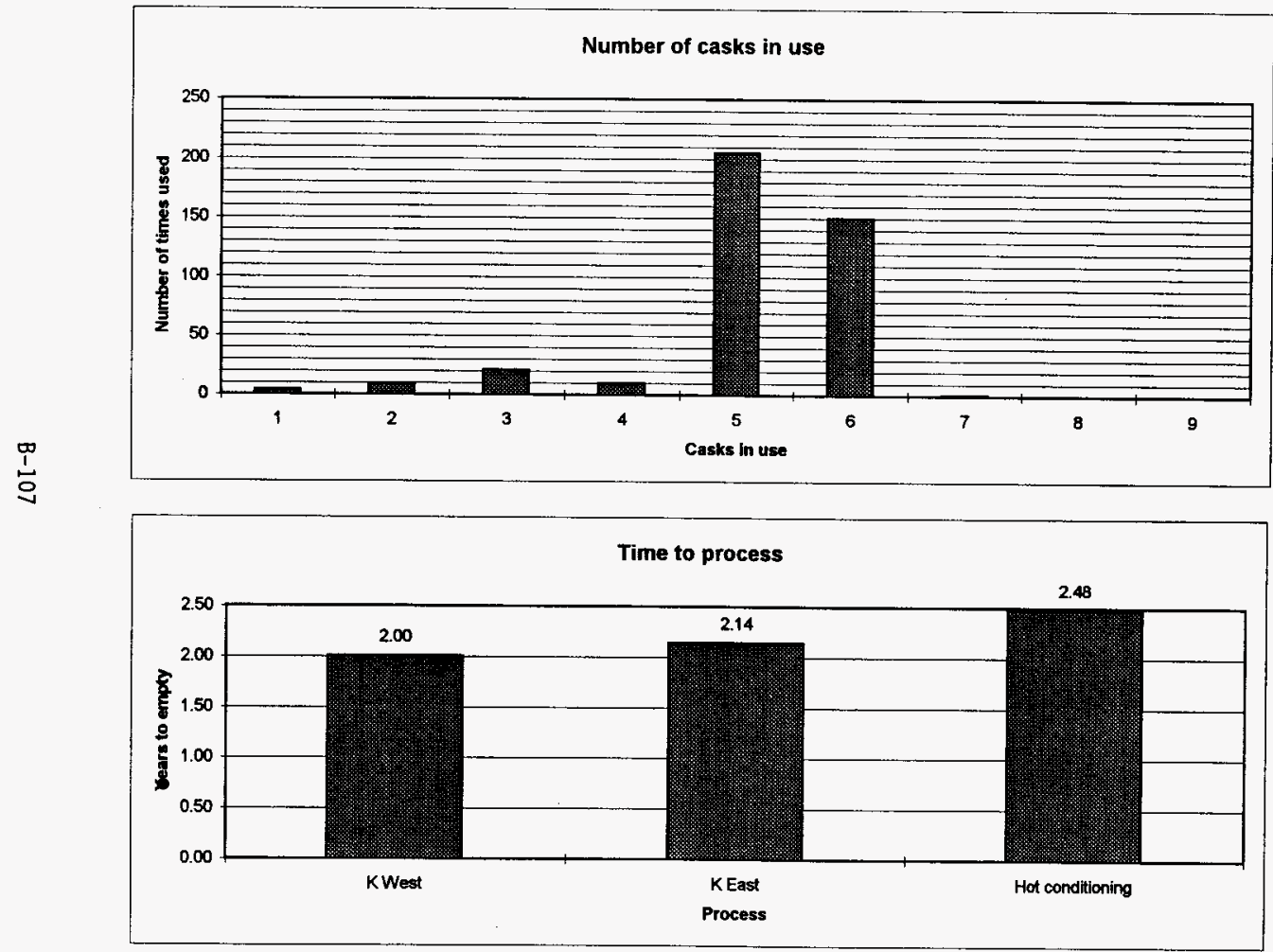




\begin{tabular}{|c|c|c|}
\hline 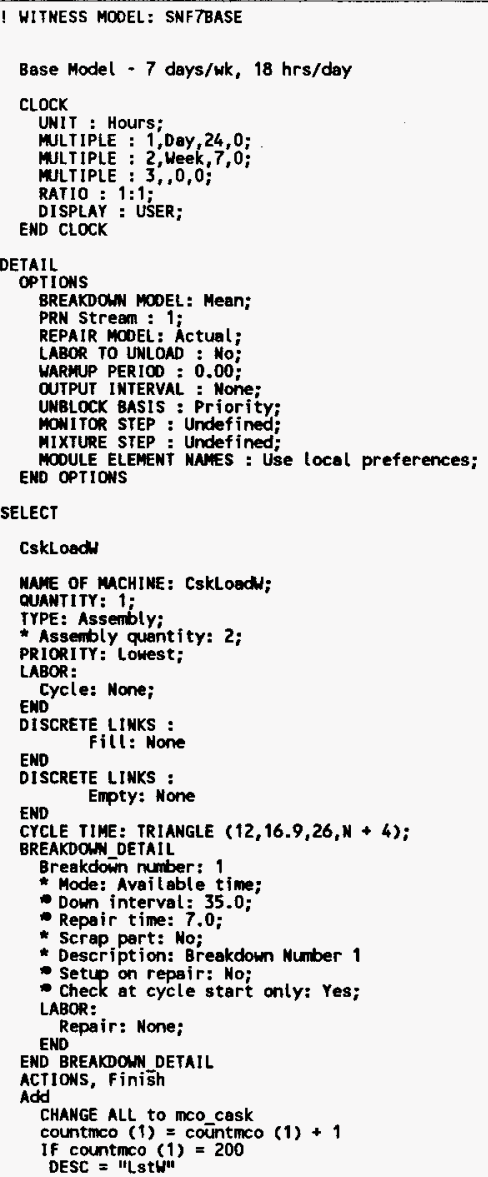 & 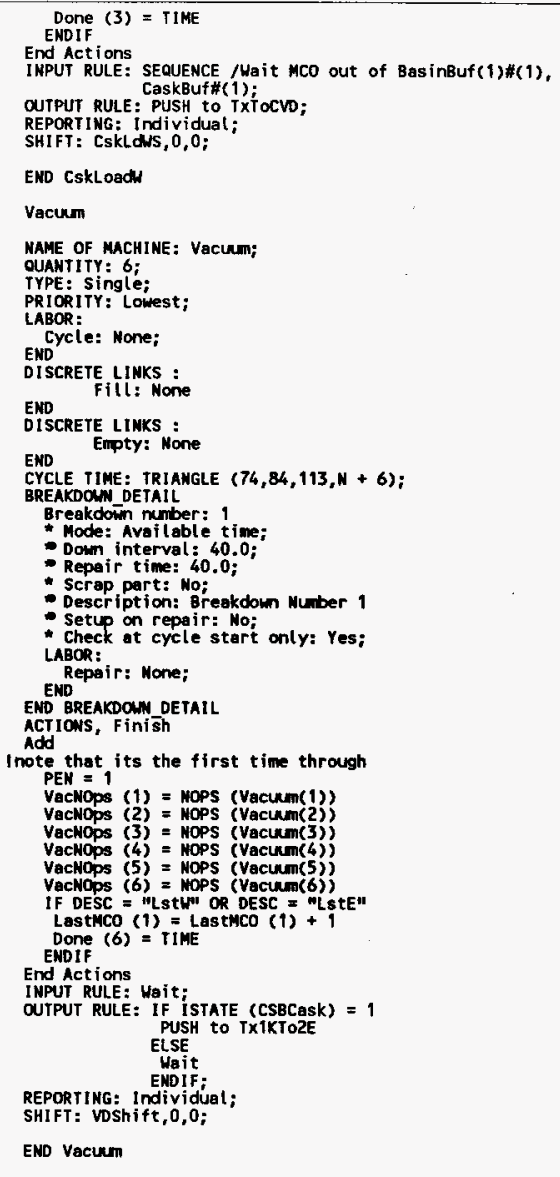 & 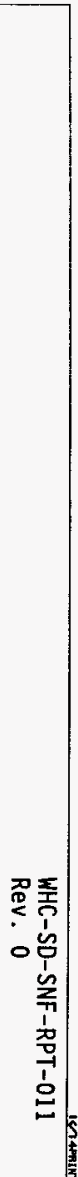 \\
\hline
\end{tabular}




\begin{tabular}{|c|c|c|}
\hline 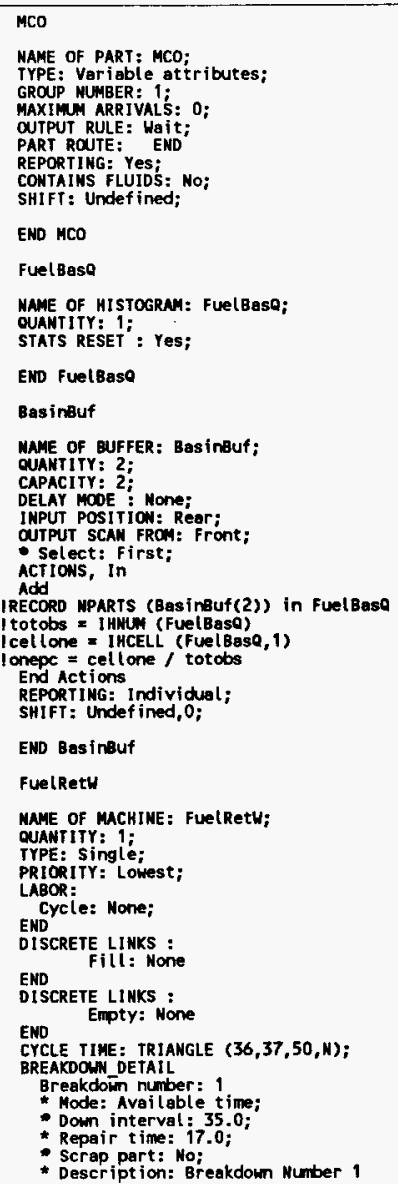 & 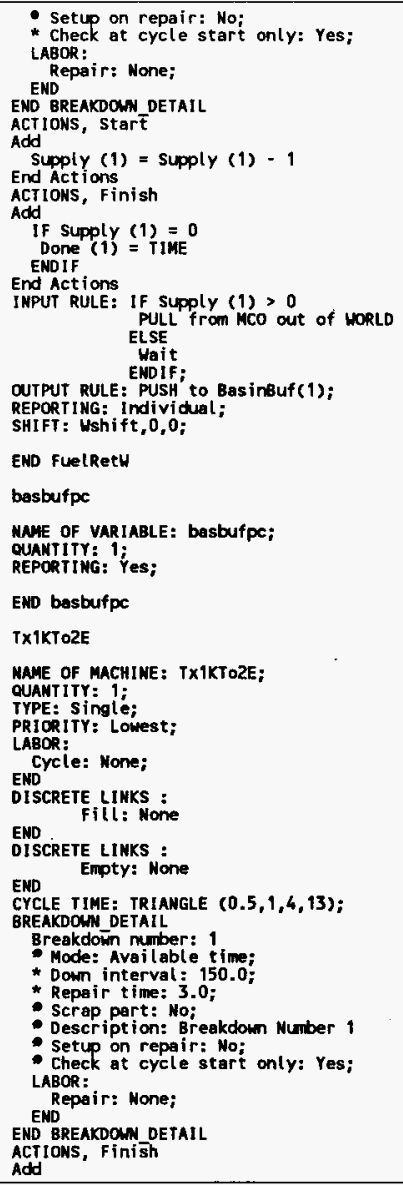 & 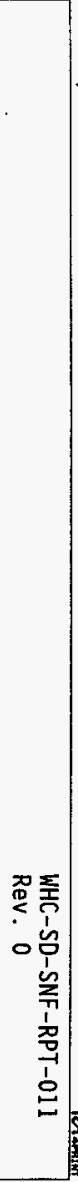 \\
\hline
\end{tabular}




\begin{tabular}{|c|c|c|}
\hline 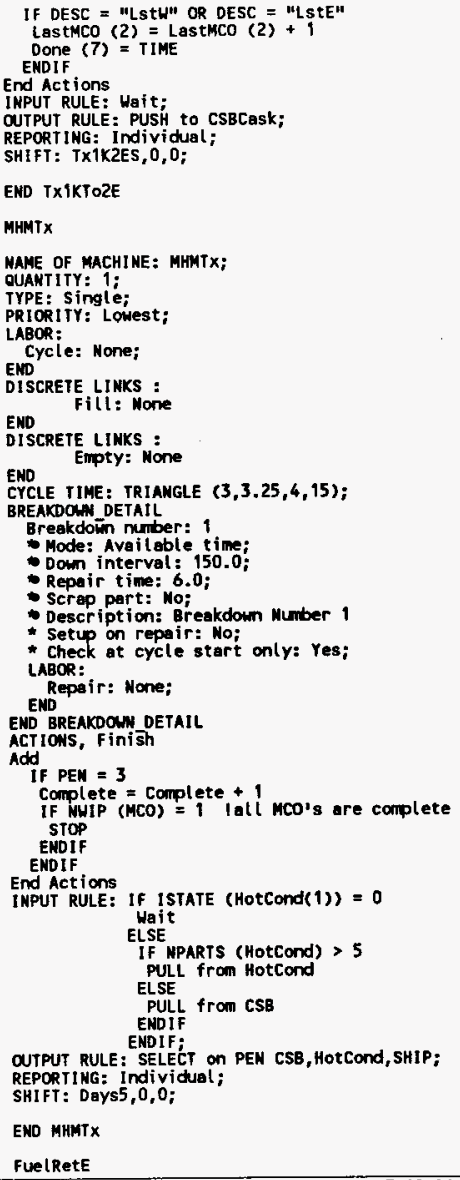 & 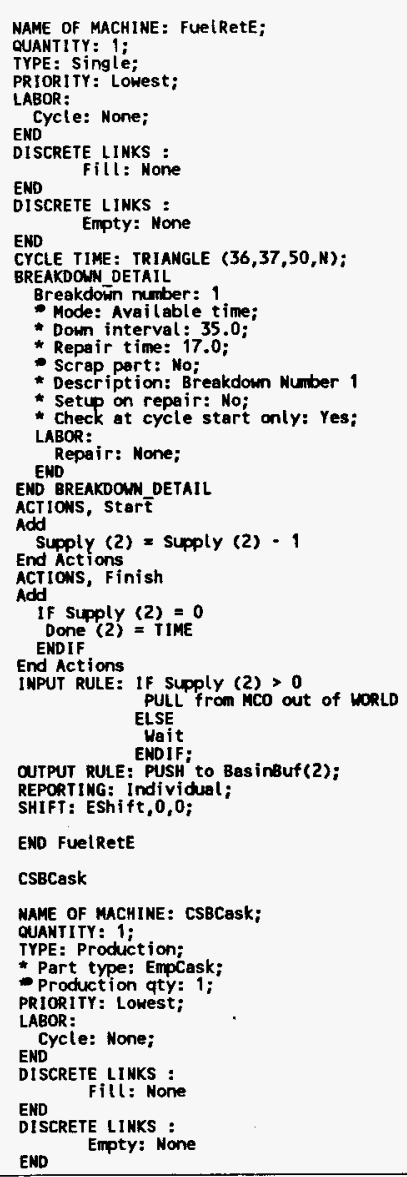 & 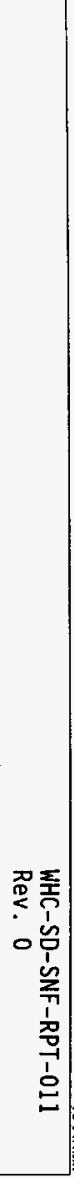 \\
\hline
\end{tabular}




\begin{tabular}{|c|c|}
\hline 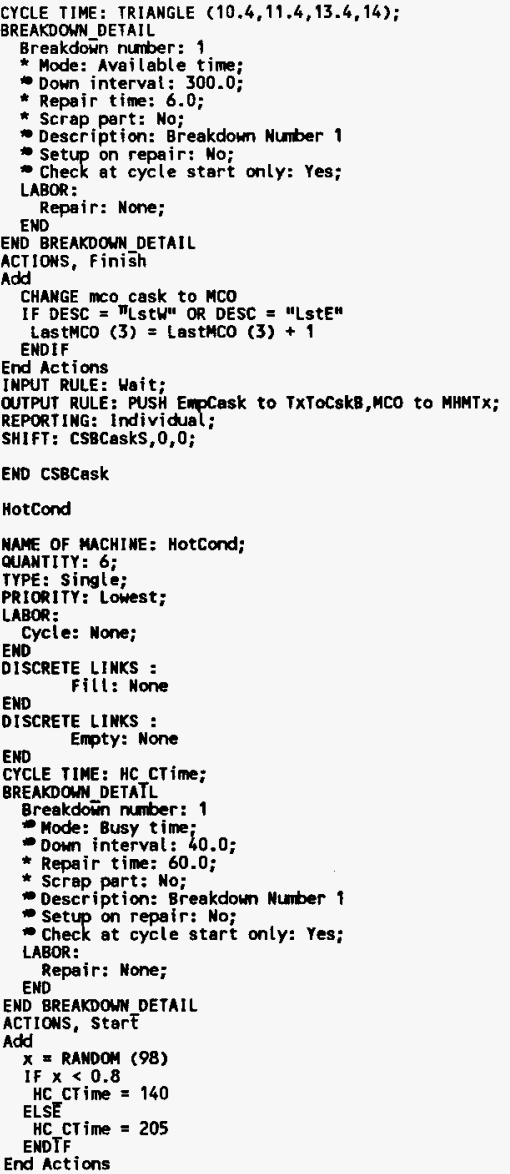 & 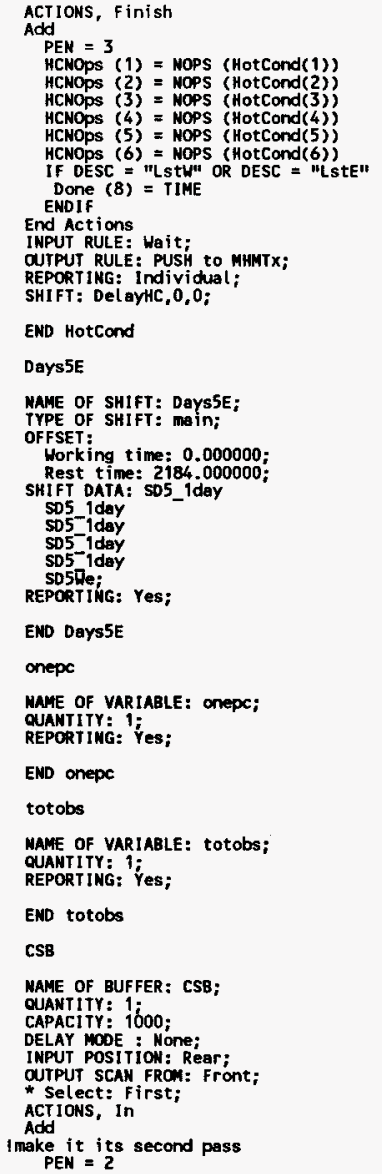 \\
\hline
\end{tabular}




\begin{tabular}{|c|c|}
\hline 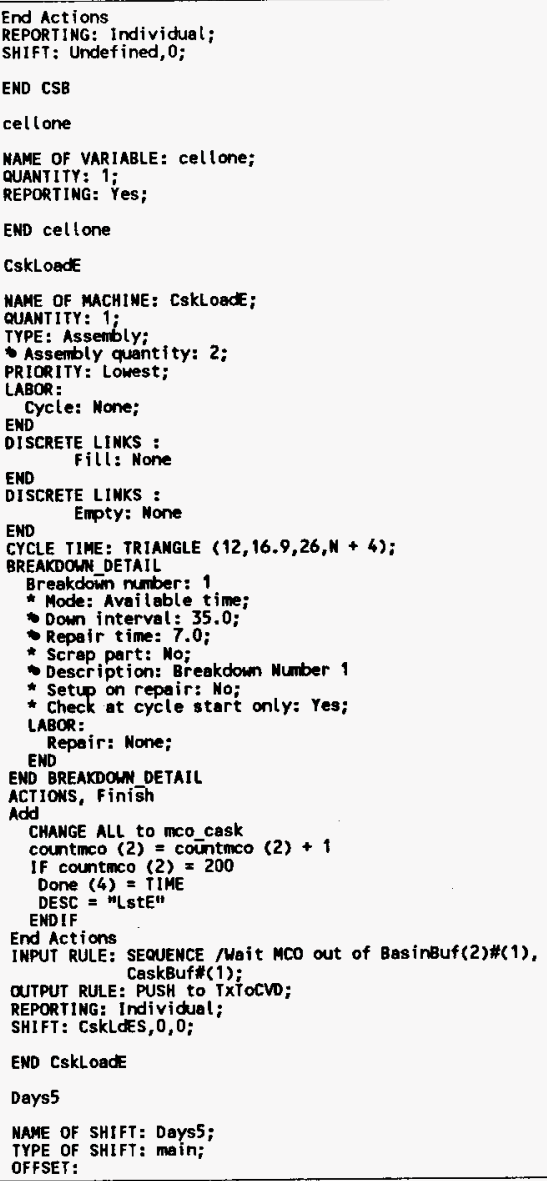 & 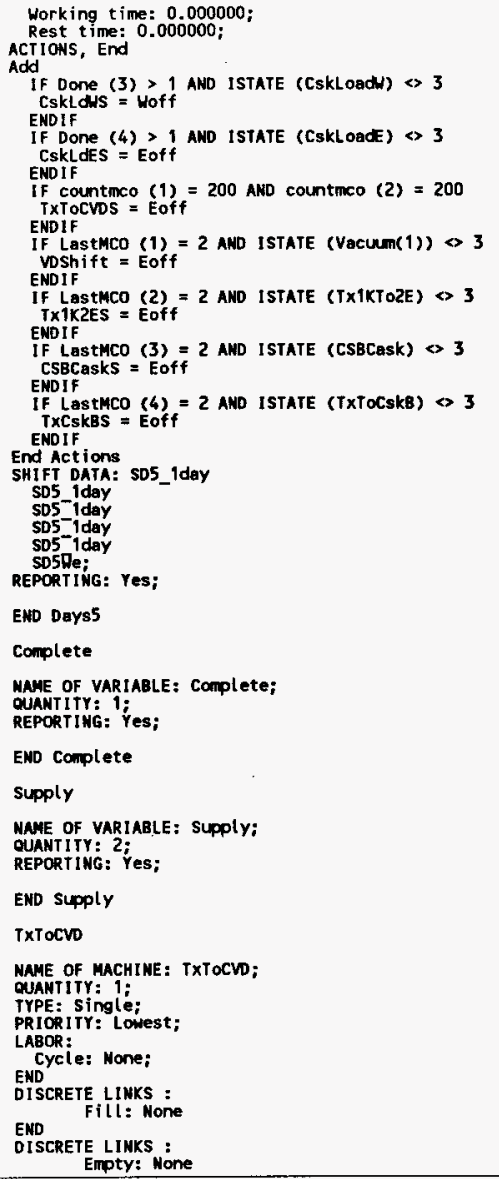 \\
\hline
\end{tabular}




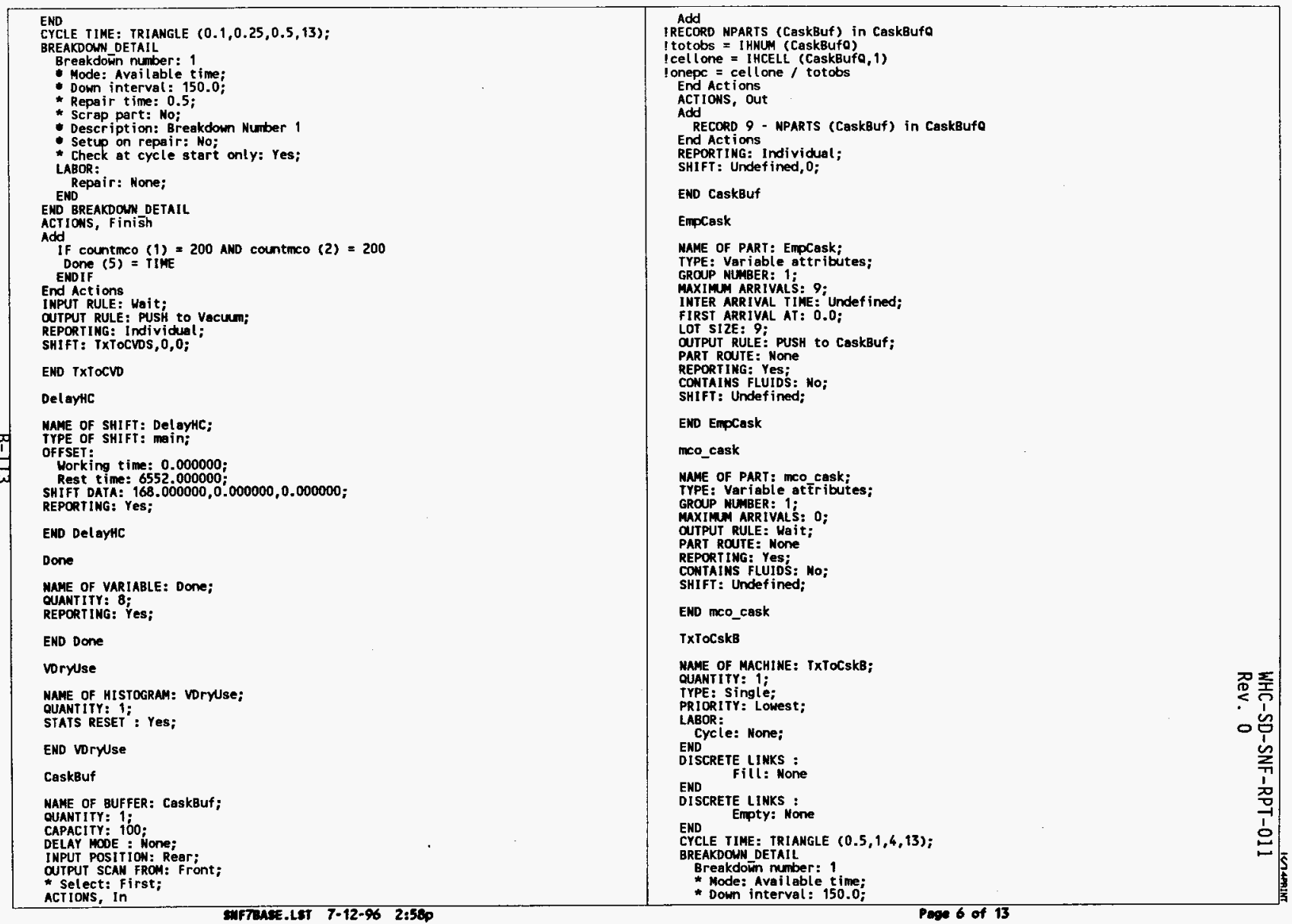




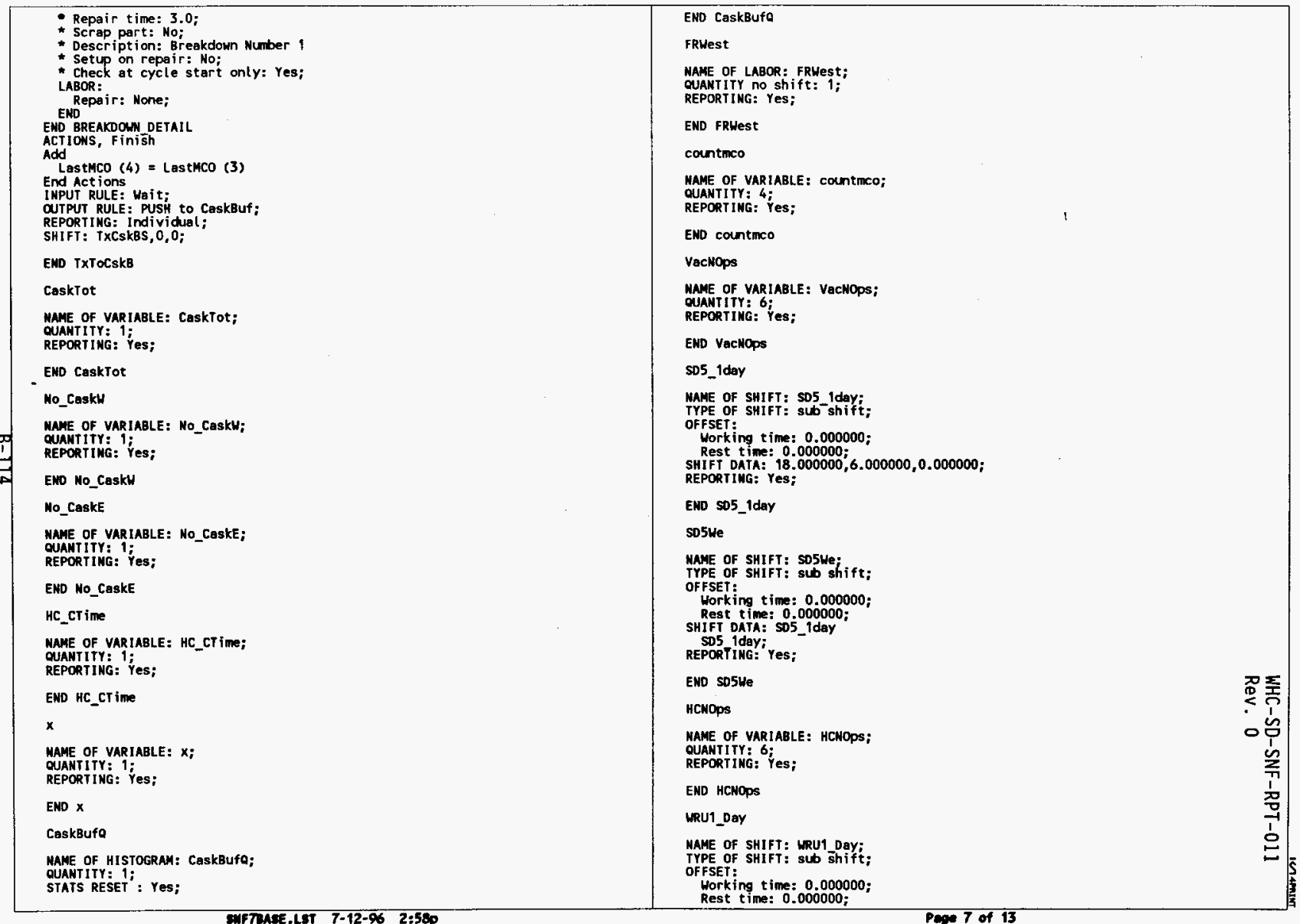




\begin{tabular}{|c|c|c|}
\hline 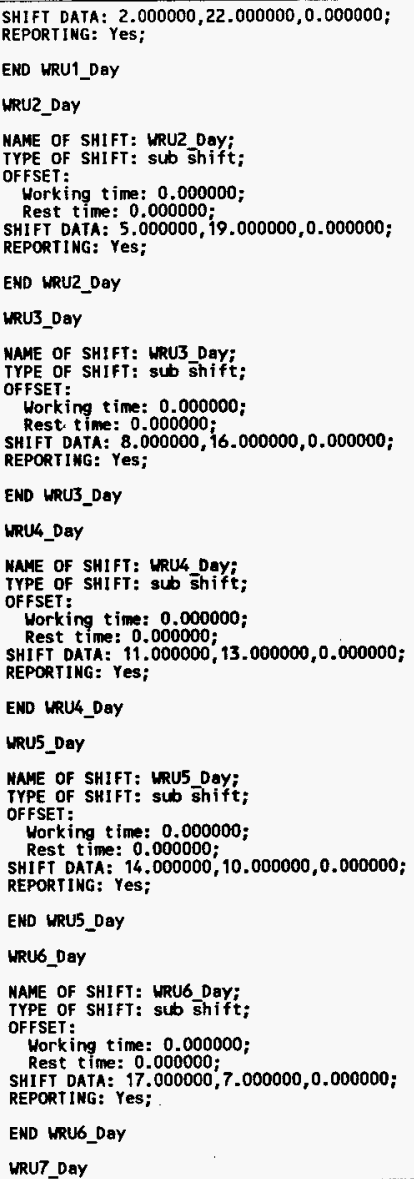 & 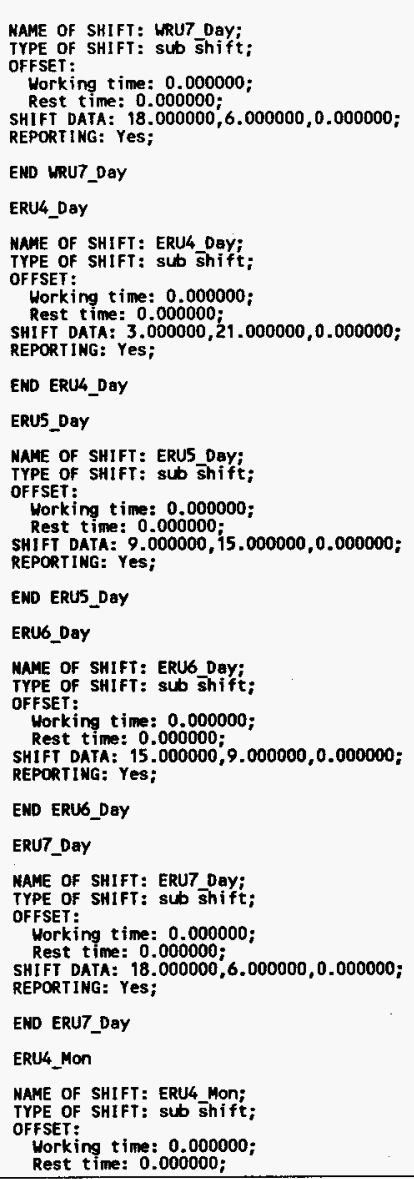 & \\
\hline
\end{tabular}




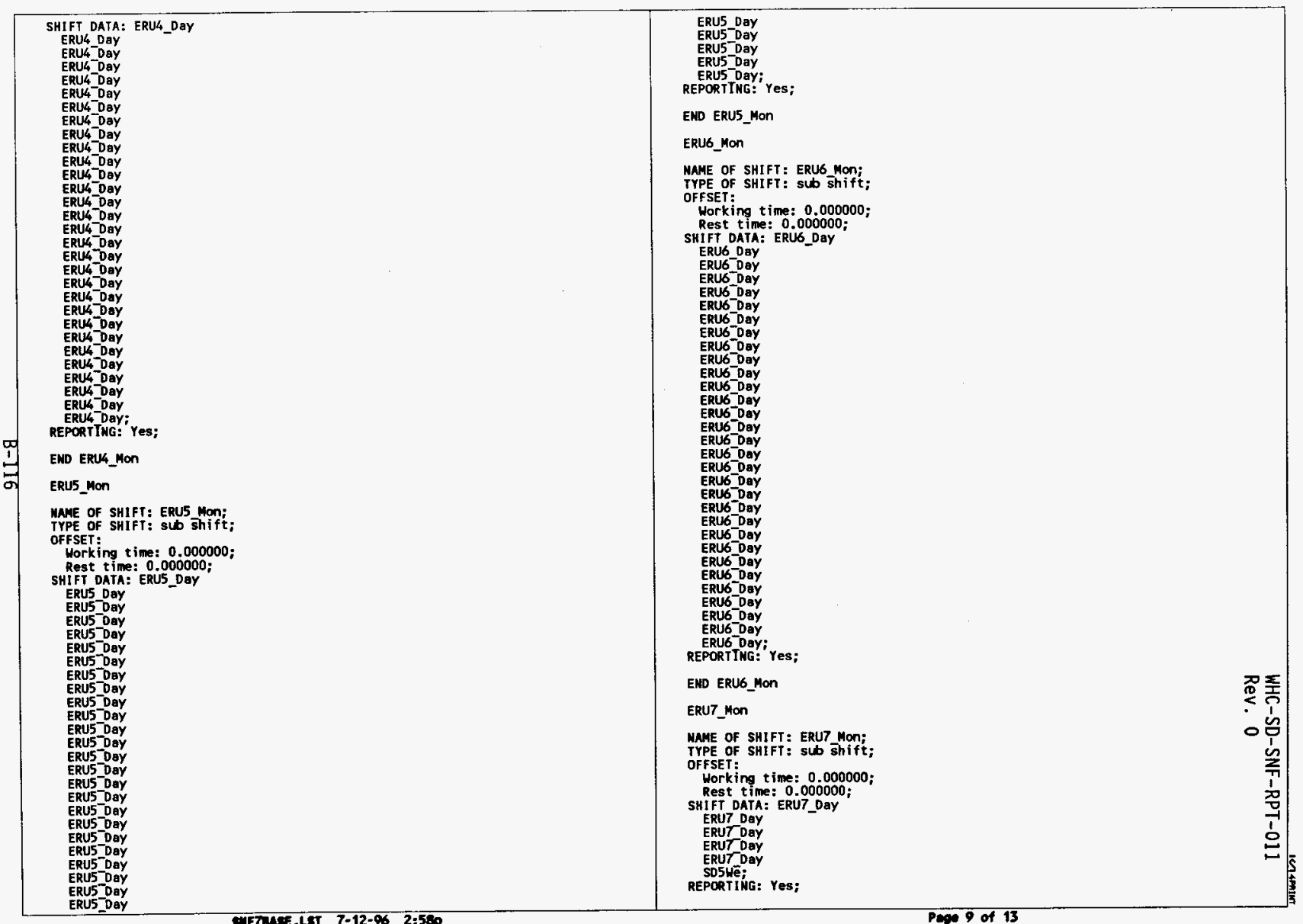




\begin{tabular}{|c|c|}
\hline 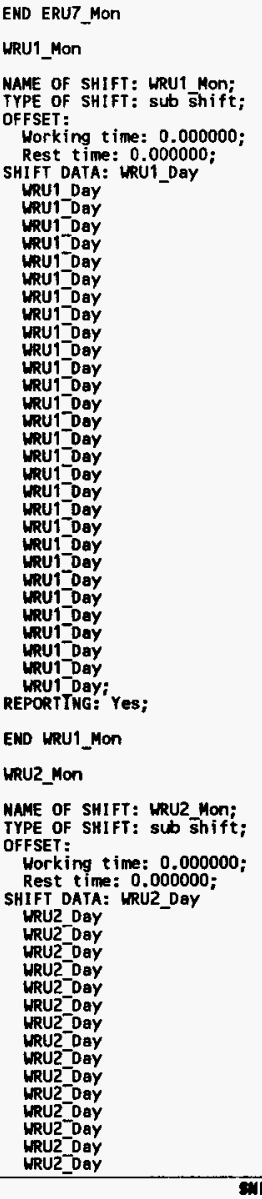 & 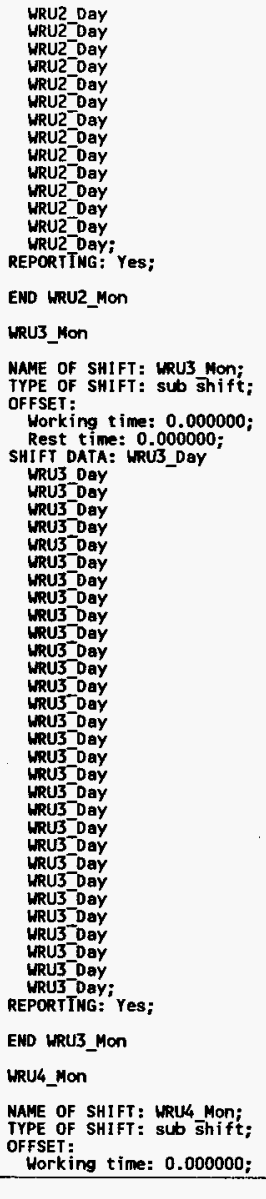 \\
\hline
\end{tabular}




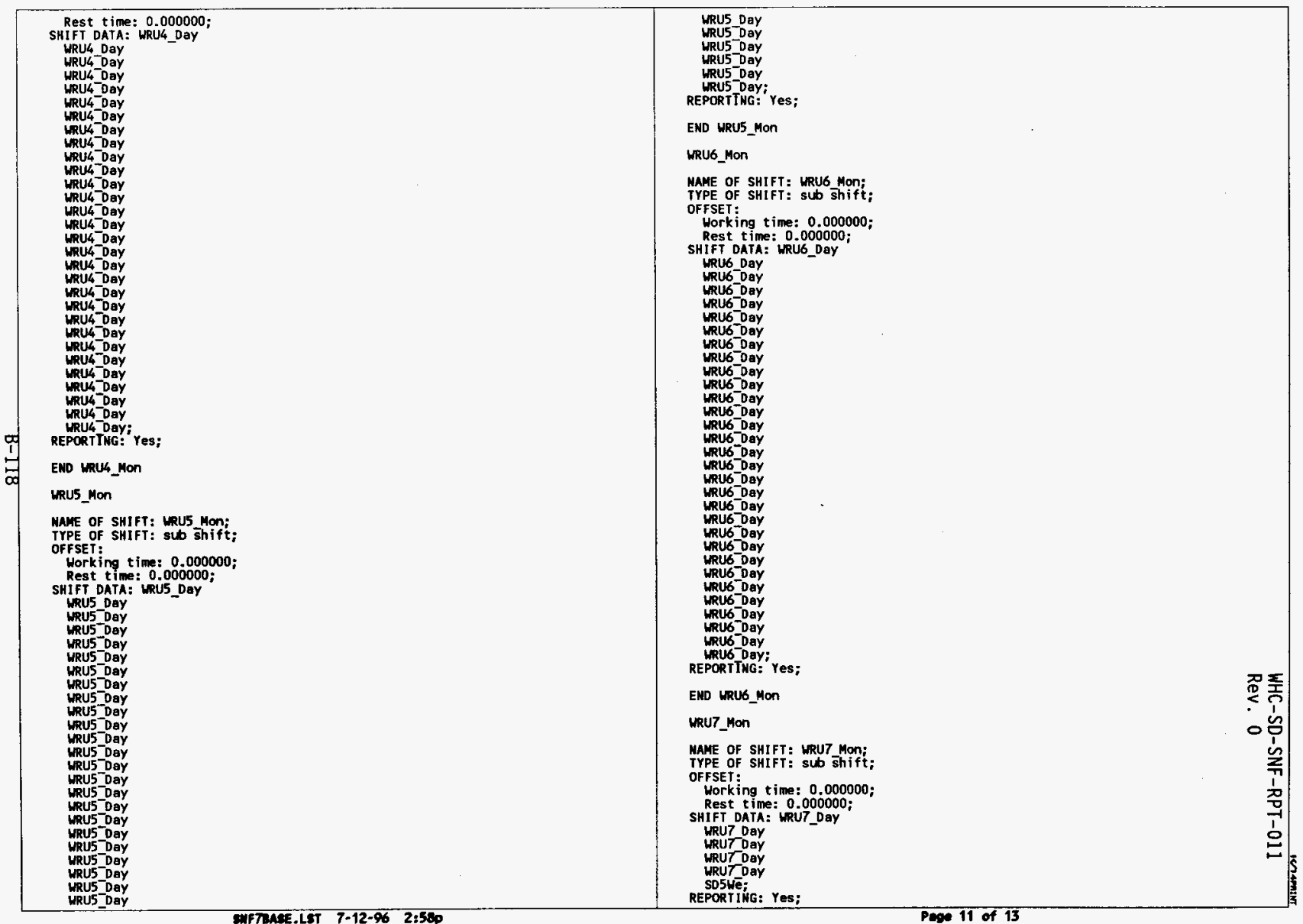




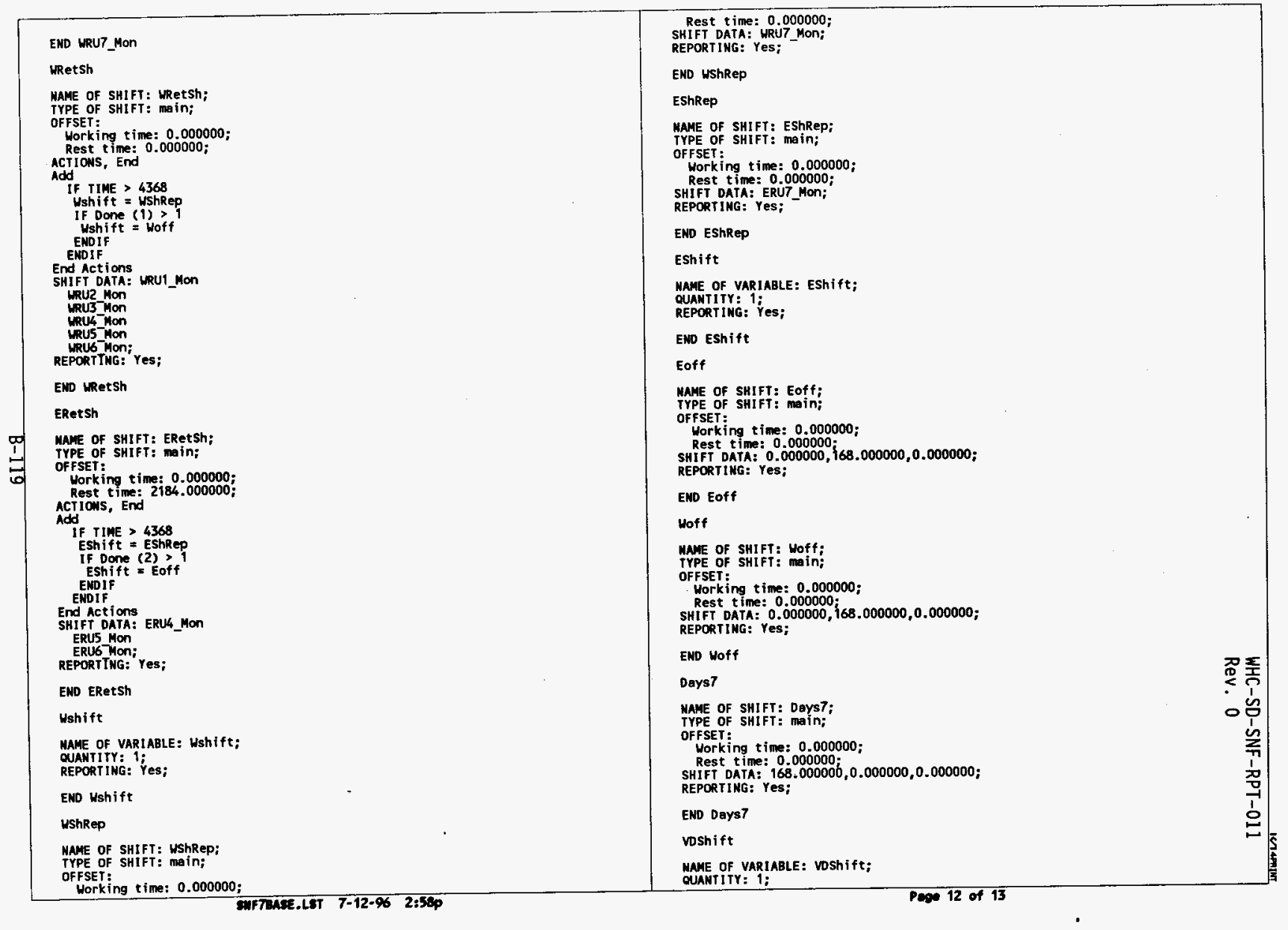


REPORTING: Yes;

END VDShift

Cskldus

MAME OF VARIABLE: CskL dWS;

OUANTI TY: 1 ;

REPCRTING: Yes;

END CskLdus

CskLdes

MAME OF VARIABLE: CsKLdES;

QUANTITY: 1;

END CskLdES

Txtocvos

MAME OF VARIABLE: TXTOCVDS;

QUANTITY: 1;

REPORTIMG: Y'es;

END TXTOCVDS

TX1K2ES

NAHE OF VARIABLE: TX1K2ES;

CUANTITY: $1 ;$

END TX1K2ES

CSBCasks

NAME OF YARIABLE: CSBCaskS;

QUANTITY: 1;

REPORTING: Ýes:

END CSBCasks

TXCskBs

NAME OF VARIABLE: TXCskBS;

QUANTITY: 1 ;

REPORTING: Yes;

END TXCskBS

LastMCo

MAME OF VARIABLE; LastMCO;

QUANT IIY: 4;

REPORTING: Yes;

END LestMCO

END SELECT

ENO DETAIL

IMITIALISE

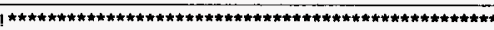

Time Units are in HOURS

I

IKE Basic

Supply (1) $=200$

Bas in

Supply $(2)=200$

Hshift = WRetSh

EShift = ERetSh

Csk $=$ Days5

TXToCys = Days 5

TXTocvs = Days5

TX1K2ES =

csBCasks $=$ Days5

CsBCasks $=$ Days5
TXCskBS $=$ Days 5

End Actions

END INITIALISE 
WHC-SD-SNF-RPT-01I

Rev. 0

CASE 7. TWO 12 HR SHIFTS/DAY, 7 DAYS/WEEK. 
SNF Project operating 2 twelve hr shifts, 7 days/week.

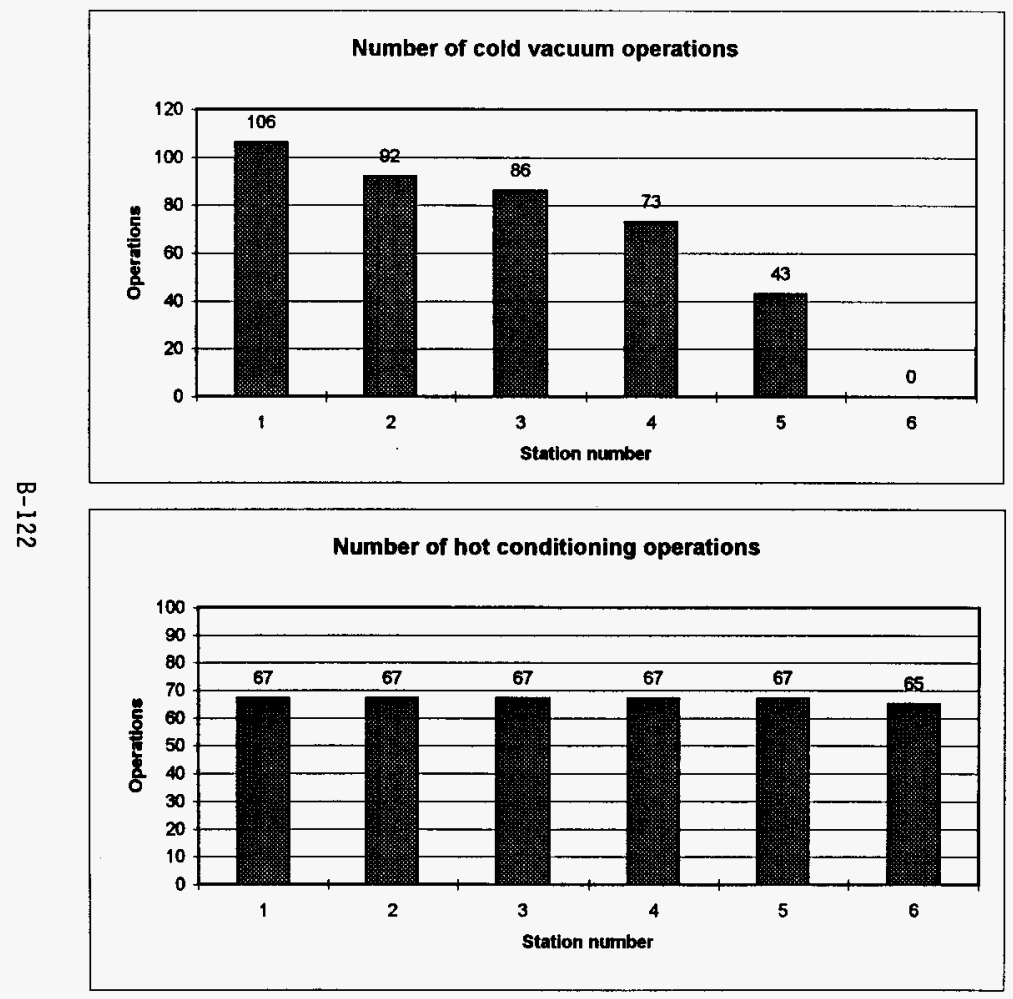


SNF Project operating 2 twelve hr shifts, 7 days/week.

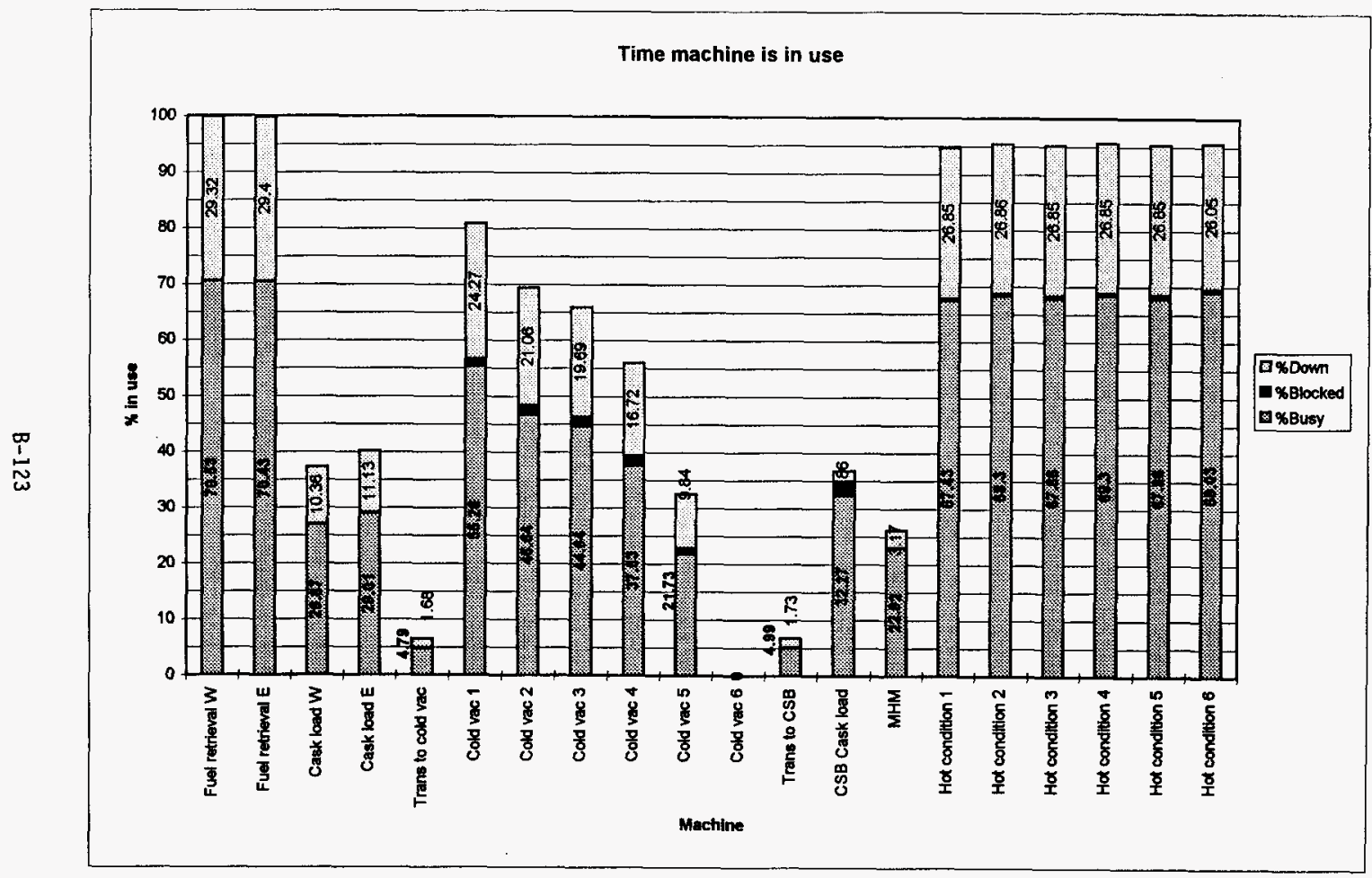

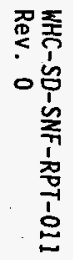



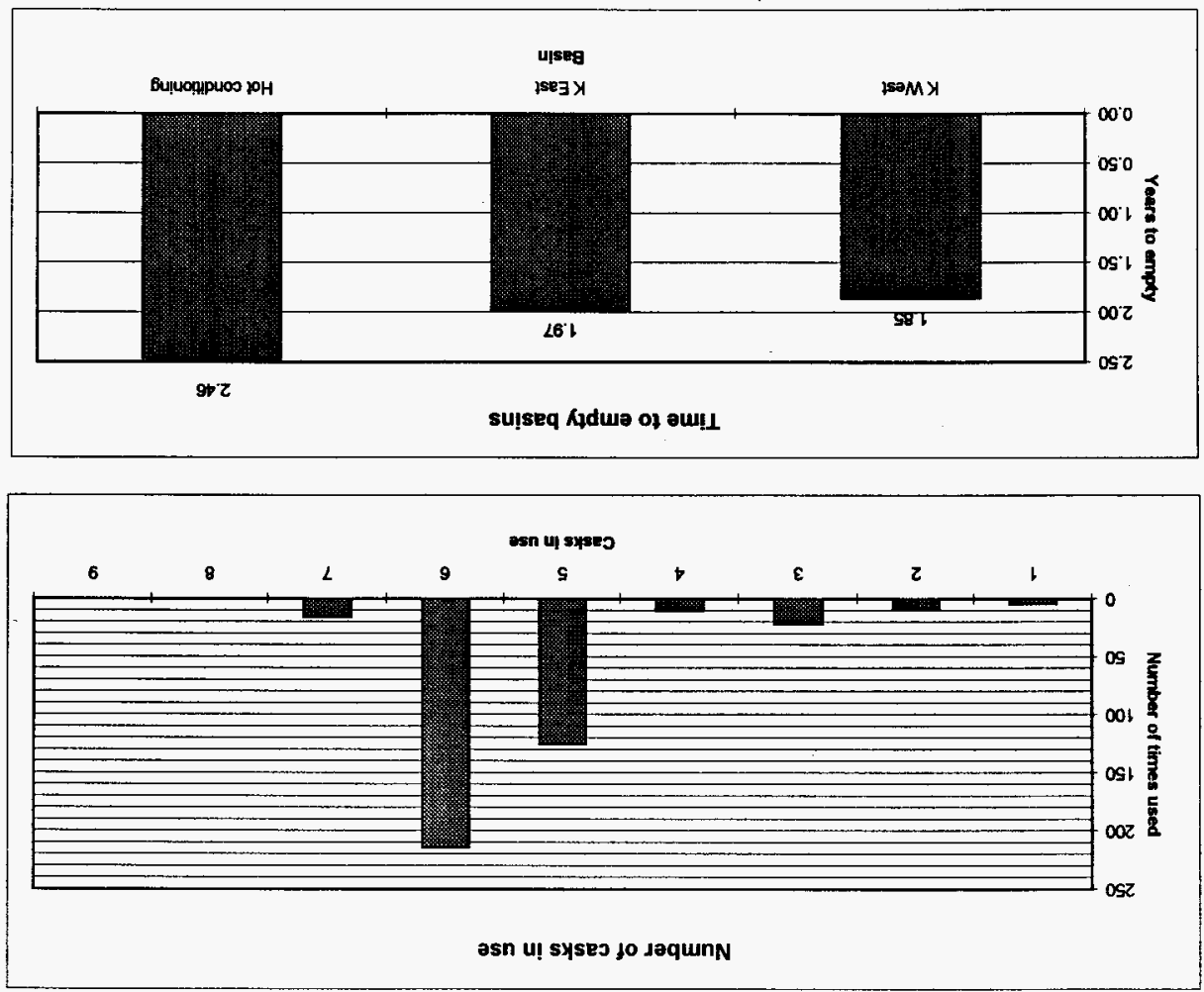


\begin{tabular}{|c|c|}
\hline 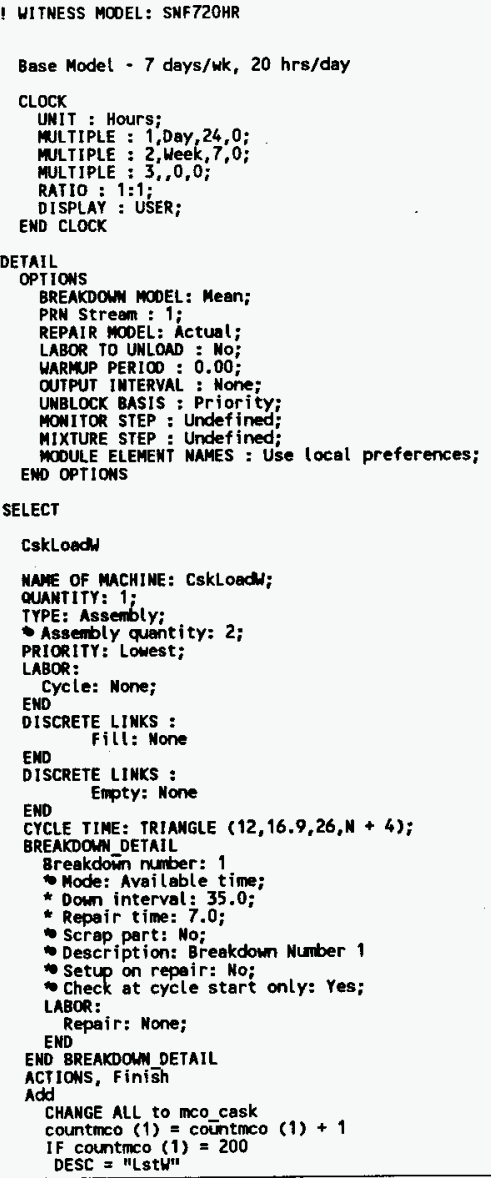 & 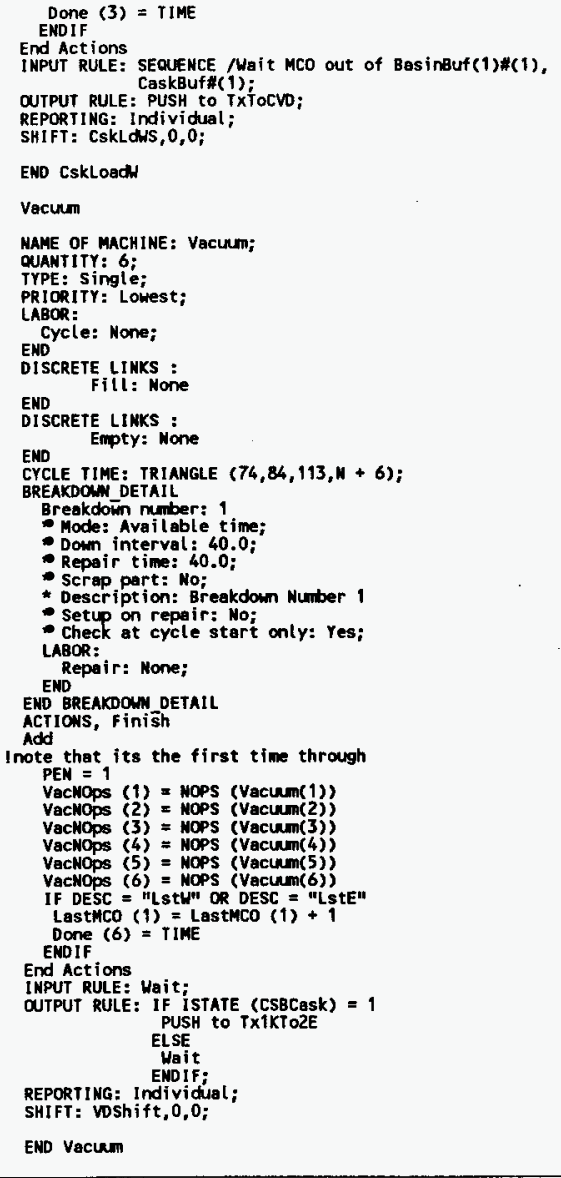 \\
\hline
\end{tabular}




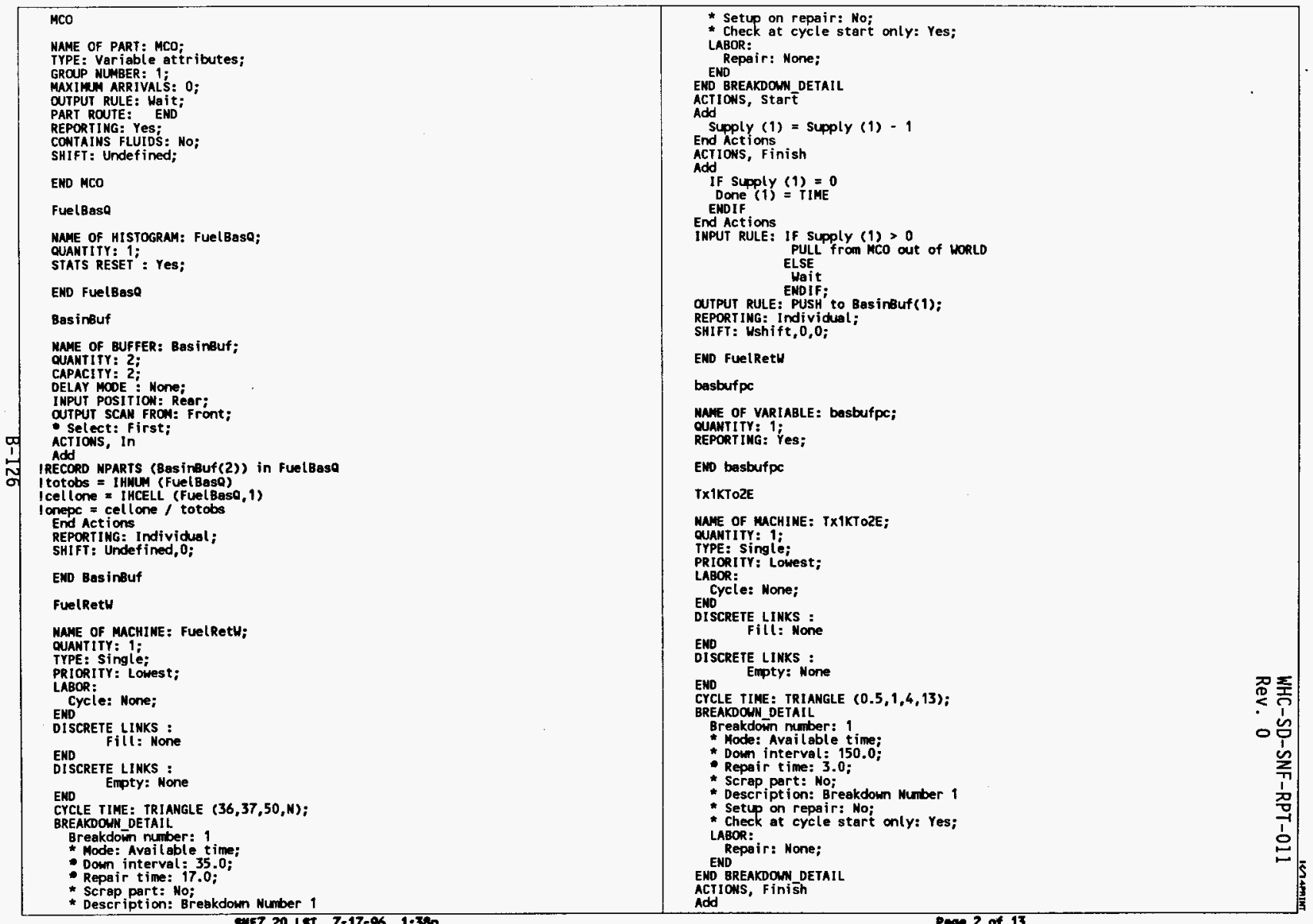




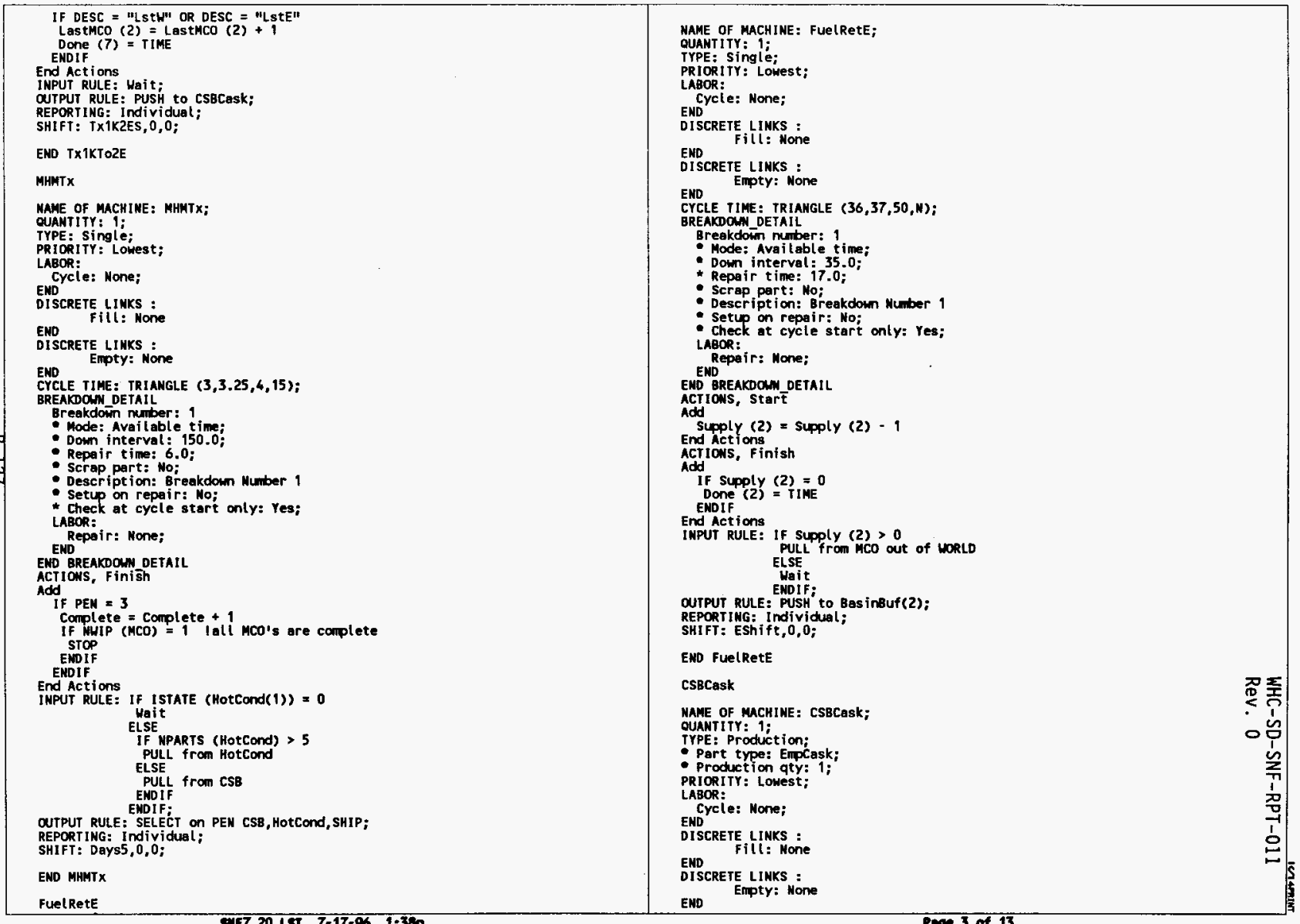




\begin{tabular}{|c|c|c|}
\hline 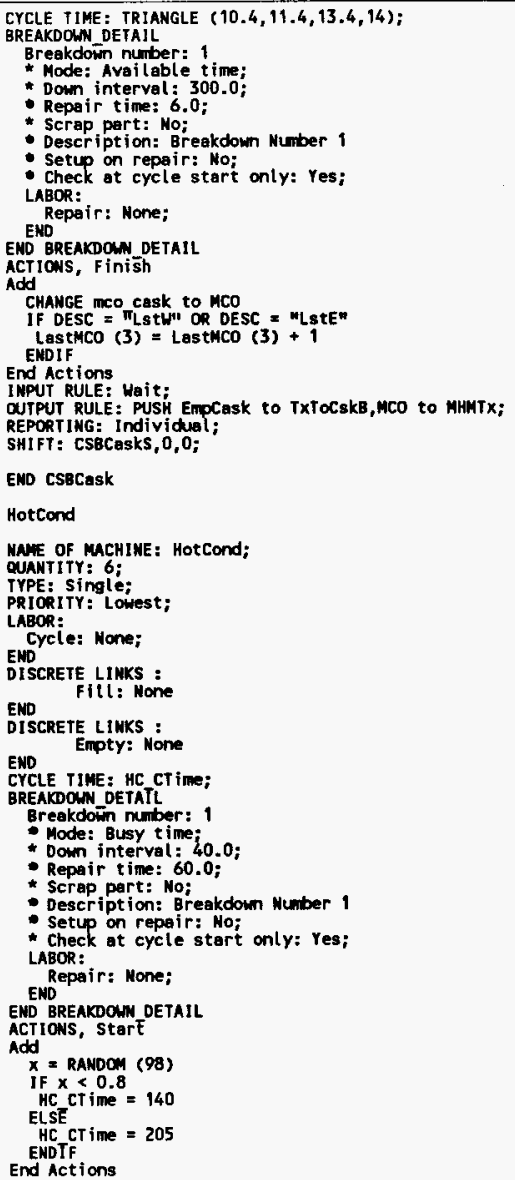 & 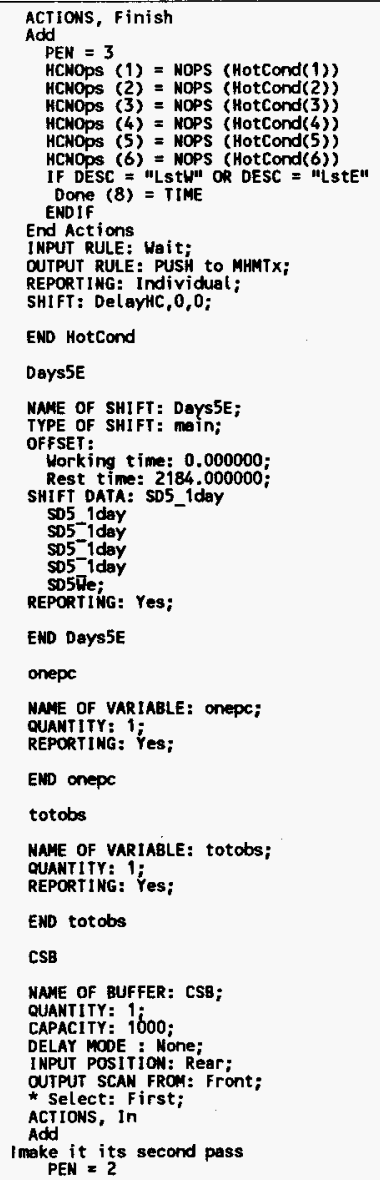 & 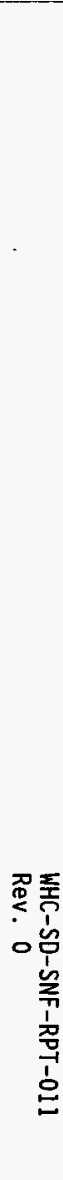 \\
\hline
\end{tabular}




\begin{tabular}{|c|c|c|}
\hline 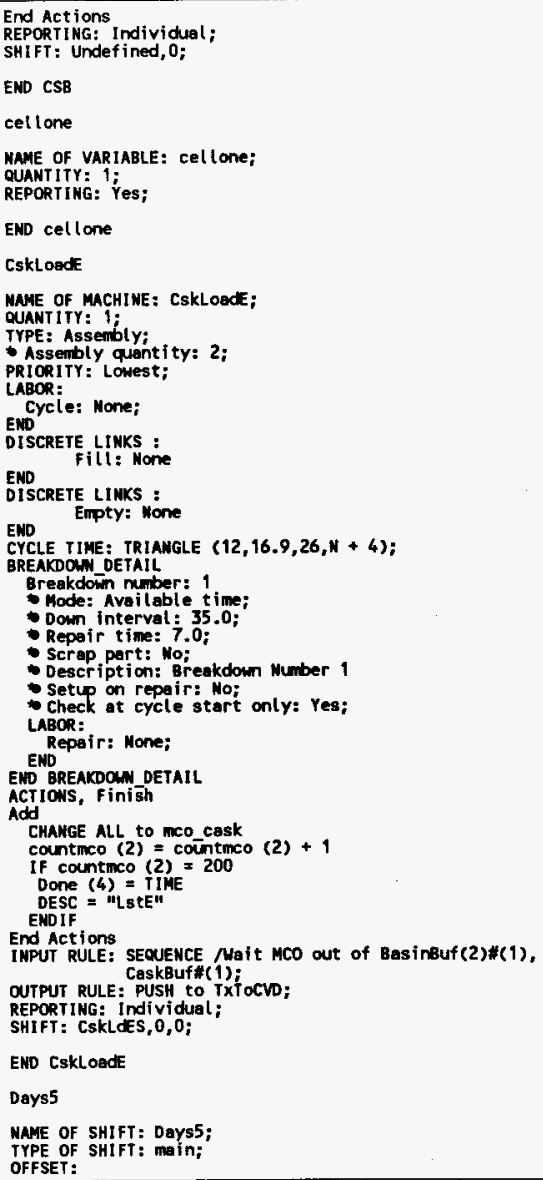 & 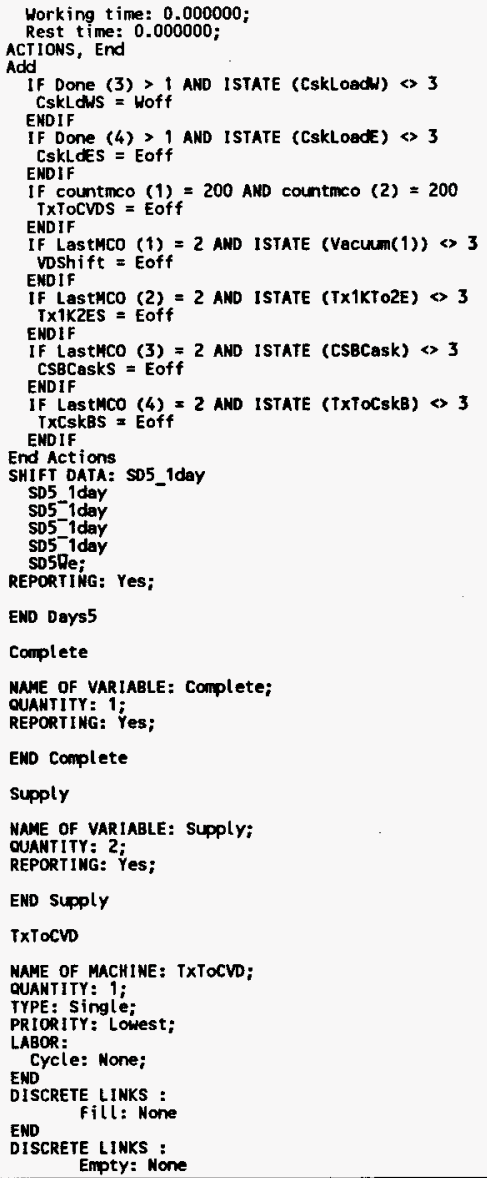 & 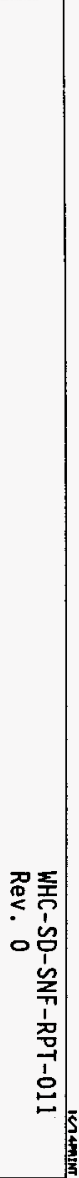 \\
\hline
\end{tabular}




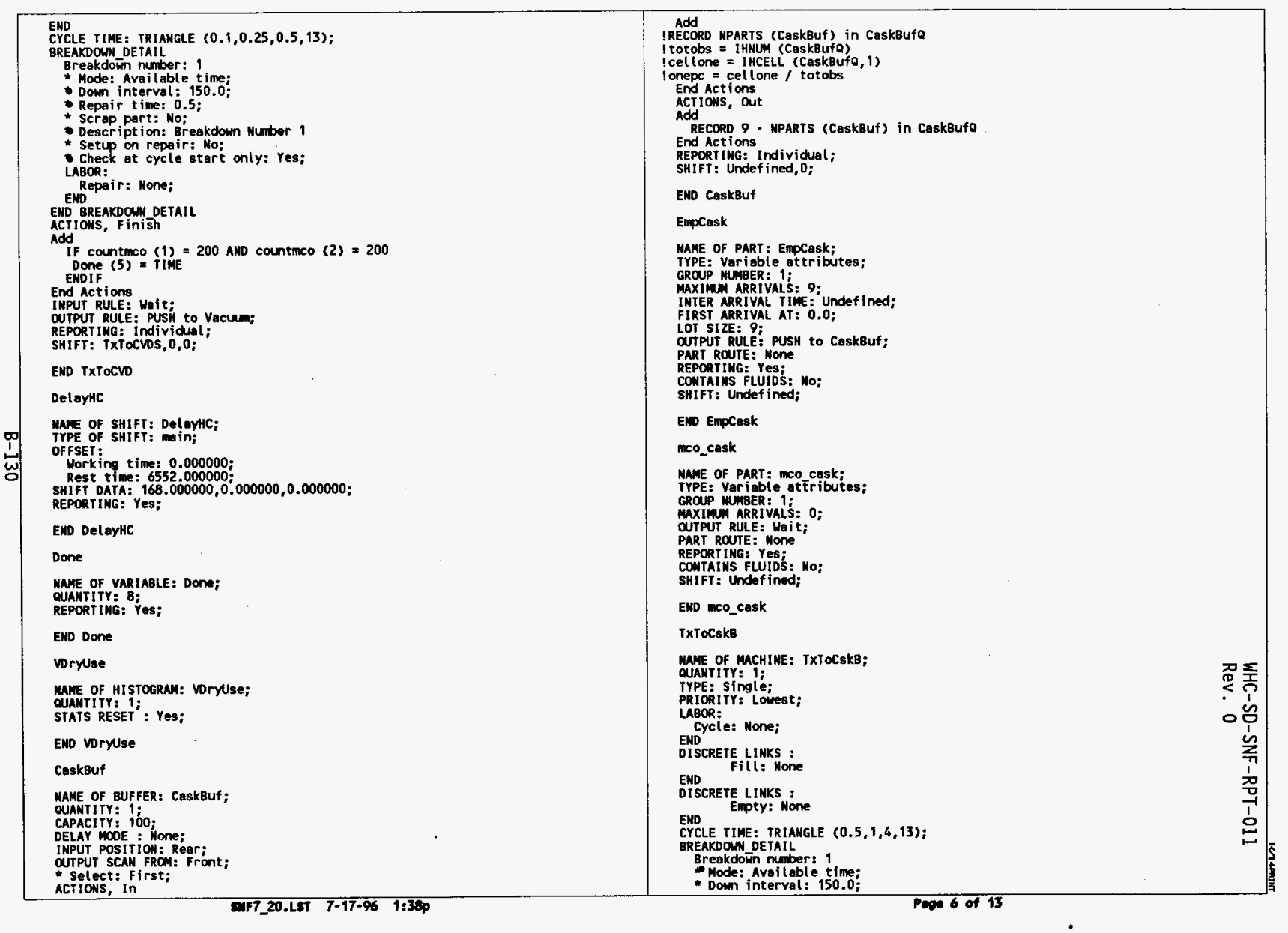




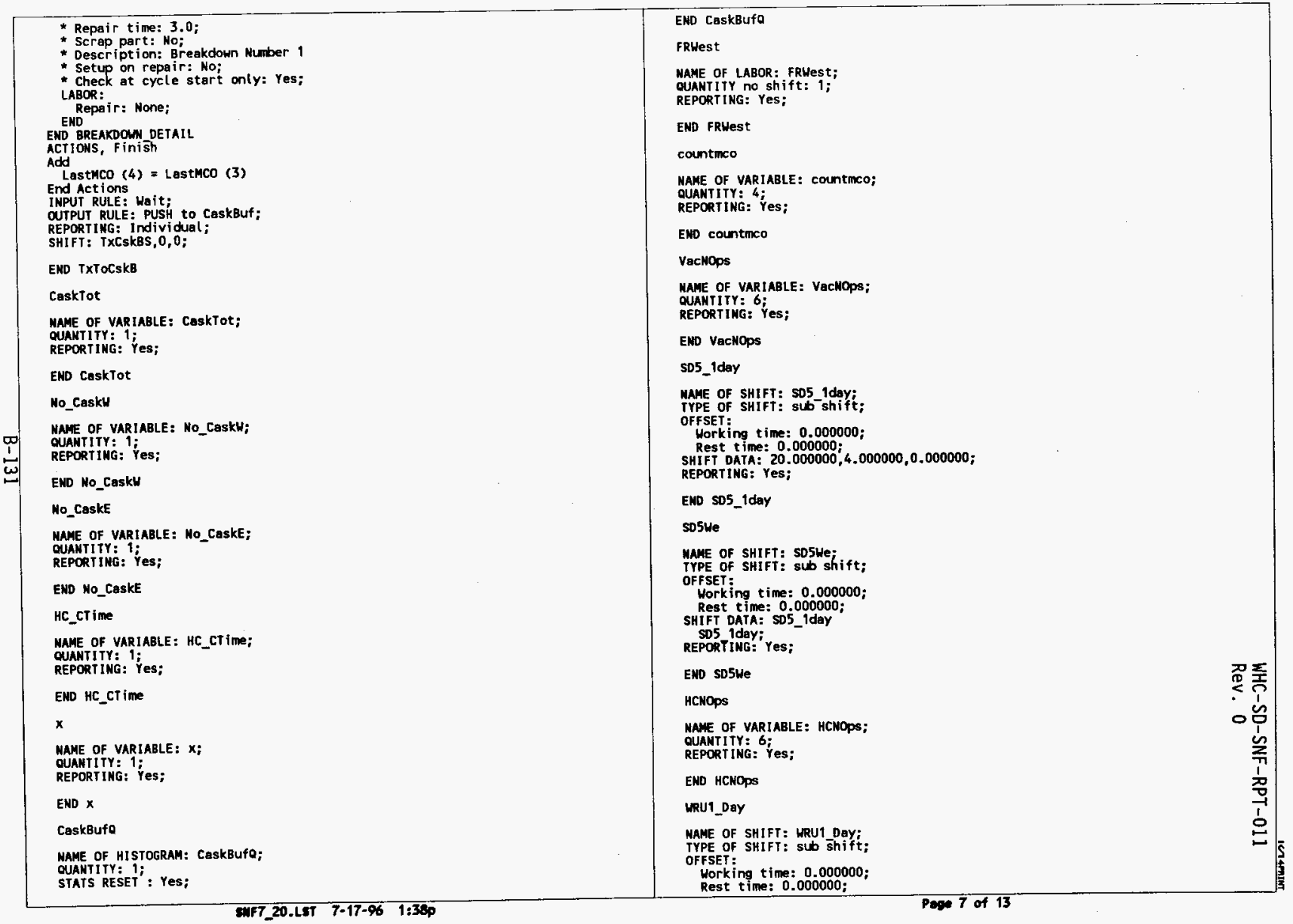


SHIFT DATA: $2.000000,22 . \overline{000000,0.000000 ;}$
REPORT ING: YES;

END WRU1_DaY

WRU2_DaY

NAME OF SHIFT: URU2 DaY;

TYPE OF SHIFT: sub shift;

Uorking time: 0.000000;

SHIFT DATA: $5.000000,19.000000,0.000000$;

REPORTING: YES;

END URUZ_DaY

\section{MRU3_oay}

MAME OF SHIFT: WRU3 DaY;

TYPE OF SHIFT: sub shift;

OFFSET:

Working time: 0.000000

RHIFT DATA: $8.000000,16.000000,0.000000$;

REPORTING: Yes;

END MRU3_DaY

WRUL_Day

NAME OF SHIFT: WRU4 Doy;

TYPE OF SHIFT: sub shift.

OFFSET:

Working time: 0.000000;

Rest DATA: $11.000000,13.000000,0.000000$ REPORTING: Yes;

ENO URU4_DaY

WRU5_DQY

NAME OF SHIFT: URUS_DaY;

TYPE OF SHIFT: sub shift

Working tine: 0.000000 ;

SHIFT DATA: $14.000000,10.000000,0.000000$;

REPORTING: YeS:

END URUS_DaY

\section{URU6_Day}

NAME OF SHIFT: HRUG Day:

TYPE OF SHIFT: sLb shift;

OFFSET:

Working time: 0.000000 ,

Rest time: 0.000000 ;

SHIFI DATA: $17.000000,7.000000,0.000000$;

REPORTING: Yes;

END URU6_DaY

URU7 DaY
NAME OF SHIFT: WRUT Day;
IYPE OF SHIFT: sub shift

OFFSET:

Horking time: 0.000000

Rest time: 0.000000 :

SHIFT DATA: $20.000000,4.000000,0.000000$;

REPORTING: YeS;

END WRU7_DaY

ERU4_DaY

MAME OF SHIFT: ERU4_Day;

TYPE of SHIFT: sub shift;

OFFSET:

Norking time: 0,000000;

SHIFT DATA: $3.000000,21,000000,0.000000$;

REPORTIMG: Yes:

END ERU4_DaY

ERU5_Day

NAME OF SHIFT: ERU5 DaY;

OFFSET:

Working time: 0.000000 ;

SHIFT DATA: $9.000000,15.000000,0.000000$; REPORTING: Yes:

END ERU5_DAY

ERU6_DaY

MAME OF SHIFT: ERU6 DaY;

OFFSET:

Working time: 0.000000

Rest time: 0.000000

SHIFT DATA: $15.000000,9.000000,0.000000$;

REPORTING: Yes;

EMD ERU6_DaY

ERU?_DaY

MAME OF SHIFT: ERUT_Day:

TYPE OF SHIFT: sub shift:

OFFSET:

Horking time: 0.000000 ;

Rest time: 0.000000;

SHIFT DATA: $20.000000,4.000000,0.000000 ;$

REPORTING: Yes

END ERU7_DaY

ERU4_Mon

NAME OF SHIFT: ERU4 MON;

TYPE OF SHIFT: sub shift; OFFSET:

Working time: 0.000000 


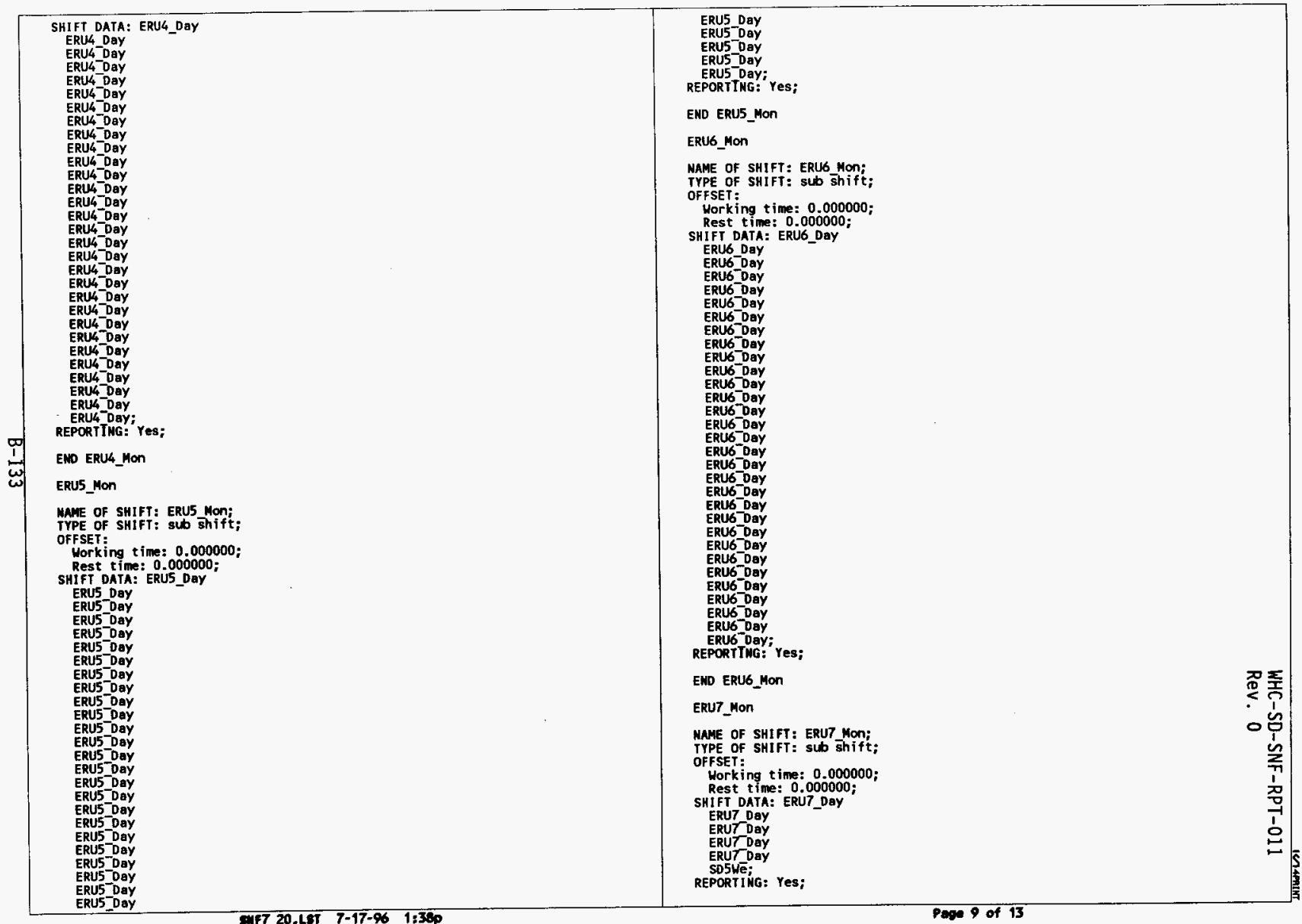




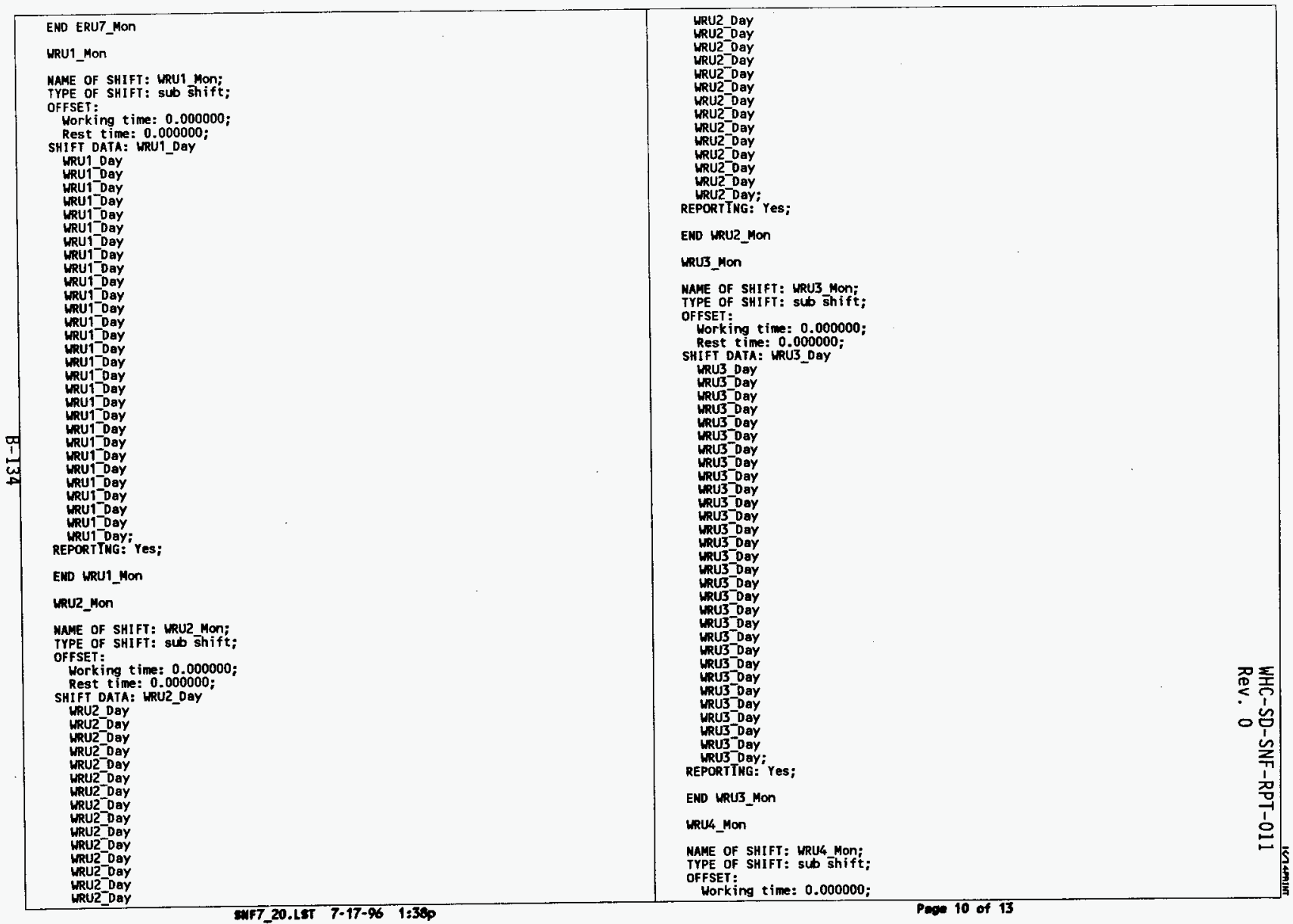




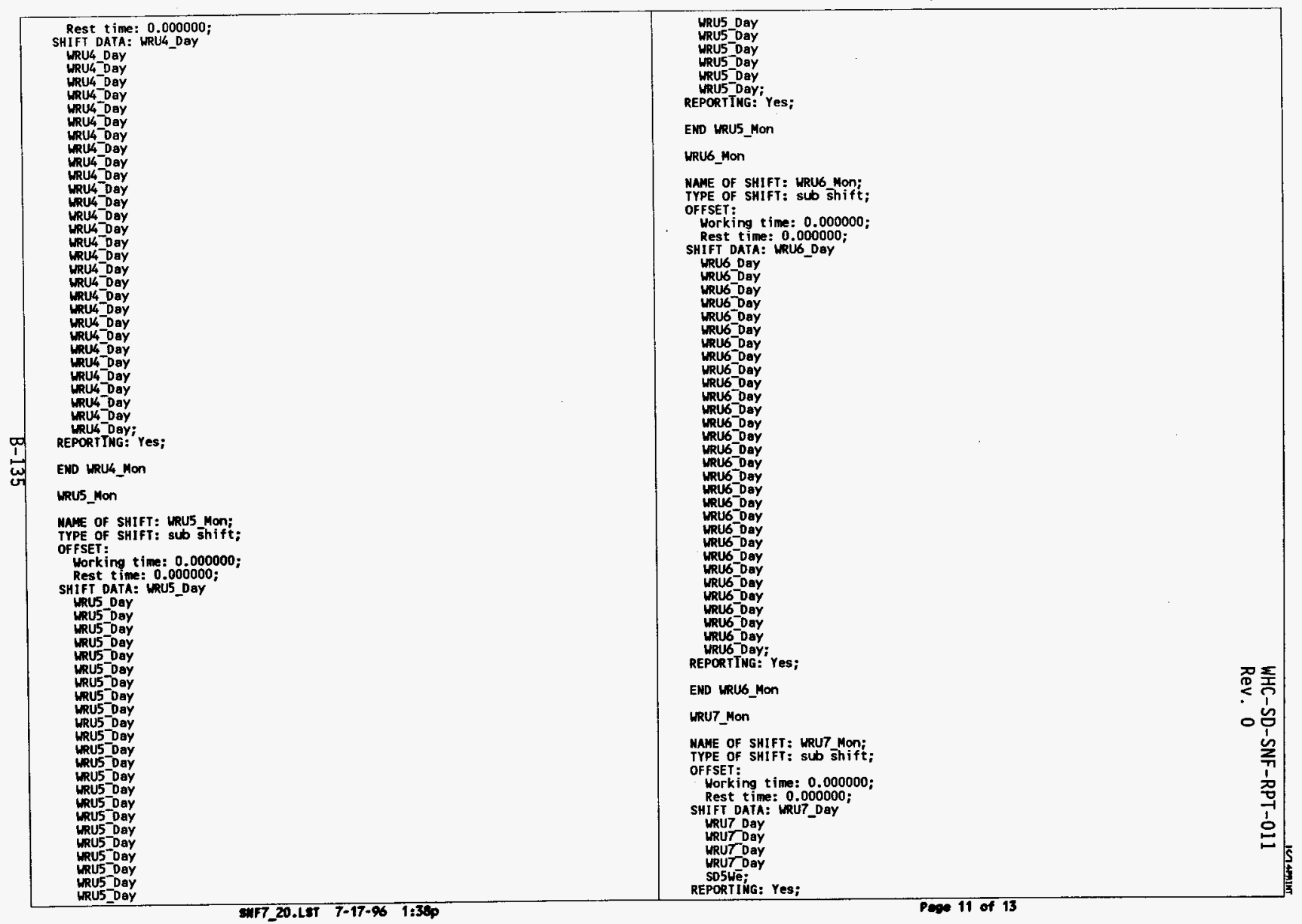




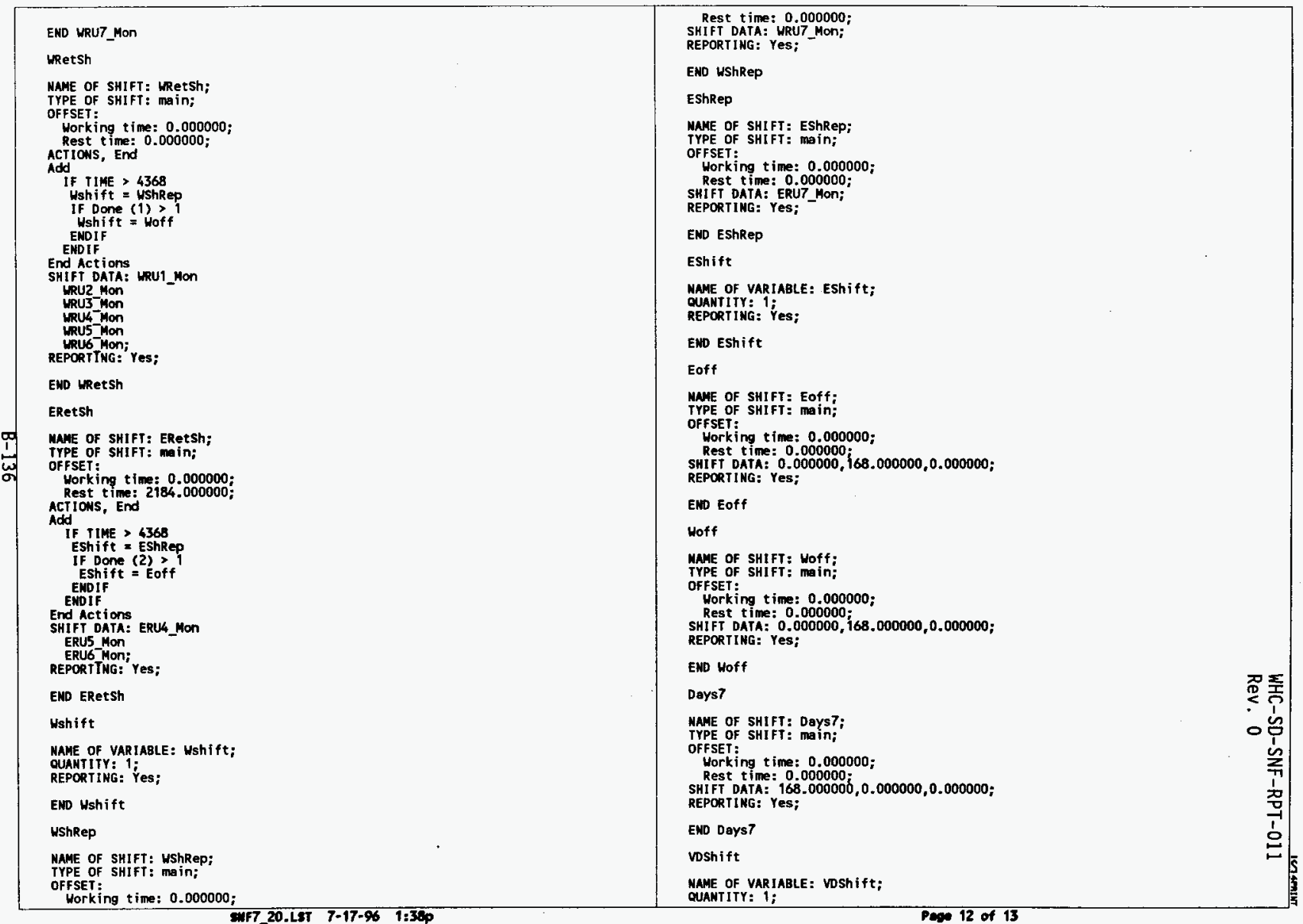




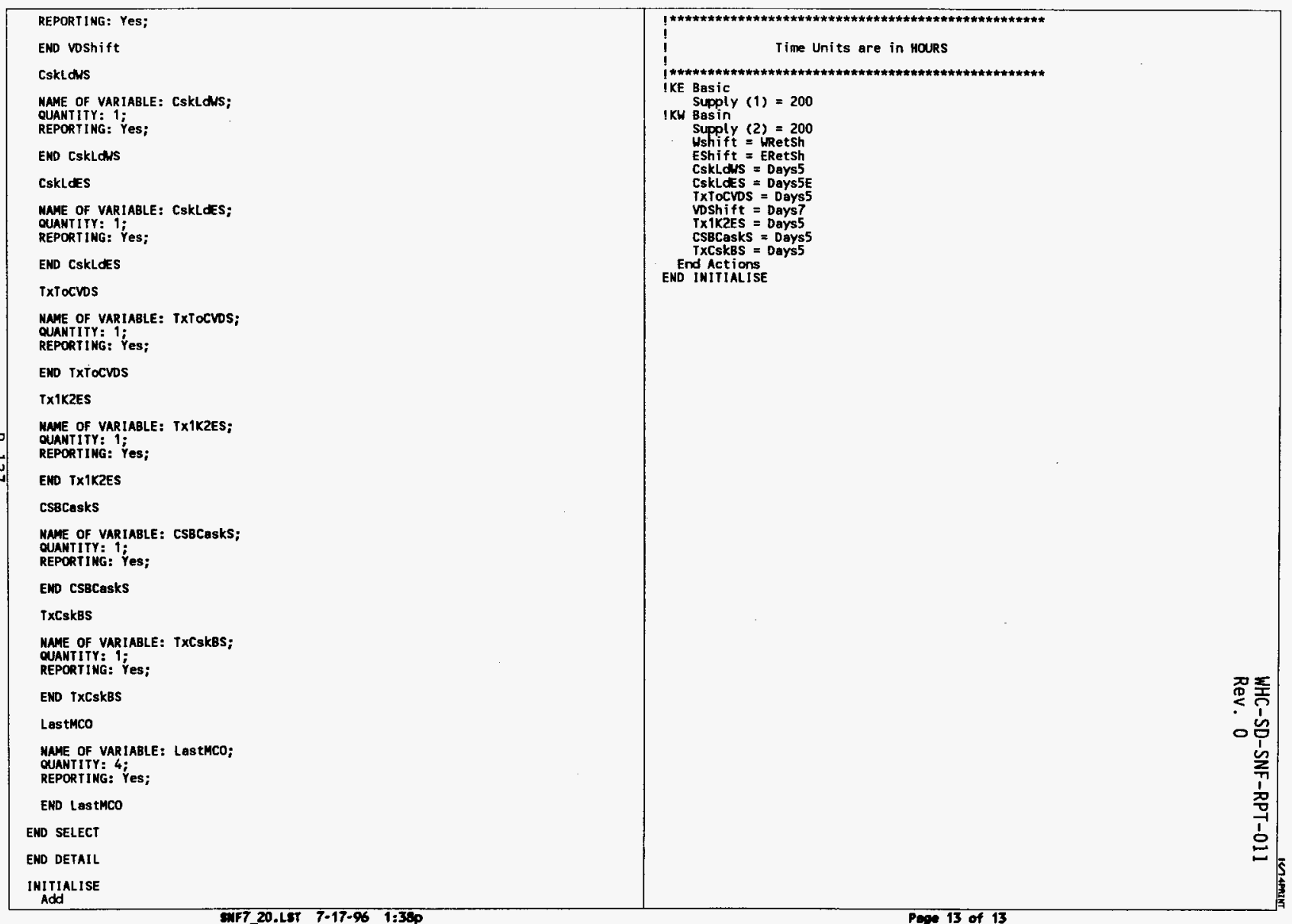


WHC-SD-SNF-RPT-011

Rev. 0

CASE 8. THREE 8 HR SHIFTS/DAY, 7 DAYS/WEEK.

USING 5 COLD VACUUM DRYING STATIONS 
SNF Project operating 3 shifts, 7 days/week. Cold vacuum drying has 5 stations

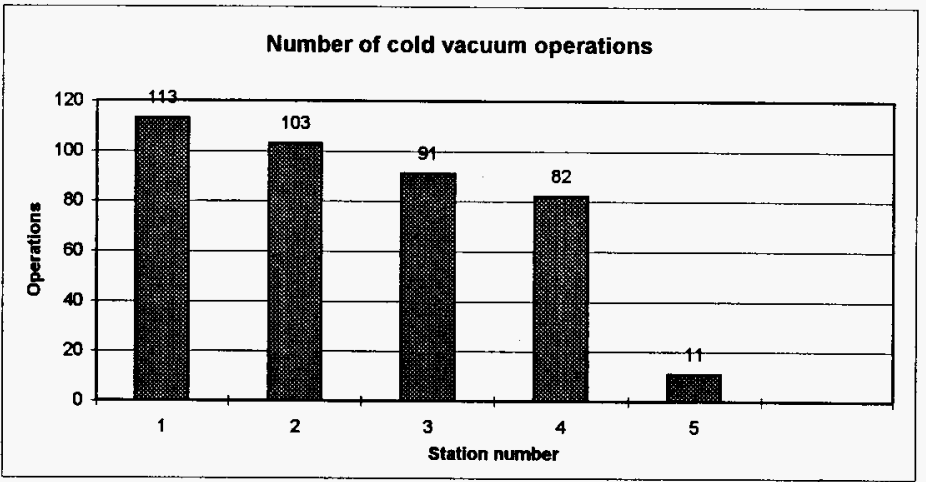

$\underset{\substack{1 \\ \omega}}{\stackrel{1}{\omega}}$

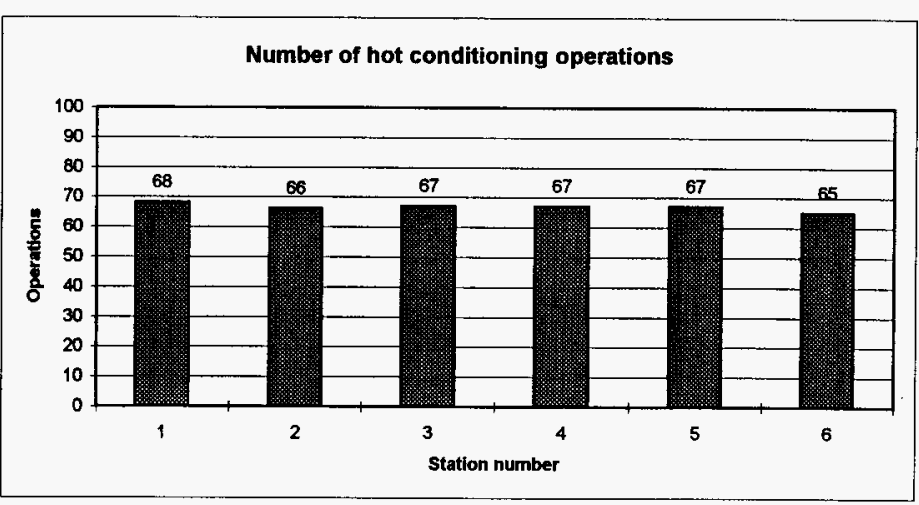


WHC-SD-SNF-RPT-011

Rev. 0

$\stackrel{\$}{\mathbb{2}}$

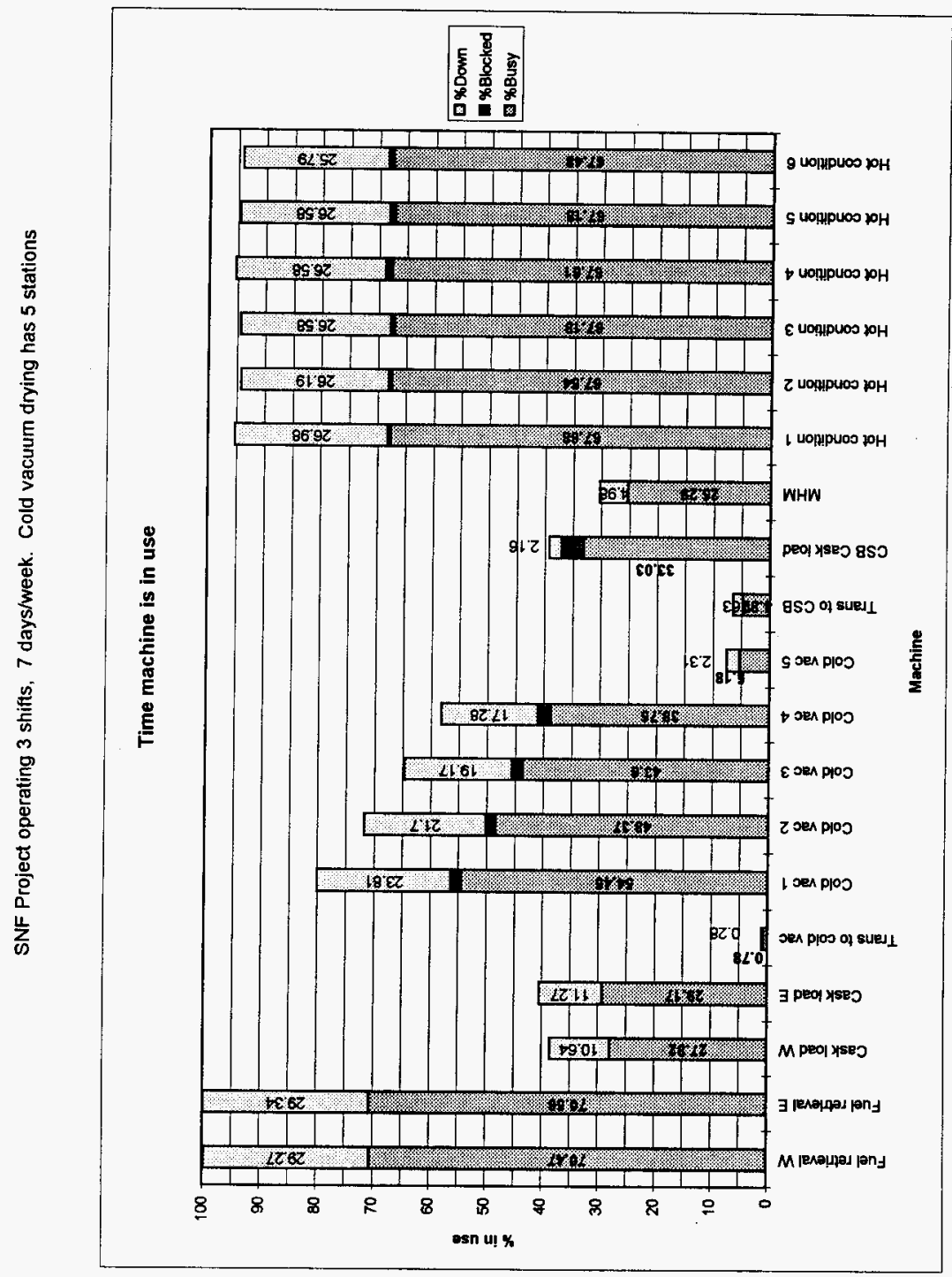

옹 
WHC-SD-SNF-RPT-011

Rev. 0
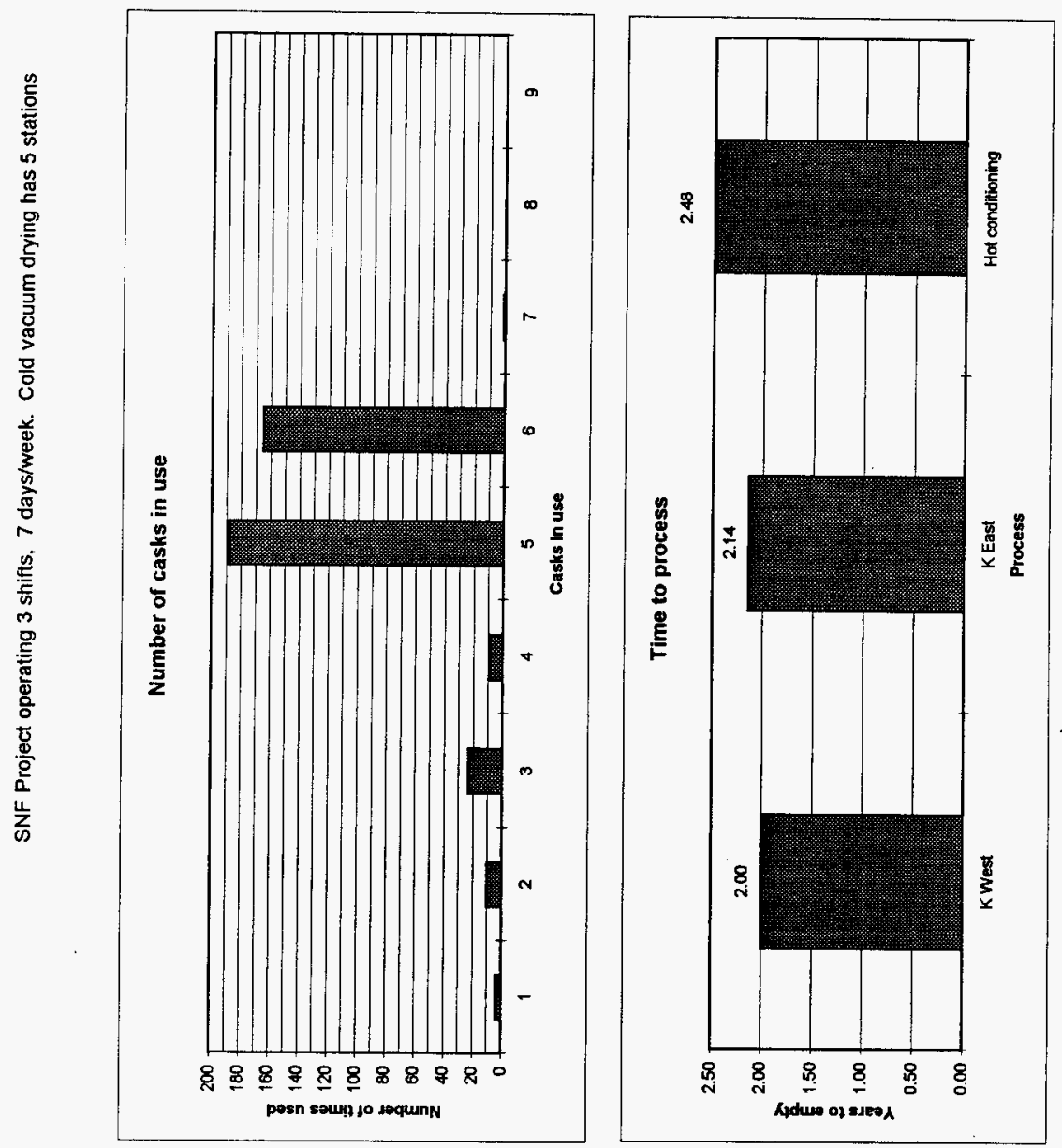

$m$
$\stackrel{5}{8}$
0

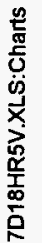




\begin{tabular}{|c|c|c|}
\hline 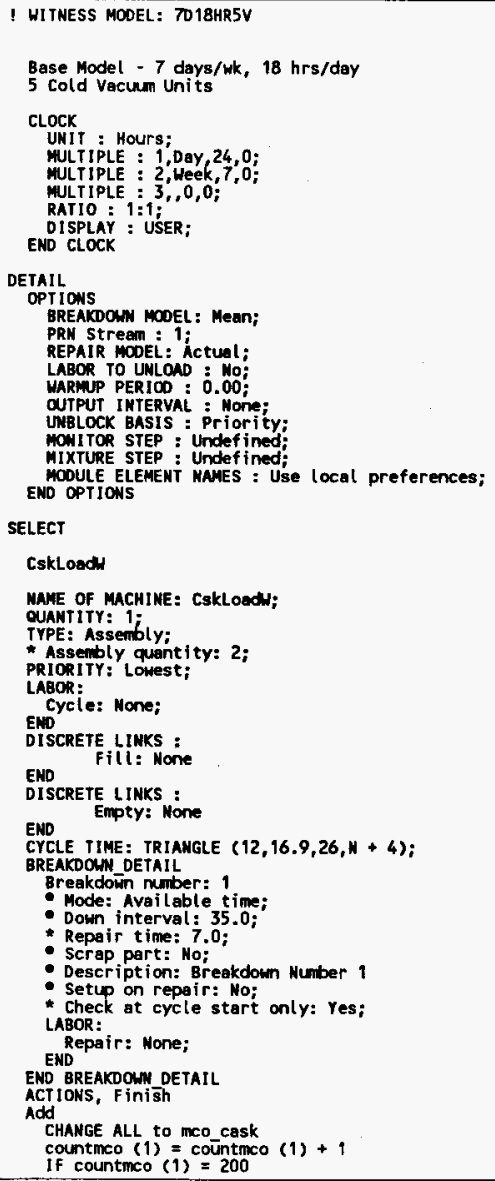 & 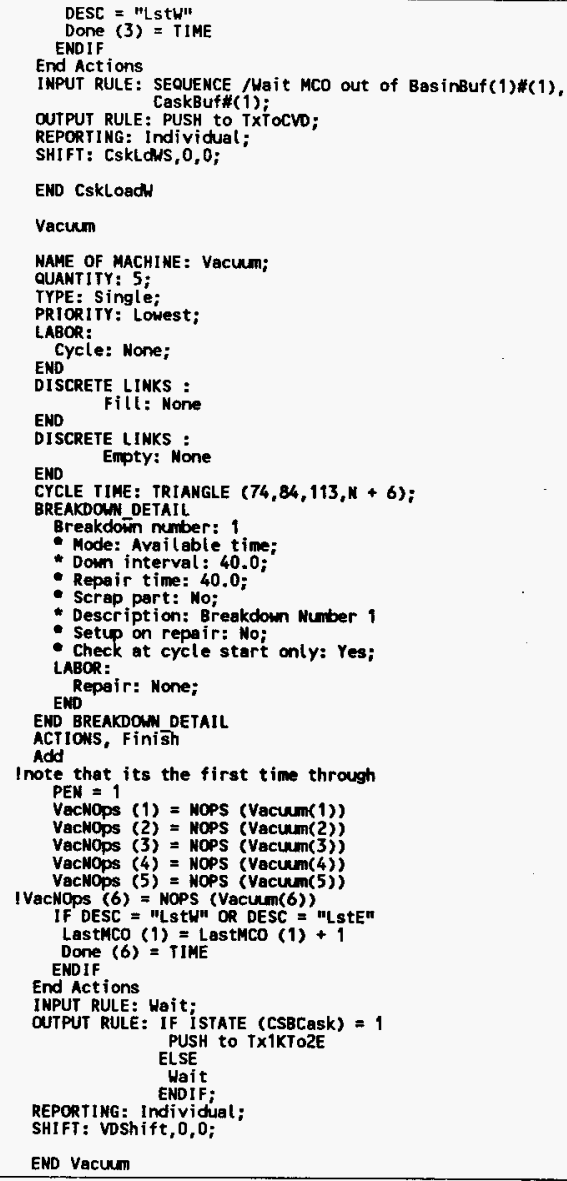 & 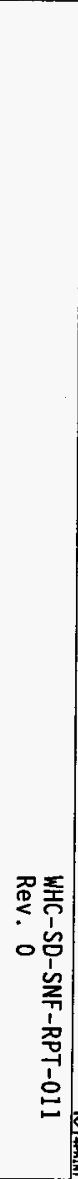 \\
\hline
\end{tabular}




\begin{tabular}{|c|c|c|}
\hline 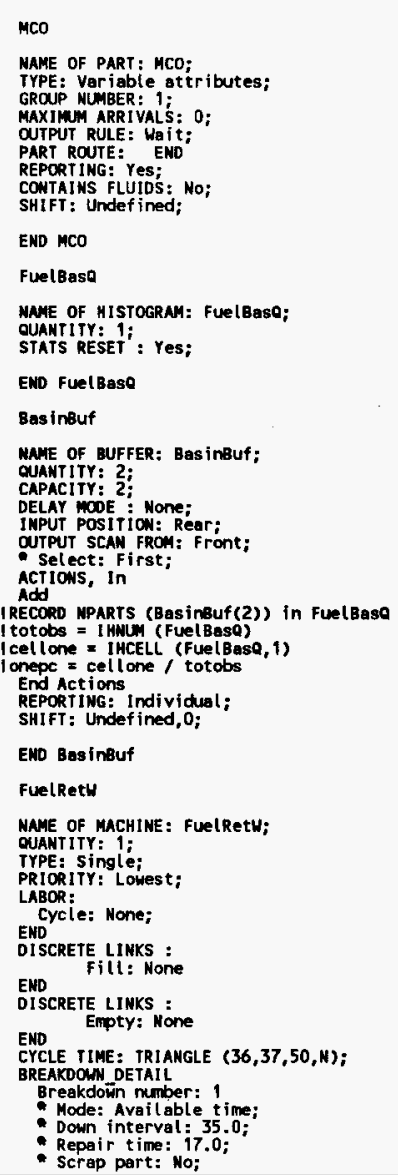 & 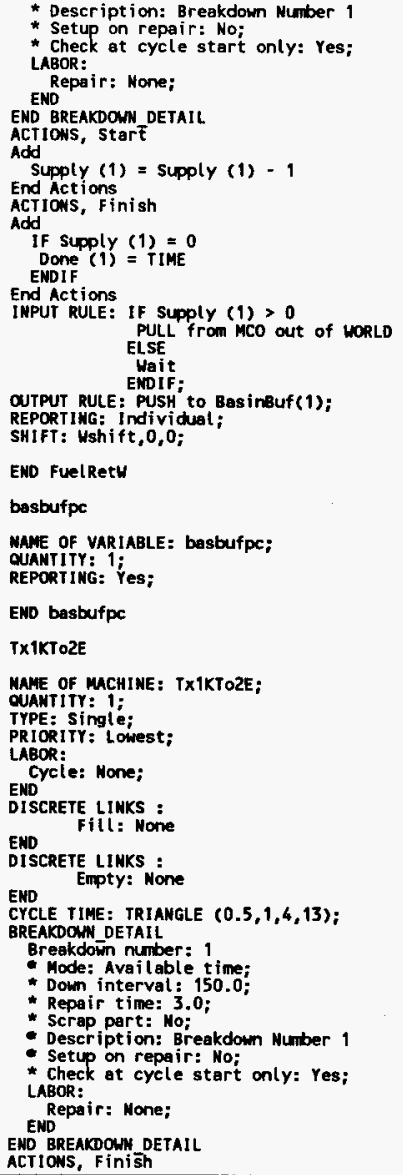 & 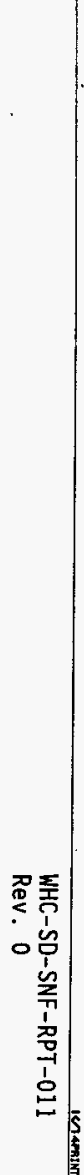 \\
\hline
\end{tabular}




\begin{tabular}{|c|c|c|}
\hline 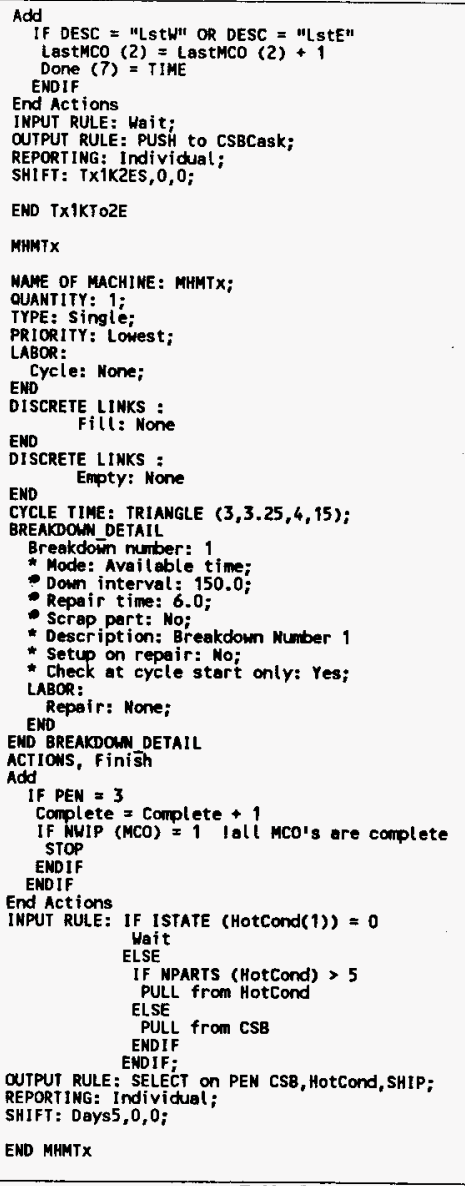 & 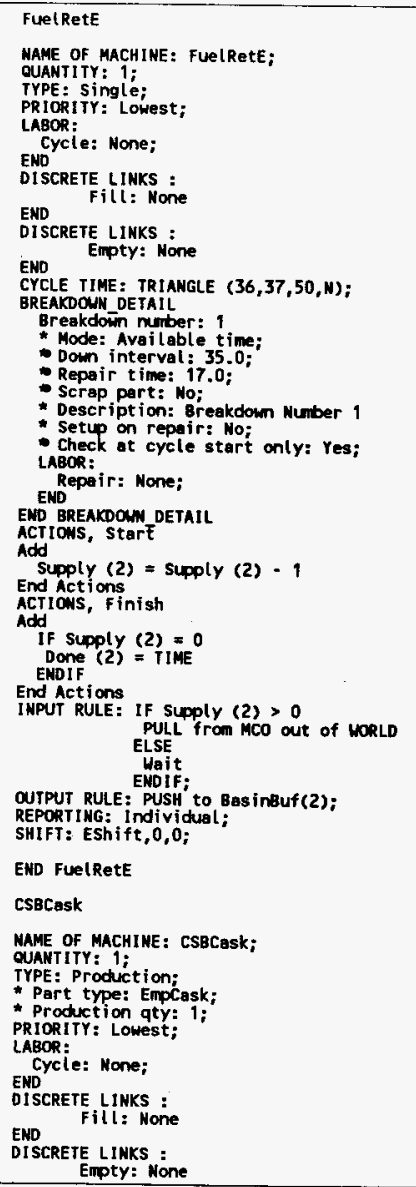 & 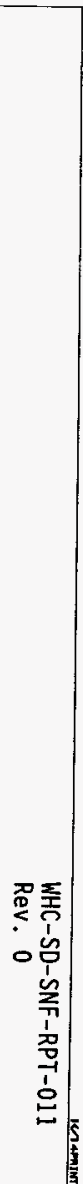 \\
\hline
\end{tabular}




\begin{tabular}{|c|c|c|}
\hline 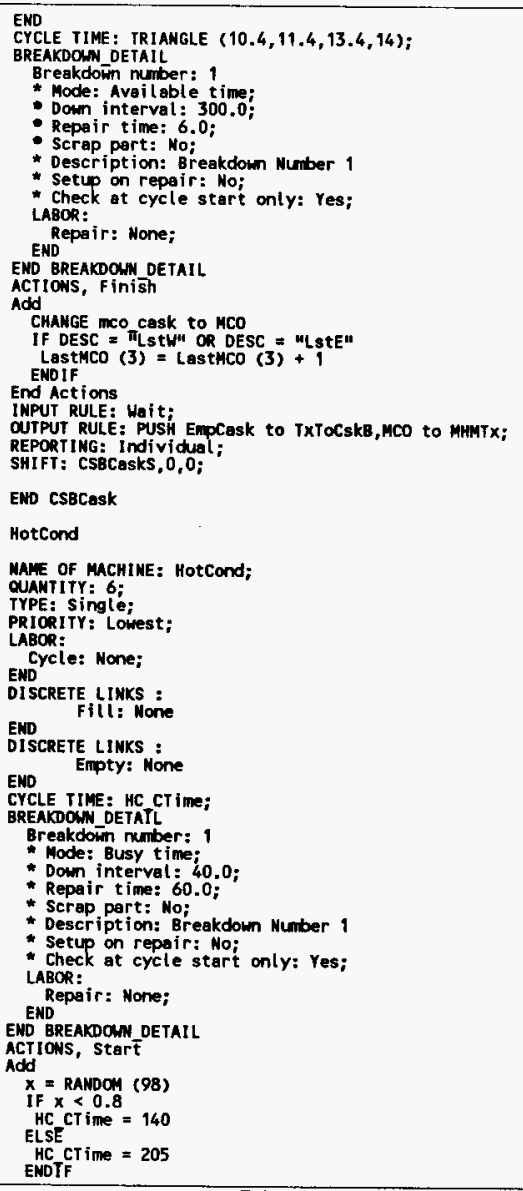 & 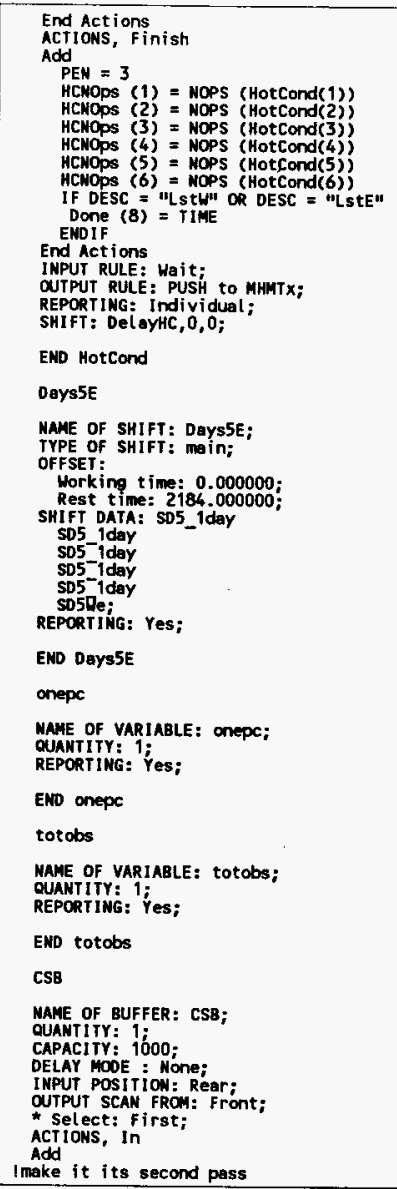 & 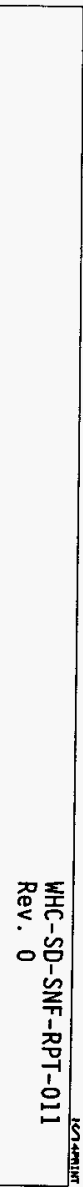 \\
\hline
\end{tabular}




\begin{tabular}{|c|c|c|}
\hline 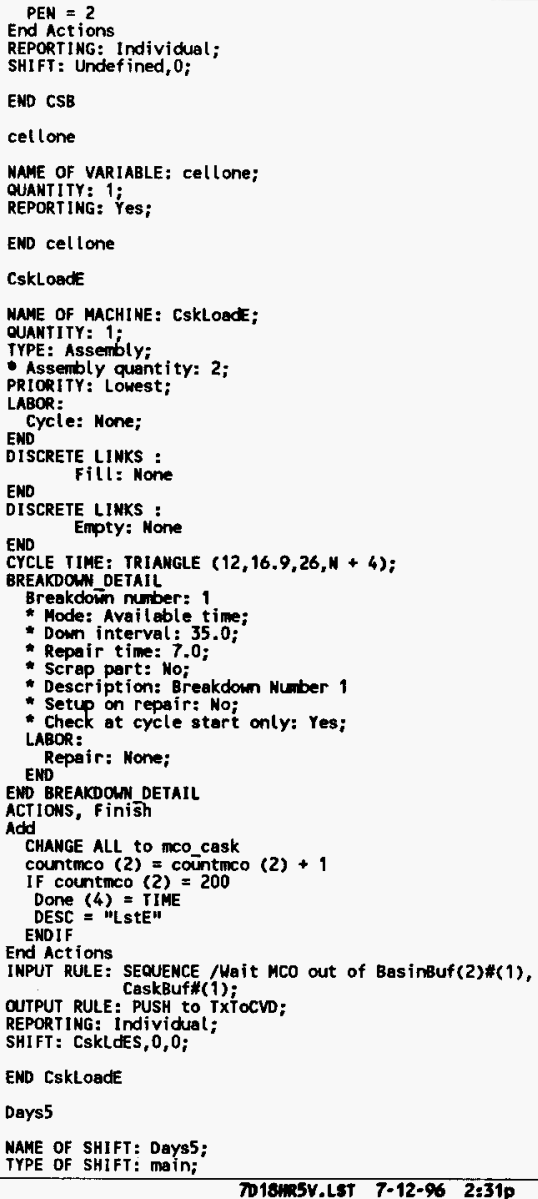 & 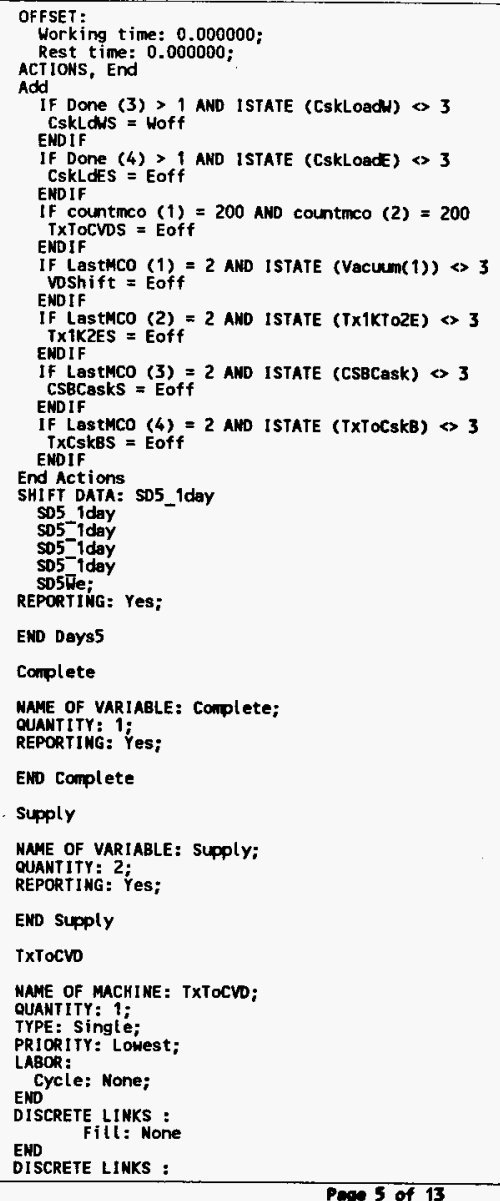 & 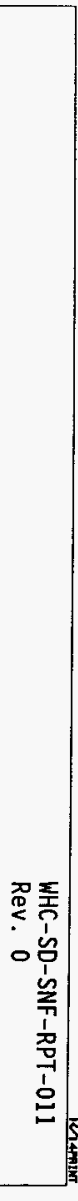 \\
\hline
\end{tabular}




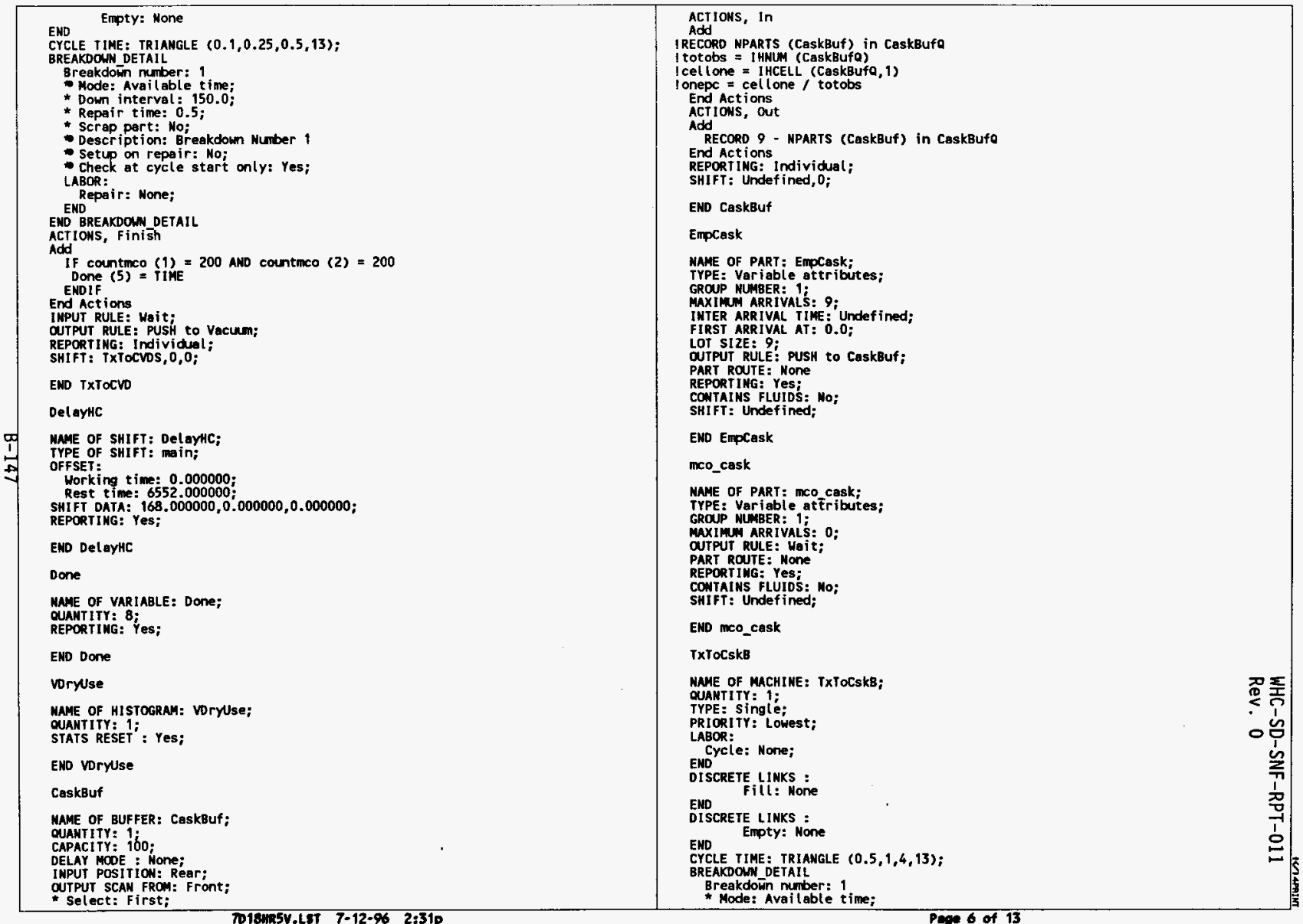




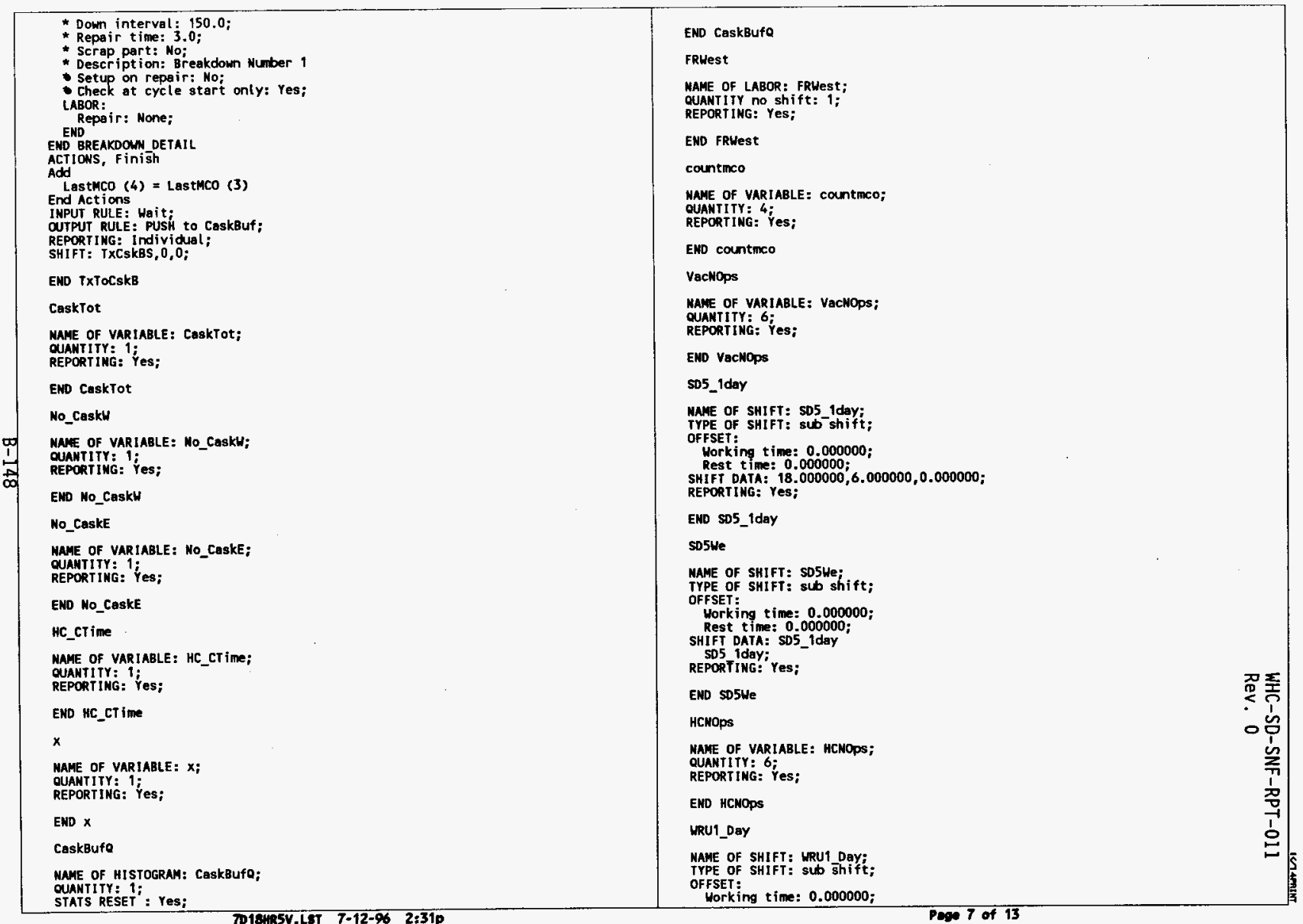




\begin{tabular}{|c|c|c|}
\hline 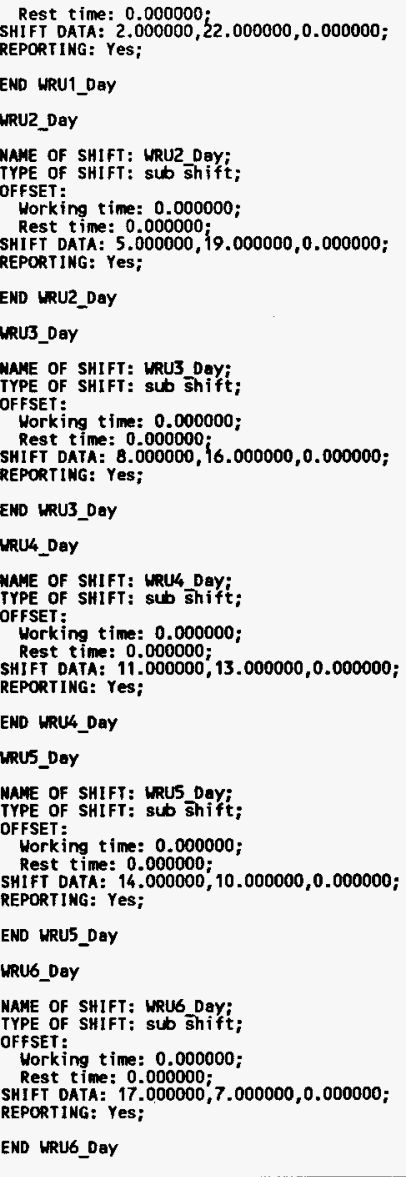 & 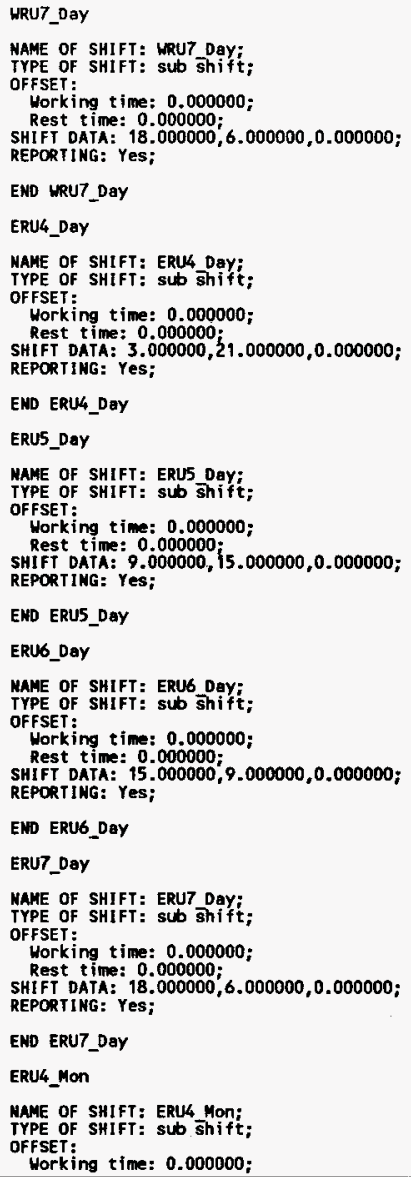 & 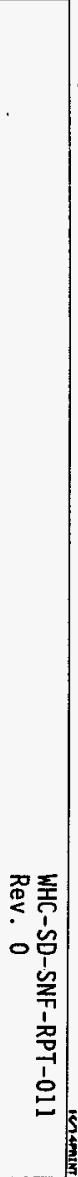 \\
\hline
\end{tabular}




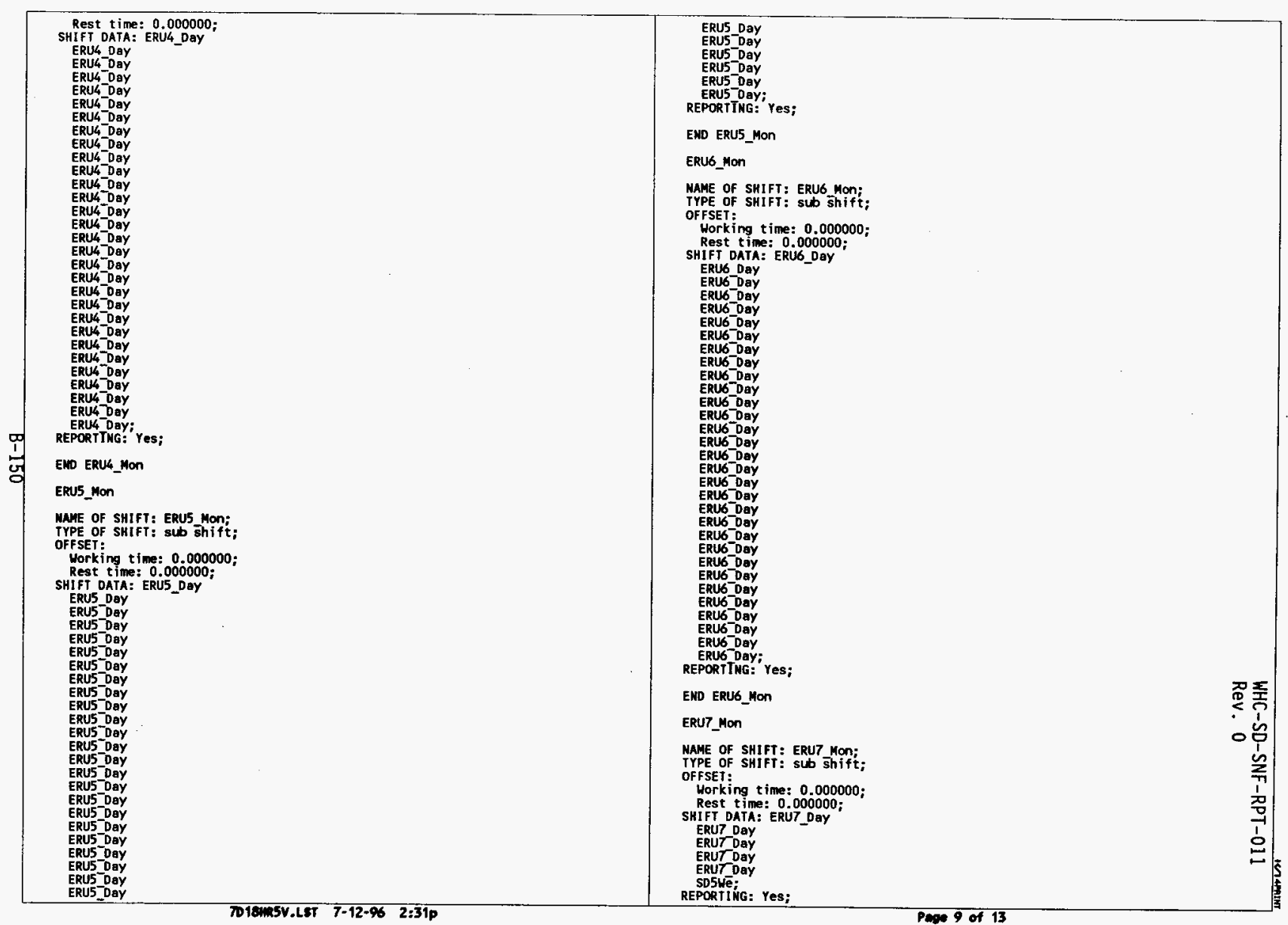




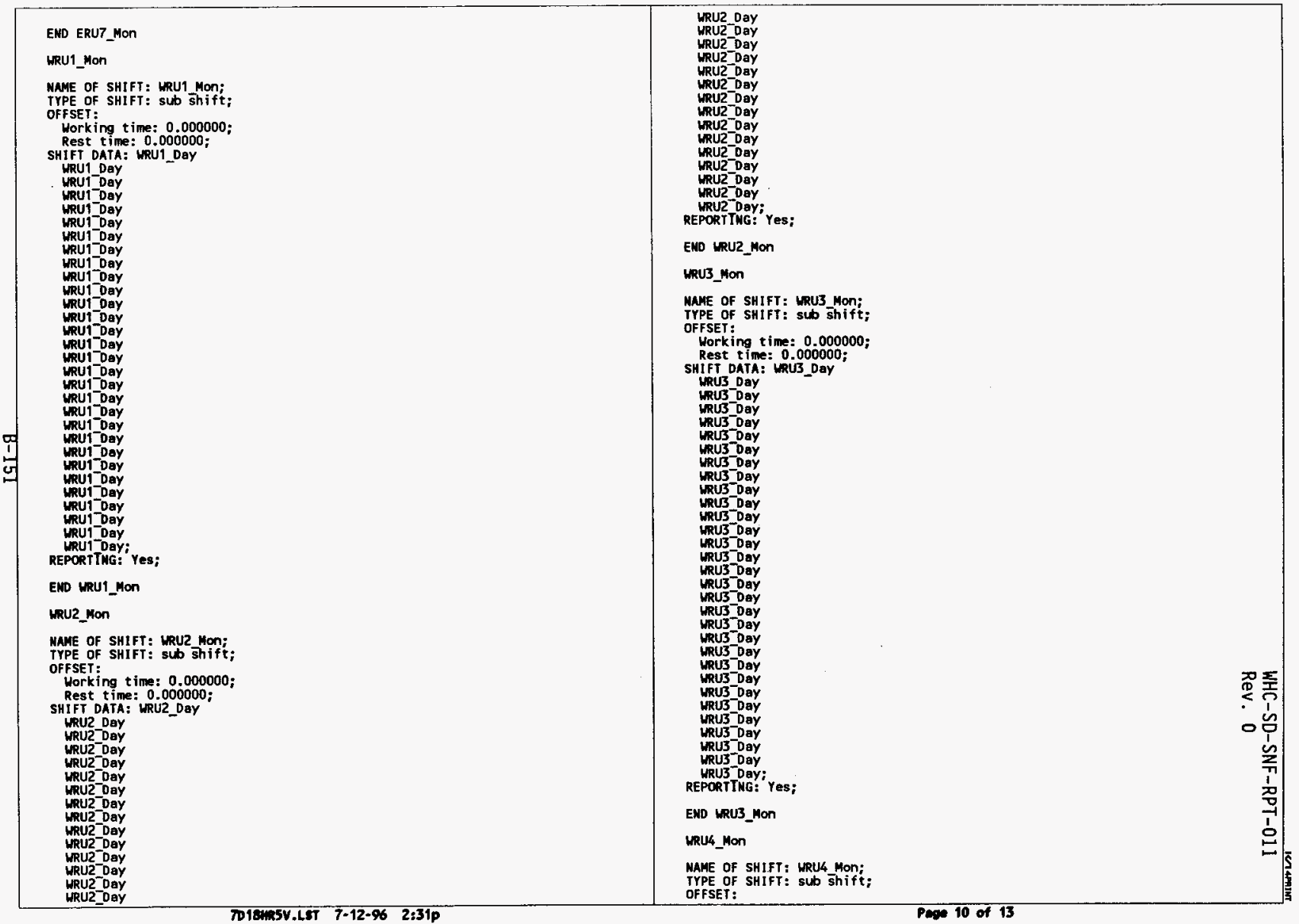




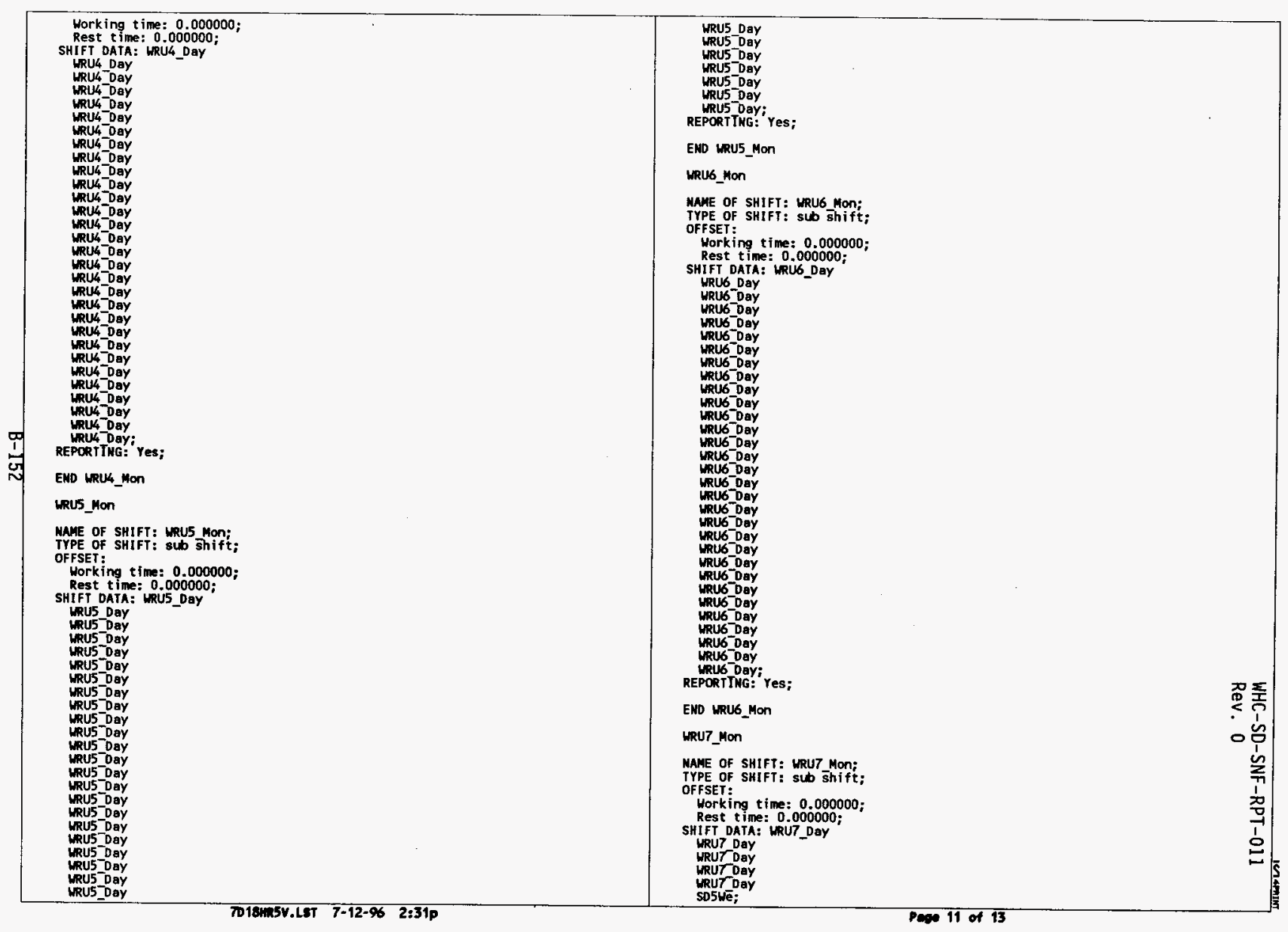




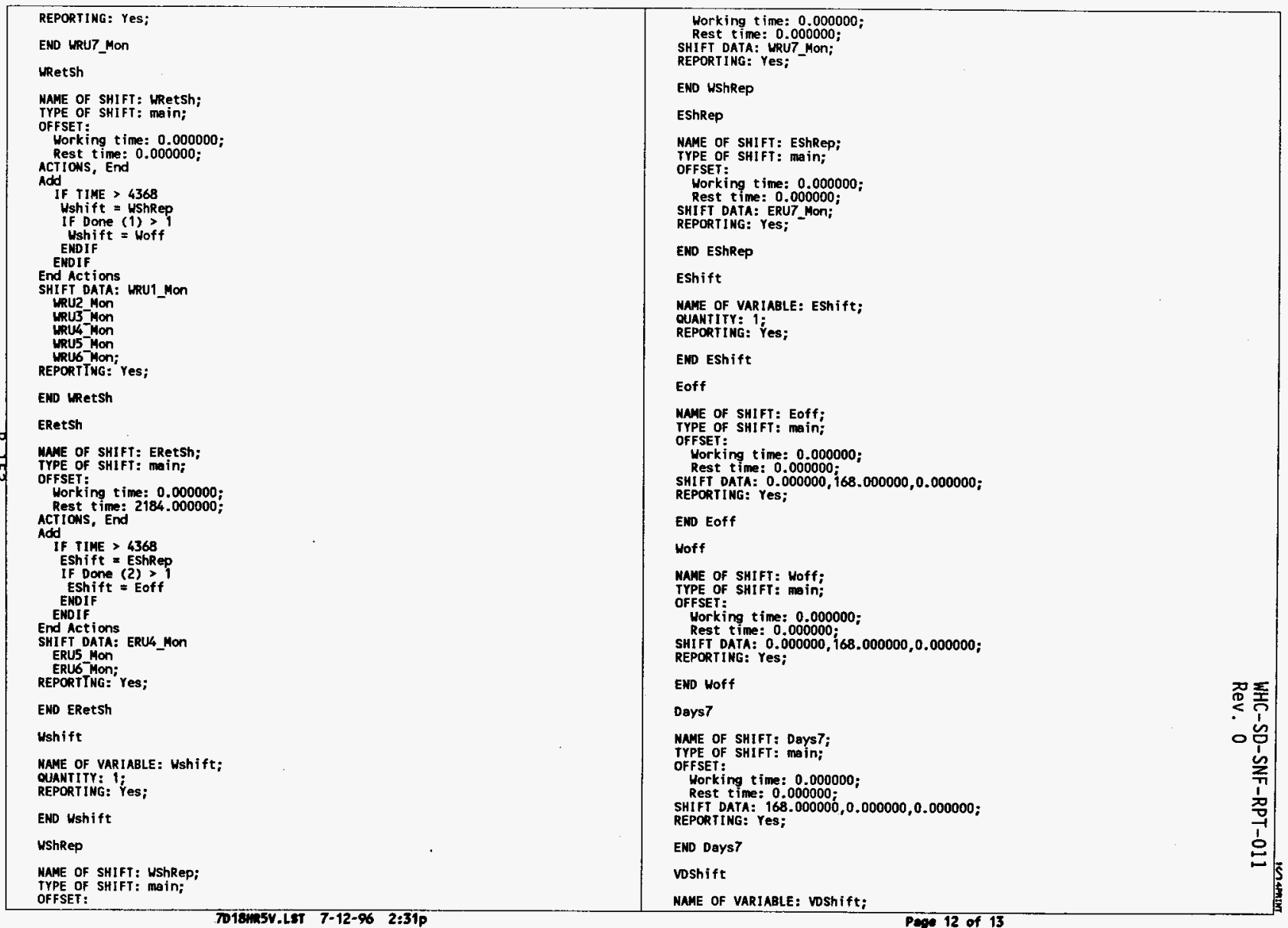


QUANTITY: 1 ;

END Voshift

Cskldus

MAME OF VARIABLE: CskLdNS;

QUANTITY: 1 ;

END CskLaNs

CskLdES

MAME OF VARIABLE : CskLdES;

OUANTITY: 1 ;

REPORTING: Yes

EWD CskLdES

TXTocros

WNE OF VARIABLE: TXTOCVOS;

OUANIIIY: 1;

REPORTING: Yes

END TXTOCVOS

TX1K2ES

MANE OF VARIABLE: TX1K2ES;

QUANTITY: 1;

REPORTING: Ýes:

END TX1KZES

CSBCasks

MAME OF VARIABLE: CSBCaskS;

OUANTITY: $1 ;$

REPORTING: Yes:

END CSBCssks

TXCskBS

MAME OF VARIABLE: IXCskBS;

QUANTITY: $1 ;$
REPORTING: Yes;

END IXCskBS

LasthCO

NAME OF VARIABLE: Las TMCO;

QUANT I TY: 4 ;

REPORTING: Yes:

ENO LastMco

END SELECT

END DETAIL

INITIALISE

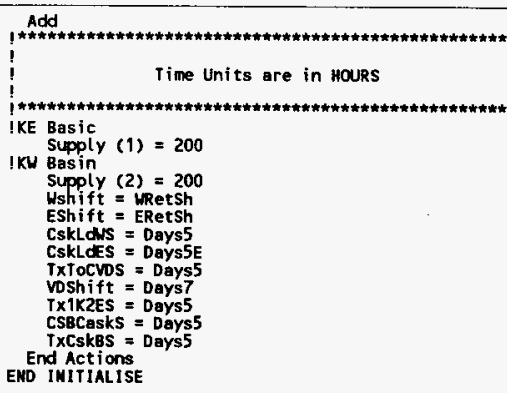

!

IKE Basic

KE Basic Supply $(1)=200$

IKU Supply

Supply (2) $=200$

Wshift = WRetSh

CskLd's = Days5

CskLdWS $=$ Days5
CskLdES $=$ Days5E

TXTocvos = Days 5

voshift $=$ Days7

TX1K2ES $=$ Days5

CSBCasks $=$ Days 5

TXCskBS = Days5

End Actions

END IMITIALISE 
WHC-SD-SNF-RPT-011

Rev. 0

CASE 9. THREE 8HR SHIFTS/DAY, 7 DAYS/WEEK.

USING 4 COLD VACUUM DRYING STATIONS. 
SNF Project operating 3 shifts, 7 days/week. Cold vacuum drying has 4 stations

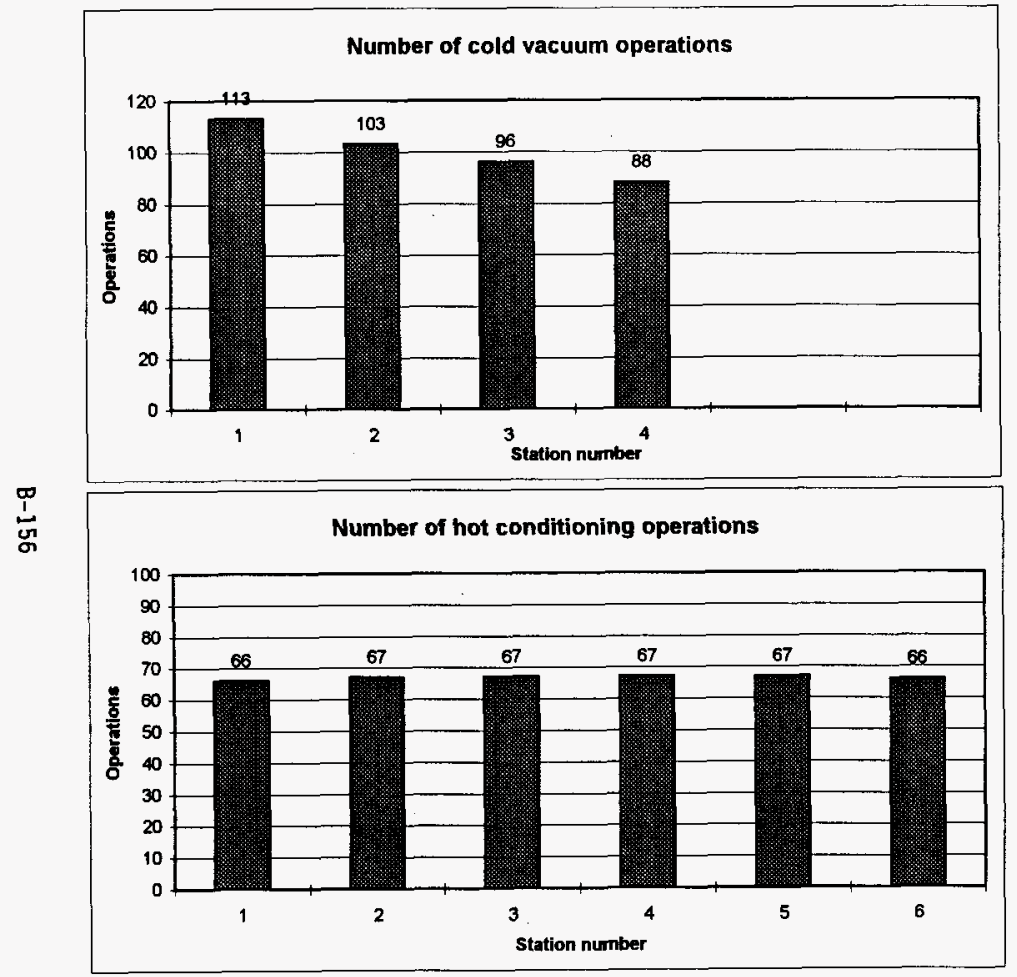




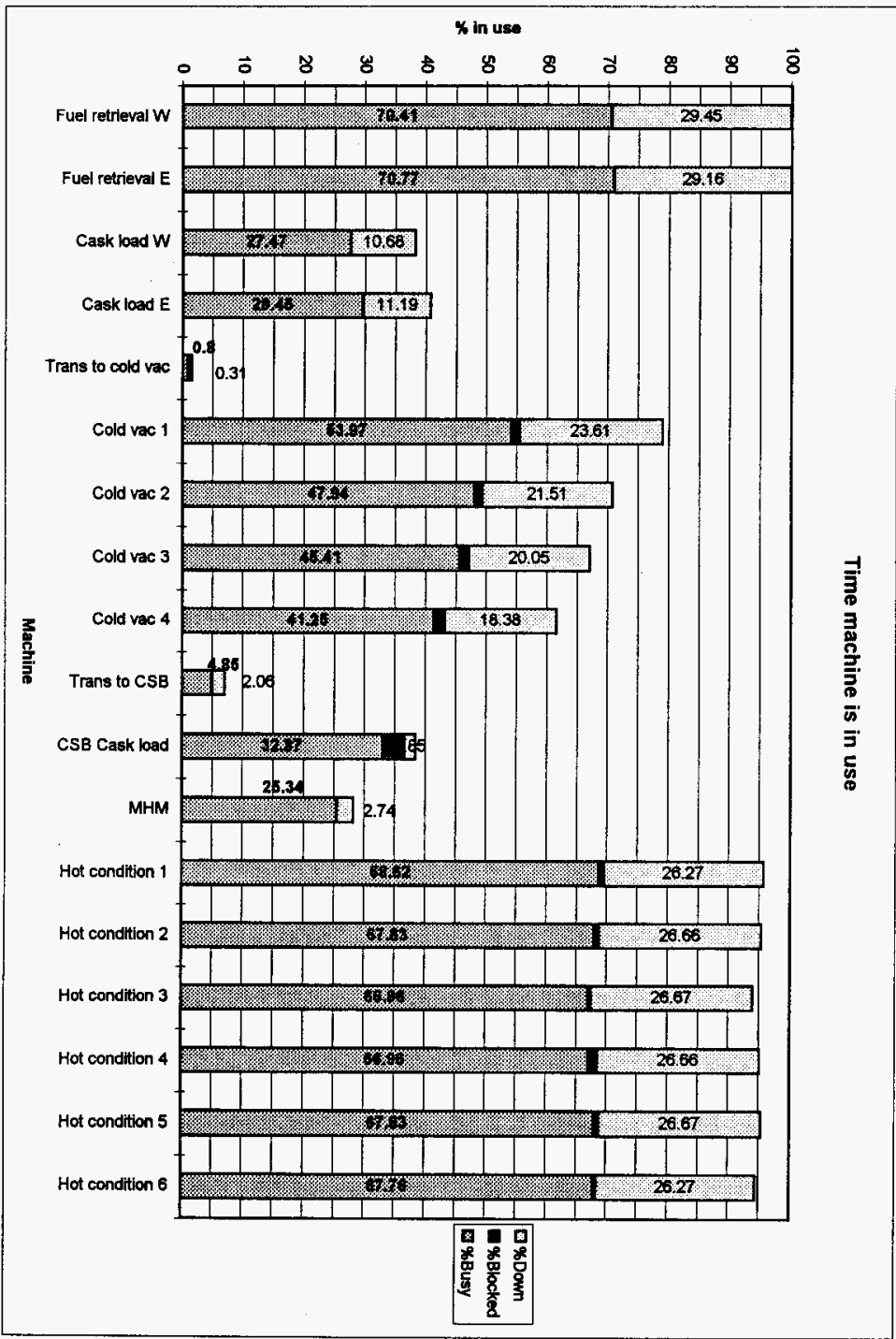

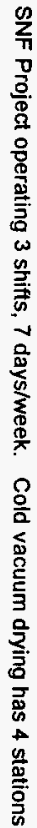

$\frac{1}{8}$ 


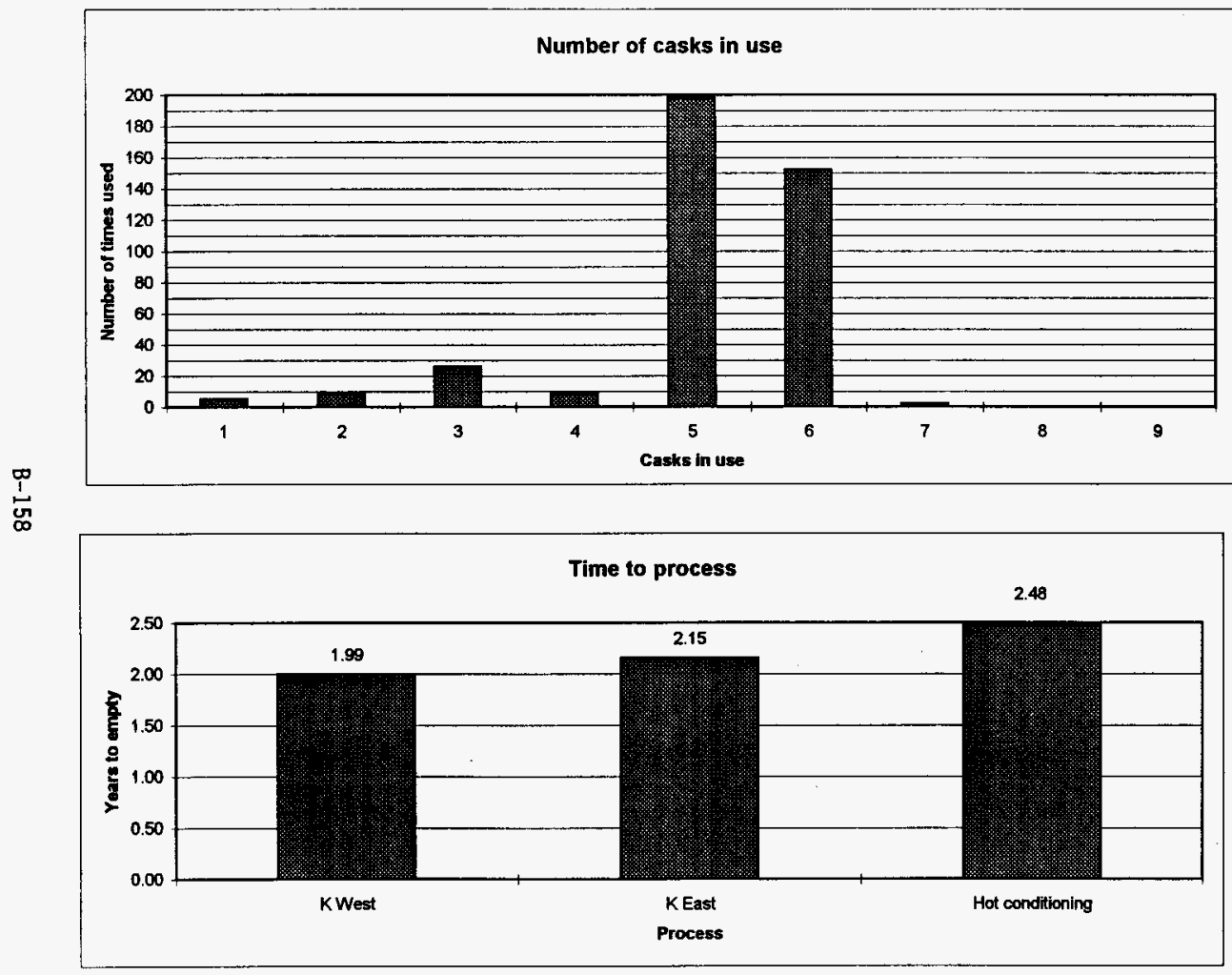




\begin{tabular}{|c|c|c|}
\hline 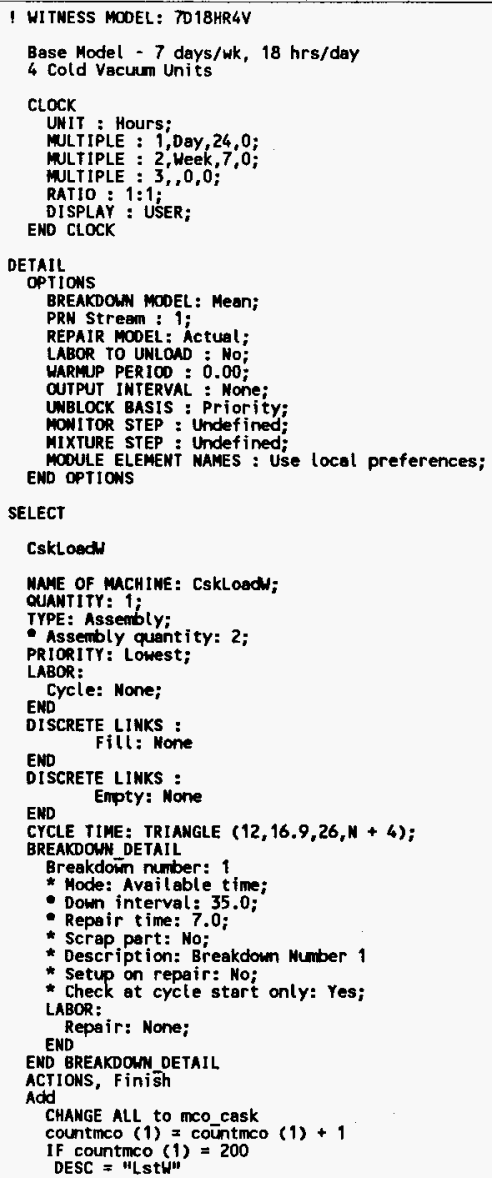 & 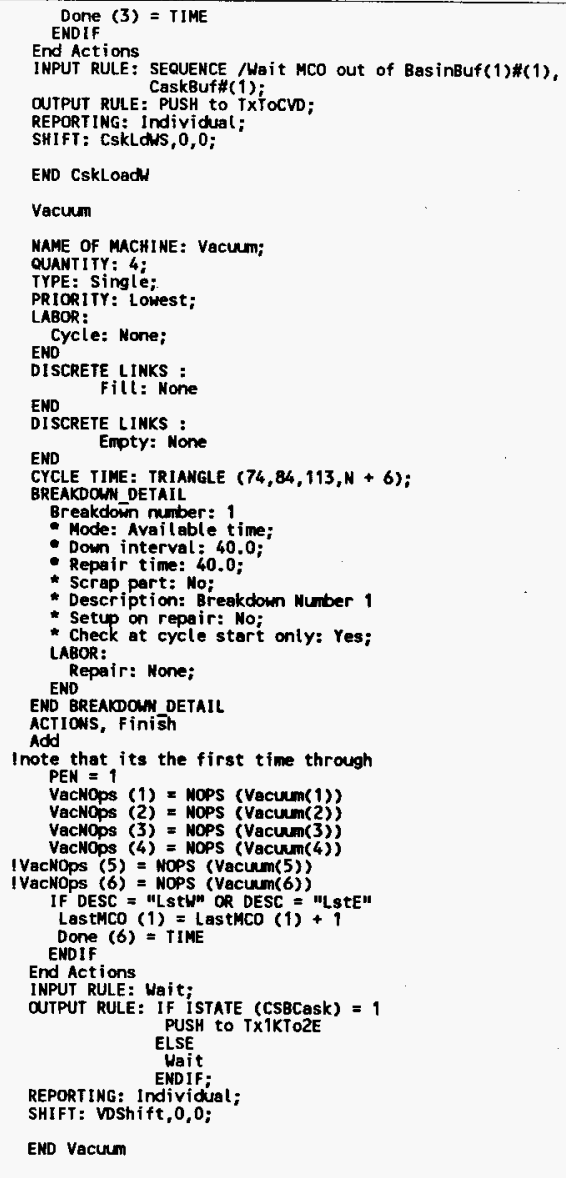 & 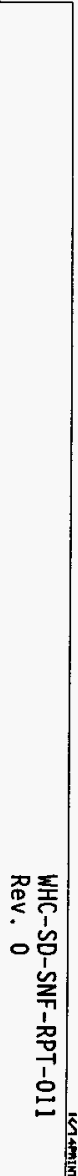 \\
\hline
\end{tabular}




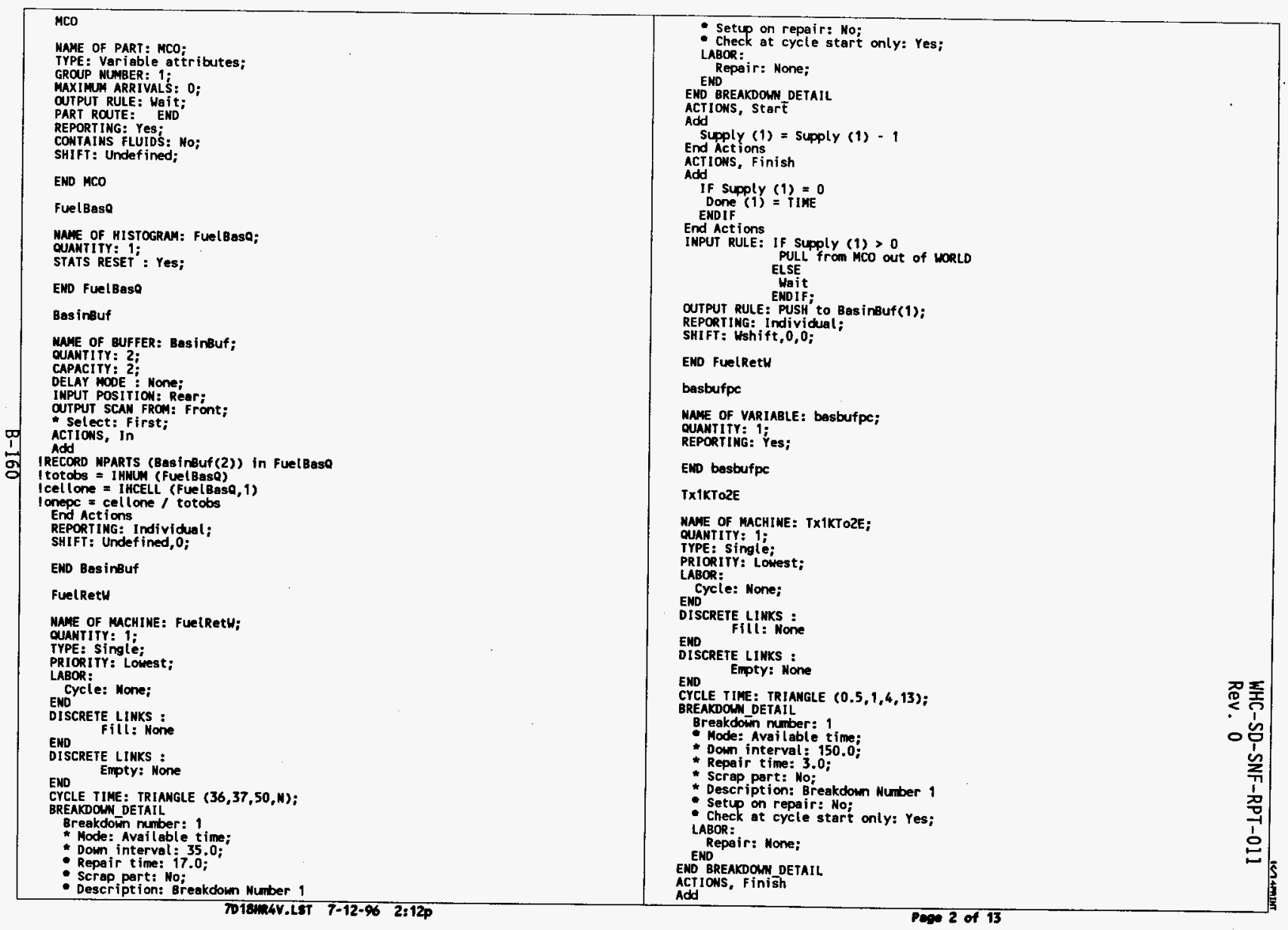




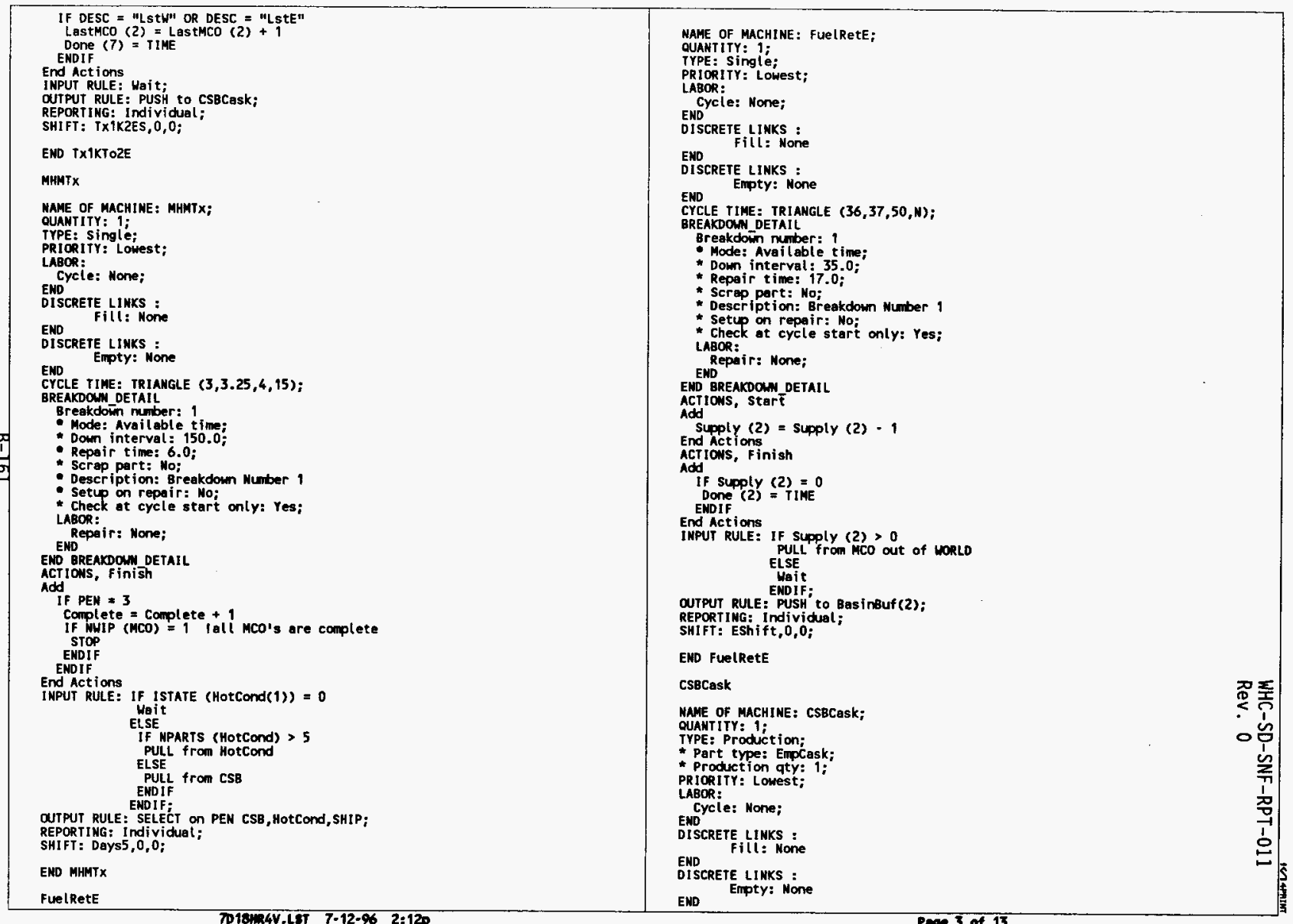




\begin{tabular}{|c|c|}
\hline 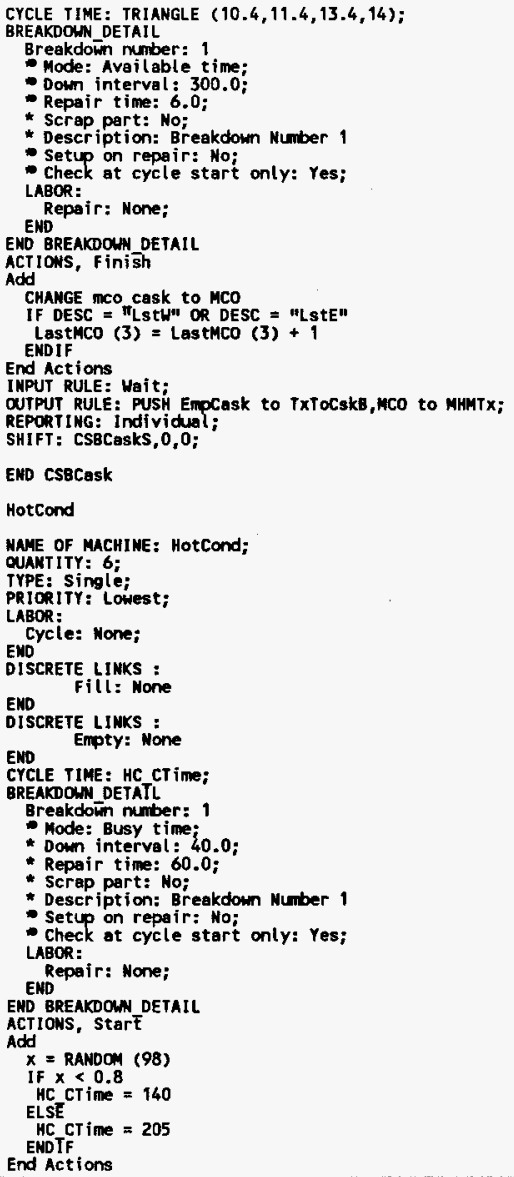 & 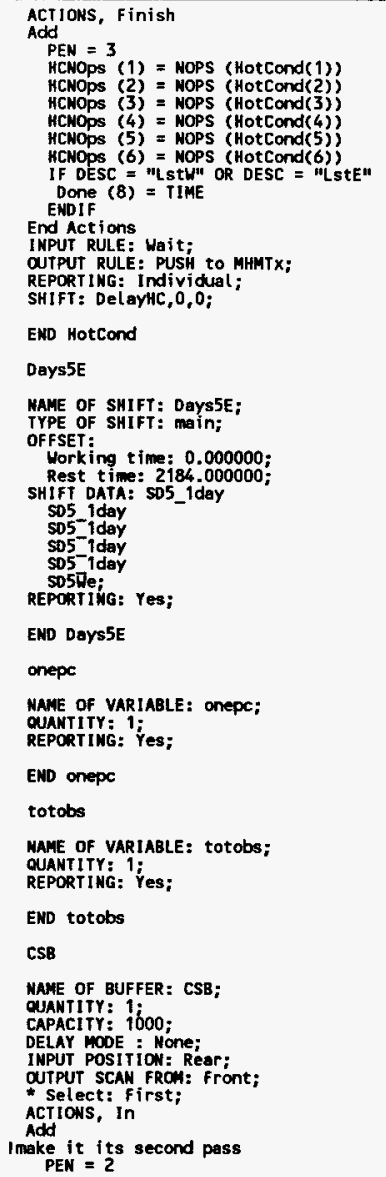 \\
\hline
\end{tabular}




\begin{tabular}{|c|c|c|}
\hline 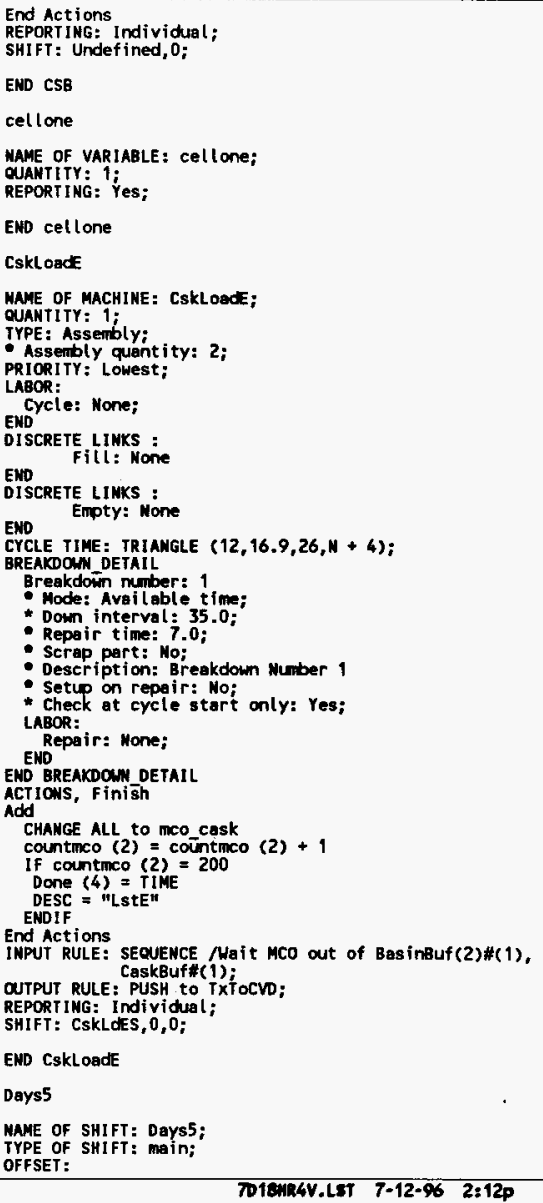 & 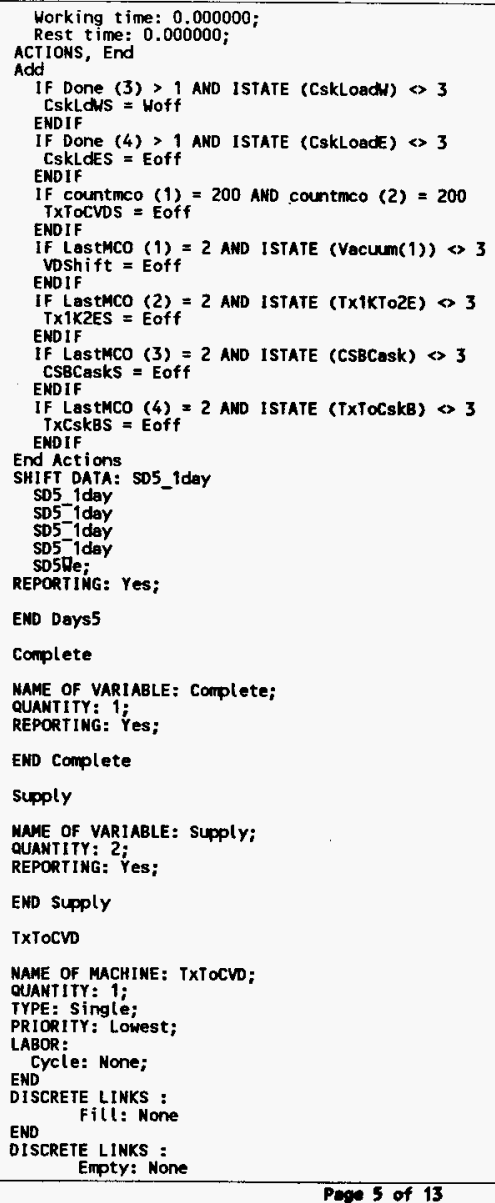 & 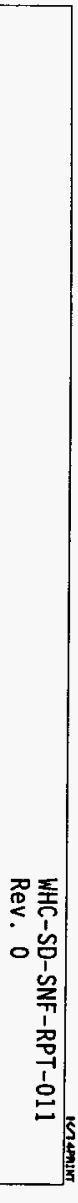 \\
\hline
\end{tabular}




\begin{tabular}{|c|c|c|}
\hline 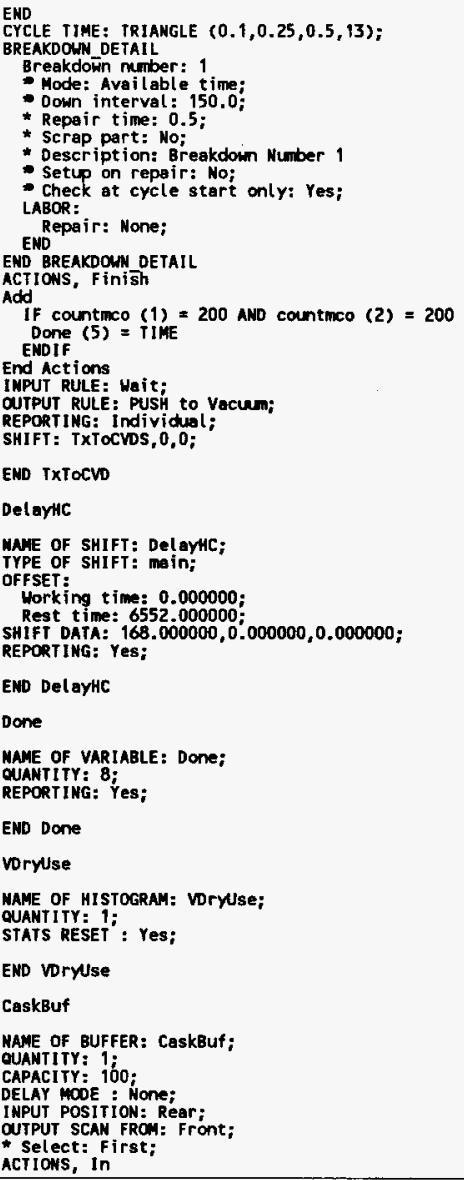 & 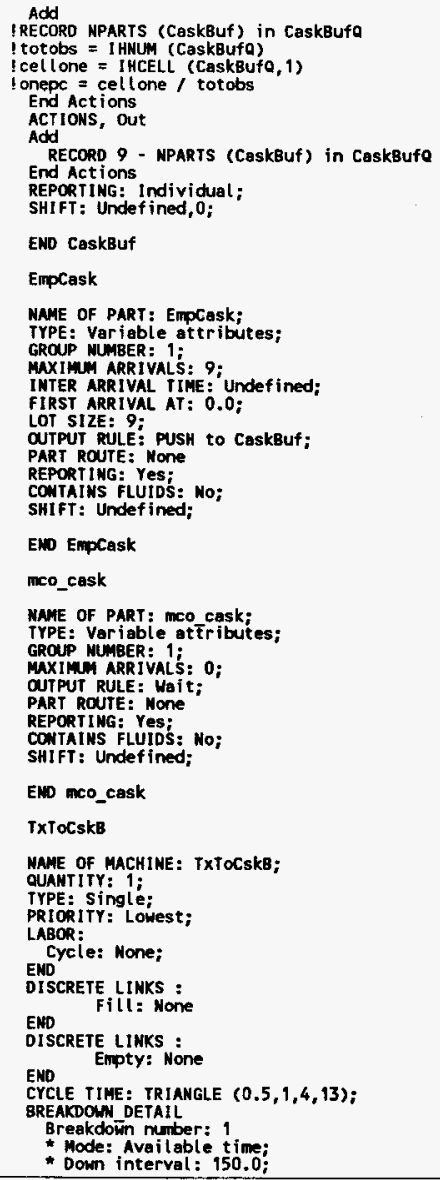 & 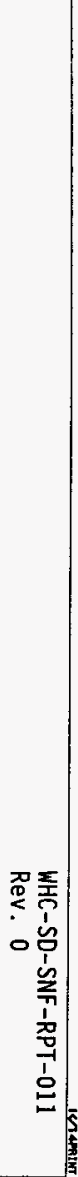 \\
\hline
\end{tabular}




\begin{tabular}{|c|c|c|}
\hline 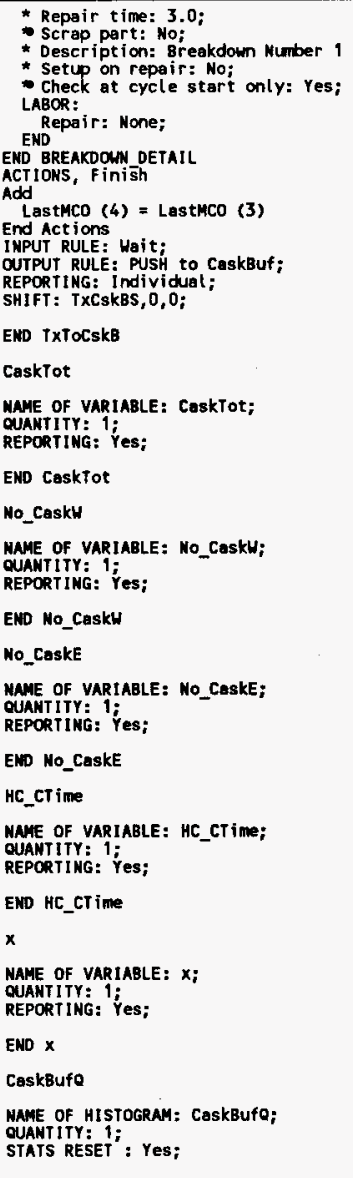 & 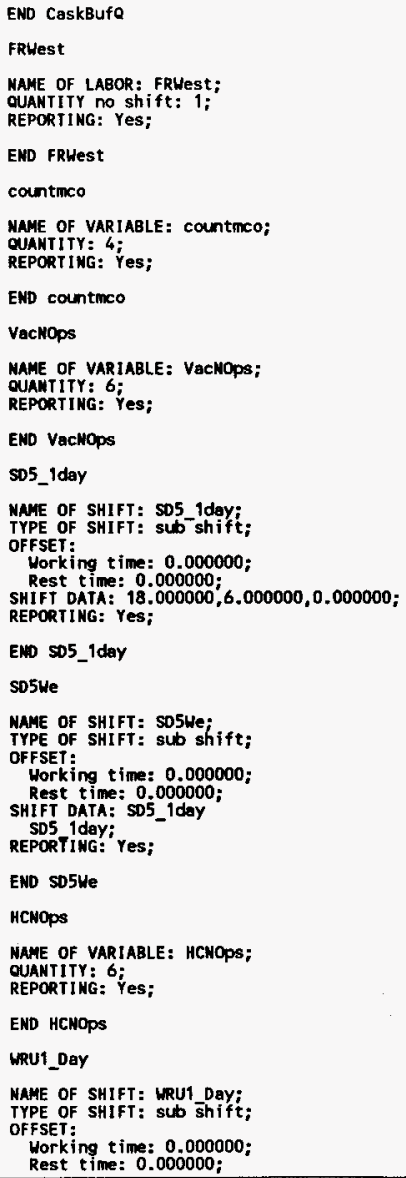 & 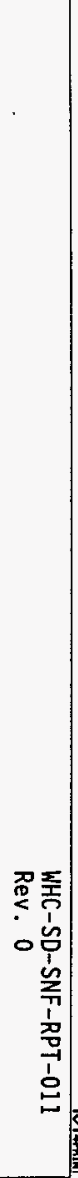 \\
\hline
\end{tabular}




\begin{tabular}{|c|c|c|}
\hline 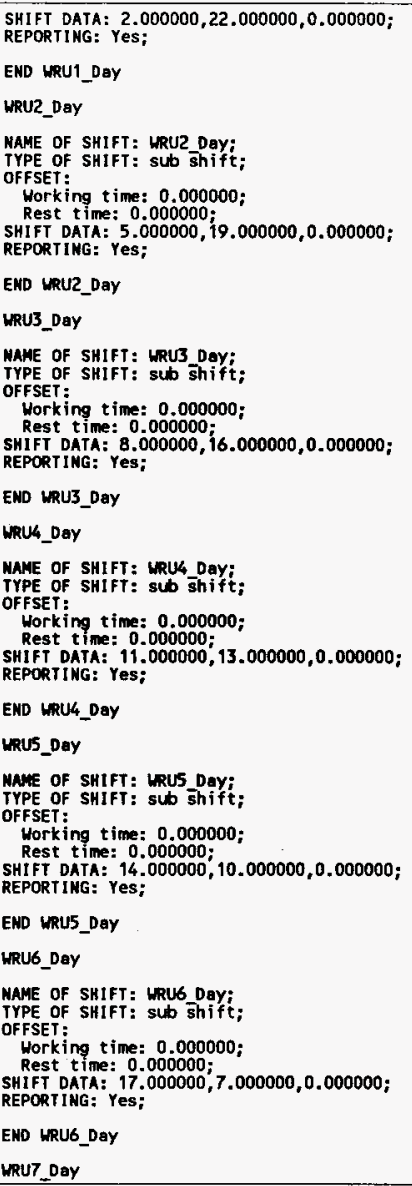 & 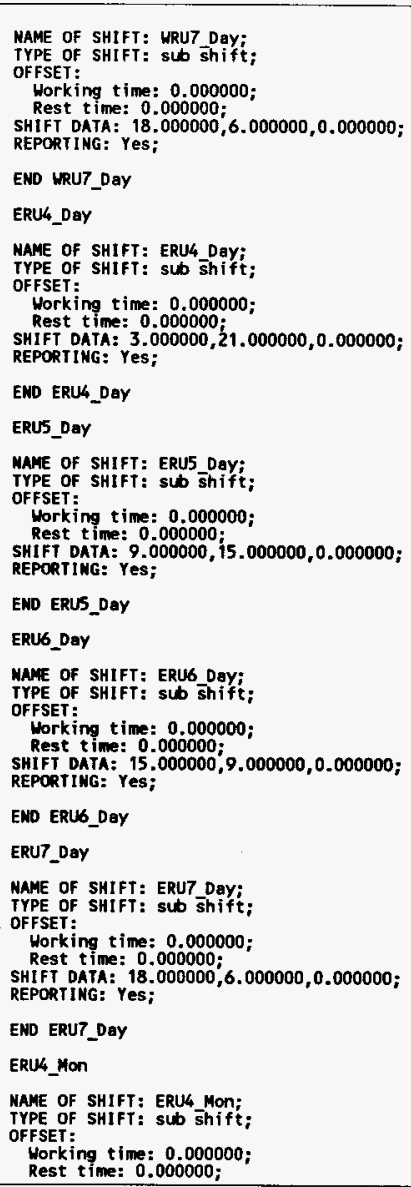 & 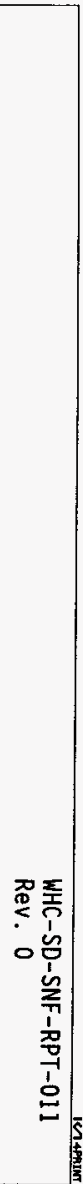 \\
\hline
\end{tabular}




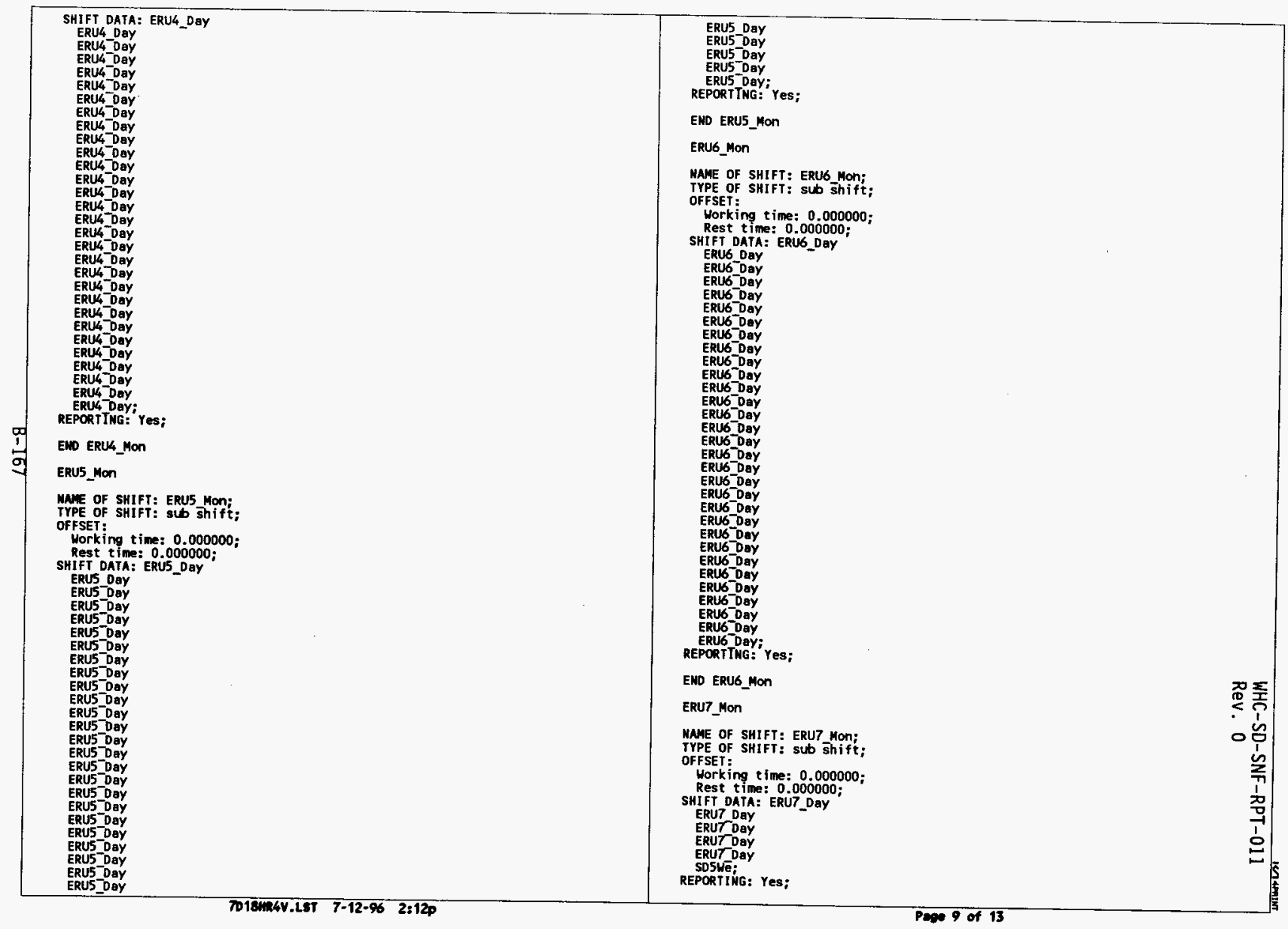




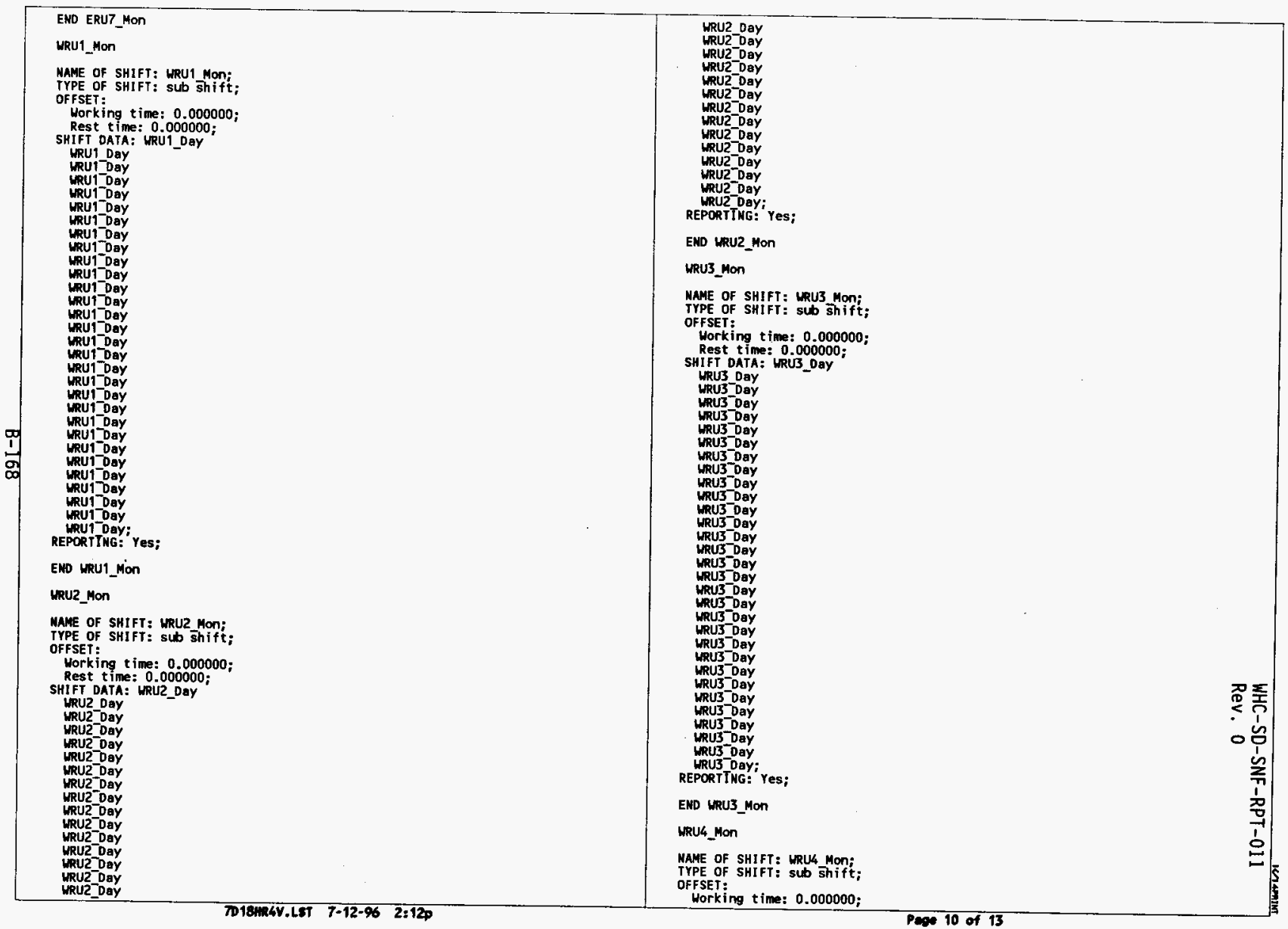


El to II oled

dZL:Z 96-ZL-L IST'Aryusto

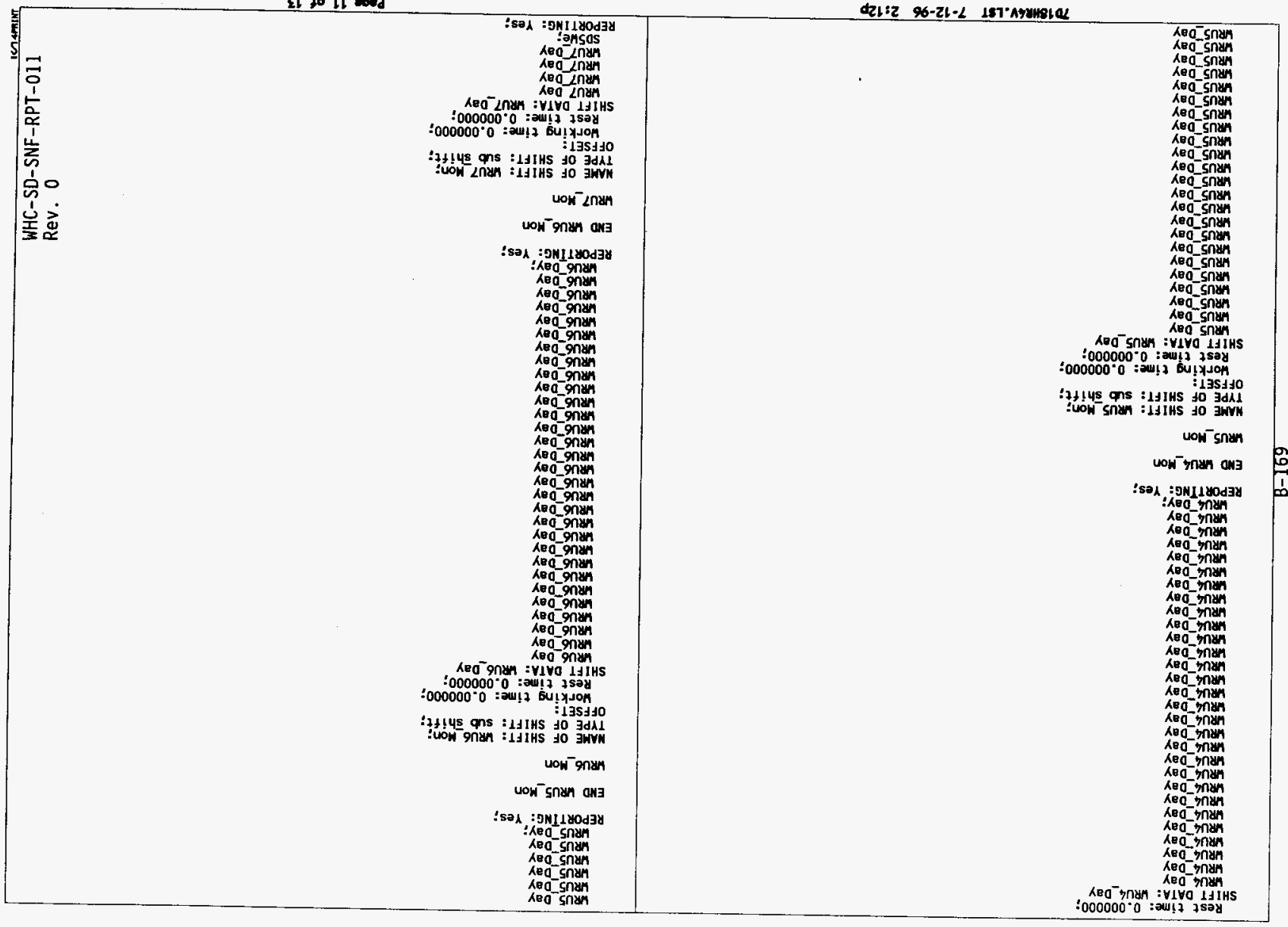




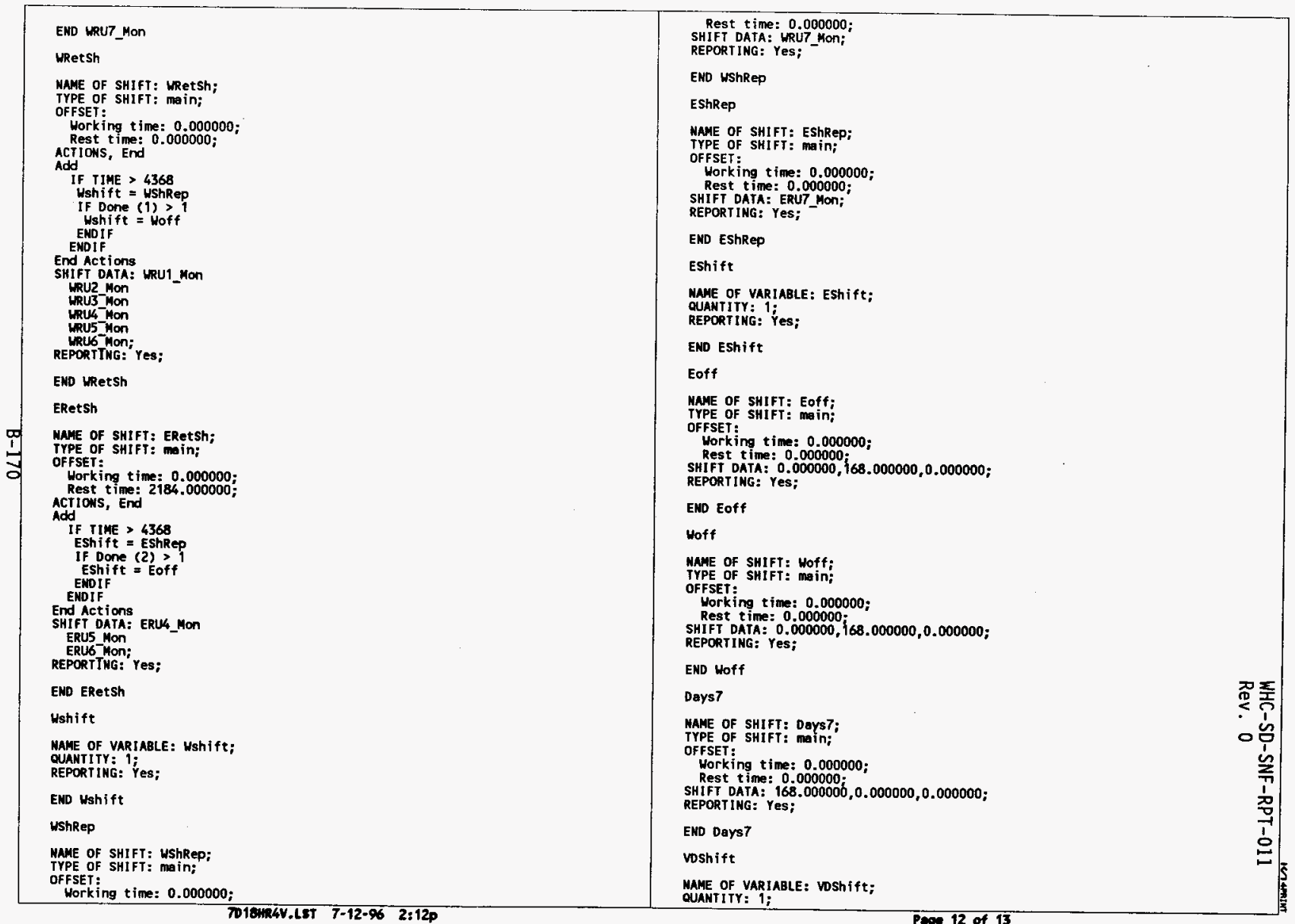




\section{REPORTING: Yes \\ END VDShift}

\section{Csktous}

NAME OF VAR IABLE: CSKLdUS; QUANTITY: 1 ;

REPORTING: Yes;

END CskLdWS

CsKLIES

MAME OF VARIABLE: CSKLLES;

QUANTITY: 1;

REPORTING: Y' Yes

END CskLdES

TXTOCVS

MANE OF VARIABLE: TXTOCVOS;

OUANTITY: 1

REPORTING: Yes;

END TXTOCVDS

TX1K2ES

MAME OF VARLABLE: TXTK2ES;

- QUANTITY: 1;

REPORTING: Ýes;

END TX1K2ES

csBcasks

MAME OF VARIABLE: CSBCasKS;

GUANTITY: 1

REPORTING: Yes;

EMD CSBCeskS

TXCskBS

MAME OF VARIABLE: TXCSKBS;

CUANTITY: 1;

EHD TXCskBs

Lastmco

MAME OF VARIABLE: Los TMCO;

OUANT ITY: 4 ;

REPORTING: Yes;

END Lastmco

END SELECT

END DETAIL

IMITIALISE

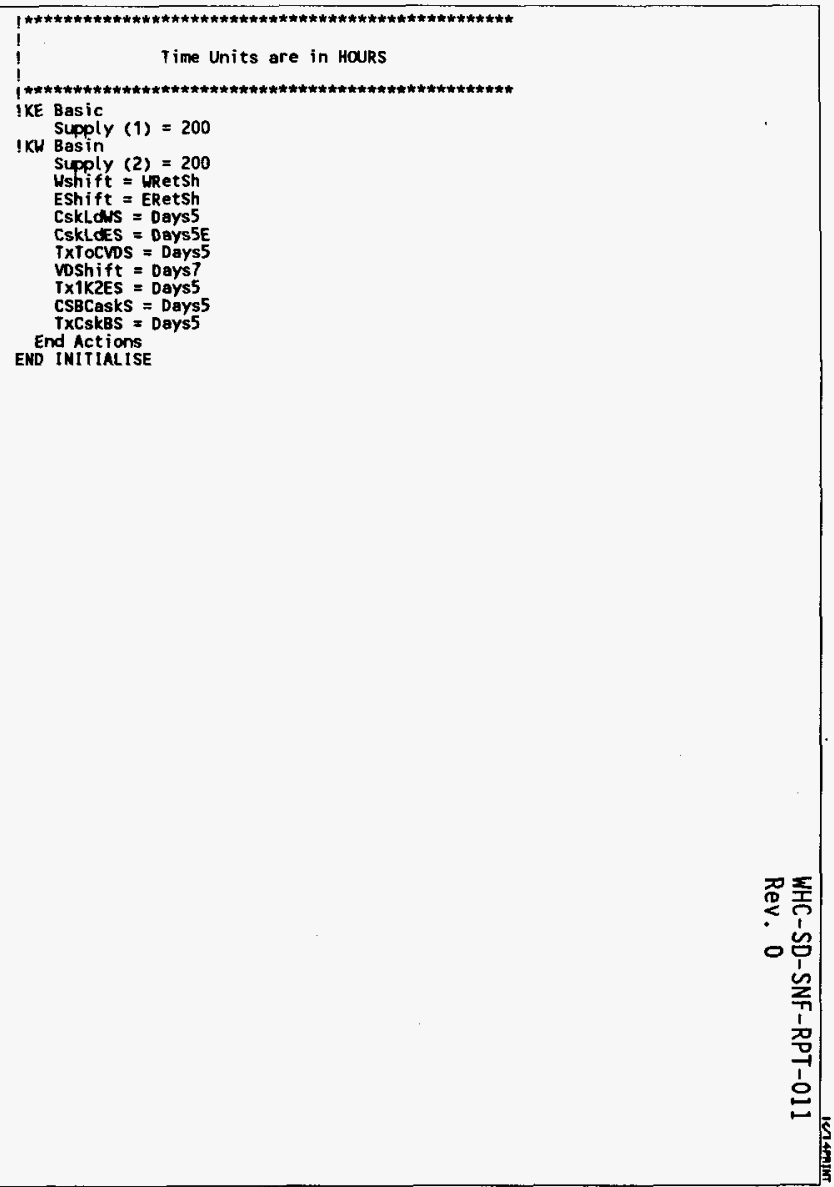

Pege 13 of 13 
WHC-SD-SNF-RPT-0II

Rev. 0

CASE 10. THREE 8HR SHIFTS/DAY, 7 DAYS/WEEK. USING 2 LOADIN/LOADOUT PITS IN THE CSB. 

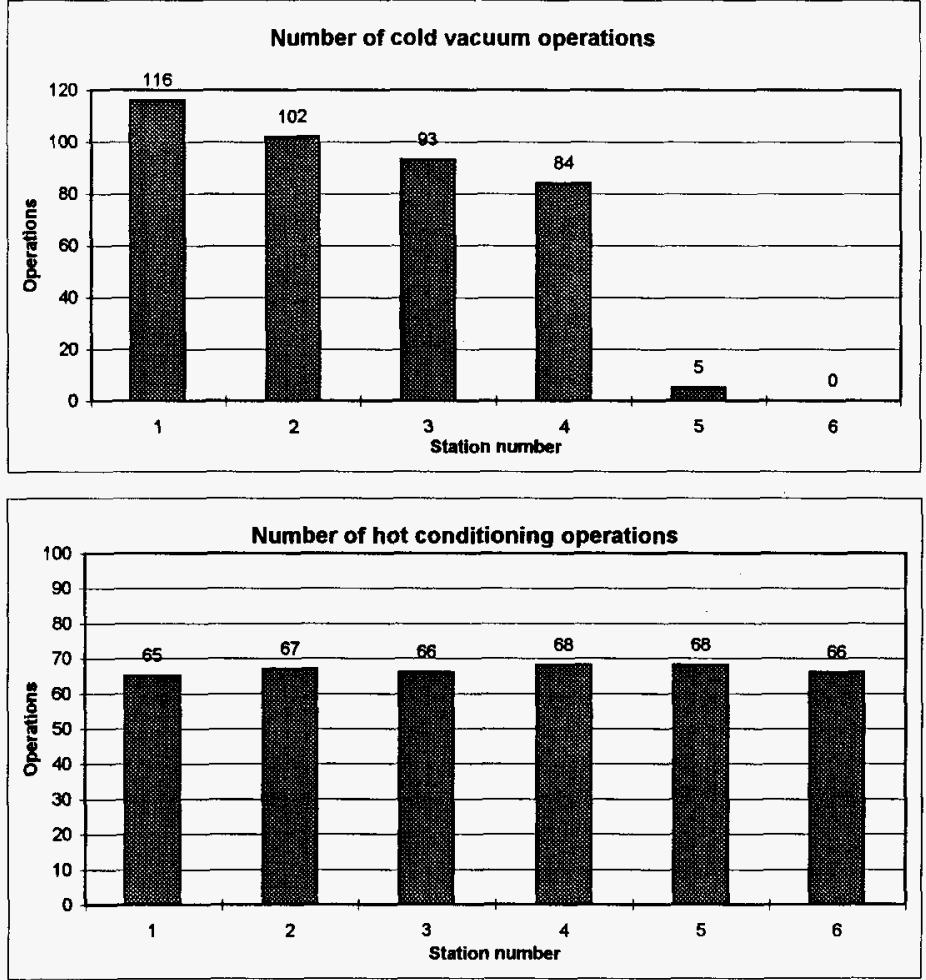


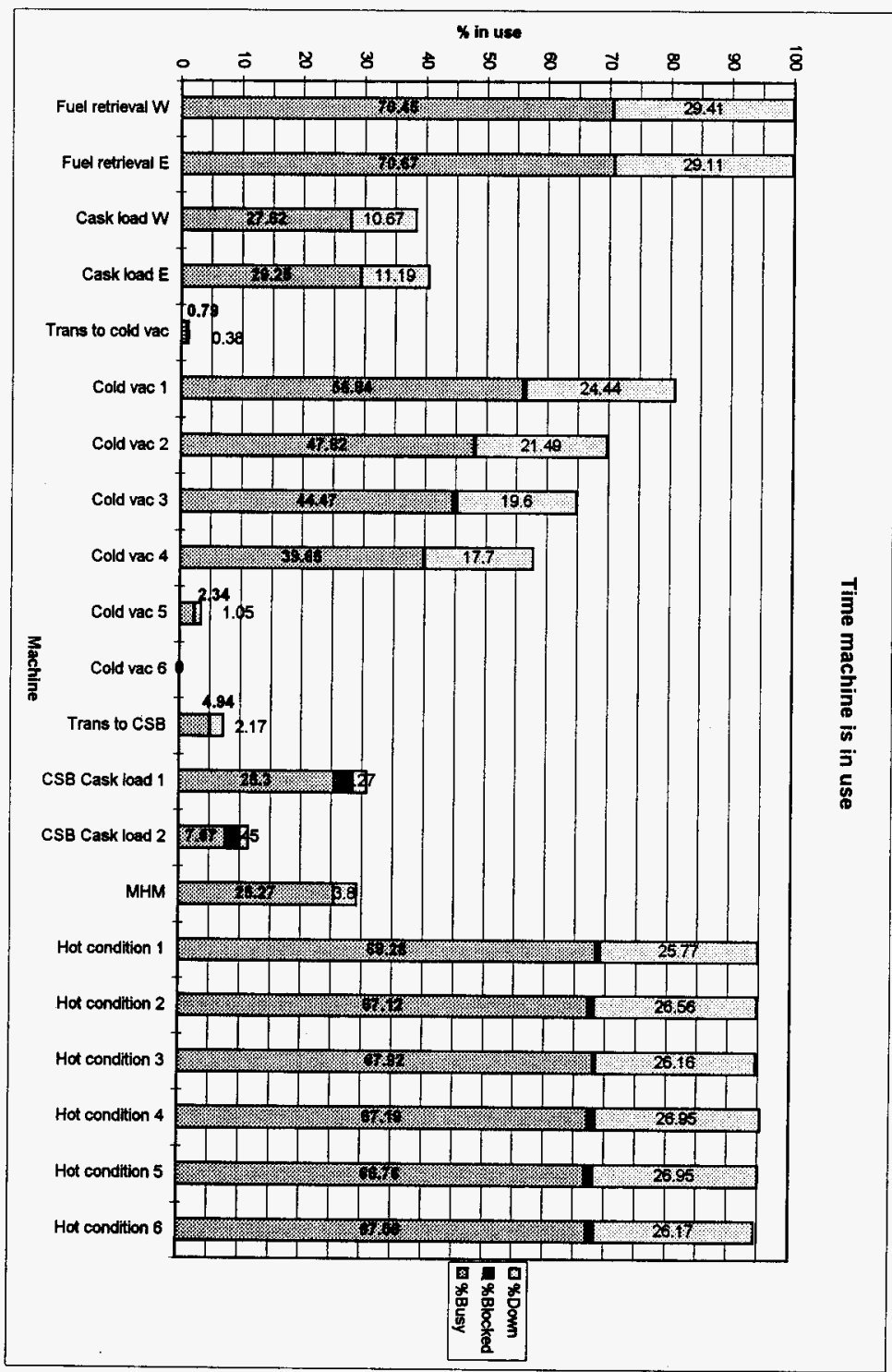

$\frac{1}{8}$ 
SNF Project operating 3 shifts, 7 days/week with two loadin/loadout pits in the CSB

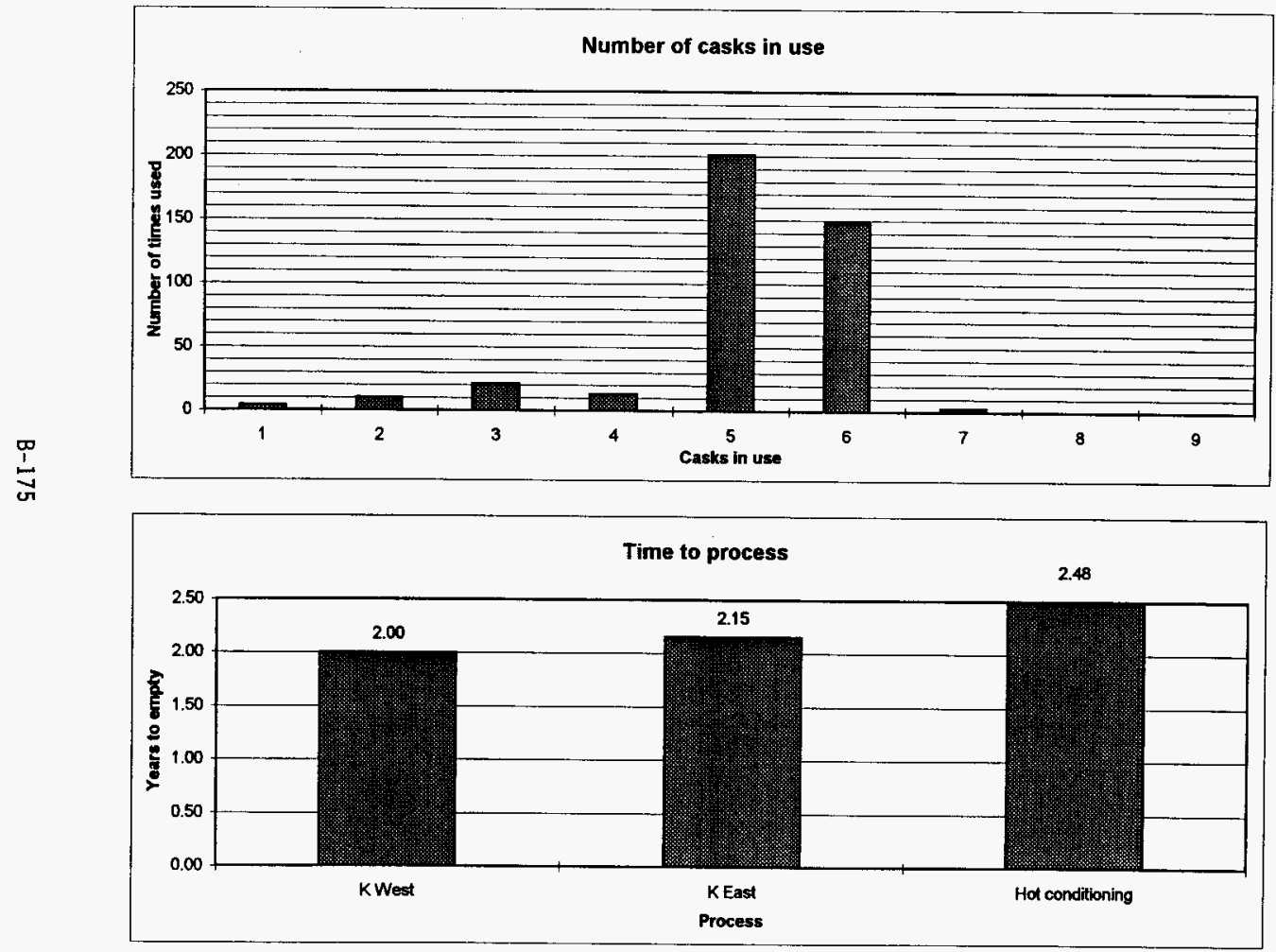




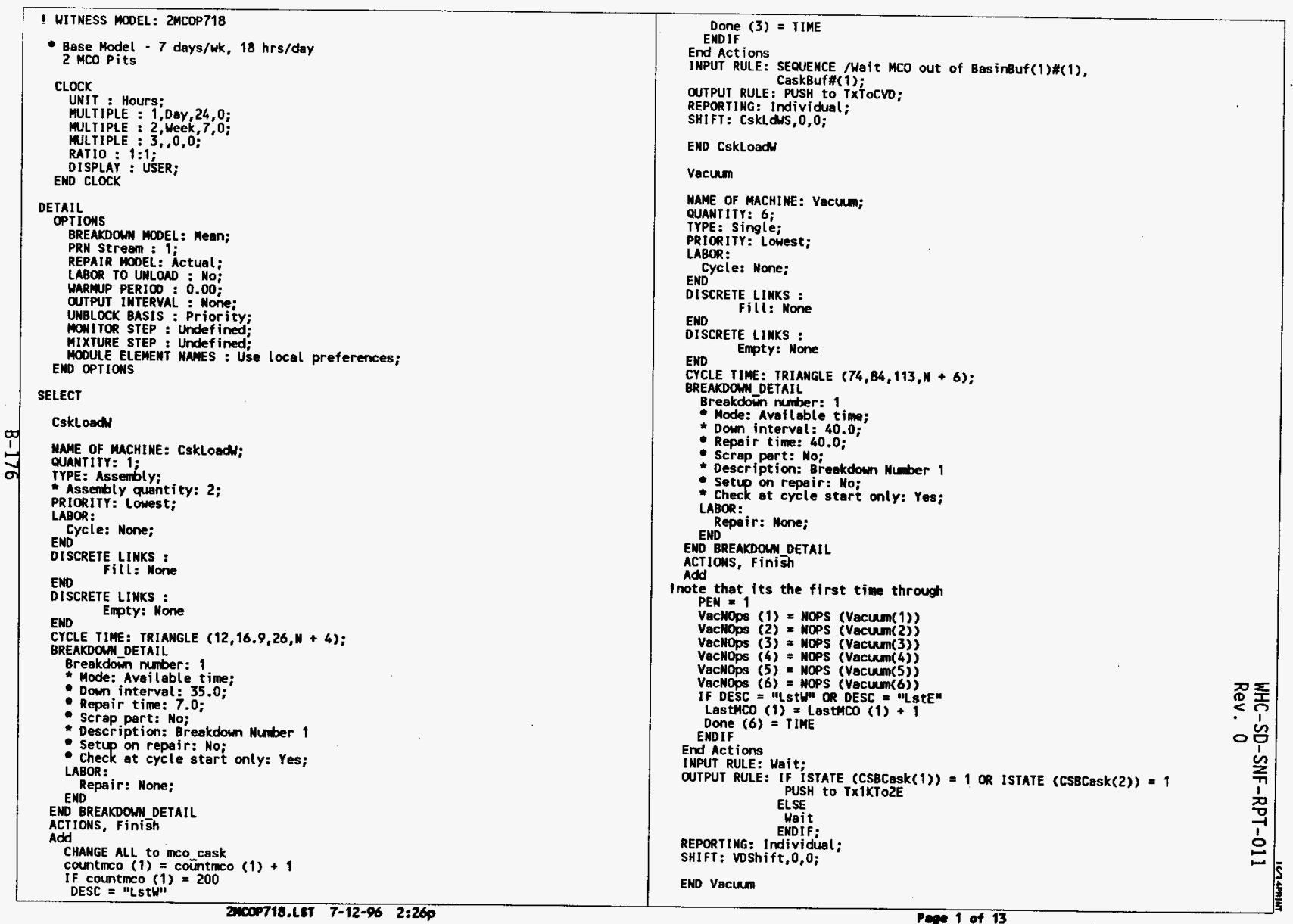




\begin{tabular}{|c|c|c|}
\hline 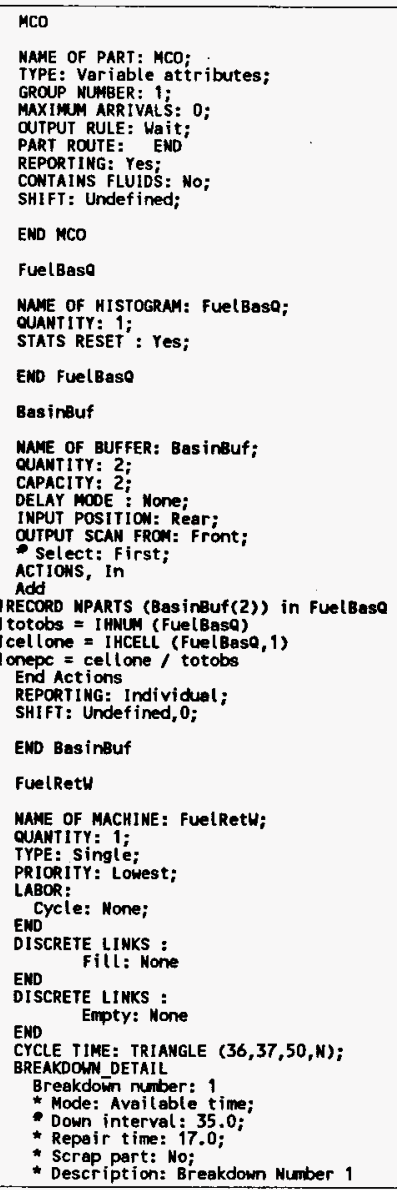 & 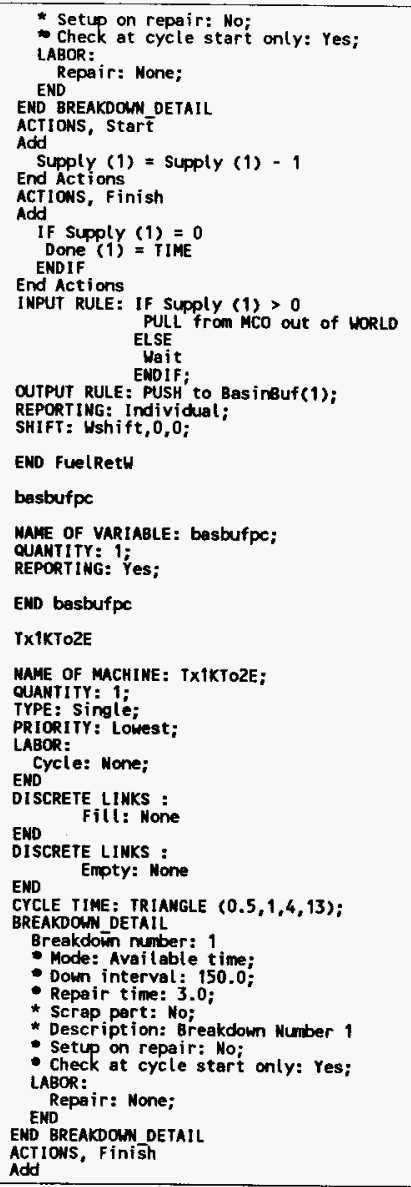 & 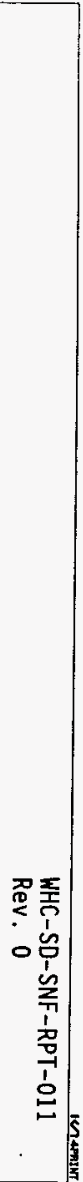 \\
\hline
\end{tabular}




\begin{tabular}{|c|c|c|}
\hline 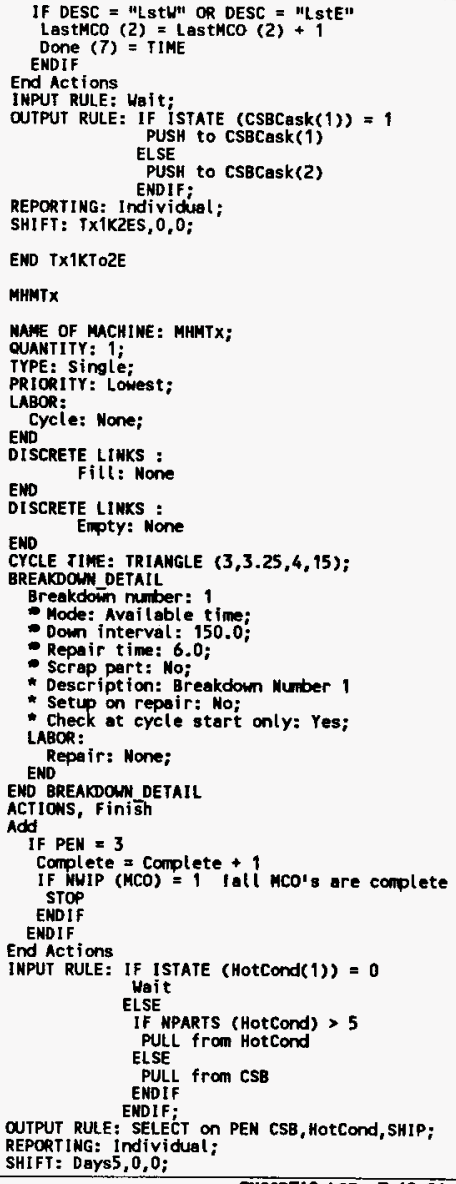 & 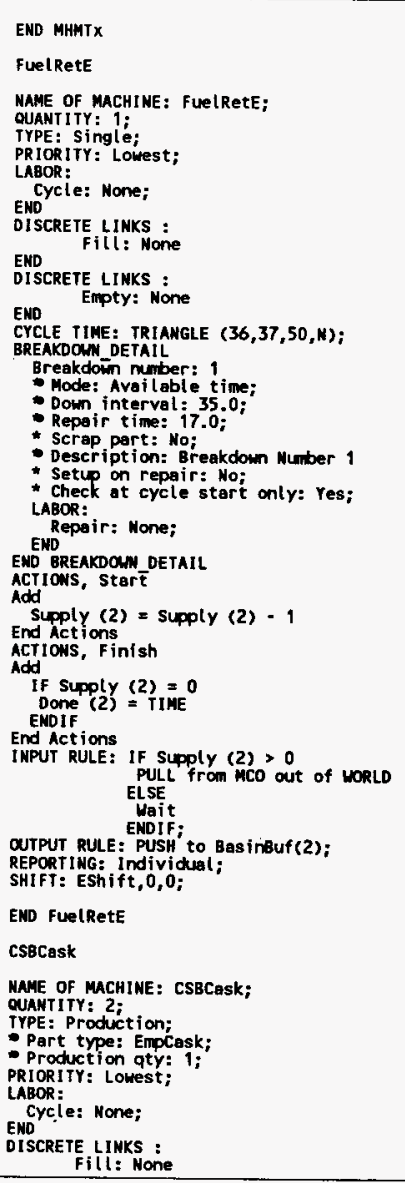 & 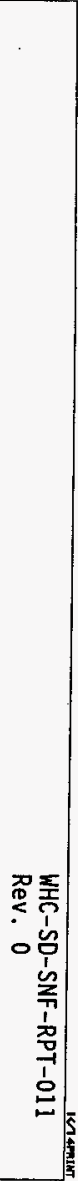 \\
\hline
\end{tabular}




\begin{tabular}{|c|c|c|}
\hline 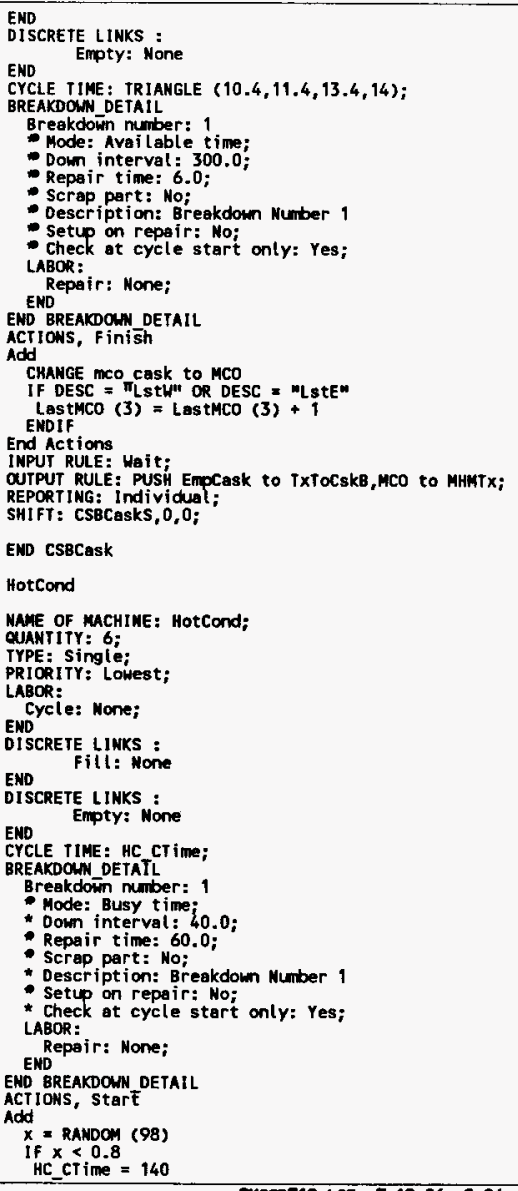 & 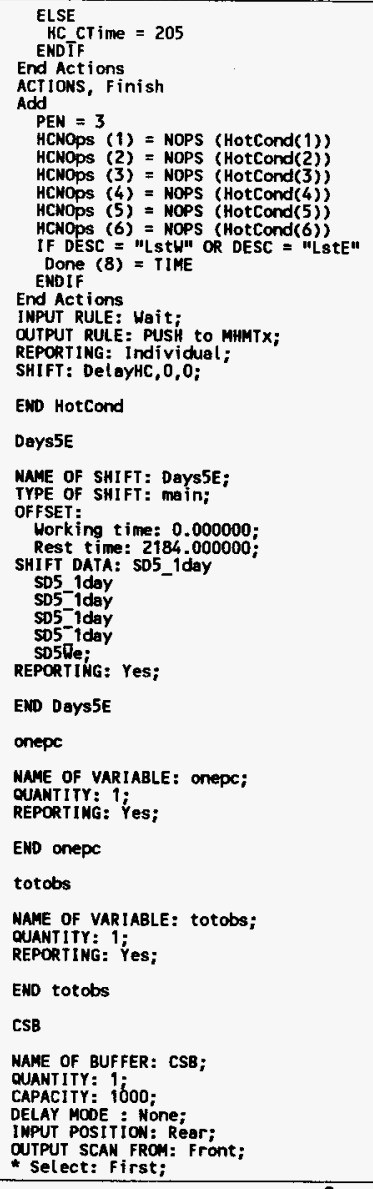 & 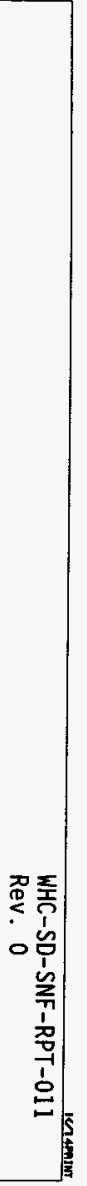 \\
\hline
\end{tabular}




\begin{tabular}{|c|c|c|}
\hline 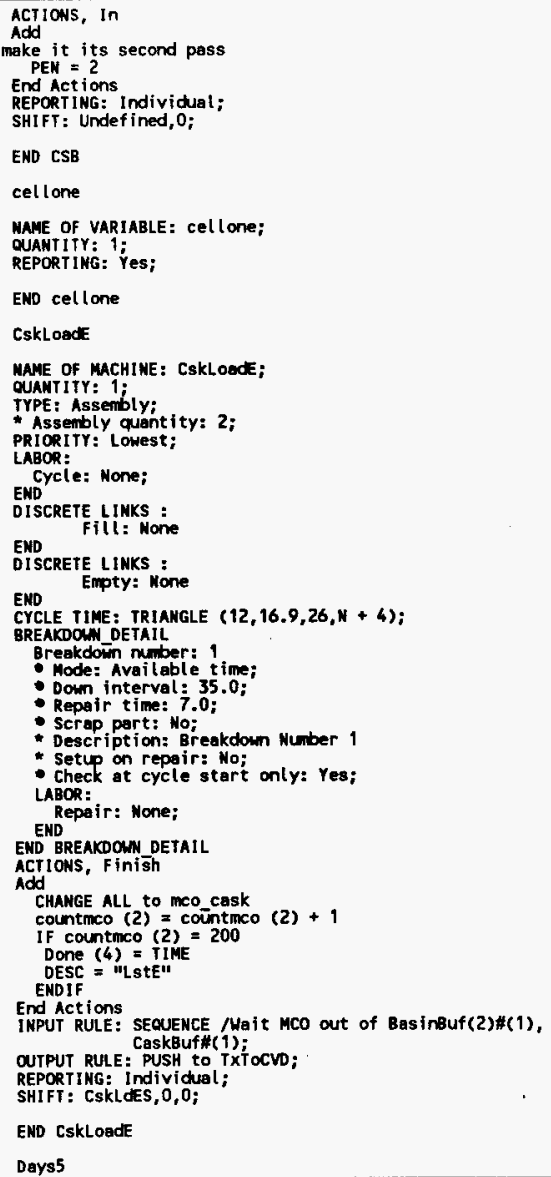 & 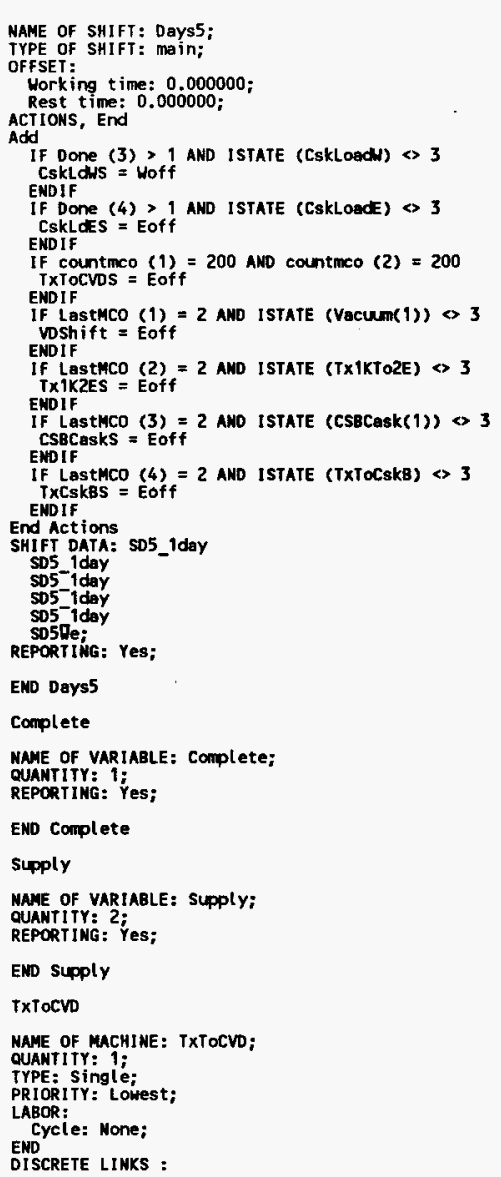 & 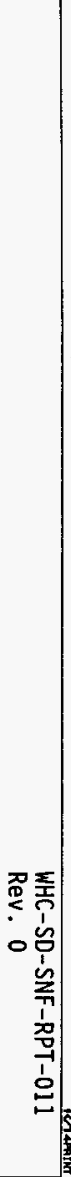 \\
\hline
\end{tabular}




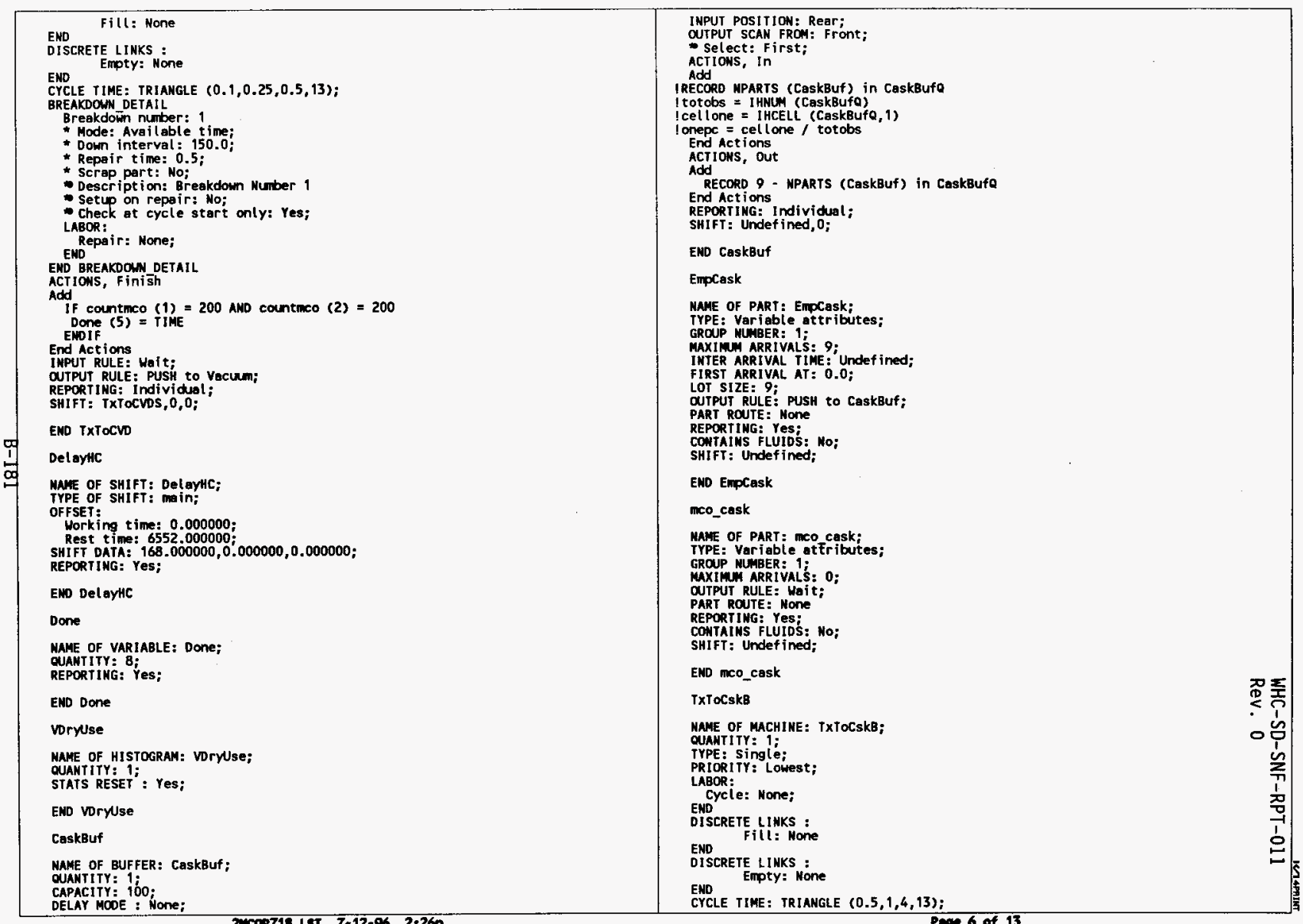




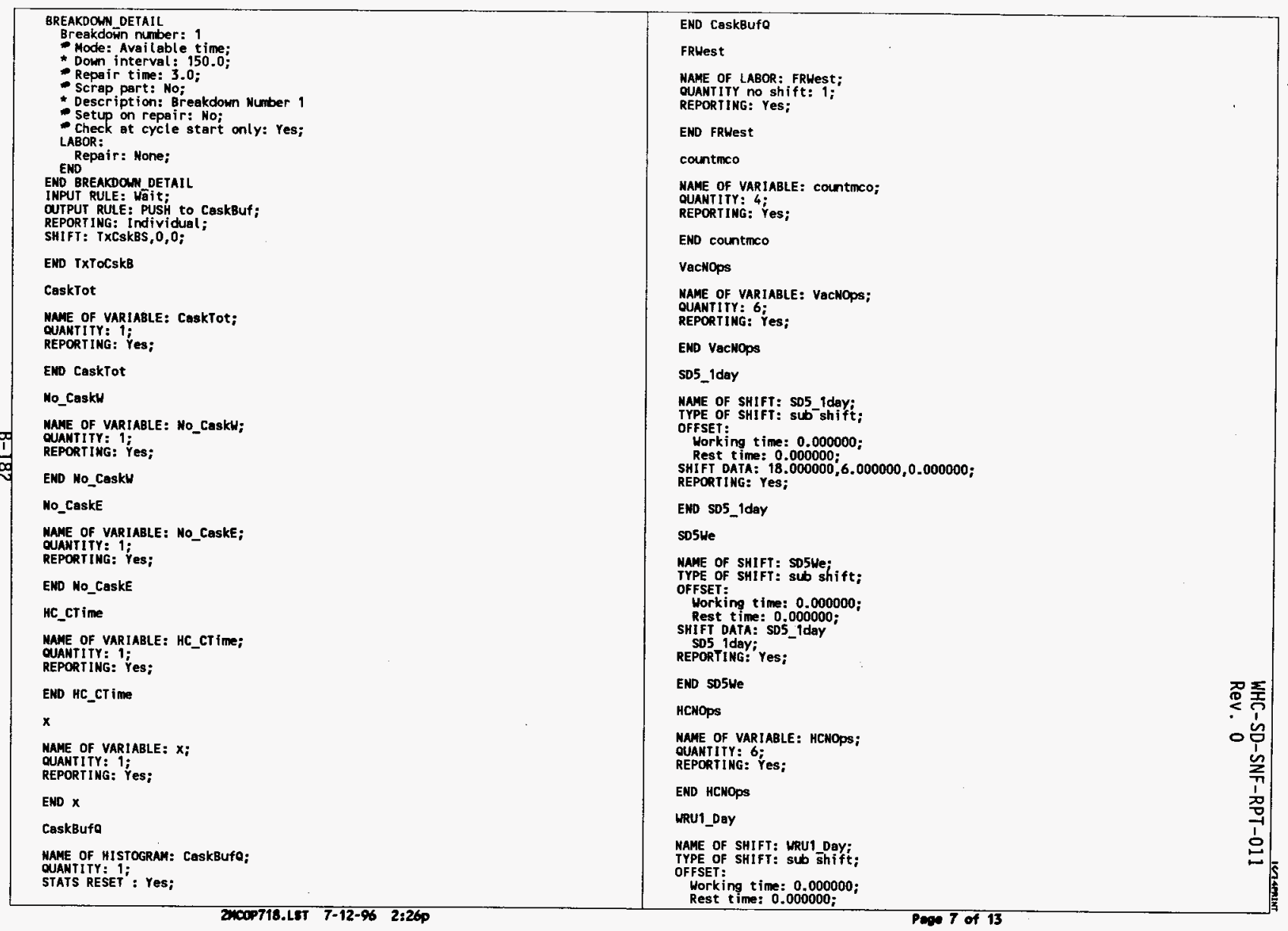




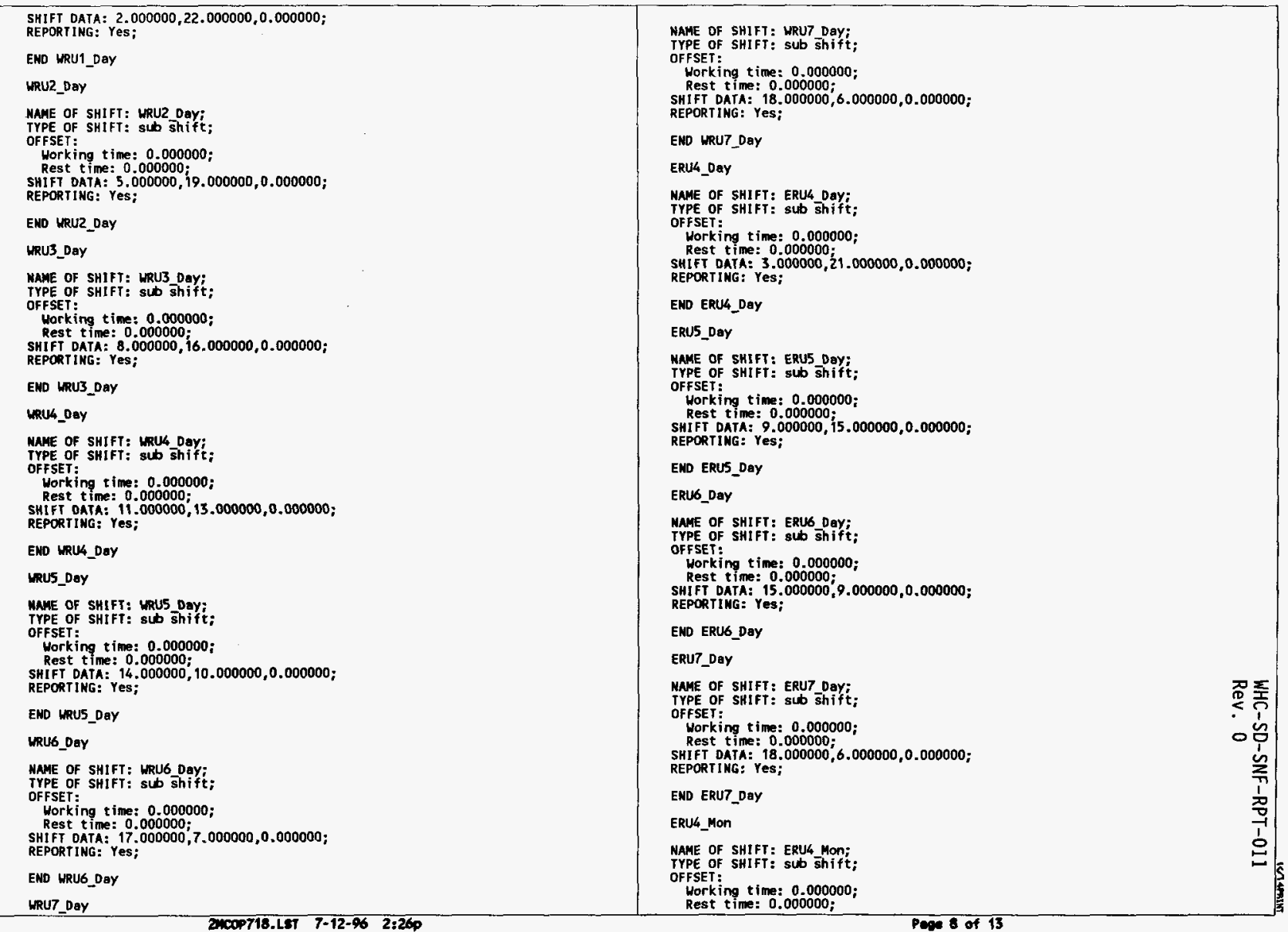




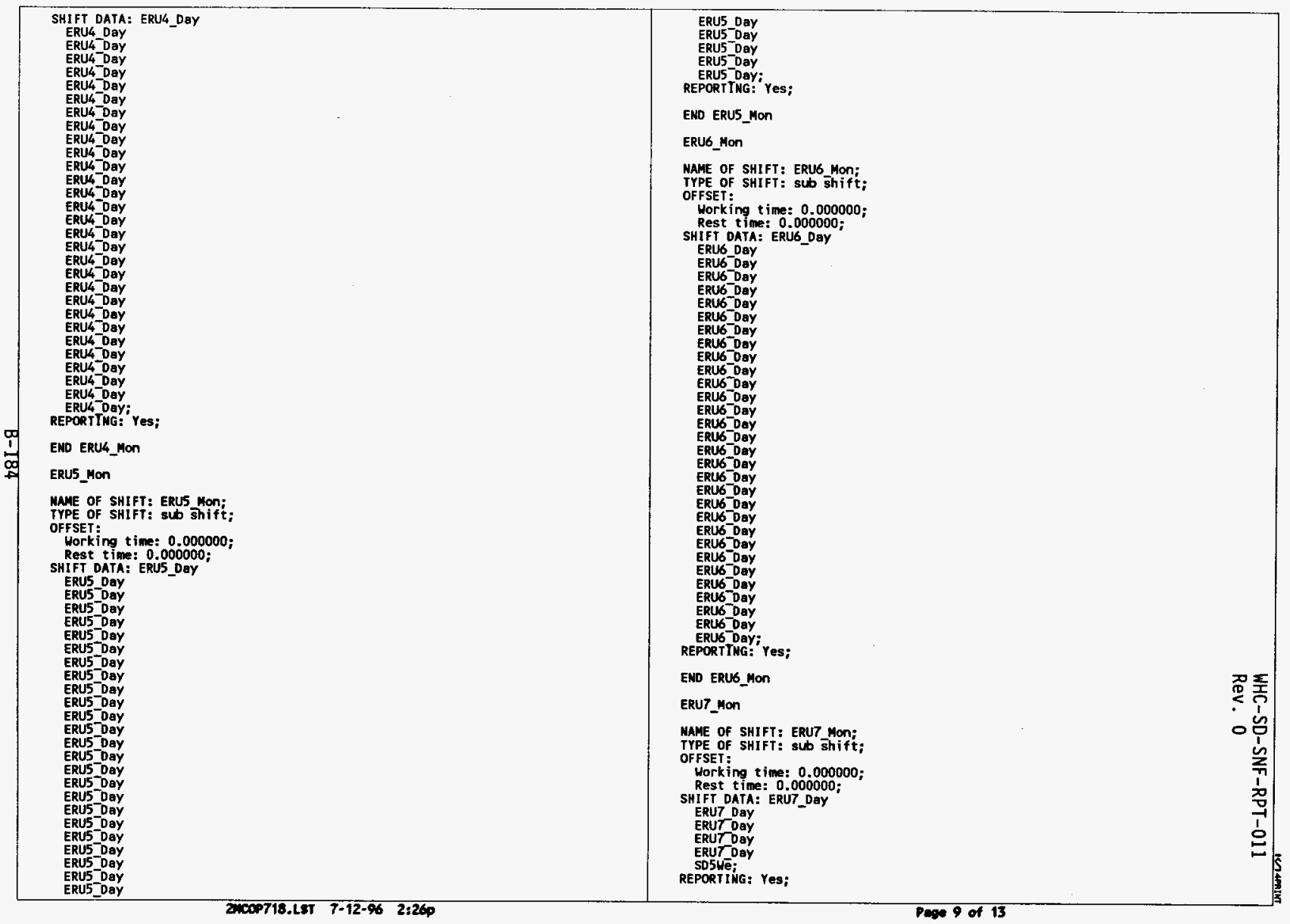




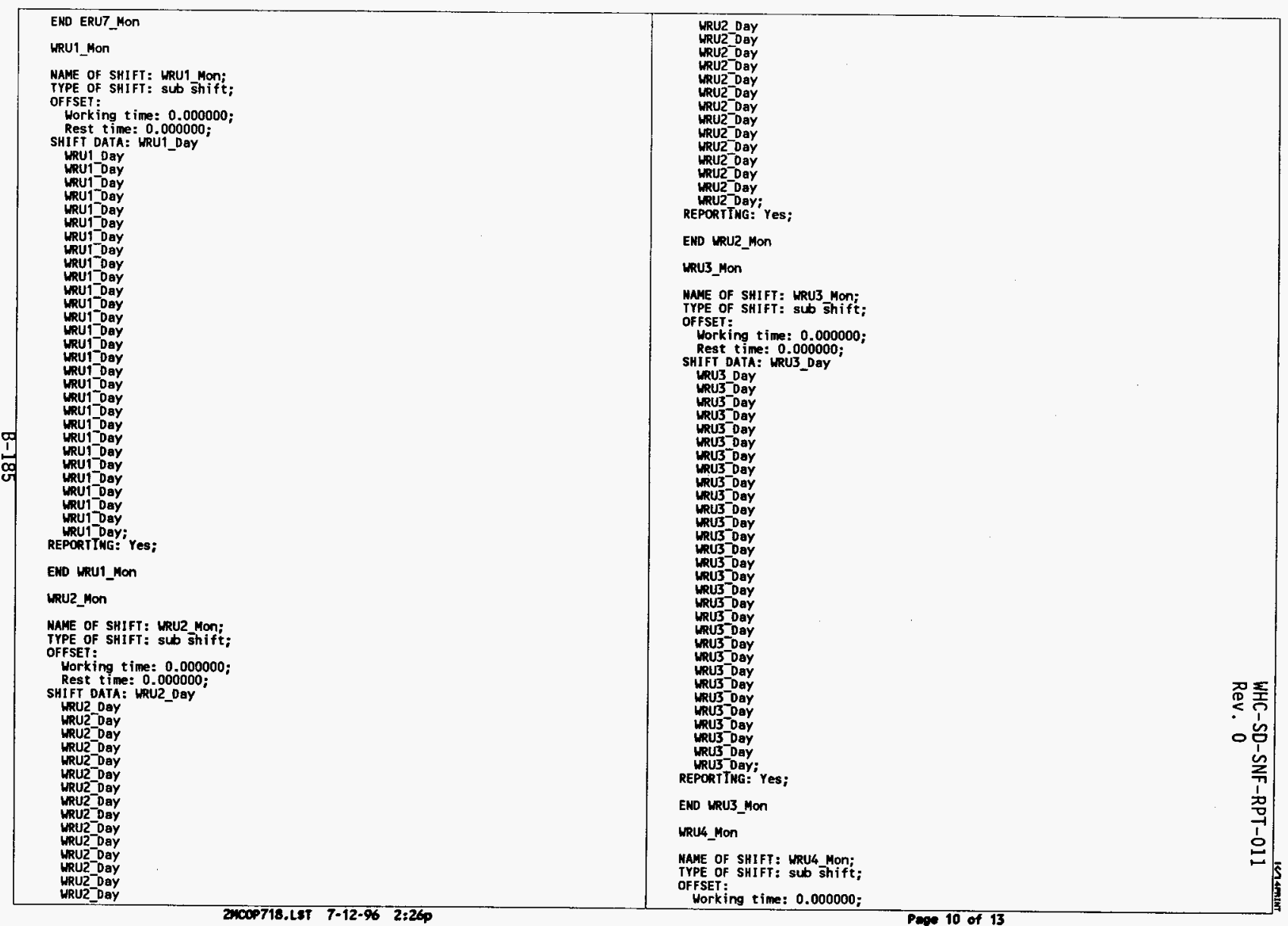




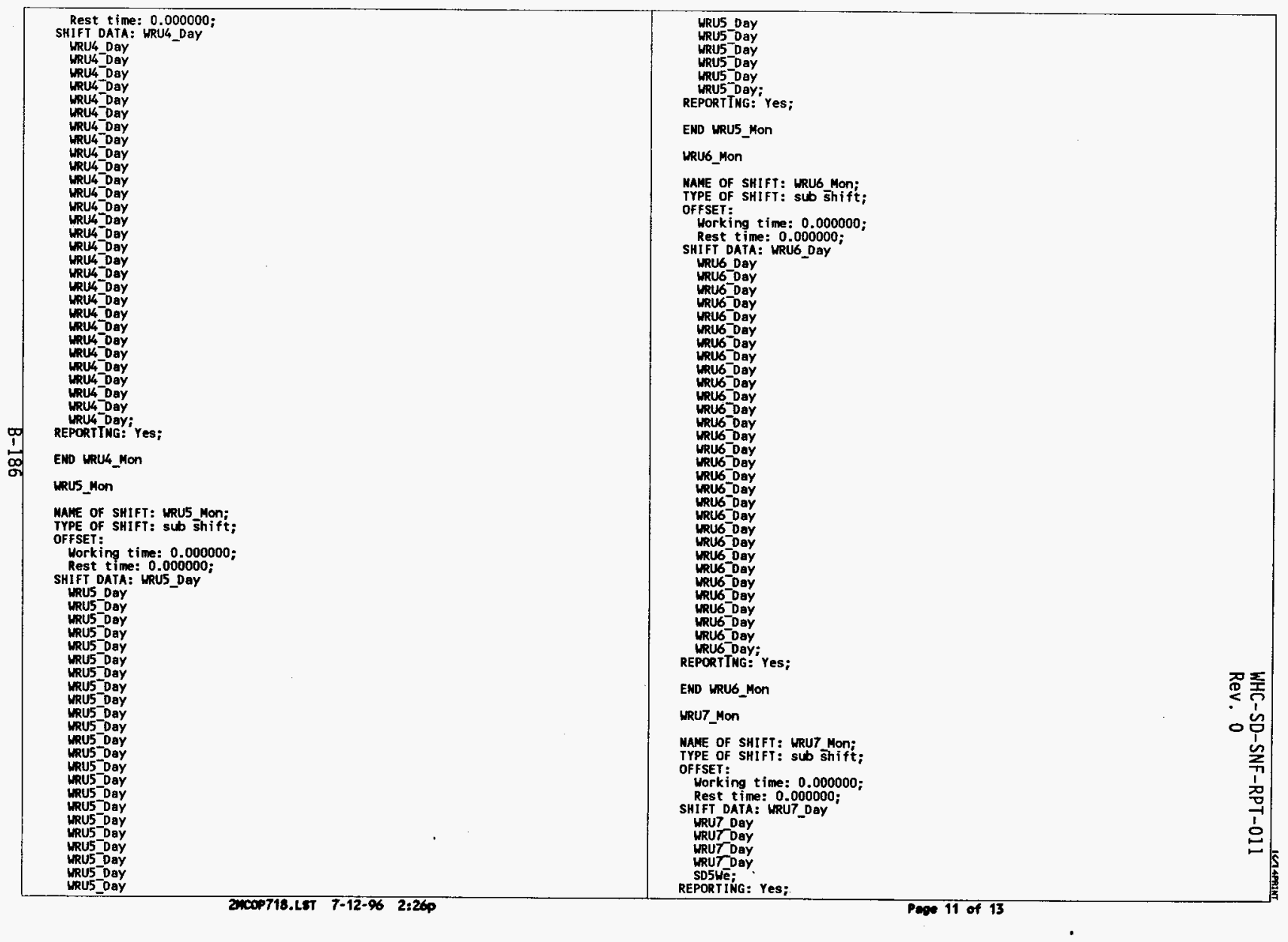




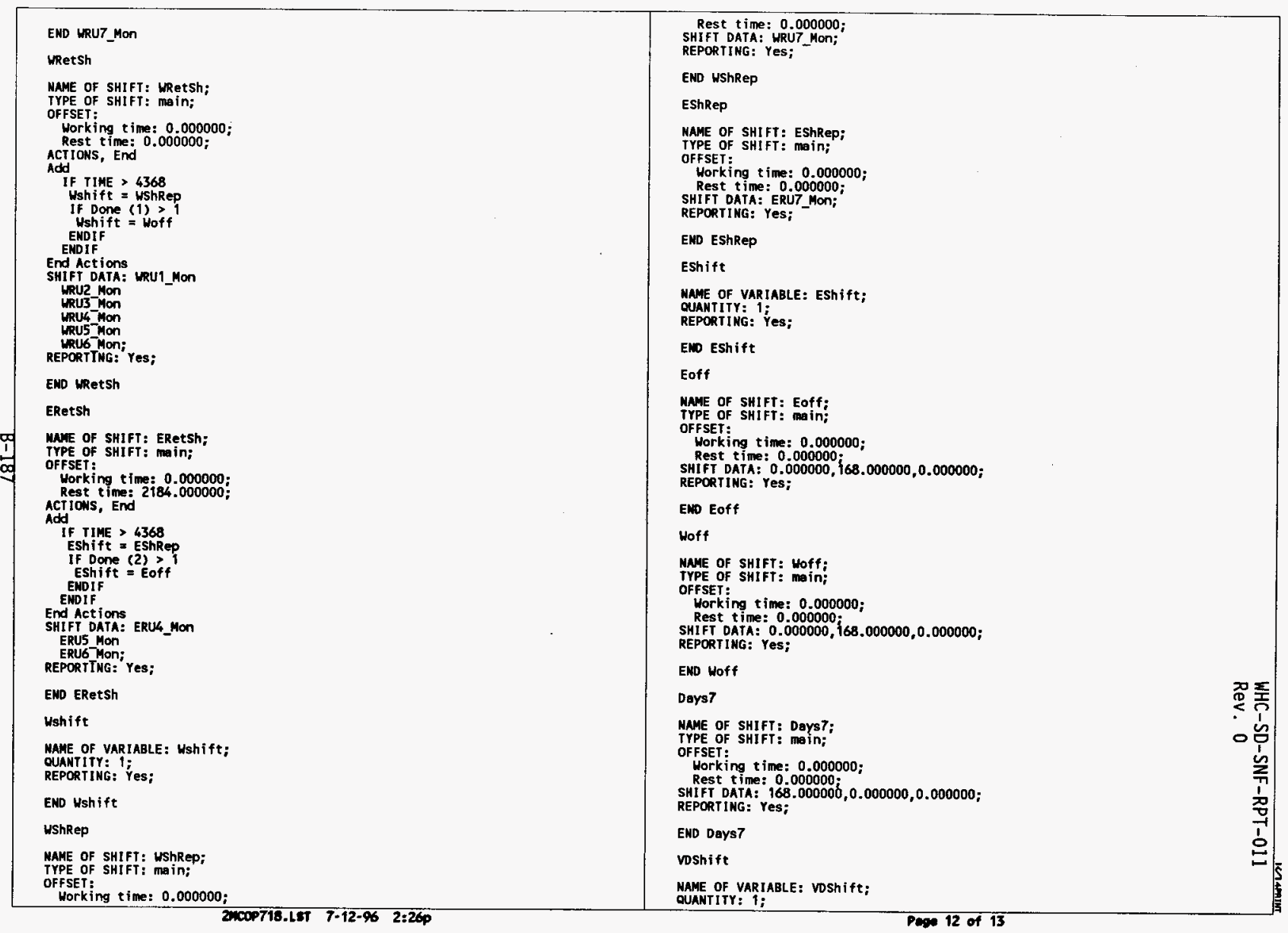




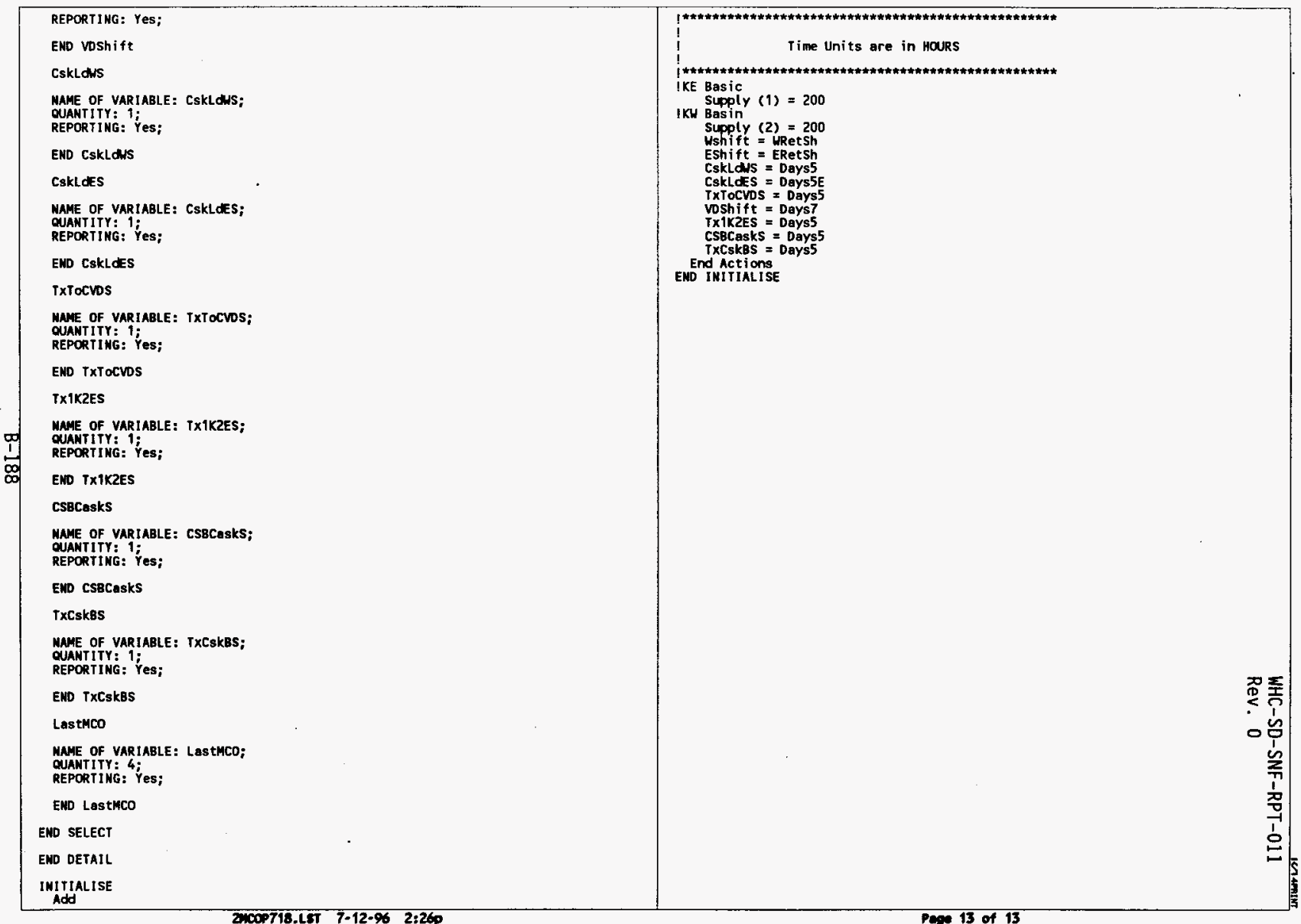


WHC-SD-SNF-RPT-011

Rev. 0

CASE 11. THREE BHR SHIFTS/DAY, 7 DAYS/WEEK. USING 5 HOT CONDITIONING STATIONS. 
SNF Project operating 3 shifts, 7 days/week. Hot conditioning has 5 stations.

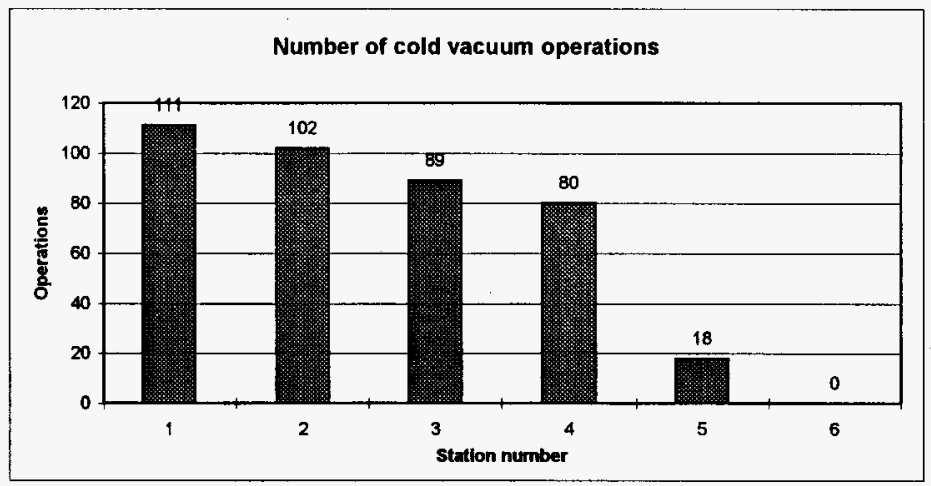

0
1
0
8

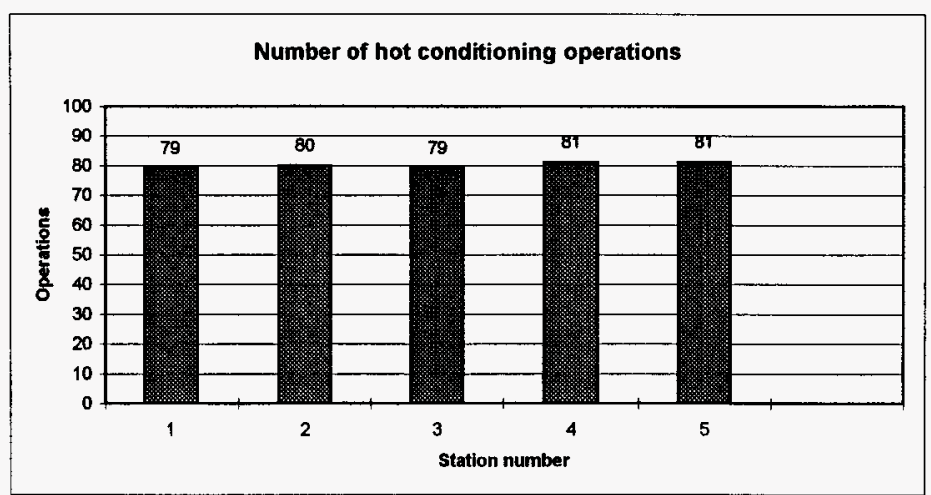




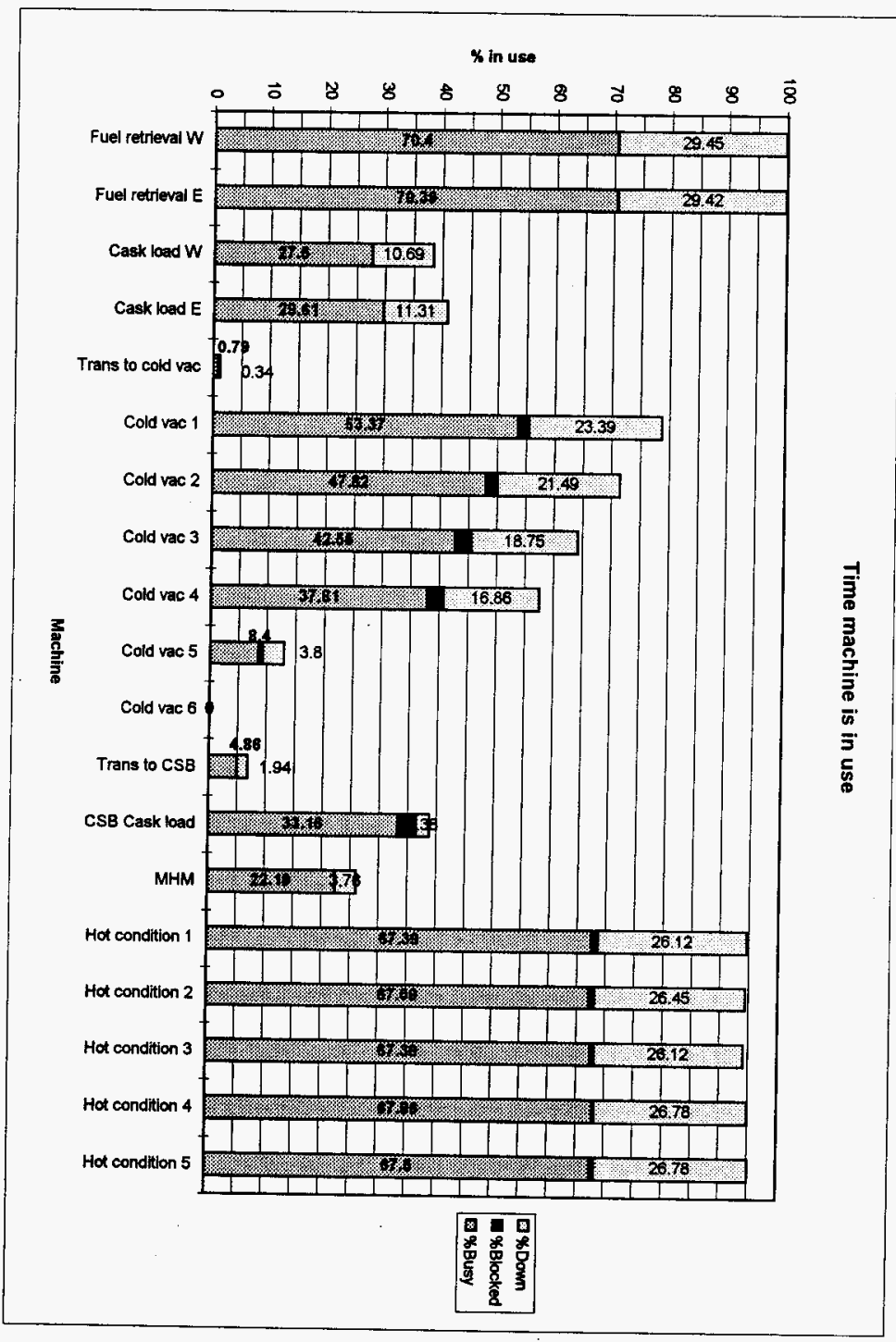

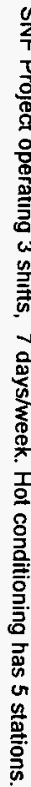

$\stackrel{1}{9}$ 
WHC-SD-SNF-RPT-011

Rev. 0
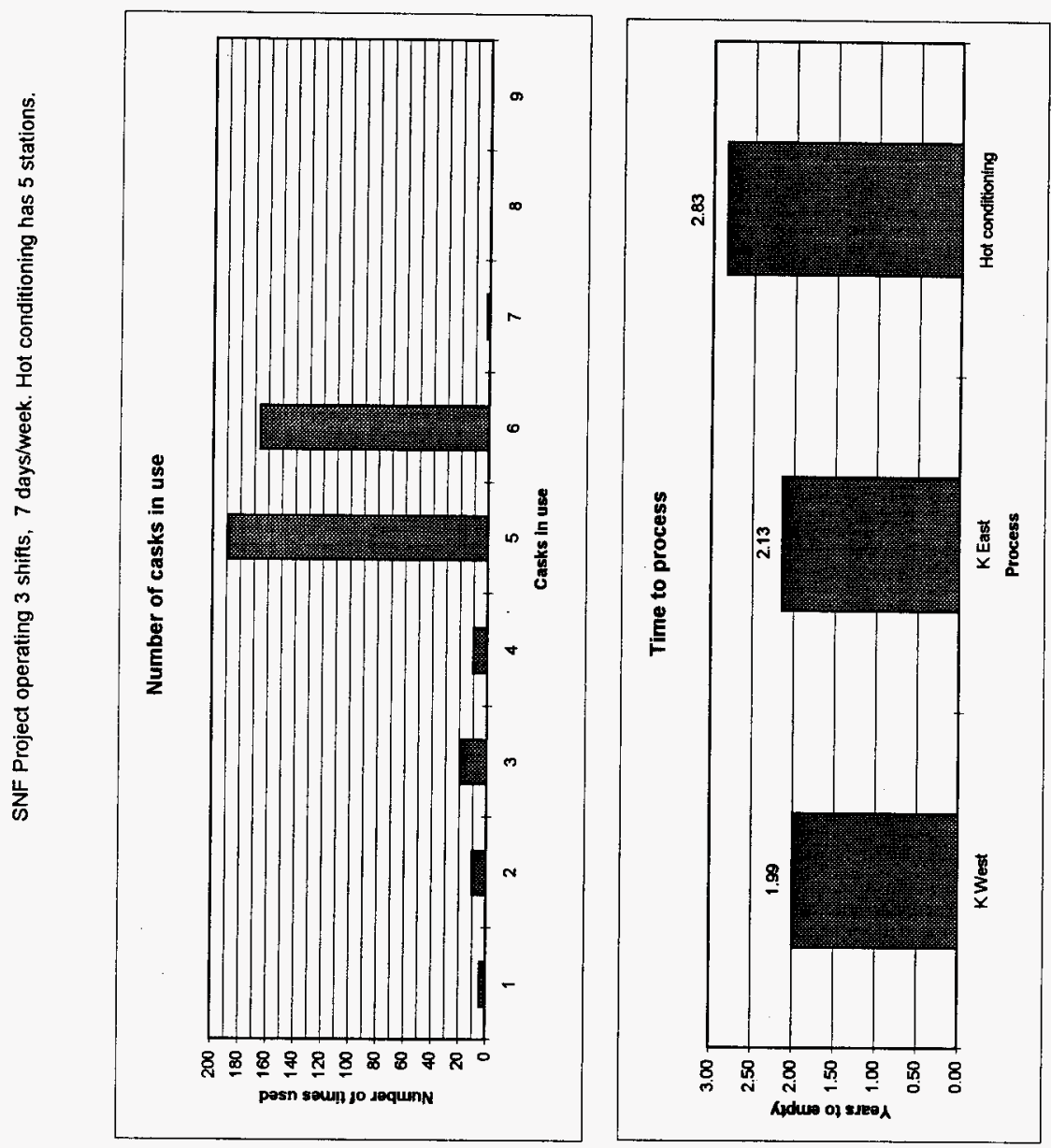

0
0
0
0 


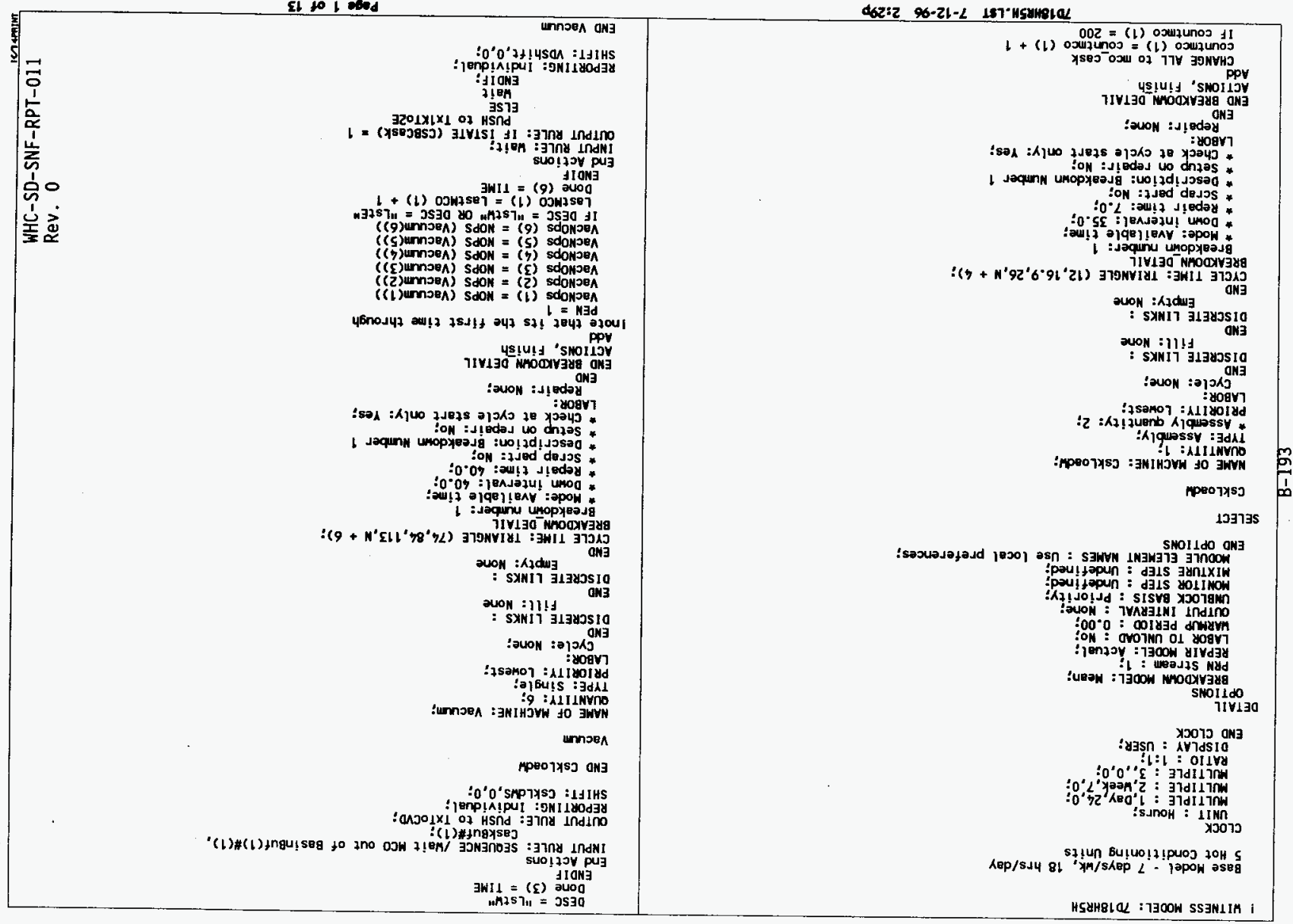




\begin{tabular}{|c|c|c|}
\hline 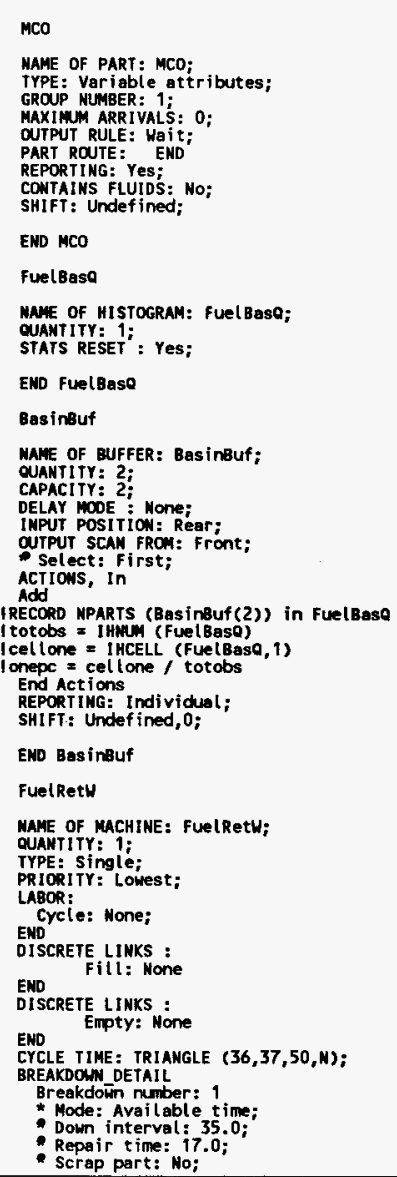 & 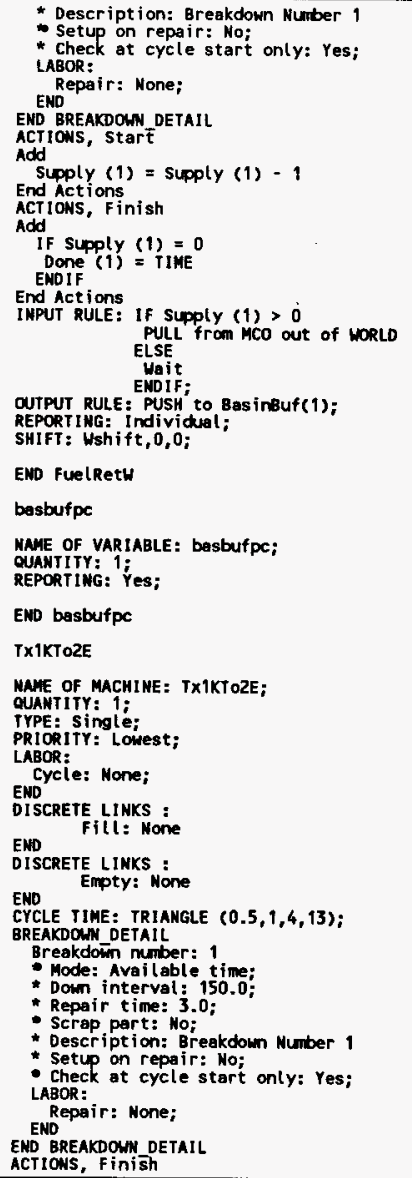 & 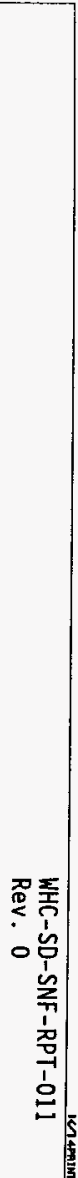 \\
\hline
\end{tabular}




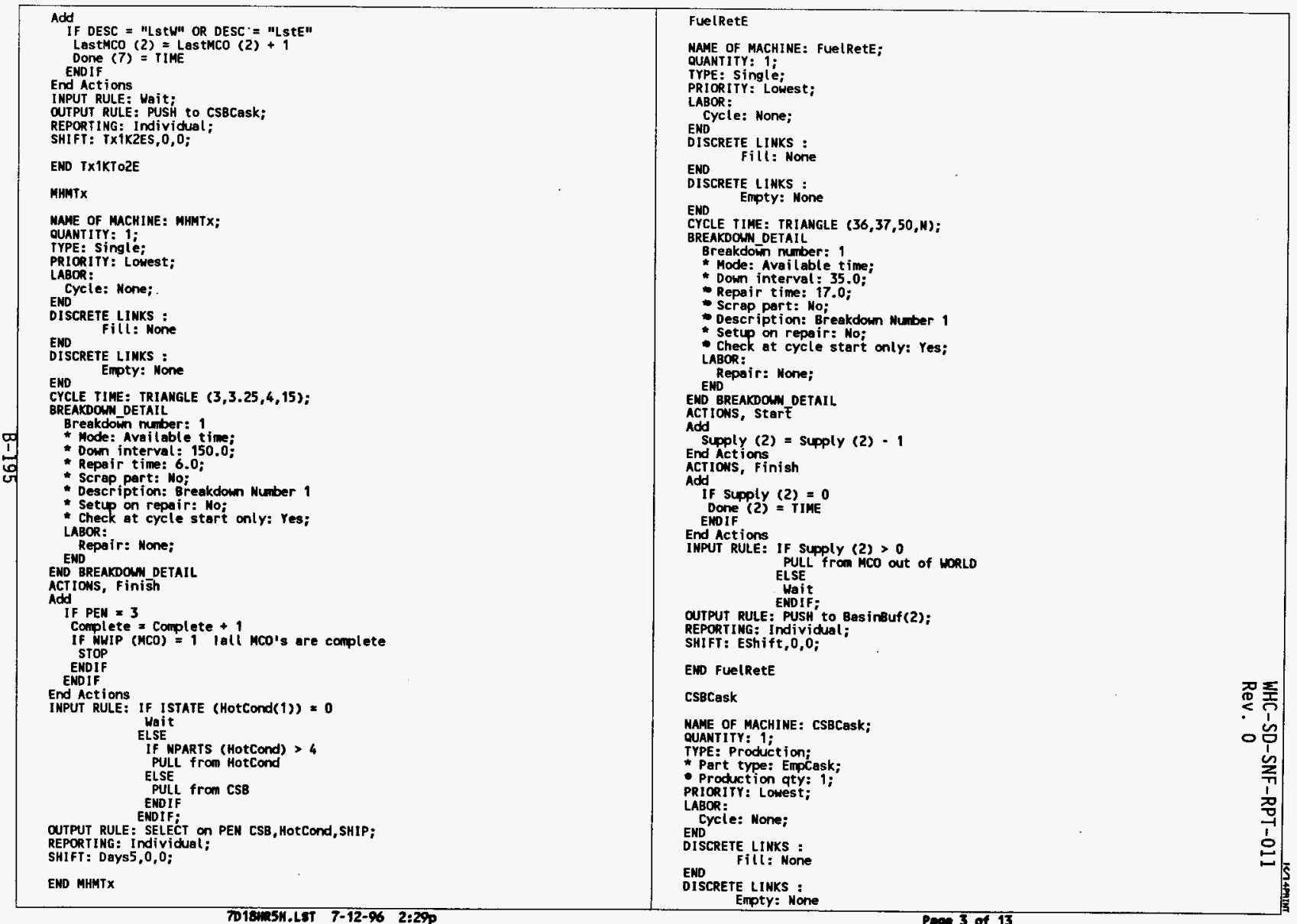




\begin{tabular}{|c|c|c|}
\hline 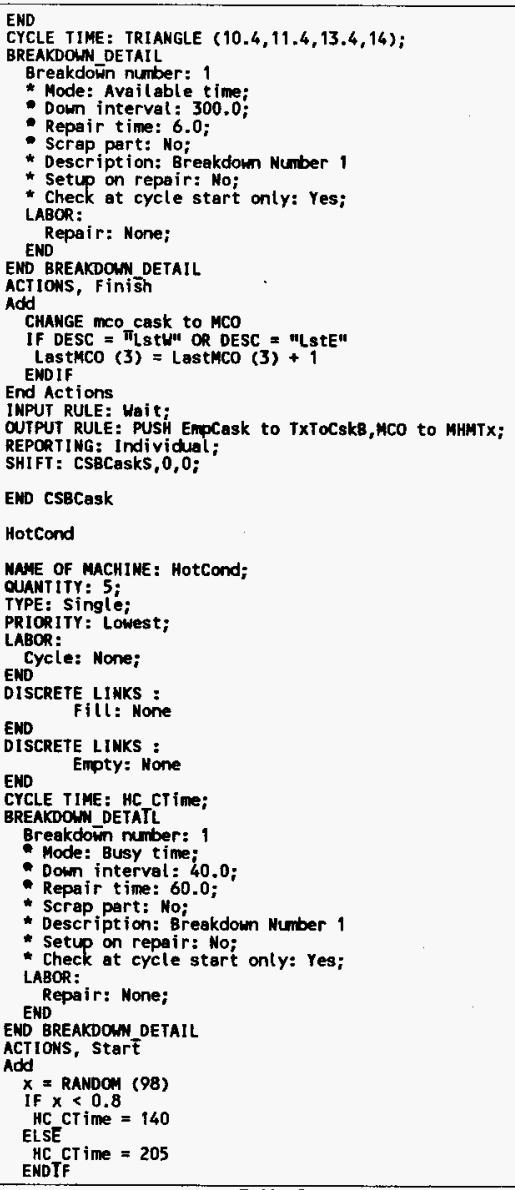 & 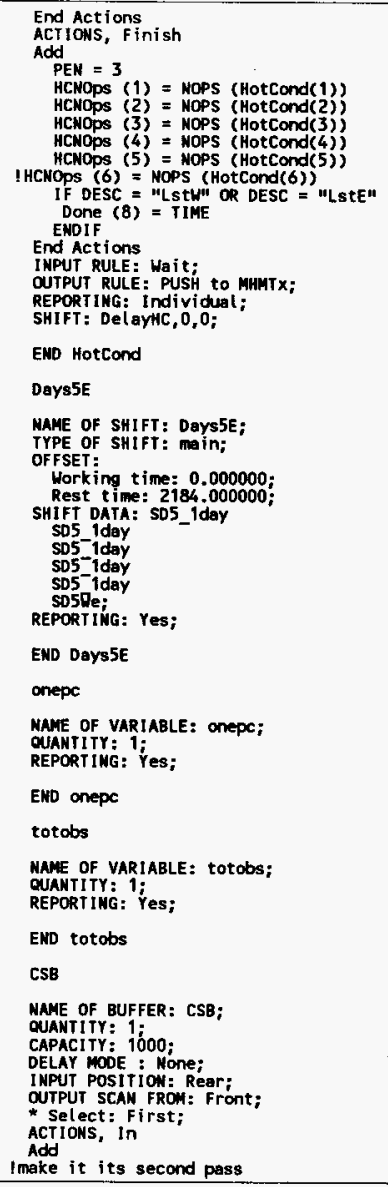 & 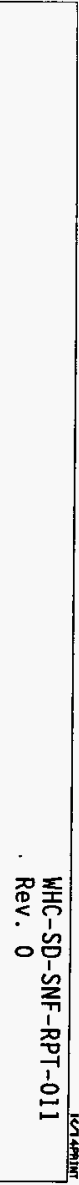 \\
\hline
\end{tabular}




\begin{tabular}{|c|c|}
\hline 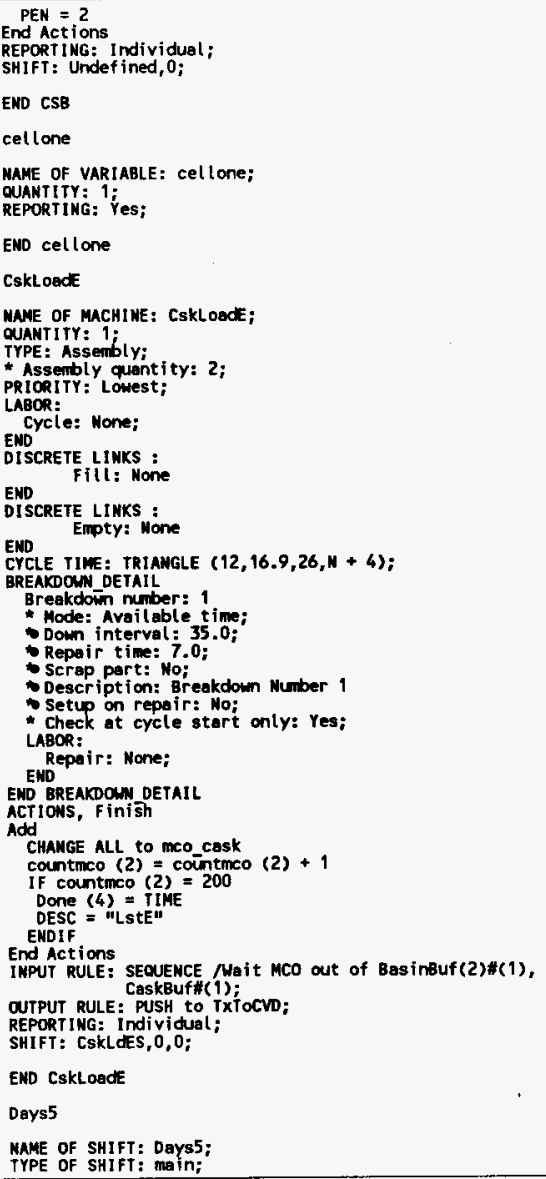 & 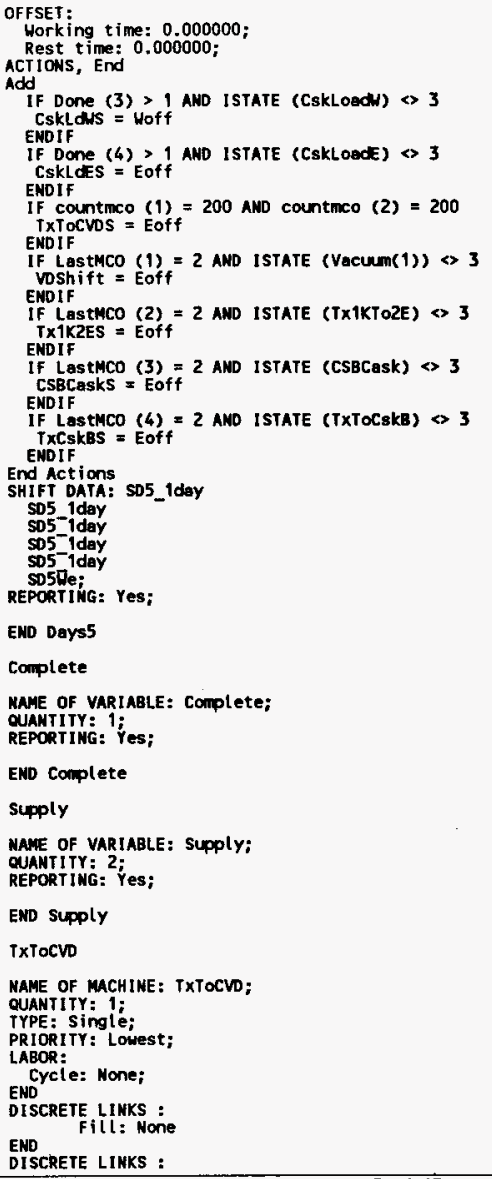 \\
\hline
\end{tabular}




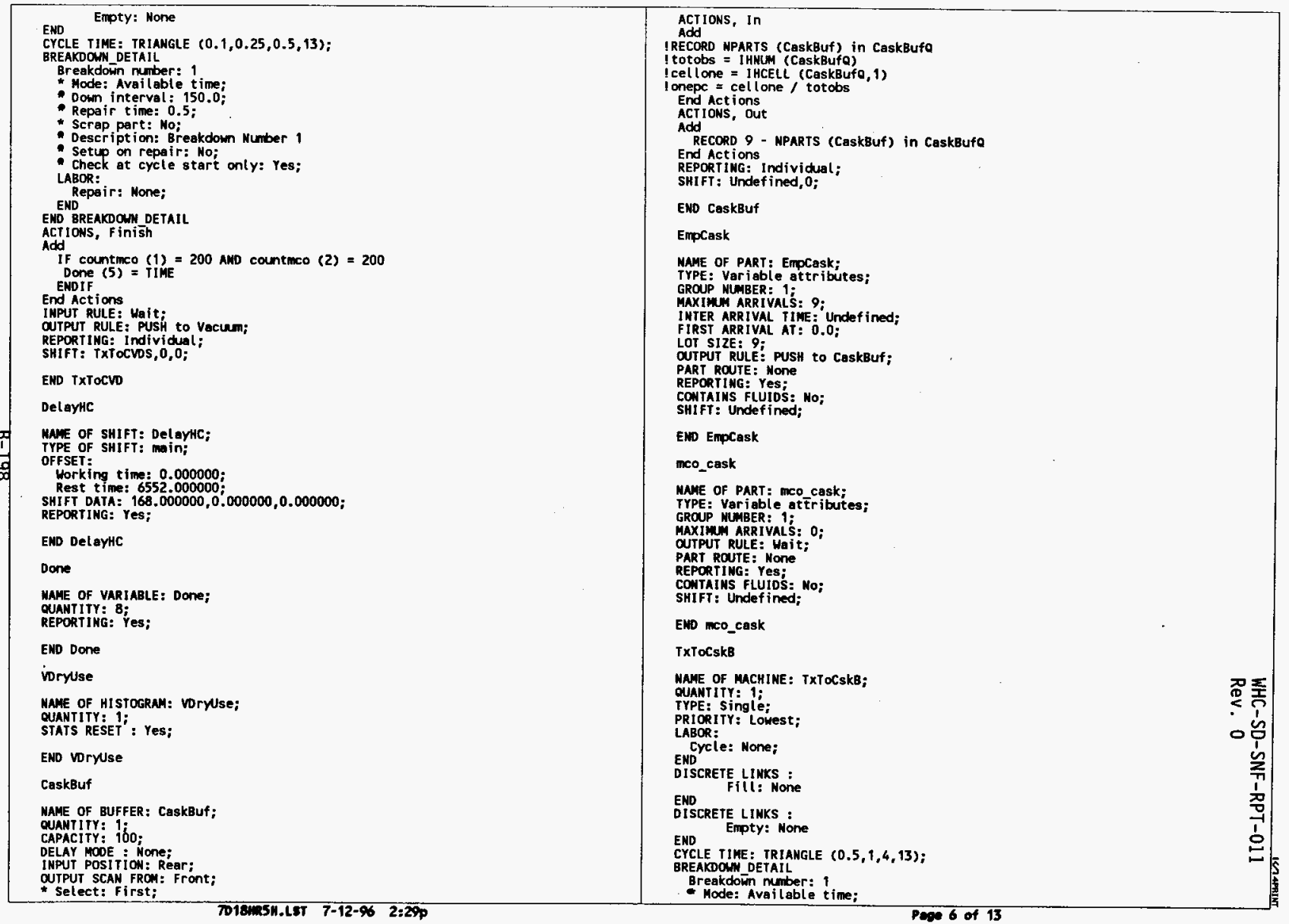




\begin{tabular}{|c|c|c|}
\hline 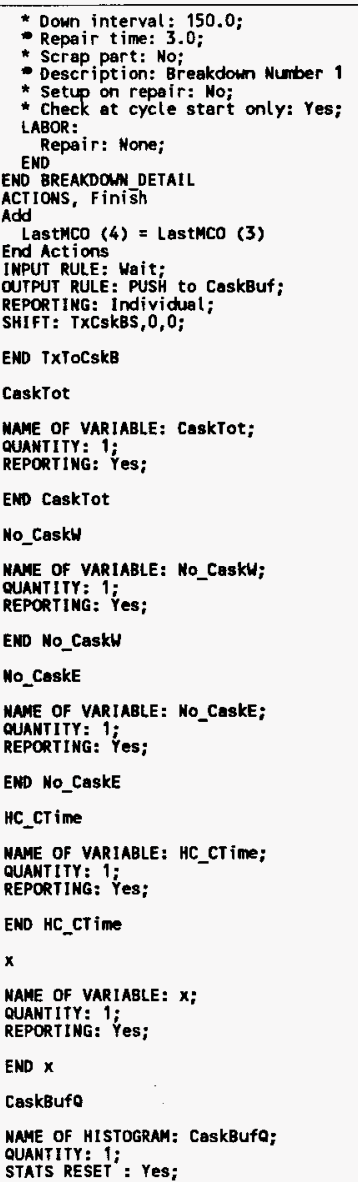 & 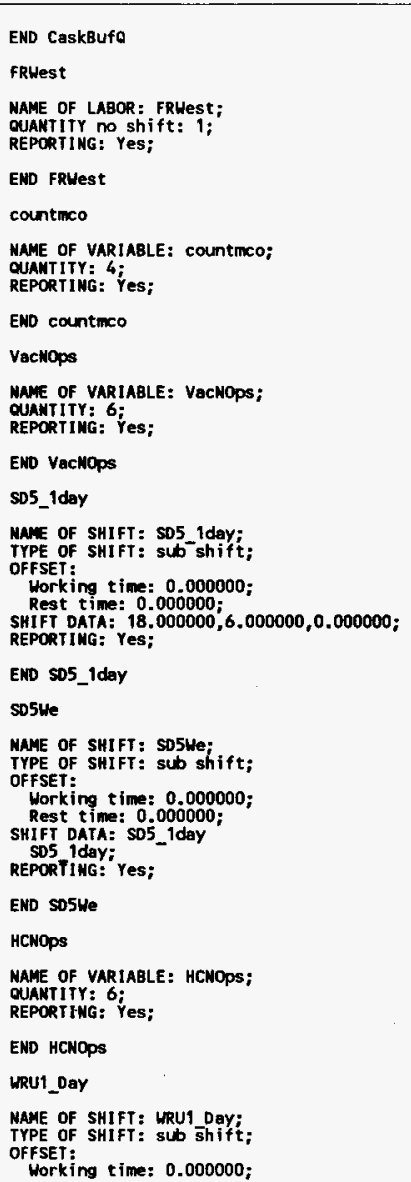 & 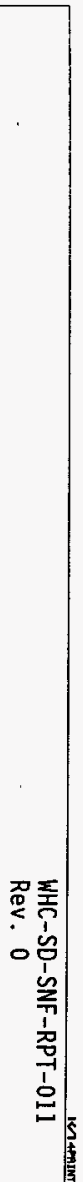 \\
\hline
\end{tabular}




\begin{tabular}{|c|c|c|}
\hline 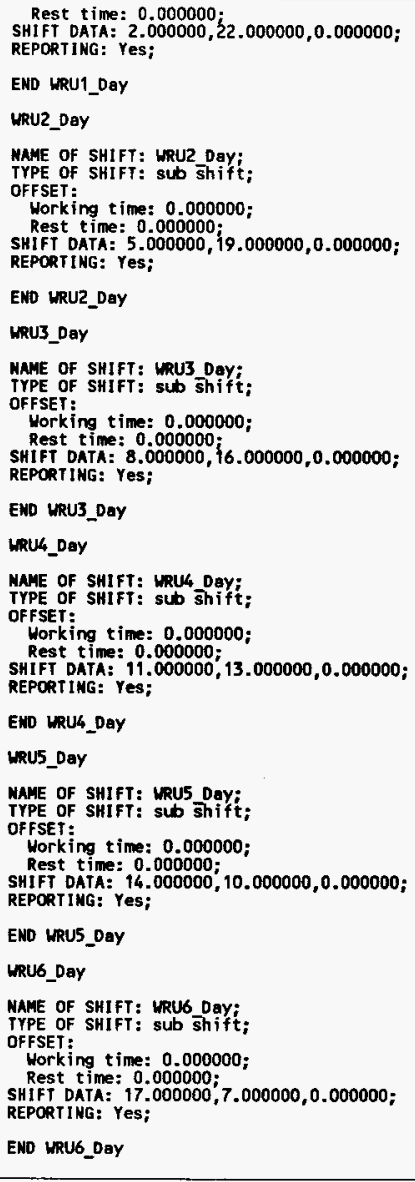 & 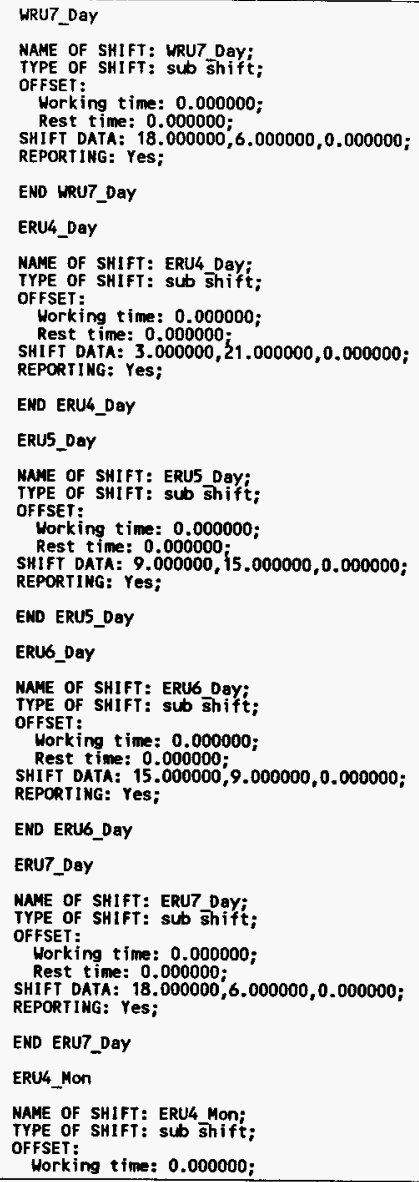 & \\
\hline
\end{tabular}




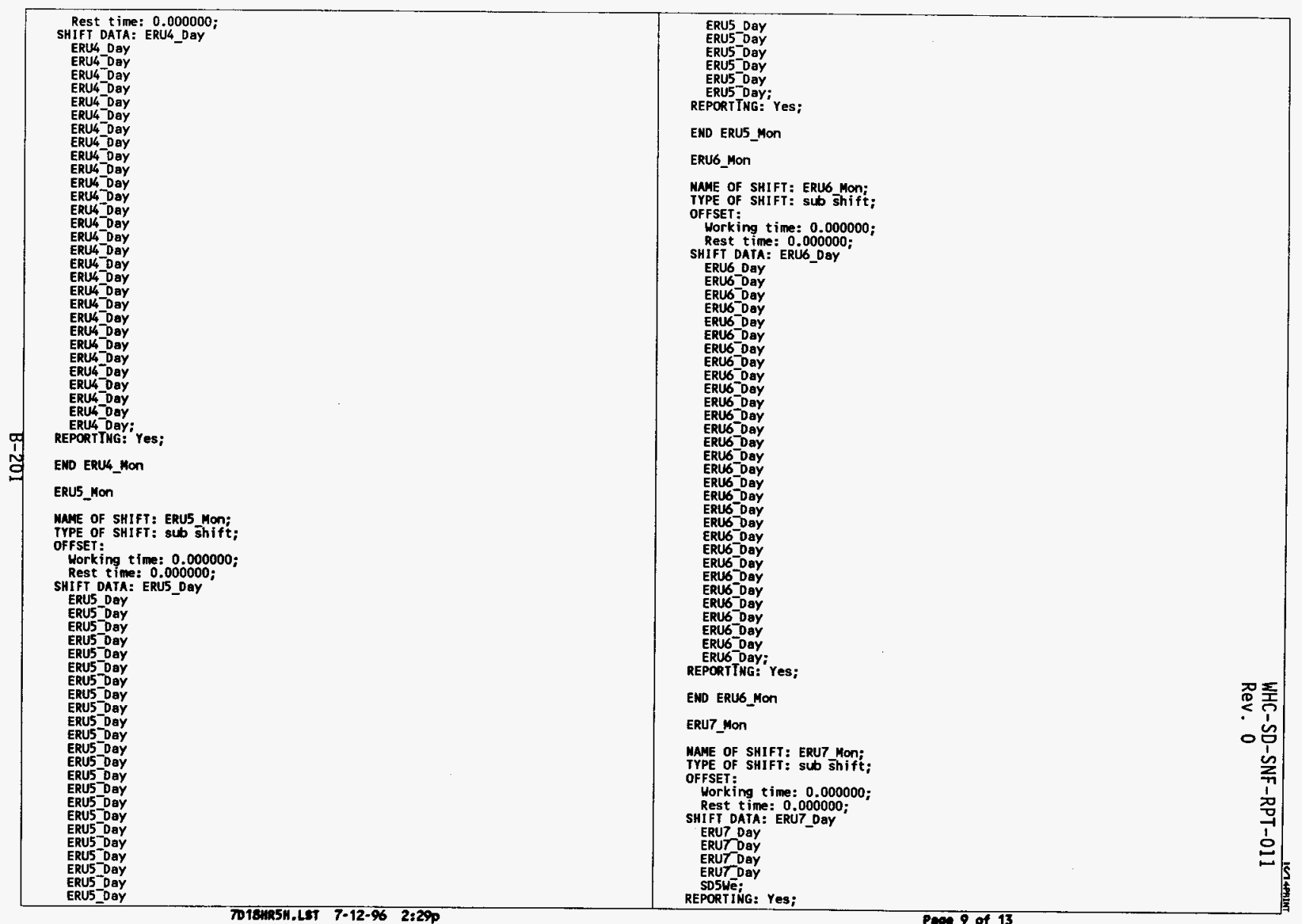




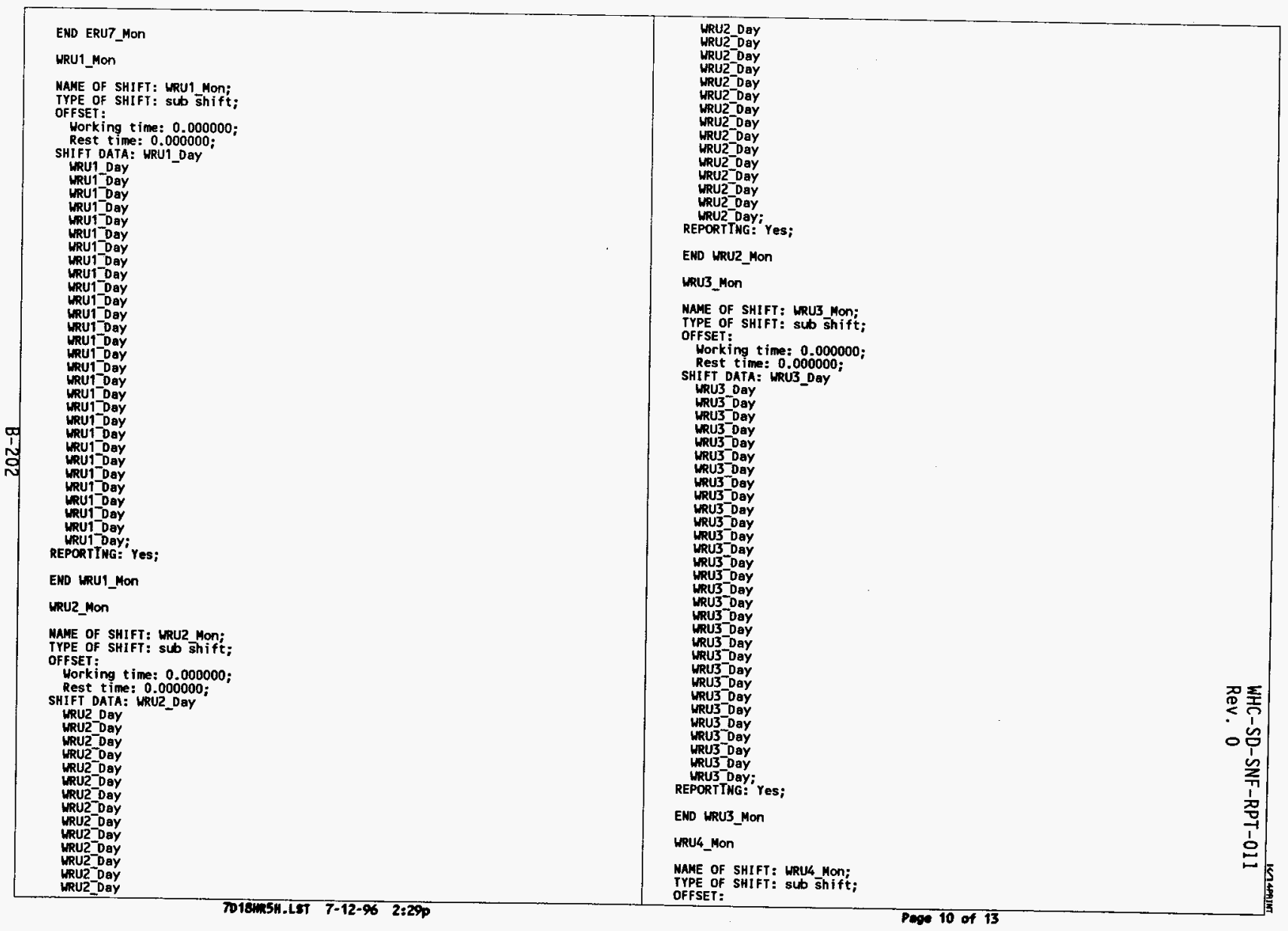




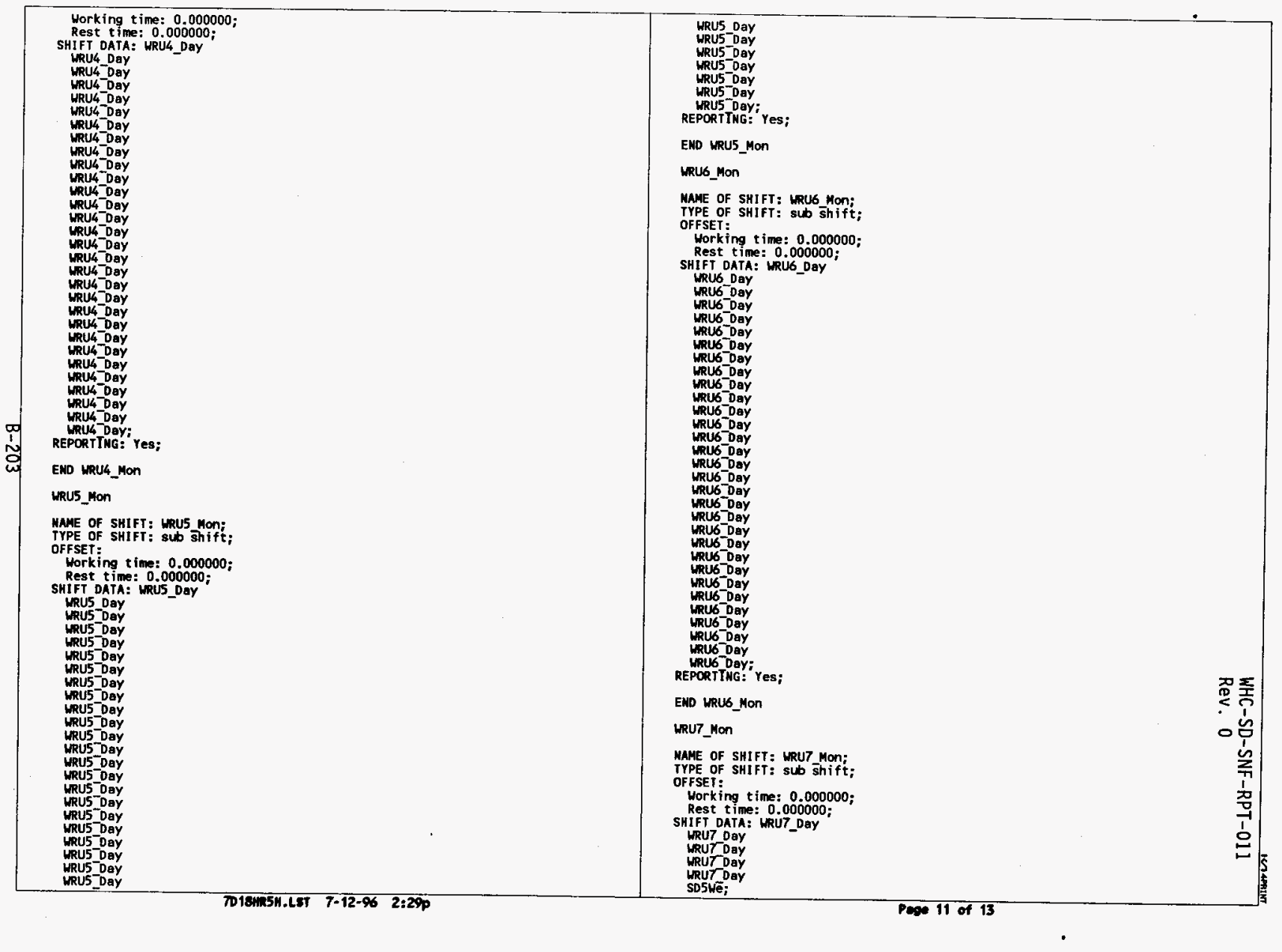




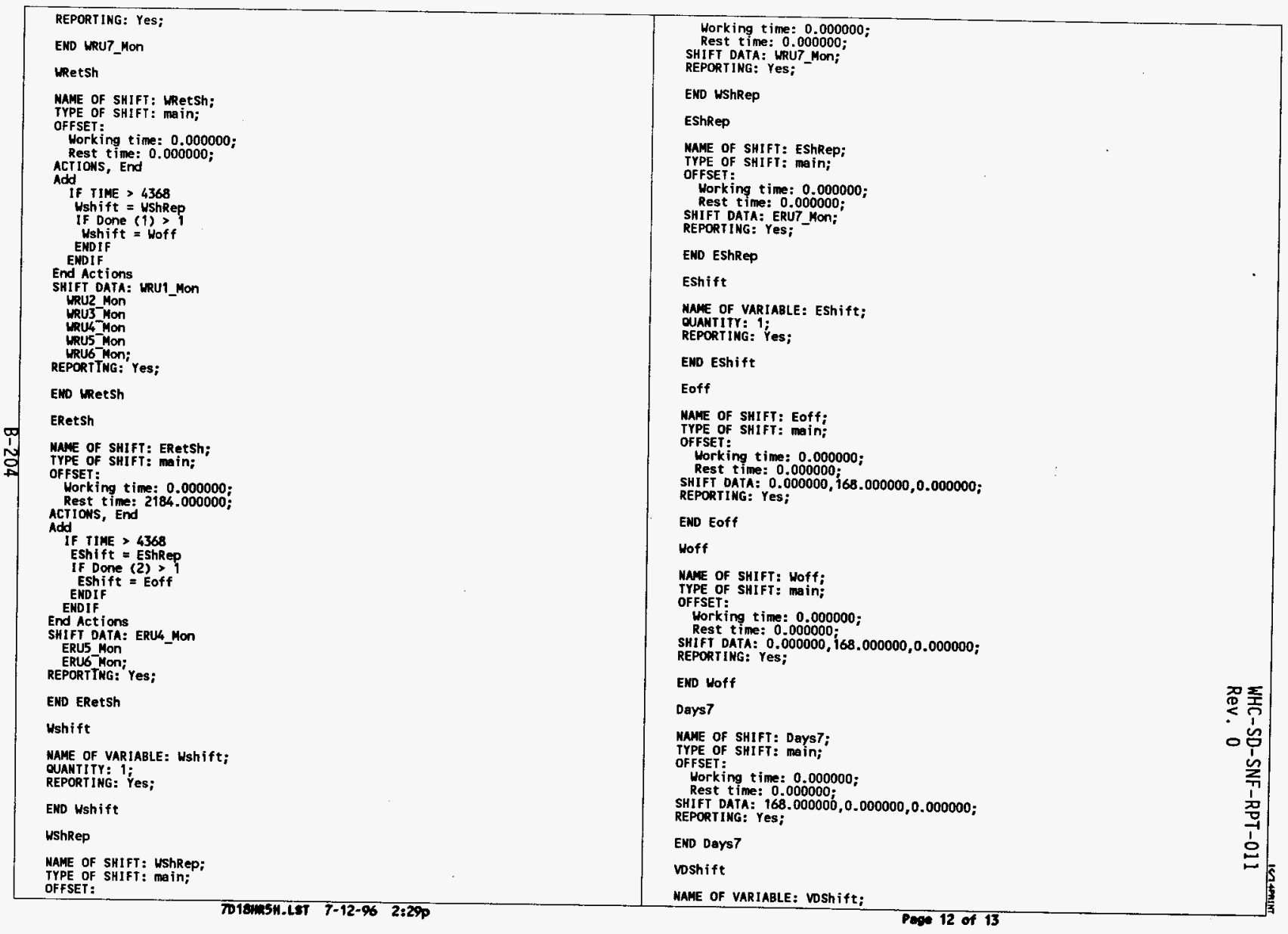




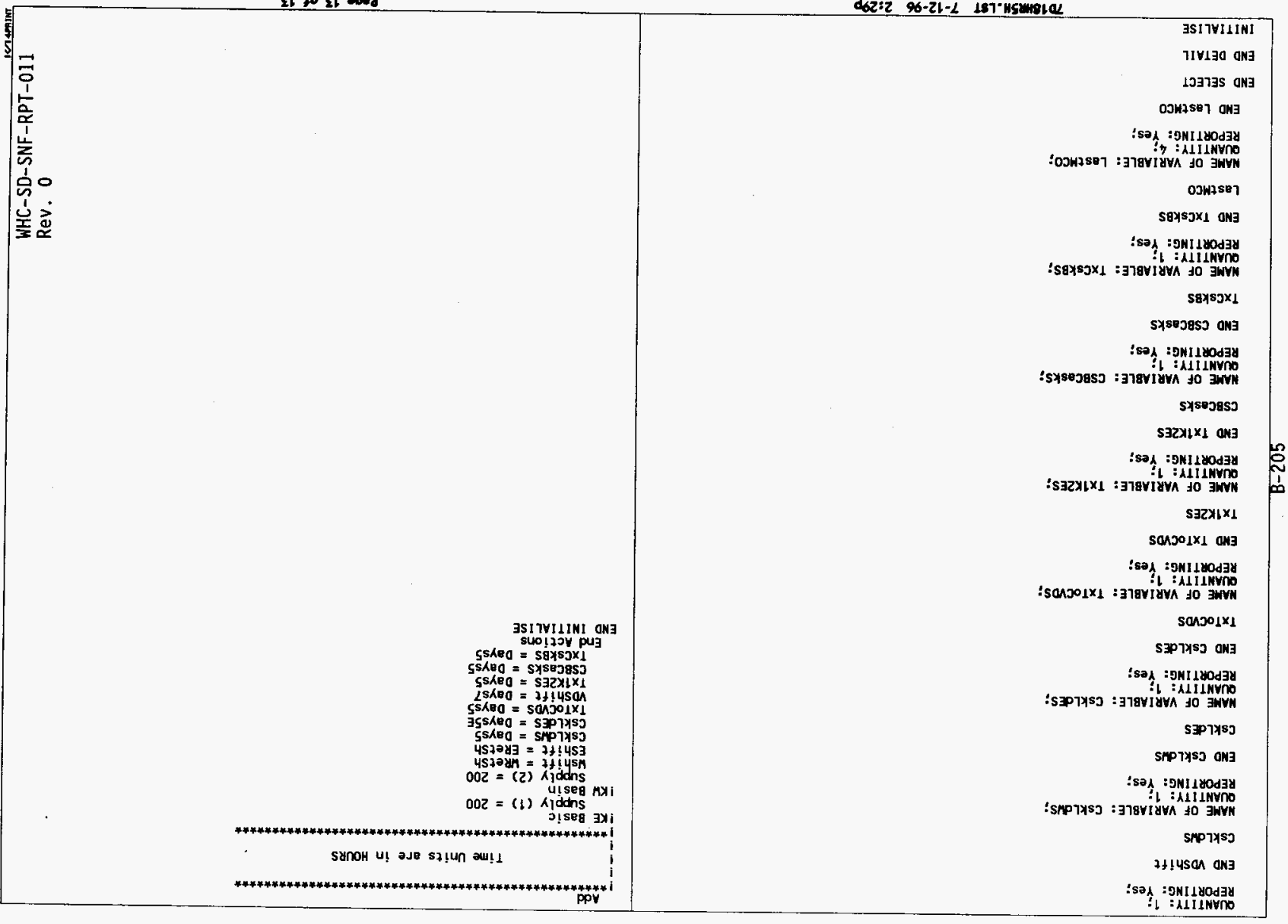


WHC-SD-SNF-RPT-011

Rev. 0

CASE 12. THREE 8HR SHIFTS/DAY, 7 DAYS/WEEK. USING 4 HOT CONDITIONING STATIONS. 
SNF Project operating 3 shifts, 7 days/week. Hot conditioning has 4 stations.

D
$\stackrel{1}{0}$
$\stackrel{0}{v}$
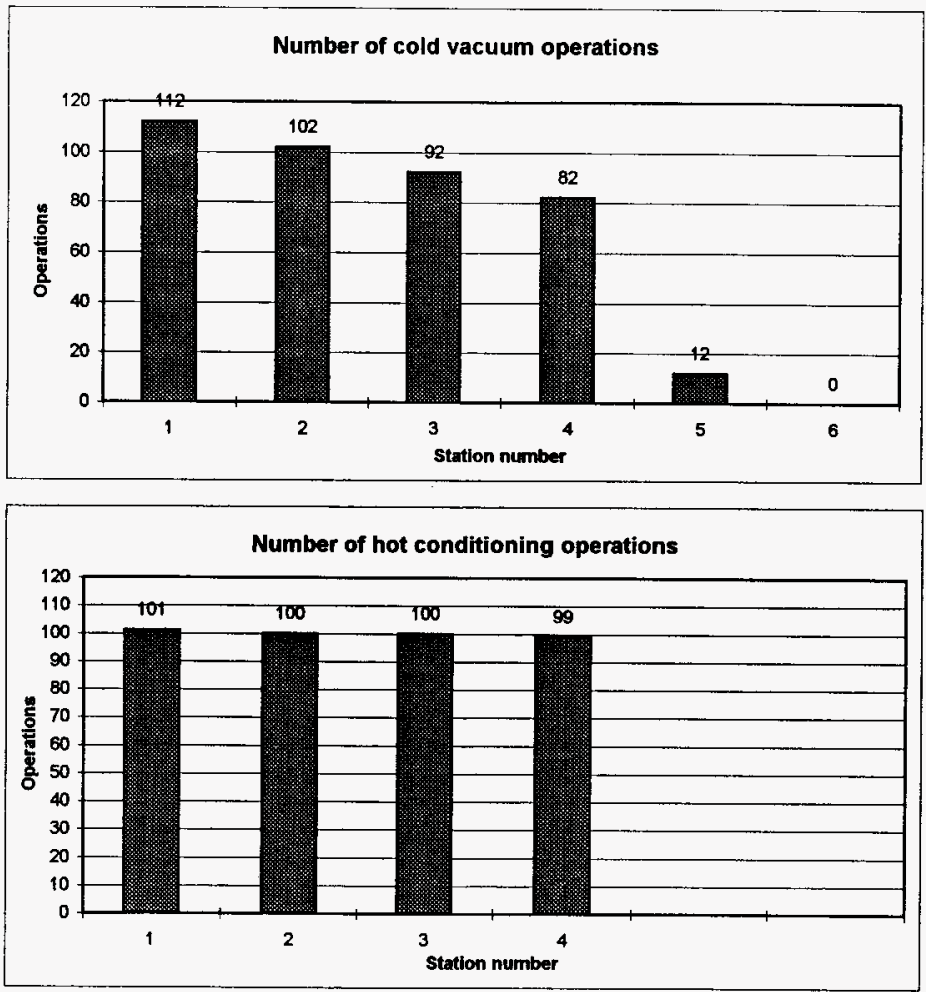


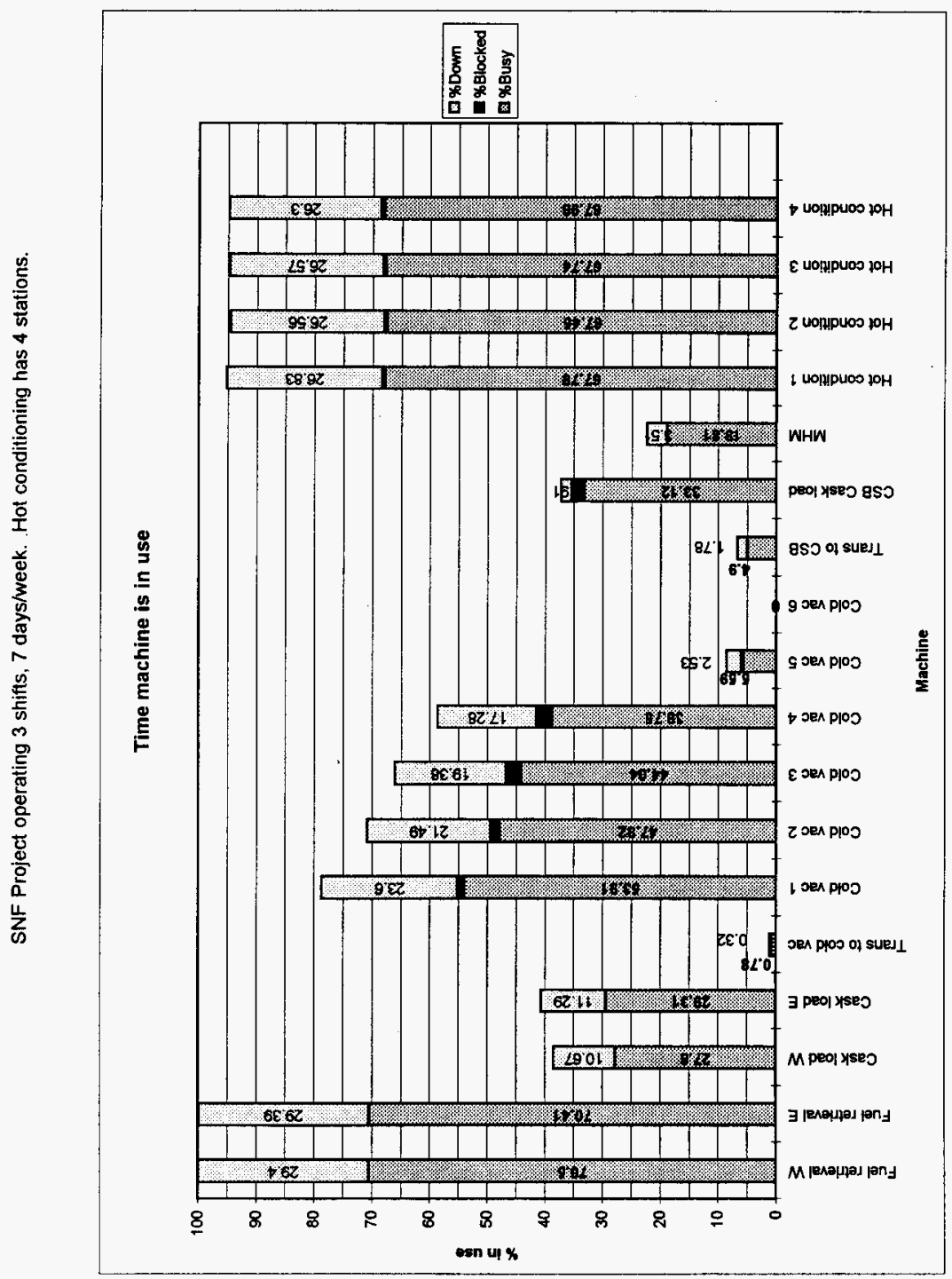

N 
WHC-SD-SNF-RPT-011

Rev. 0

$\stackrel{\infty}{\$}$
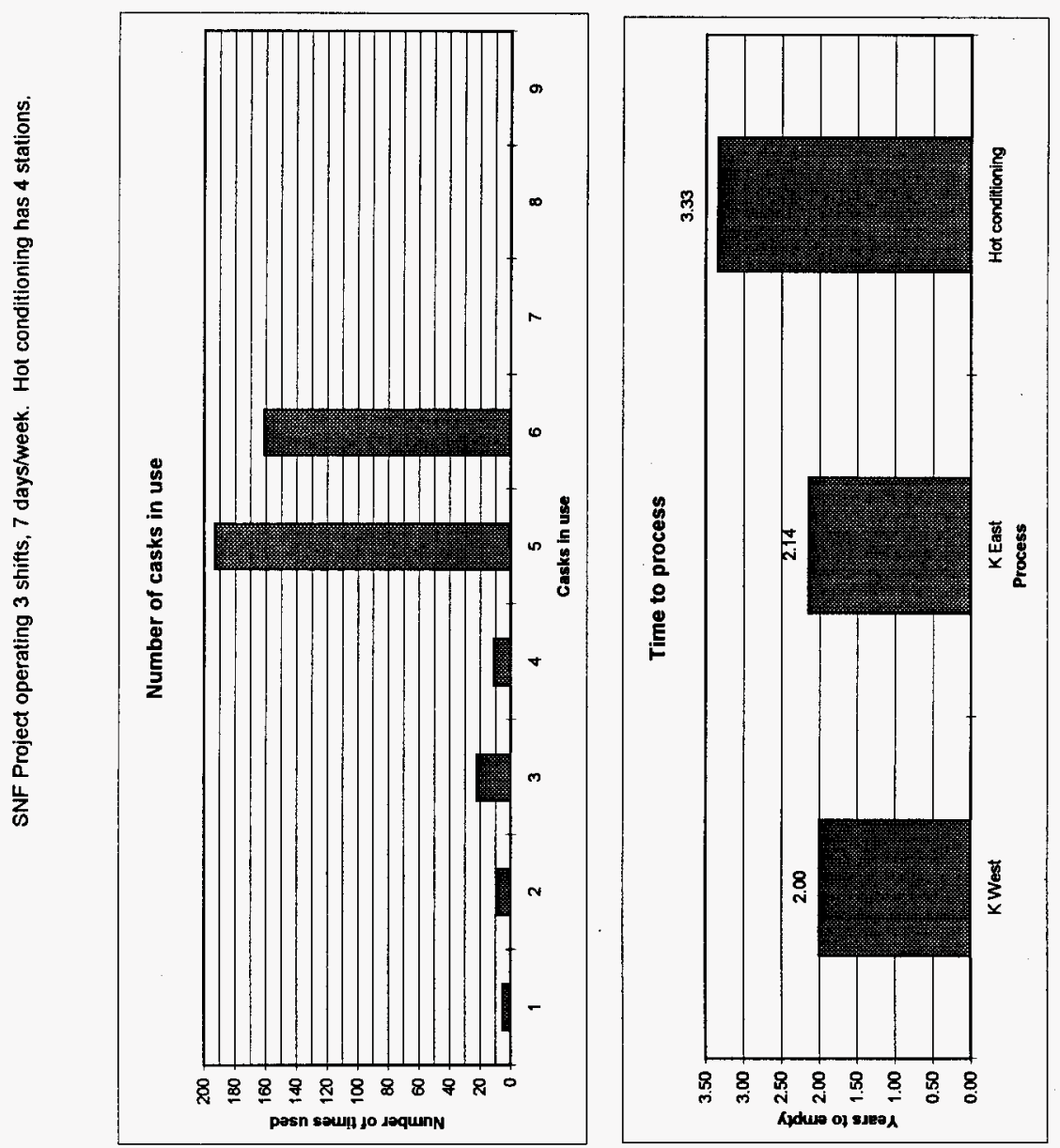

옴

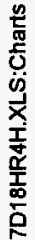




\begin{tabular}{|c|c|c|}
\hline 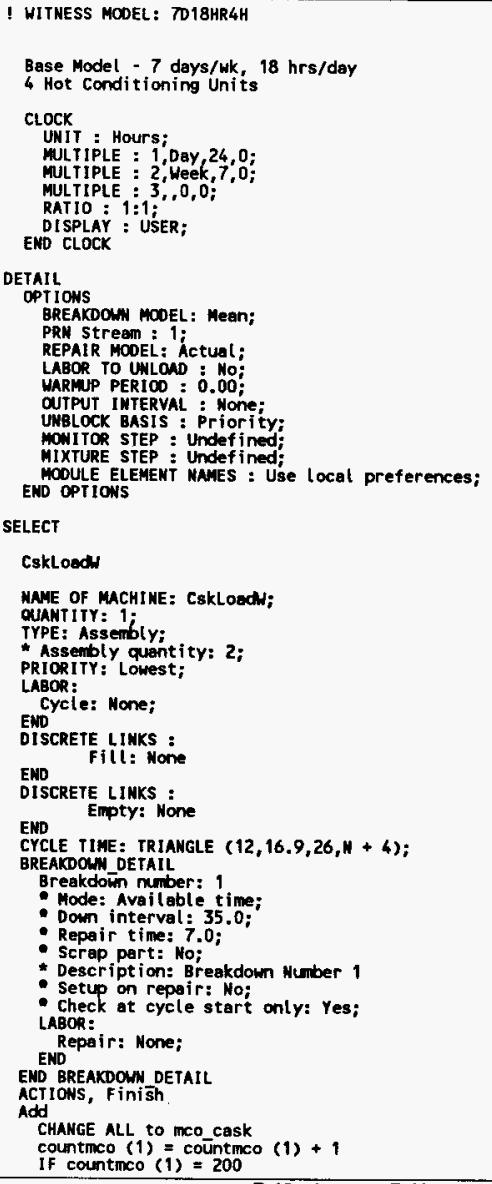 & 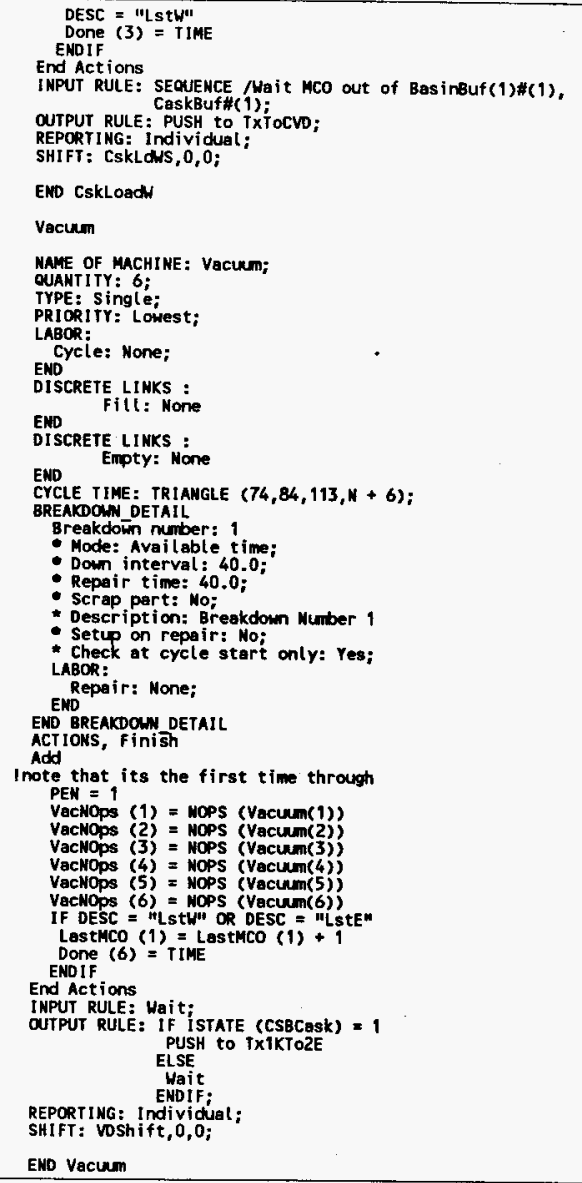 & 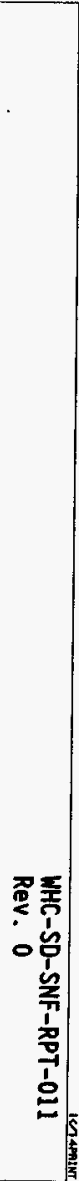 \\
\hline
\end{tabular}




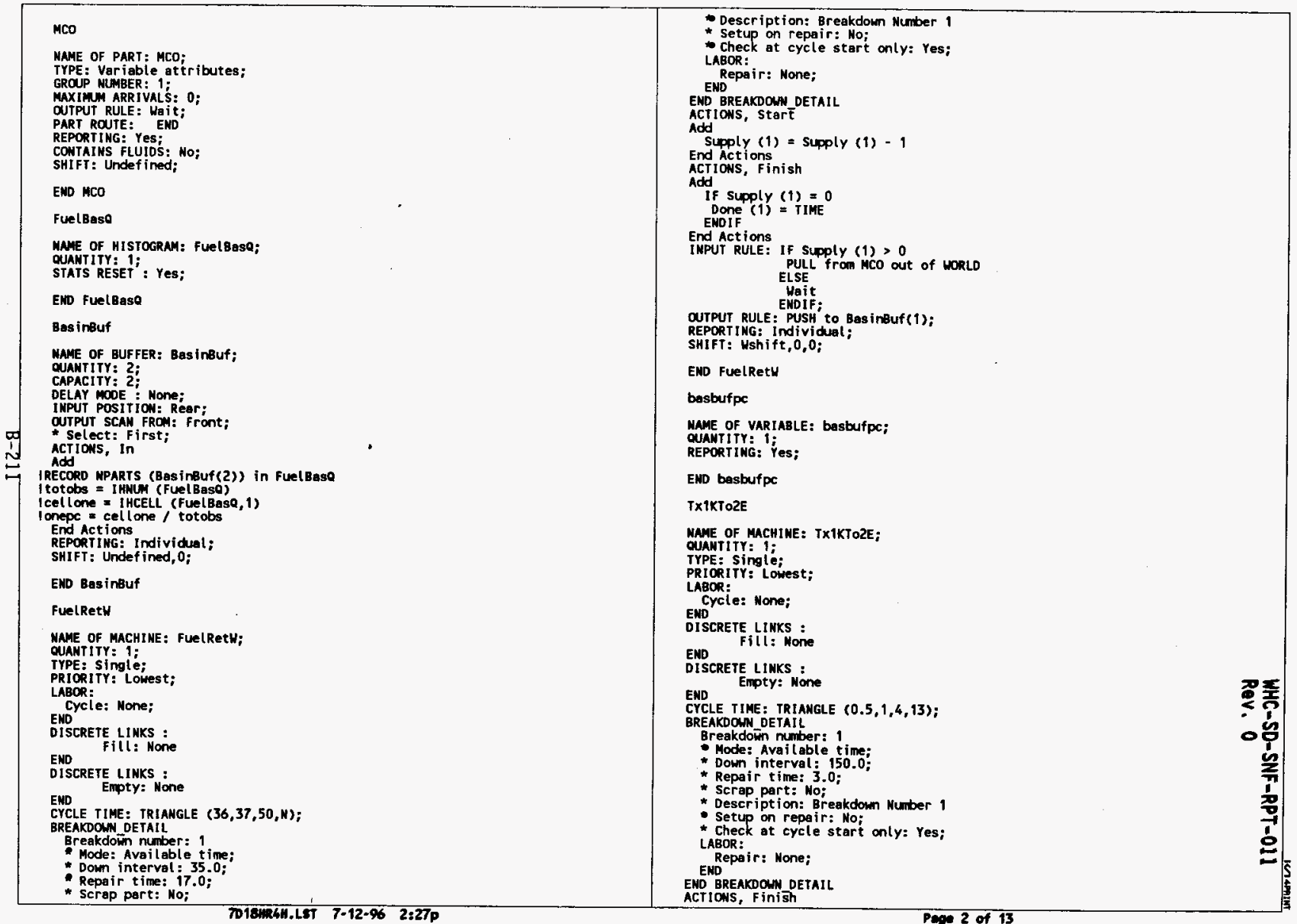




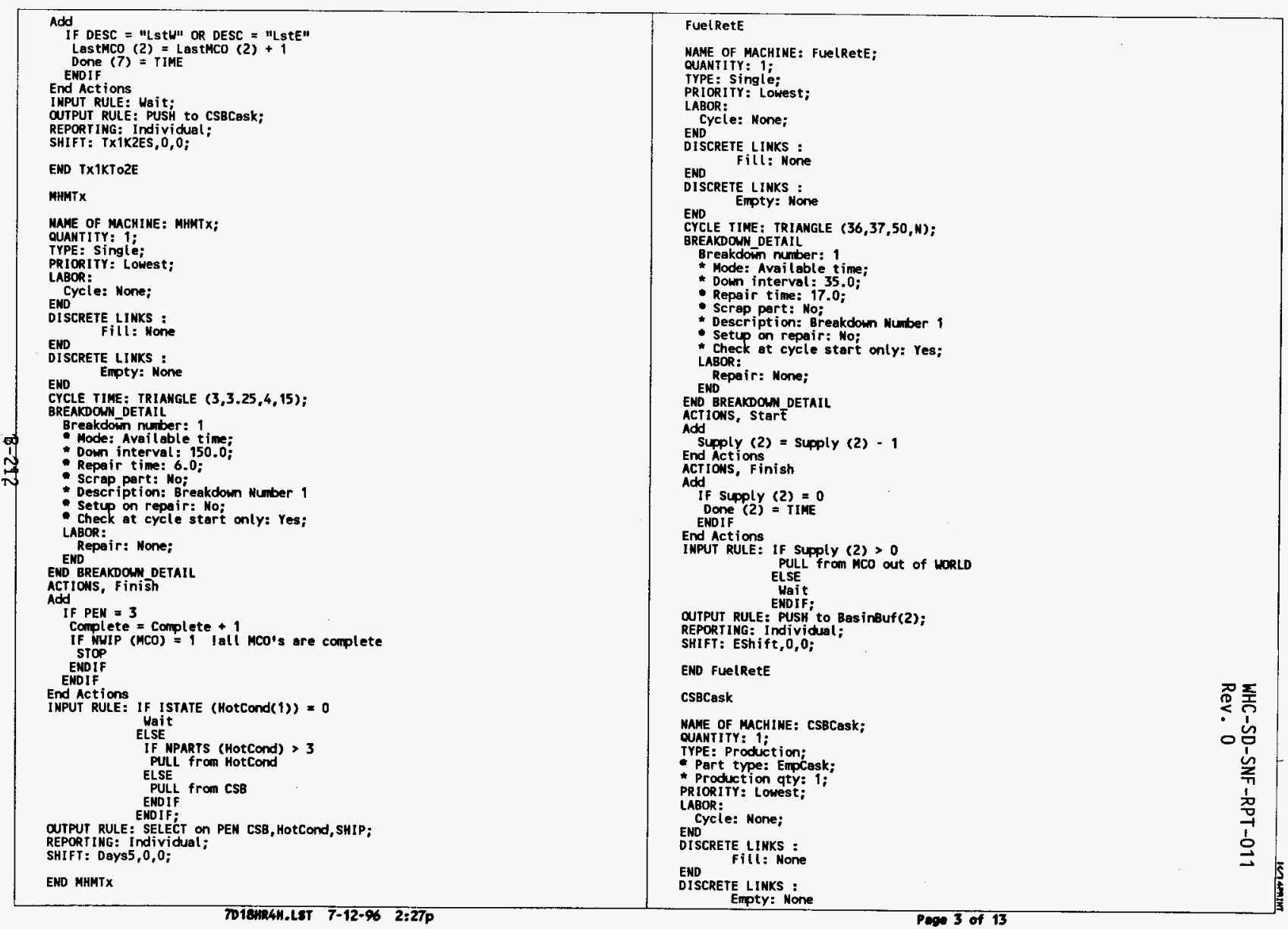




\begin{tabular}{|c|c|c|}
\hline 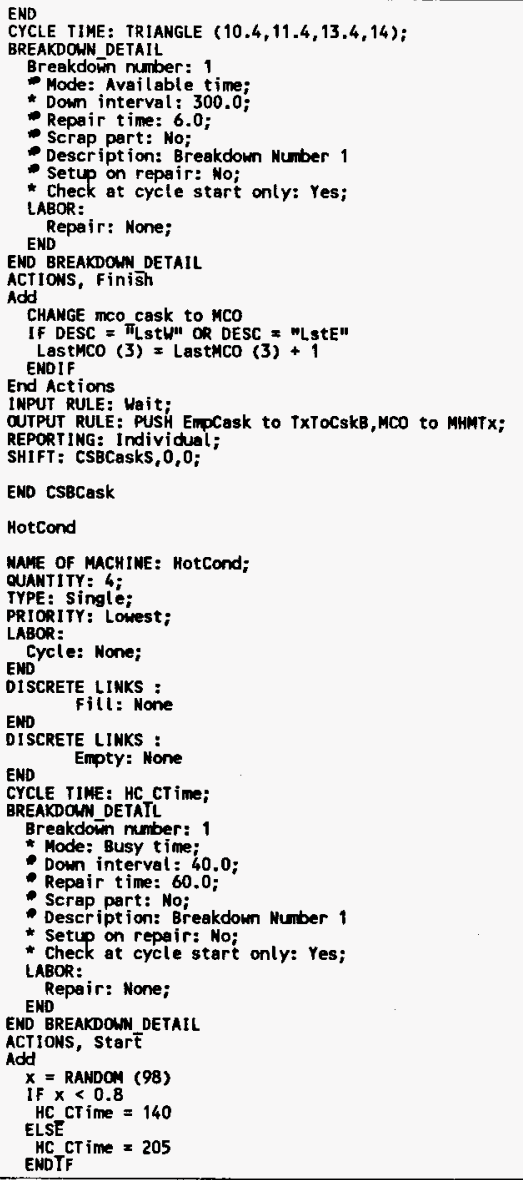 & 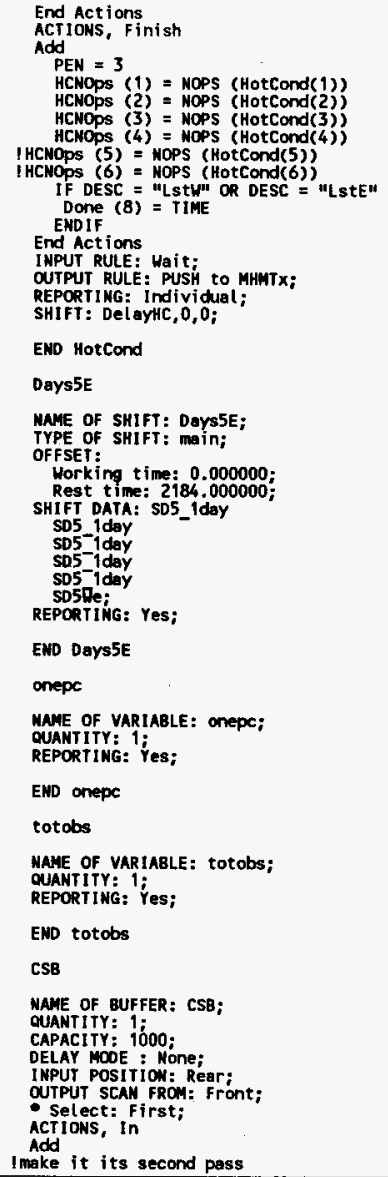 & 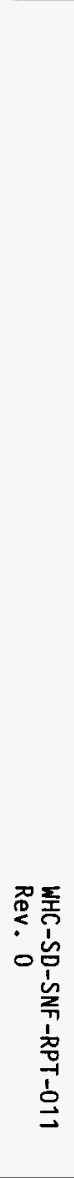 \\
\hline
\end{tabular}




\begin{tabular}{|c|c|c|}
\hline 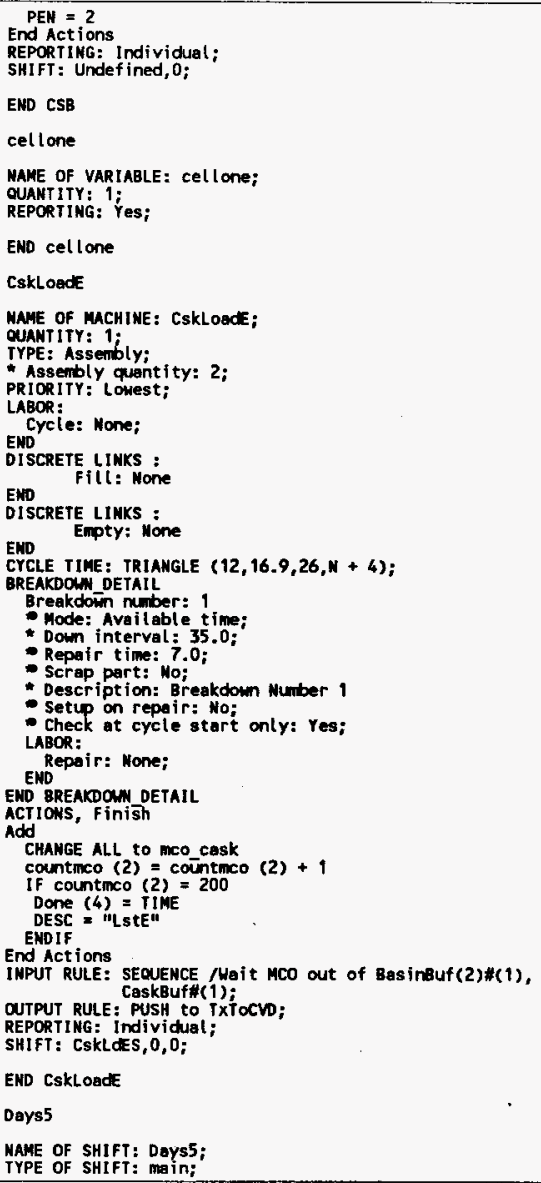 & 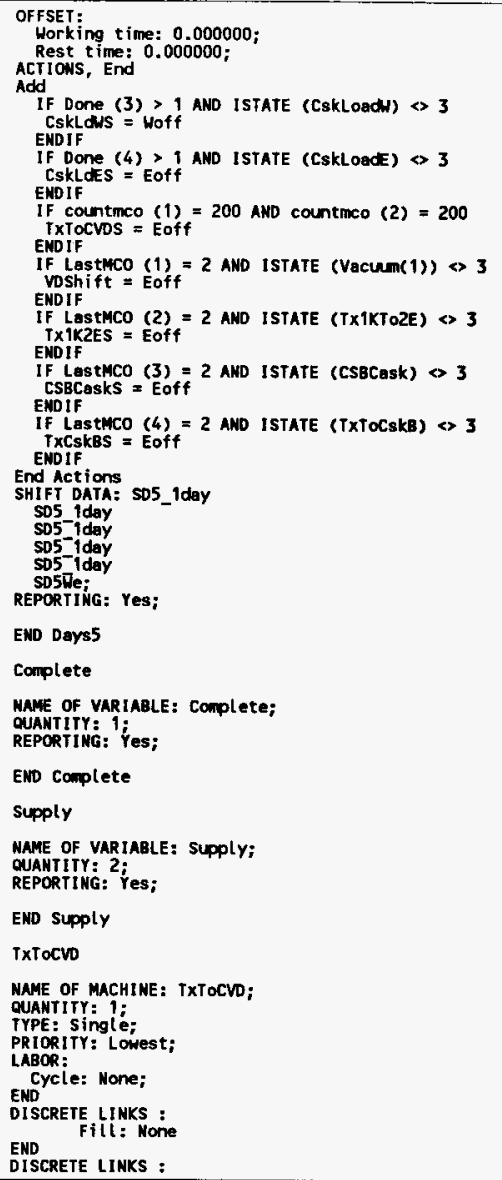 & 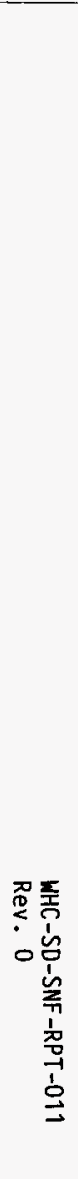 \\
\hline
\end{tabular}




\begin{tabular}{|c|c|c|}
\hline 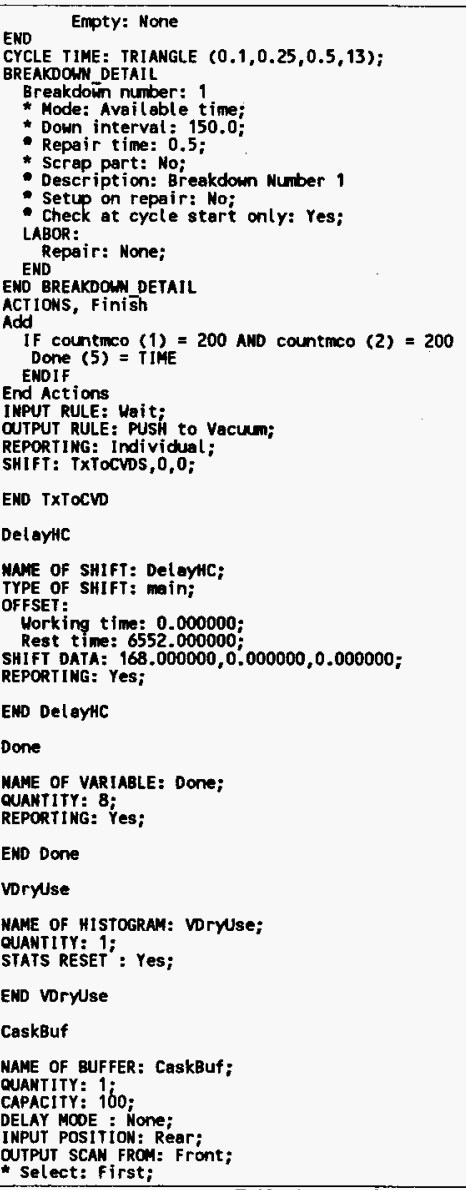 & 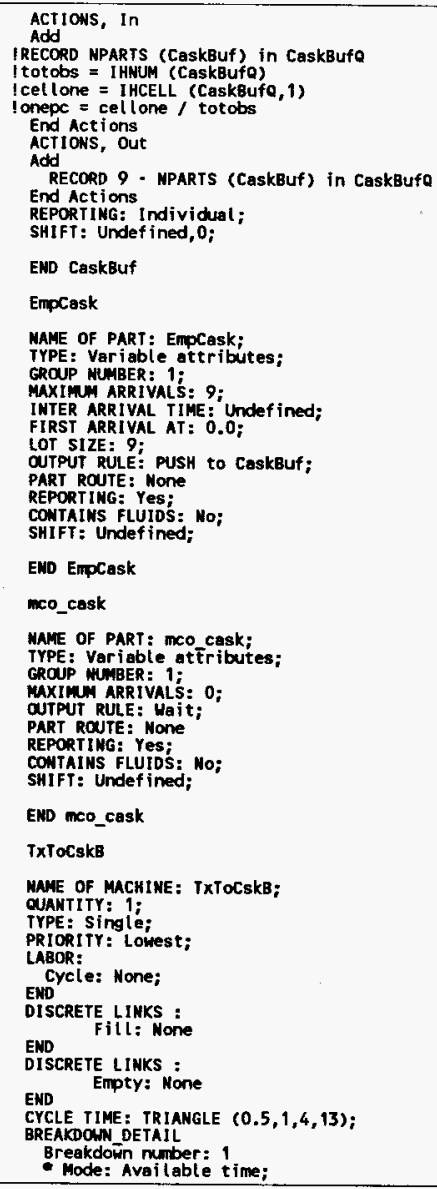 & 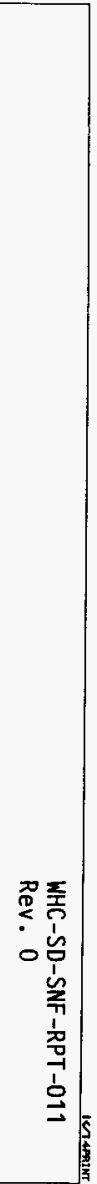 \\
\hline
\end{tabular}




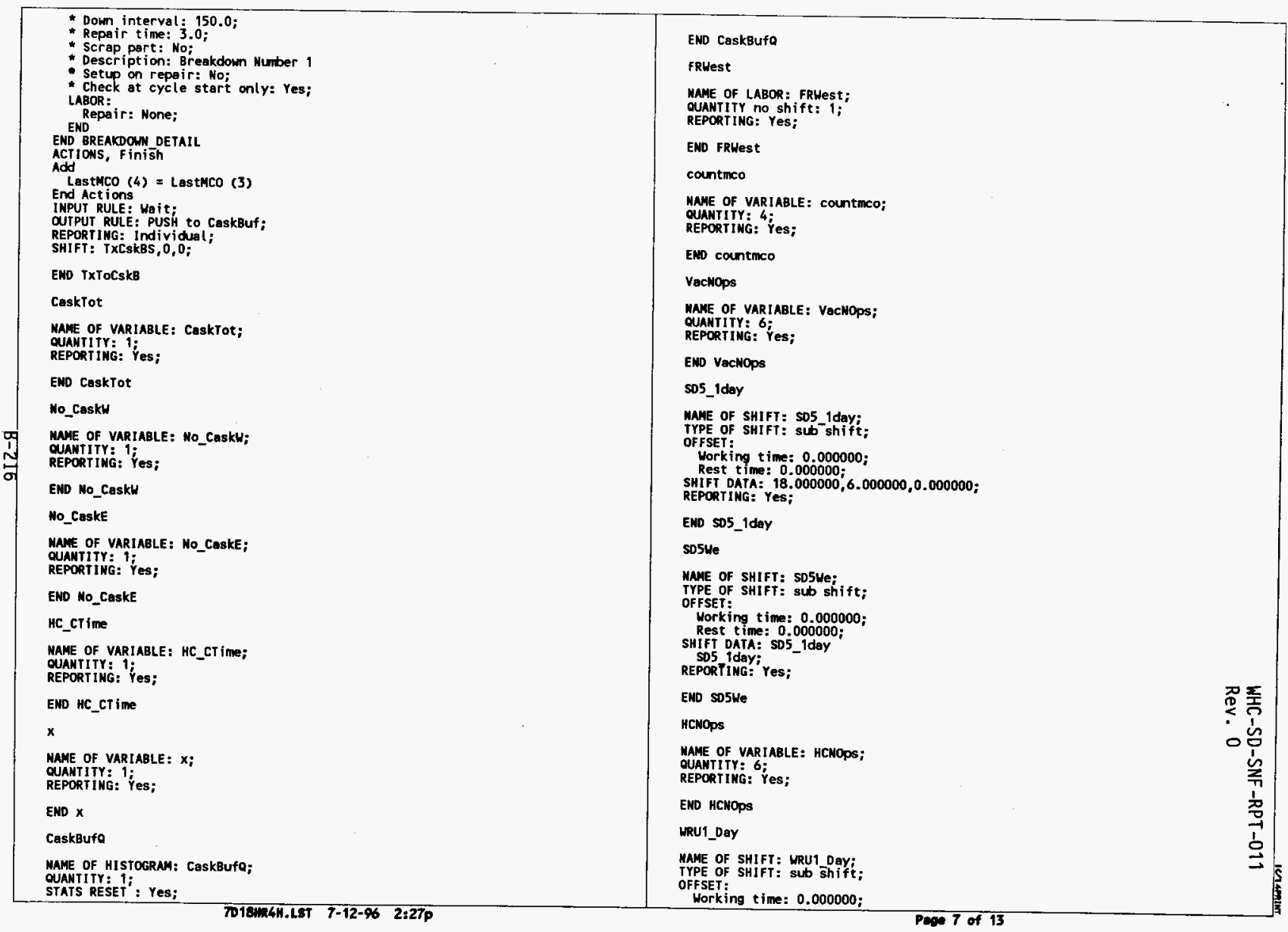




\begin{tabular}{|c|c|c|}
\hline 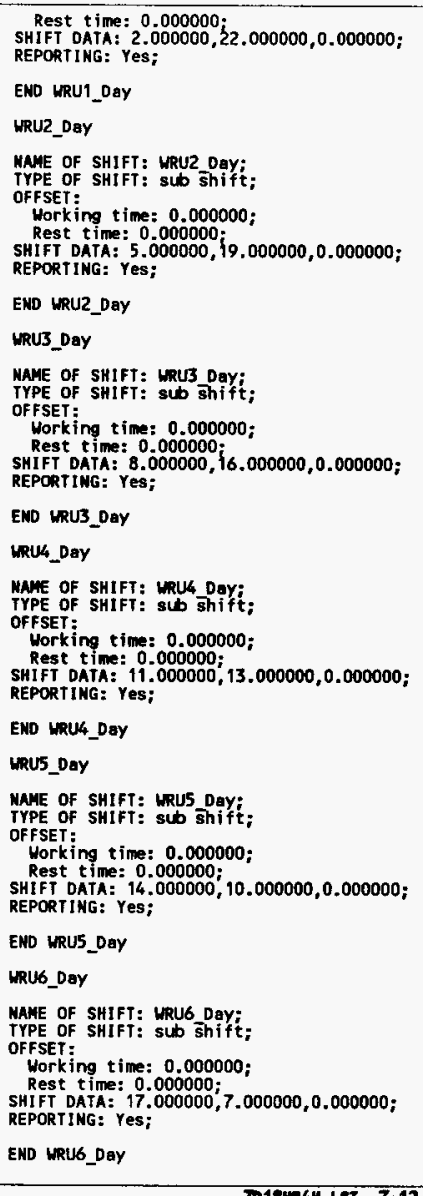 & 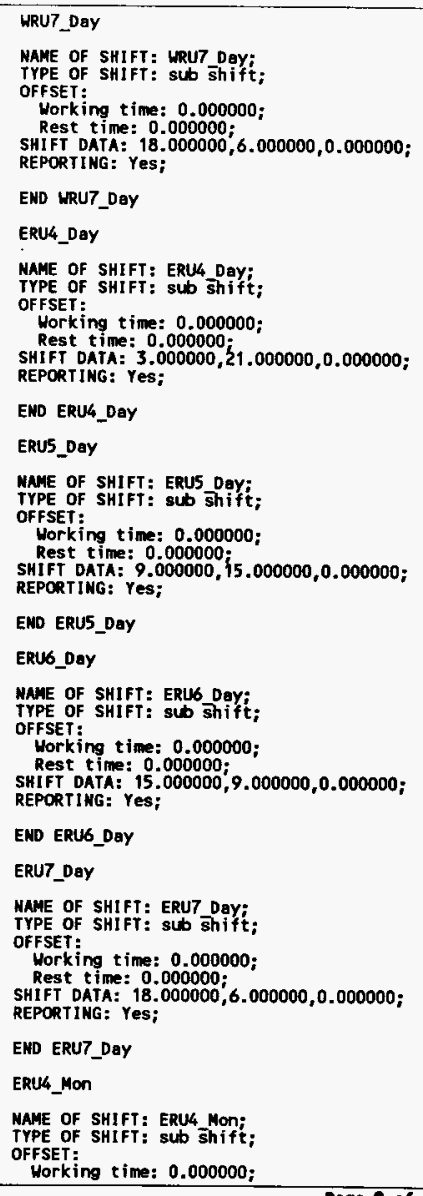 & 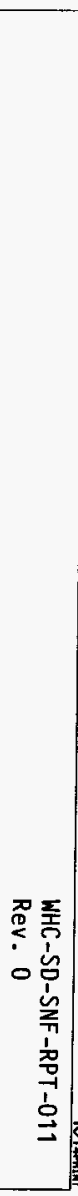 \\
\hline
\end{tabular}




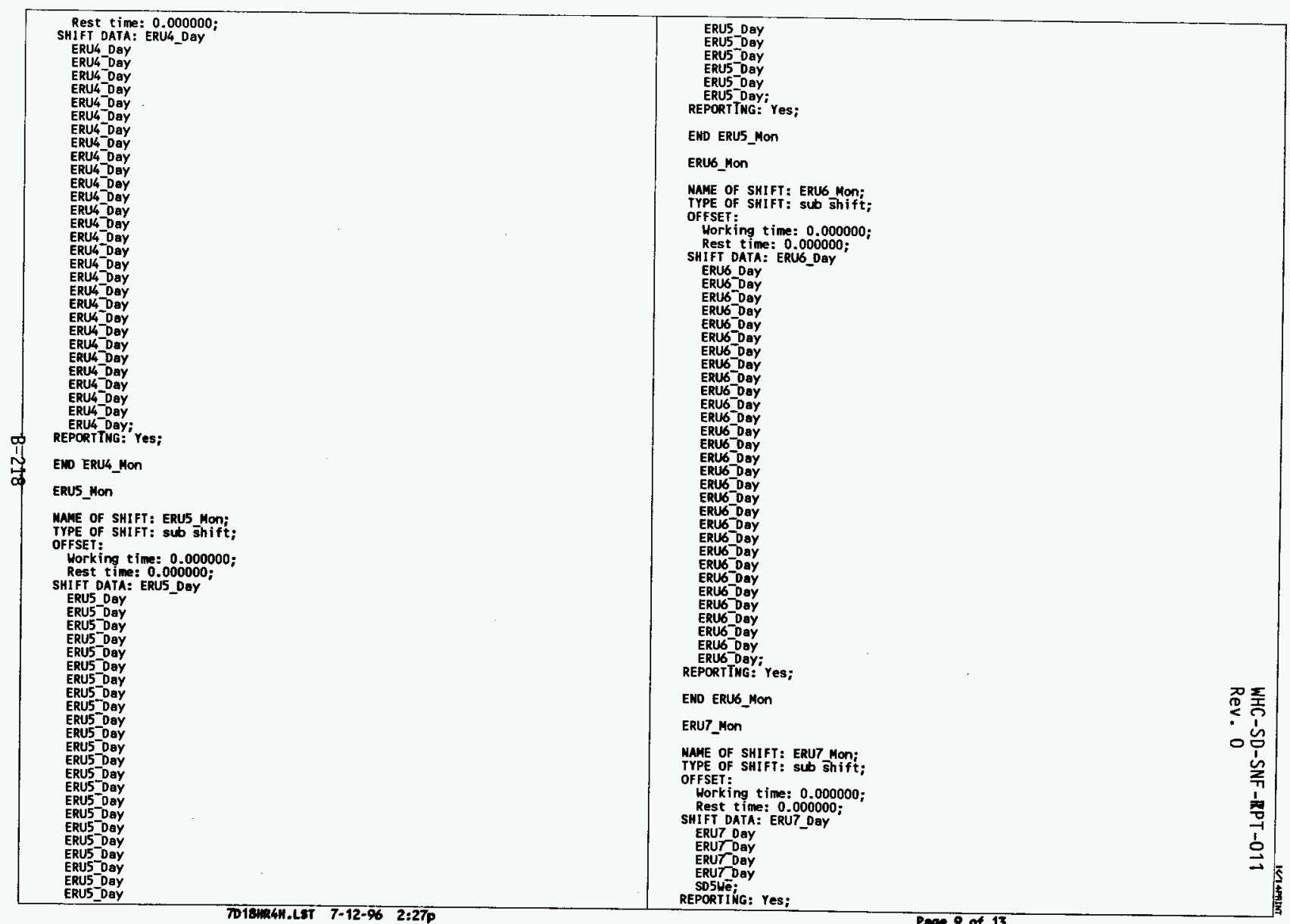




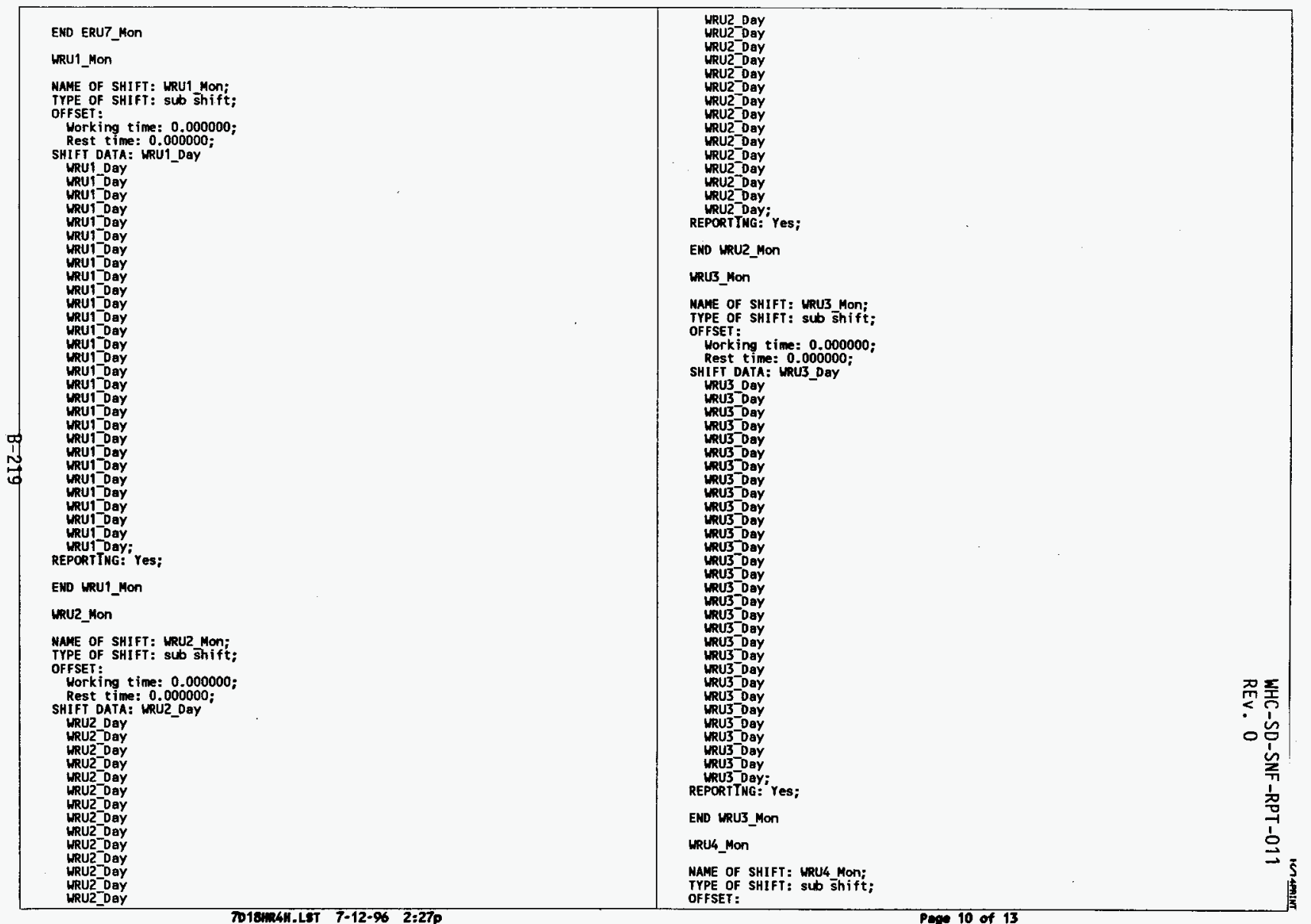




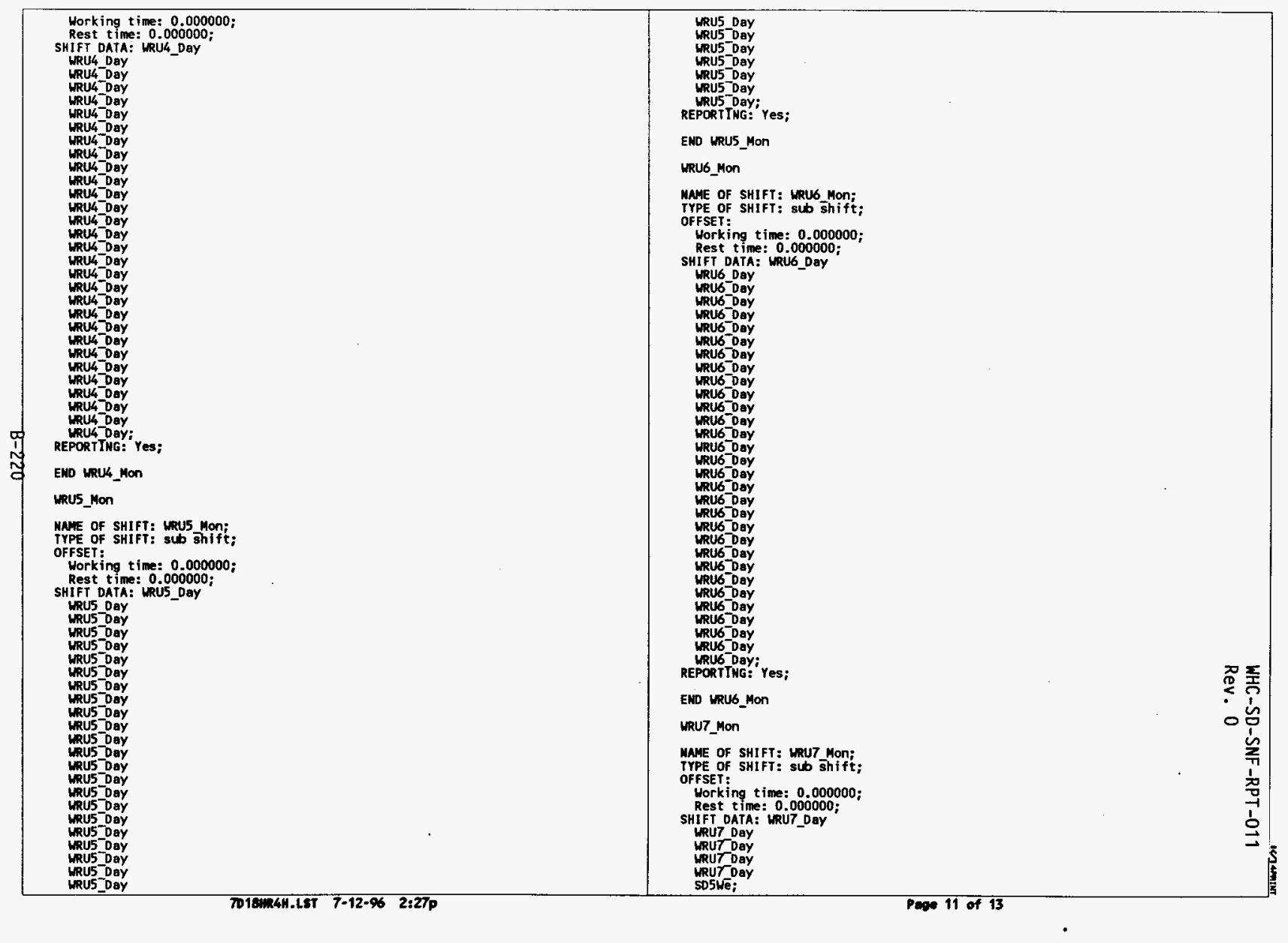




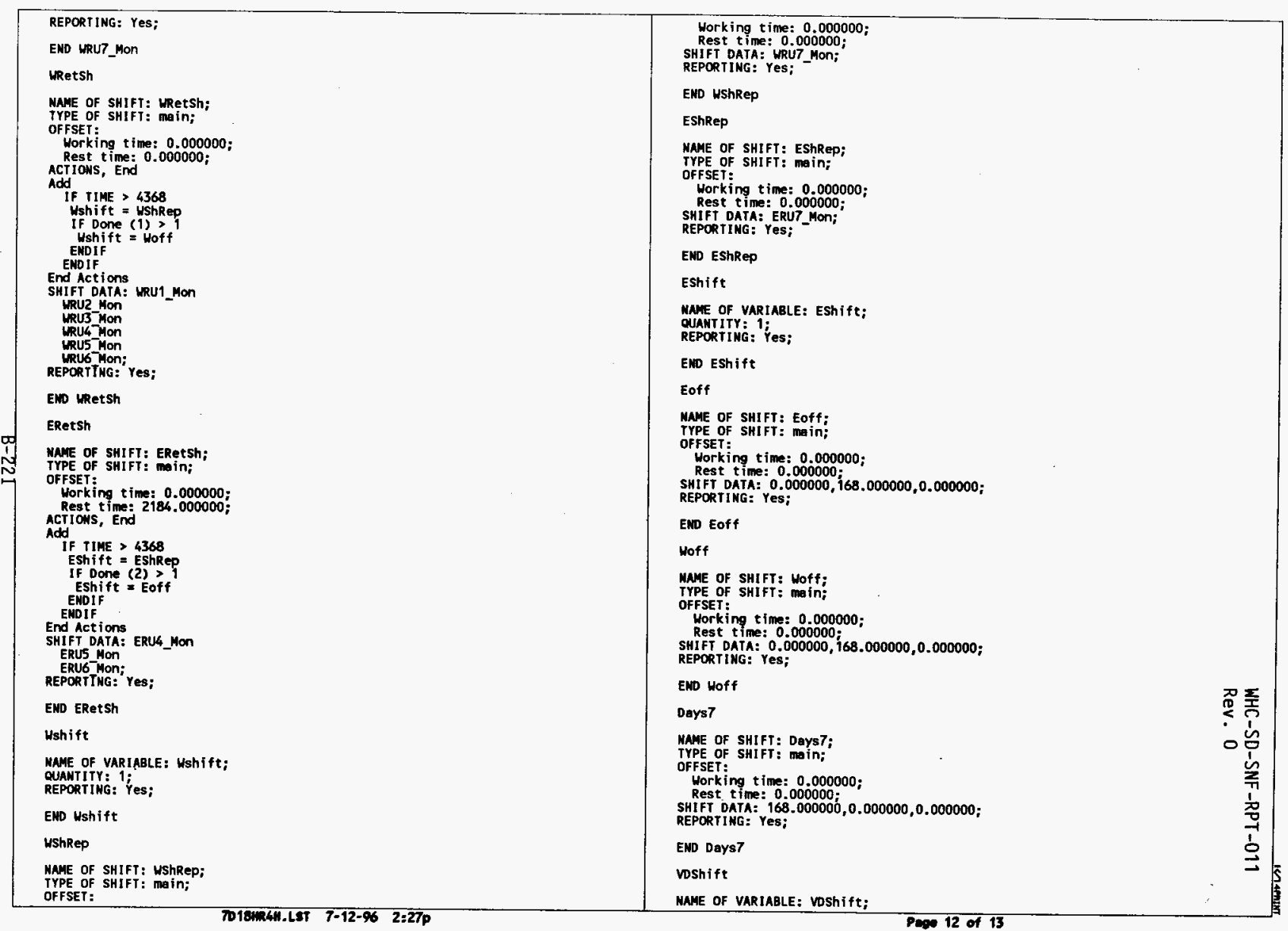




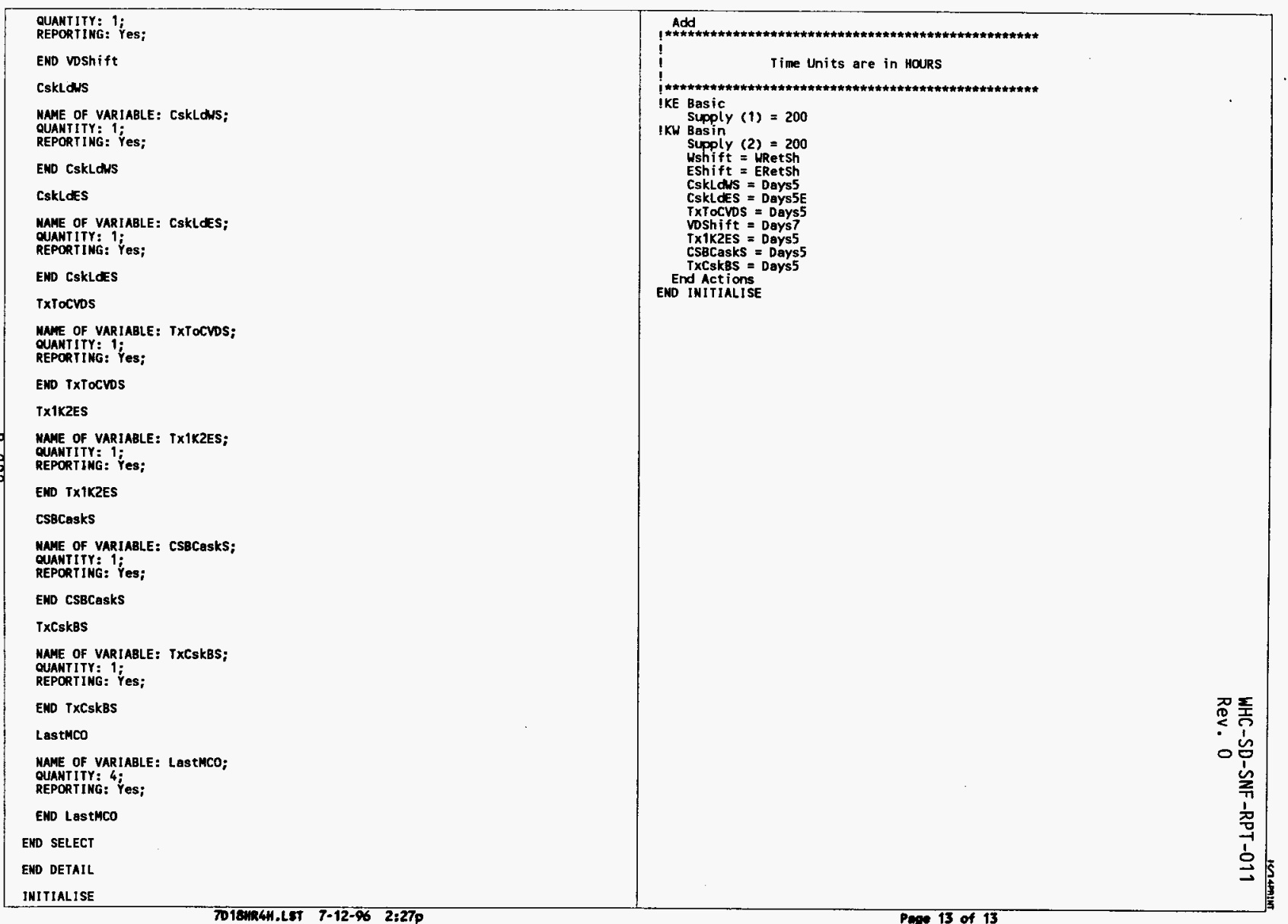


WHC-SD-SNF-RPT-011

Rev. 0

APPENDIX C

WITNESS MODEL TRIAL RUNS

C-1 
WHC-SD-SNF-RPT-011

Rev. 0

\section{APPENDIX C}

\section{WITNESS MODEL TRIAL RUNS}

While there is no record of the developer's internal testing or beta testing, the WITNESS Simulation Software has been around since 1985, and is currentiy in Revision 7 . There are over four thousand WITNESS systems in use worldwide. It is used in many industries, including automotive, chemical, electronics, aerospace, engineering, food, paper, banking, government, and transportation. Therefore, the software can be considered well verified.

The WITNESS software used in preparing this study was further verified by having the software developer, ISTEL, run two cases of a demonstration model on their system, then having Kaiser Hanford Company run the same two cases on our system, and comparing the results. The results of these trial runs are identical and are included for information in the following pages. 


\section{Memorandum}

DATE: JulY 23, 1996

TO: Maple Le日, Kaiser

FROM: Pam Markt, Lanner Inc. (formerly AT\&T ISTEL)

RE: WITNESS verification

1 have attached reports from the ACME model which shipped with WITNESS release 7.0 , as part of the DEMO subdirectory. I ran the model for 5000 time units - and for 20,000 time units, and have included reports for both of these cases.

I have also contacted the WITNESS development group in the U.K. to ask for further suggestions on verifying the operation of WITNESS software, and 1 will be in touch with you as soon as I hear from them.

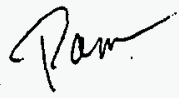




(150

bat $\quad 460$

value 140

fixture

$151 \quad 137$

Eixture

10

BELT

137

37

BELT

o

110

0

$\begin{array}{rrrr}0 & 11 & 13.63 & 407.68 \\ 0 & 11 & 9.48 & 289.67 \\ 2260 & 10 & 10.00 & 4520.0 \\ 0 & 0 & 0.00 & 0.00 \\ 0 & 0 & 0.00 & 0.00\end{array}$

QUFFER STATISTICS

REDORTED BY ON-SHIST TIME

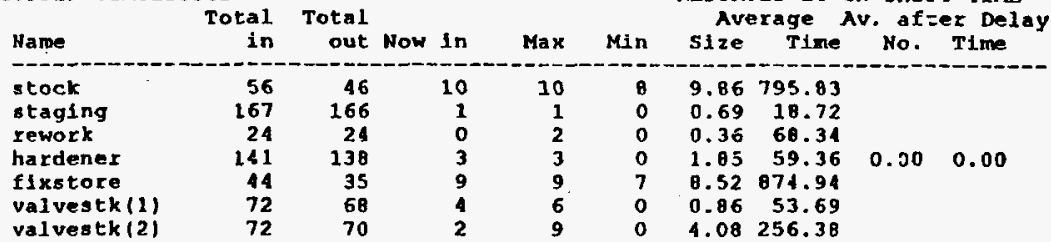

MACHINE STATISTICS

SEPORTED BY ON-SHIFT TIME

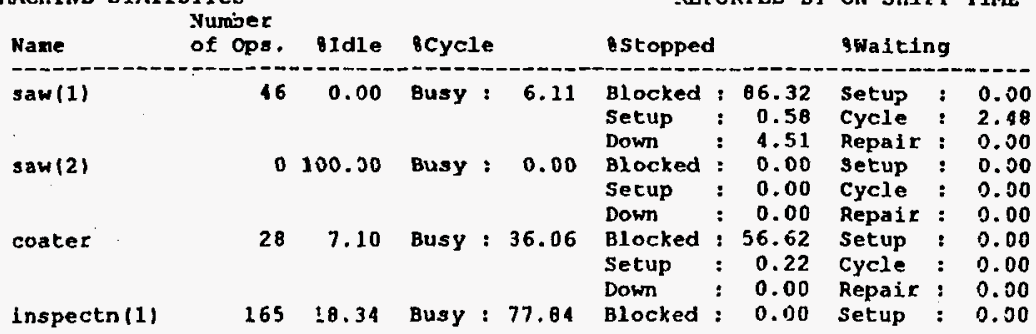


m

$\overrightarrow{7}$

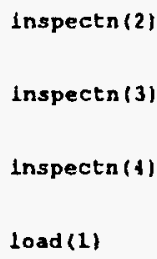

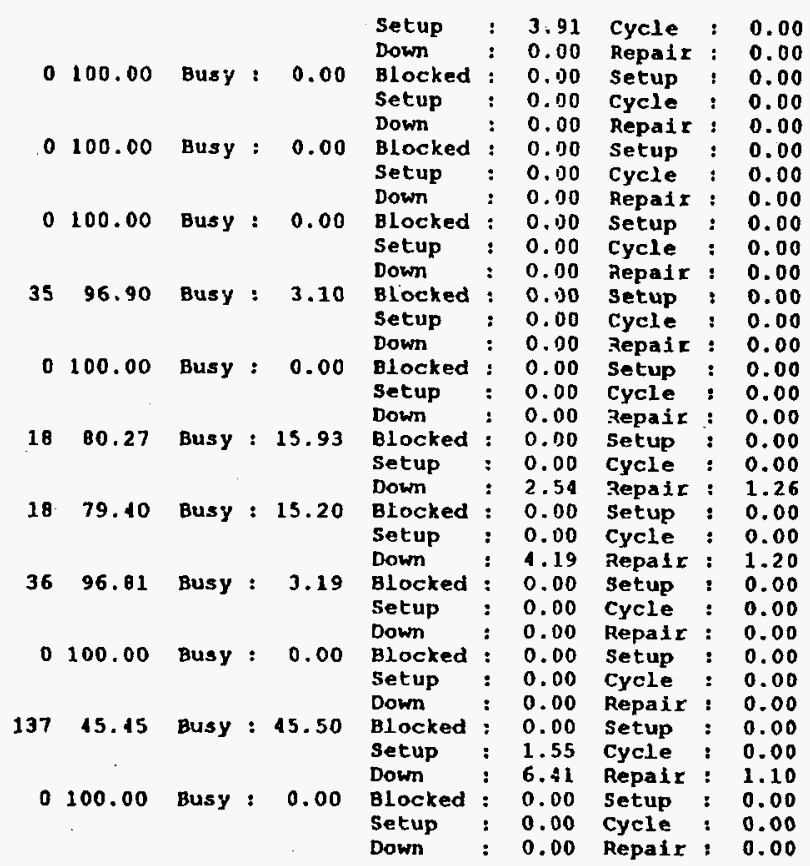

\section{CONVEYOR STATISTICS}

3EPORTED BY ON-SHIFT TIME

Now Total Av. Av.

Hame on on Size Time gmpty 8Move gBlock gQueue 8Down




$\begin{array}{lrrrrrrrrr}\text { beltcon1 } & 3 & 141 & 2.0 & 89.71 & 3.90 & 5.30 & 90.80 & 0.00 & 0.00 \\ \text { ret1 } & 0 & 36 & 0.0 & 3.00 & 97.61 & 2.39 & 0.00 & 0.00 & 0.00 \\ \text { ret2 } & 0 & 36 & 0.0 & 3.00 & 97.61 & 2.39 & 0.00 & 0.00 & 0.00 \\ \text { ROLLCON1 } & 0 & 0 & 0.0 & 0.00 & 100.00 & 0.00 & 0.00 & 0.00 & 0.00 \\ \text { BELTCON2 } & 0 & 0 & 0.0 & 0.00 & 100.00 & 0.00 & 0.00 & 0.00 & 0.00 \\ \text { ROLLCON2 } & 0 & 0 & 0.0 & 0.00 & 100.00 & 0.00 & 0.00 & 0.00 & 0.00\end{array}$

\section{LABOR STATISEZCS}

REPORTED BY ON-SHI IT TIME

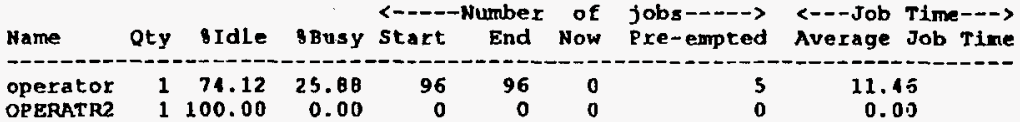

VARIABLE STATISTICS

REPORTED BY ON-SHIET TIME

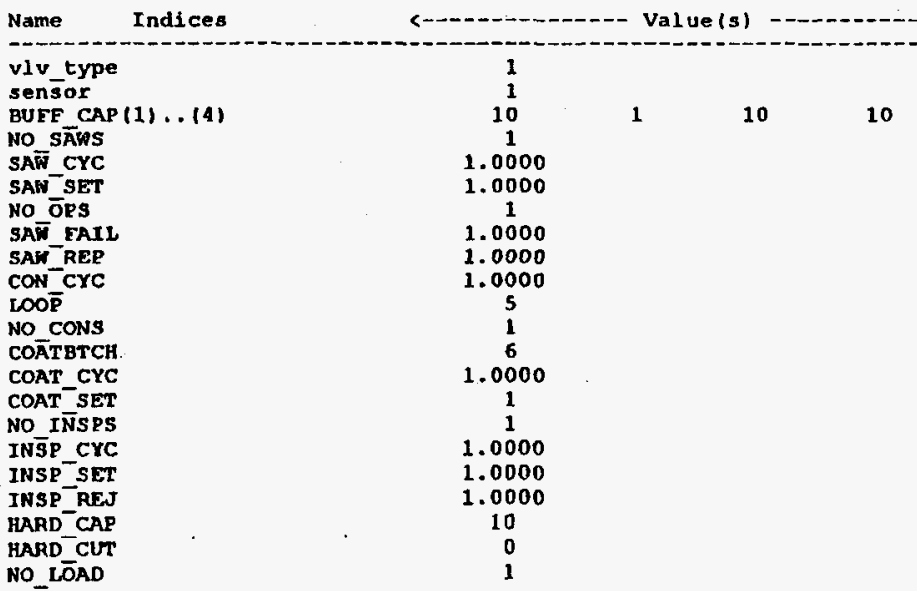


No CLEAN

GRTNDCYC

GRINEAIL

CLEANCYC

C BATCH

NĒXTVALV

C COUNT

CŌ NAME

op no

BUD̄Ger

buff new

buff $\min (1) \ldots$ (1)

user-int

userzeal

user nam

TITLES

TEXT

?ROMPT

ERROR

1

1.0000

10

1

1.0000

1.0000

10

10
1
2

2 BELT

4

1000

$\begin{array}{rrrr}0 & 10 & 10 & 10\end{array}$

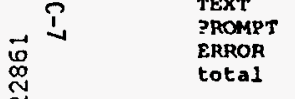

0.0000

NONE

3

6

7

$13 \frac{1}{36}$

TIMESERTES STATISTICS

REPORTED BY ON-SHIFT TIME

Maximun

Observations

gimeseries Pl Mean sD Value eTime Value eTine $n$ Time Value

THAU PUT

196.30021 .3541 .0000720 .00124 .004560 .0

12640.062 .000

22980.070 .000

331.20 .080 .000

43360.004 .000

53600.090 .000

63840.0100 .00

74000.3111 .00

- 4320.0118 .00

94560.0124 .00

$10 \quad 4800.0124 .00$ 
WHC-SD-SNF-RPT-011

Rev. 0

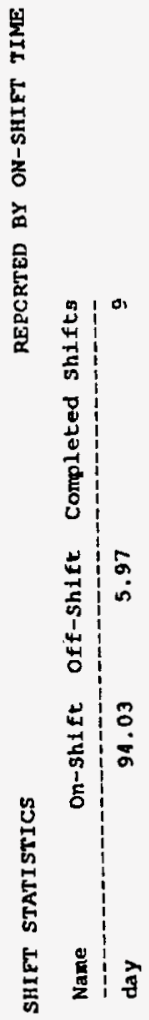

\section{C-8}




ACME Report $\quad$ Time: 20000.00

PART STATISTICS

RTPORTEJ AY ON-SHIFT TIME

\begin{tabular}{|c|c|c|c|c|c|c|c|c|}
\hline Name & $\begin{array}{l}\text { Numbex } \\
\text { Entered }\end{array}$ & $\begin{array}{l}\text { Number } \\
\text { Shipped }\end{array}$ & $\begin{array}{l}\text { Number } \\
\text { Scrapped }\end{array}$ & $\begin{array}{l}\text { Number } \\
\text { Assembled }\end{array}$ & $\begin{array}{l}\text { Number } \\
\text { Rejected }\end{array}$ & ท. I.P & $\begin{array}{l}\text { Av. } \\
\text { ผ.I.? }\end{array}$ & $\begin{array}{l}\text { Av. } \\
\text { Time }\end{array}$ \\
\hline & 1960 & 0 & 1753 & 197 & 0 & 10 & 9.98 & 99.38 \\
\hline & 604 & 0 & 0 & 592 & 0 & 12 & 13.38 & 148.61 \\
\hline valve & 596 & 583 & 0 & 0 & 0 & 13 & 9.63 & 315.37 \\
\hline fixture & 10 & 0 & 0 & 0 & 9760 & 10 & 10.00 & 19520 \\
\hline ROLLER & 0 & o & 0 & 0 & o & 0 & 0.00 & 0.00 \\
\hline BELT & 0 & 0 & 0 & 0 & o & 0 & 0.00 & 0.00 \\
\hline
\end{tabular}

BUFFER STATISTICS

REPORTEJ BY ON-SHIFT TIME

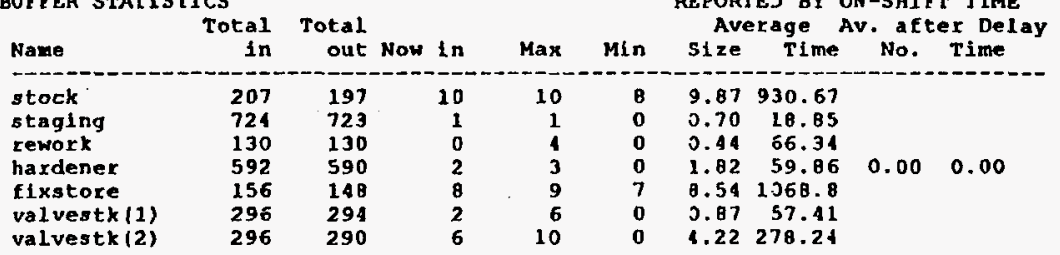

MACHIN STATISTICS

REPORT:D BY ON-SHIET TIME

\begin{tabular}{|c|c|c|c|c|c|c|c|c|c|c|}
\hline $\begin{array}{l}\text { ACHINE STAI } \\
\text { Name }\end{array}$ & $\begin{array}{l}\text { Number } \\
\text { of Ops. }\end{array}$ & Id Ie & scycle & & \&5toppe & & $T=8$ & Bwaiti & ng & TIME \\
\hline $\operatorname{san}(1)$ & 197 & 0.00 & Busy : & 6.06 & $\begin{array}{l}\text { Blocked } \\
\text { Setup } \\
\text { Down }\end{array}$ & $:$ & $\begin{array}{r}89.02 \\
0.73 \\
2.37\end{array}$ & & & $\begin{array}{l}0.00 \\
1.82 \\
0.00\end{array}$ \\
\hline $\operatorname{saw}(2)$ & 0 & 100.00 & Busy： & 0.00 & cked & : & $\begin{array}{l}0.00 \\
0.00\end{array}$ & & & $\begin{array}{l}0.00 \\
0.00\end{array}$ \\
\hline oater & 121 & 5.74 & Busy : & 36.94 & $\begin{array}{l}\text { Blocked } \\
\text { setup }\end{array}$ & & $\begin{array}{r}57.01 \\
0.31\end{array}$ & $\begin{array}{l}\text { Setup } \\
\text { Cycle }\end{array}$ & & $\begin{array}{l}0.00 \\
0.00 \\
0.00\end{array}$ \\
\hline Ispect & 722 & 17.10 & Busy : & 78.99 & $\begin{array}{l}\text { Down } \\
\text { Blocked }\end{array}$ & $:$ & $\begin{array}{l}0.00 \\
0.00\end{array}$ & $\begin{array}{l}\text { Repaiz } \\
\text { Setuo }\end{array}$ & & $\begin{array}{l}0.00 \\
0.00\end{array}$ \\
\hline
\end{tabular}




Inspectn (2)
Inspectn (3)
Inspectn (1)
load (1)

load (2)

grinder (1)

grinder (2)

uload (1)

uload (2)

cleanex $\{1\}$

cleanex $(2)$

CONVEYOR STATISTICS

$$
\text { Name }
$$

Now Total

Av.

Av.

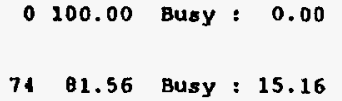

or on

$74 \quad 00.18$ Busy: 15.17

14896.91 Busy: $\mathbf{3 . 0 3}$

0 100.00 Busy: 0.00

58346.11 Busy: 44.85

0100.00 Busy: 0.00

Setup
Down
Blocked
setup
Down
Blocked
Setup
Down
Blocked
Setup
Down
Blocked
Setup
Down
Blocked
Setup
Down
Blocked
Setup
Down
Blocked
Setup
Down
Blocked
Setup
Down
Blocked
setup
Down
Blocked
Setup
Down
Blocked
Setup
Down

setup

3.95

0.00

0.00

0.00

0.00

0.00

0.00

0.00

0.00

0.00

0.00

0.00

0.00

0.00

0.00

0.00

0.00

0.00

2.52

REPORTED BY ON-SHITT TIME
0.00

0.00

0.00

0.00

0.00

0.00

0.00

0.00

Repair: 0.00

Setup: 0.00
Cycle : 0.00

Repaic: 0.00

setup : 0.00

Cycle: 0.00

Repars: 0.00

$: 0.00$

Repalc : 0.76

Setup : 0.00

Cycle: 0.00

Repair : 0.78

Setup: 0.00

Cycle: 0.00

Repair: 0.00

Setup: 0.00

Cycle: 0.00

RepaIr : 0.00

Setup : 0.00

Cycle: 0.00

Repair : 1.13

setup : 0.00

Cycle: 0.00 


$\begin{array}{lrrrrrrrrr}\text { beltcon1 } & 4 & 594 & 2.3 & 92.56 & 2.79 & 5.23 & 91.98 & 0.00 & 0.00 \\ \text { ret1 } & 0 & 148 & 0.0 & 3.00 & 97.73 & 2.27 & 0.00 & 0.00 & 0.00 \\ \text { ret2 } & 0 & 148 & 0.0 & 3.00 & 97.73 & 2.27 & 0.00 & 0.00 & 0.00 \\ \text { ROLLCON1 } & 0 & 0 & 0.0 & 0.00 & 100.00 & 0.00 & 0.00 & 0.00 & 0.00 \\ \text { BELTCON2 } & 0 & 0 & 0.0 & 0.00 & 100.00 & 0.00 & 0.00 & 0.00 & 0.00 \\ \text { RDLLCON2 } & 0 & 0 & 0.0 & 0.00 & 109.00 & 0.00 & 0.00 & 0.00 & 0.00\end{array}$

LABOR STATISTICS

REPORTED BY ON-SHIFT TIME

\begin{tabular}{|c|c|c|c|c|c|c|c|c|}
\hline Name & Qty & BIdle & EBusy & start & End & Yor & Pre-empted & Average \\
\hline $\begin{array}{l}\text { perator } \\
\text { PERATR2 }\end{array}$ & & $\begin{array}{r}76.55 \\
100.00\end{array}$ & $\begin{array}{r}23.45 \\
0.00\end{array}$ & $\begin{array}{r}393 \\
0\end{array}$ & $\begin{array}{r}393 \\
0\end{array}$ & & $\begin{array}{r}13 \\
0\end{array}$ & $\begin{array}{r}10.9 \\
0.0\end{array}$ \\
\hline
\end{tabular}

VARIABLE STATISTICS

REPORTED BY ON-SHIFT TIME

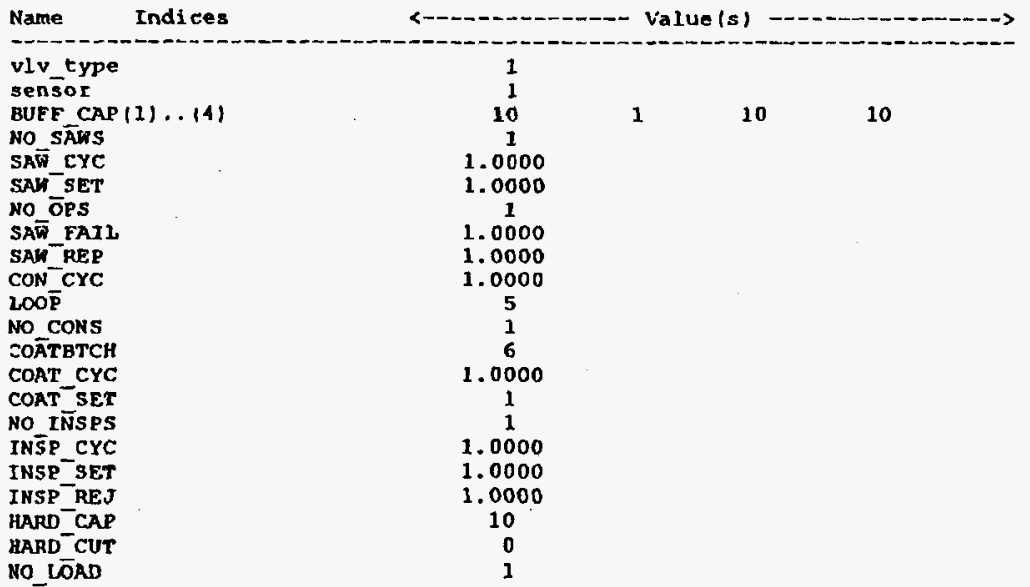




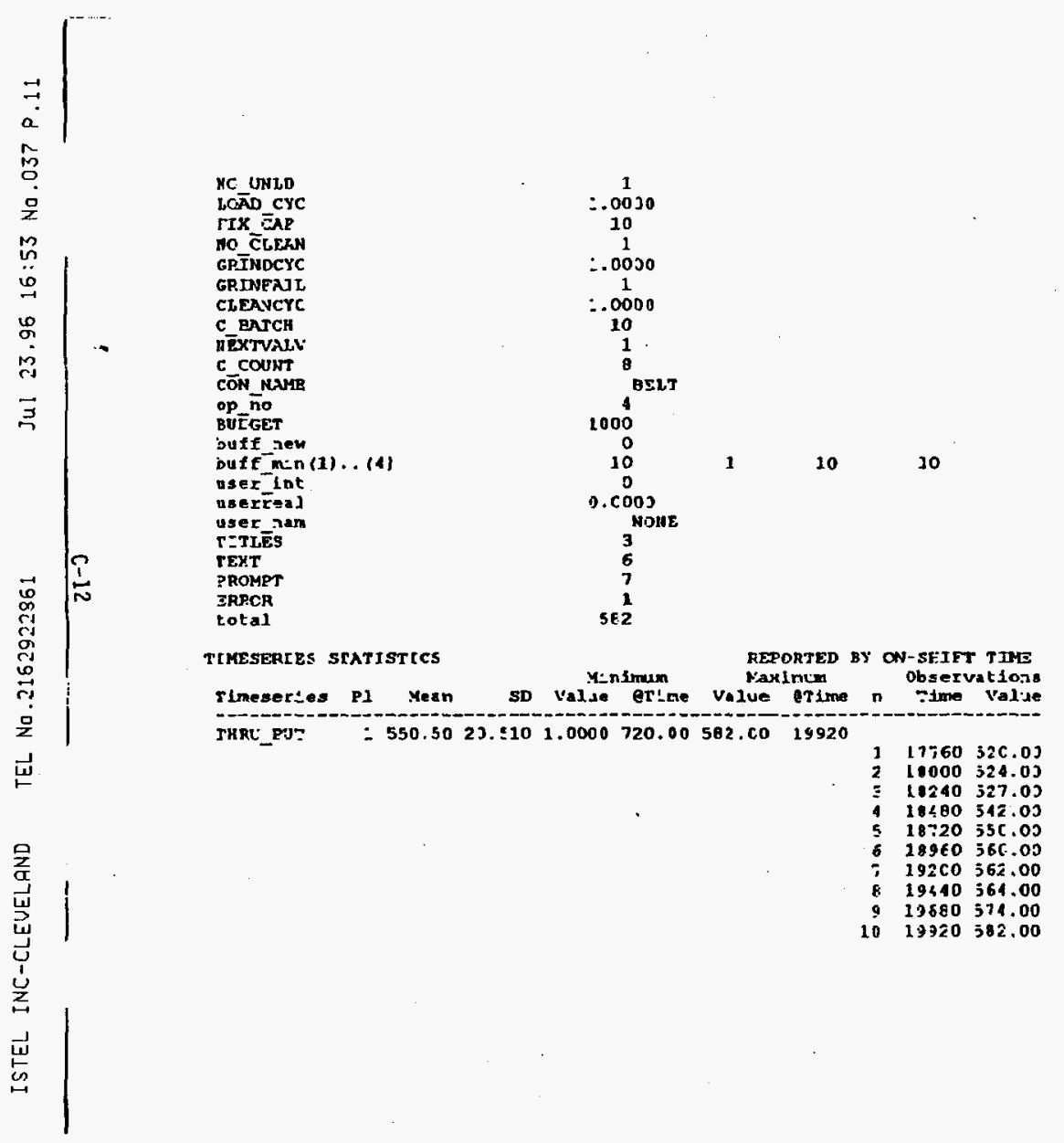


WHC-SD-SNF-RPT-011

Rev. 0

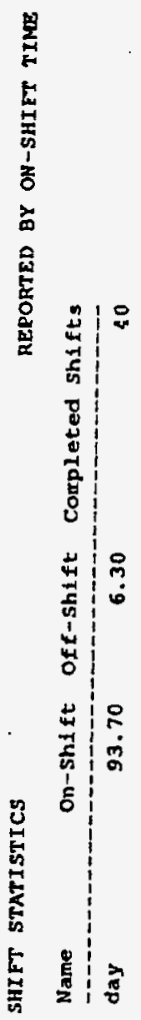


PART STATISTICS

REPORTED BY ON-SHIFT TIME Number Number Number Number Number Av. Av. Name Entered Shipped Scrapped Assembled Rejected W.I.P W.I.P Time

\begin{tabular}{|c|c|c|c|c|c|c|c|c|}
\hline bar & 460 & 0 & 404 & 46 & 0 & 10 & 10.00 & 98.23 \\
\hline block & 151 & 0 & 0 & 140 & 0 & 11 & 13.63 & 407.88 \\
\hline valve & 148 & 137 & 0 & 0 & 0 & 11 & 9.48 & 289.67 \\
\hline fixture & 10 & 0 & 0 & 0 & 2260 & 10 & 10.00 & 4520.0 \\
\hline ROLIER & 0 & 0 & 0 & 0 & 0 & 0 & 0.00 & 0.00 \\
\hline BELT & 0 & 0 & 0 & 0 & 0 & 0 & 0.00 & 0.00 \\
\hline
\end{tabular}

BUFFER STATISTICS

Total Total

\begin{tabular}{|c|c|c|c|c|c|c|c|c|c|}
\hline \multirow{2}{*}{ Name } & \multicolumn{2}{|c|}{ Total Total } & \multirow{2}{*}{ Now in } & \multirow[b]{2}{*}{$\operatorname{Max}$} & \multirow[b]{2}{*}{ Min } & \multicolumn{4}{|c|}{ Average Av. after De } \\
\hline & in & out & & & & Size & Time & No. & Time \\
\hline & - - & --- & ------ & -- & & ----- & ----- & & \\
\hline stock & 56 & 46 & 10 & 10 & 8 & 9.86 & 795.83 & & \\
\hline staging & 167 & 166 & 1 & 1 & 0 & 0.69 & 18.72 & & \\
\hline ework & 24 & 24 & 0 & 2 & 0 & 0.36 & $68 \cdot 34$ & & \\
\hline hardener & 141 & 138 & 3 & 3 & 0 & 1.85 & 59.36 & 0.00 & 0.00 \\
\hline ixstore & 44 & 35 & 9 & 9 & 7 & 8.52 & 874.94 & & \\
\hline alvestk (1) & 72 & 68 & 4 & 6 & 0 & 0.86 & 53.69 & & \\
\hline valvestk (2) & 72 & 70 & 2 & 9 & 0 & 4.08 & 256.38 & & \\
\hline
\end{tabular}

MACHINE STATISTICS

REPORTED BY ON-SHIFT TIME

Number

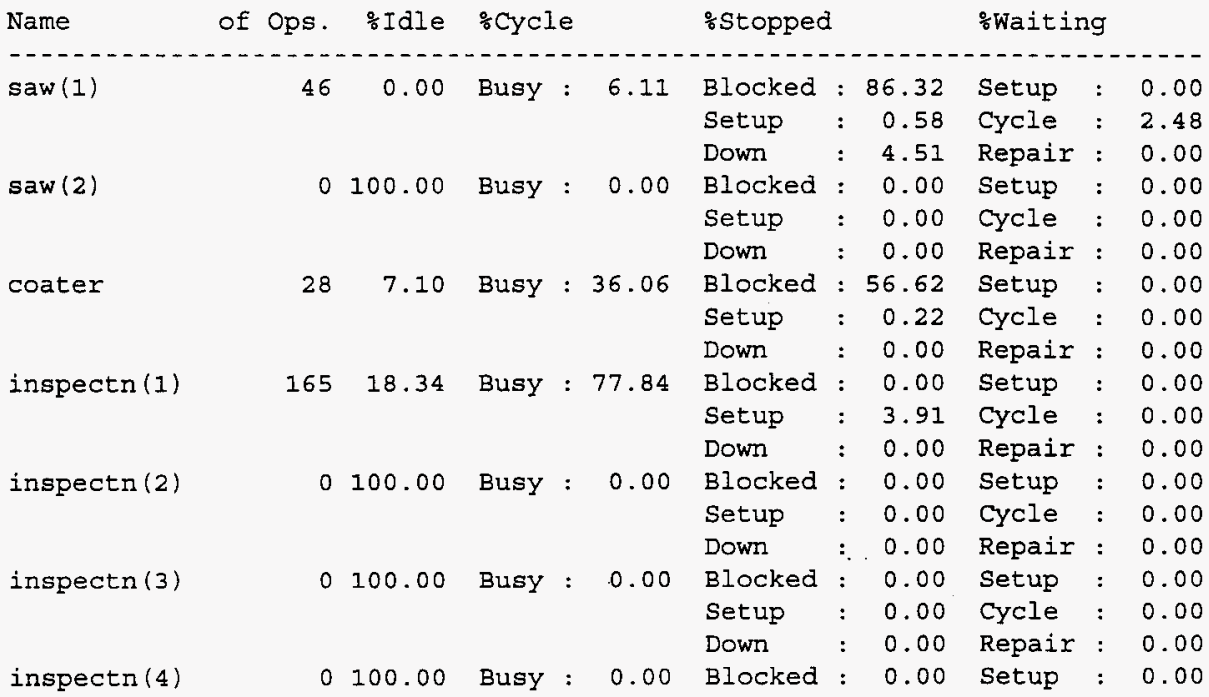




\begin{tabular}{|c|c|c|c|c|c|c|c|c|c|c|c|}
\hline & & & & & & Setup & : & 0.00 & $\begin{array}{l}\text { WHC-S } \\
\text { Rev. } \\
\text { Cycle }\end{array}$ & $\begin{array}{l}S D-S \\
0 \\
:\end{array}$ & 0.00 \\
\hline & & & & & & Down & : & 0.00 & Repair & : & 0.00 \\
\hline \multirow[t]{3}{*}{ load (I) } & 35 & 96.90 & Busy & $:$ & 3.10 & Blocked & : & 0.00 & setup & $:$ & 0.00 \\
\hline & & & & & & Setup & : & 0.00 & Cycle & : & 0.00 \\
\hline & & & & & & Down & : & 0.00 & Repair & : & 0.00 \\
\hline \multirow[t]{3}{*}{ load (2) } & 0 & 100.00 & Busy & $:$ & 0.00 & Blocked & $:$ & 0.00 & Setup & $:$ & 0.00 \\
\hline & & & & & & Setup & $:$ & 0.00 & Cycle & $:$ & 0.00 \\
\hline & & & & & & Down & $:$ & 0.00 & Repair & $:$ & 0.00 \\
\hline \multirow[t]{3}{*}{ grinder (1) } & 18 & 80.27 & Busy & $:$ & 15.93 & Blocked & $:$ & 0.00 & Setup & : & 0.00 \\
\hline & & & & & & Setup & $:$ & 0.00 & Cycle & : & 0.00 \\
\hline & & & & & & Down & $:$ & 2.54 & Repair & $:$ & 1.26 \\
\hline \multirow[t]{3}{*}{ grinder (2) } & 18 & 79.40 & Busy & : & 15.20 & Blocked & $:$ & 0.00 & Setup & : & 0.00 \\
\hline & & & & & & Setup & : & 0.00 & Cycle & : & 0.00 \\
\hline & & & & & & Down & : & 4.19 & Repair & : & 1.20 \\
\hline \multirow[t]{3}{*}{ uload (1) } & 36 & 96.81 & Busy & : & 3.19 & Blocked & $:$ & 0.00 & Setup & : & 0.00 \\
\hline & & & & & & Setup & $:$ & 0.00 & Cycle. & $:$ & 0.00 \\
\hline & & & & & & Down & $:$ & 0.00 & Repair & : & 0.00 \\
\hline \multirow[t]{3}{*}{ uload (2) } & 0 & 100.00 & Busy & : & 0.00 & Blocked & $:$ & 0.00 & setup & : & 0.00 \\
\hline & & & & & & Setup & $:$ & 0.00 & Cycle & : & 0.00 \\
\hline & & & & & & Down & $:$ & 0.00 & Repair & $:$ & 0.00 \\
\hline \multirow[t]{3}{*}{ cleaner (I) } & 137 & 45.45 & Busy & : & 45.50 & Blocked & : & 0.00 & Setup & : & 0.00 \\
\hline & & & & & & setup & $:$ & 1.55 & Cycle & : & 0.00 \\
\hline & & & & & & Down & $:$ & 6.41 & Repair & $:$ & 1.10 \\
\hline \multirow[t]{3}{*}{ cleaner (2) } & 0 & 100.00 & Busy & : & 0.00 & Blocked & $:$ & 0.00 & Setup & $:$ & 0.00 \\
\hline & & & & & & Setup & $:$ & 0.00 & Cycle & : & 0.00 \\
\hline & & & & & & Down & $:$ & 0.00 & Repair & : & 0.00 \\
\hline
\end{tabular}

CONVEYOR STATISTICS

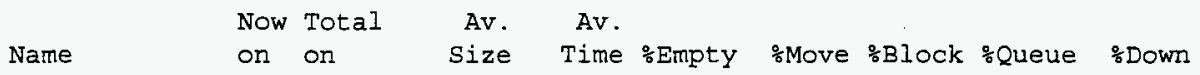

\begin{tabular}{|c|c|c|c|c|c|c|c|c|c|}
\hline beltconI & 3 & 141 & 2.8 & 89.71 & 3.90 & 5.30 & 90.80 & 0.00 & 0.00 \\
\hline ret 1 & 0 & 36 & 0.0 & 3.00 & 97.61 & 2.39 & 0.00 & 0.00 & 0.00 \\
\hline ret 2 & 0 & 36 & 0.0 & 3.00 & 97.61 & 2.39 & 0.00 & 0.00 & 0.00 \\
\hline ROLLCON1 & 0 & 0 & 0.0 & 0.00 & 100.00 & 0.00 & 0.00 & 0.00 & 0.00 \\
\hline BELTCON2 & 0 & 0 & 0.0 & 0.00 & 100.00 & 0.00 & 0.00 & 0.00 & 0.00 \\
\hline ROLLCON2 & 0 & 0 & 0.0 & 0.00 & 100.00 & 0.00 & 0.00 & 0.00 & 0.00 \\
\hline
\end{tabular}

IABOR STATISTICS

REPORTED BY ON-SHIFT TIME <----Number of jobs----> <---Job Time---> Name Qty $\frac{s}{8}$ le $\frac{\circ}{b}$ Busy Start End Now Pre-empted Average Job Time

\begin{tabular}{|c|c|c|c|c|c|c|c|}
\hline operator & 74.12 & 25.88 & 96 & 96 & 0 & 5 & 11.46 \\
\hline OPERATR2 & 1100.00 & 0.00 & 0 & 0 & 0 & 0 & 0.00 \\
\hline
\end{tabular}

VARIABLE STATISTICS

REPORTED BY ON-SHIFT TIME

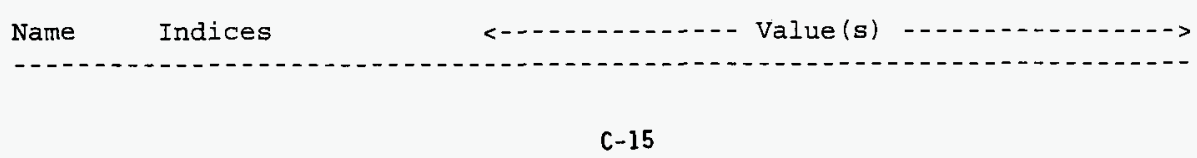




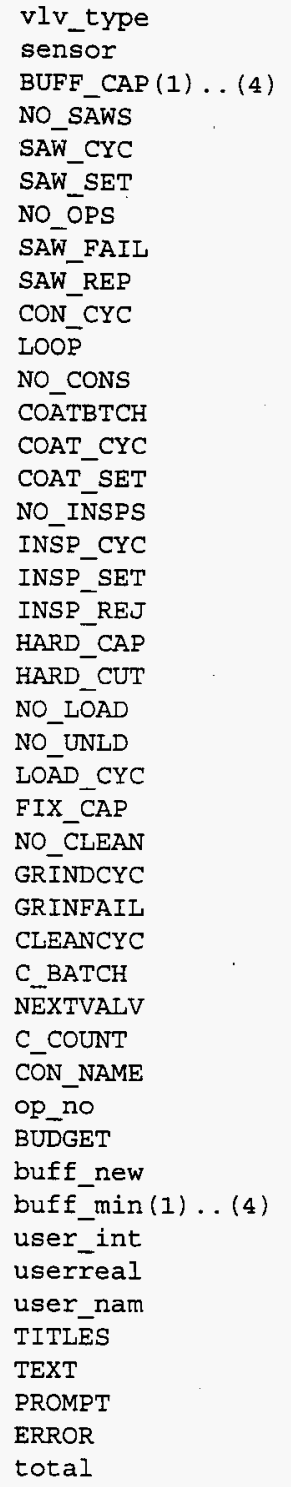

TIMESERIES STATISTICS

Timeseries PI Mean

\section{1}

1

10

1

1.0000

1. 0000

1

1.0000

1.0000

1.0000

5

1

6

1.0000

1

1

1.0000

1.0000

1.0000

10

0

1

1

1.0000

10

1

1.0000

1

1.0000

10

1

2

BELT

4

1000

0

10

0

0.0000

NONE

3

6

7

1

136
WHC-SD-SNF-RPT-011

Rev. 0

10 
Rev. 0

Name On-Shift off-Shift Completed Shifts

day

94.03

5.97

9 
PART STATISTICS

REPORTED BY ON-SHIFT TIME

Number Number Number Number Number

Av.

Av.

Name Entered Shipped Scrapped Assembled Rejected W.I.P W.I.P Time

\begin{tabular}{|c|c|c|c|c|c|c|c|c|}
\hline bar & 1960 & 0 & 1753 & 197 & 0 & 10 & 9.98 & 99.38 \\
\hline block & 604 & 0 & 0 & 592 & 0 & 12 & 13.88 & 448.61 \\
\hline valve & 596 & 583 & 0 & 0 & 0 & 13 & 9.63 & 315.37 \\
\hline fixture & 10 & 0 & 0 & 0 & 9760 & 10 & 10.00 & 19520 \\
\hline ROLLER & 0 & 0 & 0 & 0 & 0 & 0 & 0.00 & 0.00 \\
\hline BELT & 0 & 0 & 0 & 0 & 0 & 0 & 0.0 & \\
\hline
\end{tabular}

BUFFER STATISTICS

Total Total
REPORTED BY ON-SHIFT TIME

Average Av. after Delay

Name in out Now in Max Min size Time No. Time

\begin{tabular}{|c|c|c|c|c|c|c|c|c|c|}
\hline stock & 207 & 197 & 10 & 10 & 8 & 9.87 & 930.67 & & \\
\hline staging & 724 & 723 & 1 & 1 & 0 & 0.70 & 18.85 & & \\
\hline rework & 130 & 130 & 0 & 4 & 0 & 0.44 & 66.34 & & \\
\hline hardener & 592 & 590 & 2 & 3 & 0 & 1.82 & 59.86 & 0.00 & 0.00 \\
\hline Eixstore & 156 & 148 & 8 & 9 & 7 & 8.54 & 1068.8 & & \\
\hline valvestk (1) & 296 & 294 & 2 & 6 & 0 & 0.87 & 57.41 & & \\
\hline valvestk (2) & 295 & 290 & 6 & 10 & 0 & 4.22 & 278.24 & & \\
\hline
\end{tabular}

MACHINE STATISTICS

REPORTED BY ON-SHIFT TIME

Number

Name of Ops. \%Idle \%Cycle \%stopped

\begin{tabular}{|c|c|c|c|c|c|c|c|c|c|c|c|}
\hline \multirow[t]{3}{*}{ saw (1) } & 197 & 0.00 & Busy & $:$ & 6.06 & Blocked & $:$ & 89.02 & Setup & : & 0.00 \\
\hline & & & & & & Setup & : & 0.73 & Cycle & : & 1.82 \\
\hline & & & & & & Down & : & 2.37 & Repair & $:$ & 0.00 \\
\hline \multirow[t]{3}{*}{ saw (2) } & 0 & 100.00 & Busy & : & 0.00 & Blocked & : & 0.00 & setup & : & 0.00 \\
\hline & & & & & & Setup & : & 0.00 & Cycle & : & 0.00 \\
\hline & & & & & & Down & : & 0.00 & Repair & : & 0.00 \\
\hline \multirow[t]{3}{*}{ coater } & 121 & 5.74 & Busy & $:$ & 36.94 & Blocked & : & 57.01 & Setup & : & 0.00 \\
\hline & & & & & & Setup & : & 0.31 & Cycle & : & 0.00 \\
\hline & & & & & & Down & : & 0.00 & Repair & : & 0.00 \\
\hline \multirow[t]{3}{*}{ inspectn (1) } & 722 & 17.10 & Busy & $:$ & 78.99 & Blocked & : & 0.00 & setup & $:$ & 0.00 \\
\hline & & & & & & Setup & : & 3.95 & Cycle & : & 0.00 \\
\hline & & & & & & Down & : & 0.00 & Repair & : & 0.00 \\
\hline \multirow[t]{3}{*}{ inspectn (2) } & 0 & 100.00 & Busy & $:$ & 0.00 & Blocked & : & 0.00 & setup & : & 0.00 \\
\hline & & & & & & Setup & : & 0.00 & Cycle & : & 0.00 \\
\hline & & & & & & Down & : & 0.00 & Repair & : & 0.00 \\
\hline \multirow[t]{3}{*}{ inspectn (3) } & 0 & 100.00 & Busy & $:$ & 0.00 & Blocked & : & 0.00 & setup & : & 0.00 \\
\hline & & & & & & Setup & : & 0.00 & Cycle & : & 0.00 \\
\hline & & & & & & Down & : & 0.00 & Repair & $:$ & 0.00 \\
\hline .spectn (4) & 0 & 100.00 & Busy & $:$ & 0.00 & Blocked & : & 0.00 & Setup & : & 0.00 \\
\hline
\end{tabular}




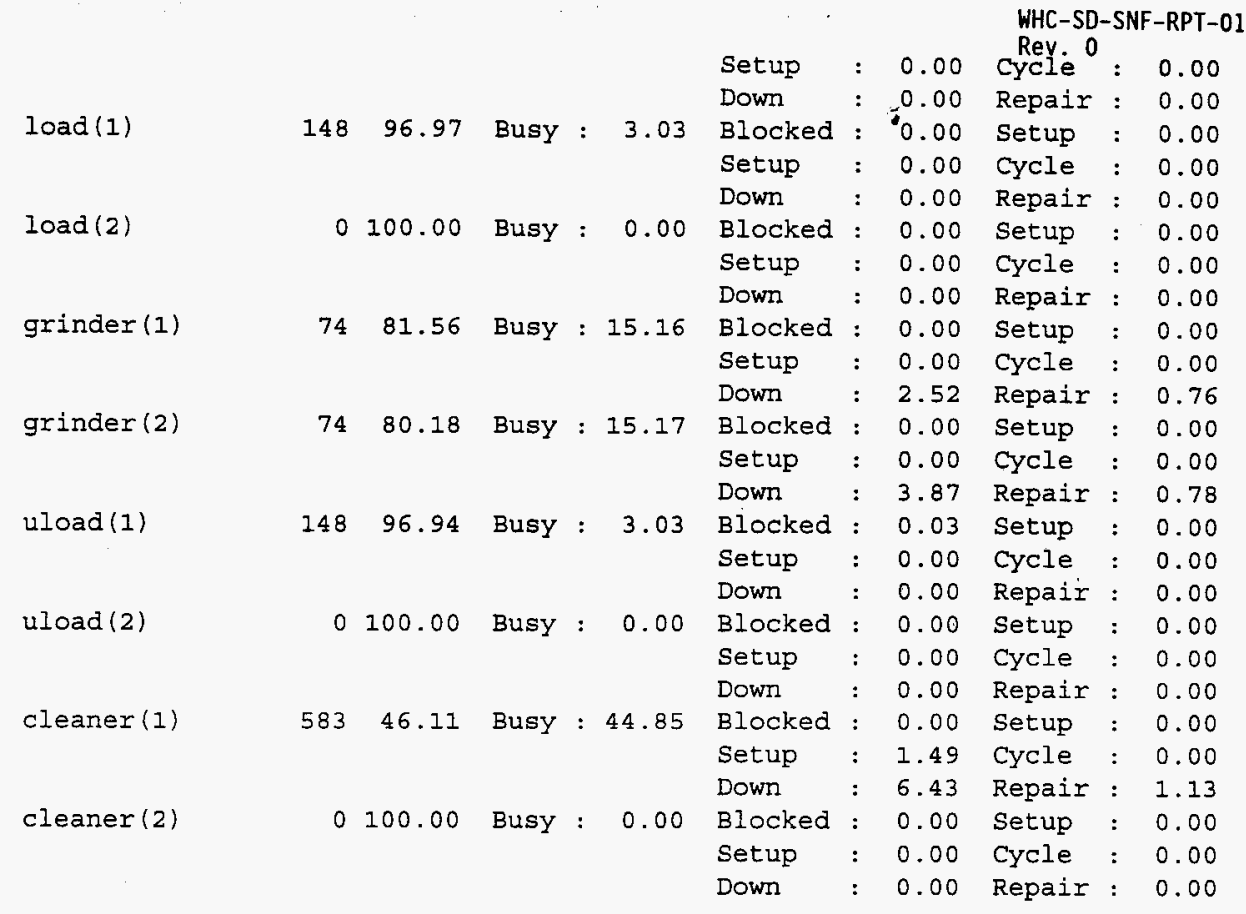

CONVEYOR STATISTICS

Now Total Av. Av.

Name on on Size Time $\%$ Empty :Move $\%$ Block $\%$ Queue $\%$ Down

\begin{tabular}{|c|c|c|c|c|c|c|c|c|c|}
\hline beltcon 1 & 4 & 594 & 2.8 & 92.56 & 2.79 & 5.23 & 91.98 & 0.00 & 0.00 \\
\hline ret 1 & 0 & 148 & 0.0 & 3.00 & 97.73 & 2.27 & 0.00 & 0.00 & 0.00 \\
\hline ret 2 & 0 & 148 & 0.0 & 3.00 & 97.73 & 2.27 & 0.00 & 0.00 & 0.00 \\
\hline ROLLCON1 & 0 & 0 & 0.0 & 0.00 & 100.00 & 0.00 & 0.00 & 0.00 & 0.00 \\
\hline BELTCON2 & 0 & 0 & 0.0 & 0.00 & 100.00 & 0.00 & 0.00 & 0.00 & 0.00 \\
\hline ROLLCON2 & 0 & 0 & 0.0 & 0.00 & 100.00 & 0.00 & 0.00 & 0.00 & 0.00 \\
\hline
\end{tabular}

LABOR STATISTICS

REPORTED BY ON-SHIFT TIME Name Qty $\%$ Idle \%Busy start End Now pre-empted Average Job Time

\begin{tabular}{|c|c|c|c|c|c|c|c|c|}
\hline operator & 1 & 76.55 & 23.45 & 393 & 393 & 0 & 13 & 10.91 \\
\hline OPERATR2 & 1 & 100.00 & 0.00 & 0 & 0 & 0 & 0 & 0.00 \\
\hline
\end{tabular}

VARIABLE STATISTICS

REPORTED BY ON-SHIFT TIME 


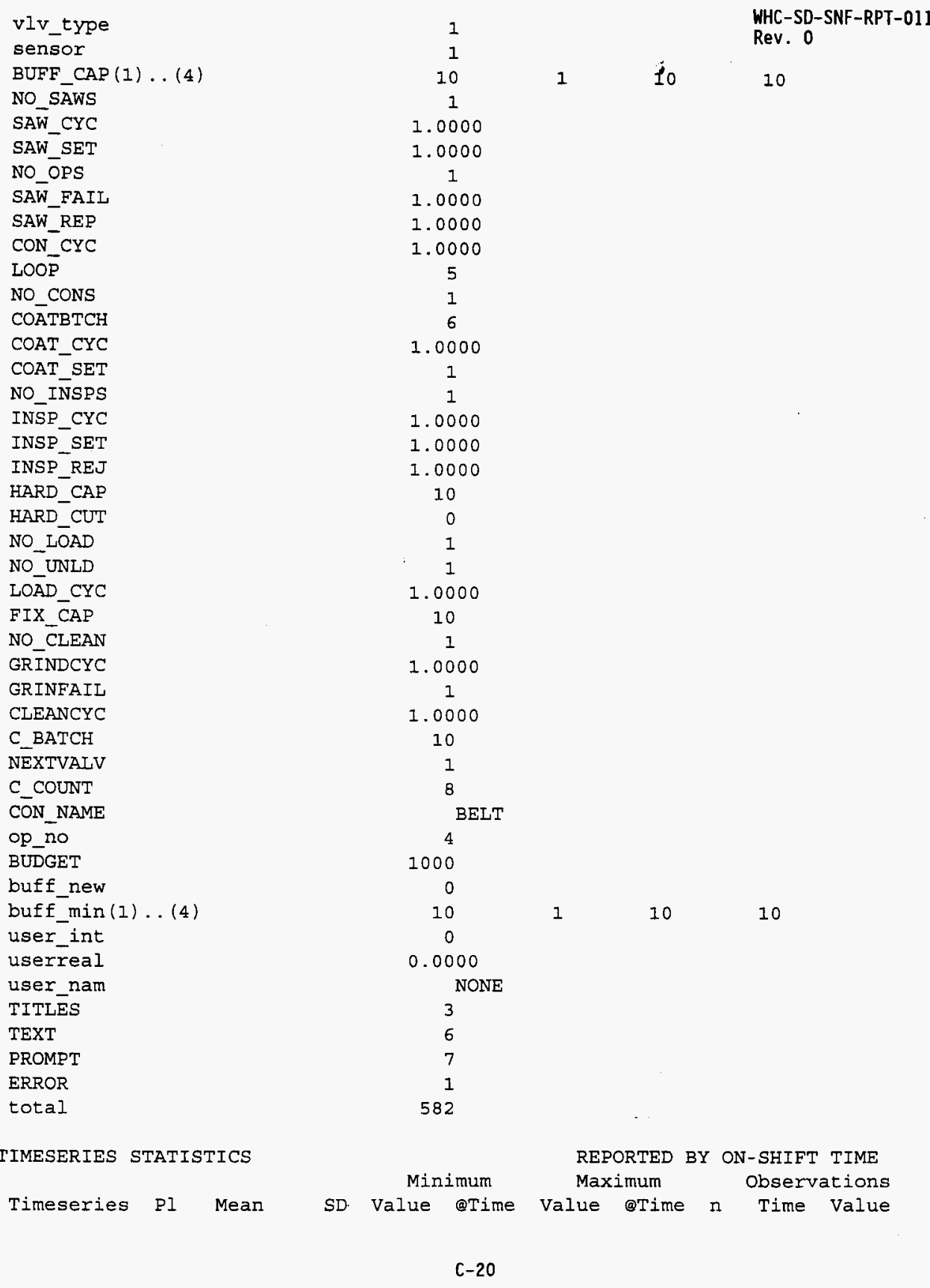


Rev. 0

THRU_PUT $\quad 1550.50 \quad 20.510 \quad 1.0000 \quad 720.00 \quad 582.00 \quad 19920$

,

$1 \quad 17760 \quad 520.00$

$218000 \quad 524.00$

$3 \quad 18240 \quad 527.00$

$418480 \quad 542.00$

$5 \quad 18720550.00$

$6 \quad 18960 \quad 560.00$

$7 \quad 19200 \quad 562.00$

$819440 \quad 564.00$

$919680 \quad 574.00$

$10 \quad 19920 \quad 582.00$

SHIFT STATISTICS

REPORTED BY ON-SHIFT TIME

Name On-Shift off-Shift Completed Shifts

-

day

93.70

6.30

40 


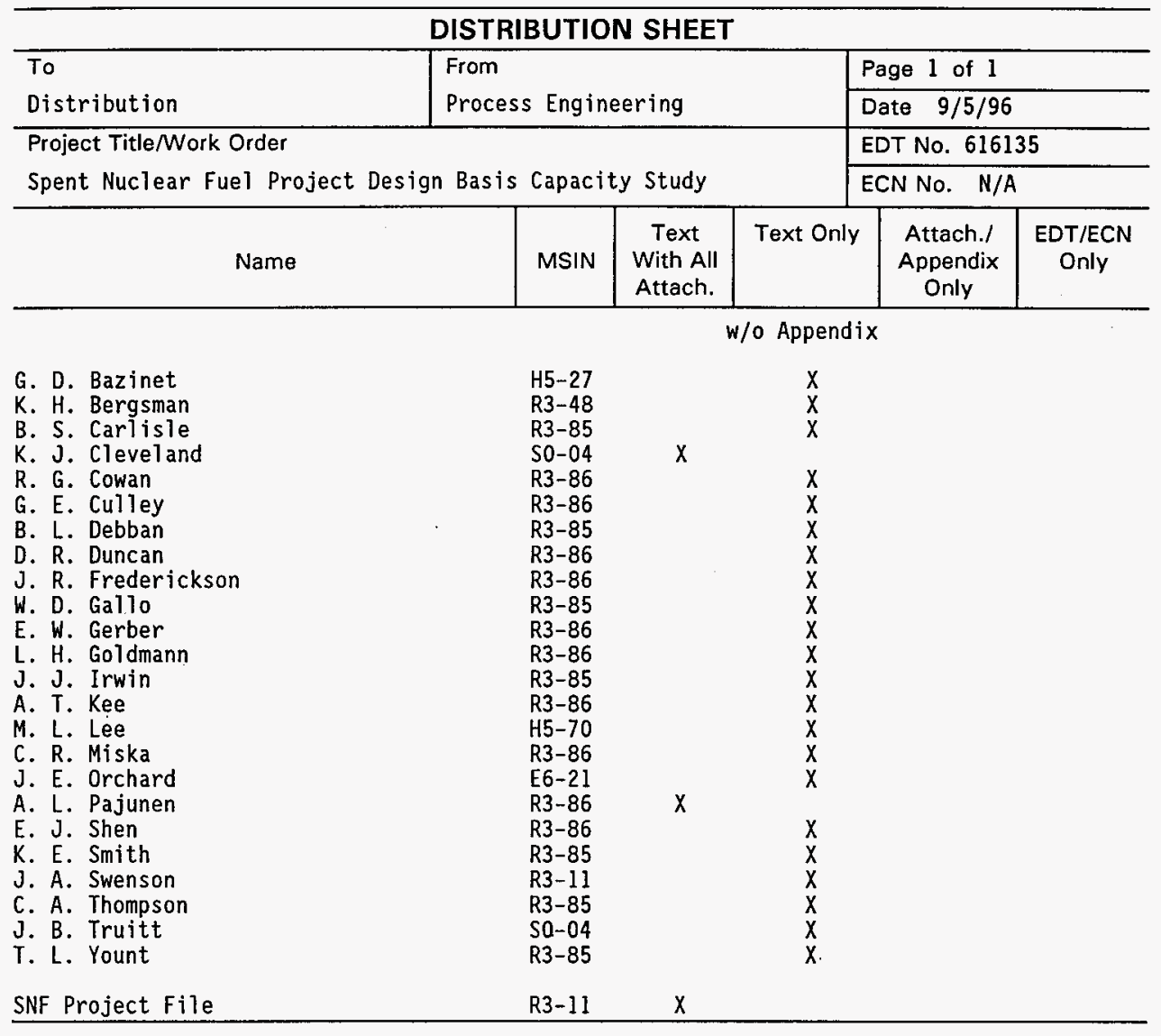




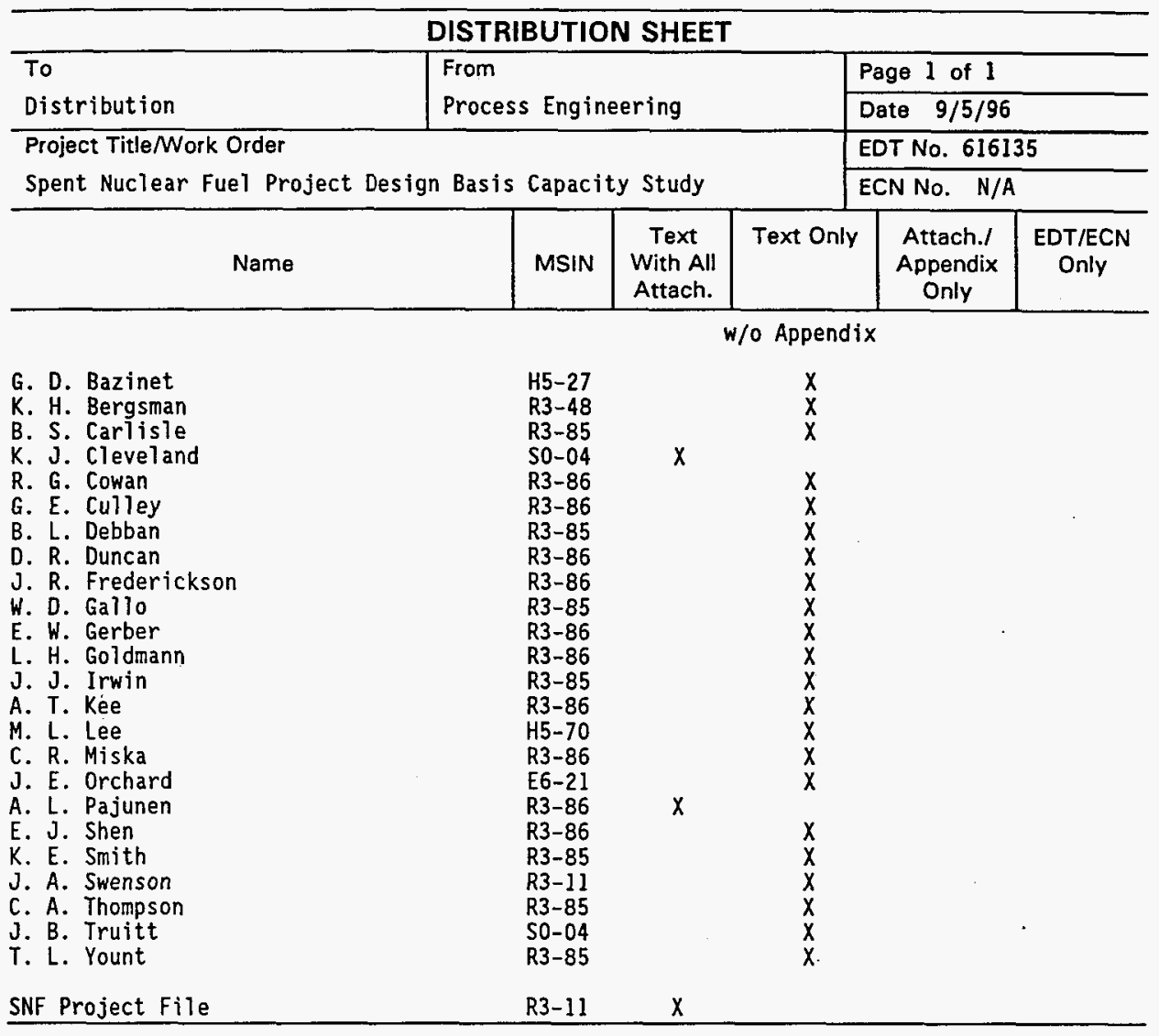

